\title{
FLEAS OF
}

WESTERN NORTH AMERICA 
The Pioneer

SIPHONAPTERISTS

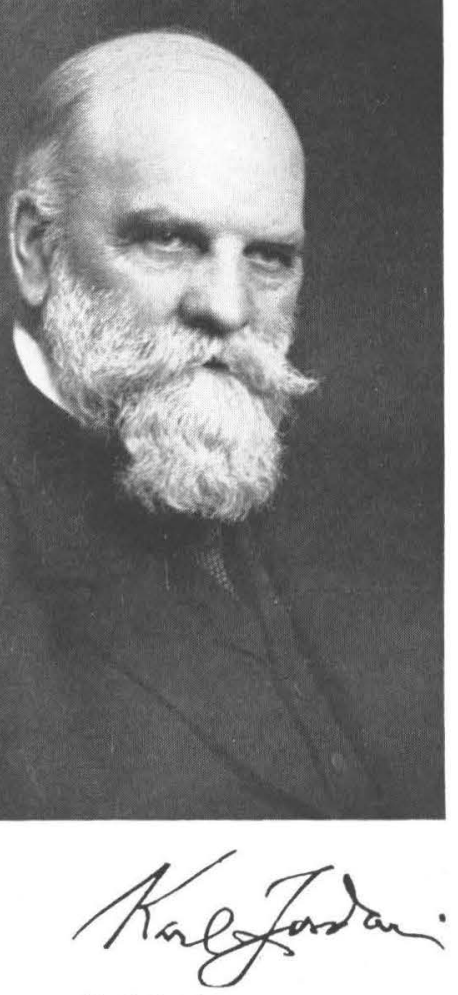

Karl Jordan 1861 -

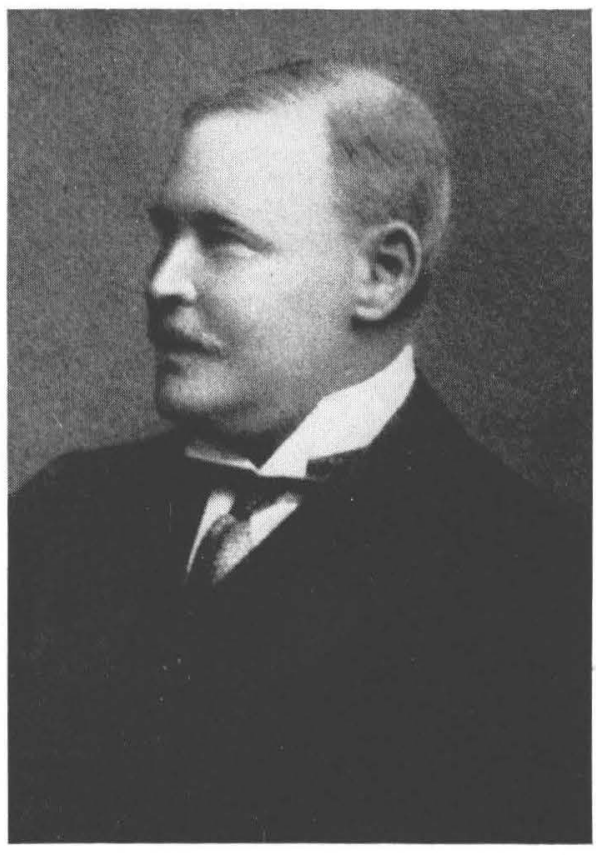

N. Charles opoteschied

N. Charles Rothschild 1877-1923
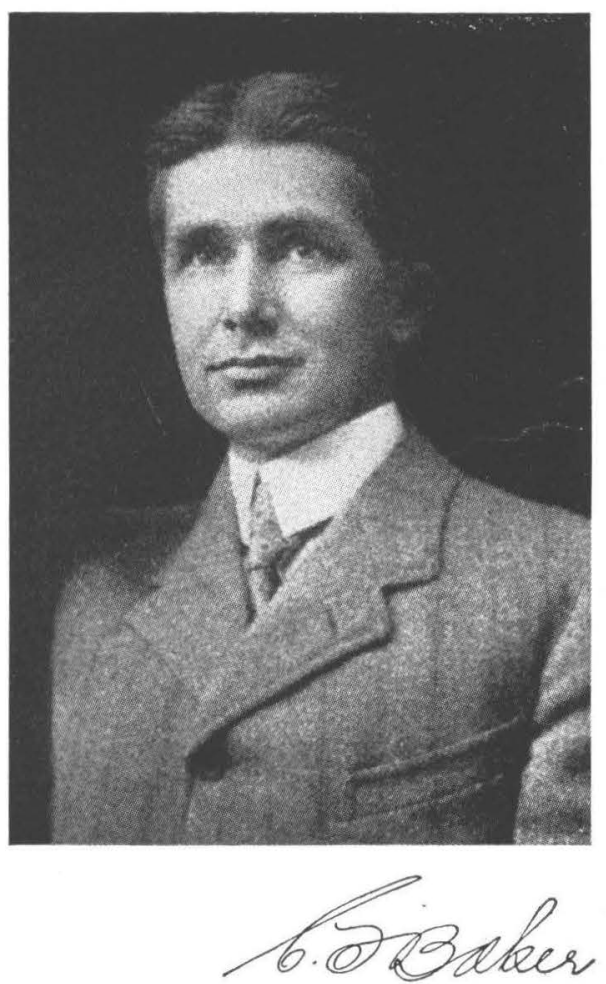

Carl (Charles) Fuller Baker 1872-1927 


\section{FLEAS}

OF

\section{Western North America}

Their Relation to the Public Health

BY CLARENCE ANDRESEN HUBBARD

Formerly Head of the Department of Biolocy

AND

Director of the Pre-Mfaic Curriculum

Pacific University, forest Grove, Oregon

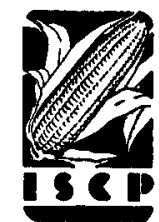

1947

THE IOWA STATE COLLEGE PRESS

AMES, IOWA 
Copyright, 1947, by

THE IOWA STATE COLLEGE PRESS

Printed at the Iowa State College Press Amrs, IowA, U. S. A. 
The writer of this treatise wishes here

to express a debt of gratitude

to

Dr. Karl Jordan, F. R. S.,

Curator

Tring Branch, British Museum

Hertz, England

Foremost student of today in the field of

Siphonaptera

and

in charge of

The N. C. Rothschild Collection of Fleas,

the greatest collection of its kind in the world.

Dr. Jordan is truly the friend and willing helper of the beginner in the field of the study of fleas.

To him the writer dedicates this treatise on the fleas of the

Great Western Country

of

North America 


\section{PREFACE}

"Fleas of Western North America"-Where does the West begin? This is hard to say, but this treatise is about the fleas, their hosts and their relation to the public health in a zone west of the 100 th meridian which includes the eastern approaches of the Rocky Mountains, the Rocky Mountains, the Great Basin, the Great Cascade-Sierra chain of mountains, the valleys between the Cascade-Sierras and the Coast Range, the Coast Range and the Pacific Slope.

In this vast territory of North America 66 genera of fleas are represented and some few more than 230 species and subspecies. When compared to the 33 genera and some 55 species known from east of the 100th meridian, the West is indeed a flea collector's paradise. The fleas of the West become tremendously more important when one realizes that among their numbers are species which are very efficient in transferring sylvatic plague from host to host, a plague which if expressed in man becomes bubonic plague. Certain of these fleas are also known to be able to transmit murine typhus, the type found in North America. Some evidence seems to point toward ability in some of these insects to transmit tularemia. Fleas often become a nuisance in homes, tormenting particularly persons allergic to these insects. On farms fleas may seriously annoy poultry and pigs. In many fleas examined, bladderworms, the cysticercus stage of tapeworms, can be found. Certain fleas, then, act as intermediate host for tapeworms. For these reasons fleas are of great medical importance.

This treatise is built around the large personally gathered collection of fleas of the writer. Thousands of personal records come from all over Oregon, Washingon, northern California, Nevada, Idaho, southern Utah, and Arizona. Gus Augustson has sent many specimens to the writer for study from southern California. M. A. Stewart has loaned materials from central California. George Holland has contributed from British Columbia. Jellison, Kohls and Mills have loaned the writer fleas from Montana. Stanford of Utah State College and Sam McCampbell of Colorado State College made available to the writer types and other material from Utah, and Colorado. Good and Prince of the Plague Suppressive Measures Laboratory at San Francisco have been very lenient in loans.

The administration of Pacific University, both under Dr. John F. Dobbs and Dr. Walter Geirsbach, is to be thanked for allowing the writer continual use of Pacific University Bulletin through 15 papers on western fleas, which in a way form the nucleus of this work. 
All American students of fleas are indebted to Dr. Karl Jordan of the British Museum, Tring, England, for his help and patience.

Thanks are here extended to the following three noted western mammologists for identification of rare western mammalian hosts: Stanley Jewett of Portland, Oregon, Alex Walker of Tillamook, Oregon, Robert Holdenried of San Francisco, California.

The staff of the entomology department of Oregon State College is here thanked for helpful suggestions. The members are Drs. Don C. Mote, H. A. Scullen, and W. J. Chamberlin.

Although including records from the following western check lists of fleas, the author has not been able to check their validity.

Augustson: Preliminary Records and Discussion of Some Species of Siphonaptera from the Pacific Southwest, 1943.

Jellison and Kohls: Siphonaptera: The Fleas of Alaska, 1939.

Jellison, Kohls and Mills: Species and Host List of Montana Fleas, 1943.

Mail and Holland: Siphonaptera of Western Canada, 1939.

Stanford: More Utah Siphonaptera, 1944.

Svihla: A List of the Fleas of Washington, 1941.

In order that students of fleas may study actual specimens of northwestern fleas at first hand the author is establishing a series of $25 \mathrm{de}$ positories, each containing 90 northwest species, to be deposited in the United States National Museum, the British Museum, California Academy of Sciences, other museums and entomology departments of universities evenly scattered over this country.

The author wishes to thank Pomona College Library for the portrait of Dr. Carl Baker; Dr. Karl Jordan for the portraits of Jordan and Rothschild; Dr. C. F. W. Muesebeck and the United States Public Health Service for the portrait of Carroll Fox; Dr. R. R. Parker of the Rocky Mountain Laboratory for portraits of Jellison and Kohls.

$$
\text { C. A. H. }
$$

Portland, Oregon

July, 1946 


\section{TABLE OF CONTENTS}

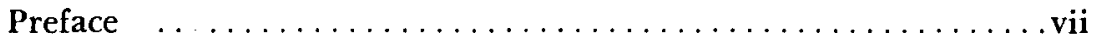

\section{PART I}

Chapter 1 Students of Western American Fleas, Their Contribution 3 Chapter 2 The Medical Importance of Fleas............. 17

Chapter 3 Field and Laboratory Technique............... 28

Chapter 4 The Anatomy of the Flea in Relation to Its Taxonomy. . 38

\section{PART II}

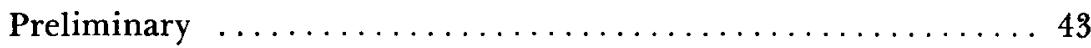

The Order Siphonaptera....................... 45

Family Hectopsyllidae ......................... 49

Family Pulicidae ........................... 56

Family Dolichopsyllidae ...................... 84

Family Hystrichopsyllidae ....................273

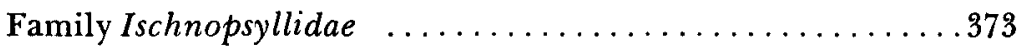

PART III

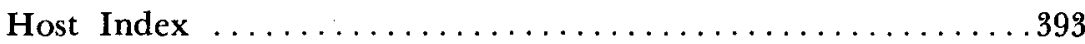

The Hosts of Western Rodent Fleas................. 395

The Fleas of Western Carnivora . . . . . . . . . . . . . . 496

The Fleas of Western Insectivora ................504

The Fleas of Western Bats..................... 508

The Fleas Reported From Man................. 510

The Fleas of Western Birds.................... 512

Selected Bibliography.......................... 515

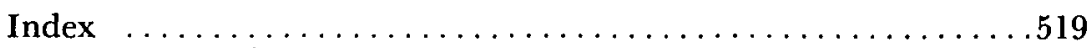


PART I

INTRODUCTION 


\section{CHAPTER 1}

\section{STUDENTS OF WESTERN AMERICAN FLEAS, THEIR CONTRIBUTIONS}

\section{THE PIONEERS}

In a sense, the pioneers in the study of western American fleas were those three men who studied these insects because of their love of them as pure science, during the period before the great American public was informed that a serious epidemic of bubonic plague was raging in San Francisco. These three men were Carl F. Baker, the American, and N. Charles Rothschild and Karl Jordan, the inseparable English duo. With the outbreak of plague in California, both the state of California and the federal government sent expert entomologists to the scene; the study of fleas then passed from a study in pure science to one of economic entomology.

CARL F. BAKER (1872-1927)

It seems that first concentrated attention was given western American fleas by Dr. Carl F. Baker. During the year 1895 in the various issues of the Canadian Entomologist, Baker published a series of 7 short papers covering about 20 pages under the title of "Preliminary Studies of Siphonaptera." Of the some 50 species of world fleas listed in these papers, 9 were western American. These 9 are known today as Cediopsylla inaequalis, Diamanus montanus, Foxella ignota, Orchopeas howardi, Opisocrostis bruneri, Opisocrostis hirsutus, Rectofrontia fraterna, Stenistomera alpina, and Tarsopsylla coloradensis. At the time this series of papers was written, Baker was a member of the staff of Colorado Agricultural College, Fort Collins, Colorado. During 1896 Baker released the description of Opisodasys keeni; 1898, Catallagia charlottensis, Thrassis arizonensis, and Anomiopsyllus nudatus; 1899, Stenoponia americana.

A period of 5 years then passed during which Baker was doubtless preparing his 2 monumental works. The first, which appeared in 1904, was entitled "A Revision of the American Siphonaptera." It appeared in the Proceedings of the United States National Museum 27, pp. 365-469, and was well illustrated. In this work. Baker added the descriptions of 22 new species which were then known to be found in western North America. This gave Baker a total of 36 species of western fleas described. During 1905, Baker's "Classification of the American 
Siphonaptera" appeared in Proceedings of the United States National Museum 29, pp. 121-170.

The year 1905 brought to an abrupt end Baker's work on fleas. It is not definitely known what caused this change of interest, but never again did Baker appear in print on the Siphonaptera.

Carl (Charles) Fuller Baker was born at Lansing, Michigan, on March 22, 1872. He received his bachelor's degree from Michigan Agricultural College during 1892. During this year he became attached to the Colorado Agricultural College, Fort Collins, Colorado, as assistant to C. P. Gillette. It was while here that he began publishing his first important contributions to entomology. He published articles on Hemiptera, Homoptera, the beet leafhopper, and as the pioneer of American flea men, released his Preliminary Studies of Siphonaptera. During 1893 he was in charge of the Colorado forestry and zoological exhibit of the Columbian Exposition at Chicago. Baker acted as zoologist in the Alabama Biological Survey during 1897-1899. The year 1898-1899 found him in the Santa Marta Mountains of Colombia as biologist of the H. H. Smith exploring expedition. Upon his return to the United States Baker become a member of the staff at Central High School at St. Louis, Missouri. During 1901 he left this position to go to Stanford University, where he studied under Vernon L. Kellog. From this institution he received his master of science degree in 1903. While at Stanford, Baker prepared his 2 large papers on American fleas which appeared in 1904 and 1905. During 1903 A. J. Cook, Professor of Biology at Pomona College persuaded Baker to become his assistant, but he remained in this position only 1 year. While at Pomona College, Baker began the publication of Invertebrata Pacifica. Baker left the United States in 1904 to become chief of the Department of Botany of the Cuban Experiment Station. With him went Baker, the flea student. Baker returned to the United States and Pomona College in 1908, but somewhere the flea student was lost, for Baker never again published work on fleas.

From this point on, the highlights in Baker's life were many. During 1909 with the assistance of Cook, Baker started the Journal of Entomology and in 1911 the Journal of Economic Botany.

In October, 1911, Cook became Horticultural Commissioner of California. The effect of this upon Baker was his withdrawal from the college to accept a position of professor of agronomy at the University of the Philippines. Here he worked under his friend E. B. Copeland, then dean, whom he succeeded in 1918.

During his long stay in the Philippines, which terminated with his death in Manila on July 22, 1927, Baker left the Islands only during a year's leave of absence (1917-1918) which time was spent as assistant director of the Botanical Gardens at Singapore.

Essig says, "Although he died comparatively young, he did the life work of many men." 
The records state that Baker died from chronic dysentery and was buried on the campus of the University of the Philippines.

\section{JORDAN AND ROTHSCHILD}

The Tring Museum, with the Rothschild collection of fleas, located at Tring, Hertfordshire, England, has become the flea center of the world. Here from the pen of Rothschild, Jordan and Rothschild, and Jordan, flea descriptions have been radiating for over half a century. Dr. Jordan, writing to the author in 1943, described the beginning of flea work at Tring as follows:

"When I (Jordan) came to Tring in 1893 he (Rothschild) was at Harrow, the great Public School; his greatest pleasure was going out and collecting insects, at that time almost exclusively butterflies and moths. From Harrow he went to Cambridge, his chief interest being Natural History. Here he saw some slides of foreign fleas which aroused his interest so much that he wished to acquire more. In 1896 Heller described Ctenophthalmus agyrtes from one of German Islands of the North Sea and as the host mouse was quite common at Tring we put out some traps one day in the hedges on the hill-side opposite the Museum and went late in the evening to inspect them; to our great joy there was a mouse and there were fleas, which seemed to be identical with Heller's agyrtes. That was the beginning here at Tring, which gradually led to the study of fleas from all regions."

In our records we find that as early as 1900 Dippie and Brooks already were sending specimens of fleas to Rothschild from western Canada. One of the first of these was an American mouse flea which Rothschild described as Hystrichopsylla dippiei from materials taken off a weasel by Dippie in Alberta on September 21, 1900, and off a mink by Brooks at Chilliwack, British Columbia, on January 2, 1900.

Since this beginning, Rothschild has issued the descriptions of 33 western North American fleas, Jordan and Rothschild 12, and Jordan an all-time high of well over 50 species.

As far as the writer is able to ascertain, neither Rothschild nor Jordan ever collected in western North America. They relied for their specimens upon the collecting activities of various field collectors.

\section{THE RGTHSCHILD COLLECTION OF FLEAS}

Dr. Jordan explains further:

"The collection grew rapidly and Charles decided to make it the property of the British Museum by deed of gift, with the condition that the collection remain his own as long as he wanted to keep it. On his death in 1923 it became definitely the property of the British $\mathrm{Mu}$ seum. The trustees agreed to leave it at Tring, as I was working at the material contained in the collection.

"In 1899 F. J. Cox was engaged as technical assistant to attend to the mounting and labeling of the specimens, which he has done ever 
since, his salary being paid from the interest on the capital which Charles had given to the British Museum for that purpose and for the purchase of specimens."

Early in the development of this collection Dr. Alfonso Dampf was asked to join the museum staff as specialist in fleas, but Dampf declined the invitation.

It is difficult to separate the Tring Museum, in which the N. C. Rothschild Collection of Fleas had its inception and in which it was nurtured, from the House of Rothschild. In 1805 Nathan Meyer Rothschild established the famous London banking house of N. M. Rothschild and Sons. It seems that there are no authentic records of this man and his family, but upon his death in $\mathbf{1 8 3 6}$ his oldest son, Lionel Nathan Rothschild, succeeded to the chief management of the great banking house. His mother was the daughter of Levi Barnet Cohen. Lionel was born in London on November 22, 1808. In 1836 he married his first cousin, the daughter of Baron Charles de Rothschild of Naples. This couple raised five children, three sons and two daughters. The first son was born in London on November 8, 1840, and was named Nathan Meyer after his grandfather. In 1872, 7 years before his death, Lionel purchased the Tring Park estate in Hertfordshire. Today all flea students recognize this as the address of Dr. Karl Jordan. Lionel is characterized as a genius of finance and a philanthropist.

Nathan Meyer Rothschild, the first baron Rothschild of Tring, established himself in the great banking firm upon the death of his father in 1879. During his life he also proved to be a financial wizard and is credited as the greatest leader of Jews of the time. He was married to Emma Louisa, daughter of Baron Karl von Rothschild of Frankfort. This couple had two sons and a daughter. The oldest son, named Lionel Walter, was born in London on February 8, 1868, and the second son was Nathaniel Charles, born 9 years later on May 9, 1877 .

THE HONORABLE NATHANIEL CHARLES ROTHSCHILD (1877-1923)

Unlike his associate Jordan, who was a research entomologist, Rothschild was a businessman, a financier, who at the time of his death in 1923 was Chairman of Alliance Assurance Company, Ltd. and during life was a partner of the firm of N. M. Rothschild and Sons, established by his great grandfather in 1805 . Rothschild became interested in fleas about 1897 and as relaxation and recreation studied and published articles on these insects from 1900 until his death, a period of some 23 years.

Nathaniel Charles Rothschild was born May 9, 1877, at London, England. His older brother was Lionel Walter Rothschild (first Lord Rothschild), who became a Trustee of the British Museum in 1899, was joint editor of Novitates Zooligicae which was published at Tring Mu- 
seum. The Museum at Tring which is referred to by Jordan as Walter Rothschild's Museum was doubtless established, maintained, and endowed by him. Like N. Charles, his brother, L. Walter was interested in natural history and published articles on various biological subjects.

Dr. Jordan has written the author as follows, "Born in 1877 he (Rothschild) was 9 years younger than his brother and 8 years younger than his sister; he felt much alone and in the way. There was the difficulty of his trend to melancholia aggravated by the wrong treatment of the very sensitive child. He became what a strict governess calls a difficult child, to be corrected and its natural tendencies to be suppressed. Psychology was not understood at that time."

Rothschild received his early education at Harrow, then earned a bachelor of arts degree in 1898 and a master of science degree in 1901 in Natural Science at Trinity College, Cambridge. He was married in 1907 to the third daughter of Captain Alfred Edler von Wertheimstein of Nagy-Varal, Hungary. The Rothschilds were the parents of a son and three daughters.

Jordan has written the author that "He (Rothschild) was a most liberal-minded man, but very anxious that nobody should know how often he helped people over difficulties without their knowing from whom the help came, and he liked nothing better than a good joke."

From 1900 through 1923 Rothschild published 27 papers on fleas as sole author. From 1906 through 1923 he published 16 papers with Jordan as co-author. Most of these papers appear in Novitates Zoologicae, the organ of the Tring Museum, edited by Rothschild's brother Walter. During December of 1915 there appeared the first issue of Ectoparasites. This periodical also issued from the Tring Museum. It was edited by Jordan and Rothschild and dealt almost entirely with fleas. This paper ran through only one volume of $\mathbf{3 7 0}$ pages, made up of five parts and an index. Its publication was suspended after the death of Rothschild in 1923. Of the 27 papers appearing in Ectoparasites on fleas, 10 are of importance to North American investigators.

After the death of Rothschild, Jordan carried on alone as siphonapterist at Tring. From 1925 through 1938 he published 21 papers on fleas, 15 of which are in Novitates Zoologicae.

\section{DR. KARL JORDAN (1861- )}

In the following lines, the Dean of world siphonapterists, Dr. Karl Jordan, has given his biography to the author:

"In a letter sent off to you last night I forgot to say that I was born on the 7th of December 1861 as a subject of George V, by the Grace of God, King of England and Hannover, as he styled himself. The village where I was born belonged to the old Bishopic of Hildesheim, which was independent until Napoleon's time, became Prussian in 1805, Westphalian in 1807, and after Napoleon's downfall was handed over by 
the Vienna Congress to Hannover, although the Bishop had been fighting hard during the Middle Ages against the aggression by the Guelphs of Hannover and Brunswick and succeeded to beat them off. In 1866 we became Prussian again. My Grandfather, who died in 1867, used to say that life was best under the Bishop: hardly any taxes and no soldiers. Hildesheim is about two-thirds Lutheran and one-third Roman; the town had the great fortune to escape destruction in the 30 years war and contains a large number of houses built shortly after 1600 and some much before that time, the woodwork carved or painted, the pictures illustrating some biblical stories in most cases, quite a show place. It was founded by the son of Charlemagne in 818 . The hills are covered with large forests, an ideal country for a budding entomologist like myself.

"My own life has been varied and interesting and still gives me much enjoyment. As the youngest of seven children of a farmer I received the usual village education and went to school for six years in the nearest town, Hildesheim, where the North German plain begins, and then studied for four and a half years at the University of Gottingen, received the degree doctor of philosophy in 1885 and passed the examination pro facultate docendi in 1886. Then I served for a year in the army at Hannover. Education was very cheap, all these years did not cost more than two years at one of the great public schools in England. As I wished to become a school master (higher grade) I was sent to Hannoversch Munden, where I remained five years, incidentally assisting the professor of Zoology at the Academy of Forestry and in the autumn of 1892 became master for mathematics, physics and natural history of the school of Agriculture at Hildesheim. Here I received a letter from Tring asking me whether I would accept a post as assistant at Walter Rothschild's Museum. I accepted after having consulted the professor of Zoology at Munden, the idea being that I should come back when the professor was due to retire. All those years I had collected Coleoptera and was much impressed by the mass of unclassified material I found at Tring, the classification of which was my first task. Soon after I was put on to the Lepidoptera, which have occupied most of my time until the death of Lord Rothschild (1923), when the Museum became the property of the British Museum. Time, however, was found chiefly in the evenings for the study of fleas and Anthribid beetles, which are now the only insects to which I devote my time."

\section{PLAGUE STIMULATES STUDY IN WEST}

After bubonic plague was discovered in San Francisco, an entirely new set of names appeared in western flea literature. Baker apparently took no part in the plague investigations, and Jordan and Rothschild were interested in fleas only as fleas. The new names were Doane, Carroll Fox, McCoy, and Mitzmain. Although plague was officially recognized in 1900 in San Francisco, the first paper on fleas and their rela- 
tion to plague did not appear until 1907 when M. B. Mitzmain issued such a paper while he was attached to the Entomological Laboratory of the University of California. This very short paper was published in California State Board of Health, Monthly Bulletin 3:38.

During the early part of 1908 Professor R. W. Doane, of the Department of Biology of Stanford University, received a large number of fleas from various public health sources in and around San Francisco. He found 6 species in the lot and published the results in August, 1908, in the Canadian Entomologist. In this 2-page paper the most interesting statement, to the author, was ". . . and 477 specimens of Ctenocephalus canis collected from a single Dachshund pup." The writer knows of no record which anywhere near approaches this infestation on a single animal.

During this year Mitzmain published in Entomological News a synopsis and biography of California fleas. in which he added 3 newly listed species. Carroll Fox the same year described the western chicken flea Ceratophyllus niger, the western mole flea Corypsylla ornata, published a note on squirrel fleas taken off rats and a 1-page report entitled "Identification of Fleas at San Francisco, Cal." in which 8 species are mentioned. This paper appeared from page 1371, Public Health Reports, September 25,1908 . It is interesting to note that there appears on the following page, prepared by Dr. Blue, whose name Fox attached the next year to the giant California gopher flea, the following:

\section{“Report from San Francisco, Calif.-Plague-Prevention Work WEEK ENDED SEPTEMBER 12.}

Date of last case. . . . . . . . . . . . Sickened, January 30, 1908

Sick inspected $\ldots \ldots \ldots \ldots \ldots \ldots \ldots \ldots \ldots \ldots \ldots \ldots \ldots \ldots \ldots \ldots$

Dead inspected $\ldots \ldots \ldots \ldots \ldots \ldots \ldots \ldots \ldots \ldots \ldots \ldots \ldots$

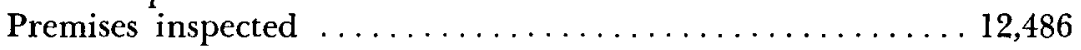

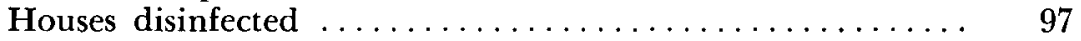

Buildings condemned $\ldots \ldots \ldots \ldots \ldots \ldots \ldots \ldots \ldots \ldots$

Houses destroyed $\ldots \ldots \ldots \ldots \ldots \ldots \ldots \ldots \ldots \ldots \ldots \ldots$

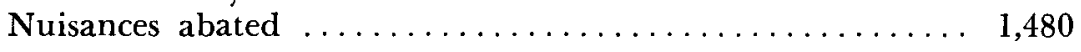

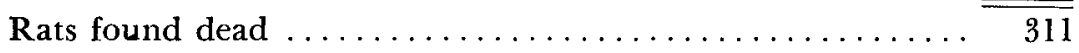

Rats trapped $\ldots \ldots \ldots \ldots \ldots \ldots \ldots \ldots \ldots \ldots \ldots \ldots \ldots \ldots \ldots, 428$

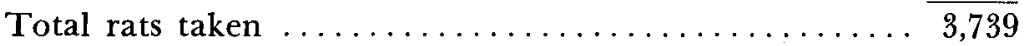

Rats identified:

Mus norvegicus . . . . . . . . . . . . . . . . . . 2,729

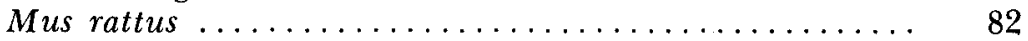

Mus musculus ...................... 739

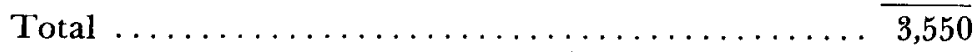

Rats examined bacteriologically $\ldots \ldots \ldots \ldots \ldots \ldots \ldots \ldots \ldots$

Poisons placed $\ldots \ldots \ldots \ldots \ldots \ldots \ldots \ldots \ldots \ldots \ldots \ldots \ldots, 8 \ldots \ldots$ 8. $\ldots \ldots \ldots$ " 
In the meantime, during October of 1907,7 cases of human plague were discovered at Seattle, Washington. The plague work carried on there appears directly under the report of Assistant Surgeon Blue:

\section{"Report from Seattle, Wash.-Plague-Prevention Work. Assistant Surgeon Glover Reports: \\ WEEK ENDED SEPTEMBER 12.}

Date of finding of last plague rat, July 9, 1908.

Rats received ............................. 1,075

Rats necropsied ......................... 949

Plague-infected rats to date $\ldots \ldots \ldots \ldots \ldots \ldots \ldots \ldots \ldots, \quad 20$

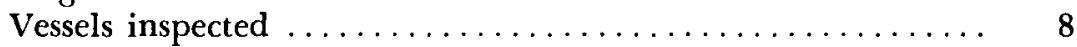

Vessels fumigated $\ldots \ldots \ldots \ldots \ldots \ldots \ldots \ldots \ldots \ldots \ldots$ 6"

Through the year of 1909 the pen of Carroll Fox was very busy. He reported from the County of San Francisco 14 species of fleas and 3 undetermined forms, and described the new fleas Atyphloceras multidentatus, Dactylopsylla bluei, and Catallagia wymani. During this year Mitzmain, who had now become technical assistant to the Plague Suppressive Measures Laboratory at San Francisco, published in Canadian Entomologist a review of the fleas of California in which he named 29 species and included a host index. Mitzmain and G. W. McCoy published 3 papers during this year, one on the regional distribution of fleas on rodents, another upon fleas observed in plague campaign in California and the third on rat and squirrel fleas biting man. During 1910 Mitzmain published his last papers on fleas. Two of these were upon the bionomics of human and rodent fleas, and a third written with McCoy was on fleas of California squirrels. McCoy released a note during this year on squirrel fleas as plague carriers. The big paper of the year was Fox's "The Flea and Its Relation to Plague," a 20-page issue in Public Health and Marine Hospital Service Bulletin No. 30.

During 1911 only 1 American paper appeared on Western fleas. This was McCoy's description of Actenophthalmus heiseri in Entomological News. This was McCoy's last paper on fleas. At the present time McCoy is professor of preventive medicine at the Medical School of Louisiana State University. $\mathrm{He}$ was born at Cumberland Valley, Pennsylvania, June 4, 1876. He received his doctor of medicine degree at Pennsylvania during 1898. For a great many years McCoy has been attached to the Public Health Service in one capacity or another.

From 1911 to 1919 only 1 American paper appeared on western fleas. This was Hygenic Laboratory Bulletin No. 97, 1914, in which Fox described several new western fleas, and advanced for the first time the taxonomic value of the female copulatory organs of the flea. The paper is beautifully illustrated.

The name of Dr. E. A. Chapin came into flea literature in 1919. Since 1934 Chapin has been curator of insects at the National Museum. 


\section{Washington, D. C., Siphonapterists}

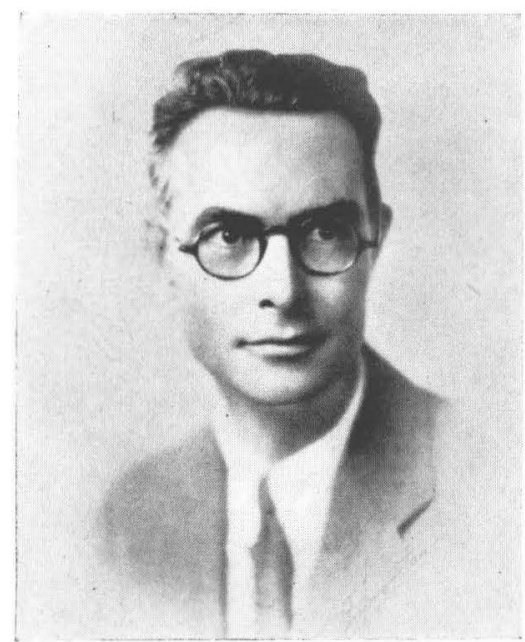

Edward A. Chapin

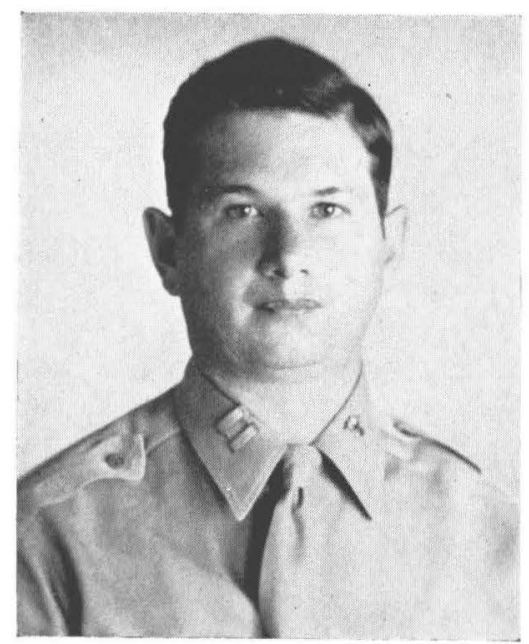

Irving Fox

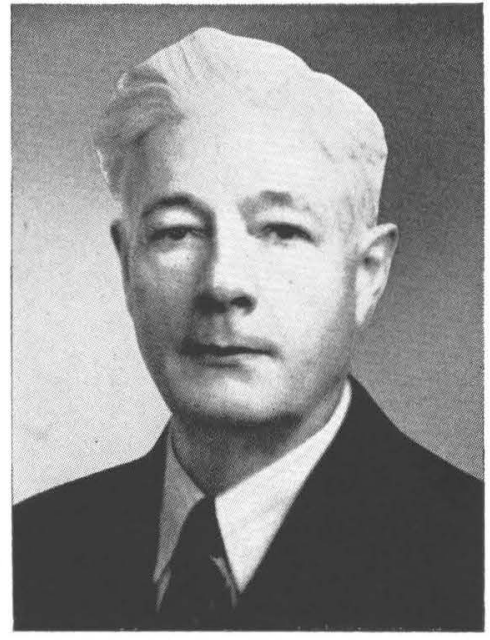

H. E. Ewing

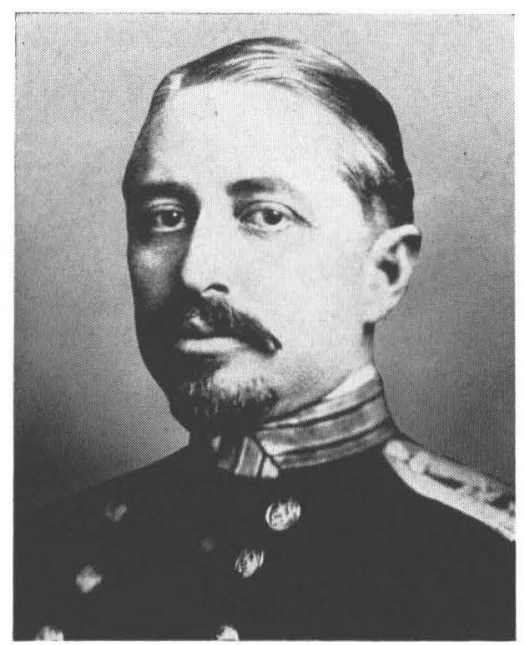

Carroll Fox 


\section{Pagific Coast Siphonapterists}

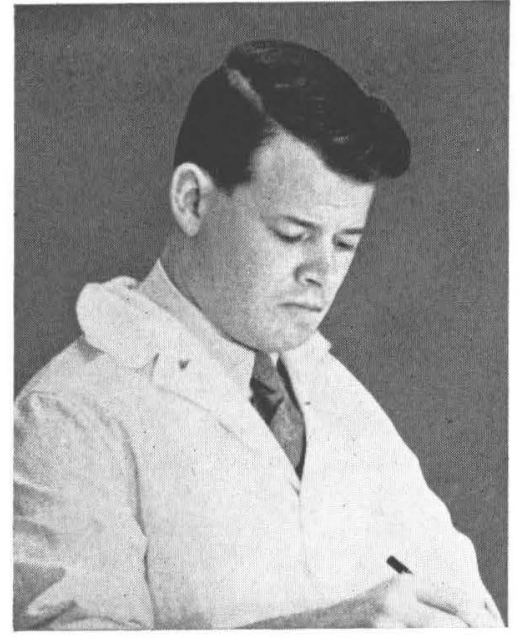

George Holland

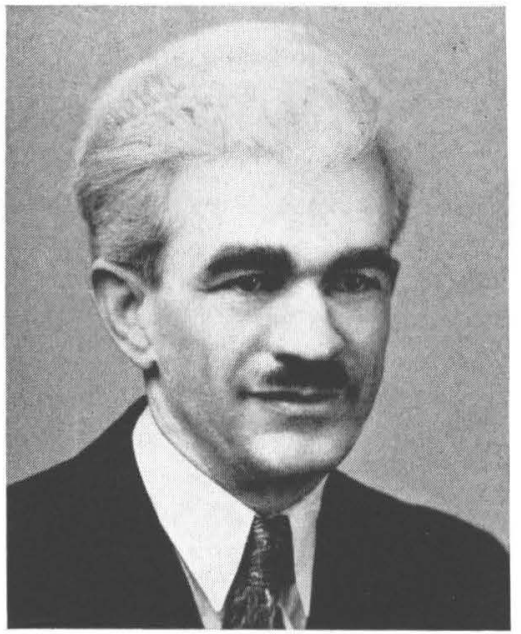

C. Andresen Hubbard

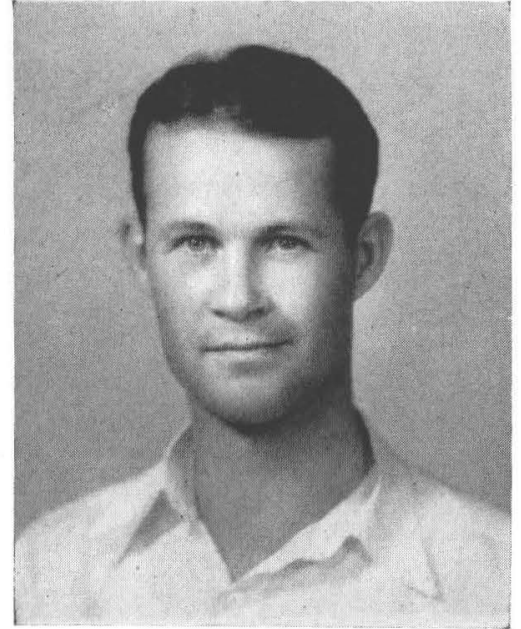

Gus Augustson

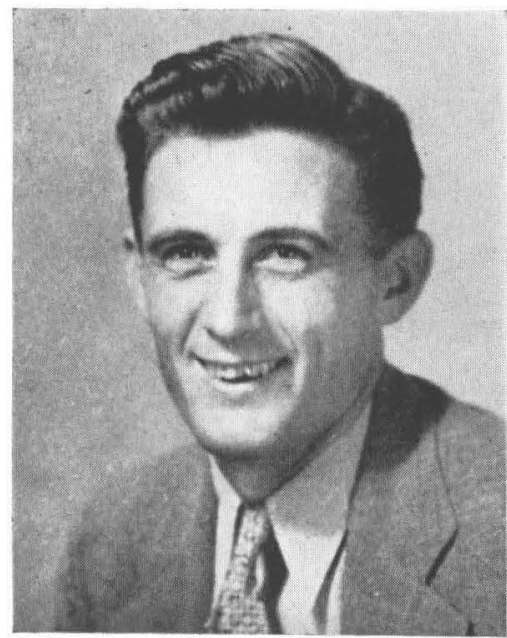

Frank Prince 
Prior to this time he was attached in one capacity or another to the Department of Agriculture. Chapin received his doctor of philosophy degree from George Washington University in 1923. He was born in Springfield, Massachusetts, January 4, 1894. During 1919 Chapin released the description of the giant northwest Mountain Beaver flea Hystrichopsylla schefferi and in 1921 the description of the giant SierraNevada Mountain Beaver flea $H$. mammoth. Chapin did not again publish on fleas.

During 1923 the name of $\mathrm{L}$. H. Dunn became associated with fleas in "Fleas Found on Wild Animals in the Bitterroot Valley, Montana." This was published with R. R. Parker in Public Health Reports 38. In this paper 25 species are mentioned, a new genus and several new species are erected. Dunn did not again publish on fleas.

It was in this year that N. A. Rothschild died and left his huge collection of fleas to the British Museum. From 1900 until 1923 Rothschild had published 27 papers and with Jordan 16; described 34 fleas found in the west and with Jordan, 12 others.

Another new name to appear about this time was that of $\mathrm{H}$. E. Ewing. In 1924 he described the smaller wild rabbit flea of California as Hoplopsylla foxi.

After an absence from the western flea field of 9 years, Carroll Fox again began publishing. During 1925 in Entomological News he erected the genus Actenophthalmus to hold the species heiseri. In 1926 he described Anomiopsyllus falsicalifornicus, Peromyscopsylla ebrighti, and Meringis cummingi, all from California; in 1927 Carteretta carteri. from California and Thrassis francisi from Utah; and in 1929 Orchopeas dieteri from California. Carroll Fox did not again publish on western fleas.

About this time another pair of names appeared in western flea bibliography. M. A. Stewart who had been publishing on eastern fleas since 1926, issued a paper "Two New Siphonaptera from Colorado" in Canadian Entomologist 60, 1928. The following year (1929) Dr. Julius Wagner, who had been publishing on fleas since 1889 , released the description of Doratopsylla c. obtusata, his first description of a western flea, the materials having come from British Columbia.

During 1930 while Stewart was still at Rice Institute, Houston, Texas, he released the descriptions of Conorhinopsylla stanfordi, Rhopalopsyllus sigmodoni, and Neopsylla texana.

Professor J. S. Stanford released, during 1931, "A Preliminary List of Utah Siphonaptera" in which was listed 9 genera and 18 species.

The year 1936 was a banner year for Wagner, as far as western fleas were concerned. From material supplied him by Professor G. J. Spencer he described 8 species from western Canada, and from materials from Professor Stanford of Utah State College he described 5 species from Utah. It was during this year that Wagner's "The Fleas of British Co- 
lumbia" appeared in the Canadian Entomologist. Fifty-three species were listed in this checklist.

In this year Professor Spencer, of the University of British Columbia, published his checklist of the fleas of British Columbia, and Collins released the description of Anomiopsyllus montanus.

\section{JELLISON AND KOHLS}

\section{OF THE ROCKY MOUNTAIN SPOTTED FEVER LABORATORY}

Jellison and Kohls became associated with western fleas about 1930. Jellison was appointed to the staff of the Rocky Mountain Spotted Fever Laboratory at Hamilton, Montana, during 1929, Kohls during 1931. Both remained at this federal laboratory until called into the armed forces of World War II.

William L. Jellison was born in Kalispell, Flathead County, Montana, on February 28, 1906. Kalispell is about 100 miles north of Hamilton, in the northwestern part of the state. Jellison received his bachelor of science degree at Montana State College during 1929. While here he acted as laboratory assistant in botany for the Experiment Station through the summers of 1926 and 1927. During 1928 Jellison acted as field agent for the Department of Agriculture. Early in 1929 Jellison became associated with the Hamilton Laboratory as laboratory assistant and in November of the same year was elevated to the rank of junior bacteriologist. Jellison received his master of science degree in 1931 from the University of Minnesota and while working for the degree acted as teaching assistant in the Department of Zoology. During May of 1931 Jellison returned to Hamilton as assistant bacteriologist. In 1935 Jellison's title was changed to assistant parasitologist. In 194I Jellison was appointed to the Malaria Commission to China with the rank of major. On April 27, 1942, he was transferred to the United States Army Service of Supply and as late as November, 1943, was serving in India.

In 1936 Jellison, with Kohls, released a paper upon the western distribution of the human flea; 1937 the description of Thrassis pandorae; 1939 a review of the prairie dog fleas with a new subspecies of Opisocrostis tuberculatus, a paper on the relation of predatory and scavenger birds to spread of sylvatic plague, a third paper which is a review of the flea genus Opisodasys, a fourth with Kohls on the fleas of Alaska; 1940 a paper completing the description of Carteretta carteri by describing the female, the description of Monopsyllus fornacis by describing the male; 1941 a review of the flea genera Amphalius and Ctenophyllus; 1943 with Kohls and Mills, Montana fleas and their hosts.

It was during 1942 that Jellison's greatest contribution appeared. This was "Index to the Literature of Siphonaptera of North America" written with Newell E. Good of the Plague Suppressive Measure Laboratory of San Francisco. This work is National Institute of Health Bulletin No. 178. 
Glen M. Kohls was born at Vesta, Minnesota, on October 23, 1905. He received his bachelor of science degree from Montana State College in 1929. In 1937 he was granted a master of science degree by the University of Minnesota. From 1925 to $1927 \mathrm{Kohls}$ was student assistant in entomology and zoology at Montana State. He acted as laboratory assistant, in local charge of tick parasite studies at Hamilton for the Montana State Board of Entomology during 1927-1928; 1929-1931 as assistant entomologist for the State Board. From 1931 to 1943 he was assistant entomologist at the Rocky Mountain Laboratory and in 1943 was elevated to associate entomologist. On April 9, 1943, he was commissioned as captain in the United States Army Sanitary Corps.

Kohls' first paper on western fleas appeared in 1937. In Journal of Parasitology he described $M$. collinsi, a bat flea from Arizona. This was followed in 1938 by the description of 2 new Meringis, dipodomys from southern California, hubbardi from Idaho. In 1939 he published on synonomy found in western rabbit fleas. Kohls' largest paper appeared in 1940 in National Institute of Health Bulletin No. 175. This was a beautifully illustrated paper on the rabbit and hare fleas of North America north of Mexico. With Jellison he published on the distribution of the human flea in 1936 and on fleas of Alaska in 1939, fleas of Montana in 1943.

In the meantime, Ewing in 1938 released the description of the Mountain Beaver flea, Trichopsylloides oregonensis, and the surgeon in charge of the Plague Suppressive Measures Laboratory at San Francisco, Dr. C. R. Eskey, published 3 papers, 1 on plague transmission, another on flea infestation of San Francisco rats and a third on fleas as vectors of plague. Eskey's largest and last contribution on western fleas appeared in 1940 as Public Health Bulletin No. 254 and is entitled "Plague in the Western Part of the United States." The co-author was Dr. V. H. Haas.

In 1939 two members of the staff of this Laboratory, Newell Good and Frank Prince, described 2 new Opisocrotis, oregonensis from ground squirrels of Oregon and washingtonensis from ground squirrels of Washington. During this year Holland and Mail of the Kamloops Laboratory published "Siphonaptera of Western Canada in Relation to Sylvatic Plague."

The year 1940 marks the beginning of a new era in flea study on the West Coast. In the north George Holland, collecting around Vancouver, B. C., began assembling material for publication out of the Kamloops Laboratory. Mrs. Ruth Svilha of the University of Washington, Seattle, began collecting in that state. Hubbard at Pacific University, Forest Grove, Oregon, had amassed a huge number of fleas, collected in Oregon, Washington, northern California, and northern Nevada. M. A. Stewart of the University of California at Davis was working central California materials and in southern California at the 
Allan Hancock Foundation of the University of Southern California, Gus Augustson was working materials from central and southern California. Irving Fox began working Rocky Mountain fleas from materials found in the National Museum.

The first paper on western fleas to appear during 1940 was "New Siphonaptera From California" by M. A. Stewart. In this paper, which appeared in Pan-Pacific Entomologist, Stewart erected 2 new genera and 8 new species. The materials upon which the paper was based were collected on the Hastings Natural History Reservation, Monterey County, California. Stewart was still entomologist at the Davis branch of the University of California at this time but has since moved to Berkeley and become attached to the Department of Parasitology there.

Hubbard followed in March and from this month on during the year published 6 papers in which were erected a new genus and 13 new species. All of Hubbard's papers to this date (1944) appeared in Pacific University Bulletin. This student of western fleas became interested in these insects in 1919 while writing a master's thesis on the Mountain Beaver at the University of Washington. Opening a nest of these animals he was amazed at the size of their fleas, Dolichopsyllus stylosus measuring over $5 \mathrm{~mm}$., Hystrichopsylla schefferi over $7 \mathrm{~mm}$. Hubbard became head of the Department of Biology at Pacific University in 1922 and retained this position for 22 years. Prior to 1934 he collected fleas occasionally, generally during summer outings, but in the summer of that year a sheepherder died of plague at Lakeview, Oregon. This event stimulated his interest in fleas, and from that time on he collected fleas by the thousands. Hubbard worked entirely alone, doing all his own collecting, mounting, determining, and labeling. He personally financed all his work on western fleas.

During early 1940 Holland with Stewart erected the genus Aetheopsylla and named septentrionalis its genotype. During this year Irving Fox described Opisocrostis ornatus from a male taken off a Prairie Dog in Colorado, Dactylopsylla rara from a male taken off a pocket gopher in Colorado and Amphipsylla neotomae from a male taken off a wood rat in California. Ewing during this year described Paratyphloceras oregonensis from a female taken off a mink in Oregon and Sternopsylla carlsbadensis from specimens taken off bats in New Mexico.

Dr. Henry Ellsworth Ewing is attached to the National Museum as entomologist and is a specialist in arachnida. He was born at Arcola, Illinois, on January 4,1883 . He received his doctor of philosophy degree from Cornell in 1911. He has taught at Knox College, Iowa State College and Oregon State College. After 1919 he was attached to the Department of Agriculture.

The year 1941 brought Gus Augustson of the Allan Hancock Foundation of the University of Southern California into print. During this year he published 2 papers in which were described 4 new species of 
Rocky Mountain Siphonapterists

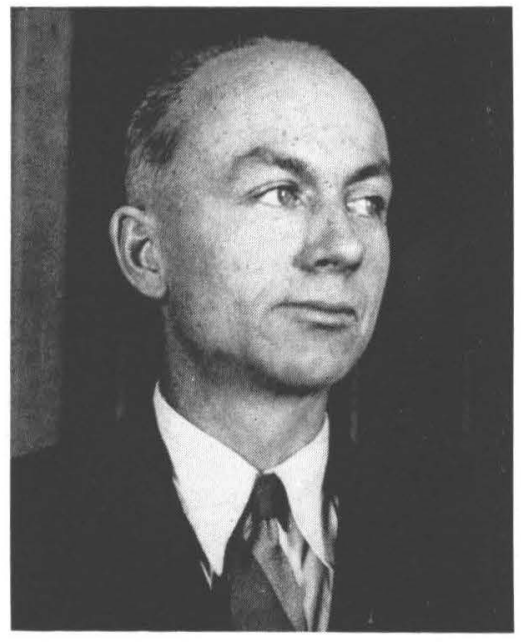

J. S. Stanford

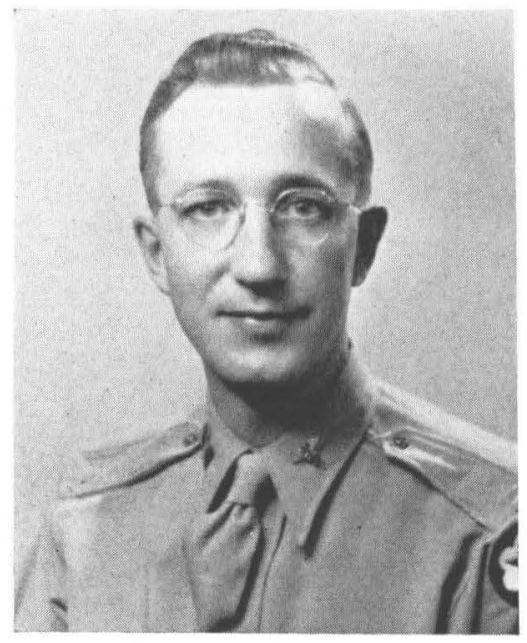

Glen M. Kohls

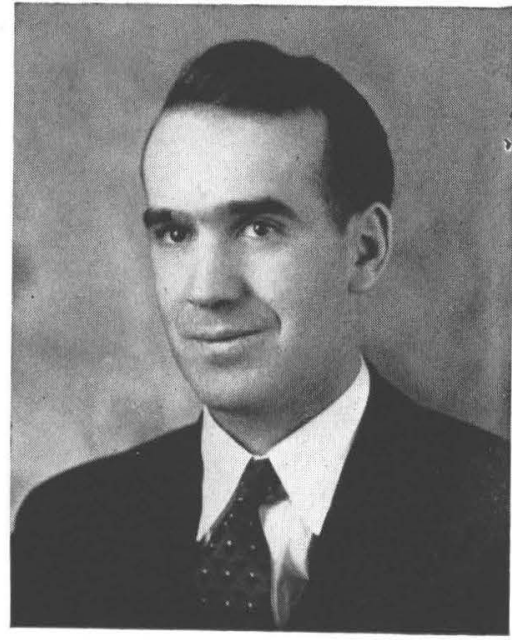

William L. Jellison

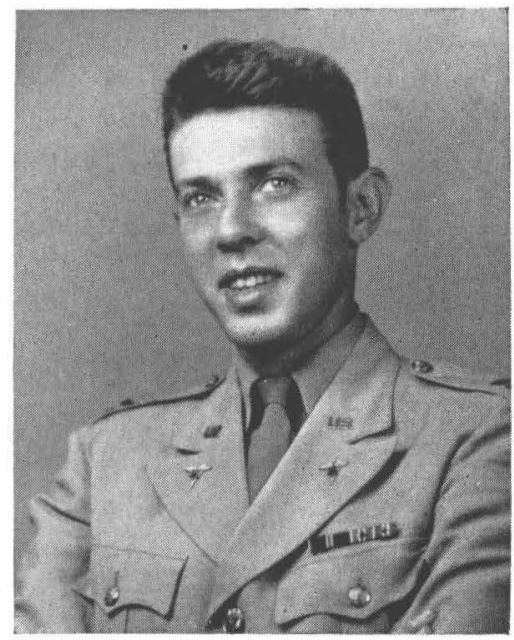

Robert Traub 
Typical Basic Trap Equipment Used by Present-Day Siphonapterists in Their Research

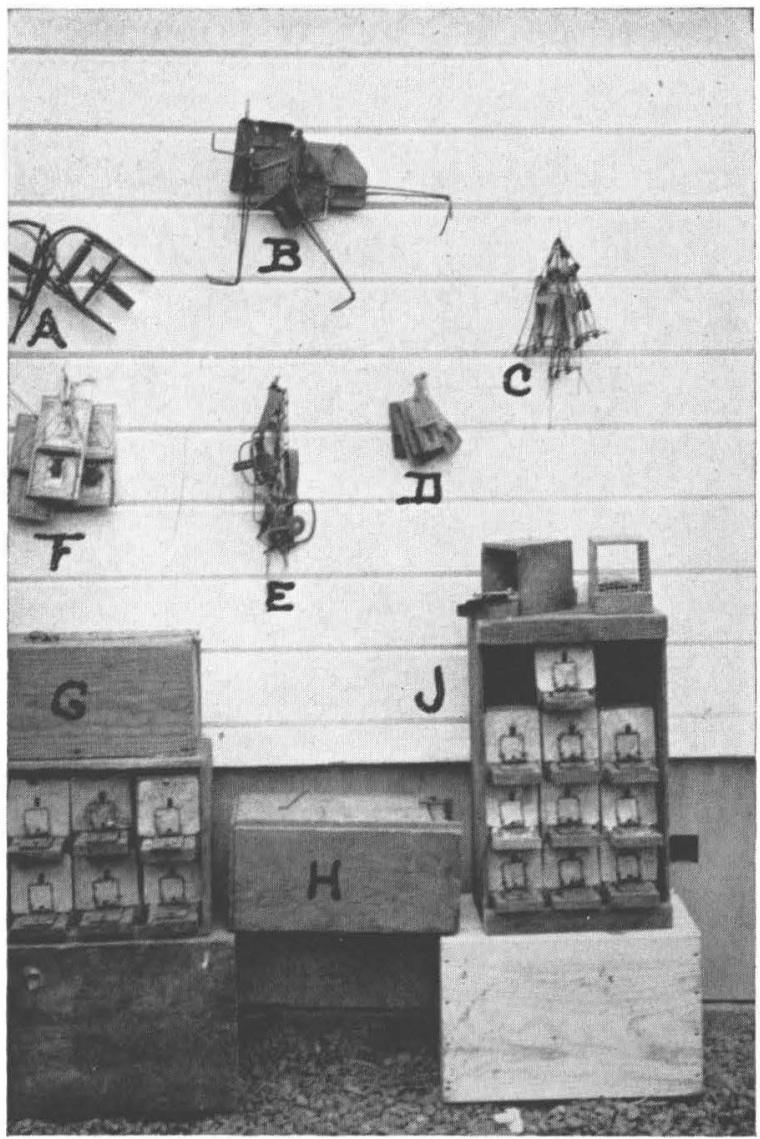

Fig. 1. Traps used by the author:
A. Out-of-sight mole trap.
B. Chinch gopher trap.
C. Macabee gopher trap.
D. Snap mouse trap.
E. Steel trap
F. Snap rat trap.
G. Hammerhead box trap.
H. Sliding door box trap.
J. Author's all-purpose live trap. 
California fleas. In 1940 Augustson wrote the author that he had been interested in the ectoparasites of southern California for about 6 years. Prior to 1938 he had been working under Dr. G. F. Ferris at Stanford University and while there was writing a master's thesis upon the ticks of his own collection. He moved to the Hancock Foundation as research associate with privilege of working toward his doctor of philosophy degree. During 1943 Augustson was commissioned lieutenant in the Army and became entomologist of the 8th Service Command Laboratory, Fort Sam Houston, Texas. From here Augustson wrote on December 31, 1943, "I have been here for nearly 2 months now, and feel that I will be here for the duration," but during May of 1944 he was shipped to the South Pacific.

Irving Fox released the description of Opisodasys jellisoni during 1941 from materials off flying squirrel taken at Boise, Idaho. Fox received his doctor of philosophy degree from Iowa State College in 1940, using for his thesis Fleas of Eastern United States which was published by the Iowa State College Press. He joined the staff of the University of Puerto Rico in 1941 as medical entomologist and in 1942 was commissioned lieutenant of the Army Sanitary Corps.

Hubbard published 4 papers during 1941, 3 of which -were host indices. A new genus and a new species appeared in these papers. During October of this year Mrs. Ruth Svihla published "A List of Fleas of Washington."

During 1942 Augustson contributed more to the literature of western fleas than anyone else writing in the year. He published 7 papers in which he erected a new genus, a series of new species, and a list of fleas and their hosts from central Sierra-Nevada Mountains of California. Hubbard during this year issued only 1 paper in which he described Thrassis rockwoodi and reviewed the northwest ground squirrel fleas. Good, of the Plague Suppressive Measures Laboratory, released his review of Stenistomera and described S. macrodactyla, and issued a key to the males of the genus Atyphloceras together with the description of the male of $A$. echis.

By 1943 World War II had pretty well drained the flea men from the west. Augustson, Fox, Jellison, Kohls were in the service. Good had returned to Washington, D. C. Stewart with offices now in Berkeley seemed to be busy with teaching and administrative duties. The only active flea men were apparently Prince in San Francisco, Hubbard at Forest Grove, and Holland at Kamloops. Augustson, however, released, while in the Army, a paper on the fleas of southern California in which he listed 48 species with their hosts. Prince released a paper on the fleas of rats west of the 102nd Meridian, and another on Opisocrotis brunneri and Thrassis bacchi as vectors of plague. Hubbard published "Fleas of California" and in a paper entitled "American Pocket Mouse Fleas" described Meringis jamesoni. Holland released a paper on syn- 
onomy and collected new records for British Columbia. Jellison and Kohls released with Mills "Species and Host List of Montana Fleas" in which were recorded 64 species of fleas.

During January, 1944, in Pan-Pacific Entomologist, Prince described 3 new species of Thrassis and Professor J. S. Stanford issued in Proceedings of the Utah Academy of Science "More Utah Siphonaptera." Fifty species and subspecies were listed in this Utah checklist, the collections having been made by Stanford, the determinations for the most part by Robert Traub.

Three other papers scheduled for late 1944 delivery were not released until early 1945. Holland issued "The Distribution of Some Plague-Important Rodents and Fleas in Western Canada" in Proceedings of the Entomological Society of British Columbia, December 1944. From materials found in the collection of Professor Stanford, Traub described two new western fleas from Utah in Zoological Series of Field Museum of Natural History, December 1944. This was Traub's first publication on western fleas and brings him in the catagory of western flea students. He was born in New York City in October 1916, attended College of the City of New York where he received his B. S. during 1938. Cornell granted his M.S. in 1939. From this time until June 1942 Traub was working for his Ph. D. at the University of Illinois. The Army commissioned him a First Lieutenant in the Sanitary Corps and during most of 1945 he was stationed as a Captain in Burma with the Army Typhus Commission, being associated there with Jellison and Kohls. The third of the papers appeared in Canadian Entomologist dated January, 1945 but which failed to reach libraries until late April. In this issue Prince described three new species of Dactylopsylla and a new subspecies of Foxella. Augustson released a study on Thrassis in Journal of Parasitology for August.

The period beginning in 1940 was, then, one of the most prolific eras in the study of western fleas; younger men like Augustson and Traub were showing intense interest, an interest interrupted by the war and the older men like Stanford and Hubbard were still very active in the field, Hubbard having covered 5,000 miles during the summer of 1944, and 12,000 during 1945. 


\title{
. CHAPTER 2
}

\section{THE MEDICAL IMPORTANCE OF FLEAS}

\author{
BUBONIC PLAGUE IN NORTH AMERICA
}

The Middle Age scourge of Europe "Black Death," known today as Bubonic Plague, first made its appearance on this continent in man in the year 1900. On March 6 of that year a Chinese man was discovered to have died of the disease in the Chinese section of the big west coast port of San Francisco. This was the beginning of a series of cases in the Chinese and Japanese quarters of this city, which extended through February of 1904. During this period 121 cases were found, of which 113 terminated fatally.

It will probably never be known when plague made its way into the rat population of the Bay area or how long it had been in these rodents before it appeared in man. It is supposed that rats infested with the Oriental rat flea (Xenopsylla cheopis) escaped off ships from the Orient into the city of San Francisco to spread the infection through uninfected rats and later to the ground squirrels. Neither the so-called domestic rats, Norwegian, Alexander, Black, nor the house mouse, nor their 3 common fleas-the Oriental rat flea (Xenopsylla cheopis), the European rat flea (Nosopsyllus fasciatus), nor the mouse flea (Leptopsyllus segnis) are native of this country. All seem to have been introduced through shipping channels. These rats and mice are very susceptible to plague; their 3 fleas are known to be vectors (transmitters) of this disease.

The history of the spread of plague in man in North America is interesting.

CALIFORNIA: After the first epidemic in North America had closed in San Francisco in February, 1904, there was no recurrence of the disease until May, 1907. During this month in San Francisco a sailor died of the disease. This was the beginning of the second epidemic. By June 30, 1908 when the last case of this series was reported, there had been 159 cases with 77 deaths. In this second epidemic the cases were scattered all over the city, not confined to the Chinese section. Nor was San Francisco the only locality touched during this period. Oakland reported 12 cases during 1907, Berkeley 1, and Contra Costa County 3. During 1908 Oakland reported 1 case, Contra Costa County 2, and Los Angeles 1. From 1909 through 1915 isolated cases appeared each year, the period covering 14 cases with 6 deaths; the infection spread to San Benito and San Joaqin Counties. Human cases 
were not again reported in California until August-September of 1919 when in Oakland a man who had been hunting ground squirrels in an infected area became ill 2 days after the hunt, and developed pneumonic plague. Twelve other cases developed, all terminating fatally. During 1920 a case terminated fatally in Alameda County. Three cases developed in 1921 with 1 death in San Benito County; 1922: I case each with no deaths in Oakland and Santa Cruz County; 1923: a nonfatal case in San Francisco.

The year 1924 stands out as an epidemic year. Between November 1,1924 , and January $5,1925,33$ cases of pneumonic plague resulted in 31 deaths, and 8 cases of bubonic plague resulted in 3 deaths, all in Los Angeles. Authorities seemed unable to trace the infection in this epidemic to rats or ground squirrels, although at the time to the north in San Luis Obispo County there had been a virulent outbreak of plague in ground squirrels.

From 1925 to 1937, 8 California counties reported 10 cases of human plague with 5 deaths. The counties in which these cases occurred were: Los Angeles 1925 and 1933, Contra Costa 1927, Santa Cruz 1928, Monterey 1928 and 1936, Santa Barbara 1928, Tulare 1934, Sonoma 1936, Placer 1936, and Fresno 1937. During 1938, 1939, and 1940, there were no cases reported from the state. Far to the north of any previous record, plague appeared in 1941 in Siskiyou County. Two children, 5year-old and a 10-year-old boy, died of the infection at Montague and Mt. Shasta City. Infected ground squirrels were subsequently found in the area. At Yreka, Siskiyou County, on November 9, 1942 a case appeared in a small $21 / 2$-year-old girl. The tot had been helping her father haul hay from a squirrel infected area. On January 10, 1943, the case terminated fatally.

To date, then, California has had 395 cases of plague in man, 268 of which terminated fatally.

OREGON: But one case of plague in man has come to the attention of authorities in Oregon. In the spring of 1934 a sheepherder made camp on Guano Creek Plateau, Lake County, north of Lakeview. The camp was in the shelter of rim rocks which afforded home sites for many marmots (woodchucks). The sheepherder became ill and died of what was diagnosed as bubonic plague. Suspicion was at once directed toward the marmots in the rocks but it was not until May 8, 1942, that these animals were found plague infested at Abert Lake to the north.

WASHINGTON: The first cases of plague in Washington appeared in Seattle during October of 1907. The records are not exactly clear as to the number, but 7 cases with 7 deaths is the largest figure. This large port town was heavily infested with rats which were found infected with plague that year and continued to be plague positive to 1917. No human cases developed after the 7 cases and no infected rats were found after 1917.

LOUISIANA: In 1912 and 1914 plague infected rats were found in 
New Orleans and between June 21 and September 8, 1914, 30 cases of human plague were recorded, of which 10 terminated fatally. A mild case of plague was found during 1915 and during 1919-1920, 22 cases occurred with 8 deaths. In 1921 this city reported 3 cases which terminated fatally. No further cases have been reported from Louisiana.

FLORIDA: In Pensacola between May 31 and August 31, 1920, 10 cases of plague in man were reported, 3 of them ending in death.

TEXAS: From June 16 to November 14, 1920, 18 cases of plague in man were reported from Galveston. There were 12 deaths. Plague infested rats failed to show in trappings after May 29, 1922. From June 19 to August 23, 1920, Beaumont reported 14 cases with 6 deaths. Port Arthur reported 1 case during 1920. It terminated fatally.

UTAH: No fatal cases of plague have been reported in man from this state, but during 1936 a mild case was reported and during 1939 another. In the latter case the 29-year-old patient was skinning coyotes and other animals prior to the onset December 4 . The case was in Millard County.

NEVADA: In 1937, a non-fatal case was reported from this state.

CANADA: Rodent plague surveys carried on in British Columbia have failed to uncover plague infection in that territory; human cases have not so far been reported from there.

During 1939, in the province of Alberta, a farmer died from what was diagnosed as acute septicemia; but other circumstances led to the belief that the death was caused by plague. The victim, a 35-year-old mink raiser had been feeding his mink on the ground squirrel Citellus columbianus collected in the vicinity. Some of the mink became ill and died. The farmer, in skinning these, scratched his hand and apparently received the fatal infection. Shortly after the death of this individual, an epizootic was noted in the ground squirrels of this part of southeastern Alberta, and an investigation proved by tissue and by flea pools that these squirrels, Citellus columbianus, were plague positive. Since that time, plague positive ground squirrels of the same variety have been found in the regions of Stanmore, Suffield, Sunnybrook, Youngstown and Hanna.

\section{SUMmary}

From its inception into man in North America in 1900, plague has been found in 506 persons, 321 of whom died of the infection. Eight states have reported human cases, the outbreaks having occurred in the following chronological order: California 1900, Washington 1907, Louisiana 1914, Florida 1920, Texas 1920, Oregon 1934, Utah 1936, Nevada 1937.

\section{A WORD OF WARNING}

Because of the small amount of plague in humans in North America in recent years, the American peoples should not be lulled into a sense of security, for any such security would surely prove a false one. Plague 
all through history has had periods of quiescence and recrudescence. No one can tell when the disease will again strike or where. Every state in the Rocky Mountains and west to the Pacific Ocean has its centers of infection in the wild rodents. The infection is there. It has only to spring forth.

\section{How Plague Works}

Plague is a bacterial disease caused by the organism Pasteurella pestis. This bacillus was first isolated during 1894. Yersin and Kitasato working independently discovered it about the same time. The bacillus is a short, plump oval rod measuring from 0.3 to $1.25 \mu$ in length. It can be found singly or in pairs, but long chains are rare. There is no characteristic arrangement. The bacilli are encapsulated, non-motile. Involution forms are common and may appear as coccus forms, large rods or swollen bodies. The plague bacillus does not produce soluble toxic substances. In general, the life of this bacteria outside the animal body is precarious. It seems to disappear speedily from soil, water, and buried bodies.

The opinion has been expressed that plague caused by this organism is primarily a disease of wild rodents, and that man is only an incidental victim. But in spite of this opinion it is said that about one-quarter of the population of Europe was carried off by this disease during the "great mortality" of Black Death of the fourteenth century. A civilization, or lack of it, in which peoples are allowed to live in filth and poverty, making them bedfellows with rats and mice, fosters outbreaks of human plague. In North America, besides the imported rats and mice, a whole series of native rodents, particularly ground squirrels, are known to harbor plague.

Plague in man is generally found to be of two types.

BUBONIC PLAGUE: This type of plague develops in a man only after he has been bitten by a flea which has become infective through sucking blood from a plague infected animal. In this type of plague diagnosis on clinical grounds is said to be relatively simple. An inflamatory swelling of the lymphatic glands occurs. These are called buboes. From these, bacilli may pass over into the blood. It is from these buboes that the disease received its name bubonic plague and from the point of attack the name of glandular plague. When the bacilli pass into the blood, they multiply extensively. Septicemia may occur and at times subcutaneous hemorrhages. These hemorrhages were far more common during the Middle Ages than now. The black patches due to the hemorrhages gave the medieval name of "Black Death." The case fatality of bubonic plague is 60 to 90 per cent.

In bubonic plague the role played by the flea is of vital importance. It is the go-between or vector. Under certain conditions the flea may transmit plague between rodent and man. These conditions are as fol- 
lows: First, the rodent must be infected and have the plague bacilli invading the blood stream. Second, the flea must feed upon the infected rodent and suck into its mouth parts and swallow into its proventriculus and stomach the blood containing the plague bacilli. Third, in the proventriculus of the flea the bacteria of plague reproduce rapidly to form an obstruction. This obstruction or dam is called a "block" and fleas so affected are said to be "blocked." Sometimes this block may occur in the esophagus. It is not possible for the flea to swallow beyond the block. Fourth, the flea is now infectious. It becomes hungry, wishes to feed. If it bites a man or an uninfected rodent it sucks the blood into its mouth parts but is unable to swallow it because of the block. As the new blood washes across the block, the plague bacilli become mixed with it. Because the flea cannot swallow, it vomits or regurgitates the now infected blood back into the bite and so the bacilli make their way into the new animal and infection begins. Blocked fleas are unusually dangerous because, being unable to satisfy their hunger, they repeatedly bite and try to feed, thus spreading the infection as they go.

Since plague bacilli can be found in the feces of fleas it has been thought that the scratching of this fecal matter into the skin could cause plague infection, but recent research tends to discredit this theory.

PNEUMONIC PLAGUE: This type of plague is also known as plague pneumonia. It occurs secondary to bubonic plague. It seems that the bubonic plague infection settles in the lungs to give a pneumonialike condition there. In this type of the disease in man no flea is necessary for the spread of the infection. In patients suffering from this type, huge numbers of the plague bacilli are found in the sputum and the infection is spread from person to person through the cough or sneeze droplets. Because of this direct spread, pneumonic plague is very much more dangerous than the bubonic type. It is also much more fatal, the case fatality being almost 100 per cent. The outbreak in Oakland, California during 1919 was of this type. In Manchuria during the years 1910-1912, 60,000 fatal cases were attributed to this lung infection.

IMMUNITY: Suspensions of attenuated or killed plague bacilli used as a vaccine have proved successful in immunizing experimental animals. Haffkine in 1897 developed a method of protective inoculation consisting of injecting heat-killed bacilli from old cultures. This method has been used extensively in India and has proved successful in some cases. Antisera may be prepared for the disease by immunization of horses and other animals, but their efficacy as therapeutic agents is doubtful. Research laboratories are constantly searching for a successful treatment of human plague.

\section{TYPHUS IN NORTH AMERICA}

Only recently has it become generally known that fleas in North America have become vectors of typhus. This disease is one of the seri- 
ous scourges of the Old World. The late Dr. Hans Zinsser of Harvard University states that it has killed more human beings than any other disease.

According to the statements of Dr. J. D. Ratcliff, Chief of the United States Public Health Service, Washington, D. C., the chief health officer of Baltimore called for the Service to examine people stricken with a high fever that ran for about two weeks, the persons having a reddish rash on their chests and abdomens. Dr. Rumreich, sent to investigate, found that the persons were suffering from typhus, the ancient killer of Eastern Europe and Asia. This disease is known to have caused Napoleon to withdraw his army from Russia. It is known to have killed 3 million Russians during World War I. But the disease in Baltimore did not possess this killing power.

Dr. Rumreich finally found in the basement of a drug store the focal center of the disease. The cellar was alive with rats. He trapped these and sent them back to Washington. In the laboratory the welltrained Dr. R. E. Dyer watched and examined the rats. The Pasteur Institute had found the louse responsible for human typhus in Europe, but the rats at hand were infested heavily with Xenopsylla cheopisthe dreaded vector of bubonic plague. Could this flea also spread typhus? Dr. Dyer found it could, by himself becoming an accidental guinea pig. One evening while preparing a salt solution of macerated remains of fleas for injection into guinea pigs, a few, quite accidentally, escaped and settled upon his body. Two weeks later the doctor had his first chill, then a temperature of 105 degrees. The doctor recovered; his disease was typhus. To quote Dr. Ratcliff, "He (Dr. Dyer) had taken the disease into the laboratory where research men could get it, and had proved the flea as the vector-the agent which passed the disease from animal to animal and from animal to man. Fleas could do the job all right: from rat to rat; from rat to guinea pig; from rat to man."

During 1941 it was reported that two pools of fleas taken from Norwegian rats in Georgia during 1939 were found to be typhus positive; these finds definitely condemned the sticktight hen flea and the European mouse flea as vectors of murine typhus. During May of 1939 on a certain farm in Georgia, where the farmer lay ill with a case of endemic typhus fever, several rats were trapped. From these were removed 135 1.* Echidnophaga gallinacea Westwood 1875, the sticktight hen flea; five 9.* Xenopsylla cheopis Rothschild 1903, the oriental rat flea; and seven 213.* Leptopsylla segnis Schonherr 1811, the European mouse flea, all of which proved typhus positive as did the brains of the rats. The strain of typhus was proved in these fleas by being passed through 14 generations of guinea pigs. The great majority of these developed clinical endemic typhus with necrotic scrotal reactions.

* See page 43 for explanation of reference numbers. 
So typhus is definitely known to be spread in America by rat fleas, the mouse flea, and the sticktight hen flea.

For some time typhus in the Old World has been considered different from New World typhus. The former was considered to have a much higher death rate than the latter. The two types of the disease were considered to be caused by a slightly different organism.

The causative agent of the disease is the organism Rickettsia prowa$z e k i i$, which is stated by some authorities to lie midway between bacteria and filterable virus. Not all investigators hold that there are two varieties of this organism but it is generally felt that Rickettsia prowazekii prowazekii causes European or epidemic typhus and R. p. mooser causes New World endemic or murine typhus.

One of the chief differences found in the two varieties of typhus organisms is that $R$. p. mooser will produce a necrotic scrotal reaction in guinea pigs while $R$. $p$. prowazekii will not. These organisms characteristically occur in the cytoplasm but not in the nucleus of the invaded cells.

In both types of the disease the incubation period in man is from $\mathbf{5}$ to 18 days. Violent headache, with fever and chills are characteristic. A macular eruption occurs after the fourth day. The crisis occurs in 12 days with recovery in about another 2 weeks. There are various complications. Case fatality may be from 2 per cent in North America to as high as 70 per cent in the Old World.

The disease is almost always associated with filth and overcrowding, with body lice in Europe and with fleas in North America. In Europe it is not known what maintains the reservoirs of typhus but in North America the reservoirs are in the domestic rats and many wild mice, thus the name murine typhus.

Typhus is not an uncommon disease in the United States. The reported cases for 1934 are over 1,308, the majority of which occur in the southern states. The disease is common in Mexico.

Clinically, it is stated that European typhus is not appreciably different from North American typhus, but it is known that the vector of the disease in Europe is the human body louse and possibly the human head louse, while the vectors of murine or North American typhus are various fleas and probably the rat louse Polyplax spinulosa.

Recovery from either type of typhus is said to result in a solid and lasting immunity to both. Vaccinations administered for murine typhus give complete protection against murine typhus only and give only incomplete protection against Old World typhus.

Since it has been a definitely established fact that the reservoirs of murine typhus are in the domestic rats and that both the rat flea and rat louse may act as vectors of the disease, it seems that strict control over rats is a very desirable method of controlling the disease at its source. 


\section{TULAREMIA IN NORTH AMERICA}

The disease tularemia is primarily one of rodents but when expressed in man it is known by a series of common names such as rabbit fever, deer fly fever, the tired disease. Early in the history of plague investigations in the state of California, tularemia came to light. McCoy working on plague in the California ground squirrel reported the discovery of the organism causing the disease in 1912 and with Chapin named the organism Bacterium tularense. It is generally understood that the organism bears the name of the California county in which it was first found, that is Tulare County.

Today a whole series of rodents and other animals are known to carry tularemia. In them it is a plague-like disease. It has been found in rabbits, meadow mice, ground squirrels, marmots, tree squirrels, prairie dogs, muskrats, beaver and other wild animals.

As early as 1922 Dr. Edward Francis stated that the California ground squirrel flea Ceratophyllus acutus (69. Diamanus montanus Baker 1895) had transmitted the disease between ground squirrels in one experiment. During 1933 in Minnesota an epizootic of tularemia among cottontail rabbits revealed tularemia infection in two pools of fleas from these rabbits. During 1934 another pool of fleas off these cottontail rabbits proved tularemia positive. During 1935 tularemia positive fleas were taken off snowshoe rabbits in Minnesota. A survey made on snowshoe rabbits between June 9 and July 28, 1937, in south central Alaska, north to Fairbanks and Circle, which involved the examination of 172 animals, proved these varying hares to be tularemia positive. During this survey both ticks and fleas were found very scarce. Some of the ticks recovered were found tularemia positive.

During 1938 tularemia positive Sage Rats (Citellus townsendi vigilis) were determined by tissue pool from animals taken at Ontario, Malheur County, Oregon.

Twenty-four prairie-dogs secured for examination during June, 1941, in Carbon County, Wyoming, supplied a pool of 43 fleas which proved tularemia positive. These fleas produced tularemia in guinea pigs in the Plague Suppressive Measures Laboratory at San Francisco. While no specific mention was made of the fleas involved, it is known that the chief flea carried by prairie-dogs in this part of the country is 76. Opisocrostis hirsutus Baker 1895.

During 1939 and 1940 spontaneous tularemia was reported from southern Montana and northern Wyoming in the beaver populations. Muskrats taken in Klamath Lake, Lake County, Oregon, during April, 1942, were found tularemia positive. In the beaver and muskrat epizootics mentioned, fleas were not involved, since these animals seem not to carry them.

A disease commonly referred to as "muskrat fever" by local physicians at Ruby Valley, Nevada, may prove to be tularemia. In Ruby 
Valley lies Ruby Lake, a large swamp 60 miles south of Wells, Elko County, Nevada. From it each year the catch of muskrat and beaver is large. During the trapping season the trappers suffer from the disease which consists of a painful ulcer on the hand or forearm. The ulcer may become multiple. Fever appears with the first ulcer and persists until recovery. No fatal cases have been reported. It is thought the disease is contracted from the muskrats while the trappers are skinning them. The disease came to the attention of health authorities during 1939 and 1940.

An Illinois natural history survey during 1939-1940 revealed tularemia in the rabbits of this state and the total of 485 human cases to that date.

On August 18, 1942, a tularemia-positive flea was found 40 miles south of Suffield, Alberta, Canada, the flea presumably off a ground squirrel.

Tularemia-positive ticks were reported from several localities in Alberta, Canada, during 1942; and a very interesting case cited for this year was of a band of 850 sheep in southern Alberta in which 24 died and many were ill of this disease. The sheep herder who tended these sheep skinned the dead animals and contracted the disease. Ticks removed from the infected animals proved tularemia positive in 1 case.

During September, 1942, a dead meadow mouse (Microtus) picked up at Newell, South Dakota, was found to be tularemia positive.

Man can contract tularemia while skinning any animal suffering from the disease if the animal's blood comes in contact with an abrasion on his person. Man can also contract this disease by being bitten by a vector of the disease. To date it is thought that certain fleas, certain ticks, and the deer fly, Chrysops discalis, can carry the disease from animal to man. The disease is widely spread in the United States. By 1936 it had been reported from 46 of our 48 states. It is far more prevalent than plague. There are thousands of cases on record.

The causative agent of the disease Pasteurella tularensis is a minute $\operatorname{rod} 0.2 \mu$ in breadth and from 0.3 to $0.7 \mu$ in length. In young cultures the organism is rod-shaped, in old cultures, coccoid. These bacteria are non-motile, non-spore forming and apparently encapsulated.

In man four clinical types of tularemia are recognized. The more common type is the glandular or ulceroglandular variety, another type is the so-called "typhoidal" variety.

Tularemia is characterized by headache, pains and fever. A papule appears where the bacteria enter the body. This later breaks down and forms an ulcer. Certain glands become painful and swollen and may break down and discharge purulent material. Infection through the eye area may cause ulcers on the eyelids. The disease runs a course of from 2 to 4 weeks. The case fatality is low, being about 5 per cent.

An attack of this disease confers a solid immunity. Second infections, if they occur, produce only a local lesion. 
Attempts to actively immunize human beings have been unsuccessful. Antisera seem to have no value.

\section{FLEA ALLERGY}

It has long been known that certain individuals suffer more severely from the bites of insects than do others. Of late, those people who suffer severely from flea bites are said to have flea allergy. There is no doubt that many adults and most children do seem to be sought out by fleas for attack. Very fair skinned individuals, often those with red hair, and tender skinned youngsters become targets for fleas, the bites starting frequently at the top of the shoes and then ranging all over the body as the flea or fleas feed. In people sensitive to flea bites the wound may be followed by swelling which can develop into large welts. The situation is aggravated by the accompanying itching and scratching. In so far as most of these attacks are from cat fleas, dog fleas and human fleas, the attack is more in the nature of a nuisance raid than one of danger.

In many places people suffering from flea allergy can clear up most of the situation by doing without pet cats and dogs, but in many coast towns and on farms where pigs are raised the numbers of human fleas are so great that control seems almost out of the question. Practically all itch allaying preparations obtainable at drug stores have been tried to sooth the bites of fleas. One investigator informed the writer that a piece of adhesive tape placed over the bite would stop the itching.

After considerable research upon flea allergy, Ely Lilly and Co., well known American drug house, took over the manufacture of a preparation which they named "Flea Antigen." This is prepared by the method of Dr. Albert C. Reed and associates at the Hooper Foundation for Medical Research of the University of California. It is an extract of the fleas of cats, dogs, and human beings in sterile phenolated isotonic saline solution. The usual initial subcutaneous dose for adults is $0.2 \mathrm{cc}$. This dose is usually increased to $0.4 \mathrm{cc}$. for 5 subsequent injections with intervals of 2 days between. The preparation number is PA-90. It may be purchased in $5 \mathrm{cc}$. vials. This preparation is thought to be effective against human, cat, and dog fleas only. It must be administered by a physician.

\section{FLEAS AS HOUSEHOLD PESTS}

The human flea, the cat flea, and dog flea can become household pests during their season of maximal abundance, which is generally during summer and fall. As sawdust burners become more and more common in basements, people are blaming the sawdust more and more for being the vehicle in which the fleas are delivered to the house. This may be true but it is difficult to see how an insect which lives entirely on blood in the adult stage and is interested mostly in host castings of one type or another in the larval stage can be associated with a pile of 
sawdust which has just come from a lumber mill out of a wet log. It is far more probable that the fleas are coming from domestic animals in the house or in the yard, their presence in the sawdust being incidental. If cats and dogs are allowed the liberty of the house, their fleas will drop their eggs everywhere on the premises. The eggs hatch into worm-like larvae which live in cracks and crevices and feed upon accumulations in these places. On farms where pigs are raised, these animals often become heavily infested with the human flea. Under such conditions the farm cats and dogs and the farmers themselves carry large numbers of these fleas into the house. Occasionally the European rat flea and the western chicken flea may contact man and get into houses.

The first point of control of fleas in the home is determining where the fleas are originating. Such determinations can only be made by examining the fleas. It is very difficult at times to make owners of pet cats and dogs realize that their pets may be bringing the fleas into the home, but too often this is the case. These household pets should be periodically powdered or bathed with a flea preparation. Floors and cracks should be cleaned of dust and castings, flea eggs and larvae. Basements should have their floors liberally sprinkled with salt water, or better still, a good application of five pounds or more of naphthalene flakes. After lying in place a day or so the flakes can be swept up and stored away for future application.

\section{FLEAS AS FARM PESTS}

Three fleas of agricultural importance may at times become startlingly common upon the farm. The western chicken flea, Ceratophyllus niger niger $\mathrm{C}$. Fox and the tropical hen or sticktight flea, Echidnophaga gallinacea Westwood may seriously menace the poultry on the farm. In the pig pens, the human flea, Pulex irritans Linnaeus, may become a serious nuisance. All three fleas can be controlled by liberal applications of kerosene or used engine oil about the premises. 


\section{FIELD AND LABORATORY TECHNIQUE}

\section{The Field Manual}

It is quite obvious that someone's field work must precede all laboratory technique. This phase, the field work, has not heretofore been stressed in any published work upon fleas. It is relatively easy to secure without much effort the various fleas that one might call domestic; that is, the human flea, which can be collected in large numbers from almost any hog pen, many lumber camps, or seashore resorts; the western chicken flea, which can readily be shaken in numbers out of almost any hen nest; the cat flea and the dog flea which appear in numbers during the summer months on the household cat and dog, but to successfully gather the other 225 species and subspecies of what one might call the wild native fleas listed herewith from the West, requires much more skill and much more patience. The great majority of these wild native fleas are to be found on the wild rodents of the vicinity. Generally it is much easier to catch the rodents than to find their nests, but in case their nests can be found, many more fleas can be taken from the nests than from the rodent hosts. Only upon rare occasions does a collector actually find wild fleas in any numbers roaming around upon the ground.

For any general collector, the wild rodents, which most of us think of as also embracing the conies, hares and rabbits, will be found to give the most fertile field for collecting. Unless these can be shot and placed in bags from which the fleas cannot escape, it is best in all cases to trap the hosts in traps which keep them alive until the collector can examine them and remove their fleas. While full directions are given for the capture of all animals mentioned with the host indices in following pages, the equipment necessary for the trapping procedure is listed here.

By far the most practical of all trapping devices for small animals is a very small box trap perfected by the writer and used by him exclusively for practically all wild nocturnal rodents. These traps are built around a common snap mouse trap and are large enough only to admit the fist of the collector. A battery of 50 of these is about all one man can care for during a field day.

These small traps can be constructed by the handy collector at the rate of about one per hour. They must be made; they cannot be purchased. Wood apple boxes which can be picked up in almost any gro- 
cery store, as empties, can well be used for the stock, or pine boards can be purchased for the purpose. The bases of the traps are made of l-inch by 4 -inch stock ( $31 / 4$ inches wide) surfaced on 4 sides and cut 7 inches long. The 2 sides and top are cut from quarter inch stock and should measure 4 by $41 / 2$ inches, the grain to run the 4 -inch way. Now build the box at one end of the base, nailing with inch brads or lath nails. Cut a piece of quarter-inch hardware cloth (screening) to fit the back, and nail in place. The back is made of screen because animals will more readily enter if they can see through. To explain the structure of the door is not so easy. A common tin shingle purchasable at any hardware store will make two doors with enough metal left over for several accessories. Set a common snap mouse trap, the wood base variety, and place it in the opening of the box of the trap. Now slip half the tin shingle over the box trap opening and slightly in front of the spring of the set mouse trap. Hold the mouse trap to the base of the box trap and spring the mouse trap. The snap at half sprung position will hold the tin shingle, which is now the door, tightly in place. Center the mouse trap, and push tightly against the door. With a pencil mark the size of the door, and then carefully mark around the snap of the mouse trap where it contacts the door. Trim the door to size with tin snips, rounding all corners slightly to prevent injury. With a small nail, punch a series of holes around the snap line, these to be used to wire the door securely to the snap. Before wiring the door to the snap cut a three-eighths inch square
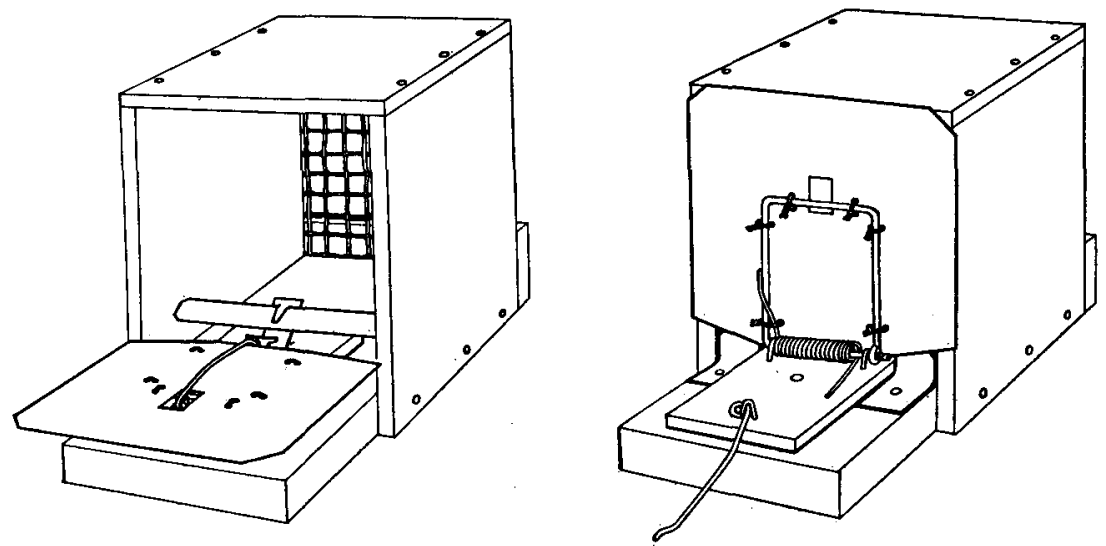

Fig. 2. Box trap designed by author.

hole just on top of and at the middle of the top line of the snap. The trigger goes through this top hole. With fine iron wire securely wire the door to the snap. Place in position so door is closed, then nail the mouse trap with lath nails securely to the base. To set the trap run the trigger through the small hole in the door as it is forced down to setting position and connect trigger connections as usual. 
Three accessories are to be made of the remaining metal of the half shingle. First cut a piece three-eighths of an inch by 3 inches, round off the corners, slip this under the hook which was made for the bait and clamp it in place with a pair of pliers. This is the treadle upon which the animal steps to set off the trap. Cut 2 pieces three-eighths inches by $11 / 4$ inches, round off the corners and bend up to right angle about a quarter inch from one end. Nail these in place, one on either side of the mouse trap so that they fill up the hole below the door. Nail a piece of lath across the back of the trap over the screen and raised about half an inch above the floor-this will prevent the bait from falling out during transit. After a model is once set up, others can be quickly built. The traps should not be built much bigger since the larger the door the more easily it can be pushed open because of the increased leverage. The trap should be just large enough to allow the collector's open hand easy entrance, and just as easy an exit when the fist is pulled out with the trapped animal.

These traps should be made. in units of 12, piled in 3 tiers of 4 each and a carrying box made for the 12. Empty dynamite boxes, because of their dovetailed joints, make excellent carrying cases. Each trap of the series of 12 should have a number on it in several places. If numbered the traps can be set out in rotation and picked up in rotation. Lost traps can be more easily located in this way.

These small traps will hold all types of mice, kangaroo rats, house rats, chipmunks, flying squirrels, conies, shrews, large and small weasels, western round-tailed wood-rats and a good percentage of bushy-tailed wood rats, golden-mantled ground squirrels and antelope ground squirrels. They will not hold anything as large as wild pine squirrels and usually the smaller sage rats will not enter them.

It is next to useless for the collector to burden himself with snap traps. On rare occasions they do prove useful. If large numbers of them are set out on a bright moonlight night, a night during which it is known that the moon will set about an hour before dawn, the mice to be caught will run at large during this hour of darkness, get into the traps and will be warm and with fleas when collected at dawn by the collector. On long dark nights snap traps are generally useless because the mice are caught early, the bodies cool and the fleas leave before the collector can pick up the catch in the morning.

Three other types of traps are needed for thorough field preparation. Pocket gophers require a special trap. The small green Macabee gopher trap, which is built in California and which retails for about 25 cents is excellent for small gophers. Larger gophers cannot generally be taken with these, but must be trapped with the Chinch gopher trap, which is built in Oregon and can be purchased for 50 cents. Either trap is set, then forced into an opened burrow and when the gopher tries to close the burrow it is caught and killed by the trap. Where lines of 
gopher traps are run, they should be frequently visited to remove the taken animals. Since but one gopher generally inhabits any one system of burrows, traps should be moved to other burrows after the owner is caught.

While the writer has captured moles with Macabee gopher traps, far better results will be secured with the special mole trap recommended by the Bureau of Biological Survey. This is the Out O' Sight Mole trap which is manufactured in the East, but which can be purchased in any hardware store for $\$ 1.25$. Moles are generally not easy to catch even with the best of traps. Since all mole traps kill, the lines must be frequently visited to remove captured animals.

Common steel traps have a wide variety of uses in the field. Most burrowing rodents can be taken in them. For some animals one has but to throw the set into the burrow and stake it down, other animals are very particular into what they step. Mountain beavers, gray diggers, wood-rats, and conies will readily step into bare traps, but sets for sage rats, Oregon ground squirrels, and some other rodents require skillfully hidden sets. Sets can be hidden by burying them shallowly after placing a ball of horse hair or soft moss under the pan.

Box traps, steel traps, mole traps, and gopher traps in fair numbers will give the necessary trapping devices to catch the host material of almost any vicinity.

The novelty of long lines of small box traps is the variety of mice and other small rodents in each night's catch. Box traps are generally set for anything that will enter them. The plan is not exactly to set the traps at random, but each location should be carefully considered as to how much shelter the small animal will have to get to the trap. The small mice depend primarily on natural shelter for their safety. Naturally then, the most profitable places to set traps are under logs, in sheltered cavities of one type or another, along fence rows, in old deserted buildings, in rim rocks. At times the collector can find dusting spots and small springs to which the rodents come to dust and drink. These afford excellent places for sets. In desert regions where there is little shelter between bushes it becomes necessary to set along the tiny trails and highways of the animals which can generally be seen running over the sands.

The matter of bait is one of question. Almost everything in the line of food has been tried to coax small animals into box traps, but a bait which practically climaxes all others as far as the tastes of the majority of small rodents is concerned is quick cooking rolled oats. A small handful of this thrown into a trap will attract a mouse for a long ways. Common rolled oats give only about 50 per cent of the results secured by quick cooking. Apple has always been an excellent bait but the moisture content runs rapidly through the intestine to badly soil the inside of the trap and muss up the feet and fur of the animal. Small 
carnivores, such as weasels and grasshopper mice, do not come into these small traps more quickly if they are baited with meat, but if they happen along they enter probably only to investigate the odors left in the traps by mice.

By far the most useful gun for the field is a .410-gauge shotgun. The small shot hardly tear the pelts at all, and therefore bleeding is brought to a minimum. Two and one-half inch shells will stop chipmunks, small squirrels, 3 inch shells will stop animals up to the size of marmots. For long distance work and large rodents a .22 caliber rifle is the most effective. A pneumatic air rifle is indispensable. It can be used to shoot pack-rats in small traps and in locations where firearms are prohibited it is a most handy weapon even for large squirrels.

The trapping day and its schedule plays an important part in the field work. Box trap lines should be set as close to dusk as possible without hurrying. Such a timing allows all available nocturnal rodents to enter the traps before morning comes with its host of daybreak loving chipmunks and ground squirrels. In the morning the chipmunks will find these traps remaining open and enter them. If the chipmunks enter in the evening they simply dirty up the traps and take the possible place of a mouse that cannot be shot during the day, as all chipmunks can.

Collections from box trap lines should be made as early after sunrise as possible. The sun irritates the small animals and soon they worry themselves to death. In the case of desert trap lines, the heat of the sun also causes quick death to the nocturnal forms.

It is the custom of this writer to kill all small mice at the trap, thus doing away with the necessity of again looking through them. Insert the hand, close it carefully and quietly over the mouse, withdraw, then force the thumb behind the ear until the neck is broken. No bleeding results if the job is done properly. Drop the mice into the clear glass jars of a biology collecting vest. Handle all mice carefully, any rough treatment will cause their fleas to hop off. In so far as there seems to be little or no correlation between the mouse and the number of fleas it will carry, it is generally not necessary to keep them in individual jars until their fleas are removed. Under no conditions mix different species or subspecies of hosts in these collecting jars. Practically all mice, chipmunks and kangaroo rats can be handled in this way. Squirrels, domestic rats, wood-rats or other animals of this size and nature are best taken back to the field laboratory and then shot with an air gun while still in the trap, or removed with a gloved hand. Such treatment prevents infection to the hands of the collector through scratches and bites of the infuriated animals.

While it is important to know where to trap, it is just as important to know where not to trap. Generally it is useless to trap in situations where farm cats are at large. Their patience generally rewards them 
with a meal off all of the more daring mice, the trapper having little or no chance where they run. It is generally useless to run a trap line at the same location a second night. All small mice seem to honor the other mouse's territory and apparently will encroach upon another's domain only after all smell of the owner has disappeared. Catches on a second night in one place fall off so sharply that it does not pay to try again the following night. While many mice can be taken from under new haycocks, most of these have abandoned old nests eleswhere to reestablish under the new haycocks and have thus left most of their fleas behind. Mouse takes from under new haycocks may be large, but the number of flea takes from the mice is generally small. Old haycocks, on the other hand, are almost always well worth-while turning over. An old well established mouse nest may often net the collector 100 fleas. Nests so collected should be placed in paper bags until they can be sorted over for fleas.

After all animals of a night's catch have been carried back to the field laboratory, preparations must be made for securing the fleas. The only equipment necessary is 70 per cent alcohol, chloroform, vials, labels, dissecting needles and a good sized white enameled dishpan. Some collectors use a comb to comb fleas off their host. Dr. Jordan suggests putting the fleas in 70 per cent alcohol to which has been added a drop or two of glycerine. This prevents hardening. The main point in removing the fleas from the hosts is that the operator get comfortable and out of the wind. Fleas will leave the hosts more readily if the hosts are cold. The collector should sit with the dishpan held between the knees. With some slight force drop the hosts out of their containers into the dishpan. The force with which they hit the bottom will jar most of the live fleas off. These can be picked out of the pan with a dissecting needle dampened in the vial of 70 per cent alcohol waiting for the reception of the fleas. After pummeling the host for a short time to force its fleas off, take the host by the tail and hind feet with one hand, then with the other rapidly run the fingers downward against the fur. This operation will force more fleas from the host. Holdenried of the Hooper Foundation said to the writer on their first trip into the field together, "I have seen fleas removed from hosts by collectors in a lot of different ways, but you are the first one I ever saw milk them off." The next operation is directed against stubborn fleas. Pour a small amount of chloroform into a clear pint jar. Dangle the host in the jar while forcing the hand over the opening for pressure. Most remaining fleas will hop off the host and die in the jar.

One school of collectors in the West holds that chloroform applied to fleas ruins them for plague work. This group of collectors uses hydrocyanic acid gas for the removal of fleas from hosts. The average collector is, however, not in a position to use this technique. A second school of collectors, just as interested in plague as the first, claims that chloroform in no way effects fleas as far as plague is concerned. 'This 
group of collectors uses chloroform altogether in removing fleas from their hosts.

After application of one or the other of these gases, dead fleas should be brushed out of the fur. In case chloroform is used, the hosts should be laid aside for a day and worked over again.

Fleas collected for plague inoculation purposes are bottled in a special salt solution and delivered to headquarters by air mail, special delivery.

All hosts which cannot be positively identified by the collector should be built into study skins with skull attached and turned over to a mammologist for identification.

It is a tedious task to remove fleas from most radent nests. It can only be accomplished by the hunt and pick method. Bit by bit pull the nest to pieces and remove the fleas. Wherever possible the host should be collected with the nest for positive identification.

A good collector places his label inside of the vial, most of us lick them and stick them on the outside so that they can fall off and cause confusion.

Field notes-every collector has his own ideas on field notes. Perhaps the writing of these gives the collector a few moments of relaxation before setting out to collect the traps set for diurnal animals or to shoot a few chipmunks and squirrels of one type or another.

\section{THE LABORATORY MANUAL}

It is not very often that one finds time in the field to mount or determine fleas. The customary procedure is to bring all specimens collected into a laboratory in the vials in which they were originally placed. When one is ready to proceed with the laboratory work it is the generally recognized custom to return all specimens to water.

A great deal of equipment is not necessary to work these insects in the laboratory. Bleach is necessary. This should be a 10 per cent solution of sodium hydroxide. Also at hand should be a 1 per cent solution of acetic acid, 25, 50, 75, and 96 per cent alcohol, carbol-xylol, cedar oil, xylene and mounting media. Carbol-xylol can be made by placing a pound bottle of carbolic acid crystals in warm water until it dissolves, then pouring half of it out of the bottle and replacing the half with warmed xylene. The solution should be strong enough so that when cold there are carbolic acid crystals precipitated on the bottom. The best of microscope slides and cover glasses should always be used. For the sake of beauty the author has always preferred to use round cover glasses.

Two things are of utmost importance in mounting fleas; first, the bleaching; second, the consistency of the mounting media.

Preparations are best carried through in watch glasses, those with ground glass edge. These stack nicely and are evaporation proof, and data can be written on the ground glass edge. 
The student should always remember that before bleaching there are many things of interest to be found on the inside of the flea which bleach will completely ruin for study. Some of these things of interest are the internal anatomy, about which little has been recorded for fleas; eggs in the abdomen of the female, these frequently differing with the species in size, shape and number; the Cysticercoid stage of the tapeworm, which at times can be seen in large numbers in the abdomens of fleas; nematodes, which sometimes completely pack the abdominal cavity; threadworm larvae which wind in seemingly endless length in the flea's body. All these should be studied before bleaching begins. To bring these things to light, remove the fleas from 70 per cent alcohol and place them in 96 per cent alcohol. After a few hours pipet off the alcohol and flood the specimens with carbol-xylol. They will begin to clear immediately. Check with microscope for interesting points and any found worth preserving can be prepared for mounting by being placed in xylene for a short time, then mounted in balsam. Very satisfactory identifications can often be made from such mounts but they are never mounts that one can look at with pride because of the cloudiness of the specimens. Carbol-xylol treatment at this time in no way affects the specimens for bleach treatment. To return the specimens to bleach, thoroughly wash balsam off them with xylene and then place in carbol-xylol. From carbol-xylol run specimens through 96, 50, 25 per cent alcohol and then to water. From water place specimens in bleach.

Remove fleas to be bleached from their vial of 70 per cent alcohol. Place each batch in a watch glass and cover with water. Place data upon the watch glass edge. Allow to stand in water for 24 hours. Drain off and then submerge the specimens in bleach. It is difficult to say how long a flea should remain in the bleach. Experience in this line is generally the best teacher. Pale fleas such as Corypsylla and Corypsylloides require very little bleaching, dark fleas such as the wild rabbit fleas seem to take endless time. If specimens are watched carefully, bleaching can be hastened by heating the bleach. The process should never be one of boiling and never should one heat the bleach to such an extent that the delicate edges of the sclerites become disfigured. Bleaching should continue until the visceral mass has completely disappeared. The author has always preferred a slow room temperature bleaching. This gives good definition to the sclerite edges and there is generally no distortion. Do not over bleach. Under bleached specimens can always be returned to the bleach, but over bleached specimens are often a total loss.

After the bleaching has been completed the specimens should be thoroughly rinsed in water, then for 24 hours suspended in a 1 per cent solution of acetic acid. This is, of course, to neutralize any bleach remaining in the specimens. After washing the acetic acid off with water, the fleas are to be run through the alcohol solutions, 25, 50, 75 and 96 per cent, several hours each. From the alcohols run the speci- 
mens into carbol-xylol. After a few hours check for clearness with microscope. If there is any trace of cloudiness, place specimens in cedar oil. If this does not clear up the cloudiness run fleas backwards through the process and rebleach. Before mounting the specimens should be as clear as glass, and in females the spermatheca and the marginal outline of the VII sternite should be very clear. In males the modified abdominal segments should show up well.

After specimens have been bleached and cleared to the satisfaction of the worker they should be changed from the clearing solution to xylene in which they should remain from a few hours to a day, depending on how much of a hurry the worker is to finish the job. When one is ready to mount, transfer the specimens to new xylene. Dry the cleansing alcohol from a slide and cover glass, place the slide in position on the mounting mat. Put a drop or two of balsam at center of slide, and gently spread over area to be covered by the cover glass. Dip the point of a dissecting needle into the balsam, then apply sticky tip to the flea to be mounted and lift it from the xylene into the balsam, center, and with a pair of forceps drop cover glass into place. The specimen or specimens should not drift. In multiple mounts care should be taken that all specimens are completely submerged in the balsam or air will seep into the fleas and cause them to turn black. In case specimens drift, raise cover glass, reset specimens and replace cover. Specimens which turn black must be unmounted, run back to the alcohol solutions and left there until the air escapes, then run back through the process again. In case balsam does not completely spread under cover glass, add a bit more with a quill or dissecting needle. Mounts look very much better if not too much mounting media is used and the cover glass rests snugly upon the specimens.

Before mounting fleas, one should prepare a mounting mat. On a white ruled index card place a microscope slide and mark around it with a pencil. Remove slide and divide outline of slide into 3 equal parts, 1 inch square. Divide the middle square with 2 lines running from opposite corners. They will cross at the center of the square. Center at the cross point a $1 / 4$-inch round cover glass, and outline with pencil. Repeat process with various other sizes of square and round cover glasses. With such a mat the specimens can be centered on the slide, as can the cover glasses and labels which go on the ends.

Various mounting media should be given trial before the student decides upon one. The author has always worked with balsam. The skill with which one mounts will depend entirely on how well he understands the working of the media. The author has always preferred to use a thin balsam in a comfortably warm laboratory. Balsam does not set rapidly but drying can be hastened in an oven. Balsam should be thinned to the consistency desired by adding xylene.

It is generally felt that all microscope slides and cover glasses should 
be washed in alcohol and dried with a linen handkerchief just prior to using.

Few persons agree as to the arrangement of fleas upon slides. However, fleas should never be thrown into the media to drift where they will as the cover glass settles down. There should always be some definite arrangement. For exchange purposes the writer prefers to place on a slide a male and a female of the same species, the male above, the female below, both with legs up, bodies parallel with top and bottom of slide, heads to the left, and equidistant between the center of the slide and the edge of a $3 / 4$-inch round cover glass. Rare specimens should be mounted singly in the center of a $1 / 2^{-i n c h}$ round cover glass. To show variation, as many as 50 medium-sized fleas can be nicely arranged in rows under a $3 / 4^{\text {-inch cover glass. }}$

It is generally not a good practice to mix species of fleas under a cover glass.

After viewing hundreds of specimens of fleas of other collectors which were placed upon slides in every imaginable position, the writer decided to mount all his specimens with head to the left. After using this method for some years, the writer was informed by Gus Augustson that Alfonso Dampf of Mexico City had written him that his specimens as well as Hubbard's were all placed on the slides backwards-that the International Congress had decided that fleas should be mounted with their heads to the right. Augustson changed over, but the writer still prefers to mount his specimens with heads to the left.

Although students of fleas have labeled slides with india ink on the glass slide ends, with special write-on-glass inks, and write-on ground ends, all meticulously prepared slides have a neat paper label pasted on each end. Labels should be affixed at the time the mount is made. In this way the label will dry out thoroughly and make a better inking surface as the balsam dries in the oven. Some key number must be placed upon the label in pencil so that, when labels are hard enough to ink in, the specimen can be referred back to the field log for collection data. If the hand is not too heavy, labeling should be done with a crow quill pen and black india ink. Type specimens should be further marked with some colored ink. If the hand is heavy any good fine writing steel pen will do. What goes on each label on the slide is a matter of choice. This collector places common name of host, location of collection, date, personal log number and name on right hand label; technical name of flea and technical name of host on left hand label. All data on labels should be carefully and neatly printed.

Before affixing labels or printing upon them, make sure legs of specimens are up.

When the slide is finished and ready to be stored away it should represent the collector and his skill, and should be something of which he can be justly proud. 


\section{THE ANATOMY OF THE FLEA IN RELATION TO ITS TAXONOMY}

As in the case of all insects, the body of the flea is divided into head, thorax and abdomen. Each of these regions with its appendages is of taxonomic importance.

Head: The division of fleas into suborders is based upon the presence or absence of a dorsal sulcus, which when present divides the head into anterior and posterior parts with free movement between. This hinging point extends from the antennal grooves over the top of the head. The antennae, one on each side of the head, lie in the antennal groove. The nature of the antenna as well as the groove occasionally has importance in classification. The antennal grooves divide the head into a post-antennal region and a pre-antennal region. The bristles and spines found upon each are of taxonomic importance. The pre-antennal region is divided into a forward frons and a lower gena. Many fleas bear on their frons a small notch or tubercle which is known as frontal notch or frontal tubercle. In many cases the lower portion of the gena is modified into a series of black flat teeth which make up the genal comb or ctenidium. In at least one case (Trichopsylloides) the lower margin of the gena is studded with genal spinelets. In fleas, eyes may be absent or there may be vestiges of varying density or simple eyes, variously shaped and generally jet black. The bristles vary in nature. Generally these taper evenly from the base to the tip, but in Stenistomera they are fattened midway along the length. In some cases bristles are heavily pigmented and stout in which case they are called spiniforms. This condition is well expressed in Ctenophyllus and Peromyscopsylla. In case there are 2 rows of bristles on the gena the lower row is called the ocular or genal row and the bristle closest to the eye or eye position is called the ocular bristle.

Of the mouth parts, generally only the labial palpi are of systematic value, the length and number of segments appearing occasionally in descriptions. In the bat fleas, however, the shape of the maxillae is important. These may be truncate or acuminate.

Thorax: Considerable space has been devoted to the structure of the siphonapteran thorax but taxonomically the only portion which has any great significance is the pronotum and the absence or presence on it of the pronotal comb or ctenidium. When present this comb varies in the number of the stout black teeth and in one case (Corypsylla) "in- 


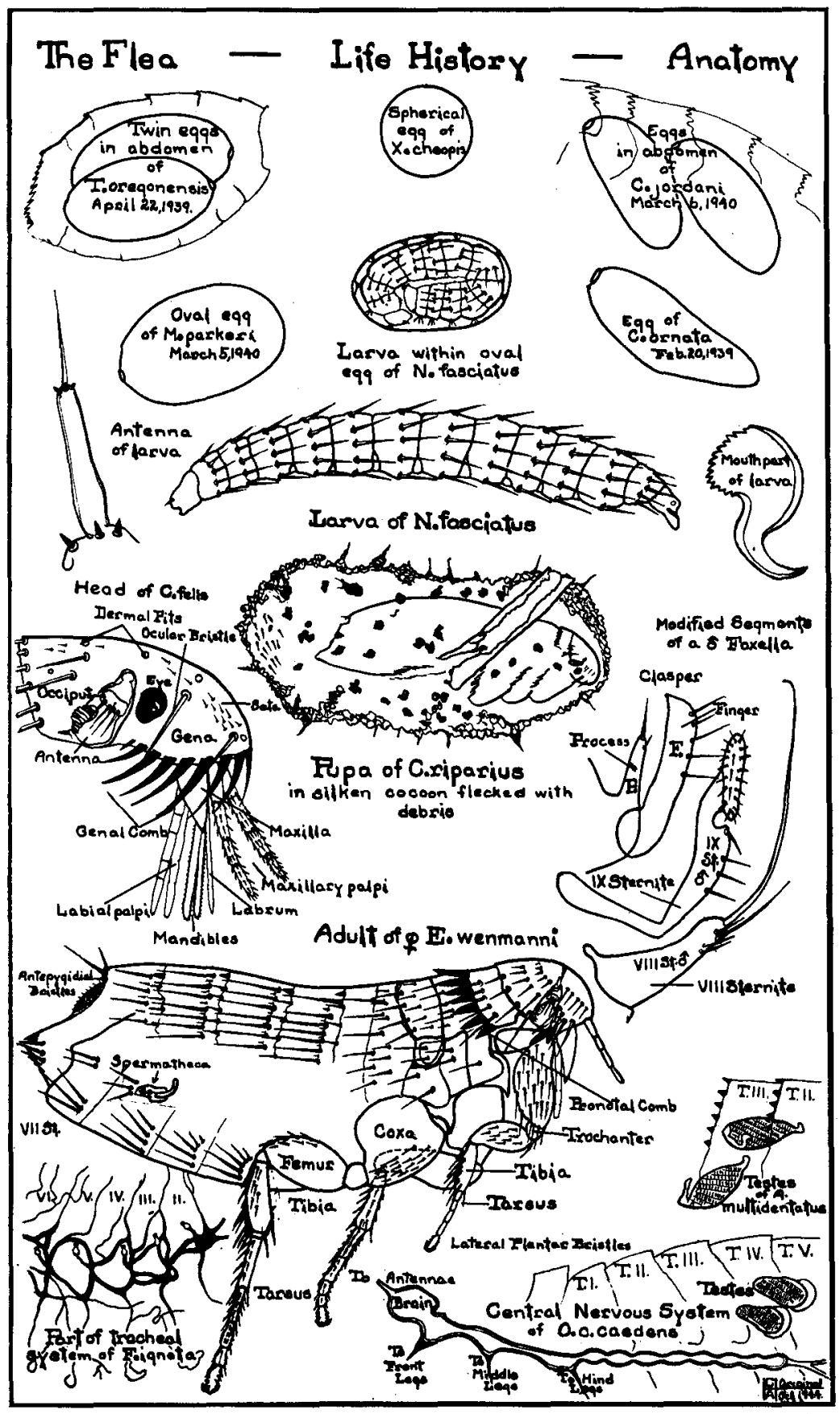

FIG. 3. Life cycle of the flea, and anatomical references used in illustrations following. 
distinct pseudospines" are present, and yet in another (Mioctenopsylla) the teeth are short and no more heavily pigmented than the pronotum itself.

LEGS: The arrangement and number of the bristles on the tarsus of the flea leg is of considerable importance in generic delineation. Occasionally the armature on the inner surface of the hindcoxa is important. In Conorhinopsylla segments I and II of the hindtarsus are hairy and bear a number of long dorsal bristles. In Tarsopsylla segment I of tarsus III is longer than II, III, and IV taken together.

ABdomen: Three features of the flea abdomen make it of importance taxonomically; the number of rows of bristles on each segment, the presence or absence and the number of antepygidial bristles, and the genitalia. Each segment consists of a dorsal tergite and a ventral sternite. The tergite may have its apical border denticulate as in Doratopsylla and this border may be armed with apical spinelets which may be pseudoctenidia as in some bat fleas, heavy and tooth-like as in Atyphloceras or just small pale teeth as in many other fleas. The VII tergite usually bears from 1 to 4 stout antepygidial bristles of varying length on each side. These are of systematic importance.

Frequently as one becomes better acquainted with fleas, he has only to glance at the genitalia to make determinations. The genitalia are then of tremendous taxonomic importance. In the male the genitalia have evolved in part from the ninth abdominal segment, the tergite forming the clasper which consists of a broad plate, ventrally prolonged to form the manubrium and dorsally bears the protuberance called the process of the clasper. Hinged to the clasper is its movable process the finger (exopodite) whose shape, size and armature are very significant. Shape, structure and armature of the ninth sternite are also taxonomically important. The penis with its springs and paramere do occasionally have systematic value. In the female the apical outline of the seventh sternite is of tremendous importance. Once in a while the armature of this sternite is important taxonomically. Some investigators have had a tendency to minimize the importance of the shape and structure of the spermatheca (receptaculum seminis), a heavily sclerotized sperm holding body within the abdomen of the female, but the author has always stressed this organ with special illustrations. The organ consists of a body or head and a tail or appendix, the appendix often with a terminal appendage. In most fleas this organ is single but in Atyphloceras and Hystrichopsylla there are two of these organs in each female. 
PART II

SYSTEMATIC CLASSIFICATION 



\section{A PRELIMINARY WORD ABOUT PART II}

In the following pages, bibliography will be brought to a minimum and the economy and biology of the flea will be expanded instead. The reason for this move is simple. During 1942 Jellison and Good issued their large work "Index to the Literature of the Siphonaptera of North America," National Institute of Health Bulletin No. 178, which is available to anyone who wishes to send to the Superintendent of Documents, Washington, D. C. The price is 25 cents. This is a book in itself, and very thorough. In the following pages, for the most part, only such bibliography will be offered as has been built up since the closing date of the work of Jellison and Good; that is, since July of 1939.

The illustrations in this volume are all the original work of the writer. As many as possible were drawn from types or paratypes, and such a note is made on the plate. All drawings were made with camera lucida, and therefore all parts of any individual illustration are in proportion, but they may not be in proportion with other individual illustrations. In practically all instances the parts of the male modified abdominal segments have been separated. Many flea illustrations are built with these parts intoto, but such an arrangement makes all the parts so small that frequently their value is entirely lost. The writer features in most cases the male finger and process generally together, but occasionally separated, the VIII and IX Sternites, and in some cases other parts. In the female some authors have included the armature on the VII Sternite but in so few cases does this armature come into importance that the writer has included these bristles only where they have taxonomic value. While many writers have not found it necessary to include good concise illustrations of the spermatheca, this writer feels this organ is of importance enough to give it special treatment so in the majority of fleas he has drawn it separate and enlarged. Some describers have failed to illustrate their descriptions of fleas. In cases where the describer has failed to include illustrations and the writer has been unable to obtain the specimens to illustrate them, a blank is left in the plate, to be filled in as the material becomes available to the student.

The numbering system is in no way involved. The Arabic numerals 1 to 236 are the reference numbers of those species and subspecies which are found in the West.

Recording the range or distribution of fleas can be only as conclusive as the research and collecting upon which the recording is based. For the most part, the writer has assumed that if a flea is found in one 
locality and then in another some distance away, it will surely be found in between, provided, of course, that its true host is found throughout that distance. For example, Meringis cummingi was described from Los Angeles, California, in 1926 off a kangaroo rat; 12 years later the writer took it off kangaroo rats 1,000 miles to the north at Klamath Falls, Oregon. There were no records of discoveries in between, but in 1940 Stewart took this flea off kangaroo rats at Jamesburg, Monterey County, California. So, as more collecting is done the gaps between the records close to complete the range record.

Seasonal distribution can only be charted for fleas by constant trappings of the hosts which they infest through the entire year. In high elevations this generally becomes impossible because of the deep blankets of snow. We know little of the winter fleas of the high mountain dwellers, such as conies. Nothing is known about the fleas which infest estivating and hibernating animals or whether fleas actually attack hosts during these periods of sleep.

The biology of the flea is practically an unexplored field. Under this heading the writer merely touches upon such items as the egg laying season, their numbers and shape, life history, life cycle and habits of the flea.

The medical importance of the flea varies from its being purely a nuisance to its provoking flea allergy, plague, tularemia and typhus. 


\section{THE ORDER SIPHONAPTERA}

The Order Siphonaptera, sometimes also known as Aphaniptera and Suctoria, consists of a series of wingless insects commonly known as fleas. In these the body is compressed laterally so that these ectoparasites can easily glide through the hair or feathers of their host. The mouthparts are modified for piercing and sucking with which the flea draws blood, its sole food, from the host. The antennae are 3-jointed, and situated on the sides of the head in the antennal grooves. The basal joint is such that the antennae can be revolved out of the groove to any position. The one most commonly seen is that with the antennae up over the head in the position of a pair of horns. Eyes, when present, are always simple, but the size and shape varies. The flea eye may be a vestige, in which case the amount of pigment present is always variable with the species. Many fleas are blind. The legs have 5-jointed tarsi and well-developed coxae. Metamorphosis is complete, running through egg, larva, pupa generally in a cocoon, and adult.

Fleas have been divided by some investigators into 2 suborders. The division is based upon the presence or absence of a so-called dorsal sulcus, which if present divides the head into 2 sections between which there is free movement. This dorsal sulcus extends up from the antennal grooves over the top of the head. Even though anything as definite as a dorsal sulcus should make it very easy to divide fleas into these 2 suborders, it seems that there are varying degrees of dorsal sulcus and so the student finds that authorities seem not to be able to agree as to what fleas shall go into each of these suborders. Establishing 2 suborders, however, is relatively simple, and a key of division employed in 1940 by Irving Fox in Fleas of the Eastern United States is:

"Preantennal and postantennal regions of the head not separated by a dorsal sulcus, although there may be a heavy sclerotization above the antenna............

$\ldots \ldots \ldots \ldots \ldots \ldots \ldots \ldots \ldots$ Suborder Integricipita

Preantennal and postantennal regions of the head separated above by a sulcus extending from the antennal groove to the dorsum and permitting motion between

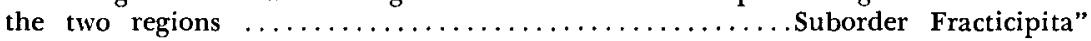

Fox then divided these suborders into families, as follows:

"SUBORDER INTEGRICIPITA OUDEMANS

Integricipita Oudemans, 1908, Tijd. v. Ent., 51:92.

KEY TO THE FAMILIES OF INTEGRICIPITA - P $/ 1 \%$

1. The three thoracic tergites together shorter than the first abdominal tergite

HECTOPSYLLIDAE

The three thoracic tergites together not shorter than the first abdominal tergite 
2. One row of bristles to each abdominal tergite

PULICIDAE

Two or more rows of bristles to each abdominal tergite

DOLICHOPSTLLIDAE

\section{SUBORDER FRACTICIPITA OUDEMANS}

Fracticipita Oudemans, 1908, Tijd. v. Ent., 51:92.

\section{KEY TO THE FAMILIES OF FRACTICIPITA}

Head with two separated genal spines only in the genus Peromyscopsylla; the spines not modified into broad plates (not on bats)

HYSTRICHOPSTLLIDAE

Head with two separated genal spines modified to form broad plates (on bats)

ISCHNOPSTLLIDAE

Dr. Karl Jordan holds that there is no basic foundation for the suborder as used by Oudemans. Other investigators have also disregarded the suborder to divide fleas directly into families. Most students of North American fleas place the number of families in this country at five.

In 1943, Irving Fox, while collaborating with $\mathrm{H}$. E. Ewing in Fleas of North America, abandoned his former division of the order into suborders and with Ewing broke the order directly into families as follows:

\section{KEY TO THE FAMILIES OF SIPHONAPTERA}

1. Thorax not greatly reduced, thoracic terga taken together longer than first abdominal tergum; gravid females moderately, if at all, enlarged

Thorax greatly reduced, thoracic terga taken together shorter than first abdominal tergum; females sometimes with a reduced number of abdominal spiracles, and when gravid, abdomen greatly distended

HECTOPSTLLIDAE BAKER

2. Gena, not divided by a vertical suture; head without helmet

3. Typical abdominal terga each with more than 1 transverse row of setae; fronto-epicranial groove frequently present

Typical abdominal terga each with but 1 transverse row of setae; fronto-epicranial groove usually absent; eyes usually present

PULICIDAE STEPHENS

4. Head seldom elongated, ventral flaps absent. Not parasitic on bats

Head usually elongated, always with 2 or 3 ventral flaps on each side adjacent to fronto-genal angle. Parasitic on bats.

ISCHNOPSYLLIDAE WAHLGREN

5. Cephalic combs absent; front not reduced; abdominal combs rarely present; abdominal apical spines rarely numerous DOLICHOPSTLLIDAE OUD
Cephalic combs, present; front frequently reduced; abdominal combs
frequently present; abdominal apical spines frequently numerous

HYSTRICHOPSTLLIDAE BAKER 
There are several genera of fleas which authorities fail to place satisfactorily in families. These are Callistopsyllus, Stenistomera, Megarthroglossus and Trichopsylloides. Good, in his review on Stenistomera, compares it with Callistopsyllus, but Ewing places Callistopsyllus in the family Pulicidae and Stenistomera as one of the most highly developed genera of the family Dolichopsyllidae. Jordan, in erecting the genus Phaneris, stated it was close to Rectofrontia, but Trichopsylloides of which Phaneris proved a synonym, is placed by Ewing in the simplest of the Dolichopsyllidae while he places Rectofrontia in the family Hystrichopsyllidae. Jordan in his discussion of Conorhinopsylla in 1937 stated that it is closely related to Callistopsyllus.

Dr. Jordan once expressed the opinion to the writer that the generic sequence in the vicinity of these genera should be Rectofrontia, Micropsylla, Trichopsylloides (Phaneris), Callistopsyllus, Megarthroglossus, Corypsylla, Nearctopsylla, and Atyphloceras.

Much of the systematic work on fleas is unsatisfactory and many of the keys so far developed are of little value. Opinions are in the state of change because of continued researches. Some investigators are attempting to solve the problem by adding many new subfamilies and subgenera, other investigators condemn such procedure, claiming such a course is a matter of convenience rather than a necessity, and lacks depth of understanding. Time, perhaps, will solve this problem of the systematics of the flea.

It is a simple matter of record that the writer issued the first check list of fleas of the Pacific Northwest of the United States during 1940, and the first check list of fleas for the state of California in 1943. In both of these he followed a generic sequence suggested to him by Dr. Karl Jordan in 1939. In the following pages this sequence, with only slight revisions and additions, will be used. 
THE FAMILIES OF SIPHONAPTERA GENERA AS HERE INCLUDED ALPHABETICALLY ARRANGED

FAMILY HECTOPSTLLIDAE, p. 49

Echidnophaga

Pulicidpe

Acetopsylla

Anomiopsylla

Cediopsylla

Amphalius

Amphipsylla

Vermipsy 1- PArctopsylla

Augustsonius

Ceratophyllus

Ctenophyllus

Dactylopsylla

Dasypsyllus
Hectopsylla Tungidae Tunga

FAMILY PULICIDAE, p. 56

Ctenocephalides

Hoplopsyllus

Pulex

Juxtapulex

Ceratoph yllidae

(FAMILY DOLICHOPSTLLIDAE, p. 84)

Diamanus

Dolichopsyllus

Foxella

Opisocrostis

Malaraeus

Megabothris

Mioctenopsylla

Monopsyllus

Nosopsyllus

Odontopsyllus
Opisodasys

Orchopeas

Oropsylla

Pleochaetis

Polygenis

Tarsopsylla

Thrassis

FAMILY HYSTRICHOPSYLLIDAE, p. 273

NO GENAL TEETH

Atyphloceras

Callistopsyllus

Catallagia

Conorhinopsylla

Delotelis

Megarthroglossus

Stenistomera

Trichopsylloides

Leptopsyllidae
2 GENAL TEETH

Epitedia

Meringis

Neopsylla

Peromyscopsylla

Phalacropsylla
3 GENAL TEETH

Carteretta

Ctenophthalmus

4 GENAL TEETH

Doratopsylla

Leptopsylla

Micropsylla

5 GENAL TEETH

Actenophthalmus

Micropsylla

Paratyphloceras

Rectofrontia
6-8 GENAL TEETH

Hystrichopsylla

12-14 GENAL TEETH

Stenoponia

HEAD WITH CREST

Corypsylla

Corypsylloides

Nearctopsylla

FAMILY ISCHNOPSYLLIDAE, p. 373

Eptescopsylla

Myodopsylla

Myodopsylloides

Sternopsylla 


\section{FAMILY HECTOPSYLLIDAE BAKER}

This family was established by Baker in 1904 on p. 373, Vol. 27, of the Proceedings of the United States National Museum to hold the genus Hectopsylla Frauenfeld, 1860. In the West three genera of this family are known to occur. Echidnophaga is represented extensively in the southwest in the flea $E$. gallinacea Westwood, the sticktight hen flea; Hectopsylla in the species $H$. psittaci Frauenfeld, a South American parrot flea discovered at Oceanside, California, and Tunga in the species $T$. penetrans Linnaeus, the jigger, or Chigeo flea which seems to have been reported from Texas. None of these fleas are native of this country; all have been introduced.

In this family of fleas the dorsal sulcus is wanting. Head angulate. Eyes are present and heavily pigmented. Genal and pronotal combs are missing. The thorax is greatly reduced and is shorter through the terga than the length of the first tergum of the abdomen. Abdominal segments may have a single transverse row of small setae. There are no antepygidial bristles. The abdomen does not have apical spinelets or combs.

Key to the Genera of HECTOPSTLLIDAE of the West

Coxa III with a patch of spinelets on inner apical surface

Echidnophaga Olliff

Coxa III with only scattered bristles on inner surface

1. Postantennal region of head with two bristles

2. Postantennal region of head without bristles

\section{GENUS ECHIDNOPHAGA OLLIFF}

Hectopsylla Frauenfeld Tunga Jarocki $\}$ Tung a

1886, Echidnophaga Olliff, Proc. Linn. Soc. N. S. Wales, 1:172.

Genotype: Echidnophaga ambulans Olliff 1886

Head distinctly angular. Genal and pronotal combs absent, as is the frontal tubercle. Conspicuous spiracle on segments II to VIII of the abdomen. Hind coxa has a patch of spinelets on the inner side, and at the apex is developed into a broad tooth. Three pairs of lateral plantar bristles occur on the fifth tarsal segment of the legs, and one or two pairs of bristles more slender in character are found to the anterior.

In the West, but one species of this genus is recorded. 


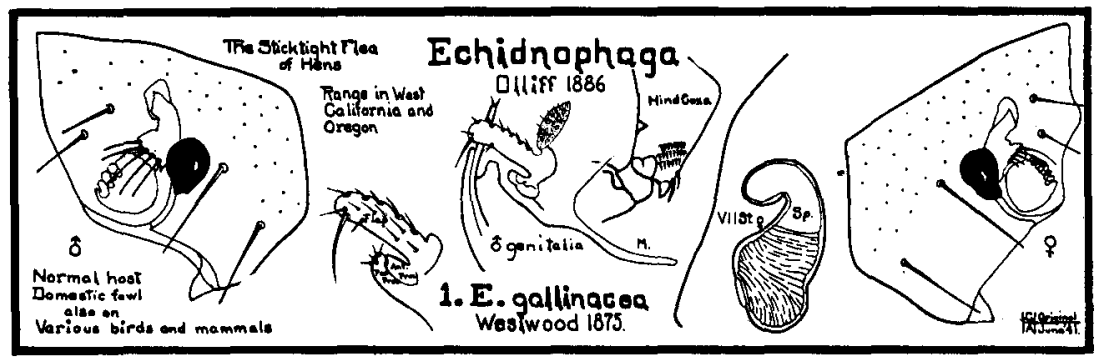

1. Echidnophaga gallinacea

Westwood 1875

1875 Sarcopsyllus gallinaceus Westwood, Ent. Mo. Mag., 11:246.

MaLE: Two bristles on the preantennal region and two on the postantennal region of the head. The oval eyes are heavily pigmented. The triangular maxillae are short and broad. The deeply serrated mandibles are long and tapering. There are three or four long bristles on the second segment of the antenna, some being about equal in length to the third antennal segment. There is a single row of bristles on the pronotum and mesonotum. There is at least one long bristle in the dorsal region of each abdominal tergite.

Modified Segmenrs: The clasper has two processes, a longer with several bristles on the anterior margin, and a smaller one. Movable finger rounded apically and curved toward the smaller process; armed with one long bristle and several smaller ones. The manubrium is long and slender. Female: Chaetotaxy similar to male. Spermatheca broader ventrally than dorsally, very characteristic in shape.

This is the sticktight, or tropical hen flea. It is one of the smallest fleas a collector finds, the male being under $1 \mathrm{~mm}$. in length.

In the Journal of Economic Entomology, Vol. 25, No. 2, p. 164, April, 1932, Dr. M. A. Stewart, now at University of California, stated that Brewer's blackbird, the English sparrow, and the Bobwhite quail are agents of dispersal for this flea. All of these birds are abundant in the Pacific Northwest, yet records for this flea are scarce in this part of the country. The writer has not found this flea in the state of Washington, nor does he know of any records from this state. Dr. J. G. Spencer, of the University of British Columbia, informs the writer that this flea has not yet been recorded from Canada.

RECORDS of this' species are:

OREGON-These tiny fleas were first encountered by the writer in 1934 on gray diggers (Citellus b. douglasi) trapped from beneath a deserted chicken house near Dufur, Wasco County, Oregon, then 3 years later 20 miles northwest of the original location, again on a gray digger. This animal was far from human habitations. The flea has doubtless, through want, changed its host from the domestic 
chicken to the gray digger and other small rodents in this part of Oregon. The writer records from Wasco County, this flea on:

Citellus b. douglasi Richardson (gray digger) at Dufur (5 miles southeast), June 5, 1934, 2 males, 3 females; Dufur (15 miles northwest), May 22, 1937, 1 female; Tygh Valley, October 19 and October 28, 1940, many specimens of both sexes imbedded in head region.

Peromyscus maniculatus gambeli Baird (gambel's deer mouse) at the Dalles (Seufert), November 8, 1940, 3 males, 20 females, imbedded in head region.

CALIFORNIA-On the West Coast the greatest concentration of these small fleas seems to be in southern California. Gus Augustson reports taking these fleas from Los Angeles County, on the following hosts besides man:

Urocyon cinereoargenteus californicus (California gray fox)

Lynx rufus californicus (California bob cat)

Citellus beecheyi beecheyi (California ground squirrel),

From Riverside County on:

Bassariscus astutus subsp.? (ringtailed cat)

Taxidea taxus neglecta (badger)

Citellus tereticaudus chlorus (round-tailed ground squirrel)

Neotoma lepida lepida (Thomas desert woodrat),

From San Bernardino County off:

Vulpes macrotis arsipus (desert kit fox)

Speotyto cunicularia hypugaea (burrowing owl),

From San Diego County off:

Citellus beecheyi nudipes (Juarez ground squirrel)

Phasianus torquata (ring-neck pheasant),

From Santa Barbara County off:

Microtus californicus californicus (California meadow mouse),

From Kern County off:

Lepus californicus richardsoni (jack rabbit) .

ARIZONA-In this state this flea has been reported off ground squirrels, and Gus Augustson reports it off the desert kit fox in Yuma County.

NEW MEXICO-The writer has specimens of this flea taken off ground squirrels at Sherman, Grant County, New Mexico, and it is reported off Alexandrian and Norwegian rats from this state.

Baker reports this flea from Texas as early as 1904. Trembley and Bishopp reported this flea in 22 states in 1940.

RANGE: This flea is abundant in the southern states, has been reported from several Rocky Mountain states, from New York and Minnesota, is fairly common in California, and now is found in Oregon. The flea is doubtless ranging north along the Pacific Coast. At the present time the Columbia River seems to form a natural barrier against its northward expansion.

Sex Predominance: Such examination as has been possible in the Northwest leads the writer to believe that there is a large predominance of females in this species.

Seasonal Distribution: The large number of this species taken off rodent hosts during October and November would suggest that it 
passed through its seasonal maxima during the fall portion of the year.

BIoLogy: The life history of this economically important flea is interesting. The egg hatches in from 4 to 14 days. The larva may pupate in anywhere from 14 to 31 days. The pupal period ranges from 9 to 19 days. After becoming engorged with food the females begin laying eggs in from 6 to 10 days after becoming attached to the host. The female once attached seems reluctant to change position, but the male roves around at night to seek new points of attachment.

Under laboratory conditions these fleas are found to die at a freezing temperature and could not live through $100^{\circ} \mathrm{F}$. in an incubator. This temperature range would doubtless have a marked bearing upon the distribution of the flea, but since the adult lives on a warm host and the larva in a warm nest, perhaps the temperature range in nature is not so critical.

ECONOMIC IMPORTANCE: The Pacific Northwest and the cooler parts of California have for one of their major industries, the poultry business-chickens, turkeys, and their eggs. The expansion of the range of a pest to poultry is serious. A heavy infestation of this flea will cause great loss among small chickens and the egg production may drop as much as 50 per cent.

The sticktight flea may be differentiated from the western chicken flea by size, color and attack. The sticktight attaches itself to the face, wattles and ear lobes where it sticks tight, the western chicken flea simply feeds upon the chicken, then leaves. The former is almost black, and small; the latter, dark brown and medium sized.

Medical Importance: In September of 1941 the sticktight or tropical hen flea was condemned by the United States Public Health Service as a vector of endemic or murine typhus fever. During May, 1939,135 of these fleas were removed from two Norwegian rats trapped on a farm in Georgia, and at Albany, Georgia, in September a rat which was shot in the city carried 30 of these fleas. Both these pools of fleas were found typhus positive and by proof the disease was passed through generations of guinea pigs which developed clinical endemic typhus with scrotal reaction.

It was reported from the University of Hawaii during 1942 that this flea under laboratory conditions had become infected with typhus. The fleas were allowed to feed upon infected rats. An emulsion of the feces of the fleas and the fleas themselves produced clinical typhus in guinea pigs.

Control: It has been suggested that the control of the dispersal agents of this flea would control its range. If this flea is to be controlled in chicken houses, the floors should be cleaned of trash periodically, and the trash burned. Liberal application of kerosene in closed houses is very effective. 


\section{GENUS HECTOPSYLLA FRAUENFELD}

1860, Hectopsylla Frauenfeld. Artzungab. d. k. Acad. d. Wiss. Wien, XL, p. 462. Genotype: Hectopsylla psittaci Frauenfeld 1860

Head not so angulate as in other genera of the family. Genal and pronotal combs absent. No frontal tubercle. Hind coxae with scattered bristles over inner surface which replace the spinelets in the preceding genus. No broad apical tooth on coxae.

In the West but one species of this genus is recorded.

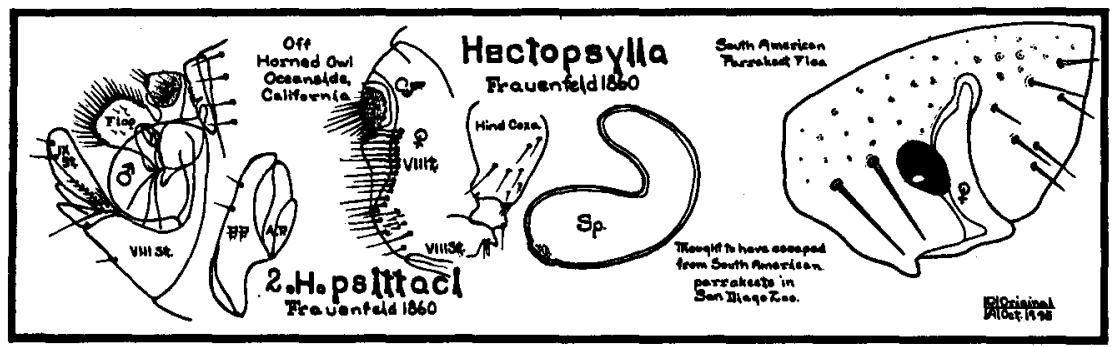

2. Hectopsylla psittaci

Frauenfeld 1860

1860 Hectopsylla psittaci Frauenfeld, Artzungab. d. k. Acad. d. Wiss. Wien, XL, p. 462.

MaLE: Two bristles on postantennal region of head at about level of top of heavily pigmented oval eye. Postantennal region of head with about 7 bristles distributed over surface in what might be series of threes. Triangular maxillae are short and broad, deeply serrated mandibles long and tapering. Pronotum with a single row of bristles. Abdomen practically nude except for bristles on modified segments.

Modified Segments: Clasper is pincher-like with 2 processes; anterior process small, posterior process much larger and armed with 2 weak bristles posteriorly. Flap is squarish, about as broad as long, and edged on 3 free sides with bristles of same length and evenly spaced.

Female: Chaetotaxy similar to the male. Armature of VIII t. characteristic, as is shape of spermatheca.

Range: This seems to be a South American parrakeet flea. However, original description was made from material off a parrot from Ceylon in the Indian Ocean. Later the flea was reported taken on an alcoholic specimen of a Nyctinomus.

RECORD:

On April 7, 1942, K. E. Stager removed from a specimen of

Bubo virginianus pacificus (great horned owl) taken at Oceanside, San Diego County, California, a series of fleas which, when they were mounted by Gus Augustson, proved to be all females of this little-known flea. It is supposed that the fleas were originally brought into this vicinity on South American birds housed in the San Diego Zoo at Balboa Park and close to Oceanside.

This flea has not again been encountered in this region, and some students doubt the specific identity of it. 


\section{GENUS TUNGA JAROCKI}

1838, Tunga Jarocki. Zoology, p. 50-52.

Genotype: Pulex penetrans Linnaeus 1758

Head distinctly angular. Maxillae reduced and completely hidden in head. Mandibles large. Eye oval and heavily pigmented. Head is without bristles, although the writer has seen very small setae along top of head in female. Inner surface of hind coxa is without patch of spinelets, these being replaced by a few scattered minor bristles. Plantar bristles slender on segment $\mathrm{V}$ of tarsus. Female without spiracles on abdominal segments II and III. No long setae on enlarged male VIII st.

This genus may be represented in southwest by the species.

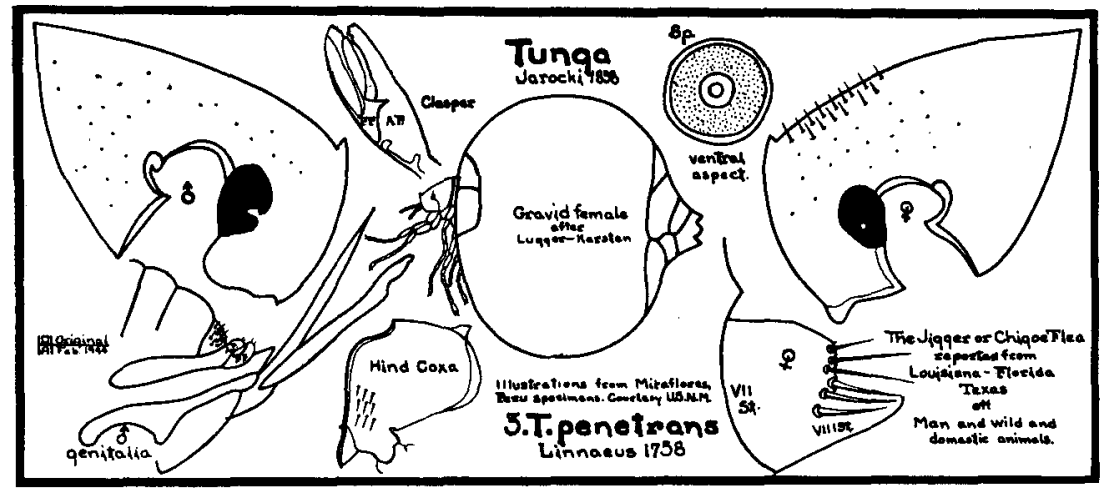

3. Tunga penetrans

Linnaeus 1758

1758 Pulex penetrans, Linnaeus, Systema Naturae, ed. 10, p. 614.

This is the flea which Baker in 1904 cautioned Louisianans, Texans, and Floridans to watch for. It was bound to show up sooner or later, but by 1940 I. Fox stated that the arrival was still anticipated. In 1943 Ewing remarked that ". . . although reported from Florida, Louisiana and Texas, it probably is not permanently established in the United States." So at present time collectors are not sure of presence of this flea in southern states.

Everything about this unusual flea is characteristic.

Head: Distinctly shaped and very angulate. Eye is oval and heavily pigmented. In specimens worked by the writer, head was devoid of any bristles but a number of minute setae were located on anterio-dorsal angle of head of female.

Thorax: Greatly reduced. There is no pronotal comb. In female abdominal segments II and III are without spiracles.

LEGS: Weak; hind pair not well-fitted for hopping. Hind coxae on inside surface is clothed with a few scattered weak bristles. Apex of the coxae is modified into a stout tooth. 
Modified Segments: Clasper of male is pincher in which posterior process is larger than anterior process. Both are armed apically with a few small bristles. Beyond this, modified segments and penis are highly complicated. For these features see illustrations. In female, apical margin of VII st. is characteristic as is VIII st. with its armature and shape of the spermatheca. Apical margin of VII st. is nicely concave below. In specimens examined VIII st. is armed apically with 3 stout and 3 medium bristles. Spermatheca is spherical.

Tunga penetrans, because it becomes a distinct nuisance to man and even at times a danger, has been given a series of appropriate and inappropriate common names. It is known as jigger, sand flea, chigoe, chique, tique, bicho, pico, tschike, nigua, tunga, tu ton, tungay and aargrani.

Medical Importance: While these fleas are found on a variety of animals and man in Mexico and Central and South America, the most interesting cases are, of course, its attacks on man. The most interesting case of human attack by this flea in the United States was reported from New Orleans, Louisiana, in 1930. Infestation occurred in a man into whose pubic and inguinal regions the larva had penetrated. It is supposed that the patient had become infested while sitting upon sisal hemp being unloaded from Yucatan.

Most generally these fleas attack man between toes or under toe nails. Once burrowed in females increase in size, cause intense itching and inflammation. Ulceration may take place. As secondary infection tetanus or gangrene may result.

In discussing this flea in 1904, Baker suggested that a sharp knife point, a little excavating and a good antiseptic wash were required to rid humans of these insects.

Biology: Life history of this species is most interesting among fleas. Female after copulation burrows into skin of host. In her burrow she feeds and continues to develop eggs. Her body becomes greatly distended, many times its original size and spherical in shape. Stretching of intersegmental membranes between second and third abdominal segments allows space for increasing number of eggs. Eggs hatch in 3 or 4 days and entire life cycle runs about 17 days. 


\section{FAMILY PULICIDAE STEPHENS}

1829 PLLICIDAE Stephens, Syst. Cat. British Insect, pt. II, p. 328.

With exception of one genus, members of this family have welldeveloped eyes. There is no frontal notch. Genal comb present or absent. Pronotal comb present or absent. On each abdominal tergite there appears a single row of bristles. Spine-like bristles may or may not be present on inner surface of hind coxae. On the fifth tarsal segment of each leg there appear 3 or 4 pairs of lateral plantar bristles.

This family is represented in the West by 8 genera.

\section{Key to the Western Genera of the Family PULICIDAE}

1. Eyes absent, antennal groove open behind

Anomiopsyllus, p. 78 Eyes present

2. Fifth tarsal segment with only three pairs of lateral plantar bristles

Fifth tarsal segment with four pairs of lateral plantar bristles

Actenopsylla, p. 63

3. Genal teeth absent

3.

Genal teeth present

4.

Pronotal comb absent

7.

Pronotal comb present

5.

6.

5. Mesosternite divided by a distinct vertical rodlike sclerotization

Mesosternite not so divided

Xenopsylla, p. 64

Pulex, p. 56

6. Pronotal comb present

7. Two or three pale tooth-like plates on gena

Hoplopsyllus, p. 67

Genal teeth straight, blunt black spines

Genal teeth curved, sharp black spines

Juxtapulex, p. 59

Cediopsylla, p. 74

Ctenocephalides, p. 60

\section{GENUS PULEX LINNAEUS}

1758, Pulex Linnaeus. Systema Natura. 10th Ed., p. 614.

Genotype: Pulex irritans Linnaeus

This genus is characterized by the absence of genal and pronotal combs. Two bristles on gena at about mid-eye level. Eye heavily pigmented, oval to grape seed shaped. No vertical rod-like sclerotization dividing mesosternite.

Only a single species of the genus occurs in West. 


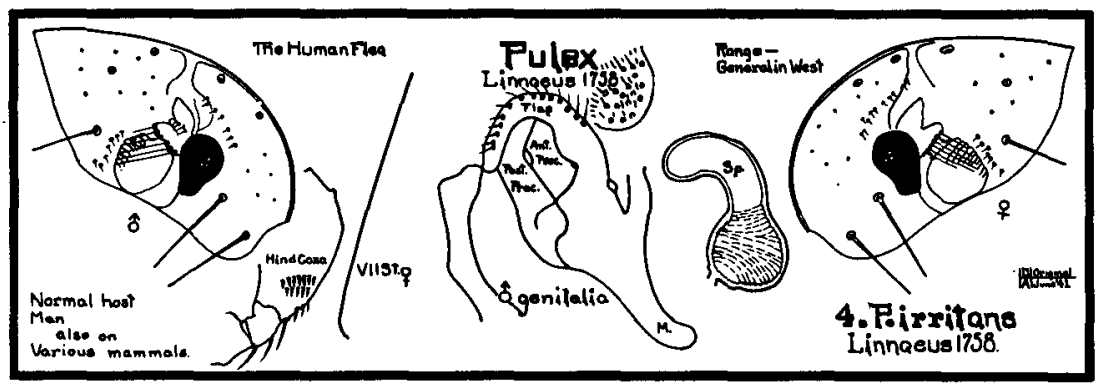

\section{Pulex irritans}

\section{Linnaeus 1758}

1758 Pulex irritans Linnaeus, Systema Natura., p. 614.

It will be remembered, say Jordan and Rothschild in Ectoparasites 1:312, that Pulex irritans differs from all other fleas in absence of vertical internal rod which connects midcoxa with upper margin of mesopleurite.

MALE: Preantennal region of head with 2 bristles. Numerous small setae on dorsal region of head. Serrated mandibles. Labial palpus extending more than half the length of the anterior coxa. A number of small setae range back to third antennal segment. One bristle occurs on postantennal region. One row of bristles, long alternating with short ones, arms each segment of thorax. Modified Segments: Clasper with 2 pincher-like processes, above which is a broad flap, margin of which is covered with thin curved bristles. Four or 5 small bristles on posterior process; anterior process without bristles. Manubrium short and curved. Ffmale: Chaetotaxy of head and general structure same as male. Sternite VII without sinus. Spermatheca with round head and finger-like tail.

RANGE: This is the human flea which commonly attacks man in Europe. It has been introduced into United States and is now probably found in every state. As time goes on, range of this flea steadily enlarges. On West Coast this flea is common in practically all lumber camps, sawmill towns, transient camps, flop houses and slums-almost everywhere there is a large moving population. In farming communities this flea is found to be a constant parasite of hogs and dogs, as well as the farmers. In wide open spaces it is found upon skunks, coyotes and other wild animals.

Medical ImPORTANCE: One of the species which habitually attacks man and is responsible for flea allergy in West. It has been experimentally infected with plague, but is not known to be able to transmit the disease.

Control: Where control is necessary for this flea, a good insect 
powder will be effective against adult, and a sprinkling of salt water, where it can be used, is effective against the larva.

ReCoRns: Records of this flea in West are:

OREGON-During July, 1931, the writer uncovered a large infestation of these fleas at Springwater, near Estacada. Fleas were taken in large numbers off the hogs of vicinity. Fleas were viciously attacking farmers. During July, 1938, a very large male specimen of this flea was secured at Portland, off man. The collection at the Rocky Mountain Laboratory at Hamilton, Montana, has this flea from deer sp., Curry County, Oregon, and from coyote in Josephine County, Oregon. The writer removed a female of this flea from:

Lepus californicus wallawalla Merriam (Oregon jack rabbit) Grass Valley, March 27, 1932, and off

Odocoileus columbianus columbianus Richardson (blacktailed deer) Reston, September 10, 1942, 1 male and 1 female.

CALIFORNIA-As early as 1908, Carroll Fox reported this flea from San Francisco off man and the Norwegian rat in connection with his plague suppressive work in that city, and in 1909 in Entomological News, January, p. 10, he writes, "The Pulex irritans seems to be a constant parasite of the skunk (Mephitis occidentalis) " in San Francisco County, California.

A vial of fleas sent to the writer from Crescent City, California, during June, 1938, contained, among other fleas, Pulex irritans. These fleas were taken from pet cats and dogs, and humans, and were apparently responsible for flea allergy in that region.

In southern portion of state Augustson reports this flea taken off the following hosts in Los Angeles County:
Spilogale gracilis microrhina (spotted skunk)
Mephitis mephitis holzneri (common skunk)
Urocyon cinereoargenteus californicus (gray fox)
Canis latrans ochropus (coyote)
Canis familiaris (dog).

He also reports it off:

Didelphis virginianus virginianus (opossum) from Kern and San Diego Counties,

Lynx rufus subsp. (bob cat) from San Diego County,

Lepus californicus deserticola (jack rabbit) from Kern County,

Mephitis mephitis estor (common skunk) from Riverside County,

Vulpes macrotis arsipus (desert kit fox) from San Bernardino County,

Odocoileus hemionus californicus (California mule deer) from Santa Barbara and Ventura Counties.

Through the southwest and north in the Rocky Mountains the human flea is a constant parasite upon prairie-dog, and coyote.

MONTANA-In this state where flea collecting has been going on for some period of time, the human flea has been taken off 8 hosts:

Gallus domesticus (chicken) from Gallatin County

Speotyto cunicularia (burrowing owl) from Beaverhead County

Canis familiaris (dog) from Gallatin, Ravalli Counties

Canis latrans (coyote) general over state

Mustela spp. (weasel) from Park County

Taxidea taxus (badger) from Madison County

Cynomys ludovicianus (prairie-dog) general over state

"Rabbit" from Madison and Petroleum Counties. 
To the east the writer has specimens off coyote and from many homes in Brookings County, South Dakota, and to north and west these fleas are reported generally from Alberta, British Columbia, and Washington.

\section{GENUS JUXTAPULEX WAGNER}

1933. Juxtapulex Wagner. Berlin Zool. Mus. Mitt. 18:431.

Genotype: Juxtapulex echidnophagoides Wagner 1933

Head angulate or broadly rounded. Eyes heavily pigmented, oval to grape seed shaped. Genal row of bristles 2 or 3, at level with top of eye. Gena with broad ventral lobe armed apically, toward anterior, with 2 or 3 pale tooth-like flat triangular plates which the describer calls genal spines. Mandibles enlarged and strongly serrate. Metepimeron extended vertically much more than longitudinally. Row or patch of spinelets on inner surface of the hind coxae. VIII st: plate of the male large, broad and unmodified.

This genus is represented in the West by a single species.

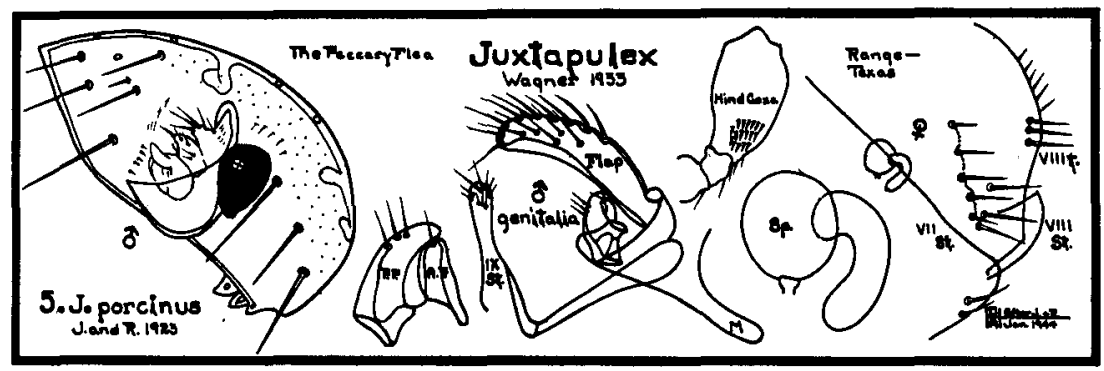

5. Juxtapulex porcinus

Jordan and Rothschild 1923

1923 Pulex porcinus Jordan and Rothschild, Ectoparasites 1:312.

HEAD: Well rounded. Gena armed with a row of 3 bristles at level with about top of the oval, black eye. The broad gena is armed apically with 2 or 3 pale thin triangular tooth-like extensions which the describers have chosen to call genal spines. Above eye a row or patch of small setae. Six or 7 bristles on postantennal region. Small setae along lower edge of antennal groove.

Thorax: Tergites with 1 row of bristles. Mesonotum is very little over half as long as the metanotum. Metepisternum with 2 bristles, metepimerum with 2 rows.

Ardomen: Bristles on $\mathrm{I}$ t. in 2 rows, on II t. to VII t. in 1 row.

Legs: Patch of short spinelets on inside of hind coxae.

Modified Segments, Male: On VIII st. a vertical row of 4 bristles, in front of row some minute hairs. Clasper made up of 3 processes, a narrow fairly long flap armed with numerous bristles and somewhat arched over the pincher-like pair of processes. Pincher not very large 
but posterior process very much larger than anterior. Pincher armed with a few small bristles. Vertical arm IX st. rounded at apex and gradually narrowing downward. FEMALE: VII st. longest ventrally, the apical margin slanting. Spermatheca is said by describers to be like that of Pulex irritans but original illustrations seem not to show this similarity.

LENGTH: The original length is given as males $1.6-2.1 \mathrm{~mm}$., females $2.7-2.8 \mathrm{~mm}$.

RANGE: This American wild hog or peccary flea has a limited range in West, probably extending throughout range of its host which is southwestern Texas and southeastern New Mexico.

\section{GENUS CTENOCEPHALIDES S. AND C.}

1930. Ctenocephalides Stiles and,Collins. United States Public Health Report, $45: 1308$.

Genotype: Pulex canis Curtis 1826

Both genal and pronotal combs present. Genal comb more or less horizontal, consisting of long sharp spines. Frontal incrassation is quite distinct. Ocular bristle above eye or on a level with it.

This genus is represented in West by common dog flea and common cat flea.

Key to the Western Species of Ctenocephalides

Frons high and well rounded

C. canis, p. 62

Frons low, flat and not well rounded

C. felis, p. 60

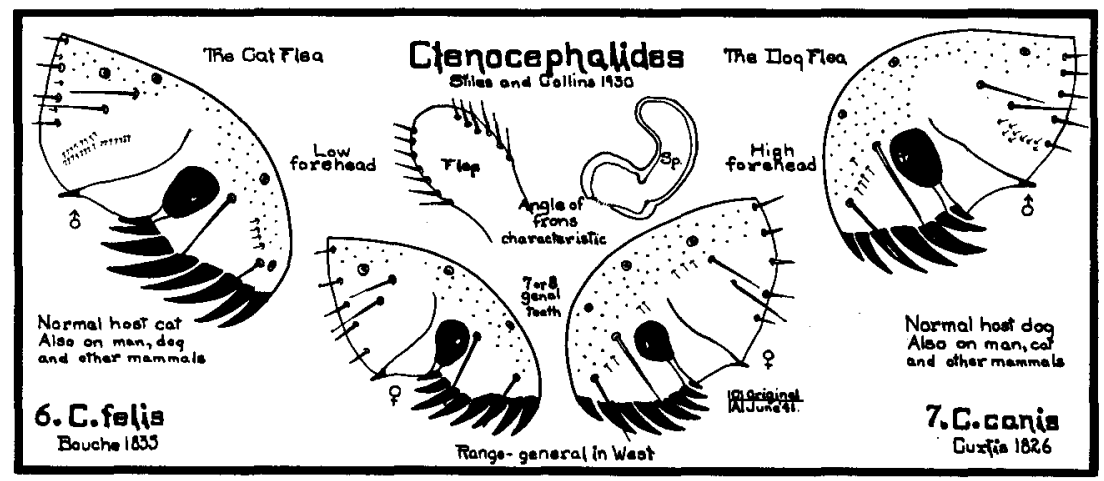

6. Ctenocephalides felis

Bouche 1835

1835 Pulex felis Bouche, Nov. Act. Acad. Leop. Carol,, 17:505.

1940 Ctenocephalides felis Holland, Proc. Ent. Soc. B. C. No. 36.

1940 Ctenocephalides felis I. Fox, Fleas of the Eastern United States, p. 24.

This is the domestic cat flea which, with the dog flea, can be distinguished from all other fleas by presence of 7 or 8 sharp black genal teeth. It can be told immediately from dog flea by its low, sloping 
forehead. While its normal host is the house cat, it readily attacks dogs. Occasionally it is found on wild animals. Its distribution over the West is far more general than that of dog flea.

LENGTH: Cat flea is a medium-sized flea. There is some variation in size but males are generally under $2 \mathrm{~mm}$., females generally over $2 \mathrm{~mm}$. Difference in size of the sexes and a slight difference in color generally lead people to believe their pet is carrying 2 species of fleas.

RANGE: General throughout the United States.

Medical Importance: This flea becomes a serious pest to man during its seasonal maxima in June, July and August. During these months the increased numbers of adults cause many of them to find their way onto man. They bite him severely. Individuals super-sensitive to flea bites suffer greatly during this period; bites swell to large welts with intense itching. Itching can be reduced by placing a piece of adhesive tape over the welt. "Flea Antigen" may be resorted to.

This flea has been experimentally infected with plague but there is no evidence that it can transmit disease to other animals.

The tapeworm Dipylidium caninum which has its final stage in man, dog, and cat has this flea for its intermediate host. As in case of many fleas examined, the Cysticercoid stage can readily be seen in the body cavity of the flea. This flea is also said to be intermediate host of nematode Dirofilaria immitis.

CONTROL: Flea powders are successful against any one batch of these fleas upon a cat, but just as soon as the cat is again allowed access to the outside, it picks up more fleas from its neighbors, so powder dustings must be repeated periodically. Flea larvae in basements or sheds or barns can be controlled by applying salty water liberally to floors.

RECORDS from the West are:

OREGON-Two interesting records of the writer are from:

Rattus norvegicus Erxleben (Norwegian rat). Fifth and Hoyt Streets, Portland, September 10, 1938, 1 male.

Brachylagus idahoensis Merriam (Idaho pigmy rabbit). Summer Lake, June $17,1937,1$ female.

CALIFORNIA-As early as 1909 Carroll Fox reports this flea off man, cats, and Norwegian rats at San Francisco.

During June of 1938 the writer received fleas from Crescent City, Del Norte County, from homes in which the occupants were suffering severely from what seemed to be flea allergy. The most numerous species in the series was the cat flea.

Augustson reports this flea off the following hosts in Los Angeles County:

Urocyon cinereoargenteus californicus (gray fox)

Canis latrans ochropus (coyote)

Canis familiaris (dog).

From San Diego County off the following hosts:

Felis domestica (cat)

Lynx rufus subsp. (bob cat).

The writer has studied specimens of this flea off a jack rabbit taken in Arizona and off house cats from Montana and South Dakota. 
WASHINGTON-This species is reported infesting most of the cat and dog pounds in the state of Washington.

BRITISH COLUMBIA-Holland removed 4 specimens of this species from Norwegian rats (Rattus norvegicus Erxleben) at the city dump of Vancouver, on September 8, 1938.

\section{Ctenocephalides canis}

Curtis 1826

1826 Pulex canis Curtis, British Entomology, Vol. III, No. 114.

1940 Ctenocephalides canis I. Fox, Fleas of Eastern United States, p. 27.

This is the common dog flea. Like the common cat flea, it has a genal comb of 7 or 8 black, stout, curved genal teeth. It is said that in dog flea first genal tooth is shorter than second, while in cat flea it is as long as second. This is sometimes hard to demonstrate and a far better point of difference is angle of frons. In cat flea frons is low, flat and not well rounded, while in dog flea forehead is high and well rounded. Other features of the 2 fleas are very similar.

Favored host of this flea is doubtless the domestic dog, but it is taken frequently off cats, wild dogs of one type or another, and attacks man readily during summer months when season of maximum abundance is at hand.

LENGTH: Dog flea is a medium-sized flea. There is some variation in size. Males are generally under $2 \mathrm{~mm}$. in length while females may be as long as $3.5 \mathrm{~mm}$.

RANGE: This flea has a fairly general distribution through West. This writer does not feel that it is as abundant in West as is cat flea, although some investigators think reverse is true.

Medical ImportanCE: This flea becomes a nuisance to man during the summer. Persons allergic to flea bites should not have cat or dog pets about the house during the warm season: Flea powders give only temporary relief to flea nuisance situation.

This flea is an intermediate host of the tapeworm Dipylidium caninum which is known to be found in man. Cysticercoid can readily be seen in many cleared fleas. It has also been reported intermediate host of tapeworm Hymenolepis diminuta which has been found in man, and intermediate host of Dirofilaria immitis, Leishmannia donovani and Leishmanni infantum.

ConTrol: Periodic bathing and powdering of pet cats and dogs, and thorough cleansing of their beds and bedding will check to some extent the number of fleas they carry. Reinfestation easily takes place, however, if these animals are allowed out of doors.

Brology: Complete life cycle of this flea requires only from 2 to 4 weeks. Adults have been known to live 234 days while feeding upon man alone. 
RECORDS from the West for this flea are:

OREGON-Infestation of dogs and cats and occasionally man, general throughout the state.

CALIFORNIA-This flea was reported by Carroll Fox as early as 1908 off Norwegian rats, black rats, man, and dogs from San Francisco. During the summer of 1938 the writer received from Crescent City, Del Norte County, vials of fleas which contained, among others, the dog flea. These fleas were taken from the pets in homes where the family members were suffering terribly from flea attacks. The attacks caused considerable swelling and discomfort. In the southern portions of the state Augustson reports this flea off:

Citellus beecheyi nudipes (Juarez ground squirrel)

Didelphis virginianus virginianus (opossum)

from San Diego County, and from Los Angeles County off:

Urocyon cinereoargenteus californicus (gray fox)

Canis latrans ochropus (coyote).

In Montana this flea has been taken off the domestic dog and captive blue foxes. In South Dakota it is found on domestic dog. There are many records of the occurrence of this flea on dogs in Alberta and British Columbia, Canada. In Washington the flea is found generally upon dogs.

\section{GENUS ACTENOPSYLLA J. AND R.}

1923. Actenopsylla Jordan and Rothschild. Ectoparasites I:309.

Genotype: Actenopsylla suavis Jordan and Rothschild 1923

Head strongly rounded. No tubercle or angle. Gena with 2 long bristles, one in front of eye, other near ventral margin. No genal comb. Club of antenna segmented all around.

Pro- and mesothoracic tergites and abdominal tergites II to VII with 1 row of bristles. Metepimerum with a bristle above stigma. Stigma III to IX of equal size. Hind coxa on inner side with a row of 6 to 8 spinelets. Segment V of all tarsi with only 3 pairs of lateral plantar bristles.

There is but 1 species in this genus. It was recorded from nest of Cassin's auklet off shore of Lower California.

\section{Actenopsylla suavis}

Jordan and Rothschild 1923

1923 Actenopsylla suavis Jordan and Rothschild 1923, Ectoparasites, I:309.

HeAd: In original description it is stated that there are 3 large bristles above antennal groove, third belonging to subapical row; this row with a few dorsal bristles, but no lateral ones besides long one. In male, occiput has a very deep dorsal groove. The proboscis nearly reaches to apex of forecoxa.

Pronotum without a comb, but armed with a single row of bristles. 
Modified Segments, Male: VIII st. large, divided by a deep lateral slit into 2 parts, lower triangular in lateral aspect, upper part rounded apically. Outer flap $\mathbf{P}$ of clasper very large, quadrangular, widest distally, clothed with bristles along dorsal and posterior edges, and a stout, short, black abtuse spine on inner surface of a nose-like projection at posterior apical angle. Upper inner process $\mathrm{F}^{\mathbf{1}}$, small nearly bean shaped, with apex produced as a short slender cylinder which bears a very thin, long apical bristle. Second process $\mathrm{F}^{2}$, is very long and broad at base, first directed posticad, then curved upwards. Vertical arm of IX st. is concave ventrally, but apically convex, armed with 6 long bristles and a few short ones. Female: VII st. deeply excised, margin below sinus almost vertical and rather close behind row of bristles; ventral margin of lobe above sinus nearly horizontal. Head of spermatheca almost globular; tail more than half as long again as head.

LENGTH: Lengths of the original mounted specimens were given as male $1.8 \mathrm{~mm}$., females $2.7 \mathrm{~mm}$.

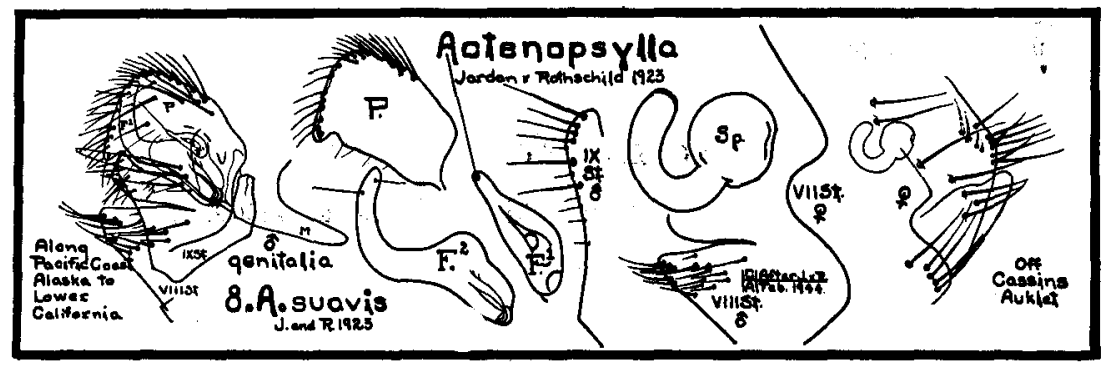

RANGE: One male and 7 females were collected from nest of a Cassin's auklet (Ptychorhamphus aleuticus) during May of 1913 on Coronado Island off shore of Lower California. Since Cassin's auklet is found on many islands and rocks off shores of Pacific Coast it is suggested that this flea may be found in nests and burrows of this bird all along West Coast.

GENUS XENOPSYLLA GLINKIEWICZ

1907. Xenopsylla Glinkiewicz. Sitzber. Ak. Wiss. Wien, 116:386.

Genotype: Xenopsylla pachyuromyidis Glinkiewicz 1907 $=$ Pulex cheopis Rothschild 1903

Head broadly rounded. No genal teeth. Frontal tubercle absent. Eye heavily pigmented, circular in shape. Antennal club is short, not segmented on anterior face. Pronotal comb absent. Pronotum with a single row of bristles. Broad mesosternite is divided vertically by a rodlike sclerotization. Hind coxa with row or patch of spinelets on inner surface. Fifth tarsal segment with 4 pairs of lateral plantar bristles.

In West this genus is represented by a single species, Oriental rat flea, which is one of most efficient known vectors of bubonic plague. 


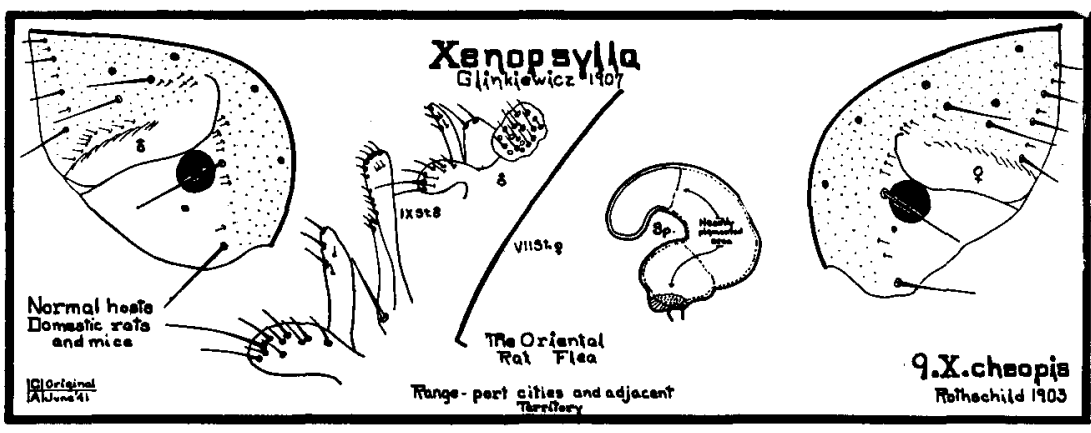

9. Xenopsylla cheopis

Rothschild 1903

1903 Pulex cheopis Rothschild, Ent. Mo. Mag. (2nd ser.), 14:85, Pl. I, figs. 3, 9; Pl. II, figs. 12, 19.

1939 Xenopsylla cheopis Roudabush, Science, 89:79.

1940 Xenopsylla cheopis Holland, Proc. Ent. Soc. B. C. No. 36.

1940 Xenopsylla cheopis I. Fox, Fleas of the Eastern United States, p. 16.

MaLE: Preantennal region of the head has a bristle situated at base of maxilla, and one over the eye, with a few setae between 2 bristles. Labial palpus almost as long as the forecoxa. There are about 10 bristles of various sizes situated on first antennal segment, while second antennal segment bears 4 long bristles. Twelve small setae are found posterior to third antennal segment. Three rows of bristles are on the postantennal region-first and second rows are composed of 1 bristle each, while 5 bristles and 4 setae, situated alternately, comprise third row. Single row of long bristles, alternating with setae, are found upon each segment of the thorax. Modified SFGments: Of 2 processes of clasper, 1 is narrow and curved outward, while other is flat and has a row of bristles on its upper margin. Posterior arm of IX st. broad at apex and bears a number of bristles. Female: Chaetotaxy of head and general structure same as in male. Spermatheca large and prominent, characteristically shaped.

This is the oriental rat flea which, according to Jordan and Rothschild (1908), had its original home in Nile Valley. From this point it has been introduced into countries on every continent. Carrier of this flea has been the common rats, Norwegian, black, and roof. Via water trade routes from Orient, this rat flea has been introduced into West through harbor ports. It is one of chief vectors of bubonic plague in Old World and as such is a menace wherever introduced. Although Wagner in 1936 did not mention this flea from British Columbia, Canada, Holland later recorded it from Vancouver, and it is reported from the three Pacific Coast states.

Length: Oriental rat flea is a medium-sized flea. Males are about $1.5 \mathrm{~mm}$; females about $2.0 \mathrm{~mm}$. in length. 
Range: Through port towns this flea has made its way into North America. With Norwegian rat it has followed man to many points inland. Its distribution is spotted. While its greatest concentration is in port areas, flea is known to reach far north on Mississippi River. In Rocky Mountains there are records of it from Salt Lake City, Utah. It seems established in western British Columbia and is probably spreading north and east in Canada from west.

Medical Importance: There is little doubt that this flea is the most dangerous species in America. It has been known to be one of the most efficient vectors of plague for a long time. It seems to have the honor of being the insect which spreads plague from harbor rats to ground squirrels about San Francisco Bay, California. Lately this flea has been found to be a vector of endemic or murine typhus fever in this country. In dried feces of this flea, investigators have found the virus of this disease to be alive after 651 days. Xenopsylla cheopis, then, seems at this time to be Public Enemy No. 1 of fleas, made more dangerous than efficient native flea vectors of plague because it, with its chief host Norwegian rat, lives almost as a domestic animal of man, while native fleas on their hosts are insects, generally of great wide-open spaces.

ConTROL: While it would be difficult to control Oriental rat flea itself, it is generally felt that campaigns against rats will greatly reduce numbers of rats and so number of fleas. Such campaigns have been in progress almost everywhere since plague first appeared in San Francisco in 1900. Rat proofing buildings has become an art. A good index of rat population may be had at any city garbage dump. In small towns where incineration is not practiced, garbage dumps with their large amount of food become a mass of seething rat life. Unless the public of such towns demands that collectors using dumps control rats, these animals may become a menace to the community.

Brology: While it is reported that a temperature of $40^{\circ} \mathrm{F}$. is fatal to eggs of this flea, warm nests of rats in which they are deposited or fall, form a warm incubator in which the temperature probably seldom falls to this level. Larva of flea may survive for as long as a month without food. Larval period may run from 12 to 84 days. Pupal period within cocoon may last from 7 to 182 days. Adults may live for 100 days.

RECORDS from the West are:

OREGON-The writer has collected from:

Rattus rattus rattus Linnaeus (black rat). Front Street (Water front), Portland, August 25, 1935, 2 males, 3 females.

Rattus norvegicus Erxleben (Norwegian rat). Fifth and Hoyt Street, Portland, September 10, 1938, 1 female.

CALIFORNIA-On page 1371 of Public Health Reports, Vol. 23, for 1908, Dr. Carroll Fox reports, in connection with his plague work in San Francisco, the presence of this flea on: 
Rattus norvegicus (Norwegian rat) in fair numbers

Rattus rattus rattus (black rat) in very limited numbers

Mus musculus (house mouse) on only one occasion.

Since this report, the name of this flea has constantly appeared in plague literature of this state.

Augustson reports this flea off a black rat taken at El Segundo, Los Angeles County, and Prince reports it off the Norwegian rat in the following California cities: San Diego, Riverside, Palm City, Oroville, Chico, Stockton, Red Bluff and Colusa. Prince also reports this flea from the following inland cities: Phoenix and Nogales, Arizona; Albuquerque, New Mexico; Denver, Colorado; and Salt Lake City, Utah.

WASHINGTON-In 1936, Public Health Bulletin No. 232, "Review of Plague in Seattle (1907)," Dr. L. D. Fricks reports this flea as being 22.7 per cent of the flea population taken between April, 1927 and August, 1929 off rats in this large northwest port city.

BRITISH COLUMBIA-Holland reports taking 9 specimens of this species off Rattus norvegicus Erxleben at the city dump of Vancouver, B. C., on September 8, 1938.

\section{GENUS HOPLOPSYLLUS BAKER}

1905. Hoplopsyllus Baker. Proc. United States Nat. Mus., 29:128.

Genotype: Pulex anomalus Baker 1904

Preantennal region with two bristles and a few setae. No genal comb, but pronotal comb present. Rod-like sclerotization divides mesosternite vertically.

This genus is represented in West by 5 closely related species, two of which are strictly Pacific Coast species, one west from Rocky Mountains in southwest, and two Rocky Mountain species which range to the east.

These fleas are found chiefly upon rabbits and hares, although one species is a true ground squirrel flea. Females of these species are difficult to key.

Key to the Western Species of Hoplopsyllus (males only)

Rocky Mountain Species

Lower process of clasper not more than twice as long as the upper process, Arizona, adjacent territory and east H. affinis, p. 71

Lower process of the clasper more than twice as long as the upper process, Idaho, adjacent territory and east $\quad H . g$. lynx, p 70

Pacific Species

Upper claspers elongate inverted plowshare shape, host generally ground squirrels

H. anomalus, p. 72

Upper claspers not elongate inverted plowshare shape, host rabbits and hares

Lower process of clasper about twice as long as upper; upper process armed with about twelve bristles H. $g$. foxi, p. 68

Lower process of clasper very long and slender, nine and one-half times as long as broad at base; upper process armed with eight long, stout bristles H. g. tenuidigitus, p. 69 


\section{Hoplopsyllus glacialis foxi Ewing 1924}

1924 Hoplopsyllus foxi Ewing, Parastiology 16:350-351.

1926 Hoplopsyllus powersi C. Fox, Pan-Pacific Ent. 2, No. 4, 184.

1926 Hoplopsyllus minutus C. Fox, Pan-Pacific Ent. 2, No. 4, 185.

1939 Hoplopsyllus foxi Kohls, Public Health Rep., 54:45, 2020.

Ewing described this western rabbit flea from specimens taken off a cottontail rabbit, Lepus bachmani, from near San Francisco, California. Kohls in 1939 decided that Carroll Fox had redescribed this flea in 1926 as Hoplopsyllus powersi from specimens taken off a cottontail at Los Angeles, and as Hoplopsyllus minutus from a dwarf specimen of a female taken off a cottontail collected at San Francisco during 1908.

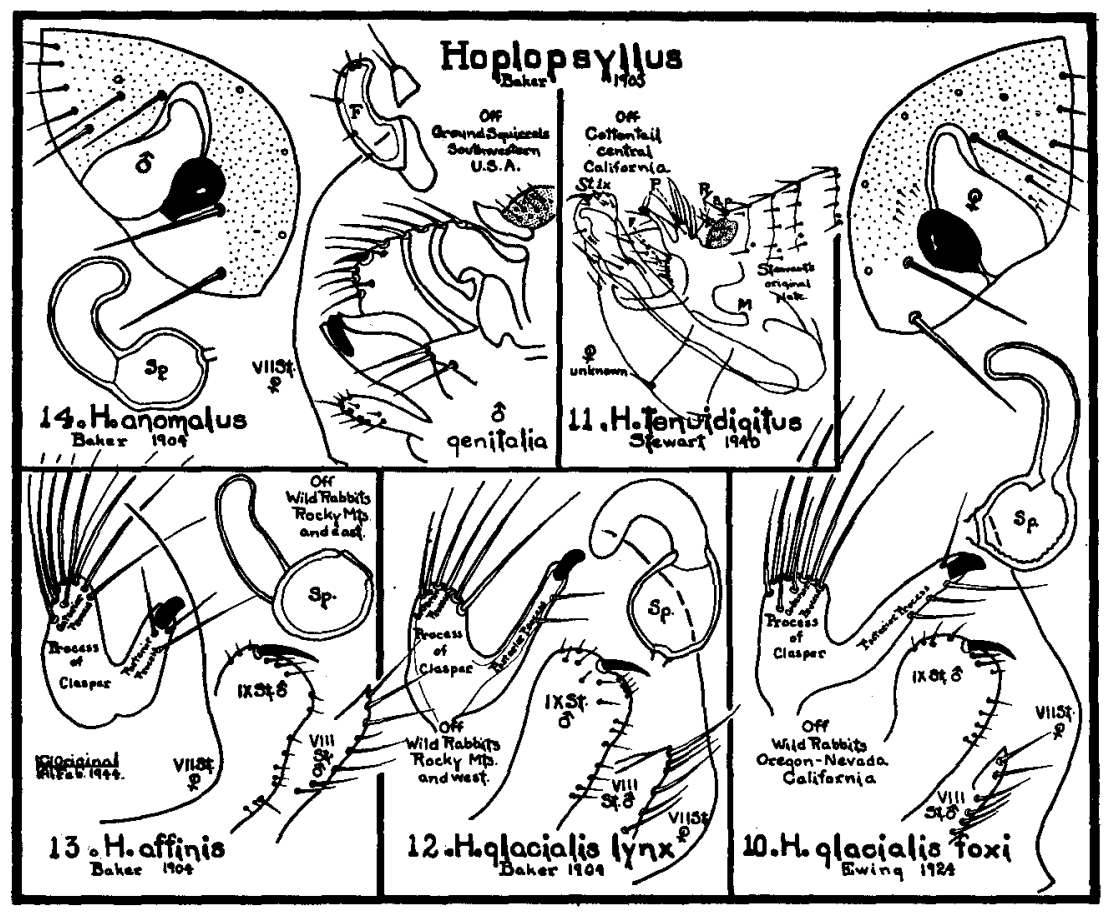

Head: Well rounded in both male and female. Postantennal region is armed with two bristles, one at eye position about one-fourth down, second at outer edge of gena. Eye oval, large and well pigmented. Above eye a few setae. Postantennal region with two heavy bristles in region of antennal groove, and along posterior border of head a row of 4 or 5 bristles. A few setae at antennal groove.

Pronotal comb of about 22 heavy black teeth.

Modified Segments, Male: Clasper teapot shaped without movable finger. Spout or posterior process about twice as long as pot or anterior 
process. Posterior process armed apically with a heavy curved black spiniform and along its lower margin with 3 or 4 bristles. Anterior process of the clasper is armed apically with about 12 thick-set bristles. IX st. expanded apically and armed with series of short bristles and stout black curved spiniform. Female: Apical margin of VII st. with shallow valley toward ventral, followed by upper lobe nicely rounded but not very high. Spermatheca with globular body and tail twice as long as diameter of body and apically crooked. See illustrations.

LENGTH: Most of specimens of this flea to come to attention of writer have been small, measuring about $1.5 \mathrm{~mm}$. in both sexes. Some individuals may reach $2 \mathrm{~mm}$. in length.

RANGE: This flea is primarily a California rabbit flea. The subspecies is, however, found in southern Oregon. The writer has secured specimens in Jackson and Josephine Counties. It was described from San Francisco. Augustson reports it from Los Angeles and Riverside Counties of southern California.

Medical Importance: Although plague and tularemia abound in the range of this rabbit flea there seems no evidence to date that the flea can transmit either of these diseases.

RECORDS: In writer's collection are specimens personally taken in: OREGON-From:

Lepus californicus californicus Gray (California jack rabbit). Waldo, Josephine County, August 23, 1937, 12 males, 15 females; Brownsboro, Jackson County, June 22, 1939, 5 males.

\section{CALIFORNIA-From:}

Sylvilagus nuttalli nuttalli Bachman (sagebrush cottontail). Modoc Lava Beds, Modoc County, Tule Lake, June 27, 1939, 2 males, 6 females.

Augustson reports this flea from Riverside County off:

Sylvilagus auduboni arizonae (cottontail rabbit).

From the San Gabriel Mountains of Los Angeles County off:

Sylvilagus bachmani cinerascens (cottontail rabbit).

\section{Hoplopsyllus glacialis tenuidigitus}

\section{Stewart 1940}

1940 Hoplopsyllus tenuidigitus Stewart, Pan-Pacific Ent., Vol. 16, No. 1, 18, fig. 3.

Describer states that this species is known only from male, and in modified segments upper process of immovable claspers bears 8 long, stout and very close-set bristles on dorsal and anterior margins. Lower process very long and slender, $91 / 2$ times as long as broad at base. Distal tooth of this process is nearly one-fifth as long as entire process, and about as wide as rest of process, 4 long, thin bristles on distal half of posterior margin of this process. Movable process of claspers inconspicuous and somewhat lance-shaped. IX st. is dilated distally, broadly rounded at apex, and bears single stout, curved spine, and several short, stout bristles. 
This species was collected off Sylvilagus auduboni subsp. '(cottontail) near Jamesburg, Monterey County, California during July, 1938.

Stewart does not give measurements for this flea. Holotype male is deposited in his private collection. This flea is known only from the type locality. Nothing is known about its range. Opinion generally expressed by California collectors is that this flea is only a slight variation or dimorphic form of Hoplopsyllus glacialis foxi Ewing.

\section{Hoplopsyllus glacialis lynx \\ Baker 1904}

$190+$ Pulex $\operatorname{ly} n x$ Baker, Proc. United States Nat. Mus., 27:383, P1. X, figs. 7-11, Pl. $\mathrm{XI}$, figs. $1,2$.

1905 Hoplopsyllus lynx Baker, Proc. United States Nat. Mus., 29:130.

1929 Hoplopsyllus glacialis lynx Jordan, Nov, Zool., 35:175.

1937 Hoplopsyllus glacialis lynx Jordan, Nov. Zool., 40:283.

1940 Hoplopsyllus lynx I. Fox, Fleas of the Eastern United States, p. 15.

HeAD: Well rounded in female but somewhat angulate in male. In both the eye is large, somewhat oval, and heavily pigmented. Two stout bristles arm gena, one at eye about one-quarter way down from top, other at outer genal margin. There is a patch of small setae over eye. On postantennal region are 2 major bristles and marginal row of about 5 . At posterior ventral angle a patch of setae.

Pronotal comb made up of about 16 sharp black teeth.

Modified SEGments, Male: In clasper of this flea posterior process is only about $11 / 2$ times as long as anterior process. Posterior process armed apically with a black thumb-like spiniform and several bristles on posterior face. Anterior process armed apically with about 6 closeset bristles. IX st. not much expanded apically, armed in this region with a black claw-like spiniform and a series of short bristles. Female: Apical margin of VII st. a not too well rounded lobe. Spermatheca with subglobular body and a tail not much longer than diameter of body which arches nicely over it.

LENGTH: Original description of this flea did not include measurements. Specimens in collection of the writer range around $2 \mathrm{~mm}$. in length, males slightly under, females slightly over.

TYPE MATERIAL: From Moscow, Idaho, taken off "Lynx canadensis" and deposited in the United States National Museum.

RANGE: This is a Rocky Mountain rabbit flea which ranges as far south at least as Montana and Idaho, thence northwest through British Columbia into Alaska. Records seem also to place it in New England states.

Host Preference: This flea is a true rabbit flea, but is also commony found upon the predators of rabbits.

Medical IMPORTANCE: While this flea was not found tularemia positive at the time varying hares were reported with this disease in 
southern Alaska in 1937, there is the possibility that the flea might have been partially responsible for the spread of this disease. This flea has not so far been associated with plague.

REconos: The following interesting records are available for this flea:

ALASK A-From:

Lepus americanus (varying hare), Circle, Rapids

Lynx sp. (bob cat), Yukon.

BRITISH COLỤMBA-From:

Lepus americana macfarlani (varying hare), Atlin

Lynx fasciatus (bob cat).

IDAHO-From:

Lynx canadensis (bob cat), Moscow.

MONTANA-In Ravalli County this rabbit flea has been taken from:

Canis latrans (coyote)

Lynx canadensis (bob cat)

Tamiasciurus hudsonicus (pine squirrel)

Lepus bairdi (snowshoe rabbit) .

There are records of this flea off varying hare and bob cat from Maine and New Hampshire.

\section{Hoplopsyllus affinis}

Baker 1904

1904 Pulex affinis Baker, Proc. United States Nat. Mus., 27:382.

1905 Hoplopsyllus affinis Baker, Proc. United States Nat. Mus., 27:130.

1940 Hoplopsyllus affinis I. Fox, Fleas of the Eastern United States, p. 14.

HEAD: Head of female is nicely rounded, but in male slightly angulate. Postantennal region with 2 bristles, one at top level of eye, other at outer genal margin. Eye is very large, heavily pigmented and somewhat oval with spur below. Numerous setae above eye. Postantennal region with 2 bristles and a row of 5 along margin. There are a few setae at posterior ventral angle. Pronotal comb of about 18 sharp black teeth.

Modified Segments, Male: Posterior process of clasper of this flea is as long as or shorter than anterior process. Posterior process armed apically with black spiniform and several bristles. Anterior process armed apically with about 8 stout bristles. Female: Apical outline VII st. slightly concave. Spermatheca with globular body and almost straight tail.

Lengin: Original lengths were given as male, $2.0 \mathrm{~mm}$., female, 2.5 $\mathrm{mm}$.

Type Material: Male and female from near Grand Canyon, Arizona, off Lepus, deposited in United States National Museum.

RANGE: This Rocky Mountain rabbit flea was described from near Grand Canyon of Arizona. From here it ranges north and east through Rocky Mountains and Great Plains. 
Host Preference: This is a true rabbit flea, but it can frequently be taken from rabbit carnivores.

Medical Importance: Although the range of this flea is through country ridden with plague and tularemia, it seems not to have been associated with either disease.

RecoRds: The following records are available for this flea:

ARIZONA-From:

Lepus (rabbit) near Grand Canyon

Lepus alleni alleni (antelope jack rabbit)

Lepus californicus (jack rabbit).

UTAH-From:

Lepus californicus deserticola (jack rabbit), Salina

Sylvilagus auduboni warreni (cottontail rabbit), Henry Mountains.

COLORADO-From:

Sylvilagus auduboni (cottontail rabbit), Colorado Springs

Sylvilagus auduboni baileyi (cottontail rabbit), Weld County

Lepus californicus (jack rabbit).

MONTANA-From:

Felis catus (domestic cat), Ravalli County

Lepus bairdi (snowshoe rabbit), Ravalli County

Lepus townsendi (white-tailed jack rabbit), Carter County

Sylvilagus spp. (cottontail rabbit), Custer, Ravalli Counties.

SOUTH DAKOTA-From:

Lepus townsendi (white-tailed jack rabbit), Brookings.

OKLAHOMA-From:

Sylvilagus floridanus (cottontail rabbit)

Sylvilagus aquaticus (swamp rabbit)

Lepus californicus (jack rabbit).

IOWA-This flea has been reported as far east as lowa where at Ames it was taken from:

Rattus norvegicus (house rat)

Sylvilagus sp. (cottontail rabbit)

Vulpes fulva (red fox).

\section{Hoplopsyllus anomalus Baker 1904}

1904 Pulex anomalus Baker, Proc. United States Nat. Mus., 27, 381, P1. X, figs. 1-6. 1906 Hoplopsyllus anomalus Baker, Proc. United States Nat. Mus., 29.

This is one of few fleas which Baker personally collected of many he described. Specimens from which the description was made were taken off a large gray-brown spermophile at Arboles, in southern Colorado, in 1899. Baker states that flea was in many respects congeneric with irritans, but possesses a strong pronotal comb of about 9 teeth in male, 16 in female. In this flea, head of female is normal but in male is flattened and thickened at top. Frontal notch is completely absent. Two heavy bristles on gena, vertex with 10 to 12 bristles, gena below eye not projecting over antennal groove. Hind margin of antennal 
groove with only 2 small bristles below. Abdominal segments each possess but single row of bristles, 11 or 12 on tergites, 4 to 6 on sternites. Tergites apparently without minute teeth. One medium antepygidial bristle on each side. $\mathrm{X} \mathrm{t}$. of the male is a large sclerite, rounded only above, with stout tooth at posterior upper angle and numerous bristles along upper margin. Upper claspers are of an elongate inverted plowshare shape, with point dissected cephalad and with a few weak hairs on posterior border. Female: Apical outline of VII st. is a weakly rounded lobe with a slightly flattened apex. Spermatheca has a somewhat pear-shaped body with a very strong tail crooked apically.

LENGTH: The original lengths given for this flea are, male $1.5 \mathrm{~mm}$., female $2.5 \mathrm{~mm}$.

Type Material: Bears number 6,897 and is deposited in United States National Museum.

RANGE: This flea ranges from the type locality in southern Colorado south and west into southern California, thence north through the state into Siskiyou County. It is not found in the state of Oregon.

Host Preference: Although found on a variety of hosts, this flea seems to be a definite ground squirrel flea.

Medical IMPoRTANCE: This flea is one of the major parasites of central and southern California ground squirrels. Its name appears again and again in plague literature from this state. Fox lists it as early as 1908, and Dr. Eskey mentions it repeatedly in 1939. It is a proven vector of bubonic plague, and one of most efficient known transmitters of the disease.

RECORDS of this species are:

CALIFORNIA-From:

Citellus beecheyi beecheyi (California ground squirrel). As early as 1910 McCoy and Mitzmain reported this flea on this squirrel in 12 counties south of the San Francisco Bay region

Rattus norvegicus (Norwegian rat), 1909 from San Francisco and Los Angeles

Sylvilagus auduboni (cottontail rabbit) , 1909

Speotyto cunicularia hypugaea (burrowing owl), 1909.

Augustson reports this flea from:

Citellus beecheyi nesioticus (Catalina Island ground squirrel), Santa Catalina Island, Los Angeles County

Citellus beecheyi beecheyi (California ground squirrel), Los Angeles County

Citellus beecheyi nudipes (Juarez ground squirrel), San Diego County.

COLORADO-From:

Citellus sp. (ground squirrel), Arboles.

UTAH-From:

Citellus grammurus utah (Utah rock squirrel), Salina

Citellus lateralis lateralis (mantled ground squirrel), Salina

Citellus leucurus cinnamomeus (antelope ground squirrel), Henry Mountains. Citellus variegatus utah Merriam (Utah rock squirrel) Kanab, Kane County, July 7, 1945, 9 males, 24 females. (Col. C.A.H.)

\section{NEW MEXICO-From:}

Cynomys gunnisoni zuniensis (Zuni prairie-dog), Bernalillo County

Citellus grammurus variegatus (rock squirrel), Grant County. 
ARIZONA-From:

Citellus grammurus spp. (rock squirrel), Pima County

Sylvilagus auduboni arizonae (cottontail rabbit), Maricopa County.

Citellus variegatus grammurus Say (Colorado rock squirrel) Grand Canyon, Coconino County, July 4, 1945, 2 pair. (Col. C.A.H.)

NEVADA-The author collected this flea off:

Citellus (Ammospermophilus) leucurus leucurus Merriam (antelope ground squirrel), Pyramid Lake, Washoe County, June 19, 1944, a series.

Citellus leucurus leucurus Merriam (antelope ground squirrel), Searchlight, Clark County, June 30, 1945, 10 pair.

\section{GENUS CEDIOPSYLLA JORDAN}

1925. Cediopsylla Jordan. Nov. Zool. 32:103.

Genotype: Pulex simplex Baker

Jordan states that this genus is like Spilopsyllus, but labial palpus consists of 4 segments instead of 2 . Gena with 2 bristles. Frons with distinct incrassation. Head angulate in front. Genal comb consists of thick, straight, black teeth which are nearly vertical, but slanting slightly. Pronotal comb present. rabbits.

Two species of this genus are found in West, and are parasitic on

Key to the Western Species of Cediopsylla

Clasper of male with from 7 to 12 bristles on posterior border; VII st. of female without distinct lobe $\quad$ C. i. inaequalis, p. 74

Clasper of male with distal group of 2 or 3 bristles and a proximal group of 4 to 6 bristles on posterior border; VII st. of female with a distinct lobe

C. i. interrupta, p. 76

\section{Cediopsylla inaequalis inaequalis Baker 1895}

1895 Pulex inaequalis Baker, Canad. Ent. 27:164.

1896 Pulex inaequalis Osborn, Div. Ent., Dept., Agr. Bul. 5:153.

1909 Ctenocephalus inaequalis Baker, Proc. United States Nat. Mus., 17:385.

1906 Spilopsyllus inaequalis Baker, Proc. United States Nat. Mus., 29:131.

1925 Cediopsylla inaequalis Jordan, Nov. Zool. 32:103.

This flea was described by Baker from part of materials obtained by Professor A. B. Cordly on Lepus near the Grand Canyon, in Arizona. Afterwards, Baker collected same thing on Lepus at Arboles, Colorado, and Professor Aldrich sent him specimens from Moscow, Idaho.

In 1895 Baker described the flea as Pulex inaequalis, in 1904 listed it as Ctenocephalus inaequalis, in 1905 as Spilopsyllus inaequalis, and in 1925 Jordan shifted it to his newly erected genus Cediopsylla.

This flea is a true rabbit flea. It is listed from all over Rocky Mountain area, and Great Basin region of Oregon and Washington where it is most common flea found upon jack rabbits and cottontails. The writer has taken as many as 200 specimens of this flea off a single cot- 


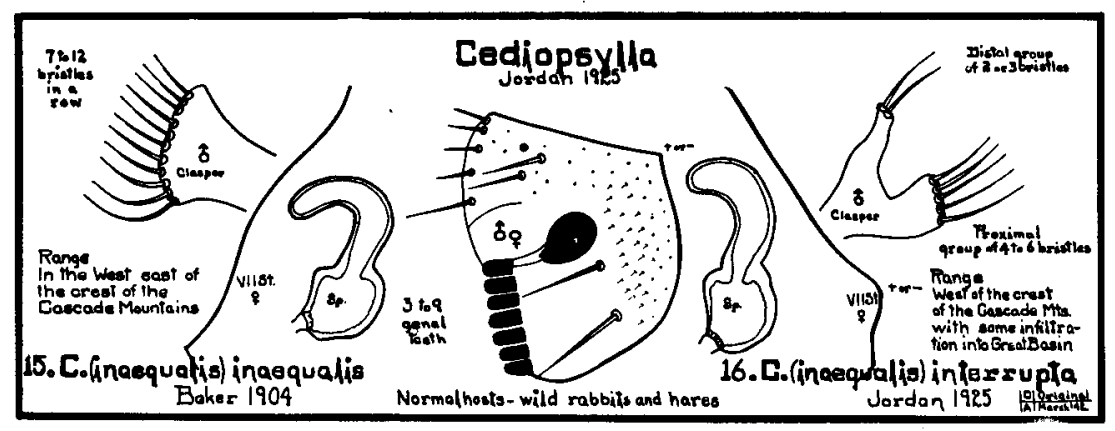

tontail in eastern Oregon, but on the non-nest building jack rabbits only a few, if any, is the rule.

This species can be readily recognized by its stout, black genal teeth, which vary in number from 3 to 8 , and can be separated from following species with which it is sometimes closely associated, by presence of from 7 to 12 bristles evenly spaced along ventral margin of male clasper and in female by absence of a distinct lobe on apical margin of VII st.

Seasonal maxima for this species seems to be May and June.

RANGE: This flea can be found on rabbits everywhere east of crest of Cascade, Sierra Range. Its range is probably extending westward. The writer has personal records from all over Great Basin region of Oregon and Washington and from New Mexico. Species is listed from Montana and Alberta, Canada, but Fox does not list it from eastern United States.

RECORDs: Listed as representative records of the writer are:

OREGON-From:

Lepus californicus californicus Merriam (jack rabbit), Ontario, Malheur County, May 10, 1932, 1 male, 5 females

Sylvilagus nuttalli nuttalli Bachman (sagebrush cottontail), La Grande, Baker County, April 15, 1937, 40 males, 60 females.

WASHINGTON-From:

Lepus californicus wallawalla Merriam (Washington jack rabbit), Mabton, Yakima County, (15 miles south), May 29, 1938, 1 female

Sylvilagus nuttalli nuttalli Bachman (sagebrush cottontail), Donald, Yakima County, May 6, 1939, 9 males, 7 females.

CALIFORNIA-While Kohls in 1940 ranged this flea only as far west in the southwest as Arizona, Augustson reports that it has been taken from:

Sylvilagus auduboni arizonae (cottontail rabbit) at Lancaster, Antelope val-

ley, Los Angeles County. This location is far nearer the coast than it is to the Arizona state line and should be in the range of the following subspecies which Augustson also reports from this area. Augustson claims in making the record that Cediopsylla inaequalis inaequalis is a fall flea in this region while Cediopsylla inaequalis interrupta is a spring flea on the same host, same region. 
NEVADA-The writer has taken this flea in Washoe County, from:

Lepus californicus californicus (California jack rabbit)

Sylvilagus nuttalli nuttalli (desert cottontail rabbit).

ARIZONA-Baker as early as 1895 reported this flea from near the Grand Canyon from:

Sylvilagus (cottontail rabbit)

Lepus (jack rabbit).

NEW MEXICO-A parcel of fleas received by the writer from Grant County had in it a specimen of this flea from:

Sylvilagus nuttalli pinetis (Rocky Mountain cottontail rabbit).

UTAH-This flea is reported from Salina, Sevier County, off:

Sylvilagus nuttalli grangeri (Rocky Mountain cottontail rabbit)

Lepus californicus deserticola (desert jack rabbit) .

IDAHO-As early as 1904 Baker reported this rabbit flea from Moscow, Latah County.

COLORADO-Baker in 1904 reported this flea from Arboles, Archuleta County, from:

Lepus sp. (jack rabbit).

In 1926 McCampbell reported it from:

Lepus californicus melanotus (jack rabbit).

The writer has worked specimens of this flea taken at Gunnison, Gunnison County, from:

Sylvilagus nuttalli grangeri (Rocky Mountain cottontail rabbit).

MONTANA-Quite a series of Montana records are available for this flea. The writer here first lists the true hosts, the various rabbits of Montana, then the carnivores, and last accidental occurrences. The following wild rabbits of Montana carry this flea:

Lepus bairdi (snowshoe rabbit), Ravalli County

Lepus californicus (black-tailed jack rabbit), Beaverhead County

Lepus townsendi (white-tailed jack rabbit), general in state

Sylvilagus nuttalli grangeri (Rocky Mountain cottontail), general

Sylvilagus idahoensis (Idaho pygmy rabbit), Beaverhead County.

This flea is reported from the following carnivores:

Canis latrans (coyote), general in state

Felis catus (domestic cat), Beaverhead, Ravalli Counties.

As accidental occurrences this flea has been taken from:

Citellus columbianus (Columbian ground squirrel), Ravalli County

Citellus richardsoni (Richardson ground squirrel), Gallatin County.

ALBERTA-In this Canadian province this flea has been reported from:

Sylvilagus spp. (cottontail rabbit), Waterton Lakes.

\section{Cediopsylla inaequalis interrupta Jordan 1925}

1925 Cediopsylla inaequalis interrupta Jordan, Nov. Zool. 32:103.

In his description of this flea in 1925, Jordan states that it is very similar to preceding species, but that "The row of long bristles at ventral margin of male clasper divided into a proximal group of 4 to 6 
and a distal group of 2 or 3." Female has a distinct lobe on the apical margin of VII st. Type locality is given as Palo Alto, California. In collection of Stanford University were specimens from fox. Carroll Fox listed material from Lepus bachmani at San Francisco and Carl Baker had a series from Lepus from Claremont, California.

This is the common small black rabbit flea of west of Cascade Sierra Range through Pacific Slope. Large numbers can generally be taken off coast cottontail and California jack rabbits. During the seasonal maxima (April, May, and June) for this species, infestation on cottontail is so great that fleas can be seen swarming over the rabbit and many of them have their heads deeply buried in fringes of the rabbits' ears. This species also has a variable number of genal teeth, anywhere from 3 to 9 . Wild rabbits are the true hosts of this species. Frequently these fleas can be found upon carnivores which kill wild rabbits for food.

RANGE: In small numbers this flea can often be taken side by side with preceding species off cottontails east of the Cascades in Oregon and Washington. This might indicate that species is migrating eastward into and through the Great Basin region. This flea is far more abundant west of the Cascade Sierra Range than it is in the Great Basin region.

Medical Importance: The two preceding subspecies of western wild rabbit fleas are found commonly in regions where plague and tularemia are rampant. Plague has been found in both Sylvilagus (cottontail rabbits) and Lepus (jack rabbits), but it seems to be the concensus of opinion that the western wild rabbit fleas here under consideration are very difficult, if not impossible, under laboratory conditions to infect with plague. It seems likely that this also would be the condition in nature. On the other hand, this might not be the case at all. It is probable where wild rabbits suffer from plague that infection comes through the bite of an infected ground squirrel flea. Tularemia is often reported in western wild rabbits, but to this time no tularemia-positive fleas of the subspecies here under discussion have been found.

Although Stanford in "More Utah Siphonaptera," 1944, records this subspecies from City of Rocks and Carey, Idaho, off Sylvilagus n. grangeri and Lepus sp. from Logan, Utah, the author doubts the presence of this flea so far east.

RECORDS: As typical infestation, the writer presents from personal records:

OREGON-Off:

Sylvilagus bachmani ubericolor Miller (coast cottontail), Gaston, Washington County, January 30, 1932, 40 males, 50 females

Sylvilagus nuttalli nuttalli Bachman (sagebrush cottontail), Sisters, Deschutes County, July 18, 1936, 2 males

Lepus californicus californicus Gray (California jack rabbit), Newberg, Yamhill County, April 12, 1939, 15 males, 10 females. 
Accidental occurrence:

Urocyon cinereoargenteus townsendi Merriam (gray fox), Blodgett, Benton County, December 10, 1940, 2 males.

WASHINGTON-From:

Sylvilagus nuttali nuttali Bachman (sagebrush cottontail), Mabton, Yakima County, May 29, 1938, 1 male, I female.

CALIFORNIA-From:

Sylvilagus bachmani ubericolor Miller (coast cottontail), Smith River, Del Norte County, June 15, 1939, 20 males, 40 females.

During the early plague studies of central California, McCoy and Mitzmain reported in 1909 and 1910 taking this flea, but under the designation Spilopsyllus inaequalis, from:

Sylvilagus bachmani (brush cottontail rabbit)

Sylvilagus auduboni (cottontail rabbit)

Procyon psora (racoon)

Citellus beecheyi (California ground squirrel) .

Augustson reports this flea off the following hosts in southern California:

From Los Angeles County off:

Lepus californicus (California jack rabbit)

Sylvilagus auduboni arizonae (cottontail rabbit)

Sylvilagus bachmani cinerascens (brush cottontail rabbit)

Urocyon cinereoargenteus californicus (gray fox)

Lynx rufus californicus (bob cat).

From San Diego County off:

Didelphis virginianus virginianus (opossum).

\section{GENUS ANOMIOPSYLLUS BAKER}

1904. Anomiopsyllus Baker. Proc. United States Nat. Mus., 27:425.

Genotype: Typnlopsylla nudata Baker

No eyes. Maxillary palpi exceed fore coxae. No pronotal comb. On dorsal line pronotum and mesonotum are of equal length, while metanotum is shorter. Body almost wholly nude, number of spines on legs greatly reduced. Rounded emargination found distally on hind margin of fore and middle coxae at junction of coxa and its epiphysis.

This genus is made up of western fleas which in 5 species range from Montana south through the Rocky Mountains into Arizona, west into southern California, then north perhaps to San Francisco Bay. Genus is not represented in the Pacific Northwest.

Key to the Western Species of Anomiopsyllus (males only)

With three spiniforms on movable finger $\mathbf{F}$. of the clasper

Spiniforms along posterior border and far apart

A. nudatus, p. 79

Spiniforms in transverse row close to apex

Finger F. with distal dilation

Finger F. without distal dilation

With two spiniforms on movable finger $F$. of the clasper

Finger F. boomerang-shaped

Finger F. thumb-shaped, expanded proximally

A. falsicalifornicus, p. 80

A. congruens, p. 81

A. montanus, p. 82

A. amphibolus, p. 83 
On October 23, 1945, Dr. Karl Jordan wrote the author that according to his ideas of flea phylogeny Anomiopsyllus should be associated with Stenistomera, Callistopsyllus, Conorhinopsylla and Megarthroglossus.

\section{Anomiopsyllus nudatus \\ Baker 1898}

1898 Typhlopsylla nudata Baker, Journ. N. Y. Ent. Soc., 6:56.

1904 Anomiopsyllus nudatus Baker, Proc. Nat. Mus., 27:426.

1914 Anomiopsyllus nudatus C. Fox, Hyg. Lab. Bul., 97:XIX, Fig. 53.

1915 Anomiopsyllus nudatus Rothschild, Ectoparasites, I, p. 45.

1915 Anomiopsyllus californicus Rothschild, Ectoparasites, I, p. 45.

1926 Anomiopsyllus nudatus C. Fox, Pan-Pacific Ent., 2:184.

Baker originally described this flea from two females collected at Tucson, Arizona, from nest of Neotoma albigula (wood rat).

According to description of female given by Baker, lower row of genal bristles consists of one very weak and slender one on margin of antennal groove and similar one on lower margin of head. There are no other bristles on head excepting one or two at each lower angle of

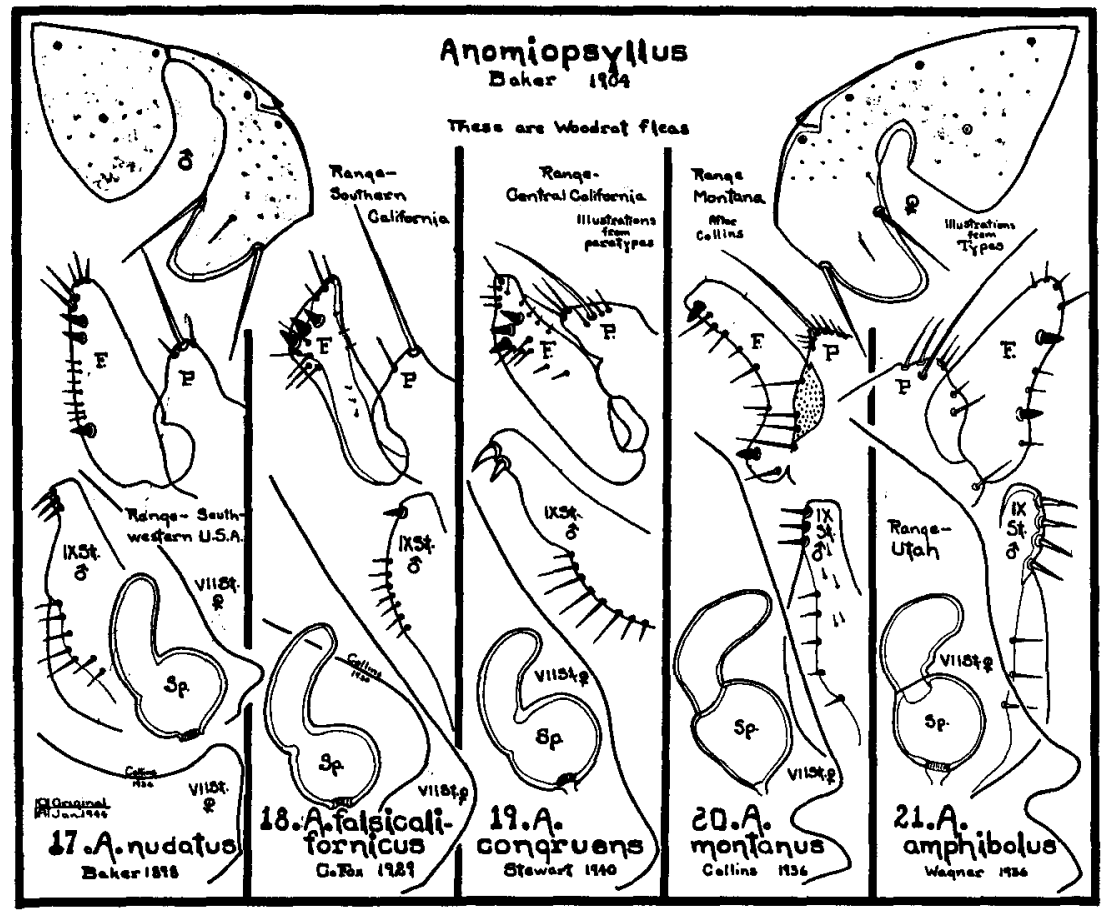

hind margin, and a few short ones on second antennal joint. The thorax is without bristles excepting one on either side of pronotum at each lateral angle.

The abdominal tergites each have a single row of about 6 very 
weak and slender bristles. One small slender antepygidial bristle on either side. Hairs on pygidium very fine but longer than usual. Style about 3 times longer than wide at the base, and slightly narrowed at the tip, where there is a long bristle. Margin of VII st. seems variable. Collins in 1936 drew outline with a narrow lower lobe rounded off at the dorso-ventral angle. Specimens in collection of the writer have a gently slanting margin with a small rounded lobe near the base. Spermatheca has a globular body and a slightly bent tail.

Rothschild, p. 45 of Ectoparasites I, 1915, pictures for first time modified segments of male of this flea. Process $P$ of clasper is armed with 1 stout spine and about its base 2 weak bristles. Movable finger $\mathbf{F}$ is armed with 3 black spiniforms on posterior border, 2 above and fairly close together, 1 below; about 6 weak spines along posterior border.

LENGTH: This is a small flea. Males in collection of the writer are just under $1 \mathrm{~mm}$. in length, the females just over $1 \mathrm{~mm}$.

Medical Importance: Although plague has been recorded found in wood rats in California and Nevada, this California wood rat flea has never been used in plague experiments.

RANGE: Southern California eastward through Arizona.

RECORDS of this flea are:

CALIFORNIA-In Los Angeles County this flea has been reported by Carl Baker under the designation Anomiopsyllus californicus Baker 1904, taken off:

Neotoma fuscipes (wood rat)

Spilogale phenax (spotted skunk).

Augustson also reported from this county records of this flea off:

Neotoma sp. (wood rat)

Neotoma fuscipes macrotis (large-eared wood rat)

Neotoma lepida intermedia (desert wood rat)

Peromyscus eremicus fraterculus (deer mouse).

From Orange County off:

Neotoma sp. (wood rat).

ARIZONA-On July 4, 1945, the author collected 2 pair of this flea off:

Neotoma albigula albigula Hartley (white-throated wood rat), Grand Canyon, Coconino County. This flea also has been reported off:

Neotoma albigula (white-throated wood rat), Tucson

Rattus (rat), Paradise

Mephites (skunk), Paradise.

\section{Anomiopsyllus falsicalifornicus \\ C. Fox 1929}

1929 Anomiopsyllus falsicalifornicus C. Fox, Ent. News, 40:218; 1:18.

1940 Anomiopsyllus falsicalifornicus Stewart, Pan-Pacific Ent. 16:17.

HEAD: Fairly well rounded but flattened. Genal armature a row of 2 long slender bristles and a short weak one midway between. Long 
bristles at edge of antennal groove and at outer edge of gena at about eye position. There is no eye. Postantennal region nude with exception of small setae at lower marginal angle. Frontal tubercle prominent.

Thorax: There is no pronotal comb. Pronotum, mesonotum, and metanotum with single row of weak bristles.

Abdomen: Two anterior tergites with apical spinelets and all with single row of weak bristles. One well developed antepygidial bristle to the side.

Modified Segments: Process $\mathbf{P}$ of clasper not dipping anteriorly below the major spine, as in $A$. nudatus, but as in nudatus armed with heavy bristle at apex and at its base 2 small bristles. Movable finger $\mathbf{F}$ with distal dilation above which is found oblique row of 3 black spiniforms, about 6 weak bristles below spiniforms, and about same number above spiniforms at apex. About 4 weak bristles evenly scattered over anterior border. Female: Marginal outline of VII st. seems somewhat variable. Collins in 1936 illustrated outline as low rounded lobe, but specimens in collection of the writer seem to represent a nicely slanting outline with a low rounded lobe apically and ventrally. The spermatheca has a globular body and a slightly curved tail. Tail is longer than body.

LENGTH: Specimens of this flea in collection of the writer are much larger than $A$. nudatus. Where $A$. nudatus measures about $1 \mathrm{~mm}$., this species is almost $2 \mathrm{~mm}$. in length in both sexes.

RANGE: Specimens of this species so far collected seem to be limited to Los Angeles County, California, but Augustson suggests that flea should show up in Ventura County to west. Augustson further states that this flea is common parasite on wood rats and deer mice of chaparral areas of northern Los Angeles County. follow:

Records: Auguston's records from Los Angeles County for this flea

Neotoma sp. (wood rat), Beverly Glen, Los Angeles

Neotoma fuscipes macrotis (wood rat), Santa Monica Mountains

Peromyscus californicus insignis (deer mouse), Santa Monica Mountains.

\section{Anomiopsyllus congruens \\ Stewart 1940}

1940 Anomiopsyllus congruens Stewart, Pan-Pacific Ent., 16:17.

Stewart states that this species is most closely related to $A$. falsicalifornicus C. Fox 1929. Features which mark it off from preceding forms are: Labial palps slightly exceeding forecoxae in length and a trifle shorter than maxillary palpi. Frontal tubercle is located high up on frons. Three bristles in frontal row, 1 on anterior margin of antennal groove, 1 on lower margin of head, third midway between other 2 . First abdominal tergite with 3 apical teeth on each side, second with but 1 on each side. 
Modified Segments, Male: Movable finger $F$ convex on anterior margin and rather symmetrically proportioned; armed with a set of 3 black spiniforms closely set together in a more or less horizontal row, spiniforms not being so widely separated as in A. falsicalifornicus, and a smaller tooth on proximal posterior margin. Row of fine bristles on posterior margin of $F$. IX st. is truncate at tip, and has 2 prominent teeth at ventro-posterior angle and with row of about 7 bristles slightly more than half way up horizontal arm. Female: Stylet acutely pointed with 1 long apical bristle; about 3 times as long as broad at base. Spermatheca with a spherical body and a relatively thick tail. VII st. broadly and evenly rounded on posterior margin.

Holotype and allotype in collection of describer.

RANGE: Nothing is known about the range of this species.

RECORDS:

CALIFORNIA-Type locality is Jamesburg, Monterey County, where this flea has been taken off:

Spilogale gracilis subsp. (spotted skunk)

Peromyscus californicus subsp. (deer mouse)

Neotoma fuscipes subsp. (wood rat).

\section{Anomiopsyllus montanus \\ Collins 1936}

1936 Anomiopsyllus montanus Collins, Ent. News 47:129-130.

This is the flea which Dunn in 1923 listed from the Bitterroot Mountains of Montana as $A$. nudatus.

In this species head structure, structure of thorax and abdomen as well as armature of these parts is same as for preceding species. Difference comes in modified segments.

Modified Segments, Male: Finger $F$ of clasper is most characteristic of this genus of fleas. Finger is boomerang in shape with single black spiniform at dorsal and ventral posterior angles. Along posterior face of finger and between spiniforms is a series of bristles. Posterior arm of IX st. is characteristic both in armature and shape. Female: VII st. with apical margin cut by sinus close to ventral, otherwise face is gentle slope and flat. Spermatheca seems to have lost to some extent globular body characteristic of genus, but the crooked finger is still persistent. Shape is characteristic.

RANGE: This species has been reported only from Ravalli County, Montana.

RECORDs: It seems that the only records of this flea available are the original, which were from

Bubo virginianus (great horned owl), 1922

Neotoma cinerea (bushy-tailed wood rat), 1923. 


\section{Anomiopsyllus amphibolus \\ Wagner 1936}

1936 Anomiopsyllus amphibolus Wagner, Zeit. f. Parasit. 8:654-655.

Through the courtesy of Professor J. S. Stanford of Utah State Agricultural College, allotype and holotype of this species were made available to the writer for study. Species has characteristics common to genus.

Head: Fairly well rounded but flattened. Eye absent. Three genal bristles at about eye position. Two long slender ones at genal edges, third a much shorter one between them. Postantennal region nude.

THORAx: No pronotal comb. But single row of weak bristles on pronotum, mesonotum, and metanotum.

AвDomen: Two anterior tergites with apical spinelets. All with a single row of weak bristles. One antepygidial bristle to side.

Modified Segments: Finger $F$ of clasper thumb shaped with expanded proximal posterior area. Two black spiniforms situated about equidistant from each other and end of finger. Few short bristles at apex and between spiniforms. IX st. blunt apically, and armed on posterior face with 4 spine-like bristles. Below several small bristles. FEMALE: Apical outline of VII st. with a sinus below followed dorsally by small rounded lobe, then slightly convex area and a shallow upper rounded lobe. Spermatheca with well rounded body and heavy crooked tail.

LENGTH: This flea in both sexes is under $2 \mathrm{~mm}$. in length.

Range: Known only from type locality at Salina, Sevier County, Utah, where it was taken off Neotoma desertorum (wood rat). 


\section{FAMILY DOLICHOPSYLLIDAE BAKER}

1905 DOLICHOPSYLLIDAE Baker, Proc. United States Nat. Mus., 29:127.

1909 DOLICHOPSYLLIDAE Oudemans, Nov. Zool., 16:156.

1915 CERATOPHYLLIDAE Rothschild, Ent. Mo. Mag., 51:156.

1926 CERATOPHYLLIDAE Dampf, Ent. Mitt., 15:380.

1929 DOLICHOPSYLLIDAE Ewing, Manual External Parasites, p. 165.

1936 CERATOPHYLLIDAE Wagner, Tierwelt Mitteleuropas, Bd. 6, Abt. 17, x. 4. 1940 DOLICHOPSYLLIDAE I. Fox, Fleas of the Eastern United States, p. 29.

The members of this family have 2 or more rows of bristles on each abdominal tergite. In genera of this family to follow, the eye is well developed except in Foxella, Dactylopsylla, and Dolichopsyllus, where it is absent. All but Polygenis and Arctopsylla have pronotal comb but in none is there a genal comb.

Most of material listed in this family was in genus Ceratophyllus Curtis prior to 1933. Up to that year few inroads had been made into content of this bulky, overburdened genus. In Notitates Zoologicae for October, 1933, beginning on p. 70, there appears Dr. Karl Jordan's "A Survey of the Classification of the American Species of Ceratophyllus." In this review Jordan lists 18 American genera to replace the old Ceratophyllus. His order is used hereinafter; his key, with slight modification, follows:

\section{KEY TO THE WESTERN GENERA OF DOLICHOPSYLLIDAE}

I. Pronotal comb absent

a. Ocular row of 3 bristles

Polygenis, p. 86

b. Ocular row of 4 bristles Arctopsylla, p. 88

II. Pronotal comb present

A. On inside of genal area a rod-like sclerite; upper eye bristle above level of eye.

a. Anterior row of genal bristles spiniform, on Ochotona (cony)

Ctenophyllus, p. 270

b. Anterior row of genal bristles normal,

1. On wild rabbits and hares

2. On Ochotona (cony)

Odontopsyllus, p. 266

Augustsonius, p. 268

B. No rod-like sclerite on inside of genal area, upper eye bristle on level with middle of eye (at middle of eye position in blind fleas).

1. Eye absent

a. Circle-like thickening in gena at about eye position

Hindtibia with fewer than 20 stout, dorsal bristles

Foxella, p. 172 
Hindtibia with more than 20 stout, dorsal bristles

Dactylopsylla, p. 185

b. Circle-like thickening in gena at about eye position not present

Dolichopsyllus, p. 264

2. Eye well developed

a. Tibia III with a comb-like row of 3 or 4 shorter outer bristles between long, middle, and apical bristles

Tibia III without such a comb.

Amphipsylla, p. 260

$$
\text { (Dr. Jordan's key follows) }
$$

Group A. Outer surface of forefemur with 1 or no lateral bristles; no thin longish bristles on inside of mid- and hindcoxae from base to apex.

a. Segment I of hindtarsus longer than II to IV

Tarsopsylla, p. 263

Segment I of hindtarsus shorter than II to IV. . b.

b. Male: VIII st. with apical membranous appendage, F. with 4 to 7 short spiniforms directed upwards, female: ventral margin of $\mathrm{X}$ st. distinctly angulate near middle

Orchopeas, p. 90

Male: VIII st. without apical membranous appendate, F. with 2 or 3 spiniforms directed downwards or distad. Female: Ventral margin of $\mathrm{X}$ st. not distinctly angulate

Opisodasys, p. 109

Group B. Outer surface of forefemur with several small lateral bristles; on inside of mid- and hindcoxae longish thin bristles from base to apex.

c. Male: ejaculatory duct deeply curved twice, directed frontad. Female: stylet stout, cylindrical, with numerous bristles at apex

Amphalius, p. 169

Male: ejaculatory duct normal. Female: stylet with 1 apical bristle, which is long

d. Male: VIII t. large, not reduced to a narrow horizontal sclerite. Female: Basal abdominal sternite without patch of lateral bristles, head of spermatheca broader than long, stylet with 2 or 3 lateral bristles Thrassis, p. 116 (On Kangaroo rats Thrassoides), p. 144

Male: VIII st. quite small. Female: Dorsal lateral bristle of stylet much smaller than ventral one Diamanus, p. 147

Male: VIII st. narrow, horizontal, with apical bristles and apical membranous flap. Female: basal abdominal sternite with patch of lateral bristles, head of spermatheca broader than long

Opisocrostis, p. 150 
Male: VIII st. narrow, horizontal, with apical bristles but with apical membranous flap. Female: Head of spermatheca longer than broad, ovate or pyriform

Oropsylla, p. 162

Group C. Outer surface of forefemur with a number of small lateral bristles: on inner side of mid- and hindcoxae longish thin bristles, most in apical half.

e. Spines of comb quite short

Mioctenopsylla, p. 194

Spines of comb normal

f. Stigma of VIII $t$. much enlarged

Megabothris, p. 210

Stigma of VIII t. normal

g. In comb 24 or more spines. Eye not reduced

In comb fewer than 24 spines

g.

h.

h. Third pair of plantar bristles of tarsal segment $V$ moved on to ventral surface

Dasypsyllus, p. 258

Third pair of plantar bristles lateral

Ceratophyllus, p. 248

i. Occiput with 2 or more longish bristles behind base of antennal groove and 3 or more in middle Pleochaetis, p. 246

Occiput with 1 or no longish bristles behind base of antennal groove

j. Eye distinctly reduced, its longitudinal diameter shorter than the distance of eye from apex of incrasate portion of genal lobe

Malaraeus, p. 196

Eye not reduced

k.

k. Male: VIII st. vestigial, without bristles. Female: Apex of bursa copulatrix rolled up as a spiral Nosopsyllus, p. 206

Male: VIII st. a narrow horizontal sclerite with bristles and an apical membranous flap. Female: Apex of bursa copulatrix not rolled up as a spiral

Monopsyllus, p. 219

\section{GENUS POLYGENIS JORDAN}

1939. Polygenis Jordan. Nov. Zool. 41:444.

\section{Genotype: Pulex roberti Rothschild}

No genal or pronotal comb. Conspicuous acuminate frontal tubercle directed dorsad. Two large bristles below eye on gena. Eye well developed, black, oval. Three rows of postantennal and preantennal bristles. Dense row of very small spiniforms along posterior margin of antennal groove. One long antepygidial bristle to side. Four pairs of lateral plantar bristles and apical submedian pair on each fifth tarsal segment.

This genus is represented in West by but a single species which is generally taken off cotton rats but has been reported off various other mammals. 


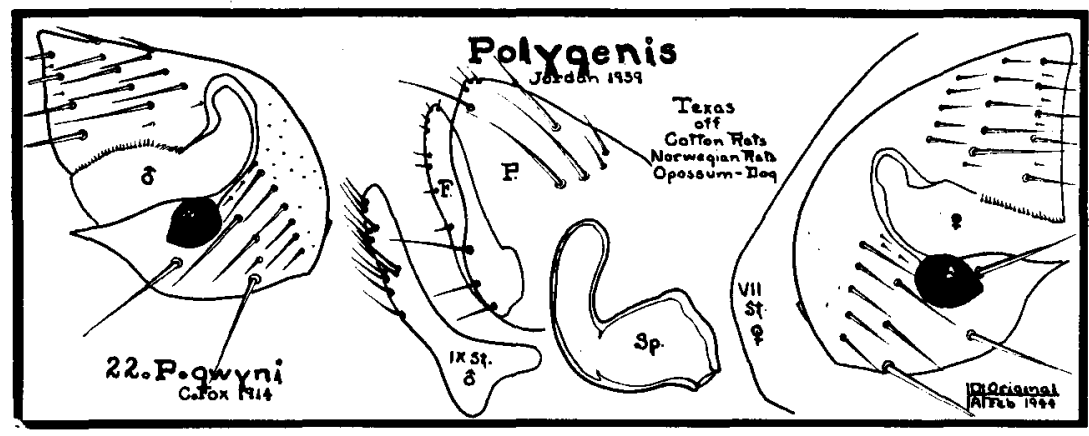

22. Polygenis gwyni

C. Fox 1914

1914 Rhopalopsyllus gwyni C. Fox, Hyg. Lab. Bul. 97:5, 10-11.

1930 Rhopalopsyllus sigmodoni Stewart, Canad. Ent. 62:175.

The following description is taken for the most part from original description of $R$. sigmodoni Stewart 1930. During November, 1944, Dr. $M$. A. Stewart, describer of $P$. sigmodoni, while in conference with the author in Portland, Oregon, stated that he was thoroughly convinced that $R$. sigmodoni was same flea as $R$. gwyni C. Fox 1914 .

There were before Stewart at time he described $R$. sigmodoni 52 males and 79 females off Sigmodon hispidus subsp. (cotton rat), 2 pairs off Norwegian rats, female off dog, and male off opossum. These were all collected at Houston, Texas, during 1928 and 1929, in months of January through May, and October.

HEAD: Well rounded in both sexes. Frontal tubercle conspicuous. Eyes large, oval, black. No genal teeth. Both post- and preantennal regions with 3 rows of bristles. Small spiniforms along posterior margin of antennal groove.

Pronotum without comb.

Modified Segments, Male: Process of clasper is roughly triangular. Finger is very thin and evenly rounded at apex. It possesses row of very fine short bristles on posterior margin and 3 long bristles in proximal half of this margin. IX st. finger-shaped, armed with a series of ventrally placed bristles. FEMALE: VII st. fairly well rounded in outline. Spermatheca characteristically shaped.

LeNGTH: Originally listed as male $2.1 \mathrm{~mm}$., female $2.8 \mathrm{~mm}$.

RANGE: Probably throughout range of cotton rat, which now extends from Lower Colorado River Valley in California east at least through Texas.

Biology: Stewart reports that a female of this species fed upon his arm for a period of $7 \frac{1}{2}$ minutes after having fasted for 4 days. Insect spent about a minute in preparation then stood on her head, balancing with her legs and started feeding. Maxillae were held at right angles 
to the mandibles during act of feeding and were not in contact with skin at all. Not slightest pain or irritation was felt during or after the process of feeding.

Records: The writer has in his collection a pair of these fleas collected in Brewster County, Texas, on March 31, 1942, off:

Sigmodon hispidus subsp. (cotton rat).

\section{GENUS ARCTOPSYLLA WAGNER}

1930. Arctopsylla Wagner. Kat. der Palaearktischen Aphanipteren p. 40.

Genotype: Pulex tuberculaticeps Bezzi 1880

In this genus frontal tubercle is vestigial. Apically antennal club is pointed. Well developed eyes are present. Labial palpi are long, extending to or beyond the apex of trochanter I. Seven to 10 segments. Post and preantennal regions of head with 3 rows of bristles. No genal or pronotal comb. Upper sclerite of metepisternum not distinctly separated from metepisternum proper but separated from metanotum by an internal sclerotized ridge. Metepimeron not fused along the upper part with metepisternum. Antepygidial bristles undifferentiated. VIII st. of male broad, large and unmodified. IX st. much reduced.

This genus is represented in the West by 2 species which are found upon carnivores.

Key to the Western Species of Arctopsylla

1. Process of male apically rounded VII st. female not sinuate

A. ursi, p. 88

2. Process of male apically flat VII st. female deeply sinuate

A. setosa, p. 89

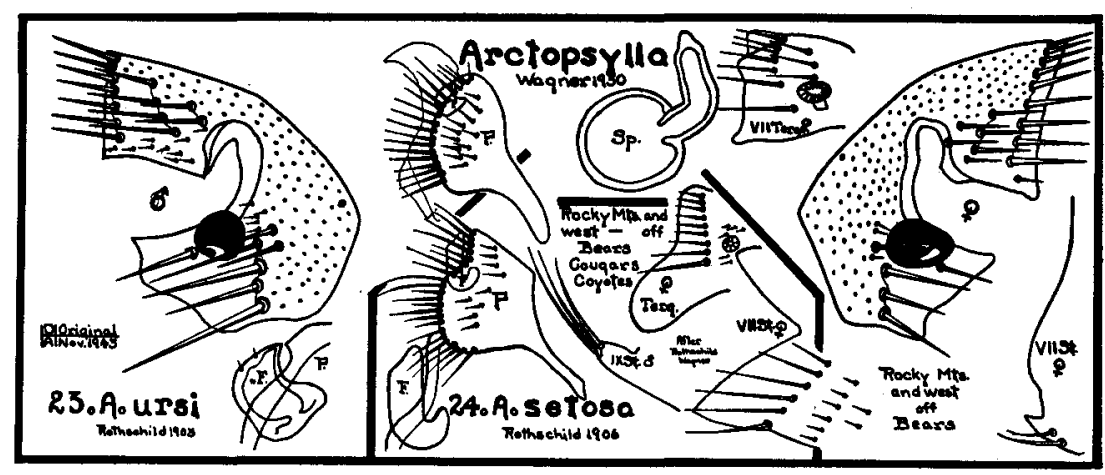

23. Arctopsylla ursi

Rothschild 1902

1902 Pulex ursi Rothschild, Ent. Record, 14:62.

This species was described from a large series collected off Ursus horribilis (grizzly bears) by G. F. Dippie, who collected the material 45 miles west of Calgary, Alberta, Canada on April 29, 1901. 
HeAD: In this species head is angulate in both sexes. Eyes are oval to round and well pigmented. Preantennal region bears 3 rows of bristles. Lower genal row consists of single bristle situated below eye. Second row of 3 or 4 long bristles is just above eye level. Third row is made up of 1 or 2 medium bristles, close to antennal groove and not too far above second row. Small group of setae above eye. Postantennal region with 3 rows of bristles and some setae along antennal groove. There is no pronotal comb.

Modified Segments, Male: Process of clasper is broad and apically rounded. Slightly incurved on posterior border. Armature of many medium and short bristles. Finger very small, hook shaped. Female: VII st. with apical outline in inconspicuous lower triangular lobe, followed by upper flattened rounded lobe. Spermatheca with globular body and hooked tail.

LENGTH: Variable with amount of blood engorged. Holland reports to writer a series taken off a grizzly bear measuring $8 \mathrm{~mm}$. long.

RANGE: This bear flea has been recorded from Montana, Alberta, British Columbia, and Alaska. It can probably be found on various bears of Rocky Mountains and west.

Preferred Host: This species seems to be a true bear flea.

RECORDS: Besides the original Canadian record from Alberta, this species is also recorded from:

BRITISH COLUMBIA-Off:

Ursus horribilis (grizzly bear), Wigwam. Holland, at Kamloops, informs the writer by letter that he took 60 specimens of this flea, most of them females, off a single grizzly bear.

ALASKA-On September 3, 1935, Jack O'Connor removed 23 males and 33 females off:

Euarctos americanus (black bear), collected at Funny River, Anchorage.

MONTANA-In this state this flea was collected off:

Euarctos americanus (black bear), Ravalli County, during 1930.

\section{Arctopsylla setosa \\ Rothschild 1906}

1906 Chaetopsylla setosa Rothschild, Canad. Ent. 38:321.

1936 Chaetopsylla setosa Wagner, Zeit. f. Parasit. 8:335.

1942 Arctopsylla setosa Jellison and Good, Nat. Inst. Health Bul., No. 178, p. 23.

This species was described from female specimens taken off Canis latrans (coyote) collected at Eagle River and Sicamous, and off Ursus horribilis (grizzly bear) collected at Mabel Lake, British Columbia. It was not until 1936 that Wagner described male from materials off grizzly bear collected in British Columbia.

In 1942 Jellison and Good assigned this species to Arctopsylla.

This species can readly be distinguished from $A$. ursi by its well 
rounded head, shape of abdominal sclerites, and modified abdominal segments.

Head: Well rounded head is armed with long bristle below well developed circular eye; row of 4 stout bristles just above eye; third row of 4 medium bristles and above these a pair of short bristles at antennal groove. Postantennal region with 3 rows of bristles. Setae along antennal groove and fine hairs over top of head.

There is no pronotal comb.

Modified Segments, Male: Process of clasper much broader than in A. ursi. It is apically flat. Dorsal face is not so broad as ventral face, due to expanded lower portion. Armature of a good number of medium bristles which radiate out from posterior border, and some small bristles. Finger not hook-like as in $A$. ursi but with anterior and posterior faces about parallel with apex rounded. Female: VII st. deeply sinuate with upper and lower lobes somewhat triangular.

LENGTH: Original length given for female, $3.5 \mathrm{~mm}$.

Range: This species is reported from British Columbia and Montana off various carnivores.

ReCORDs: This species is reported from the state of Montana from: Canis latrans Say (coyote), Carter, Lake, and Petroleum Counties, 1936.

Felis oregonensis hippolestes Merriam (Rocky Mountain cougar), Mineral County, 1936.

Euarctos americanus Pallas (black bear), Lincoln County, 1941.

\section{GENUS ORCHOPEAS JORDAN}

1933. Orchopeas Jordan. Nov. Zool., 39:71.

Genotype: Pulex wickhami Baker

Pronotal comb of about 20 teeth. Fifth tarsal segment of each leg is armed with 4 pairs of lateral plantar bristles and a basal and an apical submedian pair. Movable finger $F$ of clasper of male ham-shaped, wedge-shaped or rectangular and armed with a row of 4 to 7 short, black spiniforms. Body of spermatheca more or less barrel shaped with crooked appendix. Females with 3 stout antepygidial bristles on each side; males with 2 stout and 1 minute antepygidial bristles on each side.

This genus is represented in West by 8 species, one of which has been broken into 7 subspecies, another into 2 .

Students of fleas well realize difficulties which lie in the genus Orchopeas as far as identification is concerned. Many subspecies together with considerable variation in characteristics, which have been picked from individual specimens rather than series, have led to confusion which even authorities many times fail to escape. Certain flea specialists refuse in many cases to render a subspecies identification unless they are absolutely familiar with species in question. At times not only do authorities disagree upon subspecies but will even reverse 
themselves on Orchopeas species. There is little doubt that as time goes on, range will play a far greater part in identifications than it has in past. However, range may become void as species of fleas become transplanted into new territories by transfer of their hosts, as in case of tree squirrels being moved from one section of country to another for park or game purposes.

Key to the Western Species of Orchopeas (males only)

The western species of Orchopeas are immediately distinguishable in the male by the shape of the finger $F$ of the clasper and the number of spiniforms which make up its armature.

1. Finger $\mathbf{F}$ more or less pointed at apex and armed with 5 to 7 black spiniforms $\quad$ O. sexdentatus, p. 92

2. Finger $\mathbf{F}$ more or less rectangular and armed with 4 black spiniforms

a. Spiniforms spaced evenly

Central California and north $\quad$ O. nepos, p. 99

Southern California

Finger flat apically $\quad$ O. latens, p. 101

Finger angulate apically $\quad O$. dieteri, p. 102

b. Spiniforms 2 below, close together, 2 evenly spaced above

3. Finger $\mathrm{F}$ ham-shaped and armed with 4 or 5 spiniforms

O. s. neotomae, p. 98

O. caedens, p. 102

O. leucopus, p. 105

4. Finger $\mathrm{F}$ swollen ventrally at the ventral angle and armed with 4 spiniforms (wickhami)

O. howardi, p. 107

Besides the above species Baker in 1904 described from a single female specimen taken at Moscow, Latah County, Idaho, off a lynx O. labiatus, p. 108

\section{Orchopeas sexdentatus Baker}

West of the 100th meridian this species has been broken into 7 subspecies to this date (1944). Characteristics which are common to all follow:

HeAD: Well rounded in female but flattened on top in male. Frontal tubercle small. Eye heavily pigmented and oval or grape seed shaped. Lower genal row of bristles 3 in number and at level with top of eye. Bristles in this row stout, middle one about half as long as outer one. A second row of 2 medium bristles followed along antennal groove by 3 medium bristles, the 5 at times appearing as if they were a single row. A few setae above eye. Postantennal region with 2 medium bristles and a marginal row of 5 or 6 , the lower one in the male, the second lowest one in the female stout and long. Setae along the antennal groove.

Thorax: Pronotum with a row of bristles and a comb of about 20 black teeth. Mesanotum and metanotum with 2 rows of bristles.

Aвдомen: Tergites with 2 rows of bristles and first to third armed also with apical spinelets. 
Length: These are medium sized fleas. In majority of subspecies males average $2 \mathrm{~mm}$. in length, the females $3 \mathrm{~mm}$.

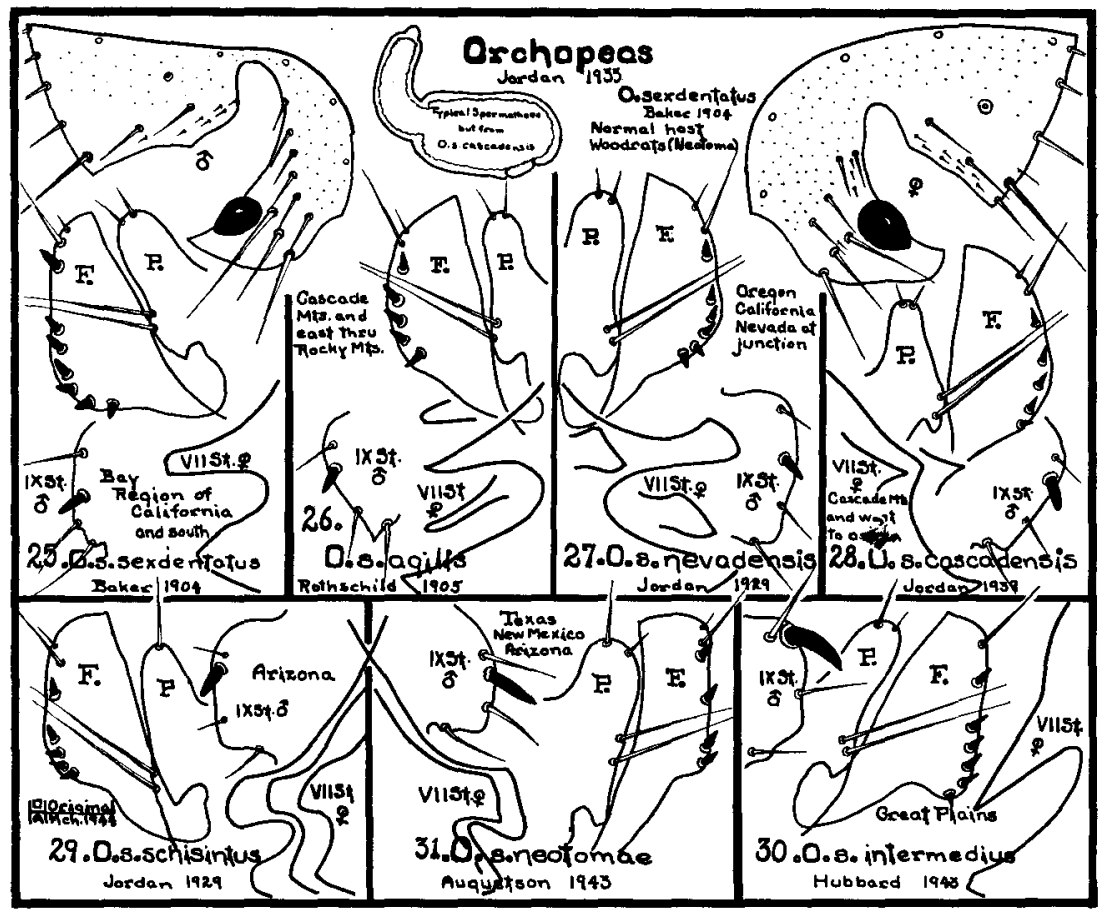

\section{Orchopeas sexdentatus sexdentatus}

Baker 1904

1904 Ceratophyllus sexdentatus Baker, Proc. U. S. Nat. Mus., 27:403, Pl. XXVI. Figs. 8-14.

1929 Ceratophyllus sexdentatus sexdentatus Jordan, Nov. Zool., 35:30.

1933 Orchopeas sexdentatus Jordan, Nov. Zool., 39:71.

This flea was described by Baker from materials sent him by Edward Ehrhorn from a few miles south of Stanford University, California, at Boulder Creek, where the specimens were taken off a Neotoma (wood rat).

Modified Segments, Male: Process $P$ of clasper nicely rounded and fairly broad, armed apically with several small bristles. Finger $F$ of clasper seems to be swollen more proximally and more pointed apically than fingers of other subspecies. Five to 7 short black spiniforms are along posterior edge, 1 isolated above, 4 to 6 below and evenly spaced. Lower lobe of IX st. much less angulate proximally than in other subspecies. This lobe is armed with a single short, straight, black spiniform and 2 bristles below and 1 above it. 
Female: VII st. probably somewhat variable but generally with an upper somewhat rectangular lobe which may extend slightly beyond lower somewhat triangular lobe. Sinus between lobes fairly deep and broad. Spermatheca with barrel shaped body and crooked tail, which has an apical appendage.

RANGE: This subspecies of wood rat flea ranges south of San Francisco Bay, California, almost everywhere in southern half of this state.

Medical Importance: Preferred host of this flea, wood rat, was found plague positive in Alameda County, central California, as early as 1909. Plague infection was found in wood rats in San Luis Obispo County in 1935, in San Bernardino County in 1937 and 1942, and in Los Angeles and Monterey Counties in 1942. All of these records of plague-positive wood rats are in range of this subspecies of flea. Flea is known to be an efficient vector of plague, and the wood rat, its preferred host, is thought to be a reservoir to plague in West, with significance second only to the ground squirrel.

RECORDS: Augustson reporting from southern California, records this flea:

From Los Angeles County off:

Mephitis mephitis holzneri (common skunk)

Peromyscus californicus insignis (deer mouse)

Neotoma fuscipes macrotis (large-eared wood rat)

Neotoma lepida lepida (Thomas wood rat)

Neotoma lepida intermedia (wood rat),

From Riverside County off:

Peromyscus eremicus eremicus (deer mouse)

Peromyscus crinitus stephensi (canyon deer mouse)

Neotoma lepida gilva (yellow wood rat),

From Santa Barbara County off:

Peromyscus maniculatus gambeli (Gambel's deer mouse).

The writer has specimens in his collection. from Boulder Creek, Santa Cruz County, the type locality for the subspecies.

\section{Orchopeas sexdentatus agilis \\ Rothschild 1905}

1905 Ceratophyllus agilis Rothschild, Nov. Zool., 12:167, P1. VII, Figs. 16-18.

1929 Ceratophyllus sexdentatus agilis Jordan, Nov. Zool., 35:30.

Rothschild, in describing this flea, stated that it was very close to $C$. sexdentatus Baker and suggested that intermediate forms would probably be found in other localities confirming his supposition that he had here to do with varieties rather than distinct species.

Type material came from Banff, Alberta, Canada, where it was taken off Neotoma cinerea (wood rat).

Today agilis is considered a subspecies of sexdentatus. The characteristic of "6 short, stout, black teeth" (Baker) in sexdentatus and only 5 in agilis on margin of finger $\mathrm{F}$ of males is known not to he constant. 
Modified Segments, Male: Process $P$ of the clasper well rounded at apex. It is armed apically with several small bristles. Finger $F$ of clasper pointed apically. Proximal portion not noticeably dilated. Five short, black spiniforms evenly spaced along posterior border. Lower lobe of IX st. with an angular ventral angle. Single black, short spiniform is placed more or less median, and distal bristle is at some distance from curve of margin. Female: Apical outline of VII st. variable. Upper lobe not so long as the lower, and may be rounded or pointed apically. This lobe may be long and narrow or long and broad in case apex is rounded. The sinus is deep and broad. The lower lobe is narrow and somewhat triangular. Spermatheca is typical.

RANGe: Through Cascade Mountains north of Pitt River in northern California, this subspecies is common wood rat flea. It ranges east through Oregon, Washington, and British Columbia. The writer has personal records from many points north of Modoc Lava Beds, Siskiyou County, California. Typical of these are from Neotoma cinerea occidentallis Baird (western bushy-tailed wood rat).

Medical Importance: To this time there has been no plague reported in the wood rats in the range of this flea. This flea has, however, been infected with plague, and its close relatives, the following two subspecies, are known to be efficient vectors of the disease. Therefore, the hosts of this flea should be carefully watched in Northwest for plague infection, particularly in those areas known to harbor plague-positive ground squirrels.

RECORDS: The author has collected this flea off Neotoma cinerea occidentalis Baird (Western bushy-tailed wood rat), as follows:

WASHINGTON-Toppenish, Yakima County, March 15, 1940. Grand Dalles, Klickitat County, December 28, 1942. White Salmon, Klickitat County, December 15, 1943.

OREGON-Parkdale, Hood River County, June 1, 1934. Klamath Falls, Klamath County, June 26, 1939. Wallowa Lake, Wallowa County, July 14, 1939.

CALIFORNIA-from:

Neotoma fuscipes fuscipes (round-tailed wood rat), taken at: Modoc Lava Beds, Siskiyou County, June 28, 1939, and Macdoel, Siskiyou County, June $7,1943$.

UTAH-off:

Neotoma desertorum Merriman (desert wood rat), Kanab, Kane County, July 8, 1945, a pair

ARIZONA-Off:

Neotoma desertorum Merriam (desert wood rat), Fredonia, Coconino County, July 8, 1945, 2 males, 3 females.

MONTANA-Investigators report this flea general, taken off its normal host:

Neotoma cinerea (western bushy-tailed wood rat),

Off the following carnivores:

Bubo virginianus (great horned owl), Beaverhead County

Martes sp. (pine martin), Ravalli County

Mustela spp. (weasel), Ravalli, Beaverhead Counties, 
Off the following Lagomorpha:

Lepus bairdi (snowshoe rabbit), Ravalli County

Ochotona princeps (cony), Ravalli County

Sylvilagus sp. (cottontail rabbit), Ravalli, Rosebud Counties.

ALBERTA-This flea has been reported from this Canadian province off:

Neotoma cinerea (wood rat), Banff

Ochotona princeps (cony), Banff

Tamiasciurus hudsonicus (red squirrel), red deer

Mustela longicaudatus (weasel), Canadian National Park.

BRITISH COLUMBIA-In this western province of Canada this flea has been reported off the following hosts in many localities:

Neotoma cinerea occidentalis (western bushy-tailed wood rat)

Ochotona princeps (cony)

Mustela longicaudatus (weasel), and the writer collected it off:

Ochotona princeps cuppes Bangs (Bangs Cony), Crambrook, July 25, 1945, 1 female.

\section{Orchopeas sexdentatus nevadensis \\ Jordan 1929}

1929 Ceratophyllus sexdentatus nevadensis Jordan, Nov. Zool., 35:30.

In describing this subspecies, Jordan states that the male is close to Ceratophyllus s. agilis, female not constantly different from $O$. s. sexdentatus. Description is based upon 3 males and 5 females off Mustela arizonensis, collected by A. B. Howell at Pine City, California, during July, 1922.

Modified Segments, Male: Anterior lobe of IX st. ventrally straight, longer than in Ceratophyllus s. sexdentatus, spiniform placed beyond middle of this lobe and distal bristle at curve of distal margin; apical lobe of IX st. is nearly evenly rounded at apex, not rotundatetruncate. Finger $F$ with 5 spiniforms, sometimes 4 on each side. FEMALE: Sinus of VII st. is deep, as a rule extending nearer to row of bristles than in C. s. sexdentatus; upper lobe is narrow but sometimes widened at apex.

RANGE: There is little doubt that this flea, although described off a weasel, is common wood rat flea of southeast quarter of Oregon, northeast portion of California, and all of Nevada.

This flea is also reported from south central Utah.

During 1938 this flea was found to be a constant parasite on Neotoma desertorum (wood rat) in Clark County, Nevada, and Kane County, Utah.

Medical Importance: Field workers during 1938 noticed a great many deserted nests of Neotoma desertorum (desert wood rat) in Clark County, Nevada, and Kane County, Utah. Examination of many nests revealed dead animals within. While no plague tissue was found in wood rats, pools of their fleas were found to be plague positive. Bulk 
of some 1,500 fleas collected during this study was of this subspecies. Orchopeas sexdentatus nevadensis, then, is considered today to be a vector of bubonic plague.

Records: Typical records of the writer come from:

Neotoma lepida nevadensis Taylor (Nevada round-tailed wood rat) from the rocky rimrocks in:

OREGON-Narrows, Harney County, July 18, 1935, 5 males, 3 females; Adel, Lake County, 12 miles south, June 24, 1937, 1 male, 2 females.

CALIFORNIA-Fort Bidwell, Modoc County, June 25, 1937, 2 males, 3 females.

NEVADA-Coleman's Ranch, Washoe County, June 26, 1937, 1 female.

\section{Orchopeas sexdentatus cascadensis Jordan 1939}

1939 Orchopeas sexdentatus cascadensis Jordan, Nov. Zool., 41:317

According to Dr. Karl Jordan, after a study of a few of many wood rat fleas in the collection of the writer, there is a subspecies of sexden. tatus ranging from crest of Cascade Mountains to Pacific Ocean, in which females are quite different from either agilis or nevadensis. This new subspecies has been named cascadensis by Dr. Jordan. According to data of the writer, agilis seems to confine itself to Cascade Range and east, while cascadensis ranges in Cascades and west to Pacific Ocean, and is found upon 3 subspecies of Pacific Northwest wood rats.

Modified Segments, Male: Process $P$ of the clasper more truncate than in other subspecies. Finger $F$ of clasper not particularly characteristic. It is armed with 5 short, black spiniforms. IX st. not characteristic. Females XII st. with only a small somewhat triangular lobe about midway along apical slope and between lobe and ventral a shallow bay. Spermatheca typical.

RANGE: This wood rat flea ranges through Cascade Mountains and west to Pacific Ocean in northern California, Oregon and Washington.

Medical Importance: To the present time plague has not been reported in wood rats which this subspecies of flea infests. This flea has not come under plague investigation; therefore, it is difficult to give its status as a vector of this disease. However, Citellus beecheyi douglasi (ground squirrel) has been found plague positive in southwestern Oregon in foothills of Siskiyou Mountains where this wood rat flea is common, as is also its host the round-tailed wood rat. It seems that it will be only a matter of time until only ground squirrel flea in these parts Diamanus montanus Baker, a very efficient vector of plague, carries plague to wood rats and then disease may be carried among them by their own flea, Orchopeas sexdentatus cascadensis Jordan.

RECORDS: Typical from records of the writer are: 
OREGON-From:

Neotoma cinerea occidentalis Baird (western bushy-tailed wood rat), Odell Lake, Klamath County, July 31, 1936; Estacada, Clackamas County, January $\mathrm{I}, 1932$.

Neotoma cinerea fusca True (dusky bushy-tailed wood rat), Neskowin, Tillamook County, October 19, 1931; Powers, Coos County, August 22, 1937.

Neotoma fuscipes fuscipes Baird (round-tailed wood rat), Salem, Marion County, November 15, 1938.

CALIFORNIA-Gasquet, Del Norte County, June 16, 1939; Smith River, Del Norte County, January 29, 1944.

WASHINGTON-From:

Neotoma cinerea occidentalis (western bushy-tailed wood rat), Yacalt, Clarke County, November 12, 1933.

\section{Orchopeas sexdentatus schisintus Jordan 1929}

1929 Ceratophyllus sexdentatus schisintus Jordan, Nov. Zool., 35:31.

This wood rat flea is reported so far only from Arizona. In the description of this subspecies one finds one of the few very brief descriptions ever offered by Jordan. Entire original description follows: “Apparently differs in the female only: the upper lobe of VII st. broad and short, the lower one absent or quite short. Exopodite of the male with 5 or 6 spiniforms. Habit. Arizona, a series off Neotoma, collected by $\mathrm{O}$. C. Duffner."

RANGE: Although this flea has been reported only from southern Arizona, it seems likely that in time it will be reported from northern New Mexico.

Medical Importance: This subspecies of wood rat flea has never been condemned as a vector of plague. Wood rats in its range have not as yet been found plague positive.

RECORDS: In collection of the writer are a few specimens of this subspecies taken in Pima County, Arizona, off:

Neotoma albigula albigula (white-throated wood rat), Tucson

Neotoma lepida harteri (wood rat), Organ Pipe Catcus Nat. Mon.

\section{Orchopeas sexdentatus intermedius}

Hubbard 1943

1943 Orchopeas sexdentatus intermedius Hubbard, Pacific Univ. Bul. 39, No. 10, 1-2.

This, the latest addition to subspecies of Orchopeas sexdentatus, was described by the writer from a pair of these insects collected in Meade County, Kansas, and may represent Great Plains variation of these common wood rat fleas.

Modified Segments, Male: Process $P$ of clasper rounded apically and not materially broadened; armed apically with several small bristles. Finger $\mathbf{F}$ of clasper with heel portion more expanded than in other 
subspecies; armed with 6 short black spiniforms, 5 below and evenly spaced and one above. IX st. armed with a much more conspicuous black spiniform than in other subspecies. This spiniform is curved and situated at the dorsal angle of the lobe. Lobe also carries 3 bristles. FeMALE: Apical outline of VII st. very characteristic. Upper lobe distinctly wedge-shaped and pointed, its angle distinctly oblique which causes the sinus to be deep, narrow and also at an oblique angle.

RANGE: While known only from Meade County, Kansas, the type locality, this flea may be a constant parasite of the wood rats of the Great Plains.

LENGTH: Unlike other subspecies of Orchopeas sexdentatus, this insect seems same length in both sexes, that is, $2.15 \mathrm{~mm}$.

Type Material: Deposited in United States National Museum.

\section{Orchopeas sexdentatus neotomae \\ Augustson 1943}

1943 Orchopeas sexdentatus neotomae Augustson, Bul. Southern Calif. Acad. of Sci. 42:49.

This new wood rat flea of Pacific Southwest has caused some comment among flea students of West. Several who have had opportunity to study the flea feel that it should be definitely elevated to the rank of a species, that its position as a subspecies of $O$. sexdentatus is doubtful. The writer is of this opinion.

Modified Segments, Male: Process $P$ of clasper well rounded at apex and armed with 2 short bristles. Finger $F$ of clasper roughly rectangular in shape and armed on posterior edge with 4 black spiniforms,

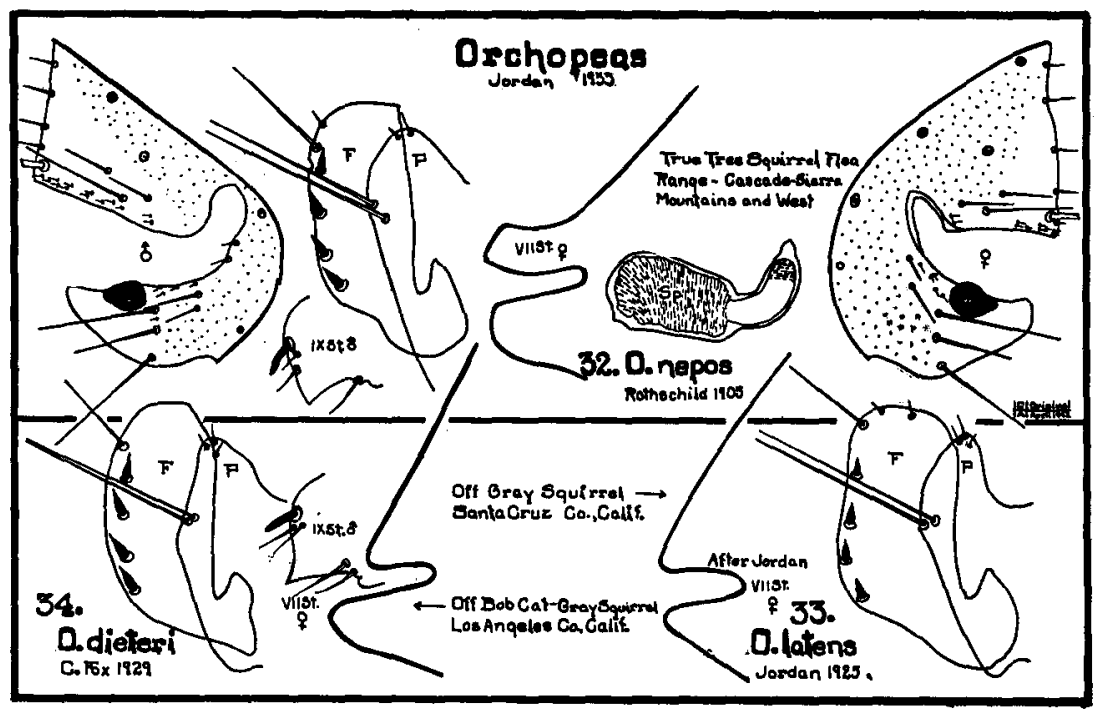


2 below and close together at heel and 2 above equally spaced. IX st. with black spiniform and 3 bristles. Female: VII st. with upper angular lobe which may be expanded at tip. It approaches at times the lobe of $O$. s. schisintus. Spermatheca typically Orchopeas.

Range: Type material was collected at South Entrance, Grand Canyon National Park, Coconino County, Arizona, off Neotoma lepida devia (wood rat). The writer has seen specimens of this flea from other parts of Arizona and from New Mexico and it is said that the flea is also found in western Texas.

In Arizona he has collected it off:

Neotoma albigula albigula Hartley (white-throated wood rat), Grand Canyon, Coconino County, July 3, 1945, 7 males, 33 females.

\section{Orchopeas nepos \\ Rothschild 1905}

1905 Ceratophyllus nepos Rothschild, Nov. Zool., 12:167.

1933 Orchopeas nepos Jordan, Nov. Zool., 39:71.

1936 Orchopeas nepos Wagner, Can. Ent., 68:199.

Rothschild states, "A very close ally of $C$. sexdentatus and wickhami. Head is practically the same as in $C$. wickhami. Finger bears 4 spines as in C. wickhami . . . . in so far as we have only one pair of this insect we do not know how far distinction mentioned will prove constant. We have 1 male and 1 female, Chilliwack, British Columbia, Canada, November 1, 1899, from Spilogale latifrons (spotted skunk), collected by Allen Brooks."

Wagner says in his "Fleas of British Columbia," "My collection contains I male and 2 females from Abbotsford, B. C., from Sciurus sp. Very likely Sciurus is its proper host.:"

The writer has several hundred specimens of this flea in his collection and he believes as Wagner suggests that this flea is a true tree squirrel flea, having for its favored hosts the various pine squirrels of west of Great Basin region and silver gray squirrel.

HEAD: Well rounded in female but flattened on top in male. Frontal tubercle small. Eye oval and well pigmented. Genal row of 3 stout bristles at level with top of eye. Middle one about two-thirds as long as outer one. Above these at antennal groove a single stout bristle which may at times have beside it to form a second row of 2 much weaker bristles. There may be 2 weak bristles above these and along antennal groove. Setae over eye and along groove. Postantennal region with bristles at least 1 of which is stout and long (others may be) and a marginal row of 5 or 6 , the lower one stout and long. Setae along antennal groove.

Thorax: Pronotum with a row of bristles and a comb of about 20 black teeth. Mesanotum and metanotum with 2 rows of bristles. 
Abdomen: Tergites with 2 rows of bristles and first 4 also armed with apical spinelets.

Modified Segments: In this species finger $\mathrm{F}$ and apical margin of VII st. of female mark it off from all other fleas. MALE: Finger $F$ is almost rectangular, not pointed apically as in sexdantatus, not hamshaped as in caedens. Black spiniforms are 4 in number and are fairly even in their distribution on the posterior border. Proximal lobe of IX st. of male bears a longer spine than in sexdentatus. VIII t. of male bears 3 bristles near ventral edge sexdentatus bears but 2 in this position. In female, apical margin of VII st. has dorsal lobe slightly longer than ventral lobe, and is about same width throughout, with squarish end.

Length: Males of this species average about $2 \mathrm{~mm}$. in length, females about $3 \mathrm{~mm}$.

RANGE: Through the Cascade Mountains and west in California, Oregon, Washington, and British Columbia and to east where Tamiasciurus douglasi is found. cies.

Host Preference: Western tree squirrels are preferred by this spe-

ReCords: Personal records of the writer for this flea are far too numerous to record, but they come from all over the Cascade Mountains and the Puget Sound Trough. Typical of these are:

\section{OREGON-From:}

Sciurus griseus griseus Ord (silver gray squirrel), Gaston, Washington County, May 22, 1933; Crater Lake, Klamath County, July 1, 1933; Portland, Multnomah County, May 20, 1934; Sisters, Deschutes County, July 18, 1936; Holland, Josephine County, June 18, 1939; Brownsboro, Jackson County, June 21, 1939 (from a female nursing young) 5 males, 22 females

Tamiasciurus douglasi douglasi Bachman (Douglas pine squirrel), Tualatin, Clackamas County, February 3, 1935

Tamiasciurus douglasi cascadensis Allen (Cascade pine squirrel), Mitchell, Wheeler County, (Ochoco National Forest), August 20, 1940.

Accidental occurrences:

Glaucomys sabrinus oregonensis Bachman (flying squirrel), Gaston, Washington County, February 12, 1938

Marmota flaviventris flaviventris Aud. and Bach. (woodchuck), Cloud Cap Inn, Mt. Hood, June 12, 1934

Eutamias townsendi townsendi Bachman (Townsend's chipmunk), Dodge Park, Clackamas County, July 26, 1934

Citellus beldingi oregonus Merriam (Oregon ground squirrel), Paulina Lake, Deschutes County, August 1, 1936

Neotoma cinerea occidentalis Baird (western bushy-tailed wood rat), Fish Lake, Linn County, Santiam Nat. Forest, July 20, 1938.

WASHINGTON-On April 7, 1942 the writer secured 4 nests of:

Sciurus griseus griseus Ord (silver gray squirrel) at Vancouver, Clarke County, and from them he removed large numbers of this flea.

Other specimens were removed from:

Tamiasciurus douglasi douglasi Bachman (pine squirrel), Kalama, Cowlitz County, July 2I, 1937, 
A male was taken off a specimen of:

Ochotona princeps brunnescens Howell (Cascade cony), Goose Lake, Skamania County, August 25, 1935.

CALIFORNIA-On April 20, 1942, the writer picked up, after it had been run over by an automobile, a specimen of

Sciurus griseus griseus Ord (silver gray squirrel) at Gasquet, Del Norte County, and removed 8 males and 14 females of this species, which is a large number of fleas to be picked off this rather clean squirrel.

In the Sierra-Nevadas of central California Augustson reports taking this flea off:

Tamiasciurus douglasi albolimbatus Allen (California chickaree), Mammoth Lakes, Mono County

Ochotona schisticeps muiri G. and S. (cony), Duck Pass, Mono County

Peromyscus maniculatus sonoriensis Le Conte (deer mouse), Mammoth Lakes, Mono County

Bassaricus astutus raptor Baird (ring-tailed cat), Yosemite, Mariposa County.

BRITISH COLUMBIA-This flea was described from a pair of these insects taken off:

Spilogale latifrons (little spotted skunk), Chilliwack, Wagner reports it off:

Sciurus sp., at Abbotsford.

Although there is a record of this insect having been collected off Neotoma cinerea (wood rat), Salina Canyon, Sevier County, Utah, this writer believes the record an error in determination. He doubts presence of this flea east of the Great Basin, or for that matter, even in Great Basin area.

\section{Orchopeas latens \\ Jordan 1925}

1925 Ceratophyllus latens Jordan, Nov. Zool., 32:105.

1933 Orchopeas latens Jordan, Nov. Zool., 39:71.

1940 Orchopeas latens I. Fox, Proc. Ent. Soc. Wash., 42:67.

This species was described by Jordan from specimens taken off a gray squirrel in 1900 by Ehrhorn in Santa Cruz County, California. Of modified segments Jordan says that male is like $C$. caedens but process $P$ of clasper is narrower, subacuminate, on anterior side deeply incurved, on posterior side rounded, finger more gradually widened. In female sinus of VII st. is narrow, upper lobe a little longer than lower and not of same width throughout and squarish on end as in nepos.

Although Jordan lists habitat as California, exact extent of range of this flea in Southwest is not known.

Original lengths are listed as male, $2.0 \mathrm{~mm}$., female, $2.7 \mathrm{~mm}$.

The only other record besides that accompanying original description seems to come from Augustson, who reports that he has specimens off:

Citellus beecheyi nudipes (Juarez ground squirrel)

taken in San Diego, California. With this record Augustson says, ". . . apparently rather a rare flea, nothing much being known about it except from its original description. Some siphonapterists are evidently uncertain of its validity as a species. The specimens in the writer's collection are quite distinct from $O$. nepos, $O$. caedens, or $O$. dieteri." 


\section{Orchopeas dieteri \\ C. Fox 1929}

1929 Ceratophyllus nepos dieteri C. Fox, Ent. News, 40:218.

1940 Orchopeas dieteri I. Fox, Proc. Ent. Soc. Wash., 42:67.

In a very short description, Carroll Fox states that the immovable process of clasper of this flea is narrow, that female is similar to $C$. latens Jordan 1925; that sinus of VII st. of female is very narrow and that head of spermatheca is longer. Material from which flea was described was removed from Lynx rufus (bobcat) taken in Los Angeles County, California. Type material bears number 41820 and is deposited in United States National Museum. C. Fox described flea as a subspecies of $C$. nepos Rothschild 1905, but in 1940 after carefully studying type material, I. Fox states that flea is more closely related to $O$. latens Jordan 1925, and should have its position raised to that of a species. He also states that this species differs from both nepos and latens in male by shape of process and finger and in female by fact that upper lobe of VII st. does not extend as far posterior as lower lobe.

In male of this species process of clasper appears to be bent at apex toward movable finger. Finger is long and broad (rectangular shaped) and is armed with 4 black spiniforms of which lowermost 3 are more or less evenly spaced, while uppermost is set off from others.

RANGE: Nothing is known about range of this species.

Augustson reports the only record other than the original. It is from Sciurus griseus anthonyi (Anthony's gray squirrel) taken at Sunland, Los Angeles County, California.

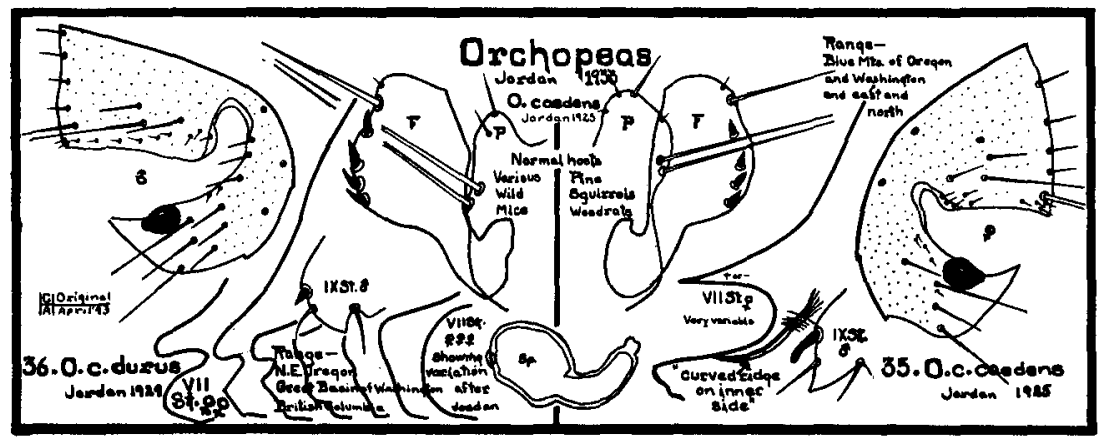

35. Orchopeas caedens caedens

Jordan 1925

1925 Ceratophyllus caedens Jordan, Nov. Zool., 32:104.

1933 Orchopeas caedens Jordan, Nov. Zool., 39:71.

Jordan states that this flea is similar to Orchopeas sexdentatus Baker 1904 and Orchopeas nepos Rothschild 1905. Description was based upon a series of both sexes collected at Banff, Alberta, Canada, by Mackey and Dippie, off Mustela americana (weasel) during October, 
1915. The writer believes this infestation to be accidental, and true host of this flea to be tree squirrels.

Head: Well rounded in female but flattened at top in males. Frontal tubercle small. Eye grape seed shaped and heavily pigmented. Genal row of 3 stout bristles above eye top level. Middle bristle one-half as long as outer bristle. One medium bristle above and in male an additional 3 weak bristles along antennal groove. Setae above eye and along antennal groove. Postantennal region with 3 bristles, 1 of which is stout and long, other 2 medium, and a marginal row of 5 bristles, the lower one being stout and very long.

Thorax: Pronotum armed with a row of bristles and a comb of 20 black teeth. Metanotum and mesanotum armed with 2 rows of bristles.

Aвдомen: Tergites with 2 rows of bristles and anterior 4 with apical spinelets.

Modified Segments: Finger $\mathrm{F}$ of male is distinctly ham-shaped. It is armed with usually 5, rarely 4, short, black spiniforms; first spiniform above middle, proximal half of $F$ narrow, greatest width at first or second spiniform. Proximal ventral lobe of IX st. of male triangular, sharply pointed; apical portion of IX st. dorsally rounded, ventrally incurved; membranous apical portion of VIII st. fringed.

In female VII st. is deeply sinuate, upper lobe is shorter than lower but very variable in width and length; on two sides together, 16 to 19 bristles.

LeNGTH: Original length is given as male, $2.0 \mathrm{~mm}$., female 2.3 to $2.8 \mathrm{~mm}$.

Range: This flea seems to be a northern Rocky Mountain species which is extending its range westward and is now found in Blue Mountains of Oregon and Washington.

RECORDS: The following information is recorded:

OREGON-From:

Taniasciurus hudsonicus richardsoni Bachman (pine squirrel), Joseph, Wallowa County, July 14, 1939, a series, by the author.

CALIFORNIA-The writer seriously doubts the presence of this flea in California. Be this as it may, California collectors have recorded this flea from the state since 1936 when Dr. M. A. Stewart made a determination which established this flea off:

Neotoma fuscipes (wood rat) from San Diego, San Diego County.

Augustson followed in 1943 with the records below off:

Reithrodontomys catalinae (harvest mouse), Santa Catalina Island, Los Angeles County

Reithrodontomys megalotis limicola (harvest mouse), Playa del Rey Salt Marsh, Los Angeles County

Peromyscus eremicus fraterculus (deer mouse), San Gabriel Mountains, Los Angeles County

Peromyscus californicus insignis (deer mouse), Del Mar, San Diego County

Neotoma fuscipes macrotis (wood rat), Santa Monica Mountains, Los Angeles County.

It is to be noted that all above records for California are from wild mice or wood rats, while normal host of this flea throughout its definitely known range is 
pine squirrel or carnivores of this squirrel. Hosts named above by these California investigators as carrying this flea would lead this writer to believe there had been an error in determination, that the flea was other than Orchopeas caedens caedens.

MONTANA-In this state this flea is reported off:

Tamiasciurus hudsonicus (Richardson's pine squirrel), Gallatin, Ravalli, Silver Bow Counties

Eutamias sp. (chipmunk), Ravalli County

Mustela sp. (weasel), Flathead, Ravalli Counties

Martes sp. (pine martin), Ravalli County

Lynx canadensis (bob cat), Ravalli County.

UTAH-During 1931 this flea was recorded from Salina, Sevier County, off:

Neotoma desertorum (desert wood rat)

Peromyscus truei (True's deer mouse).

ALBERTA-This flea was originally described from Banff, where male and female were taken off:

Martes americana (American martin).

BRITISH COLUMBIA-George Holland of Kamloops, British Columbia, sent the writer a large series of these fleas taken at Blackfalds off:

Tamiasciurus hudsonicus (red squirrel),

This flea is also reported from Kamloops, off:

Tamiasciurus hudsonicus streatori (pine squirrel). The author collected it off:

Tamiasciurus hudsonicus richardsoni Bachman (Richardson Pine squirrel), Yahk, July 26, 1945, 13 males, 19 females, and in

IDAHO-Off:

Tamiasciurus hudsonicus richardsoni Bachman (Richardson Pine squirrel), Bonner Ferry, Bonner County, July 24, 1945, 1 pair.

ALASKA-This flea is reported from Lake Bennet, off:

Tamiasciurus hudsonicus (pine squirrel).

\section{Orchopeas caedens caedens and Orchopeas caedens durus}

As early as 1933 doubt began to be expressed about the validity of these designations. Jordan in Nov. Zool. 39:71 suggested that caedens might be a synonym of Orchopeas labiatus Baker. In 1936 Wagner in Can. Ent. 68:199 also suggested that caedens might be a synonym of $O$. labiatus. He also stated at this time that he doubts distinction of $O$. c. durus from O. c. caedens. Irving Fox in Fleas of Eastern United States, p. 62, seems definitely to sink durus as a synonym of caedens but offers no explanation. In 1943 Ewing in Misc. Pub. 5oo, USDA, p. 33, clearly lists durus as a synonym of caedens, but by correspondence with the writer disclaims any responsibility for sinking, stating that Wagner in 1936 had claimed the synonym. Augustson in late 1943 in Bul. So. Calif. Acad. of Sci. 42:80 states that he is inclined to agree with I. Fox. George Holland, working at Kamloops, British Columbia, is the man who probably lives closest to these two subspecies. He tells the writer that he firmly believes there is a decided distinction between these two fleas, and to support his opinion places in hands of the writer a large series of fleas which he considers to be representative of the two subspecies. In those determined as caedens the "longitudinal, curved ridge on the 
inner side" is definitely present, while in those labeled durus this ridge is absent.

\section{Orchopeas caedens durus Jordan 1929}

1929 Ceratophyllus caedens durus Jordan, Nov. Zool., 35:29.

1936 Orchopeas caedens durus Wagner, Can. Ent., 68:199.

In describing this subspecies, Jordan says that the differences lie mostly in females, whereas in $O$. caedens caedens Jordan 1925, described from Alberta speciments, VII st. of the female is divided into a short upper lobe and a broader and somewhat longer lower one, latter bearing a conspicuous longitudinal, curved ridge on inner side; segment is devoid of this ridge in $O$. caedens durus and varies from being entire to being divided into 2 long lobes. In males of this subspecies finger $F$ is distinctly ham-shaped and is generally armed with 4 black spiniforms, rarely 5 , while in $O$. caedens caedens there are usually 5 , rarely 4.

At the time of describing, Jordan had specimens of this flea from practically all over British Columbia, Canada, and stated that all his specimens from British Columbia were of this subspecies, while all those from Alberta were of the preceding subspecies. Jordan lists his specimens off weasels and Richardson's pine squirrels.

RANGE: In the Pacific Northwest it seems that this flea has expanded its range southward out of British Columbia into Washington east of Cascade Mountains, then across Columbia River into Blue Mountains of Washington and Oregon. The flea does not seem to have scattered into Great Basin region of Oregon.

RECORDs: In the writer's collection are records as follows:

WASHINGTON-From:

Reithrodontomys megalotis nigrescens Howell (harvest mouse), Donald, Yakima County, May 8, 1939; Toppenish, Yakima County, January 29, 1942

Peromyscus maniculatus arternisiae Rhoads (Ashcroft deer mouse), Lowden, Walla Walla County, May 13, 1939

Peromyscus maniculatus gambeli (Gambel's deer mouse), Toppenish, Yakima County, January 29, 1942.

OREGON-From:

Peromyscus maniculatus artemesiae Rhoads (sagebrush deer mouse), Umapine, Umatilla County, May 14, 1939, 3 males, 3 females.

\section{Orchopeas leucopus}

Baker 1904

1904 Ceratophyllus leucopus Baker, Proc. U. S. Nat. Mus., 27:401.

1905 Ceratophyllus aeger Rothschild, Nov. Zool., 12:166.

This very common eastern deer mouse flea is somewhat of a rarity in West. It is recorded from here and there west of 100th meridian and in most cases seems to agree closely with the eastern species. 
HeAd: Well rounded in female but flattened on top in male. Frontal tubercle small. Eye well pigmented and oval. Above level of eye top a genal row of 3 bristles, middle one about one-half as long as outer one. Above these a second row of 2, the inner one longer. Along antennal groove there may be 2 more short bristles. Few setae above eye. Postantennal region with 3 bristles, 1 long and stout, and marginal row of about 5, the lower or next to lowest long and stout. Setae along antennal groove.

Thorax: Pronotum with row of bristles and comb of 18 teeth. Mesanotum and metanotum with 3 rows of bristles.

Aвdomen: Tergites with 2 rows of bristles and anterior 4 with apical spinelets.

Modified Segments, Male: Process $P$ of clasper characteristically shaped. Finger $F$ ham-shaped, armed with 4 short black sharp spiniforms. Lower lobe of IX st. armed with spiniform; lower angle angulate. Sinus narrow and as deep as upper lobe is long. Spermatheca typical.

LENGTH: Specimens in collection of the writer measure about $2 \mathrm{~mm}$. in the male and $2.50 \mathrm{~mm}$. in the female.

Range: Apparently this flea ranges in Pacific Northwest, Pacific Southwest, and east through all territory to Atlantic.

RECORDS: The author has collected this flea in

NEVADA-Off:

Peromyscus maniculatus gambeli Baird (Gambel's deer mouse), Sutcliff, Washoe County, June 20,1944, 1 male. South end Lake Tahoe, Douglas County, June 21, 1944, 1 male. Minden, Douglas County, June 24, 1944, 1 male.

Microdipodops megacephalus oregonus Merriam (Oregon gnome mouse), (16 miles s.e. Eagleville, Calif.), Washoe County, June 15, 1945, 1 male.

BRITISH COLUMBIA-George Holland of Kamloops informs the writer by letter that there are a few of these fleas taken now and then off mice in British Columbia.

CALIFORNIA-Gus Augustson reports the following occurrences from Southern California. In Riverside County off:

Peromyscus eremicus fraterculus (deer mouse), Cabazon

Peromyscus californicus insignis (deer mouse), Cabazon

Sigmodon hispidus eremicus (cotton rat), Lower Colorado River Valley

Bassariscus astutus (ring-tailed cat), Riverside Mountains.

There is no evidence at present that this flea is in central or northern California or Oregon, but in Washington specimens in collection of the writer listed above under Orchopeas caedens durus have been considered by some western flea students to be this species.

MONTANA-In Powder River County this flea has been reported off: Microtus sp. (meadow mouse)

Peromyscus sp. (deer mouse). 
ALBERTA-Jordan in 1929 stated that this flea is found "from Alberta and Arizona eastward to the Atlantic." Males and females taken at Red Deer off:

Peromyscus arcticus (maniculatus borealis) (deer mouse)

Clethrionomys gapperi saturatus (red-backed mouse).

These were the basis for Rothschild's Ceratophyllus aeger.

UTAH-This flea is reported off deer mice.

\section{Orchopeas howardi \\ Baker 1895 \\ $=$ Orchopeas wickhami}

1895 Pulex howardi Baker, Can. Ent., 27:110.

1895 Pulex wickhami Baker, Can. Ent., 27:109.

1895 Pulex gillettei Baker, Can. Ent., 27:109.

This eastern squirrel flea has long been known as $O$. wickhami, but Ewing (1943) holds that even though wickhami has page precedence over howardi, howardi was selected in 1899 by Baker as the name of the species, and so it should be known.

HEAD: Well rounded in female, flattened on top in male. Frontal tubercle small. Eye oval and well pigmented. Genal row of 3 bristles at level with top of eye, middle bristle about one-half as long as outer one. Above these, 1 or 2 short bristles toward antennal groove. Postantennal region armed with 1 to 3 bristles and a marginal row of about 5 , of which the lower one is stout and long.

THORax: Pronotum armed with a single row of bristles and a comb of 18 teeth. Metanotum and mesanotum with 2 rows of bristles.

ABDomen: Tergites with 2 rows of bristles and anterior 4 with apical spinelets.

Modified Segments, Male: Process P of clasper characteristically shaped. Finger $\mathrm{F}$ with heel portion swollen ventrally, apex angular; armed with 4 short, sharp, black spiniforms. Lower lobe of IX st. with 1 black spiniform, lower angle well rounded. Female: VII st. with 2 lower angulate lobes, sinus between broad and not too deep, upper portion of apical slant with a rounded lobe. Spermatheca typical.

LENGTH: Males in collection of writer about $2 \mathrm{~mm}$., females about 2:50 mm.

RANGE: In West this flea is probably found only where introduced with eastern squirrels.

CALIFORNIA-Augustson, reporting from Los Angeles County, states this flea was probably introduced into county with eastern fox squirrel. He records this flea off:

Sciurus niger rufiventer (fox squirrel), City of Encino

Peromyscus boylii rowleyi (deer mouse), Santa Monica Mountains

Peromyscus eremicus fraterculus (deer mouse), Santa Monica Mountains

Peromyscus californicus insignis (deer mouse), Santa Monica Mountains

Perognathus californicus dispar (pocket mouse), Santa Monica Mountains,

In 1936 Dr. M. A. Stewart determined material from California as of this species off:

Neotoma fuscipes (round-tailed wood rat). 
As early as 1898 Baker listed this species from Tucson and Yuma, Arizona, and in 1904 he recorded it from a gray squirrel taken in Santa Cruz County, California. The last record is probably an error in determination, as are the records of 1923 when Dunn, from Ravalli County, Montana, reported this flea off pine squirrel, porcupine, and weasel.

UTAH-During 1931 this flea was reported from Salina, Sevier County, off:

Neotoma desertorum (desert wood rat)

Reithrodontomys megalotis (harvest mouse).

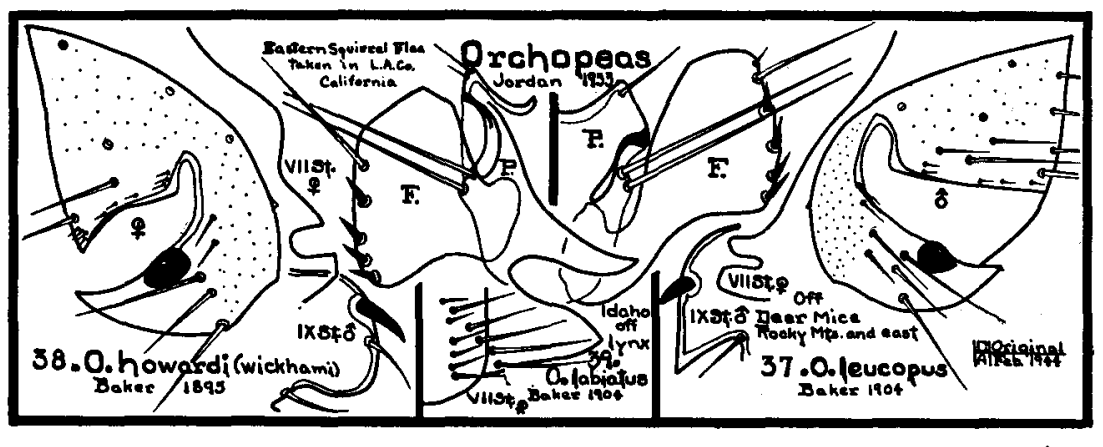

39. Orchopeas labiatus

Baker 1904

1904 Ceratophyllus labiatus Baker, U. S. Nat. Mus. Proc., 27:402.

1933 Orchopeas labiatus Jordan, Nov. Zool., 39:72.

1940 Orchopeas labiatus I. Fox, Proc. Ent. Soc. Wash., 42:67.

This is another of the much discussed Orchopeas. Jordan in 1929 named its closest relatives as $O$. caedens and $O$. nepos and stated that it was probably identical with one of these species. The flea was described from a single female taken off Lynx canadensis at Moscow, Idaho. At time of describing, Baker suggested that proper host would probably turn out to be small rodents of vicinity.

Baker's original description, slightly abbreviated, follows:

Head: Well rounded. Frontal notch minute. Gena with usual lower row of 3 stout bristles, middle bristle smaller. Second row represented by a single small bristle above upper bristle of lower row. A few small setae occur above the rather elliptical eye. Antennal groove extending to two-thirds the depth of head, with a few setae scattered along its hind margin, these setae longer below. On disc of vertex behind middle of antennal groove occurs 1 large, stout spine and 2 far smaller ones. Hind margin of head with usual bristles, but at each inferior angle there are 2, lower of which is smaller.

Pronotum with 2 rows of bristles, and on the hind margin a ctenidium of about 18 spines. Meso- and metanotum with two rows of bristles each. Metanotum and first 3 abdominal tergites each with a small tooth on either side of hind margin. Antepygidial bristles are very 
strong and 3 in number on either side, longer middle one in each group extending beyond the pygidium.

Apical margin of VII st. carried little taxonomic value in the days of Baker, so in this species it is not mentioned. This margin is similar in many ways to margin in $O$. caedens. Margin consists of a lower lobe somewhat angulate, an upper lobe, longer than lower and pointed, between them a deep fairly broad sinus. Armature a posterior row of 5 stout bristles and a row of 6 shorter bristles to the anterior.

LENGTH: Original length given as $2.6 \mathrm{~mm}$.

RANGE: Known only from original specimen taken at Moscow, Latah County, Idaho.

Type specimen is deposited in the United States National Museum under No. 6909.

\section{GENUS OPISODASYS JORDAN}

1933. Opisodasys Jordan. Nov. Zool., 39:72.

Genotype: Ceratophyllus vesperalis Jordan 1929.

Eye well developed. Genal margin more incurved and frontal tubercle somewhat smaller than in Orchopeas. Pronotal comb with more than 20 teeth, rarely 19. Incrassation of anterior margin of metasternum shorter than broad. Fifth tarsal segment of each leg armed with a basal pair, an apical submedian pair, and 4 pairs of lateral plantar bristles. Movable finger $\mathrm{F}$ of males armed with 2 or 3 black spiniforms which are directed downward or backward. Femate: Anal tergite without lateral bristles except 2, rarely 3, at angle proximally to stylet; anal sternite ventrally not angulate but ventrally slightly rounded or nearly straight, its bristles straight. Head of spermatheca longer than broad, longer than tail, dorsally convex.

This genus is represented in West by 7 species, which when viewed side by side can be distinguished one from other by shape and armature of finger $\mathbf{F}$ and process $\mathbf{P}$ of male clasper and in female by apical outline of VII st.

\section{Key to the Western Species of Opisodasys}

Northwest species

1. Finger $F$ without black spiniforms, VII st. female with one narrow, low, flat topped lobe

O. jellisoni, p. 112

2. Finger $F$ with two black spiniforms on lower half, VII st. female with small hook-like lobe

o. keeni, p. 110

3. Finger $F$ with three black spiniforms

Acetubular process short, VII st. female with broad, low, flat topped lobe O. vesperalis, p. 113

Acetubular process long, VII st. female undulate 0. pseudarctomys, p. 112 
Southwest species

1. Finger $F$ with two black spiniforms

a. Finger rectangular shaped

Anterior face flat, VII st. female with a small rounded lobe

O. enoplus, p. 115

Anterior face concave, VII st. female with pointed upper lobe and deep sinus below $\quad O$ nesiotus, p. 114

b. Finger triangular shaped, VII st. fernale with upper lobe long and apically squarish, sinus deep

O. robustus, p. 115

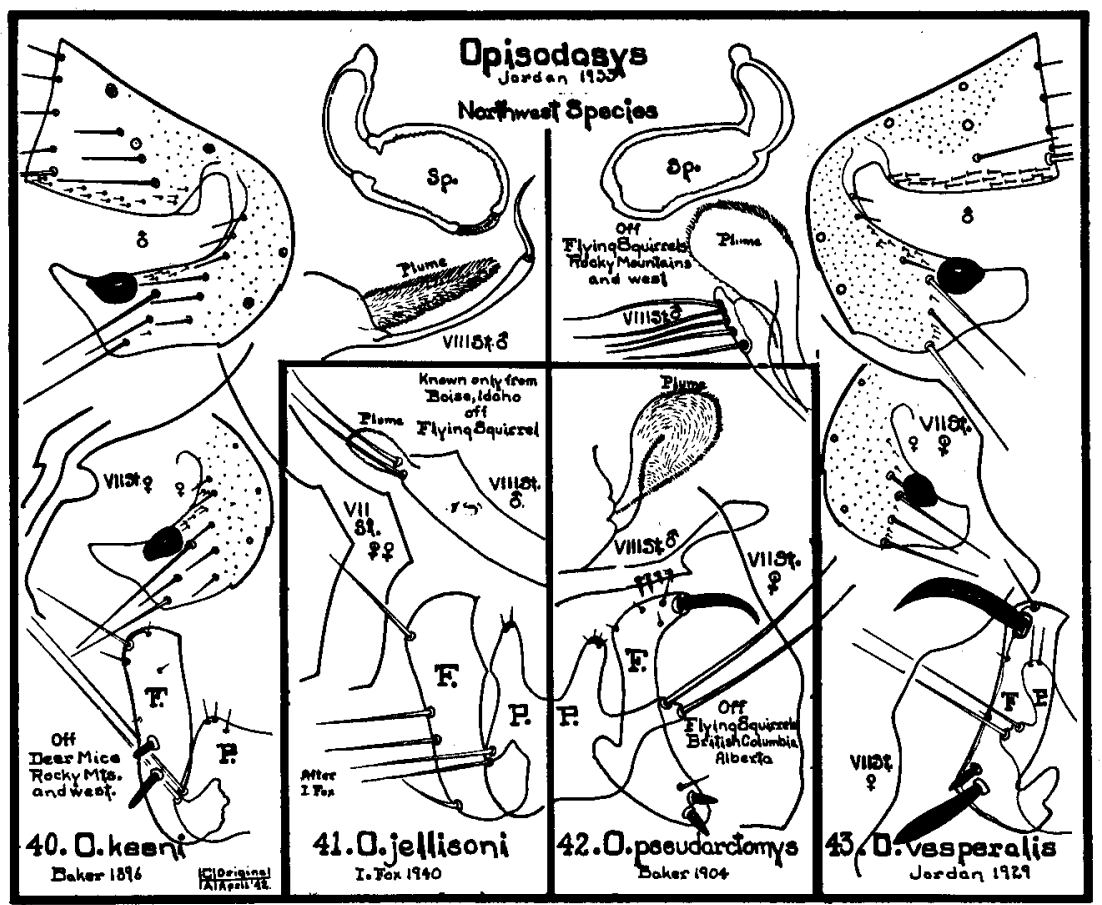

\section{Opisodasys keeni \\ Baker 1896}

1896 Pulex keeni Baker, Can. Ent., p. 234.

1904 Ceratophyllus keeni Baker, Proc. Nat. Mus., 27:400.

1933 Opisodasys keeni Jordan, Nov. Zool., 39:72.

1936 Opisodasys keeni Wagner, Can. Ent., 68:198.

1939 Opisodasys keeni Jellison, Jour. Parasitology, 25:416.

This species was described from specimens taken off deer mice at Masset, Queen Charlotte Islands, by the Rev. J. H. Keen. Modified segments of this flea are so characteristic in male and female that little else is needed to make identification. On finger $\mathrm{F}$ of male are 2 black spini- 
forms situated in lower half. Lower spiniform is long and slender pointing obliquely toward ventral, upper is less than half as long, stouter, and points toward posterior. At apex of finger is a stout bristle. Apical margin of VII st. of female is distinctly characteristic in that upper lobe, if it can be called such, is in shape of a distinct hook. In some cases this hook becomes worn off, then upper lobe is rounded, more or less.

In West this flea is most common deer mouse flea west of CascadeSierra Range. A heavily infested deer mouse may carry 12 fleas, of which half are usually of this species, the other half of various other species. West of Cascades deer mice are seldom without this species, and their nests generally house large numbers of this kind.

RANGE: Although this flea is not reported from Eastern United States by Fox, it is reported as far east as Montana. In Western States the writer has records from Pacific Ocean north of San Francisco Bay, east throughout Cascades and Great Basin region of Washington, Oregon, and northern Nevada and northeastern California, in those portions which are not distinctly desert. This species seems to shun desert region.

This flea prefers deer mice for its host but can be taken occasionally from other rodents.

RECORDs: Typical records in the collection of the writer are:

OREGON-From:

Peromyscus maniculatus rubidus Osgood (ruddy deer mouse), crest of Coast Range, Dolph, Tillamook County, November 20, 1933, 1 male.

Accidental Occurrences:

Microtus mordax mordax Merriam (Rocky Mountain meadow mouse), Summit, 5,555 ft. el., Lakeview-Adel Highway, Lake County, June 21, 1937, 1 male

Reithrodontomys megalotis megalotis Baird (harvest mouse), Plush, Lake County, July 1, 1939, 5 males, 2 females

Eutamias townsendi townsendi Bachman (Townsend chipmunk), Boyer, Tillamook County, Salmon River Cut-off, April 24, 1937, I female.

WASHINGTON-From:

Peromyscus maniculatus oreas Bangs (Washington deer mouse), Goose Lake, Skamania County, (12 miles west of Guler), August 24, 1935, 3 males, 4 females.

- Peromyscus maniculatus gambeli Baird (Gambel's deer mouse), Tampico, Yakima County, May 7, 1939, 1 male, 1 female.

NEVADA-From:

Peromyscus maniculatus sonoriensis Le Conte (Sonora deer mouse), Washoe County, 4 miles south of Denio, Oregon, July 5, 1939, 1 male, 1 female.

UTAH-Off:

Peromyscus maniculatus rufinus Merriam (tawny deer mouse), Rubys Ranch, Bryce Canyon, Garfield County, July 10, 1945. 1 pair.

IDAHO-Off:

Citellus columbianus columbianus Ord (Columbian ground squirrel, red digger), Plummer, Kootenai County, July 22, 1945, 1 male. 
CALIFORNIA-From:

Peromyscus maniculatus gambeli Baird (Gambel's deer mouse), Pine Creek, Modoc County, June 18, 1937, 2 males, 3 females

Peromyscus maniculatus rubidus Osgood (Ruddy deer mouse), Smith River, Del Norte County, June 15, 1939, 3 males, 5 females.

In the central sierra-Nevada Mountains Augustson reports this flea as far south as Tully's Hole, Fresno County, where it was taken off:

Peromyscus maniculatus sonoriensis (deer mouse).

MONTANA-This flea has been reported taken off:

Peromyscus (deer mice), in Gallatin and Ravalli Counties.

\section{Opisodasys jellisoni}

I. Fox 1941

1941 Opisodasys jellisoni I. Fox, Entomological News, 52:46.

This species was described from material taken off a flying squirrel at Boise, Idaho, during December, 1939. In so far as Boise is only about 50 miles east of the Oregon line, this species might well be found in Oregon, unless the Snake River forms a natural barrier to its westward expansion.

MALE: Preantennal region of head with 2 rows of bristles; upper row consisting of 7 bristles, lower row of 3 much longer ones. Post-antennal region with 3 bristles, in addition to a marginal row of 5 . Labial palpus almost reaching to apex of fore coxa, acuminate distally. Pronotal comb consisting of about 21 teeth. Mesopleural suture with 1 bristle, mesepimeron with 3 bristles. Supraepisternum with 1 bristle, infraepisternum with 3 bristles; emtepimeron with 2 bristles. ModIFIED Segments: Movable finger, process of clasper and sternal plate VIII as illustrated. Penis long and slender, spring short not completing a turn. Female: Chaetotaxy of head and thorax not well shown by specimens available. Bristles of upper preantennal row reduced, some of them absent. Labial palpus not acuminate distally. Supraepisternum with 1 bristle; metapimeron with 3 bristles. Sternal plate VII showing variation in depth of sinus, as illustrated. (The writer is unable to locate this sinus in original drawings of $I$. Fox which are reproduced herewith.)

LENGTH: Not given.

ReCords: Holotype and allotype from Glaucomys sabrinus bangsi (flying squirrel) at Deer Park, Boise, Idaho, in United States National Museum.

\section{Opisodasys pseudarctomys}

Baker 1904

1904 Ceratophyllus pseudarctomys Baker, Proc. U. S. Nat. Mus., 27:399.

1905 Ceratophyllus acasti Rothschild, Nov. Zool., 12:186.

1933 Opisodasys pseudarctomys Jordan, Nov. Zool., 39:72.

1939 Opisodasys pseudarctomys Jellison, Parasitology, 25:415. 
Two females and a male of this species were sent to Baker from Newport, Herkimer County, New York, where they had been taken off Marmota monax (woodchuck). Original description was based upon these 3 specimens. In 1905 Rothschild described this species as $C$. acasti from materials taken off Glaucomys sabrinus (flying squirrel) taken at Quesnel, British Columbia, Canada.

Today this species is considered to be a true flying squirrel flea.

Unusual modified segments found in this flea make it immediately separable from other species of genus.

Modified Segments, Male: Process $P$ of clasper with long acetabular process. Finger $\mathbf{F}$ of clasper concave on posterior face, distal portion armed apically with long ventrally curved black spiniform and few setae. Proximal portion of finger expanded into rounded lobe and armed with 2 short, black spiniforms. FEMALE: VII st. with apical outline undulate.

LENGTH: Baker gave original lengths as male $2.75 \mathrm{~mm}$, female 3.50 mm.

RANGE: This eastern flying squirrel flea seems to range northwestward into Alberta and eastern British Columbia, Canada.

\section{Opisodasys vesperalis \\ Jordan 1929}

1929 Ceratophyllus vesperalis Jordan, Nov. Zool., 35:28.

1933 Opisodasys vesperalis Jordan, Nov. Zool., 39:72.

1936 Opisodasys vesperalis Wagner, Can. Ent., 68:198.

1939 Opisodasys vesperalis Jellison, Jour. of Parasitology, 25:415.

Specimens from which Jordan described this species were taken off Sciuroptera alpinus (now Glaucomys sabrinus) by J. A. Munro at Okanagan Landing, British Columbia, Canada. It is generally thought that the flying squirrel is the true host of this flea.

Modified SEgments: As characteristic for this species as for the preceding. Finger $\mathrm{F}$ of male is almost straight, with anterior and posterior sides nearly parallel from lower spiniform to apex. Of 3 spiniforms, lower one is straight and longer than $F$ is broad. Above it is a short pointed spiniform, and at apex a large, almost sabre-shaped one which ends in a thin tip bent ventrally. The apical margin of VII st. in female may vary slightly but generally is of 2 shallow, modest lobes.

RANGE: Described from British Columbia, this flea has been reported as far east as Montana. In Western States it is probably to be found wherever there are flying squirrels.

Although the writer has taken many other rodents in immediate vicinity of flying squirrel trees and nests, these have never been infested with this species.

ReCoRDs: At times infestation of host is very heavy, as is illustrated by the following record: 
OREGON-From:

Glaucomys sabrinus oregonensis Bachman (flying squirrel), collected as it was chased from its nest at Gaston, Washington County, February 12, 1938, 43 males, 27 females.

Other records for this species from the flying squirrel are:

Gaston, Washington County, January 5, 1935, 7 males, 6 females

Dilley, Washington County, March 9, 1937, 4 males, 3 females

Tillamook, Tillamook County, September 15, 1937, 2 males, 5 females.

MONTANA-In Ravalli County this flea has been reported off flying squirrels and weasels.

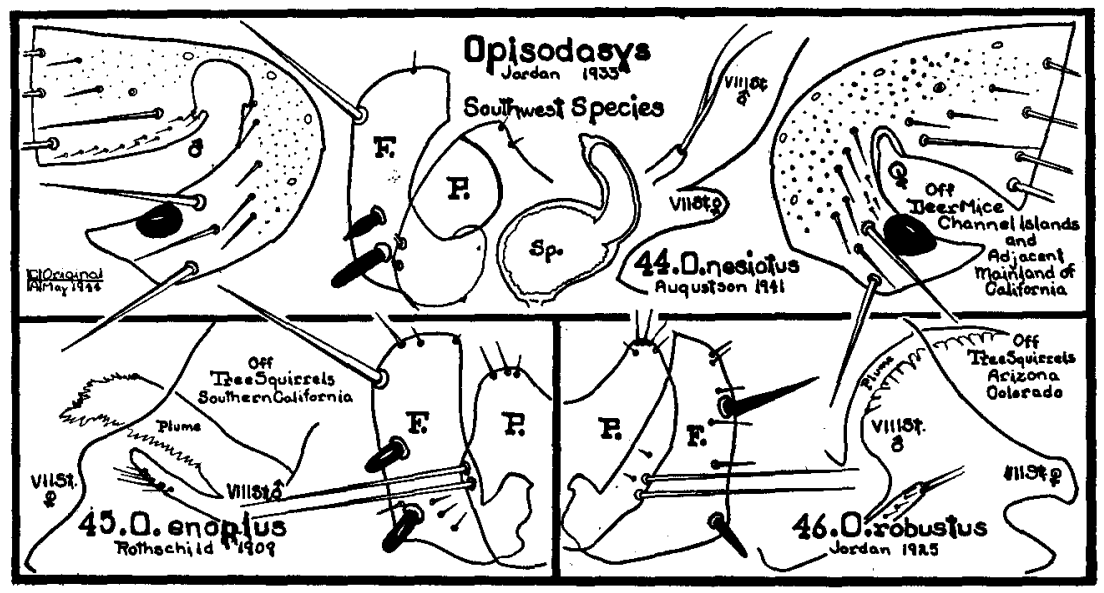

44. Opisodasys nesiotus

Augustson 1941

1941 Opisodasys nesiotus Augustson, Bul. So. Calif. Acad. of Sci., 40:101.

This species was described from a large series taken off deer mice collected on the Channel Islands of California. The species is said by the describer to be near $O$. keeni from which it can best be distinguished by the modified abdominal segments. This species differs from the closely related $O$. keeni in that the movable finger is of a shorter length compared to the height of the process of the clasper; in that the anterior face of the finger is more deeply concave, and upper and lower posterior angles of same are more evenly rounded; in that the lower spiniform of the finger is more attenuated and somewhat curved downward; and in that the VII st. has 2 terminal bristles and a bifurcated membranous flap. In the female the VII st. differs from $O$. keeni in the much deeper sinus, protruding lower lobe, and in the number and arrangement of the bristles.

LENGTH: Although the original lengths were given as male $3 \mathrm{~mm}$., female $2.4 \mathrm{~mm}$., paratypes in the collection of the writer measure males, $2.00 \mathrm{~mm}$., females from 2.00 to $3.00 \mathrm{~mm}$. 
RaNGE: The describer originally thought that the range of this flea was confined to the Channel Islands of Santa Barbara County, California, but several years later he secured specimens off:

Peromyscus maniculatus gambeli (Gambel's deer mouse)

Neotoma fuscipes macrotis (round-tailed wood rat), taken at Point Arguello, on mainland, and E. W. Jameson took it far to north April 1, 1945, at Calaveras Dam, Alemeda County, off Peromyscus truei (Trues Deer Mouse) .

\section{Opisodasys enoplus}

Rothschild 1909

1909 Ceratophyllus enoplus Rothschild, Nov. Zool., 16:53.

1933 Opisodasys enoplus Jordan, Nov. Zool., 39:72.

1939 Opisodasys enoplus Jellison, Parasitology, 35:413.

Male of this species was described from a single specimen taken off a western silver gray squirrel collected at King's River, California, by Nuttall on July 25, 1896. Jellison described female from materials gathered off western silver gray squirrels collected in Riverside County, California, during September of 1936.

Modified Segments, Male: VIII t. has upon its broadly rounded ventral margin a row of long bristles, finger of clasper rectangular and armed with long sharp spine at posterior dorsal apex, short stout spiniform in middle and another at posterior ventral angle. FEMALE: VII st. has an apical margin which possesses a short rounded posterior dorsal lobe. Three lateral bristles on anal tergite proximal to stylet; anal sternite is slightly rounded with numerous long bristles on border. Spermatheca is typical, being barrel shaped, about 11/2 times longer than wide, tail curved dorsally, tip well-sclerified.

LENGTH: Original length given for male was $2.3 \mathrm{~mm}$., but Jellison fails to give length of female with his description.

RANGE: Apparently this species does not range out of southern California.

Host Preference: Jellison believes this species to be a true silver gray squirrel (Sciurus griseus griseus) flea.

ReCords: Although all early listings for this species are from San Bernardino and Riverside Counties, California, Augustson reports taking a female off Tamiasciurus douglasi albolimbatus (California chickaree) as far north as Mammoth Lakes, Mono County, California.

\section{Opisodasys robustus Jordan 1925}

1925 Ceratophyllus robustus Jordan, Nov. Zool., 32:105.

1933 Opisodasys robustus Jordan, Nov. Zool., 39:72.

1939 Opisodasys robustus Jellison, Parasitology, 25:414.

1940 Opisodasys spatiosus I. Fox, Proc. Ent. Soc. Wash., 42:65.

The female of this species was described by Jordan from specimens which had been collected at White River, Navajo County, Arizona, 
(host not mentioned), and from Sciurus aberti (tuft-eared squirrel) taken at Ritu de los Frijoles, Sandoval County, New Mexico. The male was described during 1939 by Jellison from a fox squirrel collected at White House Canyon, Santa Rita Mountains, Santa Cruz County, Arizona.

Modified segments mark this species off from other species of genus.

Modified Segments: Process $P$ of clasper of male rounded apically and armed with 4 or 5 small bristles. Finger $F$ of clasper of male roughly triangular in shape and armed on posterior border with 2 black spiniforms, distal one longer, and bent dorsally, proximal one much shorter and straight; between them a pale weak spiniform or bristle. IX st. male with 2 pale spiniforms on proximal lobe; distal lobe with numerous pale spiniforms along posterior border. VII st. female with upper lobe longer than lower, squarish and possibly expanded at apex. Sinus deep and broad. Lower lobe triangular. Spermatheca typical.

LENGTH: Female is a large flea, original length given as $4.0-4.3 \mathrm{~mm}$. Lengths for male have never been published.

Hòst: It is generally thought by those who have had experience with this flea that its normal host is either the fox squirrel or the tufteared squirrel, or both.

Range: This flea is known only from Arizona, New Mexico, and Colorado.

RECORDS: The available records for the species are:

Sciurus aberti (tuft-eared squirrel), Riti de los Frijoles, Sandoval County, New Mexico,

Sciurus niger (fox squirrel), White House Canyon, Santa Cruz County, Arizona,

Marmota flaviventris (woodchuck), Pagosa Springs, Archuleta County, Colorado,

"Chiricahua red squirrel," Chiricahua Mountains, Arizona.

\section{GENUS THRASSIS JORDAN}

1933. Thrassis Jordan. Nov. Zool., 39:72.

Genotype: Ceratophyllus acamantis Rothschild 1905

On outer surface of fore-femur a number of small lateral bristles; on inner surface of mid- and hind-coxae longish, thin bristles from base to apex (apart from bristles an anterior margin). Basal abdominal sternite without patch of lateral bristles in upper anterior area (at most one bristle present), on outer side of hind-femur no complete sublateral row of bristles, always fewer bristles on outer side than on inside. At least 1 bristle of segment II of hind-tarsus extending well beyond IV.

MALE: VII $t$. more or less excised between the 2 sets of antepygidial bristles, VIII st. large, not reduced into a narrow horizontal sclerite, without long filamentous apical appendage. There are 1 long and 2 
minute antepygidial bristles. Anal sternite not extending beyond tergite, 2 together conical. IX t. without projecting manubrium (its frontal margin about at right angles with the manubrium angle of the clasper). Process of clasper broad, rounded at apex, finger narrow and short, vertical from close to base, more or less distinctly inclining toward anterior. Frmale: Two or 3 antepygidial bristles. Stylet with 2 or 3 long, lateral bristles. Head of spermatheca globular, or higher than long, quite short as compared with tail. Bursa copulatrix (plus its duct) long, without sclerifications at bases of ducts.

Other characteristics found more or less constant are:

HEAD: Well rounded in female but flattened on top in male. Frontal tubercle small. Eyes large and well pigmented, generally oval or grape seed shaped. Lower genal row of bristles well above eye, 3 in number, stout, middle one about half as long as outer. A second row of 2 medium bristles, sometimes but 1 and in females sometimes entirely wanting. Setae over eye. Postantennal region with 1 stout bristle and a marginal row, the lower or next to the lower one stout. Setae along antennal groove.

Thorax: Pronotum with comb of from 16 to 20 black teeth and a row of bristles, Mesa- and metanotum with 2 rows of bristles.

Aвромen: Tergites with 2 rows of bristles and anterior 3 with apical spinelets. Modified Segments, Male: Process P and finger F of clasper, VIII t., VIII st., and modified bristles of IX st. all characteristic for species. Female: Apical outline of VII st. characteristic. Spermatheca generally with globular or subglobular body and tail more or less crooked with, in most cases, an apical appendage.

This particular genus is represented west of 100 th meridian by 19 species and subspecies, 5 of which seem to prefer marmots as hosts, 9 with preference toward ground squirrels, 3 toward antelope ground squirrels, and remaining 2 without apparent host preference. This group of fleas does not lend itself kindly to key building, but can be separated according to range as follows:

$\begin{array}{ll}\text { Northwest } & \text { Southwest } \\ T . \text { acamantis } & \text { T. a. arizonensis } \\ T . \text { g. gladiolis } & T . \text { a. desertorum } \\ T . \text { h. howelli } & T . \text { a. littoris } \\ T . \text { jellisoni } & \text { T. g. gladiolis } \\ T . \text { pandorae } & T . \text { h. howelli } \\ T . \text { petiolatus } & T . \text { jellisoni } \\ T . \text { rockwoodi } & T . \text { pansus } \\ T . \text { spenceri } & T . \text { setosis }\end{array}$

Eastern Texas

T. brennani
Rocky Mountains

T. francisi

T. g. caducus

T. h. utahensis

T. pandorae

T. petiolatus

T. stanfordi

Rocky Mountains and East

T. bacci

$T$. fotus 
And according to host preference as follows:

\begin{tabular}{|c|c|c|}
\hline $\begin{array}{l}\text { Marmot } \\
\text { T. acamantis }\end{array}$ & $\begin{array}{l}\text { Ground Squirrel } \\
T . \text { a. arizonensis }\end{array}$ & $\begin{array}{l}\text { Antelope Ground } \\
\text { Squirrel }\end{array}$ \\
\hline T. h. howelli & T. a. littoris & T. a. desertorum \\
\hline T.h. utahensis & $T$. bacchi & $T . g . c a d u c u s$ \\
\hline T. spenceri & T. brennani & T. g. gladiolis \\
\hline T. stanfordi & $\begin{array}{l}T . \text { fotus } \\
T . \text { francisi } \\
T . \text { jellisoni } \\
T . \text { pandorae } \\
T . \text { petiolatus } \\
T . \text { rockwoodi }\end{array}$ & $\begin{array}{l}\text { Miscellaneous } \\
T . \text { pansus } \\
T . \text { setosis }\end{array}$ \\
\hline
\end{tabular}

As one views the western Thrassis side by side, certain characteristics seem to stand out above others. On the IX st. of male there may be modified bristles which in some cases are 2 broad flattened modified bristles, in others spike-like bristles. Apical outline of VIII st. as well as VIII $t$. with their armature are characteristic. In those species without modified bristles upon IX st., shape of finger is characteristic. In females apical margin of VII st. is characteristic.

\section{Key to the Species of Thrassis \\ Males, typical specimens}

I. Males without modified bristles on IX st.

a. Finger about same width throughout, yet coming to tip at apex, armed with 4 bristles (on ground squirrels in Northwest)

T. petiolatus, p. 120

b. Finger broad at base, gradually coming to tip at apex, triangular, armed with six bristles (on ground squirrels in Northwest)

\section{(Texas)}

T. pandorae, p. 122

T. brennani, p. 124

c. Finger plump with well rounded posterior face, armature of 6 bristles and a cone-shaped spine at apex (Nevada on ground squirrels)

II. Males with modified bristles on IX st.

a. Modified bristles in shape of knife blade

6 to 12 long bristles close to the apex of VIII t. (Northwest on marmots)

T. acamantis, p. 125

b. Modified bristles in shape of blade of grass

1. Modified bristles broad (central Rocky Mountains off ground squirrels)

T. francisi, p. 134

2. Modified bristles narrow; VIII st. without heavy bristle

(a) T. VIII well rounded (British Columbia off marmots) 
(b) T. VIII narrowly pointed (Southwest on marmots)

T. howelli howelli, p. 128

(c) T. VIII broadly pointed with 4 stout bristles (Rocky Mountains on marmots) T. howelli utahensis, p. 130 T. VIII broadly pointed with 2 stout bristles (Utah on marmots)

T. stanfordi, p. 131

3. Modified bristles narrow, VIII st. with 1 long, stout bristle

(a) Process broad apically (Southwest on antelope ground squirrels)

T. gladiolis gladiolis, p. 135

(b) Process narrow apically (Rocky Mountains on antelope ground squirrels)

T. gladiolis caducus, p. 137

4. Modified bristles narrow and a spike-like spine

(Rocky Mountains and east on ground squirrels) T. bacchi, p. 142 (Arizona)

T. setosis, p. 141

5. Modified bristles sickle-shaped (west on ground squirrels)

T. rockwoodi, p. 132

Modified bristles a spiniform and heavy bristle

On Southwest ground squirrels $\quad T$. arizonensis arizonensis, p. 138

T. arizonensis littoris, p. 140

T. arizonensis desertorum, p. 140

7. Modified bristles spine-like, one long (on ground squirrels

Rocky Mountains and east)

T. fotus, p. 143

8. Modified bristle undulate

T. pansus, p. 141

Females, typical specimens

I. Apical outline VII st. without sinus

A. Upper lobe well rounded

a. Off ground squirrels,

Northwest

Rocky Mountains

b. Off marmots, British Columbia

B. Upper lobe rounded asymmetrically

Off marmots, Rocky Mountains

T. petiolatus, p. 120

T. francisi, p. 134

T. spenceri, p. 127

C. Upper lobe angulate

Off marmots, Southwest

T. h. utahensis, p. 130

T. h. howelli, p. 128

II. Posterior face VII st. more or less perpendicular

a. Face perpendicular, West off ground squirrels

b. Slightly slanting, Arizona

T. rockwoodi, p. 132

T. pansus, p. 141

c. Face somewhat undulate, Rocky Mountains and east on ground squirrels

T. bacchi, p. 142

III. VII st. with slanting undulate outline, on antelope ground squirrels

Southwest

Rocky Mountains

Texas
T. g. gladiolis, p. 135

T. g. caducus, p. 137

T. brennani, p. 124 
IV. Apical outline of VII st. with shallow bay

On ground squirrels,

Northwest
Nevada
Arizona

T. pandorae, p. 122

T. jellisoni, p. 124

T. setosis, p. 141

V. Apical outline with sinus

A. Upper lobe small, triangular; lower lobe large, rounded
a. On marmots in Utah
b. On ground squirrels, Southwest

T. stanfordi, p. 131

T. a. arizonensis, p. 138

T. a. desertorum, p. 140

T. a. littoris, p. 140

B. Upper lobe small, rounded; lower lobe flat

On marmots, Northwest

T. acamantis, p. 125

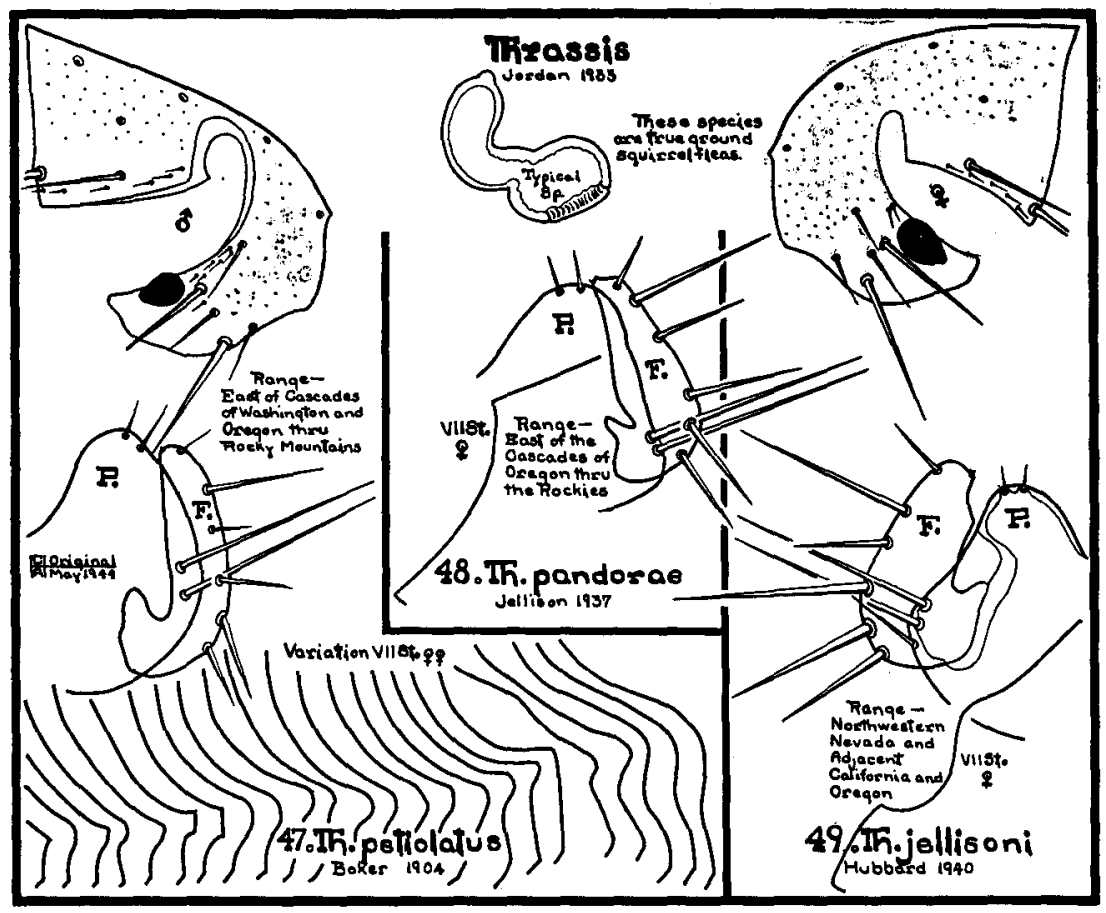

\section{Thrassis petiolatus \\ Baker 1904}

1904 Ceratophyllus petiolatus Baker, Proc. Nat. Mus., 27:415.

1928 Ceratophyllus petiolatus Jordan, Trans. Inter. Cong. Ent., Vol. II, p. 489.

1933 Thrassis petiolatus Jordan, Nov. Zool., 39:73.

1937 Thrassis petiolatus Jellison, U. S. Pub. Health Repts., 52:23: 726-729.

Baker states that in male lateral portion of IX $t$. is very large, lobe very large, scarcely narrowed toward tip, and extending as far dorsal as do the claspers. The two bristles at the junction of clasper and fin- 
ger are far up on margin and somewhat separated. Finger long and narrow with an almost straight anterior border and an evenly rounded posterior border. Finger armed with 4 bristles. Apical margin of VII st. of female is variable. Jellison states that margin is well rounded. Jordan states females to be dimorphic in this characteristic.

This flea was described by Baker from a specimen sent him by Professor Aldrich. The flea was taken off Lynx canadensis (Canada lynx) at Moscow, Idaho. Baker says, ". . . its occurrence on that host is undoubtedly wholly fortuitous." Today, the chief host of this flea is considered to be Citellus columbianus columbianus (red digger squirrel), of northeastern Oregon and eastern Washington, but it does not hesitate to attack the Oregon ground squirrel, or various sage rats of Oregon and Washington. It is common on Citellus in Idaho and Montana.

LENGTH: Specimens in collection of writer average about $2 \mathrm{~mm}$. in both sexes.

RANGE: This species is common everywhere east of Cascade Mountains in Oregon and Washington and has been reported as far east as Montana.

Medical Importance: Conclusive evidence against this flea as a vector of plague is wanting. Twenty-three per cent of 17 specimens fed upon plague-positive guinea pigs by Eskey and Haas became infected. One out of 6 of the infected fleas cleared itself of the infection. There is no reported evidence that any of the infected fleas were able to transmit the plague to healthy guinea pigs.

Being one of the most common ground squirrel fleas in the plague foci of the Northwest, there is little doubt that Thrassis petiolatus is a vector of plague, even though reported experiments fail to substantiate this.

Records: The writer records from:

\section{OREGON-off:}

Citellus townsendi canus Merriam (gray sage rat), Moro, Sherman County, June 5,1934 , a small series of both sexes

Citellus washingtoni washingtoni Bachman (Washington ground squirrel), Ione, Morrow County, April 27, 1936, 1 female

Citellus columbianus columbianus Ord (red digger), Lostine, Wallowa County, August 5, 938, 1 female

Citellus beldingi oregonus Merriam (Oregon ground squirrel), Union, Union County, May 26, 1937, a series of both sexes.

\section{WASHINGTON-off:}

Citellus columbianus columbianus Ord (red digger), Waitesburg, Walla Walla County, June 20,1933, a small series of both sexes

Citellus washingtoni washingtoni Bachman (Washington ground squirrel), Naches, Yakima County, May 6, 1939, 1 male, 3 females

Citellus townsendi yakimensis Merriam (Yakima ground squirrel), White Swan, Yakima County, May 3, 1939, 3 males, 10 females

Onychomys leucogaster fuscogriseus Anthony (grasshopper mouse), Two Rivers, Walla Walla County, (Casey-Attalia), May 11, 1939, 1 male, 1 female. 
IDAHO-Off:

Citellus columbianus columbianus Ord (red digger), Plummer, Kootenai County, July 22, 1945, 12 pair.

This species was originally described by Baker from material taken off $L y n x$ (bob cat) from Moscow, Latah County. It doubtless ranges through the entire state on various ground squirrels.

MONTANA-This species is another of the common fleas of this state. It has been recorded off the following hosts:

Citellus columbianus (Columbian ground squirrel), general over the state and of common occurrence on this squirrel

Citellus richardsoni (Richardson ground squirrel), Beaverhead, Lewis and Clark, and Madison Counties

Citellus lateralis (Mantled ground squirrel), Granite, Missoula, and Silver Bow Counties

Eutamias (chipmunk), Silver Bow County

Marmota flaviventris (woodchuck), Granite and Ravalli Counties

Neotoma cinerea (wood rat), Ravalli County

Tamiasciurus hudsonicus (pine squirrel), Missoula and Ravalli Counties

Sylvilagus (cottontail rabbit), Ravalli County.

BRITISH COLUMBIA AND ALBERTA-Off:

Citellus columbianus (Columbian ground squirrel), Kimberly, B. C. and Waterton Lakes, Alberta. The writer collected it off this squirrel at Crambrook, July 25, 4 pair.

\section{Thrassis pandorae \\ Jellison 1937}

1939 Thrassis pandorae Jellison, U. S. Pub. Health Repts., 52:23:726.

This species was described by Jellison of the staff of Rocky Mountain Spotted Fever Laboratory from Citellus elegans (ground squirrel) taken in Beaverhead County, Montana. The describer states that this species is close to T. petiolatus (Baker) 1904, and is best distinguished from it by modified abdominal segments. Of these it is stated that VIII $t$. is large, extending posteriorly beyond other modified segments, ventral lobe extending below VIII st. in many specimens, narrower than in $T$. petiolatus. VIII st. rectangular, 3 times longer than wide. Distal portion is membranous and finely spiculose, a condition found only in $T$. petiolatus of the members of this genus. The finger $\mathrm{F}$ with distal and proximal sides straight, apex acute, inclined toward the anterior, ventral margin rounded, distal margin bears several small and 5 medium sized bristles, the lower 2 longest and pointing backward and downward. The finger in $T$. petiolatus is longer, more crescentic and narrower at the base. In the female the spermatheca is very similar to $T$. petiolatus. The dorsal lobe of the VII st. is angular in comparison to the rounded condition of $T$. petiolatus.

LENGTH: Specimens in the collection of the writer measure, males $2.50 \mathrm{~mm}$., females $2.75 \mathrm{~mm}$.

RANGE: This species has been reported from Montana and Wyo- 
ming, and the writer has specimens from Washington and Oregon. The range seems to extend from the east base of the Cascade Mountains in Oregon eastward as far at least as the eastern portion of the Rocky Mountains. In Washington the species is found south of the Snake River and east of the Columbia River.

Host: This species is a common ground squirrel flea in the Northwest.

Medical Importance: The staff of the Plague Suppressive Measures Laboratory fed 152 specimens of this species upon plague-positive guinea pigs. Eighteen per cent of the fleas became infected. Of infected fleas, 7 per cent freed themselves of infection. Of those that remained infected 10 per cent were found able to transmit disease to healthy guinea pigs and so were listed as vectors. Ten per cent shows a fair degree of efficiency as a vector of plague.

RECORDS are as follows:

OREGON-The Federal Rocky Mountain Laboratory at Hamilton, Montana, has specimens of this flea taken from Citellus spp. in Harney County, Oregon. Dr. C. R. Eskey, reporting for the Federal Laboratory for Plague Suppressive Measures, San Francisco, states that his laboratory records the flea from Union and Baker Coun- ties, Oregón, off:

Citellus beldingi oregonus (Oregon ground squirrel).

The writer's records are:

Citellus beldingi oregonus Merriam (Oregon ground squirrel), Union, Union County, May 26, 1937, a small series of both sexes; Heppner, Morrow County, May 12, 1939, 2 males

Citellus columbianus columbianus Ord (red digger), Canyon City, Grant County, July 14, 1937, a small series of both sexes.

IDAHO-Off:

Citellus columbianus columbianus Ord (red digger), Smiths Ferry, Boise County, July 19, 1945, 8 pair.

WASHINGTON-From:

Citellus columbianus columbianus Ord (red digger), Waitesburg, Walla Walla County, May 3, 1933, 1 male.

MONTANA-This species is another common and widely distributed flea in this state. It has been recorded from the following hosts:

Citellus armatus (Uinta ground squirrel), Beaverhead, Gallatin, Madison and Park Counties

Citellus columbianus (Columbian ground squirrel), Ravalli County

Citellus richardsoni (Richardson ground squirrel), Beaverhead, Cascade, Madison and Park Counties

Eutamias (chipmunk), Gallatin County

Marmota flaviventris (woodchuck), Lewis and Clark, and Madison Counties Mustela (weasel), Beaverhead, Flathead, and Madison Counties

Speotyto cunicularia, (burrowing owl), (nests and burrows), Beaverhead County.

WYOMING-This species has also been reported from central Wyoming in Natrona County. 


\section{Thrassis jellisoni}

Hubbard 1940

1940 Thrassis jellisoni Hubbard, Pacific Univ. Bul., 37:6:4.

This species was described by the writer from a small series of both sexes taken off Citellus beldingi oregonus (ground squirrels) collected in northwest Nevada, 15 miles south of Denio, Oregon, about 75 miles east of the Oregon-California-Nevada state boundary junctions, July 4, 1939.

This species can be distinguished from other members of genus by shape and armature of finger in male. Finger has a well rounded posterior face, slightly indented at third bristle from apex, apex with a tiny cone-shaped spine, then toward ventral a medium bristle, then a bristle about 3 times as long followed by one one-third shorter, then a fourth almost as long as second and at ventral angle 2 stout bristles. close together, upper one longer and curved; anterior face with concave dip from apex for one-third distance of the face, ventral two-thirds about parallel with posterior face. In female the apical margin of VII st. consists of a long slanting outline at about the middle of which is a distinct shallow bay.

LENGTH: Male, $2.00 \mathrm{~mm}$., female, $2.50 \mathrm{~mm}$.

RANGE: Nothing is known about the range or seasonal distribution of this species, but its natural hosts are probably the ground squirrels and sage rats of northwestern Nevada and adjacent Oregon.

Type Material: Types are mounted on one slide bearing the describer's number 1582 and are deposited in the United States National Museum.

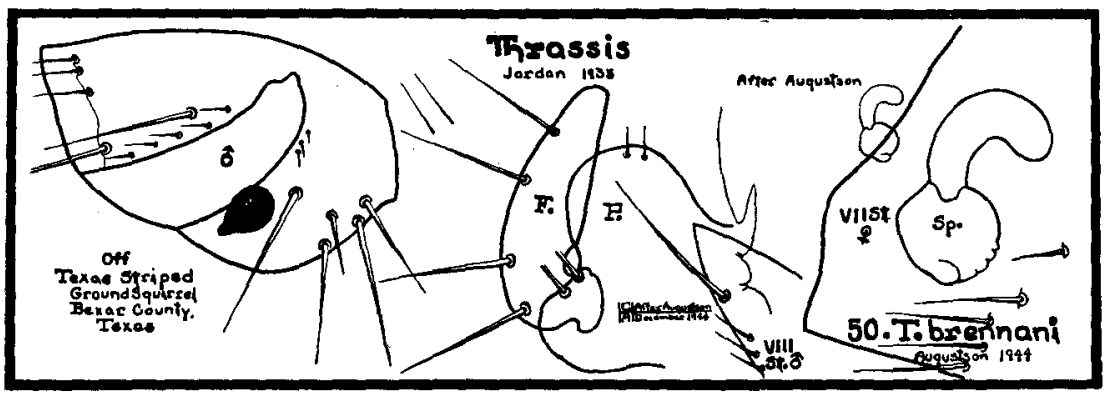

50. Thrassis brennani

Augustson 1944

1944 Thrassis brennani Augustson, Jour. of Parasitology, 39:237.

This species was described by Augustson from 6 males and 14 females taken off Citellus tridecemlineatus texensis Merriam (Texas striped ground squirrel) on April 8, 1943, at Fort Sam Houston, Bexar County, Texas. 
It is said to belong to that group of Thrassis which do not have modified bristles on the IX st. of the male.

The original description contains the following statements:

Head, Male: Frontal notch high, accuminate. Preantennal region with 2 rows of bristles, upper with 3 bristles, one at genal margin much longer than other two; lower row of 3 bristles, center one $1 / 2$ size of outer two. Eye elliptical, not heavily pigmented. Post-antennal region with 2 long bristles on margin of groove and 5 smaller ones.

Pronotal comb of 18 slender teeth. Single large antepygidial bristle. VIII t. reduced, cone shaped; process of clasper rounded, not reaching apex of finger, with a few small setae on apical margin. Finger with inner margin broadly angulate, apex narrow, posterior margin evenly rounded with 4 large bristles. Ventral lobe of IX st. short, shallow without modified bristles. Three normal bristles in a row at apex. VIII st. sharply pointed with 1 large bristle well down from apex followed by 3 smaller ones. Female: Frontal notch not so distinct as in male. Pre-antennal region with 2 rows of bristles, upper row of 2, subequal; lower row of 3 bristles, middle one shortest. Two large equal antepygidial bristles. $\mathrm{X}$ st. angulate with many large bristles. VII st. variable with indications of a shallow sinus, upper lobe smaller than lower, with 5 bristles in a row. Spermatheca distinct, body globular, arm not swollen distally.

Types of this species are deposited in United States National Museum. Nothing is known about the range or seasonal distribution.

\section{Thrassis acamantis \\ Rothschild 1905}

1905 Ceratophyllus acamantis Rothschild Nov. Zool., 12:156.

1933 Thrassis acamantis Jordan, Nov. Zool., 39:73.

This flea was described from specimens taken off Arctomys (now Marmota) flaviventris avara Bangs, at Okanagan, British Columbia, Canada during 1902.

Modified Segments, Male: The modified segments which are characteristic for the species are in the male, VIII t. very large with a patch of from 6 to 12 long bristles close to the apex. VIII st. is small, long and canoe shaped, and has many long bristles ventrally at and before apex. Process of clasper is broad and rounded, longer than finger. Finger is long and pointed, its proximal edge nearly straight, while distal edge is evenly curved. It is armed with 2 long and several short bristles. IX st. bears proximally of sinus 2 bristles and further toward base 2 flat, pointed, modified bristles, which somewhat resemble blade of knife. FEMALE: VII st. is very slightly sinuate below upper angle. Frequently margin is undulate and often upper lobe is in shape of hook. Upper angle of VIII $t$. is acute. 


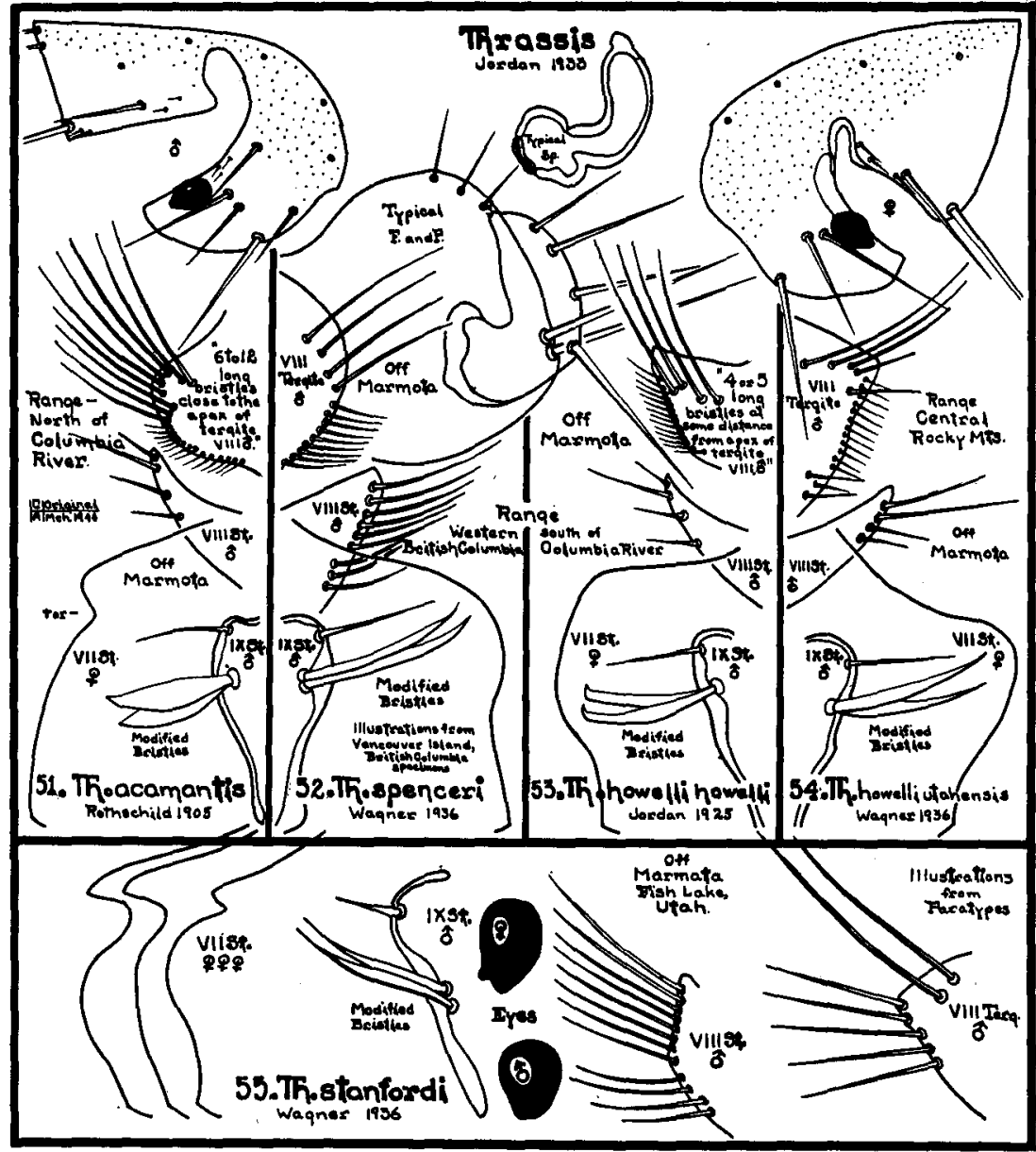

Length: Original lengths given as male, $2.8 \mathrm{~mm}$., female, $3.08 \mathrm{~mm}$.

RANGE: This is common marmot flea of Cascade Mountains. In Canada it was described from British Columbia, from where it ranges south into state of Washington to infest all marmots of the Cascade Mountains, and to east and to west. It reaches as far south as Columbia River where it can be found on marmots almost at banks of river, only a little above sea level at the towns of Bingen and Grand Dalles. It has not crossed river even though the marmots are same on both sides, but is replaced on Oregon side by Thrassis howelli Jordan, which has apparently migrated north from California.

This flea has been experimentally infected with plague.

RECORDs: Typical records in the collection of the writer are: 
WASHINGTON-From:

Marmota flaviventris avara Bangs (pallid yellow-bellied marmot), Grand Dalles, Klickitat County, April 23, 1932, 8 males, 5 females; Goldendale, Klickitat County, June 15, 1938, 3 males, 10 females.

BRITISH COLUMBIA-Some confusion has been thrown into the marmot fleas of British Columbia by the establishing of Thrassis spenceri Wagner. Specimens which the writer has had the opportunity to study through the courtesy of Holland lead him to believe that there is considerable variation in the forms, some approaching closely $T$. howelli howelli from far to south, others very close to $T$. acamantis. Holland still feels that 2 British Columbia species are distinct. From present knowledge it is difficult to separate ranges of two species. Perhaps they overlap. Older records for this species from this Canadian province are off:

Marmota flaviventris avara Bangs (marmot), Okanagan

Mephitis occidentalis spissigrade (skunk), Okanagan

Mustela vison energumenos Bangs (mink), Sumas

Canis latrans Say (coyote), Eagle River, Sicamous

Marmota (marmot), Vance Island

Citellus columbianus (Columbian ground squirrel).

\section{ALBERTA-From:}

Marmota flaviventris avara Bangs (marmot).

ALASKA-From:

Marmota caligata caligata Eschscholtz (hoary marmot), Seward.

\section{Thrassis spenceri \\ Wagner 1936}

1936 Thrassi spenceri Wagner, Can. Ent., 68:197.

Wagner's short description of this species reads as follows: "Reminds one of $T$. acamantis, but proboscis considerably shorter and extending but little beyond the anterior trochanter. Lower antepygidial bristle in female but little shorter than the middle one. VIII $t$. in male becomes gradually wider downward, ventral apical angle broadly rounded, produced not backwards; it bears some 10 short ventral bristles. Basal part of the exterior part of the chitinous apparatus of the penis, which is a good sign for distinguishing $T$. acamantis, $T$. spenceri and $T$. stanfordi, with a right ventral angle, which is not extended into a process (in $T$. acamantis this angle is extended into a long narrow process). End of the paramere of penis is pretty broad, having a rounded apex (in $T$. acamantis it is narrow beak-shaped). In female apical margin of VII st. without a sinus beneath rounded dorsal angle."

Holotype and allotype, 1 male and 1 female, in collection of Kamloops from Marmota sp. (hoary marmot, Alpine), Birch Island, B. C., 7,000' (12.VIII.31); No. 4111 in Canadian National Collection.

RANGE: While type locality for this species is in central British Columbia at Birch Island, the writer has studied a large series off marmot taken on Vancouver Island on west coast. The range seems to coincide, then, with that of $T$. acamantis in this western Canadian province. 


\section{Thrassis howelli howelli \\ Jordan 1925}

1925 Ceratophyllus howelli Jordan, Nov. Zool., 32:109.

1933 Thrassis howelli Jordan, Nov. Zool., 39:72.

In describing this species Jordan says that it is close to T. acamantis. Type material was taken at Pine City, Mono County, California, during July of 1922 by A. B. Howell, who took a male off Mustela longicauda arizonensis Mearns (mountain weasel) and a female off Marmota flaviventris sierrae Howell (Sierra marmot).

Modified Segments of this species differ from T. acamantis in that in male VIII $t$. is ventrally almost gradually widened, with ventral apical corner gradually produced, rather strongly chitinized, and at tip rounded, with patch of 4 to 5 long bristles at some distance from apex, and along ventral margin very numerous shortish but rather strong bristles to beyond patch of long ones. VIII st. is much more slender than in $T$. acamantis, but process of the clasper and its finger similar. IX st. armed with 2 knifeblade-like modified bristles with filamentous tip. Female: The apical margin of VII st. is truncate-rounded, subventrally slightly incurved, frequently one prominent lobe, above, which may be variously shaped. In this sternite on the two sides together, a row of 16 bristles and in front a row of 12 . Spermatheca is very similar to preceding.

RANGE: This is the common western marmot flea south of Columbia River. It is found abundantly on practically all marmots examined in Oregon, California, and northwest Nevada. As the marmots travel about while away from home, they shed these fleas broadcast, and the fleas are picked up by other marmots or other rodents.

Medical Importance: This flea has been experimentally infected with plague. Marmots in Asia have long been considered as natural reservoirs of bubonic plague in that country. It is little wonder, then, that plague infection was eventually discovered in American marmots of West. During 1936 plague-positive marmots were discovered in Beaverhead County, Montana, and Beaver County, Utah. Lincoln County, Wyoming, and Bannock County, Idaho, gave up plague-positive woodchucks in 1938. In 1941 plague infected marmots were taken in San Miguel County, Colorado, and in 1942 in Ada County, Idaho. Until recently marmots of this entire Rocky Mountain area were recorded as carrying Thrassis acamantis, but today it is realized that this range for most part is range of marmot flea Thrassis howelli utahensis, that determinations of Thrassis acamantis for this area were in error. During 1941 plague infection was found in marmots in Malheur County, Oregon, and in 1942 in Grant, Harney and Lake Counties, Oregon, and Lassen County, California. Marmots of this area all carry Thrassis howelli howelli. As far as the writer is aware, no plague infection has yet been found in marmots in the range of the marmot flea Thrassis acamantis. In data given below, one wonders whether data refer to 
Thrassis acamantis as stated, or whether data refer to Thrassis howelli utahensis, common Rocky Mountain marmot flea.

Data upon efficiency of marmot fleas as vectors of plague are as follows:

Twenty-two specimens of Thrassis acamantis fed upon plague-positive guinea pigs resulted in 29 per cent becoming infected. Only 1 of 8 originally infected fleas freed itself from infection. Only 1 of 8 infected fleas produced plague in guinea pig. This series of Thrassis acamantis were 13 per cent vectors.

Sixteen specimens of Thrassis howelli howelli fed upon plaguepositive guinea pigs resulted in 33 per cent becoming infected. Apparently none of these succeeded in freeing themselves of infection. Seventeen per cent of infected fleas were found capable of transmitting plague to guinea pigs.

These records which were released by the Plague Suppressive Measures Laboratory indicate that American marmot fleas so far experimented upon are only moderately efficient as vectors of plague.

Other western marmot fleas have not yet come under laboratory tests.

RECORDS: Typical records in the collection of the writer are:

\section{OREGON-From:}

Marmota flaviventris avara Bangs (pale yellow-bellied marmot). From practically all over its range in the Great Basin region of Oregon with particularly interesting records as follows: Sisters, (west central Great Basin), Deschutes County, July 14, 1936, 15 males, 18 females; Union, northeastern Wallowa Mountains), Union County, April 28, 1937, 12 males, 22 females; Summer Lake, (southwest Great Basin), Lake County, June 16, 1937, 14 males, 30 females; Summit Lakeview-Adel Highway, (south central Great Basin), Lake County, June 21, 1937, 13 males, 17 females; Summit Highway, Ochoco Mountains, (central Great Basin), Crook County, July 11, 1937, 3 males, 9 females

Marmota flaviventris flaviventris Audubon and Bachman (yellow-bellied marmot of the high Cascade Mountains). From this marmot the writer has records for about every 35 miles from north to south in the Cascades of Oregon. The points of capture and examination from north to south are: Cloud Cap Inn, Hood River County, June 2, 1934, 1 male, 2 females; Look Out Mountain, Clackamas County, August 9, 1935, 2 females; Olallie Lake, Jefferson County, August 5, 1938, 7 males, 14 females; Fish Lake, Linn County, July 20, 1938, 17 males, 9 females; Summit McKenzie Pass, Lane County, July 21, 1938, 9 males, 15 females; Lava Lake, Deschutes County, July 26, 1936, 1 males, 2 females; Crater Lake, Klamath County, July $8,1933,3$ males, 2 females; Lake of the Woods, Klamath County, June 25, 1939, 5 moles, 8 females.

Accidental Occurrences:

Citellus douglasi Richardson (gray digger), Spark's Lake, Deschutes County, $5,437 \mathrm{ft}$. el., Century Drive, Bend, July 24, 1936, 2 males, 3 females (only fleas on animal)

Neotoma cinerea occidentalis Baird (western bushy-tailed wood-rat), Summit Lakeview-Adel Highway, Lake County, June 21, 1937, 1 male

Peromyscus maniculatus gambeli Baird (Gambel's deer mouse), Chandler State Park, Lakeview, Lake County, June 19, 1937, 1 male. 
CALIFORNIA-From:

Marmota flaviventris avara Bangs (pallid yellow-bellied marmot), Ft. Bidwell, Modoc County, June 25, 1937, 8 males, 15 females

Marmota flaviventris sierrae Howell (Sierra marmot), Truckee (4 miles S.), Placer County, June 23, 1944, 10 pair.

In the central Sierra Nevada Mountains of California, Augustson reports this flea off the following hosts from Mono County:

Marmota flaviventris sierrae A. H. Howell (Sierra marmot), Duck Pass

Citellus beecheyi fisheri Merriam (Fisher ground squirrel), Casa Diablo

Ochotonia schisticeps muiri G. and S. (cony), Duck Pass.

NEVADA-In the northern portion of Washoe County, Nevada, the writer removed large series of this flea off:

Marmota flaviventris avara Bangs (pallid yellow-bellied marmot), during IDAHO-Off: July of 1937 , and in

Marmota flaviventris nosophora Howell (golden-mantled marmot), Whitebird, Idaho County, July 20, 1945, 5 pair.

\section{Thrassis howelli utahensis Wagner 1936}

1936 Thrassis howelli utahensis Wagner, Zeit. fur Parasit., 8:322.

This subspecies was described by Wagner from materials sent him by Prof. J. S. Stanford of Utah State Agricultural College, who removed the fleas off marmots taken at Logan and Salina, Utah.

In this subspecies the modified segments are characteristic.

Modified Segments, Male: Finger $F$ and process $P$ of clasper very similar to those of other related marmot fleas. VIII st. apically pointed, broader than in $T$. howelli howelli, and armed with 4 medium bristles, all different lengths. IX st. similar to howelli but with modified bristles grass blade shaped. VIII t. apically broad and angulate, armed on posterior border with row of short bristles and anterior to these 3 long bristles and below these 4 medium bristles. Female: Apical outline of VII st. with rounded lobe, the upper face of which is flattened. Spermatheca typical.

LENGTH: Original description did not include lengths. Specimens in the collection of the writer measure, males $1.75 \mathrm{~mm}$., females $2.00 \mathrm{~mm}$.

RANGE: All early records of marmot fleas from the Rocky Mountain region designated them as $T$. acamantis. It seems now that this designation was in error-that the Rocky Mountain marmot flea, at least in Utah, Colorado, and Montana, is T. howelli utahensis. This flea probably will be found also in eastern Idaho and Wyoming.

Host Preference: This flea is a true marmot flea.

RECORDS of this species are:

MONTANA-The only conclusive records of this flea come from the state of Montana, where it seems to be common and is reported off:

Marmota flaviventris (woodchuck), general over state

Citellus armatus (Uinta ground squirrel), Gallatin County 
Citellus columbianus (Columbian ground squirrel), Beaverhead, Missoula and Powell Counties

Citellus richardsoni (Richardson's ground squirrel), Park, Madison, and Blaine Counties

Cynomys ludovicianus (prairie dog), Fergus County

Eutamias (chipmunk), Park, and Lewis and Clark Counties

Neotoma cinerea (bushy-tailed wood rat), Gallatin, Park, Madison, and Lewis and Clark Counties

Peromyscus (deer mouse), Gallatin, Park and Ravalli Counties

Phenacomys intermedius (Rocky Mountain Phenacomys), Gallatin County

"Rabbit," Petroleum County

Sylvilagus (cottontail rabbit), Ravalli County

Canis latrans (coyote), Meagher and Ravalli Counties

Mephitis hudsonica (skunk), Gallatin County

Taxidea taxus (badger), Ravalli County.

COLORADO-While studying the flea collection of the Colorado State College through the courtesy of Prof. Sam McCampbell, the writer found large series of these fleas determined erroneously as Thrassis acamantis. While most of the records were listed simply as off woodchuck from Colorado, the following good records were noted:

Rabbit Ear Pass, off Marmota, August 8, 1928.

Estes Park, off Marmota, July 16, 1897.

UTAH-In this state this subspecies is reported off:

Marmota f. nosophora (golden-mantled marmot), Logan, Logan Mountains, Cache County

Marmota f. subsp. (marmot), Wasatch County

Under the designation of Thrassis acamantis, a flea is reported off:

Marmota f. engelhardti (Engelhardt's marmot), Salina Mountains and Fish Lake.

\section{Thrassis stanfordi \\ Wagner 1936}

1936 Thrassis stanfordi Wagner, Zeit. fur Parasit., 8:344.

This species was described by Wagner from specimens sent him by Professor Stanford from Logan, Salina and Fish Lake, Utah, where the fleas were taken off marmots.

Modified Segments in this species are characteristic: Male: Finger $\mathbf{F}$ and process $\mathbf{P}$ of clasper as in other closely related marmot fleas. VIII st. broad and angulate apically, armed with a marginal row of medium bristles. IX st. with proximal lobe rounded at distal angle and there armed with a sharp spine-like bristle. Modified bristles below this grass-blade shaped. VIII t. apically triangular and armed with 2 long bristles and a ventral marginal row of about 5 medium bristles. FEMALE: VII st. with apical outline in 2 lobes, lower well rounded, sinus not deep, then an upper lobe which may be almost hook shaped. Spermatheca typical.

LENGTH: Paratypes in the collection of the writer measure, males $2.50 \mathrm{~mm}$., females $3.00 \mathrm{~mm}$.

RANGE: This flea is known only from Utah and Colorado. 
UTAH-From:

Marmota flaviventris engelhardti (woodchuck), Salina and Fish Lake, Sevier County

Marmota flaviventris nosophora (golden-mantled marmot), Logan, Cache

County. Paratypes in collection of writer through courtesy of Professor Stanford off Marmota from Fish Lake.

COLORADO-In checking the flea collection of Colorado State College, the writer redetermined from old erroneous determinations, this species off:

Citellus elegans (picket pin ground squirrel) from Alma, Park County

Marmota spp.

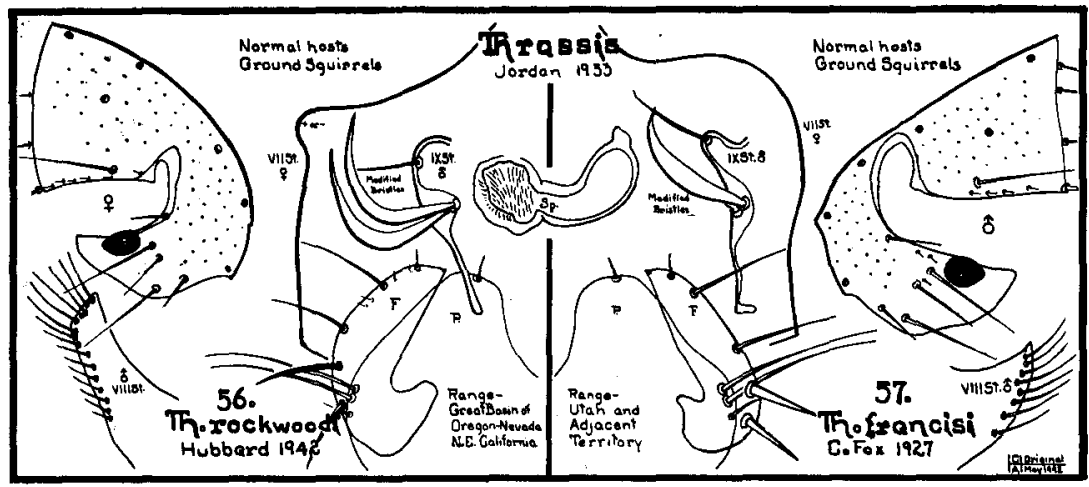

56. Thrassis rockwoodi

Hubbard 1942

1942 Thrassis rockwoodi Hubbard, Pacific Univ. Bul., 38, No. 6.

In describing this species the writer separated it from Thrassis francisi with which it was being confused, and from which it can be readily separated by the characteristic modified segments.

Modified Segments, Male: Finger F of clasper less pointed than in $T$. francisi. Four bristles on posterior border, the lower two not so stout as in $T$. francisi. The process $\mathbf{P}$ of clasper similar to $T$. francisi but apically perhaps a little less broad. VIII and IX sts. of two species are distinct. In $T$. rockwoodi VIII st. is apically angulate and posterior border has fringe of weak bristles. IX st. has proximal lobe armed with 2 sickle-shaped, modified bristles and spine at upper angle. Female: VII st. with posterior margin flat and almost perpendicular and at dorsal angle sometimes a small rounded lobe. The fragile nature of this dorsal angle often causes it to break away. The spermatheca is typical.

Lencth: This species is somewhat smaller than $T$. francisi. The males measure $1.75 \mathrm{~mm}$., the females $1.85 \mathrm{~mm}$.

Range: East of the Cascade Mountains in northern California, south half of Oregon and northern Nevada.

Host Preference: Great majority of specimens in collection of the writer from Oregon, California and Nevada are off Citellus beldingi 
oregonus (Oregon ground squirrel). A few specimens have been taken off Citellus townsendi canus (gray sage rat) and Citellus townsendi mollis Kennicott (piute ground squirrel). Occasionally a specimen is removed from other desert rodents.

Seasonat Distribution: The writer's records for this species run through April, May, June and July. Ground squirrels generally come out of hibernation during early March and return to hibernation before August, during which season this flea is almost always on them, but never in large numbers. The writer has not found the season of maximum abundance.

Writer's collections suggestive of host preference and range are: OREGON-Off:

Citellus beldingi oregonus Merriam (Oregon ground squirrel), Sisters, Deschutes County, July 18, 1936, 2 males; Summer Lake, Lake County, June 17, 1937, 3 pair; Terrebonne, Deschutes County, July 1, 1937, 2 pair; Lakeview, Lake County, July 10, 1937, 1 male, 2 females; Bly, Klamath County, June 29, 1939, 2 males, 3 females; Plush, Lake County, June 30, 1939, 4 males; Swan Lake Valley, Klamath County, June 15, 1939, 1 male,

Citellus townsendi mollis Kennicott (Piute ground squirrel), Blitzen, Harney County, July 6, 1939, 2 males, 3 females.

Citellus townsendi canus Merriam (gray sage rat), Terrebonne, Deschutes County, July 10, 1937, I pair.

Accidental Occurrence off:

Onychomys leucogaster fuscogriseus Anthony (grasshopper mouse), Blitzen, Harney County, July 6, 1939, 1 pair; Ontario, Malheur County, July 11, 1939, 2 pair

Citellus c. chrysodeirus Merriam (golden-mantled ground squirrel), Sisters, Deschutes County, July 15, 1936, 1 male.

CALIFORNIA-Off:

Citellus beldingi oregonus Merriam (Oregon ground squirrel). Tule Lake, Modoc County, April 20, 1942, 3 males, Dorris, Siskiyou County, April 19. 1942, 4 pair.

NEVADA-off:

Citellus beldingi oregonus Merriam (Oregon ground squirrel), Vya, Washoe County, June 6, 1945, 5 males, 4 females.

Citellus townsendi mollis Kennicott (Piute ground squirrel), Churchill County, April 6, 1943, 1 male, 2 females.

\section{Thrassis francisi and Thrassis rockwoodi}

\section{Early Confusion-Medical Importance}

During 1927 Dr. Carroll Fox of the United States Public Health Service described Thrassis francisi from specimens taken off Citellus townsendi mollis collected somewhere in Utah. Early in the history of plague study in Oregon the Plague Suppressive Measures Laboratory at San Francisco listed Thrassis francisi as collected off ground squirrels in the south central portion of the state. Subsequent experiments carried out on this flea to determine its efficiency as a vector of plague revealed 
that 13 per cent of this species fed upon plague-positive guinea pigs became infected with plague, and that 19 per cent of the infected fleas were able to transmit the disease to guinea pigs. During these experiments it was found that Xenopsylla cheopis, world ace as vector of plague, transmitted the disease in only 20 per cent of the cases. Therefore, it seems that Thrassis francisi is as efficient a vector of plague or perhaps more efficient than most known vectors.

While these experiments were being carried on it was generally considered that the range of $T$. francisi extended from the Cascade Mountains in Oregon east and south through the Great Basin into and through Utah. During 1939 a packet of these fleas collected in Oregon by the writer was sent to Dr. Karl Jordan of the British Museum. Dr. Jordan informed the writer that the Oregon specimens were not typical of $T$. francisi and should be described as new. During August of 1942, the writer, after carefully checking Oregon specimens with specimens from all over Utah, separated the Oregon species from $T$. francisi and gave the Oregon species the name $T$. rockwoodi.

Experiments carried out on $T$. francisi at Plague Suppressive Measures Laboratory involved 83 specimens, but whether these were from Oregon or Utah reports do not state. It is definitely known, however, that plague foci in ground squirrels are found in range of both of these fleas, so it is quite likely that both are efficient vectors of plague.

\section{Thrassis francisi \\ C. Fox 1927}

1927 Ceratophyllus francisi C. Fox, Trans. Amer. Ent. Soc., 53:210.

1933 Thrassis francisi Jordan, Nov. Zool., 39:73.

This species was described from materials taken off Citellus mollis (sage rat) in Utah.

Modified Segments, Male: Finger F of the clasper pointed as in $T$. petiolatus. Posterior border armed with 4 bristles, of which the 2 lower ones are stout and spine-like. Process $P$ of clasper truncate and armed at apex with a bristle. VIII st. apically pointed and somewhat triangular, armed with a row of medium bristles. IX st. with upper angle of proximal lobe extended into a thumb-like short lobe with a slender bristle at its apex. Below are modified bristles which the writer called knife-blade shaped. FEMALE: Apical outline of the VII st. suggestive of the old classical outline of the VII st. of $T$. petiolatus, that is, an outline with upper lobe well rounded. Spermatheca typical.

LENGTH: Specimens in collection of writer average, males $2.00 \mathrm{~mm}$., females $2.50 \mathrm{~mm}$.

RANGE: Records available to the writer lead him to believe that this species ranges in Utah and adjacent strips of adjoining states.

Host Prefrerence: All specimens in collection of the writer are off ground squirrels. This flea has been taken off prairie dogs. 
RECORDS: The following records from collection of writer are suggestive of range and host preference:

UTAH-Off:

Citellus armatus Kennicott (Uinta ground squirrel), Sevier County, May 16, 1939, a series; Box Elder County, May 28, 1938, a series

Citellus townsendi mollis Kennicott (Piute ground squirrel), Utah County, May 5, 1938, I male, 2 females; Salt Lake County, May 6, 1938, a series; Tooele County, May 13, 1938, a series; Sanpete County, May 22, 1939, a series.

Other records available are from Salina Canyon, Sevier County, off:

Citellus townsendi mollis Kennicott (Piute ground squirrel)

Cynomys parvidens Allen (Utah prairie dog).

NEVADA-The author collected this flea off:

Citellus townsendi mollis Kennicott (Piute sage squirrel), Ely, White Pine County, July 13, 1945, 7 males, 11 females, and in

IDAHO-Off:

Citellus armatus Kennicott (Uinta ground squirrel), Rogerson, Twin Falls County, July 15, 1945. 1 male, 3 females.

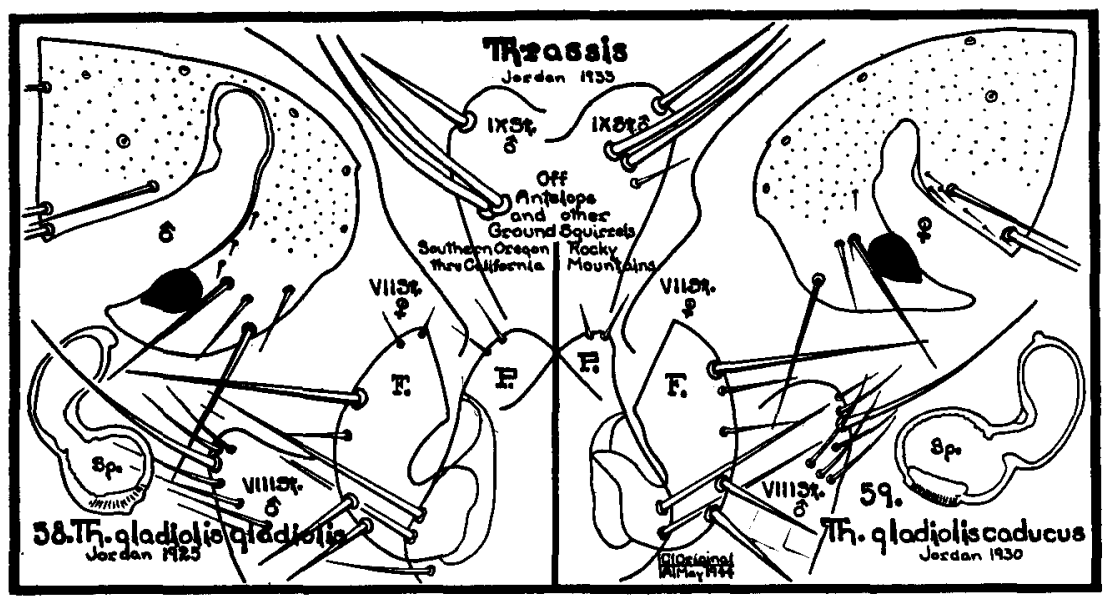

58. Thrassis gladiolis gladiolis

Jordan 1925

1925 Ceratophyllus gladiolis Jordan, Nov. Zool., 32:108.

1933 Thrassis gladiolis Jordan, Nov. Zool., 39:73.

This species was described from San Diego, California, where G. W. McCoy took the material off "Peromyscus and Tamias kept together in a cage." The writer believes this infestation was accidental and that the true host of this flea is Ammospermophilus, especially since Thrassis gladiolis caducus Jordan 1930 was described "Utah: Vernal, off $\mathrm{Am}$ mospermophilus leucurus cinnamomeus, November, 1927 (A. W. Moore), 3 males, 8 females," and since the writer's records are all from Ammospermophilus. 
Modified Segments: Jordan states that species is close to $C$. bacchi Rothschild 1905, hind-tarsal segment I being as long as II to IV together. In male hind-tarsal segment II with 2 slender bristles reaching beyond middle of $\mathrm{V}$. Apical and subapical bristle of $\mathrm{I}$ also long and slender. Process $\mathbf{P}$ of clasper evenly rounded, finger somewhat diamond shaped and armed with 6 bristles of unequal length, manubrium broad, straight, truncate. Proximal ventral lobe of st. IX broad, round, with strong apical bristle and 2 or 3 large modified bristles which are grass-blade-like in shape and with tips sometimes recurved. In the female the longest bristle of hind-tarsal segment II reaches beyond or to middle of $\mathrm{V}$, and second longest barely extends to apex of III. Head of spermatheca almost globular, tail short, scarcely at all dilated at end, with a small apical appendix.

LENGTHS: Original given as male, $1.7 \mathrm{~mm}$., female, $2.4 \mathrm{~mm}$.

RANGE: From the type locality at San Diego, California, this species ranges northward into the desert region of southeastern Oregon and southward through California.

In the collection of the writer is a series of this flea all taken in Warner Valley, Lake County, Oregon. Citellus (Ammospermophilus) leucurus leucurus, (antelope ground squirrel), from which they were collected, are never heavily infested. The writer records, also, the presence of a small series of this flea that was taken from what indications seemed to show was a kangaroo rat nest, but the kangaroo rats of this vicinity did not carry this flea.

Medical Importance: While Thrassis gladiolis gladiolis is generally considered to be a vector of plague, experimental evidence against the flea is incomplete. Twenty-seven specimens fed upon plague-positive guinea pigs at the Plague Suppressive Measures Laboratory resulted in infection of 22 per cent of them. There is no record of disappearance of infection from the 22 per cent infected, but neither is there any record that infected fleas were able to transmit the disease.

RECORDs: Typical and interesting records for this species in the collection of the writer are:

\section{OREGON-From:}

Citellus (Ammospermophilus) leucurus leucurus Merriam (antelope ground squirrel), Adel, Lake County, 10 miles southeast, on the east margin of the flooded portion of Warner Valley, June 24, 1937, 2 males, 1 female

Perodipus ordi columbianus Merriam (Columbia kangaroo rat), out of nest of shredded sagebrush bark, 6 inches beneath surface of sand, Adel, Lake County, June 23, 1937, 6 males, I female.

CALIFORNIA-In Riverside County of southern California Augustson reports this subspecies off:

Citellus leucurus leucurus (antelope ground squirrel), Palm Springs, San Gorgonio Pass, Santa Rosa Mountains

Peromyscus eremicus eremicus (d¿er mouse), San Gorgonio Pass, 
It seems that original specimens upon which the description of the species was based may have come off:

Citellus tereticaudus (round-tailed ground squirrel), taken at San Diego, San Diego County.

NEVADA-Off:

Citellus (Ammospermophilus) leucurus leucurus Merriam (antelope ground squirrel), Pyramid Lake, Washoe County, June 19, 1944, a small series, by the author.

While it has been suggested that the preferred host of this flea is the round-tailed ground squirrel, most collectors feel the true host is the antelope ground squirrel.

\section{Thrassis gladiolis caducus Jordan 1930}

1930 Thrassis gladiolis cauducus Jordan, Nov. Zool., 35:268.

Modified Segments: This flea is similar to Thrassis g. gladiolis, but from which it differs slightly in practically all the modified segments. The describer states, "MALE: As in C. g. gladiolis Jord. 1925, from California, hindtarsal segment I has a subapical and apical bristle which reach beyond II; the longer of the 2 bristles in second notch from apex does not nearly extend to apex of I, whereas in $C$. g. gladiolis male it reaches to near apex of II. Exopodite (Finger) $F$ a little broader than in C. g. gladiolis; anterior angle of paramere slightly less projecting; the pair of sword-like bristles on ventral lobe of st. IX less proximal, their distance from apex shorter than segment IV of hind tarsus, in C. g. gladiolis longer than that segment, the lobe also narrower. . . F FEMALE: Pygidium as long as, or about one-fifth shorter than its distance from stylet: in C. g. gladiolis about one-twelfth longer than this distance."

Specimens in collection of the writer lead him to believe that Process $\mathbf{P}$ of clasper of male is much less broad in caducus than in gladiolis and that VIII st. of male is much broader in caducus than in gladiolis. In female apical outline of VII st. has a much deeper upper lobe and deeper sinus in caducus than in gladiolis.

LENGTH: Males in the collection of the writer measure about $2 \mathrm{~mm}$., the females about $3.00 \mathrm{~mm}$.

RANGE: Central Rocky Mountain region of the United States.

MEdical Importance: This flea has not as yet been condemned as a vector of plague.

RECORDS: Specimens in the collection of the writer are off:

Citellus tridecemlineatus parous (13-lined ground squirrel), Sweetwater County, wyoming.

Specimens upon which the original description was based were taken off:

Citellus (Ammospermophilus) leucurus cinnamomeus (antelope ground squirrel), Vernal, Uinta County, Utah.

This flea is also reported taken off antelope ground squirrel at Baker, Nevada. 


\section{Thrassis arizonensis}

Baker 1898

This species maintained its entirety until Jordan in 1929 described Thrassis arizonensis littoris which he based upon a bristle arrangement of the VIII t. of the female. During 1940 Stewart described a flea from Riverside County, California, as $T$. desertorum. Considerable comment has been exchanged between western flea students on the validity of the two last-named fleas. Augustson, who has probably done more work in the range of this species than any other man, originally felt that he could distinguish between $T$. arizonensis and $T$. littoris. The writer arrives at this conclusion because early specimens sent him by Augustson had both designations used. Later as Augustson studied more and more specimens, he changed his views and, in 1943 in Bulletin Society California Academy of Science, 42:83, stated that it was his opinion that $T$. arizonensis could not satisfactorily be divided into subspecies. In all his experience and the experience of his associates in collecting in southern California, Augustson never mentions the flea T. desertorum; therefore, the writer concludes that Augustson was unable to separate it from $T$. arizonensis. In 1942 Jellison and Good stated that they found only very slight differences between types of $T$. arizonensis and $T$. desertorum and for the time being reduced $T$. desertorum to a subspecies of $T$. arizonensis.

It seems likely, then, that $T$. arizonensis arizonensis, $T$. arizonensis littoris, and $T$. arizonensis desertorum are all one and the same flea-namely, $T$. arizonensis Baker 1898.

Medical Importance: The Plague Suppressive Measures Laboratory working on the flea Thrassis arizonensis found that 44 per cent of 121 fleas became plague infested when fed upon plague-positive guinea pigs; that 11 of the 58 fleas infected cleared themselves of the infection and that about 5 per cent became vectors of the disease. This figure does not show a high degree of efficiency as a plague vector.

\section{Thrassis arizonensis arizonensis Baker 1898}

1898 Pulex arizonensis Baker, Jour. New York Ent. Soc,, 6:55.

1904 Ceratophyllus proximus Baker, Proc. U. S. Nat. Mus., 27:412.

1904 Ceratophyllus arizonensis Baker, Proc. U. S. Nat. Mus., 27:415.

1929 Ceratophyllus arizonensis Jordan, Nov, Zool., 35:31.

1929 Ceratophyllus arizonensis arizonensis Jordan, Nov. Zool., 35:31.

1933 Thrassis arizonensis Jordan, Nov. Zool., 39:73.

This species was originally described from a male which was taken from the nest of a "silvery mouse" at Tucson, Arizona. Later the female was described as Ceratophyllus proximus from material which was supposedly taken off a ground squirrel by Prof. H. G. Hubbard at Palm Springs, California. 


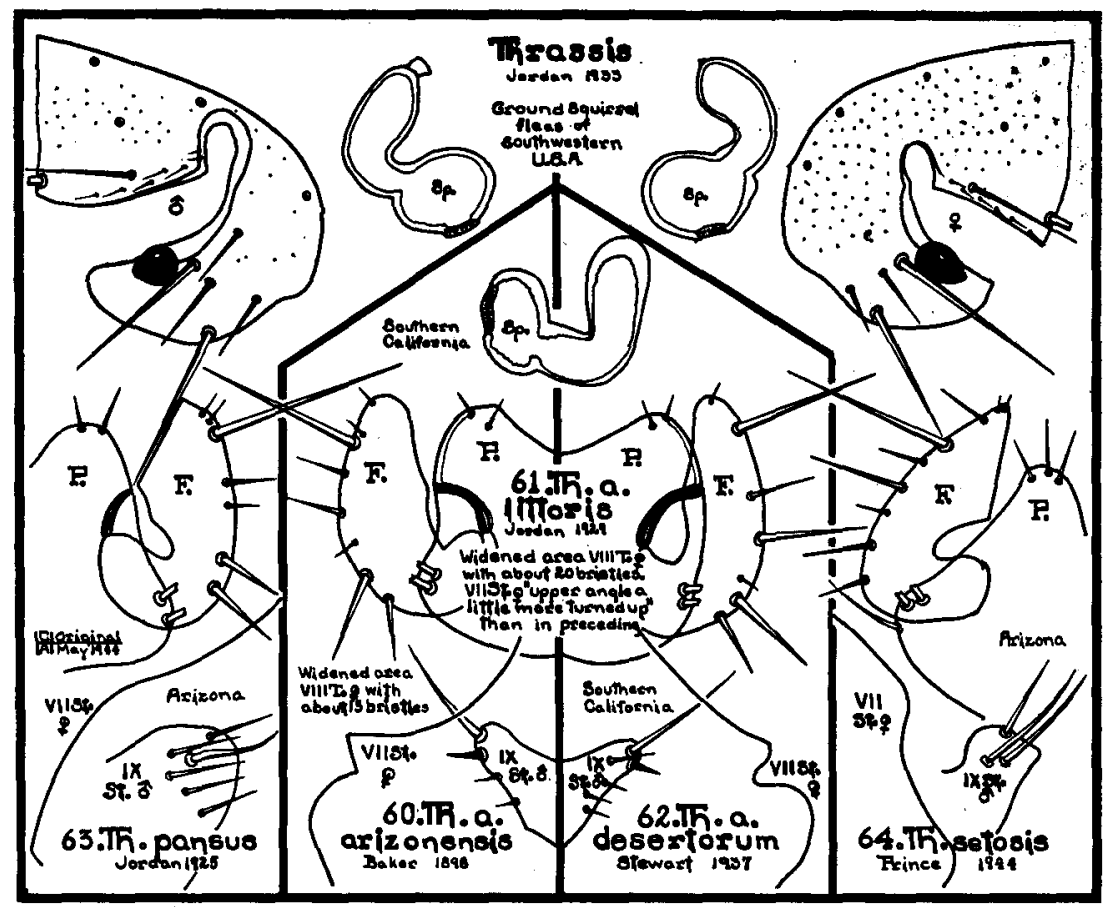

Modified Segments: Finger of the clasper of the male with a nicely rounded posterior border from anterior apical angle to junction with process; the border armed with 6 bristles, the 2 most dorsal short, then toward the ventral a long one, then one about one-third as long, then one two-thirds as long, one half as long and the most ventral one about one-third as long. Process with dorsal border slightly undulate, apical angle rounded, posterior border at almost right angles to dorsal border, 2 long bristles at junction with finger. In female ventral widened area of t. VIII with from 14 to 16 bristles. Apical margin of VII st. as a whole is well rounded and projecting from it about midway along its course a small knob.

LENGTH: Original for female given as $2.5 \mathrm{~mm}$.

RaNGE: From the type locality at Tucson, Arizona, this species ranges westward through Arizona and into and through southern California.

Host Preference: This species is a ground squirrel flea.

RECORDS:

CALIFORNIA-Augustson reports this flea off the following hosts taken from Riverside County:

Citellus (Ammospermophilus) leucurus leucurus (antelope ground squirrel), Palm Springs 
Citellus tereticaudus chlorus (round-tailed ground squirrel), Palm Springs Onychomys torridus pulcher (grasshopper mouse), Palm Springs, Santa Rosa Mountains

Peromyscus californicus insignis (deer mouse), Cabazon

Citellus tereticaudus tereticaudus (round-tailed ground squirrel), Indio, Imperial County.

\section{Thrassis arizonensis littoris Jordan 1929}

1929 Ceratophyllus arizonensis littoris Jordan, Nov. Zool., 35:31.

This species was described from San Diego, California, where it was taken off Citellus turdicaudatus (ground squirrel) by F. Stevens, March $12,1914$.

The original short description reads, "Female. Like C. a. arizonensis, but the ventral, widened, area of $t$. VIII with 21 bristles on one side and 20 on the other, instead of from 14 to 16 as in C. a. arizonensis. St. VII essentially as in $C$. a. arizonensis, its upper angle a little more turned up, but this difference probably not constant."

LENGTH: Not given.

RANGE: This species probably ranges throughout southern California.

Host Preference: This species is probably a true ground squirrel flea.

\section{Thrassis arizonensis desertorum Stewart 1937}

1937 Thrassis desertorum Stewart, Can. Ent., 69:273.

This species is described from materials collected by the United States Public Health Service in Riverside County, California, during December, 1935, off Ammospermophilus leucurus leucurus Merriam (antelope ground squirrel).

Modified Segments: Characteristic for this species. The describer says that in male, movable finger $\mathbf{F}$ of clasper slightly exceeds tip of immovable process $P$. It is angulate at about middle of dorsal margin and convex on ventral margin. Ventral margin of finger is armed with 3 bristles which are equally spaced from one another, and 4 hairs. Apex of finger is somewhat truncate. IX st. is without flat, pointed, modified bristles; it is small and lightly bristled at the tip. VIII st. bears but 2 bristles. In female it is stated that distal end of tail of spermatheca is dilated and this portion as well as the head of the spermatheca is darkened and has appearance in cleared specimens of being striated. Apical margin of VII st. is digitate latero-dorsally.

RANGE: This species is known only from the type locality, nothing is known about its range in southern California. 


\section{Thrassis pansus \\ Jordan 1925}

1925 Ceratophyllus pansus Jordan, Nov. Zool., 32:109.

1933 Thrassis pansus Jordan, Nov. Zool., 39:73.

1944 Thrassis pansus Prince, Pan-Pacific Ent., 20:18.

This flea was described by Jordan from a series of specimens taken off ground squirrels and skunk at Paradise, Cochise County, extreme southeastern Arizona, during November of 1913 by Duffner.

According to the original description this flea is close to $T$. bacchi Rothschild 1905 and in the male large bristle of finger $F$ is longer and thicker, and placed further upwards, and between it and base there are 5 marginal bristles. Two flattened modified bristles of proximal ventral lobe of st. IX much closer to apical bristle and shorter, proximally of them several smaller bristles. Paramere much more asymmetrical, ventral angle projecting distad.

Prince described the female during January, 1944, from specimens taken in New Mexico, Arizona and Texas. He says of the modified segments, "Head of receptaculum seminis globular and pigmented, tail broadest in distal half, sclerified tip. St. VII as illustrated. T. VIII bears 13 to 15 bristles. Stylet short, broad, with apical and 3 lateral bristles."

Length: According to Prince the female varies from 2.28 to 2.92 $\mathrm{mm}$., average $2.66 \mathrm{~mm}$. Males in collection of the writer about $2.50 \mathrm{~mm}$.

RANGE: This species ranges through eastern Arizona, New Mexico, and western Texas.

Hosts: According to Prince this flea has been taken off Onychomys, Citellus, Peromyscus, Dipodomys, Neotoma, and Cynomys.

\section{Thrassis setosis Prince 1944}

1944 Thrassis setosis Prince, Pan-Pacific Ent., 20:13.

This species was described by Prince from a large series taken off various rodents in Yuma and Yavapai Counties, Arizona.

The salient features of the species are, according to Prince, a pronotal comb of 16 or 17 teeth; hind tarsal segment I equal to II, III, and IV together. Modified Segments, Female: Antepygidial bristles 3, median one longest; head of spermatheca globular, tail short, broadest in distal half; st. VII without sinus, there are 8 or 9 bristles on each side; male, process $\mathbf{P}$ dome-shaped, shorter than finger; finger convex on posterior border and armed with one long bristle distally and 3 shorter pale bristles more proximally, apex with straight cut along anterior face and concave near base of finger on anterior border; st. VIII with sclerified line near ventral edge, armed with 4 or 5 apical bristles, 2 long subapical and 2 or 3 smaller bristles; internal portion of st. IX 
broadest near apex, proximal lobe broad and rounded with 3 large flattened dark spines near apex in addition to 1 or 2 pale bristles.

LENGTH: Original average lengths are female $2.55 \mathrm{~mm}$., male 1.98 mm.

RANGE: At present known only from southwestern Arizona.

HOST RECORDs: The type host is considered to be:

Citellus harrisi saxicola (Yuma antelope squirrel).

RECORDS: Other recorded hosts are:

Citellus varigatus grammurus (Say's rock squirrel)

Neotoma lepida stephensi (Stephens wood rat)

Peromyscus leucopus arizonae (deer mouse)

Zapus sp. (jumping mouse).

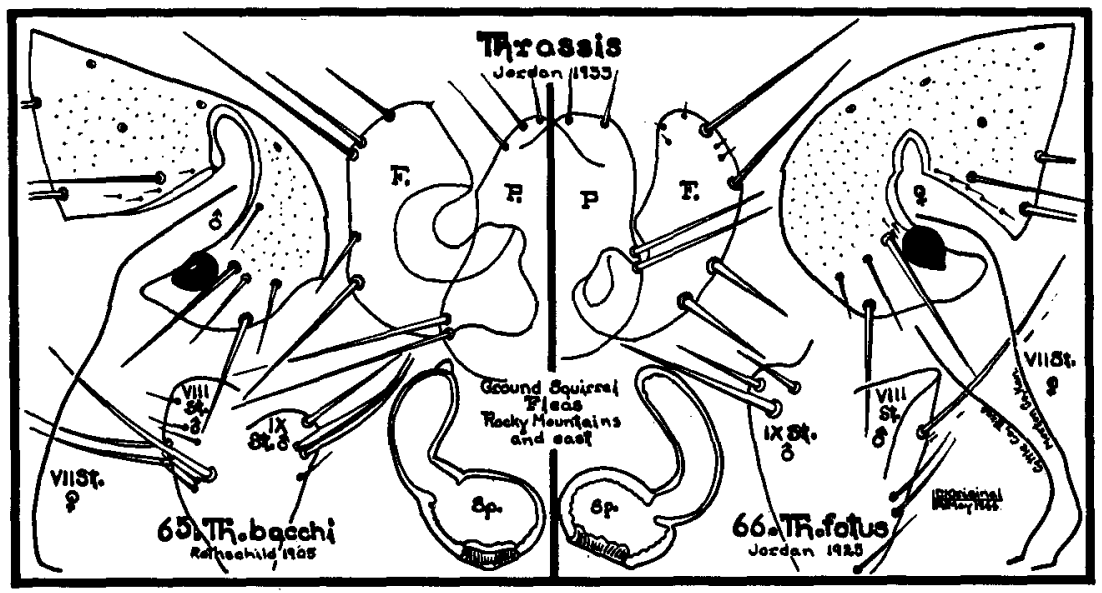

65. Thrassis bacchi

\section{Rothschild 1905}

1905 Ceratophyllus bacchi Rothschild, Nov. Zool., 12:159.

1943 Thrassis bacchi (Rothschild) Prince, Pub. Health Rept., 58:1013.

1944 Thrassis bacchi Prince, Pan.Pacific Ent., 20:18.

The male of this species was described by Rothschild from materials off Citellus tridecimlineatus, the 13-lined ground squirrel, taken at Red Deer, Alberta, Canada. Prince during January of 1944 described female from materials collected in Montana, North Dakota, and South Dakota off various ground squirrels.

Modified SEgments are characteristic for this species. In male finger $\mathrm{F}$ has a dorsal third triangular and at apex small black spiniform; below it on posterio-dorsal margin 3 bristles, lower the longest and stout. Middle third of posterior margin of finger very slightly concave and at its lower angle a long stout bristle, one short bristle about middle of this face. Lower third of margin rounded nicely to region of process. Anterior margin of finger with deep sinus at middle. Process $\mathbf{P}$ dome- 
shaped with 3 apical bristles. Posterior margin with a small angle. IX st. with proximal ventral lobe rounded and armed with 2 flattened swordlike modified bristles and a straight, stout bristle. VIII st. well rounded apically and armed with one stout long bristle, 2 medium bristles and a few short bristles. Female: VII st. with but a single lobe, posterior margin with a slight concave area at the dorsal angle. T. VIII armed with 17 to 21 bristles. Spermatheca with subglobular body and short crooked tail which bears small appendage.

LeNGTH: Females recorded by Prince as averaging $1.58 \mathrm{~mm}$., but specimens in the collection of the writer from Rolette County, North Dakota measure $2.00 \mathrm{~mm}$. in male and $3.00 \mathrm{~mm}$. in female.

RANGE: Alberta south through eastern Montana and through North Dakota and South Dakota.

MedrCAL Importance: During July of 1943 this flea was publicly denounced as a vector of plague. Prince reports experimenting with 40 specimens of this species. After feeding these 40 upon plaguepositive guinea pigs it was found that 10 became infected, and continued so until the time of their death. There seemed no evidence that any of the 10 freed themselves of the infection. By feeding infected fleas upon healthy guinea pigs it was found that 4 of 10 transmitted infection to healthy animals. Forty per cent of these fleas, then, had become successful as vectors. When Thrassis bacchi is compared with America's ace vectors Xenopsylla cheopis, and Diamanus montanus, it is as efficient or even more so as a vector of plague.

RECORDS: Male of this species was described off:

Citellus tridecemlineatus tridecemlineatus (13-lined ground squirrel), taken at Red Deer, Alberta, Canada. Female was described off the same ground squirrel taken 5 miles south of Gettesburg, Potter County, South Dakota. Other specimens were taken off:

Citellus richardsoni richardsoni (Richardson ground squirrel), Potter and Brown Counties, South Dakota; Rolette County, North Dakota; Blaine, Phillips, Valley, Daniels, Roosevelt and Sherman Counties, Montana

Citellus franklini (Franklin's ground squirrel), Spink County, South Dakota.

\section{Thrassis fotus \\ Jordan 1925}

1925 Ceratophyllus fotus Jordan, Nov. Zool., 32:107.

1928 Ceratophyllus citelli Stewart, Can. Ent., 60:150.

1933 Thrassis fotus Jordan, Nov. Zool., 39:73.

1944 Thrassis princei Hubbard, Pacific Univ. Bul., 39, No. 10.

This species was described by Jordan from a pair of fleas taken off the 13-lined ground squirrel from Colorado Springs, El Paso County, Colorado, during June of 1910.

Modified Segments, Male: Finger F of clasper plump. Posterior margin nicely rounded entire length. Four bristles on margin, apical one longest, lower two much shorter and stout and spine-like. Apex 
rounded, anterior margin slightly concave. Process $P$ not quite so long as finger, dome-shaped but slightly flattened on top and armed apically with two small bristles. Proximal ventral lobe of IX st. rounded and armed with one long stout bristle and two shorter ones. VIII st. triangular apically, armed with one long bristle and below 3 short ones. FEMALE: Apical margin of VII st. variable, sometimes the lobe is angular with posterior margin undulate, other times the lobe is low and rounded. Spermatheca characteristic, with flattened body somewhat oval, crooked long tail without appendage.

LENGTH: Original length for male given as $2.20 \mathrm{~mm}$., females in the collection of the writer about $3.00 \mathrm{~mm}$.

RANGE: Rocky Mountains of United States and east.

Host Preference: Although this flea is taken often off grasshopper mice, ground squirrels are probably its favored host.

RECORDs: The type host of this species is:

Citellus tridecemlineatus tridecemlineatus (13-lined ground squirrel), Colorado Springs, El Paso County, Colorado.

The flea has also been taken off:

Citellus spilosoma (spotted ground squirrel), Morton County, Kansas; Catron County, New Mexico; Cottle County, Texas

Onychomys leucogaster (grasshopper mouse), Meade and Morton Counties, Kansas; Grant County, Nebraska.

This ground squirrel flea has not yet been associated with plague.

\section{GENUS THRASSOIDES HUBBARD}

A New Genus

1946

This genus is close to Thrassis Jordan. 1933.

Genotype: Thrassis aridis Prince 1944.

Head: Well rounded in both sexes. Frontal tubercle more prominent than in Thrassis. Pre-antennal armature consisting of a row of 2 or 3 bristles at level of top of black, grape-seed-shaped eye, an isolated heavy bristle below these close to genal edge and above a stout long bristle far above eye. Patch of setae above eye. Post-antennal region armed with a heavy long bristle and a marginal row. Small bristles along antennal groove.

Modified Segments, Male: Finger armed with 4 stout bristles, lower two of which are not stout and spine-like as in Thrassis. Upper of these bristles longest and stoutest. VIII and IX st. without modified bristles or stout spines as in Thrassis. Female: Marginal outline of VII st. apically low and gradually slanting, whereas this outline in Thrassis is high apically. Spermatheca not Thrassis-like but with globular body and long slender finger-like tail, which is nicely bent and has apically a small appendage. 
Host: Members of this genus are generally found upon kangaroo rats, while members of genus Thrassis are found upon these animals only as a rarity.

RANGE: Two species belonging to genus have their range separated by Rocky Mountains. East of Rockies in Nebraska Ths. campestris is found, west of these mountains in Arizona Ths. aridis ranges.

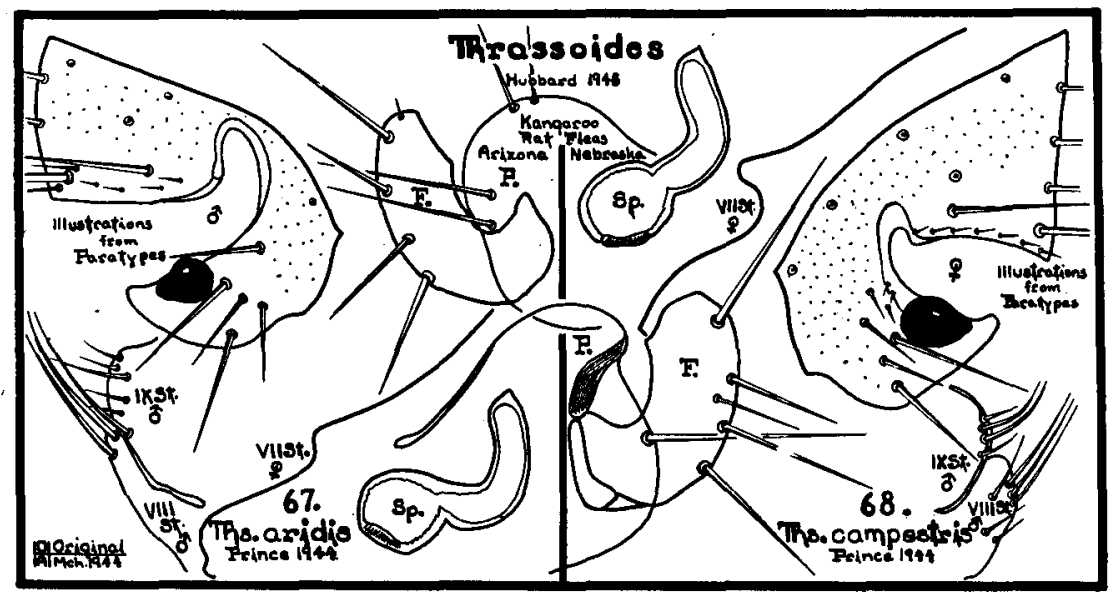

67. Thrassoides aridis

Prince 1944

1944 Thrassis aridis Prince, Pan-Pacific Ent., 20:14.

Prince described this species off Dipodomys merriami (kangaroo rat) taken in Yuma and Pima Counties, Arizona.

Modified Segments, characteristic, are described by Prince as follows: MALE: Manubrium of process gradually tapering from base to apex, curved slightly upwards. Process $\mathbf{P}$ of clasper shorter than finger $\mathbf{F}$ and with apex pointed posteriorly. Finger nearly symmetrical and with 4 bristles on posterior border, basal 2 largest. Proximal lobe of IX st. with 4 pale bristles. Distal lobe with numerous setae. Parameres bootshaped. Two long acetabular bristles. FEMALE: St. VII with sinus, upper lobe small and attenuated. There are 7 to 10 bristles on each side of st. VII. Stylet about 3 times as long as broad with 1 apical and 2 lateral bristles. Spermatheca typical.

Length: Original lengths are averaged as male $1.69 \mathrm{~mm}$., female $2.17 \mathrm{~mm}$.

RANGE: This flea is known only from Arizona and extreme southwestern New Mexico.

Hosts: The type host is listed as Dipodomys merriami. The flea is also reported off wood rat and grasshopper mouse. 
RECORDS: The hosts of this species are off:

Dipodomys merriami (kangaroo rat), Nogales, Santa Cruz County; Tucson, Pima County, Arizona; and Conchise, Pinal, and Greenlee Counties, Arizona.

Neotoma lepida (wood rat), Greenlee County, Arizona.

Onychomys leucogaster (grashopper mouse), Mohave County, Arizona; and Hidalgo County, New Mexico.

\section{Thrassoides campestris \\ Prince 1944}

1944 Thrassis campestris Prince, Pan-Pacific Ent., 20:15.

This species was described by Prince off Dipodomys ordi (kangaroo rat) from northwestern Nebraska.

Modified SEgmenTs, which are characteristic, are said by describer to be as follows: MALE, Finger F of clasper same general shape as preceding species but armed with 7 bristles on posterior border. Only 1 long acetabular bristle. St. VIII with 3 long and 4 short bristles. Proximal and distal lobes of st. IX longer and broader than in preceding species. Female: Tail of spermatheca without sclerified tip; shorter and broader than Ths. aridis. St. VII with deeper and pigmented sinus. Stylet short, about one-half as broad as long, with an apical and 3 lateral bristles.

Paratypes in collection of writer, through courtesy of describer, do not exactly meet these specifications. From specimens under study writer would describe Modified SEgments as follows: MALE, finger F much more plump than in aridis, apex considerably more blunt; armature as in aridis, 4 stout bristles on posterior border, the upper-most the more prominent. Process $\mathbf{P}$ dome-shaped apically, but recurved posteriorly. VIII st. apically much broader than aridis and armed with 3 long and several short bristles. Lower lobe IX st. well rounded and armed with several short and several long bristles. Female: Apical outline VII st. with upper prominent knob-like lobe and below it a shallow sinus. Spermatheca with body more flattened than in aridis.

LENGTH: Original average lengths are given as male, $2.16 \mathrm{~mm}$., female, $2.60 \mathrm{~mm}$.

RANGE: All records to date are from northwestern Nebraska, and northern Oklahoma. This flea probably ranges over the western portion of Great Plains.

RECORDS: This species has been recorded off:

Dipodomys ordi (kangaroo rat), Mullen, Hooker County; Ashby, Grant County; Cherry and Garden Counties, Nebraska

Onychomys leucogaster (grasshopper mouse), Grant and Hooker Counties, Nebraska

Peromyscus maniculatus (deer mouse), Garden County, Nebraska

Dipodomys spp. (kangaroo rat), Harper County, Oklahoma. 


\section{GENUS DIAMANUS JORDAN}

1933. Diamanus Jordan. Nov. Zool., 39:73.

Genotype: Ceratophyllus montanus Baker 1895

This genus is close to genus Thrassis but in male bristles of antennal segment II are short, dorsal groove of the occiput is deep, VIII st. is quite small. Finger $\mathbf{F}$ is very long and narrow and bent anteriorly and is sword-like in shape. In female there are 2 antepygidial bristles about equal length and dorsal lateral bristles of stylet are much smaller than ventral ones.

The genus is represented (west of the Rocky Mountains) by but a single species, D. montanus Baker 1895, which is found on western ground squirrels.

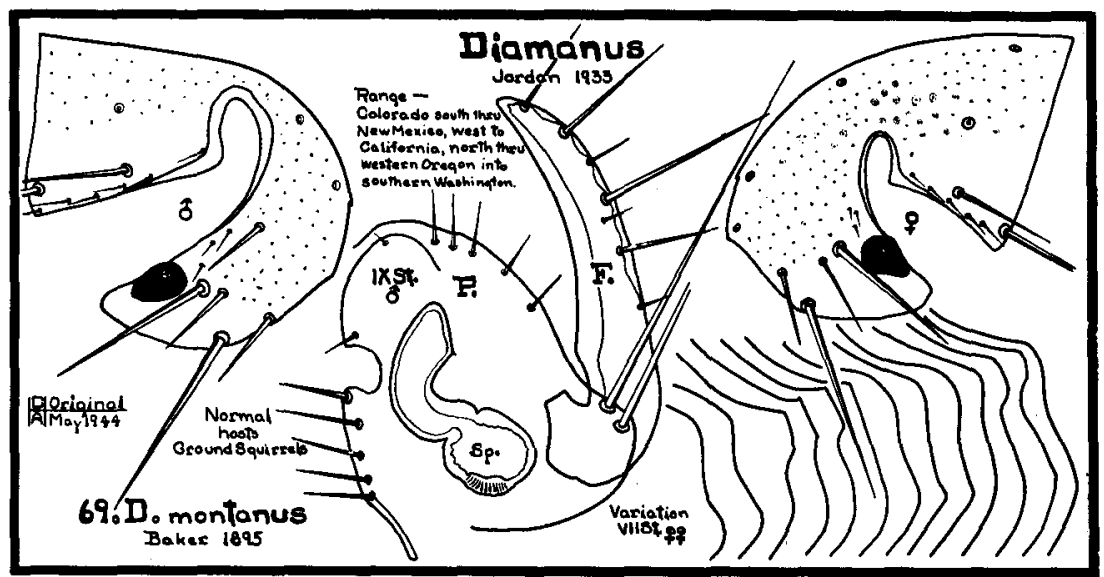

69. Diamanus montanus

Baker 1895

1895 Pulex montanus Baker, Can. Ent., 27:132.

1904 Ceratophyllus montanus Baker, Proc. U. S. Nat. Mus., 27:411.

1904 Ceratophyllus acutus Baker, Invert. Pacifica, I., p. 40.

1929 Ceratophyllus montanus Jordan, Nov. Zool., 35:31.

1929 Ceratophyllus acutus Jordan, Nov. Zool., 35:31.

1933 Diamanus montanus Jordan, Nov. Zool., 39:73.

It is known today that this species is same insect which Baker also described in 1904 as Ceratophyllus acutus from a spermophile (ground squirrel) taken at Stanford University, California. The description was written from materials off a gray squirrel taken in northern Colorado. Baker also lists this flea from ground and rock squirrels in Arizona and Colorado.

Modified Segments: Process $\mathbf{P}$ of clasper of male is well rounded but appears as if it had been pushed ventrally until most of rounded 
margin is in vicinity of junction with finger and below. At this junction are 2 stout, long bristles and above these on the margin about 4 weak bristles. Finger extends far beyond the process dorsally, and is long and slender. It curves toward the anterior. Shape is very much like that of blade of a hand sickle or scythe. There are about 6 weak bristles on posterior border, 5 on upper half. Spermatheca of female is quite characteristic, having a slightly flattened bulbous body, and a distinctly crooked tail which in some specimens has a tendency to be slightly bulbous on tip. In other specimens free end of tail is cut off at an angle. Apical margin of VII st. of females varies somewhat, sometimes being angular, at other times somewhat rounded.

Host: In Oregon country this is the chief and generally only flea on Citellus beecheyi douglasi Richardson (gray digger). Specimen after specimen of gray digger can be examined, results-only this flea. During maxima for this flea, which occurs during July and August, infestation on gray digger becomes so great that as many as 200 can be taken off a single specimen, and runs and burrows of squirrels may be teeming with them. In spite of these large numbers, this flea is found only occasionally on other rodents of immediate vicinity; fleas probably find substitute host not to their liking, so depart as soon as possible.

RANGE: Listed by Baker from Arizona and Colorado, the writer has specimens from New Mexico, and plague agencies of California have found this species wherever Citellus and Otospermophilus are found in the state. In northern California the writer has taken this species off Citellus beecheyi douglasi at Fort Dick and Smith River, close to Pacific Ocean and to east in the Modoc Lava Beds. In Oregon this flea confines its range very close to range of gray digger, which has been west of Deschutes River to Pacific Ocean. The writer has hundreds of records all through this territory. About 1910 gray digger escaped across Columbia River into Washington somewhere around town of Bingen, Klickitat County. With it went its chief flea, D. montanus. Today gray digger is found in Washington from Carson to west, and eastward to Maryhill. Through this zone of about 100 miles all gray diggers examined carried many of these fleas. In 1939, of unusual importance was discovery of this flea by the writer at Umapine, Oregon and Lowden, Walla Walla County, Washington, far to east of any previous record and close to Idaho state line. These records were from Citellus columbianus columbianus (red digger). On March 1, 1940, the writer further extended range of this flea by taking it off a specimen of Citellus townsendi canus (sage rat) at Wasco, Wasco County, Oregon, east of the Deschutes River. This infestation on sage rat opens up entire Great Basin region of Oregon to range-extending possibilities of this flea. The writer has not found this flea in Washington north of range of gray digger, which at present may be as far north as crest of Simcoe Mountains. This flea is not reported as far east as Montana. 
The Federal Rocky Mountain Laboratory has specimens of this flea from Citellus spp. from Coos, Douglas, and Josephine Counties, and from Sylvilagus from Curry and Josephine Counties, Oregon.

MEDical Importance: Seventy-two specimens of this flea, fed upon plague-positive guinea pigs at Plague Suppressive Measures Laboratory, resulted in 20 per cent of fleas becoming infected. None of these seemed to clear themselves of infection. Only 11 per cent of infected fleas were able to transmit the disease to healthy guinea pigs. This shows them only moderately efficient as vectors of plague, an efficiency about half that of rat fleas.

RECORDS: A few of the more interesting listings of the author follow:

OREGON-From:

Citellus beecheyi douglasi Richardson (gray digger), Valsetz, Polk County, August 17, 1937 (a half-grown specimen), 197 fleas, including both sexes Citellus townsendi canus Merriam (gray sage rat), Wasco, Wasco County, March 1, 1940, 2 males

Citellus beldingi oregonus Merriam (Oregon ground squirrel), Klamath Falls, Klamath County, June 25, 1939, 4 males, 1 female

Citellus columbianus columbianus Ord (red digger), Umapine, Umatilla County, May 10, 1939, 2 males, 3 females.

Accidental Occurrences:

Peromyscus maniculatus gambeli Baird (Gambel's deer mouse), Parkdale, Hood River County, May 17, 1936, 1 male

Neotoma cinerea occidentalis Baird (pack rat), Wamic, Wasco County, May 18, 1937, (from nest) 3 males, 5 females

Aplodontia rufa rufa Rafinesque (Cascade Mountain beaver), Parkdale, Hood River County, August 3, 1935, 1 male

Aplodontia rufa pacifica Merriam (Pacific Mountain beaver), Devil's Lake, Lincoln County, February 24, 1939, 14 males, 40 females

Thomomys monticola mazama Merriam (Mazama pocket gopher), Cooper Spur Junction, Parkdale, Hood River County, August 5, 1935, 1 male.

\section{WASHINGTON-From:}

Citellus douglasi Richardson (gray digger), White Salmon, Klickitat County, June 14, 1938, 5 males, 6 females

Citellus columbianus columbianus Ord (red digger), Lowden, Walla Walla County, May 10, 1939, 3 males, 4 females.

\section{CALIFORNIA-From:}

Citellus beecheyi douglasi Richardson (gray digger), Smith River, Del Norte County, June 15, 1939, 3 males, 7 females; Modoc Lava Beds, Tule Lake, Modoc County, June 27, 1939, 5 males, 4 females, Cedarville, Modoc County, June 15, 1945, large series.

Aplodontia rufa humboltiana Taylor (mountain beaver), Fort Dick, Del Norte County, June 16, 1939 (accidental), 1 male.

From the central Sierra-Nevada Mountains of California, Augustson reports this flea from Mono County off:

Citellus beldingi beldingi (Belding ground squirrel), Mammoth Lakes

Citellus beecheyi fisheri (Fisher ground squirrel), Casa Diablo

Citellus lateralis cyrysodeirus (mantled ground squirrel), Mammoth Lakes, Mammoth Mountain, Casa Diablo, Benton Crossing, 
From Fresno County off:

Tamiasciurus douglasi albolimbatus (pine squirrel), Cascade Valley

Ochotona schisticeps albata (cony), Dusy Pass,

From southern California Augustson reports this flea from Los Angeles County off:

Citellus beecheyi beecheyi (California ground squirrel), Big Pines, San Gariel Mountains, Newhall, Pasadena, San Fernando Valley

Citellus beecheyi nesioticus (Catalina ground squirrel), Catalina Island

Neotoma fuscipes macrotis (large-eared wood rat), Griffith Park

Sylvilagus bachmani cinerascens (cottontail rabbit), Pasadena

Mephitis mephitis holzneri (skunk), Glendale,

From San Bernardino County off:

Citellus beecheyi beecheyi (California ground squirrel), Big Bear Lake

Citellus chrysodeirus bernardinus (mantled ground squirrel), Big Bear Lake

Citellus beecheyi fisheri (Fisher ground squirrel), Victoryville;

From Orange County in Santiago Canyon off:

Citellus beecheyi fisheri (Fisher ground squirrel)

Neotoma sp. (wood rat),

From French Flats, Ventura County off:

Citellus beecheyi beecheyi (California ground squirrel),

From San Diego, San Diego County off:

Citellus beecheyi nudipes (Juarez ground squirrel),

During 1909 McCoy and Mtizmain reported this flea off:

Citellus beecheyi, Mustela xanthogenys, Mephitis occidentalis, Thomomys bottae, Canis familiaris, Speotyto cunicularia, Neotoma and man, and in 1910 they reported this flea from 17 California counties.

To the east the author has collected this flea in

NEVADA-Off:

Callospermophilus lateralis certus Goldman (Charleston Mountains mantled ground squirrel), Charleston Park, Las Vegas, Clark County, June 25, 1945, 2 females.

UTAH-Off:

Citellus variegatus utah Merriam (Utah rock squirrel), Kanab, Kane County, July 7, 1945, 17 pair.

ARIZONA-Off:

Citellus variegatus grammurus Say (Colorado rock squirrel), Grand Canyon, Coconino County, July 4, 1945, 3 males, 14 females.

It has been removed from ground squirrels in Santa Rita Mountains and at Tucson. In New Mexico the writer secured specimens off rock squirrels at Sherman,

Grant County. To north records stop in Utah where this flea is recorded off:

Citellus variegatus utah (Utah rock squirrel), Salina, Sevier Countv.

and in Colorado where this flea has been taken off:

Citellus variegatus grammurus (Say's rock squirrel), at Colorado Snrinos. F1 Paso County,

and off Mountain gray squirrel at Fort Collins, Larimer County.

This flea has been reported off a wolverine taken at Eagle River. British Colum.

bia. This is most northern report for this species, its authenticity is doubted.

\section{GENUS OPISOCROSTIS JORDAN}

1933. Opisocrostis Jordan. Nov. Zool., 39:73.

Genotype: Pulex hirsutus Baker 1895

Frontal tubercle is distinct, external and more or less obtuse. Bristles of segment II of antennae are long. Basal abdominal sternite has a 
number of slender bristles on upper anterior half. Hind-femur is armed on inside as well as outside with a row of sublateral bristles. In male there are 1 long and 2 minute antepygidial bristles to the side, VII t. not excised between them. VIII st. is reduced to a slender horizontal sclerite which bears 2 long bristles and an apical long filamentous appendage. Anal sternite and tergite together are conical: apical area of IX t. behind sensory plate rather large and spinulose. Process of clasper inclined distally; finger more or less elongated. In female there are 2 antepygidial bristles of which lower is distinctly shorter. Head of spermatheca is higher than long. Bursa copulatrix and its duct are long, apex curved down around bases of duct of spermatheca and blind duct is a sclerification. Anal sternite has ventral bristles from near base, outline of under surface is not angulate.

West of 100th Meridian there are 9 forms belonging to this genus, 6 of them found more or less commonly upon ground squirrels, 3 upon prairie dogs. When these species are viewed side by side, characteristics which immediately distinguish one from the other are seen in shape of finger $\mathbf{F}$ of males and apical margin of VII st. of females. A key based upon these characteristics will result in:

\section{Key to the Species of Opisocrostis}

Males, typical specimens

I. Finger scythe-blade shaped

Op. tuberculatus, p.152

II. Finger boot-shaped Op. labis, p.156

III. Finger thumb-shaped

Op. hirsutus, p.158

IV. Finger crescent-shaped with small lobe at middle of anterior face

1. Finger apically well rounded

2. Finger apically acute

Op. washingtonensis, p.161

Op. oregonensis, p. 160

V. Finger broad

1. Process apically rounded

Op. bruneri, p. 155

2. Process apically flattened

Females, typical specimens

I. Apical margin VII st. sinuate

Op. saundersi, p.156
1. Upper lobe triangular
Op. tuberculatus, p.152
2. Upper lobe rounded
Op. oregonensis, p.160
3. Sinus small, midway along border, upper and lower lobes very small
Op. washingtonensis, p.161

II. Apical margin VII st. not sinuate

1. The single lobe squarish

Off ground squirrels, 16 bristles to side

Op. bruneri, p.155

Off prairie dogs

4 bristles to side

Op. saundersi, p.156

Op. hirsutus, p.158

2. Outline slanting, undulate

Op. labis, p.156 


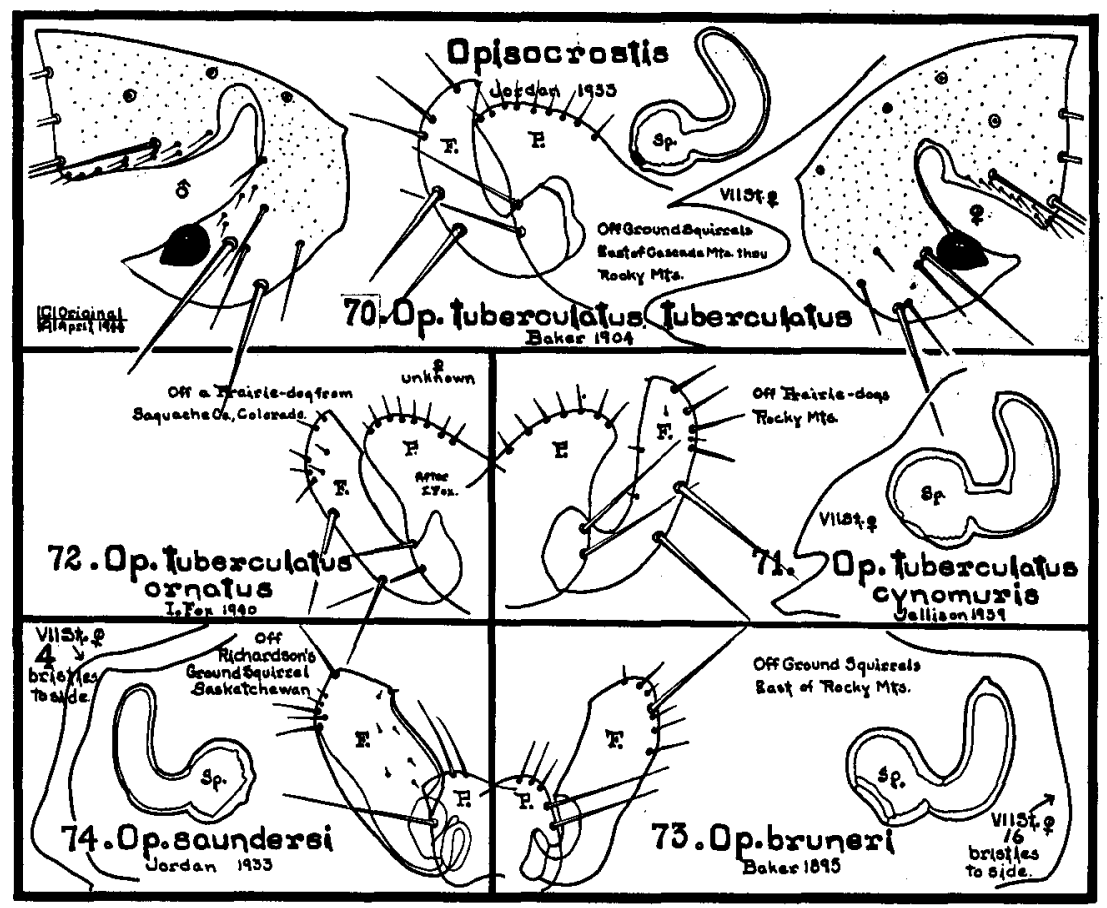

\section{Opisocrostis tuberculatus tuberculatus Baker 1904}

1904 Ceratophyllus tuberculatus Baker, Proc. U. S. Nat. Mus., 27:393.

1933 Opisocrostis tuberculatus Jordan, Nov. Zool., 39:73.

1939 Opisocrostis tuberculatus Jellison, U. S. Pub. Health Repts., 54:843.

This species was described by Baker from materials taken off Citellus columbianus (red digger) at Moscow, Idaho.

Modified Segments, MALE: Baker states that lateral portion of IX $t$. is not lobed above, but broadly rounded, finger is curved sickle fashion, acute at tip, and armed on posterior border with about 7 bristles. In female apical margin of VII st. is cut by a deep sinus, lobe above is hook-shaped, hooked portion pointing ventrally and posteriorly. Spermatheca has a globular body, with a hook-like tail. Border of tail facing body is very often flat.

Seasonal Distribution: In the Northwest this species is common during spring, numbers diminishing greatly in early summer months, upon various ground squirrels and sage rats of Great Basin region of Oregon and Washington.

LENGTH: Original listed as $2 \mathrm{~mm}$.

TyPE: Type locality: Moscow, Idaho, type host is Citellus columbianus and type specimens are deposited in United States National Museum. 
Range: Described from Idaho, this species is reported from Montana. The writer has records from practically all parts of Great Basin of Oregon east of Deschutes River. Great Basin Citelli have not succeeded in crossing Deschutes River with this flea. In Washington this flea is found as far west as Yakima ground squirrel thrives. The writer has records from White Swan, which is close to east base of the foothills of Cascade Mountains. To east in this state this species is found as far as Idaho state line.

Federal Plague Suppressive Measures Laboratory at San Francisco has specimens of this flea from Citellus beldingi oregonus from northeastern Oregon.

Medical Importance: Sixteen fleas of this species fed upon plaguepositive guinea pigs resulted in infection of 33 per cent of fleas, according to report of Eskey and Haas. Records do not show that any of 33 per cent which became infected cleared themselves of infection. Only 10 per cent of infected fleas produced plague in healthy guinea pigs.

ReCoRDs: Typical data from many records in the writer's collection are from:

OREGON-off:

Citellus washingtoni washingtoni Bachman (Townsend's sage rat), Ione, Morrow County, April 27, 1936, 3 males, 4 females

Citellus columbianus columbianus Ord (red digger), Canyon City, Grant County, July 14, 1937, 1 female

Citellus beldingi oregonus Merriam (Oregon ground squirrel), Union, Union County, April 1, 1937, 1 female.

Accidental Occurrence:

Sylvilagus nuttalli nuttalli Bachman (sagebrush cottontail), Union, Union County, Oregon, April 15, 1937, 1 male.

WASHINGTON-From:

Citellus townsendi yakimensis Merriam (Yakima ground squirrel), Wiley City, Yakima County, May 7, 1939, 1 male

Citellus columbianus columbianus Ord (red digger), Lowden, Walla Walla County, May 12, 1939, 1 male, 2 females.

CALIFORNIA-East of the Cascade Mountains in northern California the writer has removed this flea off:

Citellus beldingi oregonus (Oregon ground squirrel), Dorris, Siskiyou County, April 20, 1942, 8 pairs; Tule Lake, Modoc County, April 21, 1942, 2 males; Macdoel, Siskiyou County, April 19, 1943, 1 pair.

MONTANA-This flea is one of the common fleas of this state. It has been reported off:

Citellus armatus (Uinta ground squirrel), Gallatin, Park and Madison Counties

Citellus columbianus (Columbian ground squirrel), general

Citellus richardsoni (Richardson ground squirrel), general

Marmota flaviventris (woodchuck), general

Thomomys sp. (pocket gopher), Gallatin County

Lepus sp. (jack rabbit), Beaverhead County

Mustela sp. (weasel), Madison County. 
This flea has been reported off:

Citellus columbianus (Columbian ground squirrel), taken at Waterton Lakes, Alberta; and Kimberly, British Columbia, Canada. Species was described off this squirrel taken at Moscow, Latah County, Idaho.

Species has been reported as far east as Towner, McHenry County, North Dakota off: Citellus franklini (Franklin's ground squirrel).

\section{Opisocrostis tuberculatus cynomuris Jellison 1939}

1939 Opisocrostis tuberculatus cynomuris Jellison, U. S. Pub. Health Repts., 54:843.

In the original description of this subspecies the describer says, "The new subspecies is distinguished by the modified abdominal segments, especially in the female. MaLE: Movable process of clasper straight, rounded at apex. In $O p$. t. tuberculatus the movable process is sickle shaped, posterior margin semicircular, apex acute. FEMALE: St. VII with sinuate dorsal margin, deep posterior sinus, upper lobe subtruncate, while st. VII of $O p$. $t$. tuberculatus has a straight dorsal margin, slightly wider sinus and upper lobe very acute."

RANGE: This flea is known from Montana, Wyoming and Colorado.

Records: Types were taken from:

MONTANA-Off:

Cynomys ludovicianus (black-tailed prairie dog), Jefferson Canyon, Broadwater County.

This fiea has been taken off this prairie dog in 13 other Montana counties. It is also recorded from Custer County off:

Mustela nigripes (black-footed ferret)

Speotyto cunicularia (burrowing owl).

In flea collection of Colorado State College are specimens of this flea off prairie dogs taken at Alma, Park County; and Price Creek, Colorado. Other specimens have been taken off prairie dogs and Richardson's ground squirrel in Albany and Laramie Counties, Wyoming.

\section{Opisocrostis tuberculatus ornatus}

I. Fox 1940

1940 Opisocrostis ornatus I. Fox, Proc. Ent. Soc. Wash., 42:67.

1943 Oropsylla (Opisocrostis) tuberculata ornata Ewing, Misc. Pub. 500 USDA, p. 52.

This subspecies is known only from the male which was described from a single specimen in the United States National Museum collection under No. 53588. The specimen was taken in Sagauche County, Colorado, where Sam McCampbell collected it off Cynomys gunnisoni (prairie dog) June 26, 1926.

Describer's statements about the modified segments are, "Process of clasper broad and lobular, armed with about 9 weak bristles on the dorsal margin. Movable finger acuminate at its apex, armed with a number of bristles on its posterior margin. Penis broad and heavy appearing, truncate distally. Springs long, but not completing a single turn."

After closely examining prairie dog fleas in collection of Sam Mc- 
Campbell at Colorado State College, the writer doubts if Opisocrostis tuberculatus ornatus can be separated from Opisocrostis tuberculatus cynomuris.

RANGE: This subspecies is known only from original specimen collected in Saguache County, Colorado.

\section{Opisocrostis bruneri \\ Baker 1895}

1895 Pulex bruneri Baker, Can. Ent., 27:131.

1933 Opisocrostis bruneri Jordan, Nov. Zool., 39:73.

1943 Opisocrostis bruneri Prince, Pub. Health Repts., 58:1013.

This species was described by Baker off 13-lined ground squirrel taken at Lincoln, Nebraska, and Fort Collins, Colorado, and off Franklin ground squirrel taken at Lincoln, Nebraska.

Modified Segments, Male: Process $P$ of clasper insignificant in size when compared with finger $F$. It is dome-shaped and armed apically with 3 small bristles. Finger $\mathbf{F}$ apically rounded, anterior and posterior margins about parallel with armature consisting of 1 stout long bristle a little below apex on posterior margin and, on upper third of posterior margin, 5 or so weak bristles. VIII st. narrow with a long filament and 1 long bristle apically. The proximal ventral lobe of st. IX is armed with a spiniform and about 6 slender weak bristles along a flattened margin. Female: Apical outline of VII st. with a single somewhat angular lobe, armature consisting of 16 bristles to the side. Spermatheca with a slightly flattened globular body and long crooked tail.

LENGTH: A good sized flea measuring about $3.00 \mathrm{~mm}$. in male, and $3.75 \mathrm{~mm}$. in female.

Range: Great Plains area west into the Rocky Mountains and north into Manatoba, Canada.

Preferred Host: This is a ground squirrel flea which has been reported off Franklin ground squirrel, 13-lined ground squirrel and Richardson ground squirrel.

Medical Importance: Prince, working with this species, states that 42 specimens were received from Potter County, South Dakota, where they were taken off Richardson ground squirrels or out of their nests. When these 42 specimens were fed upon plague-positive guinea pigs it was found that 8 of them became plague infected. It was noted that 3 weeks elapsed before any of infected fleas were able to transmit disease to healthy guinea pigs. At end of experiment it was found that 4 of 8 infected $O p$. bruneri had transmitted plague to healthy guinea pigs. In other words, 50 per cent of these fleas were successful as vectors. How many of the fleas succeeded in freeing themselves of the infection was not learned. This high degree of efficiency as a vector of plague in this flea of Great Plains area is alarming because, as Prince states, "Thus, a continuous chain of fleas capable of the transmission of plague, and of 
hosts which have been found infected or of others which are very probably susceptible to infection, extends from the Rocky Mountain States and western North Dakota, in which plague prevails, to the states east of the Mississippi River."

RECoRDs: There are large numbers of records for this flea off ground squirrels in Illinois and Iowa. The flea has also been reported from Minnesota, Wisconsin, Nebraska, Colorado, Montana, South Dakota, and Manitoba, Canada.

\section{Opisocrostis saundersi \\ Jordan 1933}

1933 Ceratophyllus saundersi Jordan, The Entomologist, 66:16.

1933 Opisocrostis saundersi Jordan, Nov. Zool., 39:73.

This flea was described from a pair taken off Citellus richardsoni (Richardson ground squirrel) in Saskatchewan, Canada. The describer states that it is near Op. bruneri Baker 1895, but with fewer bristles and male genitalia markedly different, though of same type of build.

Modified Segments, Male: On t. VIII from below stigma 13 or 14 large bristles and a few small ones on each side. St. VIII narrow, but broader than in $O p$. bruneri, on each side with a long apical filament and 1 long bristle. Manubrium of clasper elongate-triangular, almost gradually narrowed from base, not curved upwards. Process $P$ of clasper apically narrower than in $O p$. bruneri, more strongly concave on inner side, the not-thinned posterior apical portion forming a longer and narrower nose. Finger $F$ shorter and much broader, less than 21/2 times (in $O p$. bruneri more than 3 times) as long as broad. Upper portion of vertical arm of IX st. not much broader than middle portion, not curved anad, gently rounded on the posterior side; proximal portion of ventral arm long, with a row of bristles, last but one of which is almost spiniform; apical lobe strongly rounded. Hooks of parameres shorter and broader than in Op. bruneri. Female: Shape of VII st. as in $O p$. bruneri, but there are fewer bristles, 8 on the two sides together. Spermatheca with tail much longer than head, head a little broader than long, nearly globular.

RANGE: Known only from Saskatchewan, Canada.

\section{Opisocrostis labis}

Jordan and Rothschild 1922

1922 Ceratophyllus labis Jordan and Rothschild, Ectoparasites, I:275.

1929 Ceratophyllus labis Jordan, Nov. Zool., 35:32.

1930 Oropsylla labis Stewart, Can. Ent., 62:152.

1933 Opisocrostis labis Jordan, Nov. Zool., 29:73.

1939 Opisocrostis labis Jellison, Pub. Health Rpts., 54:841.

This species was described from materials collected by G. F. Dippie at Calgary, Alberta, Canada, off Mustela f. longicauda (weasel) . There is little doubt that this species has for its favored host ground 


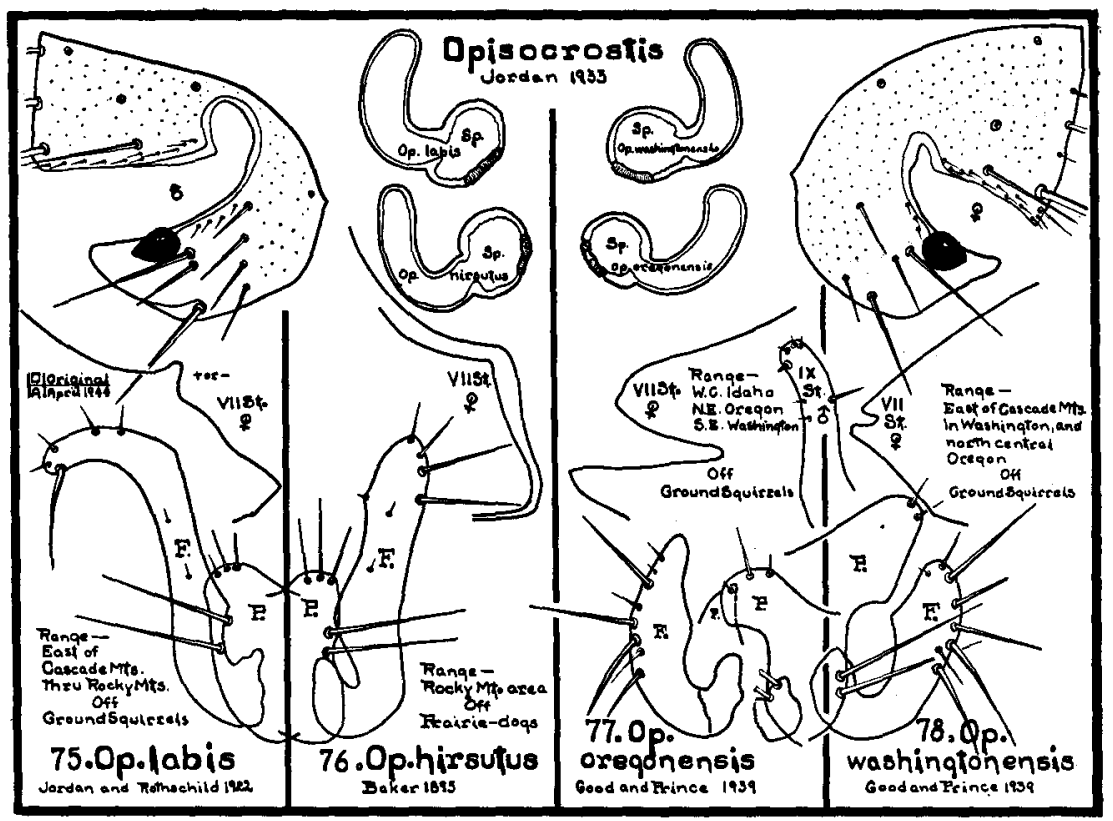

squirrels, prairie dogs, occasionally mice, its presence on weasels and other carnivores being accidental.

Modified Segments, Male: The describers state, in part, that process $P$ is short, broad, rounded with a dorsal row of 4 bristles; exopodite ( finger F) long, with apex curved distad, sclerite resembling a man's leg from knee downward, "the foot" (boot-shaped) bearing several bristles, of which one above and one below the distal angle are longest. This boot-shaped or foot-shaped finger marks male of this species from all other fleas.

It seems that female first described as $O p$. labis belonged to a different species as was pointed out by Jordan in 1929 when he described and figured the true female. Jellison states in his study of female of this species that typical specimens may be distinguished by shape of st. VII, but a number of specimens before him at time could scarcely be distinguished from $O p$. hirsutus Baker. In general, outline of VII st. can be said to be slightly undulate with a small tip-like prominence ventrally.

Range: Described from Alberta, Canada, this species seems to range southward, through the Rocky Mountains and westward. The author has records as far west as the foothills of Cascades in Washington, and to Deschutes River in Oregon.

Medical Importance: $O p$. labis was well represented in experiments carried on at Plague Suppressive Measures Laboratory. Two 
hundred ninety-one specimens were involved. After being fed upon plague-positive guinea pigs, 24 per cent were found to be infected. Of these, 12 per cent succeeded in clearing themselves of the infection. Only 10 per cent of infected fleas were found able to transmit the disease to healthy guinea pigs. This is an efficiency only one-half as high as that of the oriental rat flea, $X$. cheopis.

RECORDs: Typical records in the collection of the writer are:

WASHINGTON-From:

Citellus townsendi yakimensis Merriam (Yakima ground squirrel), White Swan, Yakima County, May 4, 1939. 1 male, 3 females.

OREGON-From:

Onychomys leucogaster fuscogriseus Anthony (grasshopper mouse), Narrows, Harney County, December 11, 1936, 2 males, 1 female.

NEVADA-Off:

Citellus townsendi mollis Kennicott (Piute sage squirrel), Ely, White Pine County, July 13, 1945, 1 male.

MONTANA-In this state this flea seems to be far more common than to the west in the Great Basin area. Records from this state are plentiful. The flea has been reported off:

Citellus armatus (Uinta ground squirrel), Gallatin, Madison, and Park Counties

Citellus columbianus (Columbian ground squirrel), Beaverhead, Jefferson and Silver Bow Counties

Citellus richardsoni (Richardson ground squirrel), general

Cynomys ludovicianus (prairie dog), Fergus County

Eutamias sp. (chipmunk), Beaverhead County

Marmota flativentris (woodchuck), Gallatin, Park, and Wheatland Counties

Canis latrans (coyote), Meagher County

Mustela sp. (weasel), Madison County.

It is generally felt that the area of densest population for this species is the central Rocky Mountain area, including Montana, Wyoming, Colorado and perhaps Utah and Idaho.

COLORADO-While studying the flea collection of Colorado State College, the writer worked specimens of this species off:

Citellus richardsoni elegans (Wyoming ground squirrel), general northwestern Colorado

Cynomys leucurus (white-tailed prairie dog), Park County.

WYOMING-This flea has been reported off prairie dogs taken in Albany and Laramie Counties.

The original description was based upon specimens off weasel from Calgary, Alberta, Canada.

\section{Opisocrostis hirsutus}

Baker 1895

1895 Pulex hirsutus Baker, Can. Ent., 27:130.

1933 Opisocrostis hirsutus Jordan, Nov. Zool., 39:73.

1939 Opisocrostis hirsutus Jellison, Pub. Health Repts., 54:840.

The female of this species was described by Baker from materials off prairie dogs taken at Stove Prairie, Larimer County, Colorado. It 
was not until 1939 that Jellison described male from specimens taken off prairie dogs collected in Jefferson Canyon, Broadwater County, Montana, collections having been made in 1934. Modified segments of this species are characteristic, particularly in the finger $F$.

Modified Segments, Male: Process $P$ of clasper insignificant in size when compared with that of finger. It is somewhat dome-shaped but flattened posteriorly. Three medium bristles arm apex. Finger $F$ is long and slender and toward middle, the two concave surfaces narrow the diameter down at this point. Armature made up of 4 bristles on posterior margin close to apex, two lower ones longest and stout. VIII st. long and slender with median pair of ventral bristles, 3 pairs of subterminal bristles, and a pair of long terminal filaments which are branches at the end. Bristle arrangement variable. FeMALE: VII st. with one lobe which is angulate with posterior margin slightly concave. Upper angle of lobe is rounded to angulate, lower angle well rounded. Spermatheca with globular body and tail which is long and crooked at almost right angle.

LENGTH: A good sized species which averages about $3.00 \mathrm{~mm}$. in males and $3.75 \mathrm{~mm}$. in females.

RANGE: This species ranges wherever there are prairie dogs north of Mexico and probably in northern Mexico also.

Host Preference: This species is a true prairie dog flea.

Medical ImportancE: Although natural host of this flea, prairie dog, has been found plague-positive in many spots throughout its range, flea itself seems not to be a very efficient vector of plague. Eskey and Haas found that 28 per cent of 124 specimens became infected after feeding upon plague-positive guinea pigs. There is no record of any of these having cleared themselves of the infection. Only 4 per cent of infected fleas were able to transmit the disease to healthy guinea pigs.

RECORDS: Beginning in northern portion of range of this flea and working south, records are:

MONTANA-From:

Cynomys ludovicianus (black-tailed prairie dog), general throughout state where there are prairie dogs

Marmota flaviventris (woodchuck), Fergus County

"Rabbit," Petroleum County

Mustela nigripes (black-footed ferret), Powder River County

Canis latrans (coyote), Big Horn County.

WYOMING-From:

Cynomys leucurus (white-tailed prairie dog), Lincoln County.

NEBRASKA-From:

Cynomys ludovicianus (black-tailed prairie dog), Dawes County.

COLORADO-From:

Cynomys ludovicianus (black-tailed prairie dog), Stove Prairie, Larimer County; Resolis and Natural Corral, El Paso County 
Cynomys sp. (prairie dog), Conejos County

Citellus sp. (picket pin ground squirrel), Waldon.

UTAH-From:

Cynomys parvidens (Utah prairie dog), Iron, Millard, Garfiield and Wayne Counties.

NEW MEXICO-From:

Cynomys gunnisoni zuniensis (Zuni prairie dog), Catron, Rio Arriba, and McKinley Counties.

ARIZONA-From:

Cynomys gunnisoni zuniensis (Zuni prairie dog), Apache County.

\section{Opisocrostis oregonensis}

Good and Prince 1939

1939 Opisocrostis oregonensis Good and Prince, Pub. Health Rpts., 54:1687.

Collection data to date led the author to believe this species is primarily found upon ground squirrels. The type host is listed as Citellus beldingi oregonus Merriam, the Oregon ground squirrel.

Modified Segments: Describers state that in males process $P$ of clasper has upper and posterior margins evenly and continuously rounded, lower posterior angle is nearly a right angle and lower margin comparatively long and nearly horizontal; finger $\mathrm{F}$, or movable process, of clasper is most similar to $O p$. tuberculatus but longer, more nearly vertical with inner (anterior) face long, straight and with a definite upper-anterior angle. St. VIII without subapical bristles. In female the spermatheca is nearly globular, tail long, thickest at tip, which is nearly truncate. St. VII has a deep V-shaped notch. Upper lobe is shorter but broader of the two.

LENGTH: While there is considerable variation in length of this species, describers give the average lengths as male $2.05 \mathrm{~mm}$., female 2.2 $\mathrm{mm}$.

TYPE: Holotype and allotype collected 8 miles south of Baker, Baker County, Oregon, on April 24, 1938, and are deposited in collection of United States Public Health Service Plague Laboratory at San Francisco.

RANGE: Plague Survey field trucks have taken this species east of the Deschutes River in Oregon, and in Idaho, off Citellus beldingi oregonus, Citellus columbianus, Citellus washingtoni washingtoni, and Citellus idahoensis.

RECORDS of the writer are from evenly scattered sources over Oregon east of Deschutes River, and northwestern Nevada.

OREGON-Typical of these are from:

Citellus townsendi canus Merriam (gray sage squirrel), Terrebonne, Deschutes County, July 10, 1937, 3 males 4 females

Citellus columbianus columbianus Ord (red digger), Wallowa Lake, Wallowa County, July 14, 1939, 6 pairs. 
Citellus beldingi oregonus Merriam (Oregon ground squirrel), Baker, Baker County, July 12, 1939, 3 males, 1 female; Silvies, Grant County, July 15, 1937, 1 male

Citellus washingtoni washingtoni Bachman (Townsend ground squirrel), Ione, Morrow County, May 12, 1939, I pair.

NEVADA-Off:

Citellus beldingi oregonus Merriam (Oregon ground squirrel) Vya, Washoe, County, June 11, 1945, 2 pair.

IDAHO-Plague Survey trucks have taken this species off:

Citellus columbianus columbianus Ord (red digger), Custer County, August 1936, 1 female

Citellus idahoensis Merriam (Idaho ground squirrel), Elmore County, June 1936, 1 male

Citellus townsendi Bachman (sic), Ada County, June 1936, 1 female.

\section{Opisocrostis washingtonensis}

Good and Prince 1939

1939 Opisocrostis washingtonensis Good and Prince, Pub. Health Repts., 54:1691.

Like preceding species, preferred host of this species seems to be ground squirrels. Type host is listed as Citellus washingtoni Howell (= C. townsendii auct.), at Lind, Washington, which is the type locality.

According to describers of this species, it is closely related to preceding species, differing from it apparently only in modified segments. Of these, they state, among other points, that in male process $\mathbf{P}$ of clasper is short, posterior margin straight, vertical, lower-posterior angle very obtuse and lower margin very short, almost obliterated; finger $F$ intermediate between those of $O p$. oregonensis and $O p$. tuberculatus, inner (anterior) face rather short, sloping, sinuous, and slightly concave; VIII st. with 2 long subapical bristles. In female spermatheca has a head similar to that of $O p$. oregonensis but tail is thickest near, but not at, tip, which is gently rounded; sinus in VII st. is very small and inconspicuous.

LENGTH: Average for male given as $1.89 \mathrm{~mm}$., female $2.50 \mathrm{~mm}$.

Holotype female and allotype male are deposited in collection of United States Public Health Service Plague Laboratory at San Francisco.

RANGE: Above-mentioned laboratory has specimens from Adams and Lincoln Counties, Washington, and Umatilla, Gilliam, and Morrow Counties, Oregon, off Townsend and Oregon ground squirrels. The writer's records are from points between Lowden and White Swan, -Washington. Range for this species would seem to be, then, everywhere in Great Basin region of Washington where there are ground squirrels and in northeastern Oregon where the Townsend ground squirrel is found. The species is not recorded from Idaho or Montana. 
RECORDS: Typical records from the collection of the writer are: WASHINGTON-From:

Citellus columbianus columbianus Ord (red digger), Lowden, Walla Walla County, May 13, 1939, 2 males, 3 females

Citellus townsendi townsendi Bachman (Yakima ground squirrel), White Swan, Yakima County, May 3, 1939, 5 males, 5 females.

\section{GENUS OROPSYLLA W. AND J.}

1926. Oropsylla Wagner and Joff, Rev. Microbiol. and Epidemiol., 5:86. Genotype: Ceratophyllus silantiewi Wagner 1898

Frontal tubercle sharp, more or less sunk into frons, rostrum reaches beyond the trochanter. Basal abdominal sternite is without patch of bristles on side, at most with 1 or 2 in or below the middle (besides the

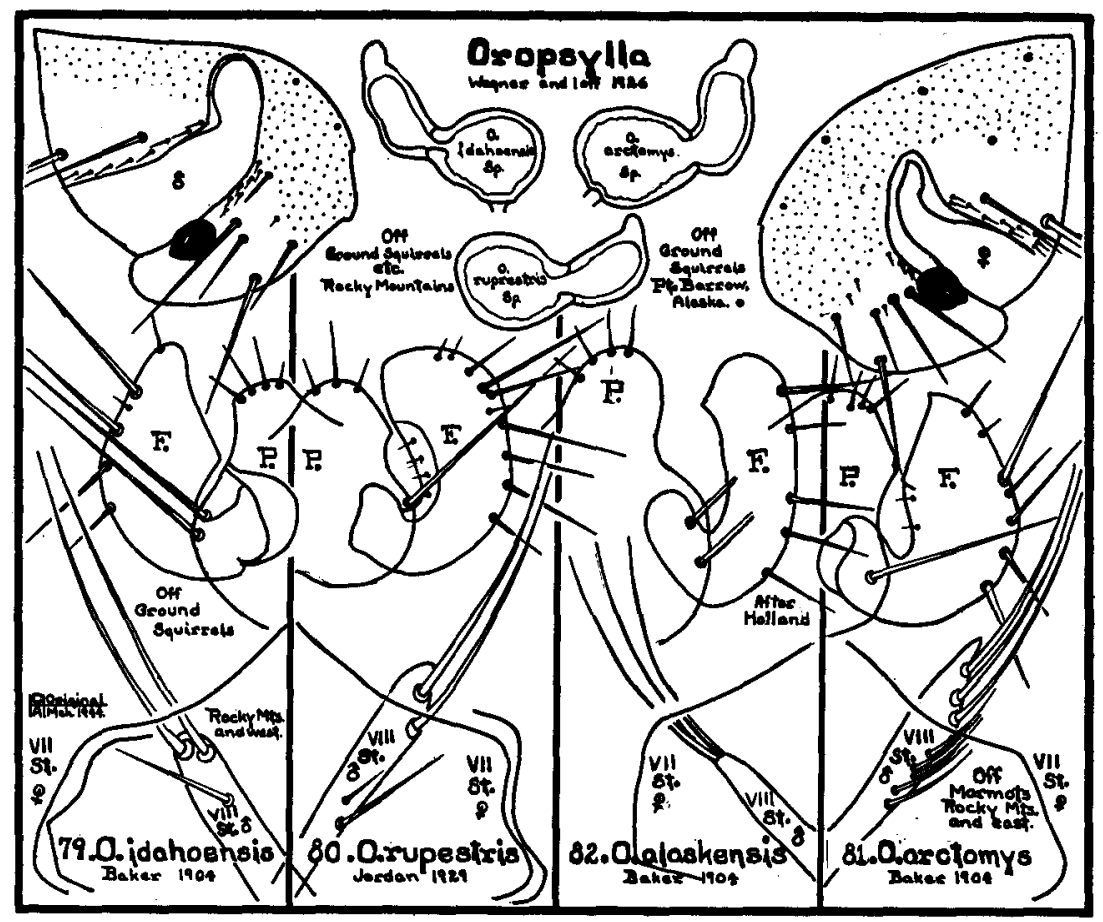

usual ventral bristles). In male bristles of segment II of antennae short (not reaching to middle of club); tergite not excised medianly between sets of antepygidial bristles; VIII st. narrow, rod-like, without mem-, branous apical appendage, apex sharply defined with long bristles. Process of clasper broad, finger claviform, armed with long bristles but without spiniforms, apical membrane area of IX t. not spinulose. In female there are 3 or more antepygidial bristles, stylet with 2 or more 
lateral bristles, head of spermatheca longer than broad, ovate or pyriform, tail short, not much longer than head, always with long appendage.

This genus is represented in West by four species, three of which favor ground squirrels, the fourth marmots, but all can occasionally be taken off other mammals as strays.

As one views fingers of males of four species, each is seen to be characteristic in shape of its apical portion. VII st. in females is characteristic only in typical specimens.

Key to the Species of Oropsylla west of 100th Meridian Males

1. Finger apically triangular
a. Tip pointed (on marmots)
O. arctomys, p. 168
b. Tip rounded (on ground squirrels)
O. idahoensis, p.163

2. Finger apically blunt

a. Apex only slightly concave

O. rupestris, p.166

b. Broad and obtuse at tip

O. alaskensis, p.169

Females

1. VII st. with shallow sinus between two feeble lobes

O. rupestris, p.166

2. VII st. with upper angle rounded

O. idahoensis, p.163

3. VII st. with upper angle angulate

O. arctomys, p. 168

\section{Oropsylla idahoensis \\ Baker 1904}

1904 Ceratophyllus idahoensis Baker, Proc. U. S. Nat. Mus., 27:413.

1905 Ceratophyllus poeantis Rothschild, Nov. Zool., 12:155.

1906 Ceratophyllus poeantis Baker, Proc. U. S. Nat. Mus., 29:134.

1906 Ceratophyllus idahoensis Baker, Proc. U. S. Nat. Mus., 29:134.

1927 Ceratophyllus bertholfi C. Fox, Amer. Ent. Soc. Phil. Trans., 53:200.

1929 Ceratophyllus idahoensis Jordan, Nov. Zool., 35:32.

1933 Oropsylla idahoensis Jordan, Nov. Zool., 39:74.

1936 Oropsylla idahoensis Wagner, Can. Ent., 68:198.

This species was described from material off Citellus columbianus collected by Professor Aldrich at Moscow, Idaho. It seems that certain statements made by Baker in original description caused N. C. Rothschild to create a synonym in Ceratophyllus poeantis. These statements as pointed out by Jordan in 1929 are: frontal tubercle is said to be absent in C. idahoensis, which Jordan states is erroneous, and it is also stated that of the abdomen, first 2 tergites bear small patches of apical teeth, while in reality tergites I to IV sometimes even I to V bear such teeth. It seems also that C. Fox created a synonym for this species in Ceratophyllus bertholfi (Jordan 1929).

This is a conspicuous and common species of Rocky Mountains, throughout Great Basin and Cascade Sierra Mountains of Oregon, Washington and California, wherever the golden-mantled ground squirrel carries it. From this, its favored host, the species makes its way onto 
various other ground squirrels and sage rats that are found within its range. The species cannot be mistaken, its spermatheca is quite distinct, as are finger and process of clasper of male.

Modified SEgments: Little is said by describer about these modified segments, although he does state that upper claspers resemble those of $O$. tuberculatus. Finger $\mathbf{F}$ of male is distinct, having a broadly rounded posterior border armed with 2 stout bristles and several smaller ones; an almost straight anterior border, apex of finger being nicely rounded. The male has 1 antepygidial bristle to side. In female margin of VII st. is almost a flat surface, only slightly concave. Spermatheca is characteristic, in having a body almost round, yet slightly oval, a tail short and bent slightly towards body at apex, and at apex a long appendage bent in general contour of tail. Female possesses 3 antepygidial bristles on each side.

Plague Suppressive Measures Laboratory of San Francisco reports this species from the Oregon ground squirrel and red digger in Oregon and Rocky Mountain Laboratory from a chipmunk, a golden-mantled ground squirrel, and from Citellus spp. in Harney County, Oregon.

RaNGE: In Washington, Oregon and California this species is found as far west and south in Cascade Sierra Mountains as golden-mantled ground squirrels range, and on beyond the Cascades in Oregon and California as far west as the Siskiyou Mountains lie. To east species is described from Idaho, reported from Montana, and the writer has seen specimens from Nevada, Colorado and New Mexico. The species probably occurs throughout Rocky Mountain belt and north into Alaska.

Type Locality: Moscow, Idaho.

Type Material: In the United States National Museum under No. 6918.

LeNGTH: Original length is given as $2.5 \mathrm{~mm}$.

Medical ImportancE: Although this flea is generally considered to be a vector of plague, evidence against it is incomplete. Eskey and Haas experimenting with 41 specimens found that when fed upon plaguepositive guinea pigs 13 per cent became infected. There is no record that any of these cleared themselves of infection nor is there any record that any of infected fleas succeeded in transmitting plague to healthy guinea pigs.

RECORDs: Typical records from the collection of the writer are:

OREGON-From:

Citellus chrysodeirus chrysodeirus Merriam (golden-mantled ground squirrel), Cooper Spur Road, Hood River County, September 28, 1935, 3 males, 3 females

Citellus chrysoideirus trinitatis Merriam (tawny-mantled ground squirrel), Oregon Caves, Josephine County, June 19, 1939, 2 males, 5 females

Citellus chrysodeirus connectens Howell (copper-headed ground squirrel), southeast of Wallowa Lake, Wallowa County, July 13, 1939, 1 male, I female 
Citellus beldingi oregonus Merriam (Oregon ground squirrel), Davis Lake, Deschutes County, July 29, 1996, 5 males, 8 females

Citellus columbianus columbianus Ord (red digger), Canyon City, Grant County, July 14, 1937, 1 male, I female,

Accidental Occurrences:

Sylvilagus nuttalli nuttalli Bachman (sagebrush cottontail), Union, Union County, April 15, 1937, 1 female

Ochotona princeps brunnescens Howell (Cascade cony), Frog Lake, Wapinitia Cut-off, Wasco County, October 3, 1931, 1 male

Thomomys monticola mazama Merriam (Mazama pocket gopher), Little Lava Lake, Deschutes County, July 27, 1936, 1 male

Microtus mordax augusticeps Bailey (Coast meadow mouse), Takilma, Josephine County, June 18, 1939, 1 male.

\section{WASHINGTON-From:}

Citellus lateralis saturatus Rhoads (Cascade golden-mantled ground squirrel), Summit Satus Pass, Yakima County, June 14, 1938, 1 male, 2 females; Guler, Klickitat County, July 17, 1943, 1 pair; Goose Lake, Skamania County, August 24, 1935, 1 pair.

\section{CALIFORNIA-From:}

Citellus chrysodeirus trinitatis Merriam (tawny-mantled ground squirrel), Happy Camp, Siskiyou County, June 15, 1939, 1 male, 2 females

Citellus beldingi oregonus Merriam (Oregon ground squirrel), Tule Lake, Modoc County, June 27, 1939, 1 male; Dorris, Siskiyou County, April 20, 1942, 20 males, 30 females,

In central Sierra-Nevada Mountains of California Augustson reports this flea in Mono County off:

Citellus beldingi beldingi Merriam (Belding ground squirrel), Mammoth Lakes

Citellus lateralis chrysodeirus Merriam (mantled ground squirrel), Mammoth Mountain and Mammoth Lakes

Eutamias quadrivittatus inyoensis Merriam (Inyo chipmunk), Duck Pass

Tamiasciurus douglasi albolimbatus Allen (Sierra chickaree), Mammoth Lakes,

From Cascade Valley, Fresno County, off:

Citellus lateralis chrysodeirus (mantled ground squirrel),

In southern California Augustson reports this flea off:

Citellus chrysodeirus bernardinus (mantled ground squirrel), Big Bear Lake, San Bernardino County.

NEVADA-The author has also collected this flea off:

Citellus beldingi oregonus Merriam (Oregon ground squirrel), Vya, Washoe County, June 8, 1945, 30 males, 50 females; Franklin's Ranch, Humboldt County, 15 miles southeast of Denio, Oregon, July 5, 1939, 2 males, 3 females.

ARIZONA-Off:

Callospermophilus lateralis lateralis Say (Says mantled ground squirrel), North Rim, Grand Canyon, Coconino County, July 6, 1945, 3 males, 1 female.

This species was listed by Rothschild as C. poeantis off:

Sciurus aberti aberti Woodhouse (Abert squirrel), San Francisco Mountains, Flagstaff, Coconino County.

IDAHO-This species was described from materials taken off:

Citellus columbianus columbianus Ord (Columbian ground squirre1), Moscow, Latah County. 
NEW MEXICO-The writer has seen specimens of this species taken as far south in the Rocky Mountains as Colfax County, from:

Tamiasciurus fremonti spp. (Fremont's chickaree),

COLORADO-In the flea collection of Colorado State College the writer found this species off:

Citellus richardsoni elegans (Wyoming ground squirrel), from Kremmling; ground squirrel nest, from Fairplay; "prairie-dog," from Price Creek.

UTAH-This species is reported from Salina Canyon, Sevier County, off:

Citellus armatus Kennicott (Uinta ground squirrel)

Cynomys parvidens Allen (Utah prairie dog).

MONTANA-In this state records reveal that this species of flea is widespread, a common flea which has been reported off the following hosts:

Citellus armatus Kennicott (Uinta ground squirrel), Beaverhead, Gallatin, Madison, and Park Counties

Citellus columbianus columbianus Ord (Columbian ground squirrel), general throughout its range

Citellus richardsoni sp. (Richardson's ground squirrel), general throughout its range

Citellus lateralis tescorum Hollister (mantled ground squirrel), Beaverhead, Granite, Missoula, Ravalli, and Silver Bow Counties

Eutamias spp. (chipmunk), Gallatin and Silver Bow Counties

Marmota flaviventris spp. (woodchuck), general in state

Phenacomys intermedius intermedius Merriam (Rocky Mountain Phenacomys), Gallatin County

Thomomys spp. (pocket gopher), Gallatin County

Mustela spp. (weasel), Madison County

Canis latrans Say (coyote), Meagher County

Buteo sp. (hawk), Beaverhead County

Pica pica hudsonia (magpie), Beaverhead County

Bubo virginianus (great horned owl), Beaverhead County

Asio wilsonianus (long-eared owl), Beaverhead County.

BRITISH COLUMBIA, ALBERTA-Under the designation of $C$. poeantis Rothschild listed this species from interior of British Columbia, off:

Citellus columbianus columbianus Ord (Columbian ground squirrel),

Callospermophilus lateralis tescorum Hollister (Hollisters mantled ground squirrel), Yahk, July 26, 1945, 2 females, collected by author.

From Blackfalds, Alberta, off:

Citellus lateralis spp. (mantled ground squirrel).

ALASKA-This species has been reported from Nagai Island, off:

Citellus parryi nebulicola Osgood (Shumagin ground squirrel) .

\section{Oropsylla rupestris \\ Jordan 1929}

1929 Ceratophyllus rupestris Jordan, Nov. Zool., 35:32.

1929 Oropsylla rupestris Wagner, Konowia, 8:314.

1937 Oropsylla rupestris Jordan, Nov. Zool., 40:284.

The female of this Rocky Mountain species was first described by Jordan and Rothschild in 1922 as Ceratophyllus labis in Ectoparasites I:275 off Mustela longicaudatus (weasel) taken at Calgary, Alberta, Can- 
ada. The describers also had specimens off Columbian ground squirrel from Calgary and off pocket gopher and "Canis" from Blackfalds and off pocket gopher at Dorthy, Alberta.

Modified SEgMENTS are characteristic: MALE, process $\mathbf{P}$ of clasper is dome-shaped and armed apically with 3 short bristles. Posterior face appears undercut. Finger $\mathrm{F}$ of clasper is broad, posterior margin with middle half flat, upper quarter nicely rounded to anterior margin, lower quarter nicely rounded to junction with process. Posterior margin armed with 7 long bristles, all different lengths, second from top longest, and a few short bristles. Anterior margin with upper half almost flat, lower half recurved and armed with a few setae. Female: Apical outline of st. VII has but a single angulate lobe which has its posterior margin concave. Spermatheca is similar to that of $O$. idahoensis but tail is less crooked, appendage less pronounced.

LENGTH: This is a medium-sized species which may vary in both sexes from $2.50 \mathrm{~mm}$. to $3.00 \mathrm{~mm}$.

RANGE: This is a Rocky Mountain species which has been reported from Colorado north into Alberta, Canada.

MedicAl IMPORTANCE: Eskey and Haas, experimenting upon 4 specimens of this species, state that after being fed upon plague-positive guinea pigs, 3 became infected. This was 75 per cent. Two of 3 specimens which became infected were able to transmit disease to healthy guinea pigs. This gave highest reached percentage of any fleas tested, 67 per cent. The writer is inclined to believe numbers of fleas in experiment was too small for conclusive results.

RECORDs of this species are:

COLORADO-Off:

Marmota flaviventris (woodchuck).

MONTANA-By far the greater number of available records come from this state where this flea seems to be common and widely spread and is reported off the following hosts:

Citellus armatus Kennicott (Uinta ground squirrel), Gallatin, Madison, and Park Counties

Citellus columbianus columbianus Ord (Columbian ground squirrel), Beaverhead, Jefferson, Lewis and Clark, Missoula, and Silver Bow Counties

Citellus richardsoni spp. (Richardson's ground squirrel), general in the state Cynomys ludovicianus spp. (blacktailed prairie dog), Jefferson County

Marmota flaviventris spp. (woodchuck), Gallatin, Madison, Park, and Wheatland Counties

Mustela spp. (weasel), Gallatin County.

ALBERTA-The original records accompanying the description of the species are off: Mustela longicaudatus (weasel), Calgary

Citellus richardsoni (Richardson's ground squirrel), Calgary

Thomomys spp. (pocket gopher), Blackfalds, Dorthy

Canis spp., Blackfalds. 


\section{Oropsylla arctomys \\ Baker 1904}

1904 Ceratophyllus arctomys Baker, Proc. U. S. Nat. Mus., 27:411.

1933 Oropsylla arctomys Jordan, Nov. Zool., 39:62.

1936 Oropsylla arctomys Spencer, Proc. B. C. Ent. Soc., 1935: 13.

1938 Oropsylla arctomys Phillips, Jour. Parasit., 24:486.

This widely spread American flea is found almost from coast to coast on woodchucks. Baker described it from materials taken at Peterboro, New York. Being one of the characteristic American species it is described here in full.

HEad: Well-rounded in female, flattened on top in male. Frontal notch distinct. Gena with 2 oblique rows of 3 bristles. A few setae above eye. Eye prominent, grape-seed-shaped. Postantennal region with a long, stout bristle toward antennal groove, a stout bristle at ventral angle of posterior margin, 2 or 3 bristles above, setae along antennal groove.

Thorax: Pronotum armed with a comb of about 18 teeth and a row of bristles, long alternating with short. Meso- and metanotum armed with 2 rows of bristles and several others. Metanotum armed also with apical spinelets.

AвромEN: Two rows of bristles on each abdominal tergite, anterior ones also bearing apical spinelets.

Modified Segments, Male: Process $P$ of clasper broad and apically dome-shaped. Armed with 4 bristles. Posterior margin undercut. One acetabular bristle. Finger $\mathbf{F}$ of clasper with posterior border nicely rounded from apex to junction with process, and armed with 4 long bristles, the upper the longest and a few shorter bristles. Anterior margin also concave. FemaLe: VII st. with but a single lobe which has its apical margin flat, its angles angulate. Spermatheca with body longer than wide and longer than tail. Tail crooked and with a prominent appendage.

LENGTH: Original lengths were given as male $2.75 \mathrm{~mm}$., female $3.75-4.00 \mathrm{~mm}$.

Range: From Alaska south into British Columbia, Canada, east and southeast through Montana and on to Atlantic Coast.

RECORDs of this species are:

BRITISH COLUMBIA-From:

Marmota monax petrensis (black marmot), general; and Vavenby.

ALASKA-From:

Marmota monax ochracea Swarth (ochraceous marmot), Fairbanks.

MONTANA-From:

Marmota flaviventris spp. (woodchuck), Beaverhead, Ravalli Counties Mephitis hudsonica (skunk), Ravalli County

Canis latrans (coyote), Glacier National Park and Toole Counties. 


\section{Oropsylla alaskensis \\ Baker 1904}

1904 Ceratophyllus alaskensis Baker, Proc. U. S. Nat. Mus., 27:387.

1929 Oropsylla alaskensis Wagner, Konowia, 8:313.

This species was described by Baker from materials taken off ground squirrels at Point Barrow, Alaska. This is the farthest north record for American fleas. It is one of rare fleas in American collections. Of it, Baker says:

HEAD: Broadly and evenly rounded in female but flattened on top in male. Gena with 3 usual heavy bristles below and only 1 at margin in upper row. Eye is small and low down. Postantennal region with 1 heavy bristle and usual marginal ones. Labial palpi extending to more than half of anterior femora.

Thoracic nota with one row of 10 to 12 large bristles and one row of smaller bristles. Female pronotal comb consists of 24 teeth, male 22.

Abdominal tergites with 3 distinct rows of bristles, principal row of 16 to 18 bristles, minute hairs between these last very inconspicuous.

Modified SEgMenTs, MaLE: VIII t. with a number of heavy bristles on upper posterior portion, in 3 rows of 4 each and with hind margin incurved. Lateral portion of IX t. with a broad rounded upper lobe, with 2 widely separated long bristles over the attachment of claspers. Upper claspers more than twice as long as wide, somewhat sickleshaped, but broad and obtuse at tip, the hind margin with a few weak bristles. Female: Antepygidial bristles, 3 on each side, two larger unequal and one smaller near the median line. VIII $t$. bears numerous rather distant short bristles. Just beneath the pygidium on either side occur 5 strong bristles. The stylet is very thick and swollen with 2 long stout bristles on the apex, and 4 or 5 just below the apex. Substylar flap has several long bristles at tip and a number of short stout ones on lower margin.

LENGTH: The original lengths were given as male $3.25 \mathrm{~mm}$., female $4.00 \mathrm{~mm}$.

RANGe: Known only from type locality at Point Barrow, Alaska, but probably throughout the range of the favored host Citellus parryi barrowensis Merriam (Barrow ground squirrel), which is the Arctic coast of Alaska from Point Hope eastward at least to Point Barrow.

\section{GENUS AMPHALIUS JORDAN}

1933. Amphalius Jordan. Nov. Zool., 39:74.

Genotype: Amphalius runatus Jordan 1923

Frontal tubercle sharp, more or less sunk into frons. Eyes are not reduced. Rostrum reaches to apex of trochanter. Bristles of segment II of antennae long. Club with more than 24 spines. Basal abdominal sternite without lateral bristles. Mid- and hind-femur without a sub- 
lateral row of bristles on outside (apart from 2 or 3 bristles toward apex); bristles on midtarsal segment II very numerous, most of them slender. First pair of plantar bristles of $\mathrm{V}$ on all tarsi somewhat shifted inward and very distinctly bent ventrad-inward. VII t. slightly projecting medianly in between two sets of antepygidial bristles.

MaLf: The VII t. is incised below cone of long antepygidial bristle, above long bristle a minute one. VIII t. very large, with a few spicules in dorsal area on inside. Stigma cavity is narrow and very long. VIII st, is narrow, fringed on upper side and before point of division there is a long bristle. A very long fringed membranous apical flap is supported by a rod-like ventral continuation of main portion of segment. Vertical arm of IX st. has a tooth above the middle of the posterior margin. Process of clasper is very long and narrow. Exopodite (finger) has a very long ventral process which is dilated at apex. Ejaculatory duct is enclosed in a very long sheath which is curved frontad, then distad, then again frontad. Pale apical area of IX t., behind pygidial plate, is about half length of that plate, and minutely spiculose at posterior margin. Anal sternite is somewhat longer than tergite, is narrow with numerous bristles at the apex.

Female: Stylet is cylindrical with apex rounded off and bearing numerous bristles. Anal sternite angulate beneath, with bristles in apical half only. Three antepygidial bristles. Bursa copulatrix, duct included, very long and broad and of nearly the same width from base to apex. Spermatheca long and without a division between head and tail, head less than one-half wider than tail.

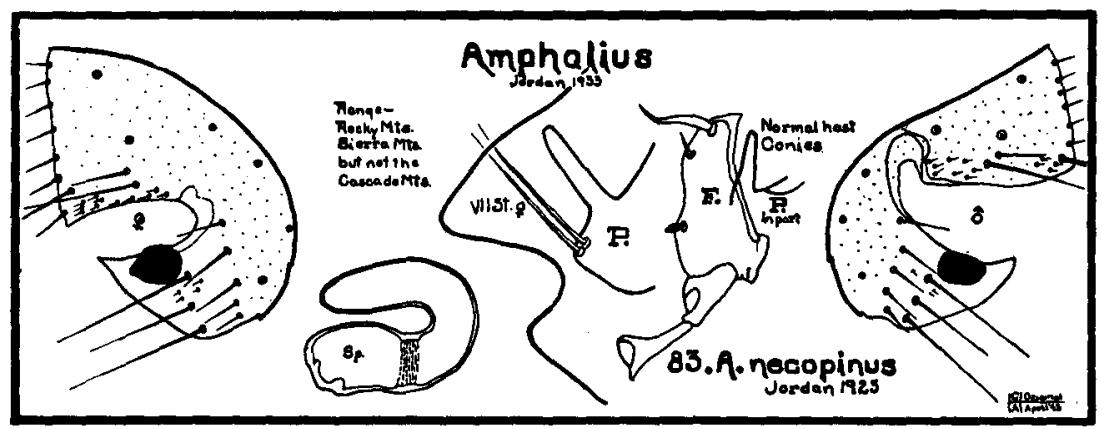

83. Amphalius necopinus

Jordan 1925

1925 Ceratophyllus necopinus Jordan, Nov. Zool., 32:110.

1933 Amphalius necopinus Jordan, Nov. Zool., 39:74.

1941 Amphalius necopinus Augustson, Bul. Southern Calif. Acad. Sci., 40:150.

1941 Amphalius necopinus Jellison, U. S. Pub. Health Repts., 56:49:2341.

Jordan, in describing this species, states that it is an interesting discovery from Pine City, Mono County, California, where A. B. Howell 
removed a small series off Ochotona muiri (cony) during July of 1922, and which is closely related to the Asiatic species $A$. clarus $\mathrm{J}$. and $\mathrm{R}$. 1922 and $A$. runatus J. and R. 1923, both of which were also taken off Ochotona, former in Tibet, latter in Transbaicalia.

Jordan's simple statements about this California species are: MaLE: Differs from $A$. runatus, to which species is nearest, in finger of clasper being much broader, particularly in lower half, anterior margin of process $P$ very little over half length of posterior margin (14:26), measured from actebulum. Female: Like that sex of $A$. runatus, which varies individually in size of spermatheca and number of bristles on t. VIII.

Modified SEgments of this species are very distinct. In male, process of clasper is long and finger-like reaching almost to apex of finger. Finger $F$ is somewhat triangular with an unusual process extending downwards and backwards from base. Armature of finger consists of a long blade-like bristle at apex and along posterior border a bristle about one-third down, then about two-thirds down a short black spiniform. VII st. outline of female consists of two lobes, triangular, upper one large and much longer than short, small lower one. Sinus is broad but not very deep. Variation occurs in shape of two lobes. Spermatheca somewhat tubular, broad at body end, gradually diminishing to end of tail. No definite mark between body and tail. Organ is bent into the shape of a U.

RANGE: This species is probably found in all cony colonies of the Sierra-Nevada Mountains of California and Nevada and in Rocky Mountains.

RECORDS of this species are:

CALIFORNIA-Augustson has been very successful in collecting this species off various conies in high Sierra-Nevada Mountains of central California. His records from this portion of state are:

Ochotona schisticeps muiri G. and S. (Yosemite cony), Tully's Hole, Fresno County, August 23, 1941, 4 pairs; Horse Heaven, Fresno County, August 24, 1941, 1 male; Duck Pass, Fresno County, August 27, 1941, 1 male

Ochotona schisticeps albata Grinnell (Mt. Whitney cony), Dusty Lakes, Fresno County, August 23, 1938, 3 males, 1 female; Mammoth Lakes, Mono County, July 26, 1941, 3 males, 1 female.

Jordan's original specimens were collected by A. B. Howell off:

Ochotona schisticeps muiri G. and S. (Yosemite cony), Pine City, Mono County, July 1922, 1 male, 1 female.

MONTANA-In the collection of the Rocky Mountain Laboratory at Hamilton are the following records for this species:

Ochotona princeps (Rocky Mountain cony), Park County, June 29, 1938, 1 male.

\section{COLORADO-From:}

Ochotona sp. (cony), Boulder County, June 15, 1939, 7 males collected by Dr. Gordon E. Davis

Ochotona sp. (cony), Rocky Mountain National Park, June 11, 1940, 3 males, 1 female, collected by R. H. Baker. 
BRITISH COLUMBIA, ALBERTA-In the collection at Livestock Insect Laboratory, Kamloops, B. C., are the following Canadian records:

Ochotona princeps cuppes Bangs (Bangs cony), Reno Mountain, Salmon, B. C., 1 male collected by T. K. Moilliet

Ochotona princeps princeps Richardson (Rocky Mountain cony), Banff, Alberta, July 14, 1939, 2 males, 1 female collected by J. D. Gregson.

ALASKA-Off:

Ochotona collaris Nelson (collared cony), Red Mountain, Mt. Hayes Section, June 13, 1941, 2 males.

\section{GENUS FOXELLA}

1930. Foxella Wagner. Konowia, 8:314.

Genotype: Pulex ignotus Baker 1895

Frontal tubercle sharp if exposed. Rostrum does not reach trochanter. Eye is rudimentary. Ocular bristle is well above the eye. Three or 4 stout bristles in lower genal row, 4 to 6 bristles in upper genal row. Pronotal comb of from 16 to 24 teeth. Hind-femur with complete row of bristles on both sides. Segment V of hind-tarsus shorter than III with all plantar bristles lateral.

MALE: Bristles of segment II of antennae short. One or two long and one very short antepygidial bristle. VIII st. is small without apical membranous lobe; close to apex a long bristle. Process of clasper narrow, conical; finger $\mathbf{F}$ very long and narrow. Apical area behind pygidial plate setiferous at apex. Apices of anal tergite and sternite on a level, tergite conical, sternite not pointed, with many apical bristles.

Female: Bristles of segment II of antennae long. Three or 4 antepygidial bristles. Basal abdominal sternite with lateral bristles. Stylet with 2 or 3 lateral bristles. Anal sternite not distinctly angulate beneath, with bristles from near the base. Spermatheca with globular body and tail more or less bent, a distinct medium appendage at its apex.

According to the views of the author this genus is represented by three species, mexicana in eastern Mexico and not in the scope of this work, utahensis, ranging in the state of $\mathrm{Utah}$ and adjacent territory, and ignota widely spread in the United States and Canada. At the time of this writing, ignota has been divided into eight subspecies. Four of these are found west of the Rocky Mountains. Roughly speaking, $F$. $i$. recula is the common northwest pocket gopher flea; $F$. $i$. franciscana the common California pocket gopher flea west of the Sierra-Nevada Mountains; F. i. acuta isolated at Jamesburg, Monterey County, California; F. i. coufferi isolated near Big Lake, San Bernardino County, California. The four remaining species of ignota are found in the Rocky Mountains and east. $F$. i. albertensis is found in the northern Rocky Mountains, ranging as far south as Montana and North Dakota; F. i. omissa is restricted to the region south of Grand 
Canyon in Coconino County, Arizona; $F$. i. apachina is found in the southern Rocky Mountains of the United States; $F$. i. ignota is the Great Plains pocket gopher flea which at points extends into the Racky Mountains and may at some points cross the Mississippi River.

These true pocket gopher fleas are often found on gopher carnivores and other mammals which run in gopher burrows.

Key to the Species of Foxella north of Mexico

Antepygidial bristles 2 in male, 3 in female

Antepygidial bristles 3 in male, 4 in female

Key to the Subspecies of Foxella ignota west of the Rocky Mountains

It is to be noted as one views these four subspecies side by side that $F$. $i$. acuta is closely allied to $F$. i. franciscana, if distinct from it, and that $F$. $i$. coufferi resembles $F$. $i$. recula, if distinct from it. VIII st. in males is characteristic as is VII st. in females.

\section{Males}

A. VIII st. male short and broad

1. With long subapical bristle

F. i. franciscana, p. 173

2. Without long subapical bristle F. i. acuta, p. 175

B. VIII st. male long and narrow and armed with

1. Prominent bristle and about 8 short ones

F. i. recula, p. 176

2. Prominent bristle and about 4 short ones

F. $i$. coufferi, p. 178

A. Apical outline of VII st.

Females

1. Without lower lobe

2. With small triangular lower lobe

F. i. franciscana, p. 173

3. With ventral lobe large, well rounded or angulate

F. i. acuta, p. 175

4. With ventral lobe narrow, angular

F. i. recula, p. 176

F. i. coufferi, p. 178

\section{Foxella ignota franciscana}

\section{Rothschild 1910}

1910 Ceratophyllus franciscanus Rothschild, Ent. Mo. Mag., (2) 21:88.

1915 Ceratophyllus ignotus franciscanus Jordan and Rothschild, Ectoparasites, 1:58.

This subspecies was described from materials collected off pocket gophers, weasels, and ground squirrels taken around San Francisco Bay region of California by Fox, McCoy, and Mitzmain.

Describer states that in this form finger $F$ and process $P$ of clasper are shorter than in other forms. VIII t. bears from 18 to 26 bristles from stigma downwards. VIII st. is shorter than in other subspecies and subapical bristle thinner. VII st. of females has an apical margin more evenly slanting in the dorso-ventral direction than in other races, segment longest subventrally, and almost pointed in the lateral aspect.

RANGE: The range of this common California pocket gopher flea is 


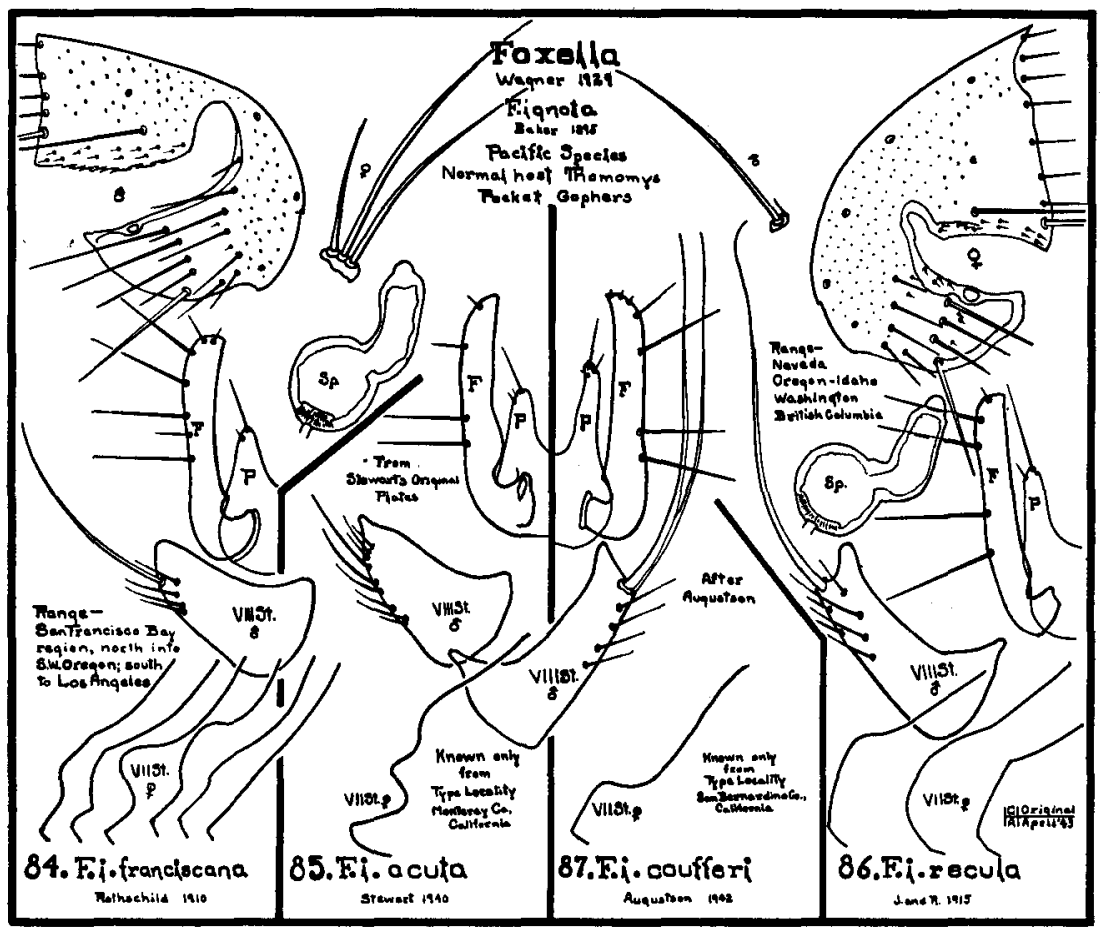

more extensive than is generally supposed. Described from the Bay region of central California the bottae group of pocket gophers has carried it north into Oregon where Thomomys bottae laticeps carries it up the coastal belt to Rogue River and Thomomys bottae leucodon carries it throughout the Siskiyou Mountains and on north as far as Cottage Grove in Lane County. It is not definitely known where the south border of the range of this flea is located. Augustson presented the writer with gopher fleas taken at Point Arguello, Santa Barbara County, California, which are typical of this subspecies. It seems, then, that south portion of range may extend at least to Los Angeles. West border is Pacific Ocean, east the Cascade-Sierra-Nevada Mountains.

LENGTH: This is a medium sized flea. Males measure about $2.25 \mathrm{~mm}$., females about $2.75 \mathrm{~mm}$.

Host Preference: This is a true pocket gopher flea. It is also found on weasels which hunt in the gopher burrows and upon other small mammals which frequent the runs.

Abundance and Seasonal Distribution: These fleas can be taken off pocket gophers in fair to large numbers all through trapping season.

Medical IMPORTANCE: Although plague has been recorded from tissue of pocket gopher in central California this flea has not been found a vector of the disease. 
RECORDs: The large number of fleas which can be taken off pocket gophers flood any collection. Below are listed only the writer's more interesting records for this subspecies:

OREGON-Off:

Thomomys bottae laticeps Baird (Homboldt Bay pocket gopher), Brookings, Curry County, August 23, 1997, I pair; Pistol River at Coast Highway, Curry County, June 14, 1939, a series; Gold Beach (Courthouse yard), Curry County, August 8, 1943, 2 males, 4 females

Thomomys bottae leucodon Merriam (white-toothed pocket gopher), Kerby, Josephine County, August 25, 1937, 2 males, 5 females; Grants Pass, Josephine County, May 17, 1942, 10 pairs; Yoncalla, Douglas County, November 15, 1943, 2 males.

CALIFORNIA-Off:

Thomomys bottae laticeps Baird (Humboldt Bay pocket gopher), Fort Dick Del Norte County, June 15, 1939, 2 pair; Smith River, Del Norte County, September 10, 1943, 12 males, 15 females

There are many reports of this flea from central California where it became associated with plague investigations as early as 1909 and 1910. Specimens in the collection of the writer from Augustson are off:

Thomomys bottae bottae E. and G. (California pocket gopher), Orinda, Contra Costa County, May 7, 1940, 3 pair

Thomomys bottae spp. (pocket gopher), Point Arguello, Santa Barbara County, March 15, 1942, 1 pair:

\section{Foxella ignota acuta \\ Stewart 1940}

1940 Foxella ignotus acutus Stewart, Pan-Pacific Ent., 16:20.

This subspecies, known only from the type material, a male and a female, was taken off Thomomys bottae subsp? at Jamesburg, Monterey County, California during May of 1938.

Describer states that this subspecies is close to $F$. $i$. franciscana Rothschild 1910. There are 20 spines in pronotal comb. Subspecies is very easily distinguished from other subspecies of $F$. ignota in males by presence of about 22 stout bristles on $t$. VIII, by having movable process of clasper long, slender and subacutely pointed at tip, immovable process of claspers somewhat conical in shape and extending slightly more than half way up movable process. St. IX long and both its anterior and posterior lobes bearing numerous bristles. Sternite VIII without a long apical or subapical bristle, but with a distal clump of 4 stout bristles on ventral margin, anterior to which there is another clump of 4 smaller bristles. Apex of st. VIII symmetrically and acutely pointed; tip of vertical arm evenly rounded and without an attenuated, dorsal projection: In female by spermatheca with spherical body and long stout tail, stylet about twice as long as broad at base, acutely pointed, bearing a long apical bristle and a somewhat shorter subapical one on ventral margin; substylar flap heavily bristled; posterior margin 
of st. VII of irregular outline in the dorso-posterior region and from there sloping regularly antero-dorsally.

Nothing is known about the range or seasonal distribution of this subspecies.

\section{Foxella ignota recula}

Jordan and Rothschild 1915

1915 Ceratophyllus ignotus recula Jordan and Rothschild, Ectoparasites I, p. 58. 1936 Foxella ignotus recula Wagner, Can. Ent., 68:198.

This subspecies was described from a small series taken off Mustela arizonensis, the mountain weasel, at Okanagan Landing, British Columbia, Canada, during July of 1913 by J. A. Munro.

Describers state that pronotal comb of this subspecies usually consists of from 16 to 18 spines, VIII $t$. bears only 20 bristles from stigma downwards, large bristle on VIII st. of male is more prominent than in most other subspecies, finger $\mathrm{F}$ is distinctly incurved on posterior side above center. VII st. of female with broadly rounded lobe.

LENGTH: This flea is slightly larger than preceding subspecies. Males measure about $2.75 \mathrm{~mm}$., females about $3.00 \mathrm{~mm}$.

Range: This flea is the representative of $F$. ignota in Pacific Northwest. It ranges south from British Columbia, into and through Washington west to the crest of Cascades, throughout Oregon east of crest of Cascades, then for some reason jumping over Cascades into coastal belt of Oregon to be found west of Coast Range from Columbia River south to Rouge River. In California this flea is found in narrow strip east of crest of the Cascade-Sierra-Nevada Mountains. Most pocket gophers in north half of Nevada carry this flea. This subspecies is also found in western Idaho.

Host Preference: This subspecies is a true pocket gopher flea. It is frequently found upon gopher carnivores and small mammals which explore gopher burrows.

Seasonal Distribution and Abundance: This flea can be taken off pocket gophers during entire trapping season. In many cases large series can be removed from hosts.

MEDICAL IMPORTANCE: This flea has not yet been proved a vector of plague.

RECORDs: Ease with which pocket gophers can be caught in special gopher traps generally floods any collection with these fleas.

BRITISH COLUMBIA-With the original description of this flea Jordan and Rothschild list it off:

Mustela arizonensis (weasel), Okanagan Landing, July 1913, the type

Thomomys talpoides (pocket gopher), Okanagan Falls, April 1913, a series

Mustela spec. (weasel), Kelowna, December 1910, a series

Mail and Holland in 1939 report this subspecies off:

Thomomys fuscus fuscus Merriam (Brown pocket gopher), from Kamloops, Nicola, and Hedley. 
The following records are those of the writer off various western pocket gophers, their carnivores, and stray occurrences:

\section{WASHINGTON-Off:}

Thomomys columbianus Bailey (Columbian pocket gopher), Lowden, Walla Walla County, May 12, 1939, a series

Thomomys douglasi douglasi Richardson (Douglas pocket gopher), Carson, Skamania County, August 20, 1935, a pair

Thomomys douglasi limosus Merriam (white salmon pocket gopher), Guler, Klickitat County, June 27, 1943, a series.

\section{OREGON-From:}

Thomomys monticola nasicus Merriam (Deschutes pocket gopher), Paulina Mountains, Deschutes County, June 16, 1937, 3 females

Thomomys monticola mazama Merriam (Mazama pocket gopher), Cloud Cap Inn, Hood River County, 7,000 ft. el., October 11, 1937, 5 males; Crater Lake, Klamath County, August 14, 1933, 2 males, 5 females

Thomomys fuscus fuscus Merriam (brown pocket gopher), Lostine, Wallowa County, August 8, 1939, 1 male

Thomomys columbianus Bailey (Columbia pocket gopher), Hermiston, Umatilla County, May 30, 1938, 8 males, 6 females

Thomomys quadratus quadratus Merriam (The Dalles pocket gopher), Mitchell, Wheeler County, August 11, 1937, 5 males, 7 females

Thomomys hesperus Merriam (West Coast pocket gopher), Devil's Lake, Lincoln County, March 26, 1939, 3 males, 2 females; Blaine, Tillamook County, July 27, 1943, 1 male, 3 females

Thomomys monticola helleri Elliot (Heller's pocket gopher), Ophir, Curry County, August 9, 1943, 5 males, 12 females.

Accidental Occurrences:

Mustela longicauda arizonensis Mearns (mountain weasel), Lostine, Wallowa County, August 8, 1938, 6 males, 14 females

Mustela washingtoni Merriam (Washington weasel), Friend, Wasco County, May 17, 1937, 2 females

Mustela cicognanii streatori Merriam (Puget Sountd weasel), Devil's Lake, Lincoln County, January 28, 1939, 1 male, 1 female

Citellus beldingi oregonus Merriam (Oregon ground squirrel), Summer Lake, Lake County, June 17, 1937, 1 male

Peromyscus maniculatus gambeli Baird (Gambel's deer mouse), Paulina Lake, Deschutes County, August 2, 1936, a pair.

\section{CALIFORNIA-From:}

Thomomys monticola monticola Allen (California mountain pocket gopher), south end Lake Tahoe, Eldorado County, June 21, 1944, a series; Donner Lake, Nevada County, June 24, 1944, large series.

\section{NEVADA-From:}

Thomomys quadratus quadratus Merriam (The Dalles pocket gopher), Coleman's Ranch, Washoe County (25 miles southeast of Adel, Oregon), June 26, 1937, 3 males, 4 females; Vya, Washoe County, June 15, 1944, 5 males, 9 females

Thomomys monticola monticola Allen (California mountain pocket gopher), south end Lake Tahoe, Douglas County, June 21, 1944, 6 males, 3 females

Thomomys townsendi nevadensis Merriam (Nevada pocket gopher), Winnemucca, Humboldt County, June 27, 1944, 2 males; Battle Mountain, Lander County, June 29, 1944, a series

Mustela longicauda arizonensis Mearns (mountain weasel), Coleman's Ranch, Washoe County, June 27, 1937, 16 pairs. 
IDAHO-Off:

Thomomys idahoensis Merriam (Idaho pocket gopher), Smiths Ferry, Boise County, July 18, 1945, 2 males, 4 females.

Thomomys fuscus saturatus Bailey (Coeur d'Alene pocket gopher), Coeur d'Alene, Kootenai County, July 23, 1945, 2 males.

\section{Foxella ignota coufferi \\ Augustson 1942}

1942 Foxella ignota coufferi Auguston, Bul. So. Calif. Acad. Sci., 51:69.

This subspecies was described by Augustson from a male and two females taken off Thomomys altivallis Rhoads (San Bernardino Mountain pocket gopher) trapped near Big Bear Lake, San Bernardino County, California, July 2, 1942 by J. C. Couffer.

Original description states that pronotal comb consists of 20 teeth in female and 18 in the male; that in female VII st. is very diagnostic, being without sinus and made up of single long, blunt to square, lower lobe; male with long slender finger of uniform width from base to apex. Process of clasper reaches to three-fourths the length of finger, and is long and acuminate. Describer further states that VIII st. of male is evidently close to $F$. $i$. albertensis from which is differs in fewer number of bristles along its ventral margin and sharper, shorter free angle above terminal bristles.

Nothing is known about range or seasonal distribution of this subspecies.

Key to the Subspecies of Foxella ignota in the Rocky Mountains and to the East

1. 3 heavy bristles on posterior face of finger

VII st. female slanting with shallow bay

2. 4 heavy bristles on posterior face of finger

a. Process $2 / 3$ as long as finger

VII st. female without sinus but with lower lobe

Canadian Rockies

F. i. apachina, p. 180

F. i. omissa p. 181

b. Process $2 / 3$ as long as finger. VII st. female with sinus and

upper and lower lobe. Great plains, approaches of Rocky

Mountains and east into Illinois

F. i. ignota, p. 179

\section{Foxella ignota \\ Baker 1895}

1895 Pulex ignotus Baker, Can. Ent., 27:110.

1895 Typhlopsylla americana Baker, Can. Ent., 27:189.

Of Foxella ignotus Baker 1895, the parent species, Jordan and Rothschild state in 1915 that of a fairly large number of specimens in their collection they are convinced that ignotus is a geographically variable species, the examples from different faunal districts of North 
American exhibit some distinctions either in both sexes or only in male.

Due to a considerable amount of individual variation in these pocket gopher fleas of Rocky Mountain area, many investigators simply record them as species ignota.

RECORDS of such are:

MONTANA-From:

Thomomys spp. (pocket gopher), Gallatin, Madison, Powder River, and Ravalli Counties

Citellus armatus Kennicott (Uinta ground squirrel), Park County

Mustela spp. (weasel), Flathead, Gallatin and Ravalli Counties

Speotyto cunicularia (burrowing owl), Beaverhead, from nests.

\section{UTAH-From:}

Peromyscus spp. (deer mouse), Salina, Sevier County

Perognathus spp. (pocket mouse), Logan Mountains, Cache County.

WYOMING-From:

Thomomys spp. (pocket gopher), Teton Mountains, Lincoln County, Laramie, Albany County.

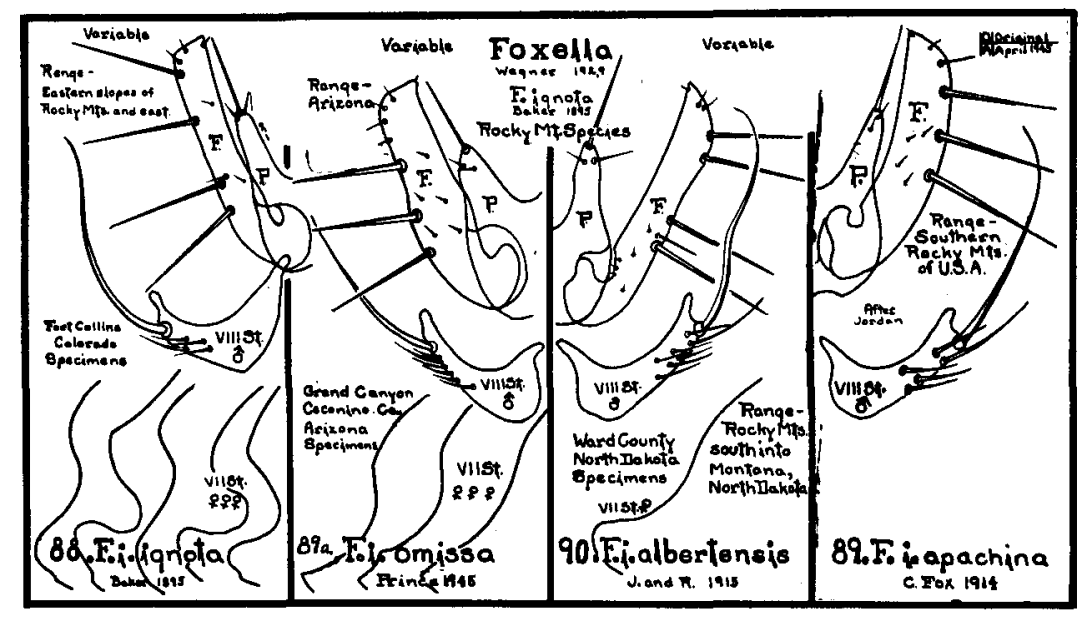

88. Foxella ignota ignota

Baker 1895

1895 Pulex ignotus Baker, Can. Ent., 27:110.

1895 Typhlopsylla americana Baker, Can. Ent., 27:189.

1904 Ceratophyllus ignotus Baker, Proc. U. S. Nat. Mus., 27:416.

1915 Ceratophyllus ignotus Jordan and Rothschild, Ectoparasites, I:54.

1930 Foxella ignotus Wagner, Konowia, 8:314.

1933 Foxella ignotus Jordan, Nov. Zool., 39:75.

1938 Foxella ignotus ignotus Jordan, Nov. Zool., 41:123.

1940 Foxella ignotus I. Fox, Fleas of Eastern United States, p. 39.

Type locality for this subspecies is generally considered to be Ames, Iowa. Type host was never named. Jordan and Rothschild have dwelled 
upon this flea time and again in their works. Best review of subspecies was released by Jordan in 1938, In it he states that vertical arm of VIII st. of male measured from ventral margin to tip is as long as ventral arm measured from anterior margin to tip of apical projection. Long bristle of this segment is always very stout proximally, thicker than in any other subspecies. Proximally of this bristle there are 1 or 2 small bristles on each side and usually indications of minute hairs. Apex of basal vertical arm of VIII st. slender and curved forward. Process P of clasper varies a little in width and length but as in $F$. $i$. franciscana generally shorter than distance from angle above the acetabulum to ventral curve of acetabulum. Finger $\mathrm{F}$ resembles that of $F . i$. recula; that is, posterior margin is feebly incurved above middle; width is variable. Paramere is long-nosed, as in $F$. $i$. albertensis. Spicules on dorsal area of inner surface of VIII t. of male is more conspicuous than in other subspecies.

VII st. of female is deeply incurved but depth of sinus is variable. Bursa copulatrix is as short as in $F$. $i$. recula. Body of spermatheca is either almost globular or ovate.

LENGTH: This subspecies is a medium sized flea measuring about $2.75 \mathrm{~mm}$. in male and 3.00 in female.

Host Preference: There is little doubt that this flea is a true pocket gopher flea.

RANGe: Great Plains of the United States into Rocky Mountains, east across the Mississippi River into Illinois.

RECoRDs: Definite records for this subspecies in Rocky Mountains are difficult to find. Ewing and Fox in February of 1943 stated that Jellison removed 55 Dactylopsylla (Foxella) ignota ignota from fledglings of burrowing owl in Montana, but Jellison in May of 1943 refers to these fleas only as Foxella ignota. The writer examined material taken off gophers at Fort Collins, Colorado, on November 14, 1914, which he thought were of this subspecies.

\section{Foxella ignota apachina \\ C. Fox 1914}

1914 Ceratophyllus apachinus C. Fox, Hyg. Lab. Bul., No. 97:14.

1915 Ceratophyllus ignotus apachinus Jordan and Rothschild, Ectoparasites, 1:56.

This subspecies was described by Dr. Carroll Fox from a female taken off a prairie dog in Apache County, Arizona. It was thought by Jordan and Rothschild to be the same as a series which they had off pocket gophers from various parts of Colorado. Jordan and Rothschild say of this subspecies that VIII abdominal tergite of male bears about 24 bristles from stigma downward, 6 to 8 of them being placed at dorsal portion of apical margin. VIII st. of male is similar to that of $F$. i. albertensis but subapical bristle is slightly thinner and bristles placed proximally to larger ones are larger. Both finger $F$ 
and process $\mathrm{P}$ of clasper are shorter than in $F$. $i$. albertensis, finger also being appreciably broader. Apical hook of paramere of penis is likewise shorter and broader than in $F . i$.albertensis.

In female, apical margin of VII st. projects ventrally rather more than in $F$. $i$. albertensis, the outline sometimes agreeing almost with outline of $F$. i. franciscana.

LENGTH: Specimens in collection of the writer from northern Arizona measure male $2.75 \mathrm{~mm}$., female $3.00 \mathrm{~mm}$.

Host Preference: This subspecies is a true pocket gopher flea.

RANGE of this subspecies is probably west of Continental Divide in Colorado and New Mexico, then westward in Utah and northern Arizona.

Records: Original female was collected off a prairie dog taken in Apache County, Arizona. Jordan and Rothschild say in 1915, "We have a series of both sexes from the Baker collection labelled ignotus and obtained at Hermosa, Colorado, from a pouched gopher, 4, vi, 99 (C. F. Baker), and Fort Collins, Colorado, on pocket gopher (C. F. Baker); and also two males from Crestona, Colorado, off Thomomys talpoides agrestis, collected by $\mathbf{E}$. R. Warrens."

UTAH-This flea is reported off:

Thomomys (pocket gopher), Wellsville Cache, Salina and Sevier Counties.

ARIZONA-Augustson presented the writer with specimens from Grand Canyon, Coconino County, taken off:

Thomomys fulvus fulvus Woodhouse (Fulvus pocket gopher), April 25, 1939, a series, collected by Louis Shellback

Peromyscus manucilatus rufinus Merriam (tawny white-footed mouse), June 3, 1942, 1 female, collected by R. L. Rutherford.

\section{9a. Foxella ignota omissa}

Prince 1945

1945 Foxella ignota omissa Prince, Can. Ent., 77:18.

According to describer this subspecies is close to $F$. $i$. recula Jordan and Rothschild but differs in modified segments. He characterizes subspecies as follows:

Female: Posterior border of VII st. only slightly incurved and the postero-ventral point more acuminate; sternite bears 17 to 20 bristles on each side. Tail of receptaculum seminis longer and tip more sclerified than in recula.

Male: Immovable process $\mathbf{P}$ of clasper much shorter and broader. Movable finger $\mathbf{F}$ of clasper is broader at its base and gradually tapering to apex, with little or no incurve on posterior border; it is armed with 3 or 4 pale bristles. T. VIII bears 25 to 28 bristles from the stigma downward. St. VIII is longer from base to apex and bears 4 to 5 small bristles in addition to an apical bristle which is smaller than in $F . i$. recula; from apical bristle to the apex of st. VIII distance is twice as great and 
apex more acuminate than $F, i$. recula. Manubrium is broader and less acuminate.

Lencth: Male, average $2.41 \mathrm{~mm}$., female, average $2.92 \mathrm{~mm}$.

TyPe Host: Probably Thomomys (types were collected from Mustela arizonensis).

Type Locality: Coconino County, Arizona.

Holotype male, allotype female and 7 male and 5 female paratypes were collected 1 mile west of Cosnino, Coconino County, Arizona, from Mustela arizonensis, April 25, 1938.

Holotype and allotype are deposited in collection of United States Public Health Service Plague Investigation Station, San Francisco, California. Paratypes are deposited in United States National Museum, Washington, D. C.

Describer further states that exact location in Apache County, Arizona, from which the mutilated female type specimen of $F$. i. apachina (C. Fox) was collected is not known. Jordan and Rothschild (Ecto. l (I), p. 56, 1915) redescribed and illustrated the subspecies from specimens collected at Hermosa, Colorado, and other points in that state. United States Public Health Service collection contains a series of both sexes of subspecies, collected at Marvel, Colorado, which is a short distance south of Hermosa, Colorado. Hubbard's illustrations of $D$. (F.) i. apachina (Pac. Univ. Bul. 49 (2), 1943) do not correspond with our specimens of $F$. $i$. apachina nor do they appear to fit the redescription by Jordan and Rothschild. Hubbard's illustrations appear to coincide with our material described above as $F$. i. omissa.

\section{Foxella ignota albertensis Jordan and Rothschild 1915}

1915 Ceratophyllus ignotus albertensis Jordan and Rothschild, Ectoparasites, 1:56.

Although describers state that they had a long series of both sexes from Blackfalls, Alberta, Canada, collected off Geomys spec,. Mustela spec., and Lynx canadensis, by A. D. Gregson, no mention was made of female. Short description of male is: VIII t. bears from 30 to 40 bristles from stigma downwards; sternite is much longer than in $F$. i. ignotus, and extends proximally less upwards, apex also being less produced. Proportional lengths of vertical and horizontal arms of this sclerite (horizontal arm measured to base of long subapical bristle) are in $F$. $i$. ignotus 34:27 and in $F$. i. albertensis 25:35, proportions being almost exactly reversed. Process $\mathbf{P}$ of clasper and finger are very long, apical hook of paramere of penis also being slender. Finger bears 4 long bristles. There is some variability in bristles of VIII st. and finger as well as in size of $\mathrm{P}, \mathrm{F}$ and VIII st.

Apical outlines of VII st. of females examined by writer consisted of a gentle slope with a shallow bay towards ventral which forms a small somewhat angular lower lobe. 
LENGTH: Between 2.50 and $3.00 \mathrm{~mm}$. in both sexes.

Host Preference: This flea is probably a true pocket gopher flea.

Range: Canadian Rocky Mountains south into Montana and North Dakota.

ReCoRDs: Jordan reported this subspecies from Round Lake, McHenry County, North Dakota, off weasel and the writer examined specimens from Ward County, North Dakota.

\section{Foxella utahensis \\ New Combination}

On January 21, 1935, Dr. J. S. Stanford of Utah State College collected a series of fleas off pocket gophers taken at Wellsville, Cache County, Utah. These were sent to Dr. J. Wagner in Belgrade for determination. Wagner pronounced them a new subspecies of Foxella ignota and in 1936 named them $F$. i. utahensis. The chief characteristic which marked these fleas off from other ignota was the presence of 3 well developed antepygidial bristles in the male and 4 in the female, other ignota carrying only one weak and one strong bristle in the male, 3 in the female.

Ten years after Stanford made his collection, the author, working north of Grand Canyon in July, took a series of male fleas off pocket gophers collected on both sides of the Utah-Arizona state line between Fredonia and Kanab which also carried 3 well developed antepygidial bristles but with different VIII sternite. Since these 2 distinct fleas show very much more relation to each other than to Foxella ignota the author here raises the rank of Foxella ignota utahensis to that of a full species to become Foxella utahensis.

Key to the Subspecies of Foxella utahensis

1. VIII st. male with well developed posterior projection and secondary terminal bristles all of same weight; VII st. female a well developed lobe without sinus

utahensis, p.183

2. VIII st. male without posterior projection, secondary terminal bristles a single heavy and a series of weaker ones; female unknown arizonensis, p.184

\section{Foxella utahensis utahensis Wagner 1936}

1936 Foxella ignota utahensis Wagner, Ztschr. f .Parasitenk., 8:655.

This subspecies was described by Wagner from materials sent him by Dr. J. S. Stanford of Utah State College, who collected them off pocket gophers taken at Wellsville, Cache County, Utah, January 21, 1935.

Brief description in German states that this subspecies is in many respects like $F$. i. apachina C. Fox 1914. Number of antepygidial bris- 


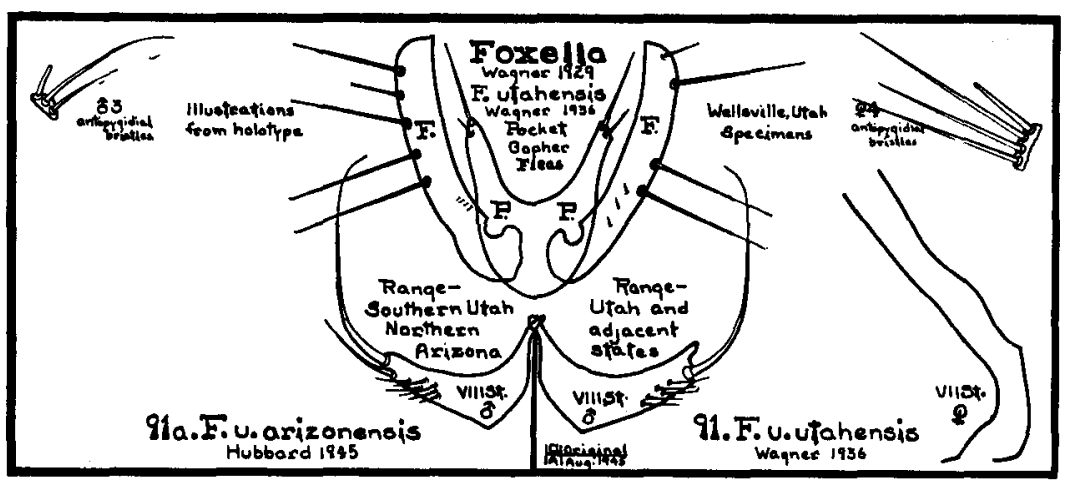

thes is very characteristic. There are on either side 4 in the female and 3 or 4 in the male, two lower ones being well developed. Wagner states also that VIII $t$. is thickly beset with bristles, there being 35 to 40 .

Range: Type locality of this subspecies is Wellsville, Cache County, Utah. The writer has examined specimens off pocket gophers from Uinta and Sanpete Counties, Utah, and Bear Lake County, Idaho. This would suggest range from central Utah north into southeastern Idaho, and east perhaps into southwestern Wyoming.

\section{1a. Foxella utahensis arizonensis}

\section{A New Subspecies}

There are before the author at this time of describing the holotype male and 3 paratype males. The female is unknown.

Anatomy: Head. Head well rounded, eye absent, but at eye position characteristic circular thickening. Gena with lower row of 4 stout bristles, upper row of 5 or 6 medium bristles. Postantennal region with heavy bristle and marginal row of 4 or 5 medium ones; setae along antennal groove. Thorax. Pronotal comb of about 20 spines.

Modified Segments: Male. Process of clasper long and slender, armed apically with two bristles; finger one-third longer than process, long, slender, fairly straight, armed posteriorly with 4 stout bristles and a medium one, all in upper half. VIII sternite, short, slender and without apical projection, armed terminally with long, well developed curved major bristle, a heavy secondary bristle and series of shorter ones.

LENGTH: Males vary from $2.25 \mathrm{~mm}$. to $3.00 \mathrm{~mm}$.

RANGE: Known only from the type locality.

TYPE Locality: Utah-Arizona state line at Fredonia and Kanab.

TyPe Host: Thomomys fossor Allen (Colorado pocket gopher).

Deposits: The holotype male bearing the author's number 2453 and dated July 9, 1945, is deposited in the United States National Museum. First paratype sent to British Museum. 


\section{GENUS DACTYLOPSYLLA JORDAN}

1929. Dactylopsylla Jordan. Nov. Zool., 35:37.

Genotype: Dolichopsyllus bluei C. Fox 1909

The genus Dactylopsylla erected by Jordan in 1929 to hold bluei and comis retained its entirety until I. Fox established the subgenus spicata in 1940 to hold rara, and Hubbard in 1943 established the subgenus foxelloides to hold pacifica and bottaceps and named comis as the genotype. In 1943 Ewing and I. Fox reduced genus Foxella to a subgenus of Dactylopsylla, but at this time the writer is not considering the reduction, but has given Foxella its original full genus standing.

Members of this genus are similar to ignota group of genus Foxella, but are more specialized.

HeAD: Frontal tubercle very small. Eyes vestigial. Gena with 2 or 3 rows of characteristically arranged bristles. Postantennal region with a stout bristle and a marginal row.

Pronotum with long slender black teeth.

Mesosternum not separated from mesepisternum by an inner ridge.

Aвdomen: With few apical spines. No posterior median process on tergal plate VII. Antepygidial bristles 3 on each side in female, one on each side in male.

Modified SEgments characteristic. Spermatheca with globular body and crooked, appendage-bearing tail.

Several lateral bristles on femur I. No patch of spinelets on inner surface of coxa III. Posterior tarsal segment I shorter than II, III, and IV taken together. Last segment of each tarsus is armed with 5 pairs of lateral plantar bristles, first pair of which is shifted ventrally.

These are giant fleas which are found upon pocket gophers and their predators.

\section{Key to the Species of Dactylopsylla Males}

A. Finger boot-shaped, apex turned posteriorly, southwest, D. bluei, p. 191 New Mexico, D. neomexicana, p. 192

B. Finger long and slender, apex turned anteriorly D. comis, p. 186

C. Finger with apex expanded bilaterally D. pacifica, p. 188

D. Finger somewhat rectangular, slightly bent, . Colorado, D. rara, p. 194 Montana, D. nuditenacula, p. 190

Females

A. VII st. with somewhat undulate outline

D. bluei, p. 191

B. VII st. with angulate lobe; 27 bristles to side, northwest, D. comis, p. 186 17 br: to side, Montana, D. nuditenacula, p. 190

C. VII st. outline with small triangular lobe; 24 bristles to side

D. VII st. with lower portion outline concave; 16 bristles to side

D. bottaceps, p. 189

D. pacifica, p. 188

E. VII st. sinuate, lobes about equal, D. neomexicana, p. 192

F. VII st. outline a well rounded lobe, Nevada, D. monticola, p. 193 


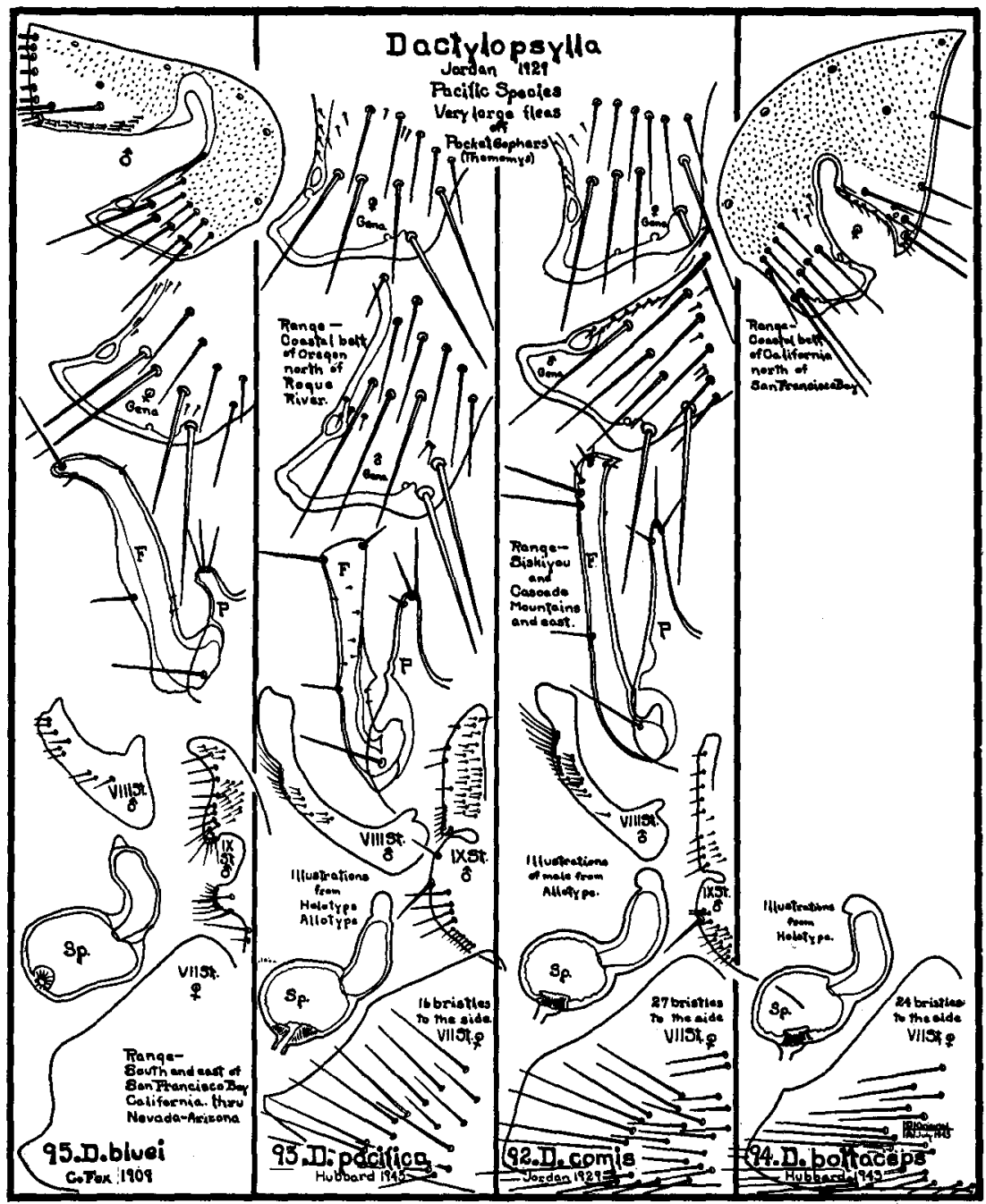

92. Dactylopsylla comis

Jordan 1929

1929 Dactylopsylla comis Jordan, Nov. Zool., 35:38.

1936 Dactylopsylla comis Wagner, Can. Ent., 58:198.

1943 Dactylopsylla comis Hubbard, Pacific Univ. Bul., 40:2:3.

Jordan described the female of this species from a single specimen taken off Thomomys fuscus (pocket gopher) at Okanagan Landing, British Columbia, Canada, where it was collected by J. A. Munro. Hubbard described the male during 1943 from a collection of seven males, the majority of which were gathered in high Cascade Mountains of 
Oregon during the summer of 1936 off Thomomys monticola mazama Merriam (Mazama pocket gopher).

Head: Frontal tubercle weak. Eyes absent, but at eye position characteristic circle. Gena with lower row of 4 stout bristles and a fifth heavy one dropped out of line and considerably below at outer genal margin; upper row of $\mathbf{5}$ medium bristles and above this along antennal grooves several short bristles. Postantennal region with 3 bristles, one stout, and a marginal row of about 5 bristles. Small bristles all along antennal groove. Female same as male, but with bristles above upper genal row missing.

Pronotal Comb: Of about 26 slender, heavy black teeth.

Modified Segments, Male: The process $P$ of the clasper is long, slender and conical, armed apically with 3 bristles, the finger $F$ long and slender and apically hooked anteriorly; armed apically with a pair of well developed bristles and several weak ones, single bristle below. VIII st. long and slender, terminating apically in short membranous flap; armed with number of small bristles and a few towards the apex which are much stronger. IX st. with proximal lobe fingerlike and armed with series of weak bristles; distal lobe rounded, armed with a long, sharp, black spiniform and a series of weak bristles. FEMALE: VII st. described as rounded and armed with 27 bristles to the side. This coincides with 16 females in collection of the writer. Spermatheca body globular, appendix crooked and with appendage.

LENGTH: Male $4.50 \mathrm{~mm}$., female $5.00 \mathrm{~mm}$.

Ravge: From base of Siskiyou Mountains at Pacific Ocean eastward through Siskiyous, thence north through the Cascades and into highlands of British Columbia.

Host Preference: The writer believes this species to be a true pocket gopher flea, but as in the case of other pocket gopher fleas, will also be found upon pocket gopher carnivores and other small animals which run the burrows of gophers.

Abundance and Seasonal Distribution: These large fleas seem rare. Dozens of pocket gophers in range of species can be examined without finding them. When found fleas are generally single on the host or occasionally in pairs. Specimens in collection of the writer have been taken from the middle of June to the middle of October. This flea may be a nest species with season of maximum abundance during winter when host cannot be trapped.

RECORDs: The writer records from:

OREGON-Off:

Thomomys monticola mazama Merriam (Mazama pocket gopher), Cloud Cap Inn, 7,000 ft. el., Hood River County, October 11, 1937, 1 male, 1 female; Cooper Spur Junction, 4,000 ft. el., Hood River County, August 3, 1937, 4 females; Summit McKenzie Pass, Lane County, 5,200 ft. el., July 22, 1938, 4 males, 2 females; Little Lava Lake, $4,700 \mathrm{ft}$. el., Deschutes County, July 27, 1936, 2 males, 2 females; 
Thomomys quadratus quadratus Merriam (The Dalles pocket gopher), PaulAccidental Occurrence:

ina Lake, 6,500 ft. el., Deschutes County, August 3, 1936, 1 female.

Citellus beldingi oregonus Merriam (Oregon ground squirrel), Little Lava Lake, 4,700 ft. el., Deschutes County, July 26, 1936, 1 male.

CALIFORNIA-Off:

Thomomys bottae laticeps Baird (Humboldt Bay pocket gopher), Smith River, Del Norte County (about sea level), June 15, 1939, 3 females.

\section{Dactylopsylla pacifica \\ Hubbard 1943}

1943 Dactylopsylla pacifica Hubbard, Pacific Univ. Bul., 40:2:4.

Hubbard described this species from 2 males and a female taken off Thomomys hesperus Merriam (West Coast pocket gopher) at Devil's Lake, Lincoln County, Oregon, on June 26, 1943, where the gophers were working in the turf of the golf course.

Head: Frontal tubercle weak. Eye absent, but with characteristic circle at eye position. Gena with what appears to be 3 or 4 rows of bristles, below at outer margin of gena a pair of stout bristles, slightly above but toward antennal groove row of 3 stout bristles, then row of 5 medium bristles and fourth row with 2 medium bristles in male but missing in female. Postantennal region with 3 or 4 bristles, one of which is stout, marginal row of 8 or 10; small bristles all along antennal groove.

Pronotal Comb of about 24 long, black teeth.

Modified Segments, Male: Process $P$ of clasper finger shaped with two wrinkles midway down on posterior face, armed apically with 3 bristles. Finger $\mathrm{F}$ of clasper without hook, apex flat and broadened with a bristle at each apical angle. At position corresponding to wrinkle on process a triangular lobe on anterior face and a not so prominent elevation on posterior face, the elevation armed with a bristle. VII st. long and slender, terminating apically in a long membranous flap; armed with a number of small bristles and a few towards the apex which are stronger. IX st. with proximal lobe thumb-like and armed with series of weak bristles; distal lobe rounded, armed with long, sharp, black spiniform and a series of weak bristles. FEMALE: VII st. shallowly concave and armed with 16 bristles to the side. Spermatheca with globular body and crooked appendix with terminal appendage.

LENGTH: Male $4.25 \mathrm{~mm}$., female $5.00 \mathrm{~mm}$.

TYPE Locality: Golf course, Devil's Lake, Lincoln County, Oregon.

TYPE Host: Known only from Thomomys hesperus Merriam (West Coast pocket gopher).

Deposits: Holotype male and allotype female are mounted on one slide bearing the writer's number 2024. They are deposited in United States National Museum. Specimens were collected on June 26, 1943. Paratype male bearing same number and data was sent to Dr. Karl Jordan for British Museum. 
RANGE: While this species is known only from the type locality, it seems likely that the probable range would extend along coastal belt of Oregon from Columbia River south to Rogue River and so coincide in this strip with range of $F$. $i$. recula, and might be expected to be found on Thomomys hesperus, niger and monticola helleri.

Abundance and Seasonal Distribution: Thomomys hesperus, type host, seems to be active only from May through October. Many of them taken all during this active period and during various years failed to yield any but the three mentioned fleas. This might suggest the maxima and seasonal distribution during period when type host cannot be trapped.

\section{Dactylopsylla bottaceps \\ Hubbard 1943}

1943 Dactylopsylla bottaceps Hubbard, Pacific Univ. Bul., 40:2:5.

This species was described by Hubbard from 2 females collected off Thomomys bottae laticeps Baird (Humboldt Bay pocket gophers) which were working in school yard at Fort Dick, Del Norte County, California, on July 3, 1943.

HEAD: Frontal tubercle weak. Eye absent, but with characteristic circle at eye position. Gena with what appears to be 2 irregular rows of bristles; below 5 stout bristles, pair very long and stout crowded close together at outer margin of gena, then 3 evenly spaced and towards antennal groove; above a row of 5 medium bristles, outer one out of line towards lower row. Postantennal region with 2 bristles, one stout and a marginal row of a few bristles. Weak bristles along antennal groove.

Pronotal Cомв of about 22 long, slender black teeth.

Modified Segments: VII st. with a distinctly angular lobe and armed with 24 bristles to the side. Spermatheca with globular body and crooked appendix terminating in an appendage.

LENGTH: $4.50 \mathrm{~mm}$.

Type Locality: School yard, Fort Dick, Del Norte County, California.

TyPe Host: Known only from Thomomys bottae laticeps Baird, the Humboldt Bay pocket gopher, a coastal belt burrower.

Deposits: Holotype female collected July 3, 1943, at Fort Dick, California, bears the writer's number 2028 and is deposited in United States National Museum. Only paratype, a female with same data as above, was sent to Dr. Karl Jordan for the British Museum.

RANGE: While this species is known only from the type locality it is probable that the range extends throughout that of type host which is from Eel River, California, north to Rogue River in Oregon.

The name bottaceps attached to this species is an appropriate blending of species and subspecies name of type host. 
Only when male of new species is collected will it be possible to state whether this species is more closely allied to comis or pacifica.

Seasonal Distribution of this species is not known to the writer. Close to 100 type hosts were trapped and examined each month from July through October near type locality but neither male nor other females were taken. It is possible flea is a nest flea with distribution during winter or spring.

\section{4a. Dactylopsylla nuditenacula Prince 1945}

1945 Dactylopsylla (Foxelloides) nuditenacula Prince, Can. Ent., 77:17.

According to the describer this species is close to $D .(F$.$) bottaceps$ Hubbard and is characterized as follows:

FEMALE: Frontal tubercle small. Eyes absent. Preantennal region with an ocular row of 3 and an upper row of 5 bristles. Postantennal region with a row of minute bristles along antennal groove and a large bristle above this row, in addition to a posterior row of 6 bristles. Labial palpi five-jointed and extending to apex of fore coxae.

Pronotal Ctrenidium of 22 spines. Apical spines on metanotum and abdominal t. I and II, 1 on each side.

Modified Segments: Antepygidial bristles 3 on each side. St. VII and receptaculum seminis as illustrated. St. VII bears 17 bristles on each side. T. VIII concave on posterior border. Stylet 3 times as long as broad and bears an apical and 2 lateral bristles.

MALE: Ocular row of 3 and upper row of 4 bristles. Labial palpi barely reaching apex of fore coxae. Other characters of head same as in female.

Apical spines on metanotum 3; abdominal t. I and III, 1; II, 2 on each side.

Modified Segments: Antepygidial bristles 3 on each side. Movable finger $\mathbf{F}$ of clasper long, almost of equal width throughout and the posterior margin without bristles. Immovable process $\mathbf{P}$ of clasper short, evenly rounded at apex and bears three pale bristles. St. VIII broad at base, apex pointed, dorsal border concave, ventral border convex and bears 5 pale bristles, one nearest apex largest. Proximal lobe of st. IX bears 7 pale bristles; distal lobe with minute bristles scattered over entire lobe.

Length: Female, $3.91 \mathrm{~mm}$.; male, $3.89 \mathrm{~mm}$.

Type Locality: Gallatin County, Montana.

Type Host: Probably Thomomys (type material from Mustela arizonensis).

The only specimens known are holotype male and allotype female collected 9 miles northwest of West Yellowstone, May 24, 1938. Holotype and allotype are deposited in collection of United States Public Health Service Plague Investigation Station, San Francisco, California. 


\section{Dactylopsylla bluei \\ C. Fox 1909}

1909 Dolichopsyllus bluei C. Fox, Ent. News, 20:195.

1914 Ceratophyllus stimsoni C. Fox, U. S. Pub. Health Serv., Hyg. Lab. Bul., 97:12. 1933 Dactylopsylla bluei Jordan, Nov. Zool., 39:75.

Carroll Fox described female of this species from a single specimen taken off a weasel collected at San Francisco, California, during 1908. He described male as Ceratophyllus stimsoni in 1914 from single specimen taken off a pocket gopher in Los Angeles, California, in 1908.

HeAD: Genal bristles variable-2 or 3 rows. Lower row of 4, 5 , or 6 heavy bristles of same length or varying length; second row of 5 or 6 medium bristles; third row, if present, of 1 or 2 small bristles. Postantennal region with 1 or 2 bristles and a posterior marginal row. Large number of minute bristles in several rows along antennal groove. Eye absent. Frontal notch distinct.

Pronotal Comb of about 22 teeth.

Modified Segments, Male: Process of clasper small, expanded at apex and armed with 3 slender, long bristles; finger boot-shaped with toe pointed backwards, toe with a long apical bristle and several short ones, shin portion with one long bristle; VIII and IX st. more easily illustrated than described. Female: At time $D$. bluei was described, value of outline of VII st. was not fully appreciated. Fox only partially illustrates this characteristic. The writer has seen but one female. In this specimen VII st. has a lower lobe followed by a shallow valley then a weak angular upper lobe. Whether this outline is constant the writer could not say. Spermatheca subglobular bodied, appendix bent to right angle, armed apically with appendage.

LENGTH: Original length of female was given as $4.12 \mathrm{~mm}$., that of male (D. stimsoni) as $2.4 \mathrm{~mm}$., but specimens measured by writer were female $3.75 \mathrm{~mm}$., male $3.50 \mathrm{~mm}$.

Host Preference: Although preferred host of these big fleas is doubtless Thomomys, they have also been taken off Putorius (weasel), Microtus (meadow mouse), Onychomys (grasshopper mouse).

Deposits: Type specimens are in collection of United States National Museum.

RANGE: From data at hand the writer would predict range of this species as south and east of San Francisco Bay through California, Nevada and Arizona.

Abundance and Seasonal Distribution: Records available point to a spring distribution during March and April. This species seems rare.

RECORDS: The following specimens have' been examined by the writer:

\section{CALIFORNIA:}

Thomomys bottae subsp. (pocket gopher), Hastings Reservation, Jamesburg, Monterey County, April 24, 1939, 1 male 
Microtus californicus (meadow mouse), Hunter Ligget Reservation, Jolon, Monterey County, March 13, 1942, 1 male.

ARIZONA:

Onychomys leucogaster capitulatus Hollister (grasshopper mouse), Mohave County, April 9, 1938, I female.

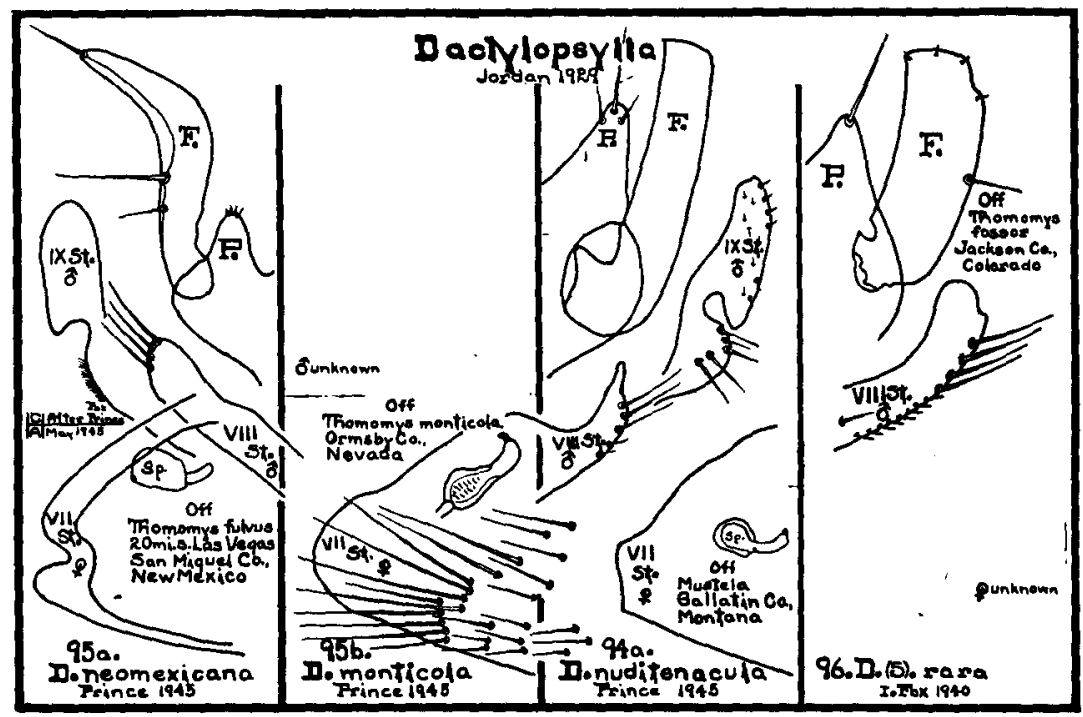

\section{5a. Dactylopsylla neomexicana}

Prince 1945

1945 Dactylopsylla neomexicana Prince, Can. Ent., 77:15.

According to the describer this species is close to Dactylopsylla bluei (C. Fox). It is described with the following characteristics:

Male and Female: Frontal tubercle small. Eyes absent. Preantennal region of head with 2 rows of bristles; ocular row with 5 to 7 bristles and upper row of bristles along antennal groove and a marginal row of 6 to 7 bristles on each side. Labial palpus five-jointed and extending approximately three-fourths the length of fore coxae. Pronotal ctenidium of 21 spines. Apical spines on the metanotum, 1, on the abdominal tergites, in male, I, II, and III, I, in female, I and II, 1 one each side. There are 3 or 4 large dark spine-like bristles on border of posterior apical sinus of mid and hind coxae.

Modified Segments, Male: Antepygidial bristles, 1 long well developed and 1 short undeveloped. Manubrium broad with apex curving upward. Immovable process $P$ of clasper short, broad, evenly rounded at apex and bears 3 to 5 bristles. Movable finger $F$ of clasper long, curving distad and acuminate. In general, finger has the appearance of a walking stick. Finger has an apical bristle and 3 bristles on 
posterior border. St. VIII concave on dorsal apical half and armed with 4 large bristles on ventral border, uppermost bristle apical. Internal portion of st. IX expanded at apex. Anterior lobe of external portion of st. IX long and bears numerous small pale bristles; upper lobe with posterior border convex and anterior border concave; there are several small bristles scattered over the upper lobe. Female: Antepygidial bristles 3 . Head of receptaculum seminis well pigmented, slightly longer than broad. Tail of receptaculum seminis shorter than head, broadest near apex, tip well sclerified, but not prominent. St. VII varies as illustrated. T. VIII concave on posterior border and armed with 40 to 50 bristles from stigma down. Stylet with an apical and 2 lateral bristles.

LENGTH: Female, 3.30 to $4.05 \mathrm{~mm}$., average $3.69 \mathrm{~mm}$. Male, 3.00 to $3.22 \mathrm{~mm}$., average $3.15 \mathrm{~mm}$.

Type Locality: San Migual County, New Mexico.

Type Host: Thomomys fulyus.

Holotype male, allotype female, 2 female and 5 male paratypes were collected 20 miles south of Las Vegas, San Miguel County, New Mexico, May 28, 1943.

Holotype and allotype are deposited in collection of United States Public Health Service Plague Investigation Station, San Francisco, California. Paratypes are deposited in United States National Museum, Washington, D. C.

\section{5b. Dactylopsylla monticola \\ Prince 1945}

1945 Dactylopsylla monticola Prince, Can. Ent., 77:17.

According to describer this species is also close to Dactylopsylla bluei and is known only from 2 female specimens which have the following characteristics:

Female: Frontal tubercle very small. Eyes absent. Preantennal region of head with an ocular row of 4 bristles, upper row of 6 bristles, several minute setae scattered over region and 1 large bristle at outer genal margin. Postantennal region of head with 1 large bristle, a row of minute bristles along antennal groove and a posterior row of 6 bristles on each side. Labial palpus five-jointed and extending to apex of fore coxae.

Pronotal Ctenidium of 22 spines. Apical spines on metanotum, 1 on each side; $t$. I and II have 2 apical spines on each side.

Modified Segments: Antepygidial bristles, 3, median one long. Head of receptaculum seminis semiglobular, ventral border almost straight, dorsal border convex. Tail of receptaculum seminis equals length of head, with large sclerotized tip. St. VII without sinus and bears 23 or 24 bristles on each side .T. VIII concave, with upper lobe acute. Stylet approximately 3 times as long as broad and bears an apical and 3 lateral bristles. 
LENGTH: $2.55 \mathrm{~mm}$. to $3.60 \mathrm{~mm}$., average $3.07 \mathrm{~mm}$.

TyPe Locality: Ormsby County, Nevada.

TYPE Host: Thomomys monticola.

Holotype female and I female paratype were collected 13 miles west of Carson City, Ormsby County, Nevada, August 19, 1937, on Thomomys monticola.

Holotype is deposited in collection of United States Public Health Service Plague Investigation Station, San Francisco, California. Paratype female is deposited in the United States National Museum, Washington, D. C.

\section{Dactylopsylla rara \\ I. Fox 1940}

1940 Dactylopsylla (Spicata) rara I. Fox, Wash. Acad. Sci. Jour., 30:275.

This species is known only from specimen upon which description is based, a male taken off Thomomys fossor (pocket gopher) in Jackson County, Colorado. Type was collected July 13, 1926 and is deposited in the United States National Museum.

Head: Lower genal row of 4 bristles, upper row of about 5. Eye absent. Postantennal region with marginal row of 6 or 7 bristles.

Pronotal Comb of about 28 teeth.

Modified SEgments: Illustration made by Fox shows process of clasper as weak, cone-shaped, while finger appears somewhat rectangular and slightly curved, both organs distinctly different from other Dactylopsylla. Posterior arm of IX st. with a number of small bristles distally. VIII st. broad, wider distally and armed on posterior margin with 5 or 6 heavily pigmented bristles and dozen or so weak ones.

LENGTH: $4.5 \mathrm{~mm}$.

\section{GENUS MIOCTENOPSYLLA ROTHSCHILD}

1922. Mioctenopsylla Rothschild. Rpt. Norwegian Exped. Novaya Zemlya 1921, No. 4.

1929. Boreopsyllus Ewing, A Manual of External Parasites 168 and 201.

Genotype: Mioctenopsylla arctica Rothschild 1921

One of the chief characteristics of this genus is the presence of an unusual pronotal comb which is made up of very pale teeth only onefifth the length of the pronotum. There are also on the pronotum 2 rows of bristles. Members of this genus made shaggy in appearance by presence of bristles on thoracic and abdominal tergites which curve slightly away from the body. Dorsal edges of abdominal tergites incurved and strongly denticulate.

Head possesses a small frontal tubercle. Eyes are large and black. Preantennal region with 2 rows of bristles and a third incomplete one; 
postantennal region with 4 irregular rows. No spiniforms. Five segments in labial palpus which does not reach to apex of coxa I.

Mid and hind coxae have rather numerous slender bristles on inner surface in apical half; hind coxa is narrow. Fifth tarsal segment is exceptionally slender, especially in hind tarsus. Segment $V$ bears usually 4 plantar bristles on one side and 5 on other.

This genus is represented in West by one Alaskan species, which is found on birds.

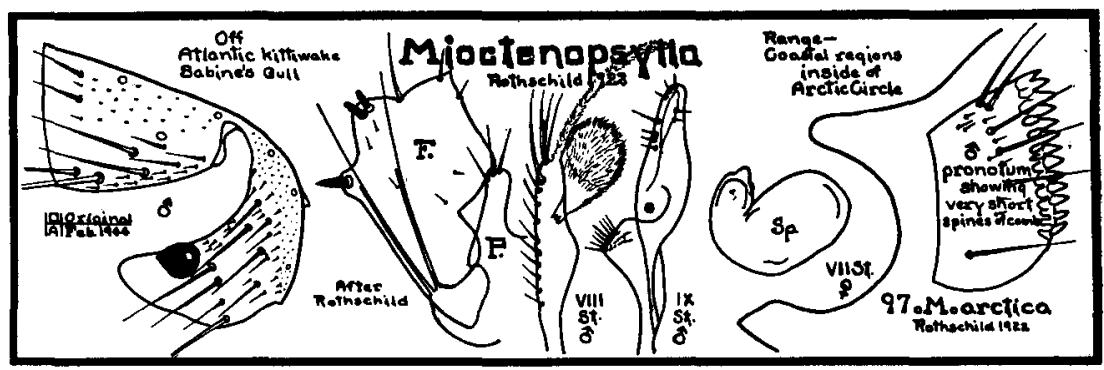

97. Mioctenopsylla arctica

Rothschild 1922

1922 Mioctenopsylla arctica Rothschild, Rept. Norwegian Exped. Novaya Zemlya 1921, No. 4, p. 4.

1927 Amphispylla hadweni Ewing, Wash. Biol. Soc. Proc., 40:89.

This species was described from 19 males and 31 females taken from nest of Rissa tridactyla (Atlantic kittiwake) on August 29, 1921, at Gribovii Fjord, Novaya Zemlya by the Norwegian Expedition of 1921. During 1927 from 2 females collected at Puffin Island, Alaska, from Xena sabini (Sabin's gull) August 6, 1920, by S. Hadwen, Ewing described this flea as $A$. hadweni.

This is a dark and fairly large species of Arctic bird flea.

Head: Frontal tubercle very prominent and sharp. Two rows of bristles on frons, lower row with 4 or 5 slender bristles and in male continued upwards at antennal groove by 2 or 3 additional bristles; second row consisting of 3 large ones and 1 or 2 smaller ones. Postantennal region with a row of 3 or 4 long bristles and 1 or 2 other long bristles and some shorter ones, number varying in individuals.

Thorax: Pronotal comb unique, pale, short. This comb is so short and pale that it may escape attention. Number of teeth vary from 22 to 30 . Teeth are one-fifth the length of pronotum.

Modified Segments, Male: Clasper short. Process $P$ resembles a boot with toe turned upwards and no heel. Two acetabular bristles are on a short truncate projection. Finger is very large. It is angulate, characteristically shaped and armed posteriorly with $\mathbf{3}$ short, black spiniforms. Two together are blunt, a sharp one is farther down, and 
above them, a few short bristles. IX st. is not curved distad, its apex is rounded-dilated on the posterior side and acuminate frontally. Ventral arm bears a pointed spine on inner surface of antimedian ventral lobe. Distal half of sternite is strongly narrowed apically. Female: VII st. with deep and broad sinus; lobe above sinus triangular with apex rounded off. There are 9 or 10 medium bristles on this sternite and 8 to 12 short ones. Spermatheca has an ovate head, the full length of which is $1 \frac{1}{2}$ times the width, and about as broad as the tail is long.

LENGTH: Original lengths given from unmounted specimens are male 2.2-3.0 mm., female $2.4-3.4 \mathrm{~mm}$.

Range: Probably throughout coastal regions inside Arctic Circle.

RECORDS: Known only from original records mentioned above.

\section{GENUS MALARAEUS JORDAN}

1933. Malaraeus Jordan. Nov. Zool., 39:76.

Genotype: Ceratophyllus telchinum Rothschild 1905

In this genus the eye is distinctly reduced, its longest diameter shorter than distance from eye to apex of angle of strongly chitinized portion of genal lobe. There are from 2 to 4 median bristles on occiput. Bristles of segment II of antennae short in male, reaching beyond

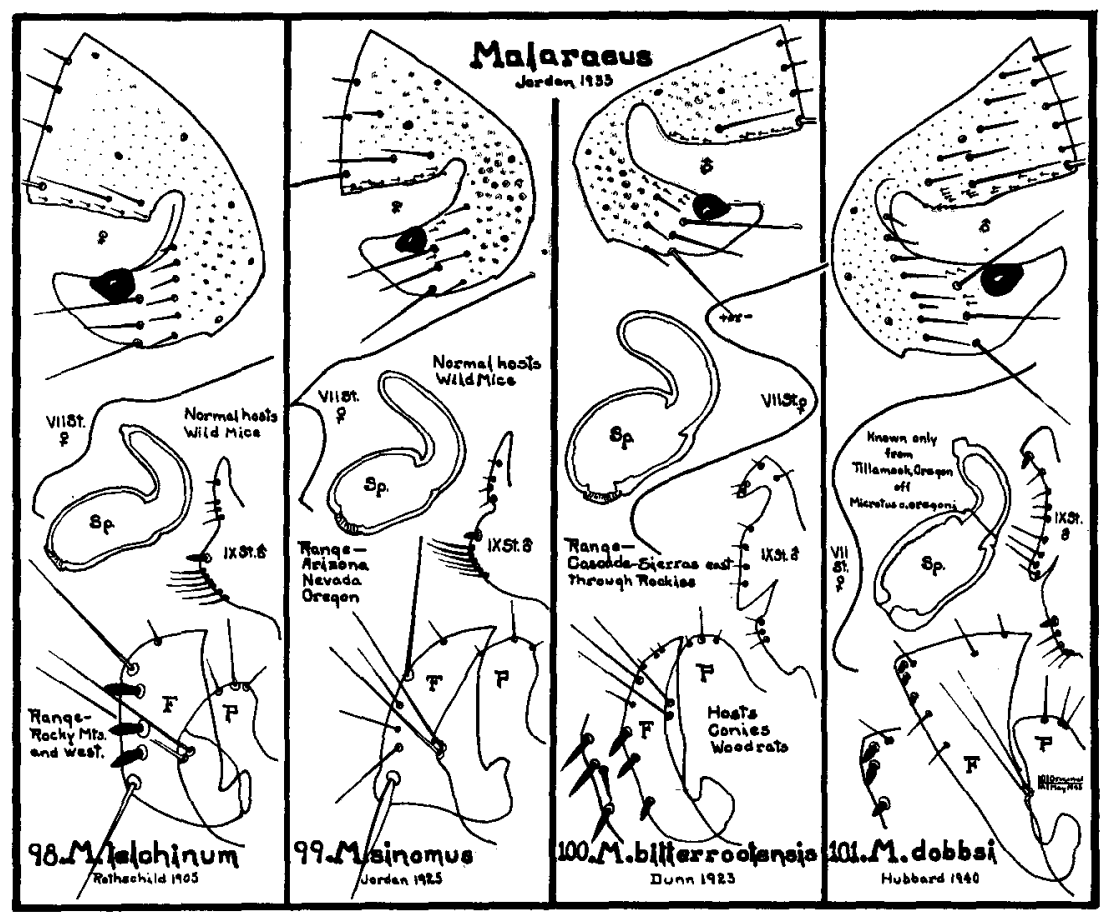


middle of club or shorter in female. In male VIII t. at most with traces of spiculose area at dorsal margin, VIII st. quite reduced in $M$. telchinum and $M$. sinomus or long and narrow and bearing one long apical bristle and fringed membranous flap in $M$. bitterrootensis and $M$. dobbsi. Apex of vertical arm of IX st. rounded on posterior side, little or no dilation. Female: Stylet without a dorsal lateral bristle. Stout bristles on anal sternite markedly curved. Head of spermatheca broad, more or less barrel-shaped, but concave beneath, widest either near orifice or in middle, much longer than broad, twice as wide as tail.

This genus is represented west of the 100th Meridian by 7 species, 6 of which are found upon mice, the seventh upon conies.

As one views side by side, 5 species here involved, it is apparent that each can be told from other by shape and armature of finger $F$ of clasper of male and by apical outline of VII st. of female. These characteristics brought into a key will result in:

Key to the Species of Malaraeus West of the 100th Meridian

1. Finger oblong, bearing bristle at each posterior corner, with three black spiniforms;

Apical outline of VII st. of female a single lobe, slightly swollen at dorsal

M. telchinum, p. 198

2. Finger somewhat triangular, armed with sharp blackish spine below and 4 stiff bristles above it;

Apical outline of VII st. of female with pointed lobe, sometimes almost hook-like

M. sinomus, p. 201

3. Finger somewhat scythe-blade-like armed posteriorly with 3 black spiniforms and a prominent bristle and a few shorter ones;

Apical outline of VII st. of female deeply sinuate, upper lobe shorter, less prominent than lower, lower rounded, upper with tendency to be pointed

M. bitterrootensis, p. 202

4. Finger in shape of blade of fireman's axe and armed with 3 short black spiniforms at posterior-dorsal angle;

Apical outline of VII st. of female with upper angle well rounded, lower lobe not so well rounded, sinus shallow

M. dobbsi, p. 204

5. Finger in shape of flattened isosceles triangle with 2 short black spiniforms at apex which points towards posterior;

Apical outline of VII st. of female deeply sinuate, well developed upper lobe as long as smaller lower triangular lobe; Alaska off mice

M. penicilliger dissimilis, p. 204

N.B.-The writer is not in possession of sufficient data to key or illustrate M. euphorbi off mice from British Columbia or M. eremicus off mice from Arizona. 


\section{Malaraeus telchinum Rothschild 1905}

1905 Ceratophyllus telchinum Rothschild, Nov. Zool., 12:153.

1925 Ceratophyllus telchinum Jordan, Nov. Zool., 32:115.

1933 Malaraeus telchinum Jordan, Nov., Zool., 39:76.

1936 Malaraeus telchinum Wagner, Can. Ent., 68:202.

1940 Malaraeus telchinum Hubbard, Pacific Univ. Bul., 37:6:2.

This flea was described from specimens received by Rothschild from G. F. Dippie who collected 2 males, one off Evotomys gapperi (Rocky Mountain red-backed mouse), the other off Sorex richardsoni (shrew), both from Kicking Horse Canyon, British Columbia, Canada, during October of 1903.

Modified Segments, Male: Describer says VIII t. is large and bears behind stigma a patch of hairs and further back 6 or 7 long bristles, VIII st. is very small, being almost concealed by VIIth. Process of clasper is short and round, bearing 3 bristles at apex and 2 long bristles at junction with finger; finger is broad, almost oblong, bearing close to distal edge 1 stout bristle at lower corner, a longer one at upper corner, and between them 3 short stout spine-like bristles; IX st. bears a patch of long thin bristles proximally of sinus. FEMALE was not known at time of original description, but today it is known to have a spermatheca that is somewhat barrel-shaped and slightly concave on ventral surface, much longer than broad with a tail bent hook-like and with membranous appendage at tip. Apical margin of VII st. is but a single lobe which has a small'swelling at dorsal angle.

LENGTH: Original length of male was given as $1.8 \mathrm{~mm}$. Females in collection of writer measure $2.5 \mathrm{~mm}$.

RANGE: Records of this species from Montana, Utah, Idaho, Nevada, California, Oregon, Washington and British Columbia. These would suggest a range from the Rocky Mountains west through Great Basin, into and through the Cascade-Sierra-Nevada Mountains, thence on west through the Siskiyou Mountains of Oregon and California almost to Pacific Ocean, through central California and south to ocean and in Washington as far west as Vancouver, Clark County. To north flea was described from British Columbia but it has not as yet been recorded from Alaska or Alberta.

Seasonal Distribution: This flea can be taken off its host during all seasons of year.

Host Preference: While generally taken off Peromyscus (deer mice), this species is frequently found on other wild mice such as $M i$ crotus (meadow mice), Clethrionomys (red-backed mice), Reithrodontomys (harvest mice), and their carnivores.

Medical Importance: Eskey and Hass (1940) failed to have any of 75 of these fleas transmit plague to guinea pigs even though blockage developed in them. Wheeler and Douglas (1941) failed to obtain trans- 
mission of plague by this flea in mass feedings involving white mice. During 1944 A. L. Burroughs of Hooper Foundation at San Francisco reported successful transmission of plague by this flea. Seventy-five of these fleas fed upon a plague infested Peromyscus maniculatus (deer mouse) transmitted plague to a Microtus (meadow mouse); 100 fed upon a plague-positive Microtus transmitted plague to another Microtus, and 75 fed upon a plague-positive white mouse transmitted plague to Microtus. Degree of effectiveness as a vector of plague had not at the time been determined for this species.

RECORDs: This rather common western species has many recorded occurrences, a few of which follow:

BRITISH COLUMBIA-off:

Clethrionomys (Evotomys) gapperi (red-backed mouse), Kicking Horse Canyon, 1 male

Sorex richardsoni (shrew), Kicking Horse Canyon, 1 male.

WASHINGTON-The writer has collected this flea as far west at Vancouver, Clark County, and in many localities east into the Great Basin of this state, off:

Peromyscus maniculatus oreas Bangs (Washington deer mouse), Camas, Clark County, May 21, 1943, 2 pairs; Cape Horn, Skamania County, April 2, 1943, 1 male

Peromyscus maniculatus gambeli Baird (Gambel's deer mouse), Guler, Klickitat County, May 15, 1943, 2 females; Grand Dalles, Klickitat County, June 14, 1938, 1 male

Reithrodontomys megalotis nigrescens Howell (dusky harvest mouse), Toppenish, Yakima County, January 29, 1942. 1 male

Microtus mordax mordax Merriam (Rocky Mountain meadow mouse), Bickleton, Klickitat County, June 16, 1938, 2 males.

OREGON-The writer has collected this species off:

Peromyscus truei gilberti Allen (Gilbert's big-eared deer mouse), Oregon Caves Junction, Josephine County, August 27, 1937, 1 male

Peromyscus maniculatus gambeli Baird (Gambel's deer mouse), Wamic, Wasco County, May 18, 1937, 3 pair

Peromyscus maniculatus rubidus Osgood (ruddy deer mouse), Takilma, Josephine County, June 18, 1939, 1 male

Reithrodontomys megalotis megalotis Baird (desert harvest mouse), Plush, Lake County, July 1, 1939, 1 male

Reithrodontomys megalotis longicaudus Baird (California harvest mouse), Watkins, Josephine County, January 5, 1942, 1 female; Merlin, Josephine County, December 29, 1941, 1 male; Brownsboro, Jackson County, January $2,1942,2$ males

Clethrionomys californicus mazama Merriam (Mazama red-backed mouse), Crater Lake, Klamath County, 7,200 ft. el., August 29, 1933, 1 male

Microtus mordax mordax Merriam (Rocky Mountain meadow mouse), Adel, Lake County, June 30, 1939, 2 males, 1 female

Neotoma cinerea occidentalis Baird (western bushy-tailed wood-rat), Wamic, Wasco County, May 18, 1937, 1 male

Mustela longicauda saturata Merriam (Cascade weasel), (accidental), Fall Creek, Lane County, January 10, 1932, 1 male.

CALIFORNIA-The writer has the following records from northern California off:

Peromyscus maniculatus rubidus Osgood (ruddy deer mouse), Smith River, 
Del Norte County, December 30, 1941, 1 male, 4 females

Peromyscus maniculatus gambeli Baird (Gambel's deer mouse), Macdoel, Siskiyou County, March 21, 1943, 1 male; Tule Lake, Siskiyou County, April 19, 1942, series; Pine Creek, Modoc County, June 18, 1937, 1 male; Fort Bidwell, Modoc County, June 25, 1937, 1 male; Truckee (4 mi. s.), Placer County, June 23, 1944, 1 male

Around the San Francisco Bay region of central California, Mitzmain recorded this flea off Microtus californicus as early as 1909. Holdenried, collecting materials for Burrough's plague experiments (1944) upon this species, took large numbers of them off Microtus californicus, Peromyscus maniculatus, and Rattus norvegicus at an undisclosed locality around San Francisco Bay. Although Augustson did a great deal of collecting in central Sierra-Nevada Mountains of California, he did not list this species as secured.

Augustson's records for this species in southern California are many, off:

Peromyscus maniculatus gambeli Baird (Gambels deer mouse), Los Angeles, Riverside, Santa Barbara, and San Diego Counties.

Peromyscus californicus insignis Rhoads (southern parasitic mouse), Los Angeles, Riverside, Santa Barbara and San Diego Counties

Peromyscus eremicus fraterculus Miller (San Diego desert mouse), Los Angeles County

Peromyscus boylii rowleyi Allen (Rowley deer mouse), Los Angeles County

Microtus californicus sanctidiegi R. Kellogg (southern California meadow mouse), Los Angeles and Riverside Counties

Microtus californicus stephensi, Playa Del Rey Salt Marsh, Los Angeles County

Microtus sp. (meadow mouse), Big Bear Lake, San Bernardino County

Neotoma fuscipes macrotis Thomas (large-eared wood rat), Santa Monica Mountains, Los Angeles County

Neotoma lepida intermedia Rhoads (Rhoads wood rat), San Gabriel Moun. tains, Los Angeles County •

Neotoma sp. (wood rat), Santiago Canyon, Orange County

Reithrodontomys megalotis longicaudus Baird (California harvest mouse), Santa Barbara and Los Angeles Counties

Rattus rattus rattus Linnaeus (black rat), Santa Catalina Island, Los Angeles County

Dipodomys sp. (kangaroo rat), Santa Barbara County.

NEVADA-The writer has procured this flea throughout the northern half of this state off:

Peramyscus maniculatus gambeli Baird (Gambel's deer mouse), Wells, Elko County, July 6, 1944, 1 male; Contact, Elko County, July 2, 1944, 1 pair; Battle Mountain, Lander County, June 30, 1944, 2 males; Vya, Washoe County, June 16, 1944, 2 pair, and in

IDAHO-off:

Peromyscus maniculatus gambeli Baird (Gambel's deer mouse), Burley, Cassia County, July 4, 1944, 1 male.

ARIZONA-Off:

Peromyscus maniculatus rufinus Merriam (tawny deer mouse), North Rim, Grand Canyon, Coconino County, July 7, 1945, 2 pair; and in

UTAH-Off:

Peramyscus maniculatus rufinus Merriam (tawny dear mouse), Rubys Inn, Bryce Canyon, Garfield County, July 10, 1945, 1 male. 
From this state reported as "probably telchinus (sic.) Roths" off: Peromyscus spp. (deer mouse), Etna and Fillmore Neotoma spp. (wood rat), Logan Canyon.

MONTANA-From Ravalli County this species is reported off: Microtus spp. (meadow mouse) Peromyscus spp. (deer mouse) Sylvilagus spp. (cottontail).

\section{Malaraeus sinomus Jordan 1925}

1925 Ceratophyllus sinomus Jordan, Nov. Zool., 32:110.

1933 Malaraeus sinomus Jordan, Nov. Zool., 39:76.

1940 Malaraeus sinomus Hubbard, Pacific Univ. Bul., 37:6:2.

This species was described from materials gathered by O. C. Duffner off "Mus" during December of 1913 at Paradise, Arizona. Describer states this species is close to M. telechinum and that hind-tarsal segment I of male, as in that species, with long slender bristles, and st. VIII vestigial, without bristles. In female, stylet with one long lateral bristle, and occiput with small bristle above long median one. MaLE: Process $\mathbf{P}$ of clasper broad, of nearly even width, not acuminated, finger $F$ triangular, reaching only to apex of $\mathbf{P}$, posterior margin rounded, apex pointed, directed capitad, at lower angle which is rounded off, a long stout, straight, sharp spine, from this blackish spine upward a row of 4 stiff bristles, all much thinner than spine, lower 3 also shorter, upper 1 longer.

LENGTH: Specimens in collection of writer measure, male $2 \mathrm{~mm}$., female $2.2 \mathrm{~mm}$.

RANGE: Probable range of this species extends from Columbia River, southeast through Great Basin region of Oregon, Nevada, and Arizona, thence westward through southern California.

Host Preference: This species seems to be a Peromyscus (deer mouse) flea, and can also be found upon its carnivores.

RECORDs: The writer has but few records for this species:

OREGON-Off:

Peromyscus maniculatus gambeli Baird (Gambel's deer mouse), Mitchell, Wheeler County, May 13, 1939, 3 males, 1 female.

Although repeated trappings were carried on at this location to secure more specimens, no others were taken.

NEVADA-Off:

Onchomys leucogaster fuscogriseus Anthony (Oregon grasshopper mouse), Humboldt County ( 4 miles south of Denio, Oregon), July 5, 1939, 2 females

Peromyscus maniculatus gambeli Baird (Gambel's deer mouse), south end of Lake Tahoe, Douglas County, June 21, 1944, 1 male. Searchlight, Clark County, July 1, 1945, 7 males, 4 females

In eastern Nevada, Stanford reports this flea off Peromyscus spp. and Neotoma spp. taken at Wilson Ranch. 
CALIFORNIA-Augustson, working in southern California, seems to have found a dense population of these fleas there and has offered many records, some of which are from Palm Springs, Riverside County, off:

Onychomys torridus pulcher Elliot (desert grasshopper mouse)

Peromyscus crinitus stephensi Mearns (Stephens canyon mouse)

Peromyscus eremicus eremicus Baird (desert deer mouse)

Peromyscus eremicus fraterculus Miller (San Diego desert mouse), Santa Monica Mountains, Los Angeles County

Peromyscus californicus insignis Rhoads (southern parasitic mouse), Los Angeles, Santa Barbara, and Riverside Counties

Peromyscus californicus sanctidiegi, San Gabriel Mountains, Los Angeles County

Reithrodontomys megalotis longicaudus Baird (California harvest mouse), San Gabriel Mountains, Los Angeles County.

ARIZONA-Augustson has also taken this flea off:

Peromyscus crinitus stephensi Mearns (Stephens canyon mouse), Alvardo Mine, Yavapai County

Peromyscus eremicus eremicus Baird (desert deer mouse), Cibola, 30 miles north, Yuma County.

The materials from which the species was described came off "Mus" taken at Paradise, Cochise County.

UTAH-This species has been reported off:

Peromyscus maniculatus subsp. (deer mouse), Logan Canyon, Cache County Peromyscus spp. (deer mouse), Salina, Sevier County

Neotoma spp. (wood rat), Salina, Sevier County.

\section{Malaraeus bitterrootensis Dunn 1923}

1923 Ceratophyllus bitterrootensis Dunn, U. S. Pub. Health Repts., 38:47:2771.

1925 Cerotophyllus isus Jordan, Nov. Zool., 32:110.

1929 Ceratophyllus bitterrootensis Jordan, Nov. Zool., 35:36.

1933 Malaraeus bitterrootensis Jordan, Nov. Zool., 39:76.

1936 Malaraeus bitterrootensis Wagner, Can. Ent., 68:202.

1940 Malaraeus bitterrootensis Hubbard, Pacific Univ. Bul., 37:6:2.

This species was described from two males taken off Neotoma (wood rat) west of Darby, Montana. During 1925 Jordan also described this species under the name of $C$. isus from a small series of both males and females taken off "Mus" by A. D. Gregson on Red Deer River, in Canadian Rocky Mountains of Alberta, Canada. Jordan says of this species in his description, that in male there are only 2 long bristles near ventral margin of $t$. VIII, st. VIII long and slender, bearing apically 3 long bristles on each side, one behind the other, and a fringed membranous flap. Proximal ventral lobe of st. IX long, apical lobe strongly excised ventrally before apex, hook-shaped. In collection of the writer are 12 males in which finger $F$ is more or less scythe blade shaped, with lower half of posterior border armed with 3 stout blackish bristles which approach spiniforms in shape, all about same length and generally pointing downwards and backwards, upper half armed with one long bristle, one medium bristle below it and several smaller 
ones above. Process $P$ is well rounded with 2 or 3 small bristles at apex and where it joins with $\mathrm{F} 2$ long bristles. Of female, Jordan says that st. VII is deeply sinuate, upper lobe narrow, variable, much shorter than lower lobe, which is rounded subacuminate, stylet twice as long as broad, cylindrical to two-thirds or beyond, with one longish lateral bristle, upper angle of widened portion of t. VIII a little projecting.

LENGTH: Jordan's original lengths are, male 2.3 to $2.9 \mathrm{~mm}$., female 2.8 to $3.3 \mathrm{~mm}$.

While the original description was based on materials taken off wood rats and Jordan described from materials off "Mus", it seems to this writer that the preferred host, probably the true host, of this species is the cony. Evidence to support this belief consists of 12 males and 14 females in collection of the writer, all but 2 males and 1 female of which were collected from conies. One male was collected from a pine squirrel which lived in a cony slide and 1 male and 1 female were taken off a wood rat which was trapped in a cony slide. Twelve pairs were taken off 80 conies which seems to show rather light infestation; collections were made from June through mid-October.

RANGE: Described from Darby, Montana, and Red Deer, Alberta, Canada, both locations in Rocky Mountains, species ranges to west and is found in all cony colonies of Washington, Oregon, and probably northern California, and Nevada.

RECORDS: Representative data from the collection of the writer are: OREGON-Off:

Ochotona princeps brunnescens Howell (Cascade cony), Cloud Cap Inn, 5,500 ft. el., Hood River County, July 3, 1935, 1 pair

Ochotona fenisex fumosa Howell (dusky cony), summit of McKenzie Pass, Lane County, July 14, 1938, 1 male

Ochotona schisticeps taylori Grinnell (Warner Mountain cony), site of old Fish Hatchery, Adel-Lakeview Highway, 22 miles east of Lakeview, Lake County, June $30,1939,2$ females

Ochotona schisticeps jewetti Howell (Blue Mountain cony), Wallowa Lake, Wallowa County, July 14, 1939, 1 pair.

Accidental Occurrences off:

Sciurus douglasi cascadensis Allen (Cascade pine squirrel), (shot in a rock slide where conies were plentiful), Fish Lake, Santiam National Forest, Linn County, July 21, 1938, 1 male

Neotoma cinerea occidentalis Baird (Western bushy-tailed wood rat), Wal1 lowa Lake, Wallowa County, July 14, 1939, 2 males, 1 female.

WASHINGTON-Off:

Ochotona princeps brunnescens Howell (Cascade cony), Goose Lake, Skamania County, August 12, 1935, 1 pair.

CALIFORNIA-Augustson reports this flea from the central Sierra-Nevada Mountains off:

Peromyscus maniculatus sonoriensis Le Conte (Sonoran deer mouse), Mammoth Lake, Mono County, August 10, 1941, 1 male,

Between October 19 and 22, 1944, the writer removed this flea off:

Peromyscus maniculatus gambeli Baird (Gambel's deer mouse), Eagleville, Modoc County, 1 male; and between same dates in 
NEVADA:

Vya, Washoe County, 6 males.

UTAH-This species is reported from Logan, Cache County, off:

Neotoma c. cinerea (wood rat)

Peromyscus maniculatus (deer mouse)

Microtus (meadow mouse)

Peromyscus truei truei Shufeldt (True deer mouse), Fillmore, Millard County.

MONTANA-In the state of Montana there is more evidence of this flea being taken off wood rats than off conies, which has led to belief in some circles that this species is a wood rat flea, rather than a cony flea. Available records for this state are, off:

Neotoma cinerea (wood rat), Beaverhead, Madison, Ravalli Counties

Ochotona princeps (cony), Ravalli County.

BRITISH COLUMBIA-Records available for this species from this Canadian province state simply B. C. (Spencer).

ALBERT A-Specimens from which Jordan described Ceratophyllus isus in 1925 were taken off "Mus" at Red Deer River, Canadian Rocky Mountains.

\section{Malaraeus dobbsi \\ Hubbard 1940}

1940 Malaraeus dobbsi Hubbard, Pacific Univ. Bul., 37, No. 6.

This species was described from a series of both males and females taken off Oregon creeping meadow mice secured from one trap line on August 30, 1937, at Tillamook, Oregon. The species has not again been found by the writer, although the location has been repeatedly trapped.

Both male and female are quite different from other western species of this genus. Post-antennal region of head of both sexes differs from preceding species by presence of 3 distinct rows of bristles totaling about 15, preceding species having only a few bristles. Finger $F$ of male is very prominent and in shape of blade of a fireman's axe. At posterior-dorsal angle it is armed with 3 short, black spiniforms, 2 close together at angle, one slightly to ventral. Few minor bristles on finger. In female spermatheca is quite barrel-shaped, tail having a distinct appendage at its apex. Apical margin of VII st. of female has an upper lobe well rounded, a lower and lesser lobe, not so well rounded, sinus between, shallow.

LeNGTH: Males $2.50 \mathrm{~mm}$., females $3.00 \mathrm{~mm}$.

RECORD: The only record for this species in collection of the writer is from:

Microtus oregoni oregoni Bachman (Oregon creeping meadow mouse), Tillamook, Tillamook County, Oregon, August 30, 1937, 10 males, 6 females, the types.

\section{Malaraeus penicilliger dissimilis \\ Jordan 1938}

1938 Malaraeus penicilliger dissimilis Jordan, Nov. Zool, 41:119.

In describing this subspecies Jordan states that this is the Alaskan race of a species that ranges from Lapland to the Alps, and to western 


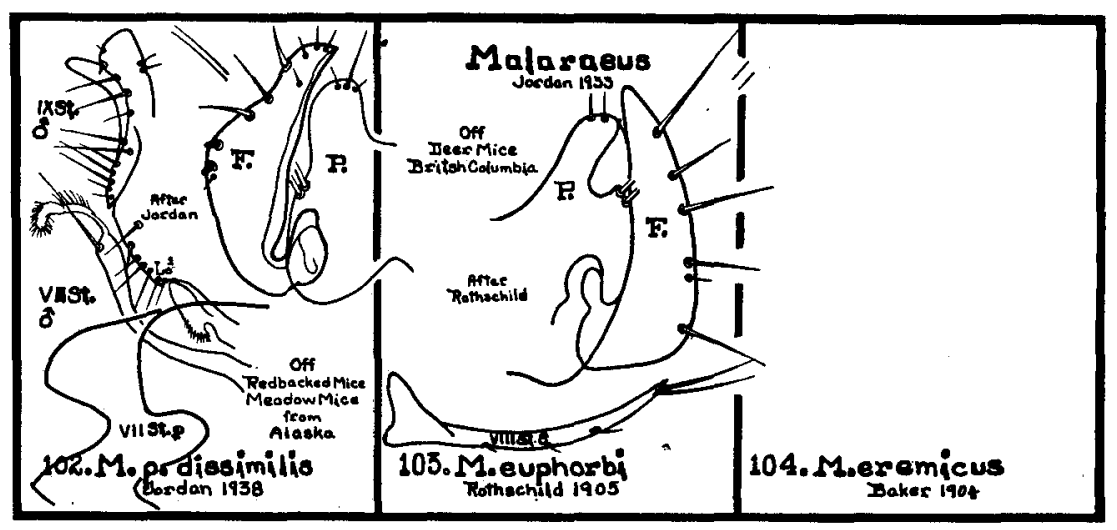

mountains of Transylvania, and from England to Japan.

Specimens upon which the description is based were 7 males and 3 females taken off red-backed mice and meadow mice at Rapids and Fairbanks, Alaska, during July of 1937. Specimens were sent to Dr. Jordan by Dr. Parker of Spotted Fever Laboratory at Hamilton, Montana.

Modified Segments, Male: In comparing Alaskan race with Old World races Jordan says process $P$ of clasper is longer and that acetabular bristles, of which there are sometimes 3 , are thinner and shorter. Finger $\mathrm{F}$ is as broad as in $M$. p. penicilliger at widest point, but much longer, therefore appearing slenderer, dorsal rounded bay between short pedicel and main body of $\mathrm{F}$ wider than in Old World examples. After studying Jordan's illustrations the writer would describe finger as somewhat in shape of a much flattened isosceles triangle with apex pointing posteriorly and at apex 2 short blunt black spiniforms. Above spiniforms a somewhat modified long stout bristle, then a normal long bristle followed by a third bristle which is modified and long. At apex of finger several short bristles. Jordan further states that proximal, elongate-oblong partion $\mathrm{Lo}^{1}$ of IX st. longer and its subspiniform bristle shorter and thinner than in penicilliger, and that st. VIII is narrower, especially widened apical portion, and this portion and widened basal one farther apart, i. e., the narrow median portion, longer. Process of paramere longer and narrower. FEmale: According to Jordan VII st. is deeply sinuate, upper lobe variable, broad, dorsally rounded.

RANGE: Northern portion of northwestern North America.

RECORDS of this species are:

ALASK A-Off:

Microtus sp. (meadow mouse), Flat, March 1925

Evotomys dawsoni (red-backed mouse), Rapids, July 1937, 3 males and 3 females (Jordan)

Microtus sp. (meadow mouse), Fairbanks, July 1937, 2 males; Cantwell, 1937, 1 male

Lepus americanus (varying hare), Rapids, July 19, 1937, 1 male. 


\section{BRITISH COLUMBIA-Off:}

Peromyscus maniculatus borealis (deer mouse), Atlin, August 10, 1931, 2 females (Jordan).

\section{Malaraeus euphorbi Rothschild 1905}

1905 Ceratophyllus euphorbi Rothschild, Nov. Zool., 12:165.

This species was described from a single male taken off Peromyscus canadensis (deer mouse), by G. F. Dippie, October 13, 1903, at Horse Creek, Upper Columbia Valley, British Columbia.

Modified SEgmeNTs: Rothschild says VIII $t$. bears 4 bristles at dorsal edge from stigma to apex, first being thin and short and fourth standing close underneath third. There are, moreover, about 5 more bristles further down, and a vertical row of 3 near ventral margin. VIII st. is long, rod-like and curved, bearing one bristle at apex on each side. Process of the clasper is broad, rounded at apex, nearly reaching to tip of finger and bearing at distal side a pair of long bristles half way down towards insertion of finger. Finger is long, almost straight on proximal side, but evenly rounded on distal side. It bears 5 bristles on distal side of which ventral one is stoutest and uppermost is longest.

LENGTH: Original length of male is given as $2.5 \mathrm{~mm}$.

RANGE: Nothing is known about the range of this species.

\section{Malaraeus eremicus \\ Baker 1904}

1904 Ceratophyllus eremicus Baker, Proc. U. S. Nat. Mus., 27:417.

1933 Malaraeus eremicus Jordan, Nov. Zool., 39:76.

Baker described this species from 2 females taken out of nest of Peromyscus eremicus (deer mouse), collected in Santa Rita Mountains, Arizona. One of chief characteristics marking this species from others of Malaraeus is length of first segment of hind tarsus, which is said to be longer than that of second, third and fourth combined. During 1933 Jordan stated that male genitalia of $M$. eremicus are remarkably different from those of other species of Malaraeus.

Little else is known about this Arizona species. Illustrations for it have never been released.

\section{GENUS NOSOPSYLLUS JORDAN}

1933. Nosopsyllus Jordan. Nov. Zool., 39:76.

Genotype: Pulex fasciatus Bosc 1801

Similar to Malaraeus but segment I of hind-tarsus a little shorter than II and III together, no bristles of segment II and III reaching beyond the segment following. Eye well developed. Ocular bristle on level with or slightly above upper margin of eye. Frontal tubercle 
small and acuminate. Pronotal comb with 18 or 20 teeth. Male: Posterior process of st. IX dilate, sinus dividing 2 lobes, finger $F$ without spiniforms. Female: Anal sternite angulate in middle, spermatheca with large head, which is more strongly rounded above than below, tail long and curved about head.

This genus is represented west of 100th Meridian by but a single species which is parasitic upon Norwegian, black and roof rats, and can be occasionally taken as a stray off other rodents.

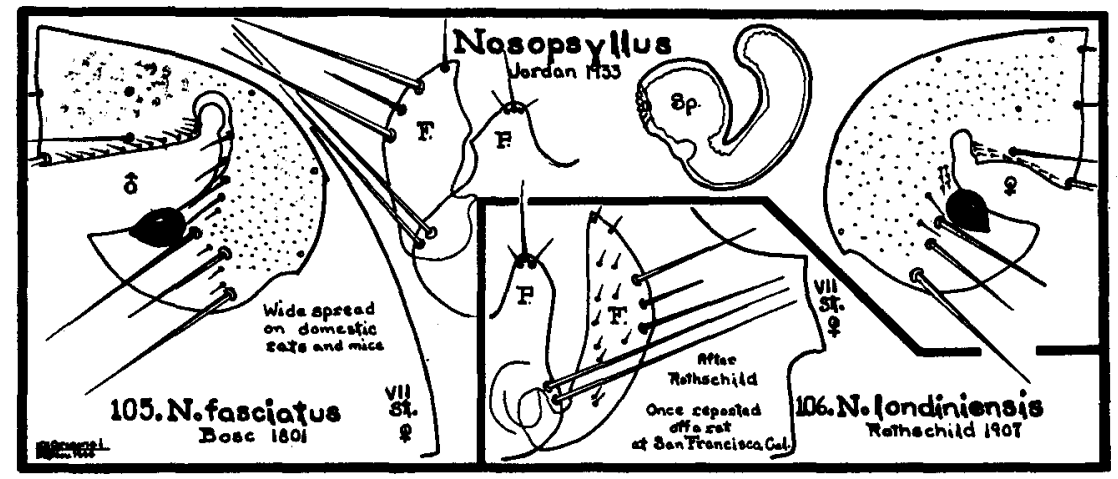

105. Nosopsyllus fasciatus

Bosc 1801

1801 Pulex fasciatus Bosc, Bul. de Sci. p. Soc., Philo. No. 44, Vol. II, p. 156.

1895 Pulex fasciatus Baker, Can. Ent., 27:111.

1896 Pulex fasciatus Osborn, USDA Div. Ent., Bul. V (n.s.), p. 148.

1904 Ceratophyllus oculatus Baker, Proc. U. S. Nat. Mus., 37:387

1904 Ceratophyllus canadensis Baker, Proc. U. S. Nat. Mus., 37:388.

1940 Nosopsyllus fasciatus I. Fox, Fleas of the Eastern United States, p. 73.

1940 Nosopsyllus fasciatus Holland, Ent. Soc. B. C., No. 36.

1943 Nosopsyllus fasciatus Prince, Pub. Health Repts., 58:700.

This common species, found generally wherever there are house rats and mice, needs little introduction. In both male and female the species can be differentiated from all other fleas by characteristic ModIFIED SEGments, and their presence upon their normal hosts, the house rats and mice. MALE: Three antepygidial bristles on each side, middle one about 3 times as long as upper bristle, lower one reduced to a small seta. Process $\mathbf{P}$ of clasper is broad, with a prominent posterior angle, armed at apex with 2 or 3 small bristles. Finger $F$ is evenly rounded posteriorly, the posterior margin bearing 2 stout bristles, between which there is a much smaller one and 1 or 2 others at the apex. Female: Three antepygidial bristles on each side, uppermost being shorter than others. Apical margin of VII st. is irregularly rounded or slanting. Head of spermatheca is globular, tail about $1 \frac{1 / 2}{2}$ times as long as head and curved around it. 
This is common rat flea found on house mice and rats all over Europe and North America. It has long been condemned as one of those fleas most concerned in bubonic plague transmission in these two continents. West of Rocky Mountains this flea is found wherever there are Norwegian, black or roof rats or house mice. At times where other rodents come in contact with farmyard rats and mice, these also will occasionally carry this flea as accidental infestation.

Infestation of this flea on rodents is at its minimum during winter months. A sharp increase in number of the fleas can be noticed after the middle of April and they are abundant and at their maximum during hot summer months, then occurs a sharp decline in numbers until winter minimum is reached.

RECORDS in collection of the writer are:

\section{OREGON-Off:}

Mus musculus musculus Linnaeus (house mouse), Forest Grove, Washington County, January 4, 1935, 1 male, I female

Rattus norvegicus Erxleben (Norwegian rat), Forest Grove, Washington County, September 1, 1931, 5 males, 4 females

Rattus norvegicus Erxleben (nest under old hay cock), Corvallis, Benton County, March 24, 1939, 20 males, 15 females

Rattus rattus rattus Linnaeus (black rat), Portland, Multnomah County, August 25, 1935, 1 male, 2 females,

Accidental Occurrences off:

Peromyscus maniculatus rubidus Osgood (ruddy deer mouse), taken close to a chicken yard, Cherry Grove, Washington County, November 22, 1933, 1 male

Tamia-sciurus douglasi douglasi Bachman (pine squirrel), shot from roof of a . stable, Albany, Linn County, May 7, 1938, I male

Fiber zibethicus occipitalis Elliot (Oregon coast muskrat), captured at a stream running through a barnyard, Forest Grove, Washington County, October 3, 1931, 1 male.

WASHINGTON-Off:

Rattus norvegicus Erxleben (Norwegian rat), Kalama, Cowlitz County, September 15, 1938, 2 males, 3 females

Citellus columbianus columbianus Ord (red digger squirrel), trapped from a stable yard, Lowden, Walla Walla County, July 15, 1939, 1 male.

CALIFORNIA-As early as 1908 Carroll Fox in Public Health Reports 23:1371 says that Ceratophyllus fasciatus is the common rat flea of San Francisco, California locality, while Xenopsylla cheopis follows, not a very close second, the proportion being about 3 to 1 .

BRITISH COLUMBIA-Holland records 23 specimens of this species from Norwegian rats at Vancouver, September 8, 1938.

By far the largest study on the range of this species in West comes from F. M. Prince of the Plague Suppressive Measures Laboratory at San Francisco. During 1943 he reported this flea:

From Rattus norvegicus Erxleben (Norwegian rat), as follows:

CALIFORNIA: San Diego, Berkeley, Oroville, Walnut Grove, Colusa, Maxwell, Willows, Orland, and Nicolaus. 
COLORADO: Fort Collins, Denver, Edgewater, and Limon.

IDAHO: Lewiston.

MONTANA: Sidney and Savage.

NEBRASKA: Chadron, Alliance, and Sidney.

NEW MEXICO: Los Lunas and State Line.

OREGON: Corvallis, Marshfield, Roseburg, Eugene, Newport, The Dalles, and Lexington.

TEXAS: Amarillo.

UTAH: Salt Lake City, Provo, and Payson.

WASHINGTON: Spokane, Cheney, Spangle, Plaza, and Medical Lake.

WYOMING: Fort McKenzie.

From Rattus rattus alexandrinus Geoffrey (Alexandrine or roof rat) .

CALIFORNIA: Modesto.

NEVADA: Reno and Sparks.

TEXAS: Newman.

UTAH: Salt Lake City.

From Rattus rattus rattus Linnaeus (black rat).

OREGON: Newport.

\section{Nosopsyllus londiniensis \\ Rothschild 1903}

1903 Ceratophyllus londiniensis Rothschild, Ent. Record, 15:64.

1910 Ceratophyllus londiniensis Rothschild, Bul. Ent. Research, 1:95.

Carroll Fox reported this Old World flea off "black rat, Mus rattus" from San Francisco County, California, during 1909. The flea has not again been recorded from this country.

Rothschild's original description appears much as follows: This species is allied to Ceratophyllus fasciatus and resembles that insect in absence of VIII st. in male. It differs, however, in being much smaller and paler and having more bristles on hind tibia. Modified SEGMENTS are, however, abundantly distinct. Process $\mathrm{P}$ is boot-shaped and bears at its apex 3 bristles, of which one is longer than process. "Movable finger" $F$ is much longer than that of $C$. fasciatus. It bears, as in that species, 2 long ventral bristles and a few small ones in addition. Two long bristles have a different position from those of $C$. fasciatus, being much more proximal in position. Distance between second bristle and pointed apex of finger is more than twice as great as distance from one bristle to other. IX st. is deeply sinuate ventrally. It bears many hairs, which are very small with the exception of 1 or 2 on proximal lobe close to sinus. The VII st. of female with truncate lobe, each side bearing about 9 bristles.

In 1910 Rothschild stated, "The comb of the prothorax consists of 18-20 spines. The movable process of the clasper of the male is longer than in C. fasciatus, pointed and widest near the center; its proximal 
margin is nonangulate. The sternite of the seventh abdominal segment of the female has a broad truncate lobe. The species is widely distributed on rats and mice. It is apparently rare, but a large number of specimens were once taken in London (South Kensington)."

LeNGTH: Original lengths given as male $1.9 \mathrm{~mm}$., female $2.5 \mathrm{~mm}$.

RANGE: As far as North America is concerned, this species has been recorded only once, from San Francisco off a black rat.

Original description was based upon a large series taken off house mouse (Mus musculus) from South Kensington(London), May 1900.

\section{GENUS MEGABOTHRIS JORDAN}

1933. Megabothris Jordan. Nov. Zool., 39:77.

Genotype: Ceratoplyllus walkeri Rothschild 1902

Stigma cavity of VIII t. very large, stigmata of metapimerum and abdominal segment II rather large and appearing doubled up (as in Ceratophyllus). Pronotal comb with about 10 teeth to side. Eye not reduced. No bristles of hind tarsal segments I and II reaching beyond segment following. Fifth tarsal segment of each leg with basal pair of plantar bristles noticeably displaced toward median line, other 4 pairs of plantar bristles unchanged. MALE: Longest bristle of segment II of antenna extending to near or beyond middle of comb. VIII st. narrow, with 1 or 2 apical bristles (each side) and a membranous flap. IX st. widest at apex. Finger $F$ with 1 or more heavily pigmented spiniforms on posterior margin. Female: Bristles of segment II of antenna reaching to or near apex of club. Stylet with at least 2 lateral bristles. Head of spermatheca much longer and broader than tail, of even width or somewhat narrowed toward tail.

West of 100th Meridian there are 7 species of this genus, all of which are found upon rodents. Only 3 of these are so far recorded from western United States.

When these 3 species are viewed side by side, it is quite evident that fingers of males and apical outline of VII st. of females are distinct. A key based upon these characteristics would result in:

Key to the species of Megabothris West of the 100th Meridian in the United States

1. Finger $\mathbf{F}$ more or less leg-shaped

a. More leg-shaped with long pointed spiniform from kneecap, 2 short spiniforms from toe.

VII st. of female with upper lobe squarish or angular M. asio orectus, p. 216

b. Less leg-shaped 'with long pointed spiniform and small bristle at kneecap, small bristle at toe.

VII st. of female with a single rounded ventral lobe $\quad M$. quirini, p. 211

2. Finger $\mathbf{F}$ about rectangular, posterior face undulate with 3 black

spiniforms, ventral one long, pointed, upper 2 short.

VII st. of female with rounded prominence in middle of posterior face

M. abantis, p. 213 


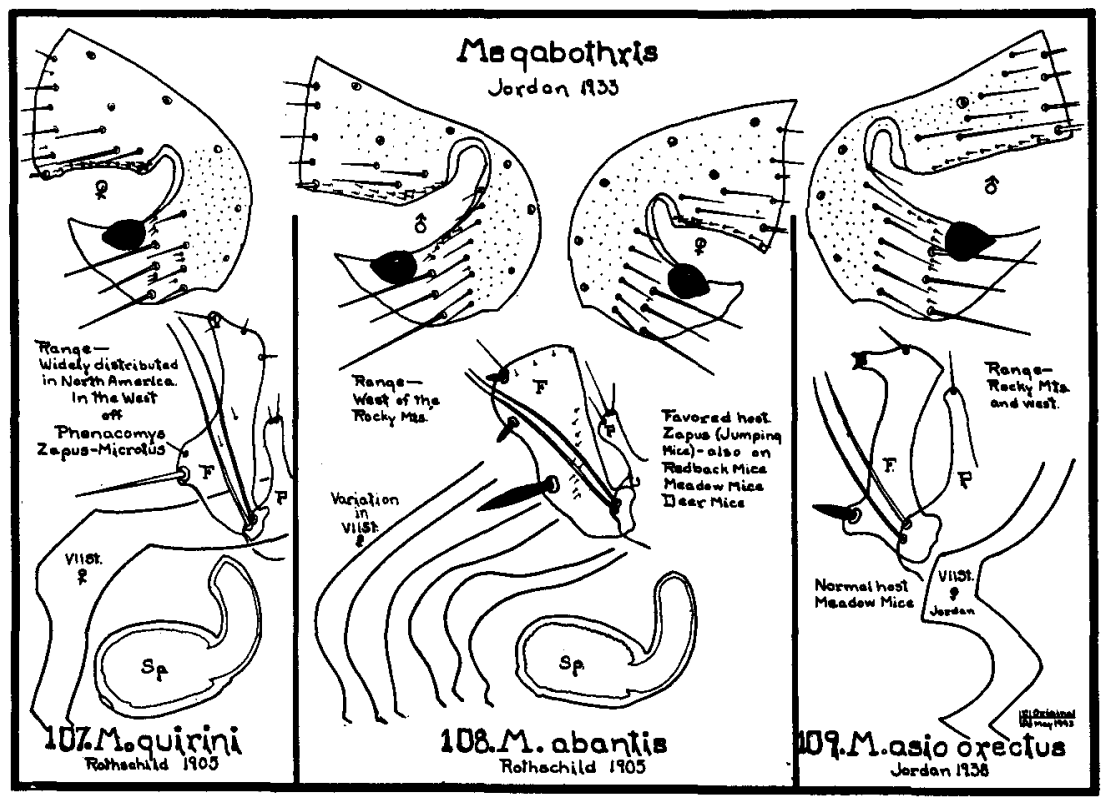

\section{Megabothris quirini \\ Rothschild 1905}

1905 Ceratophyllus quirini Rothschild, Nov. Zool., 12:163.

1905 Ceratophyllus quirini Baker, Proc. U. S. Nat. Mus., 29:133.

1929 Ceratophyllus quirini Jordan, Nov. Zool., 35:174.

1933 Ceratophyllus quirini Stewart, Jour. New York Ent. Soc., 41:256.

1933 Megabothris quirini Jordan, Nov. Zool., 39:77.

1936 Megabothris quirini Wagner, Can. Ent., 68:201.

1937 Megabothris quirini Jordan, Nov. Zool., 40:284.

1940 Megabothris quirini I. Fox, Fleas of Eastern United States, p. 70.

Original description of the male of this species was made by Rothschild from 5 males collected off red-backed mice at Red Deer, Alberta, Canada, during April and August of 1901 by G. F. Dippie. Wagner says in his paper on "Fleas of British Columbia" (1936), "A species widely distributed in Canada on Microtinae." I. Fox in his volume on the "Fleas of Eastern United States" says that his illustrations of female were taken from a specimen loaned him by Dr. Karl Jordan which had been taken from $M . p$. drummondi (meadow mouse) at Atlin, British Columbia. While Fox lists species from Maine, Minnesota, and New York, his specific data cover only 1 male from a flying squirrel taken in Maine, August 23, 1928 . The Hamilton, Montana, Spotted Fever Laboratory does not list this species as being found in that state. The few records of this flea in the collection of the writer are all females. These are listed from different mice. 
Modified Segments, Male: In his original description Rothschild says that VIII $t$. bears only some short bristles behind and below stigma and 2 long ones near ventral margin, VIII st. bears 2 very long bristles at apex, one on each side, and several short hairs in front of them, manubrium of clasper is obtuse, process of clasper is long and slender, finger is peculiar in shape, long with distal margin angulate below middle and concave between this angle and apex, a long heavy bristle at angle, with short one above it, another small bristle stands at apical margin near distal corner; proximal portion of IX st. bears a row of bristles at ventral edge, distal portion is curiously curved, bearing row of bristles at ventral edge, which row extends from sinus of sternite twofifths of way to apex.

LENGTH: Original for male $2.3 \mathrm{~mm}$., females in the collection of writer measure $3.00 \mathrm{~mm}$.

Range: Listed from Maine to east and from Oregon, Washington, and British Columbia to west, this species seems to have a limited swath across the entire North American continent, an area centering, perhaps along Canadian-United States boundary.

SEAsonal Distribution: Scarcity of records for this species leads the writer to believe that it might be a nest flea, preferring security of host's nest, leaving it only by accident, so although data on hand come from most months of year, it would be difficult to determine seasonal distribution for this species.

Host Preference: Apparently Microtus (meadow mice) are favored host. Occasionally found on other mice.

While first record below has been definitely determined for the writer by Dr. Karl Jordan as this species, outline of the VII st. does not correspond with that illustrated by I. Fox and except for a slightly more receding outline toward the dorsal, females listed below from Oregon and Washington approach closely M. abantis Rothschild 1905.

RECORDS of the writer are:

OREGON-Off:

Phenacomys silvicola A. B. Howell (dusky tree mouse), Newberg, Yamhill County, February 11, 1938, 1 female

Zapus trinotatus trinotatus Rhoads (northwest jumping mouse), Devil's Lake, Lincoln County, August 10, 1937, 1 female

Microtus mordax abditus A. B. Howell (Tillamook long tailed meadow mouse), Forest Grove, Washington County, March 12, 1937, 1 female

Microtus oregoni oregoni Bachman (Oregon creeping meadow mouse), Devil's Lake, Lincoln County, April 8, 1939, 1 female.

\section{WASHINGTON-Off:}

Microtus townsendi Bachman (Townsend meadow mouse), Kalama, Cowlitz County, August 22, 1938, 1 female.

This flea is also reported from

BRITISH COLUMBIA-Off:

Microtus pennsylvanicus drummondi A. and B. (Drummond deer mouse), Atlin. 
ALASKA-Off:

Clethrionomys dawsoni dawsoni Merriam (Dawson red-backed mouse), Rapids, July 13, 1937, 1 pair

Microtus spp. (meadow mouse), Fairbanks, July 13, 1937, 3 males, 1 female.

ALBERTA-Off:

Clethrionomys gapperi saturatus Rhoads (B. C. red-backed mouse), Red Deer, 5 males.

\section{Megabothris abantis \\ Rothschild 1905}

1905 Ceratophyllus abantis Rothschild, Nov. Zool., 12:164.

1906 Ceratophyllus abantis Baker, Proc. U. S. Nat. Mus., 29:146.

1933 Megabothris abantis Jordan, Nov. Zool., 39:77.

1936 Megabothris abantis Wagner, Can. Ent., 68:201.

This species was described from 2 males collected by G. F. Dippie, one in Canadian National Park, Alberta, off Putorius longicaudatus (longtailed weasel) (doubtless accidental), August 17, 1899, other male at Horse Creek, Upper Columbia Valley, British Columbia, off Microtus drummondi (meadow mouse), October 13, 1903.

Modified Segments, Male: Describer states that VIII t. bears 4 bristles along dorsal edge from stigma backwards and on side 8 more, besides 2 long ones which stand near ventral margin, one above other; VIII st. is dilate in middle, being lancet-shaped and bearing 2 bristles at tip and a row of hairs from apex to middle, besides a number of very minute hairs; manubrium of clasper is rounded at apex; process $P$ of clasper is club-shaped; finger $\mathbf{F}$ is very large, being broadest at apex, bearing near distal edge 3 heavy spines, of which ventral one is long and acute, while 2 others are less than half the length and blunt, third stands at rounded apical distal angle with a thin bristle above it, while second is placed halfway between first and third; finger is emarginate between first and second spines; IX st. is similar to M. quirini. Females in collection of the writer and taken with males in most cases, are very similar to specimens in his collection determined by Dr. Jordan as $M$. quirini. Slight difference in the apical outline of VII st. consists of a more angular lobe in $M$. quirini, a more rounded lobe in this species.

LENGTH: Original given for male $2.8 \mathrm{~mm}$.; females in collection of writer about $3.00 \mathrm{~mm}$.

RANGE: With records of Rothschild and Wagner from various points in British Columbia, and those of the writer from all over Oregon and Washington where meadow mice can live, it appears that the range of this species is from Pacific Ocean east throughout Oregon, Washington, California, and British Columbia and on east into the Rocky Mountains.

Seasonal Distribution: Although this species never seems plentiful, the 50 records in collection of the writer are from almost every month in the year. 
Host Preference: Wagner in his "Fleas of British Columbia," states that "It is probable that different species of Microtinae are its usual hosts." The writer has specimens off various species of Microtus (meadow mice), Peromyscus (deer mice), Zapus (jumping mice) and a cony and a weasel. With exception of a few $M$. quirini, this is the only species taken to date by the writer from Zapus.

RECORDS of the writer's are:

\section{OREGON-Off:}

Microtus townsendi Bachman (Townsend meadow mouse), Newberg, Yamhill County, April 18, 1937, 1 male

Microtus mordax mordax Merriam (Rocky Mountain meadow mouse), Lostine, Wallowa County, August 7, 1938, 1 female

Microtus richardsoni arvicoloides Rhoads (Cascade meadow mouse), High Rock Forest Camp, 4,750 ft. el., 35 miles east and south of Estacada, Clackamas County, September 24, 1938, 1 male

Microtus oregoni oregoni Bachman (Oregon creeping meadow mouse), Devil's Lake, Lincoln County, April 8, 1939, 1 female

Microtus canicaudus Miller (gray-tailed meadow mouse), Forest Grove, Washington County, March 23, 1939, 1 female

Microtus montanus montanus Peale (Peale meadow mouse), Hart Mountain, Lake County, July 2, 1939, 5 males, 4 females

Zapus trinotatus montanus Merriam (mountain jumping mouse), Parkdale, Hood River County, (Cooper Spur), August 5, 1937, 1 male

Zapus princeps oregonus Preble (Blue Mountain jumping mouse), Wallowa Lake, Wallowa County, July 14, 1939, 1 male, 9 females

Peromyscus maniculatus rubidus Osgood (ruddy deer mouse), Harbor, Curry County, August 27, 1937, 1 male

Peromyscus maniculatus gambeli Baird (Gambel's deer mouse), Lava Lake, Santiam Nat. Forest, Linn County, September 30, 1939, 1 male, 1 female

Peromyscus maniculatus artemisiae Rhoads (Sagebrush deer mouse), Wallowa Lake, Wallowa County, July 14, 1939, 1 male

Clethrionomys gapperi saturatus Rhoads (British Columbia red-backed mouse), Lostine, Wallowa County, August 8, 1938, 1 male, 2 females

Eutamias townsendi townsendi Bachman (Townsend chipmunk), Coaledo, Coos County, August 21, 1937, 1 male

Mustela longicauda arizonensis Mearns (mountain weasel), Lostine, Wallowa County, August 8, 1938, 1 male, 2 females.

WASHINGTON-Off:

Microtus richardsoni arvicoloides Rhoads (Cascade meadow mouse), Government Mineral Springs, Carson, Skamania County, August 21, 1935, 1 male

Microtus mordax mordax Merriam (Rocky Mountain meadow mouse), Bickleton, Klickitat County, July 16, 1938, 2 females

Ochotona princeps brunnescens Howell (Cascade cony), Goose Lake, Skamania County (west of Guler), August 23, 1935, 1 male

Eutamias townsendi townsendi Bachman (Townsend chipmunk), Spirit Lake, Lewis County, August 8, 1938, 1 male, 2 females.

CALIFORNIA-In the northern portion of the state the writer has collected this species off:

Peromyscus maniculatus rubidus Osgood (ruddy deer mouse), Smith River, Del Norte County, September 19, 1943, 1 pair

Microtus montanus montanus Peale (Peale meadow mouse), Tule Lake, Siskiyou County, April 19, 1942, 1 female, 
From the central Sierra-Nevada Mountains of California Augustson reports as follows:

Tamiasciurus douglasi albolimbatus Allen (pine squirrel), Horse Heaven, Fresno County, August 24, 1941, 1 female; Mammoth Lakes, Mono County, July $5,1940,1$ female

Peromyscus maniculatus sonoriensis Le Conte (Sonoran deer mouse), Mammoth Lakes, Mono County, July 5, 1940, 1 male

Microtus montanus dutcheri Bailey (Dutcher meadow mouse), Tully's Hole, Fresno County, August 25, 1941, 3 males, 2 females; Mammoth Lakes, Mono County, August 28, 194I, I pair

Microtus mordax sierrae R. Kellogg (Sierra meadow mouse), Tully's Hole, Fresno County, August 23, 1941, 1 male, 3 females; Cascade Valley, Fresno County, August 27, 1941, 1 male

Zapus pacificus alleni Elliot (Allen's jumping mouse), Tully's Hole, Fresno County, August 23, 1941, 1 pair.

NEVADA-The writer removed a male of this flea off:

Peromyscus maniculatus gambeli Baird (Gambel's deer mouse), Vya, Washoe County, October 20, 1944.

From the Rocky Mountain area this species has been collected by author from

ARIZONA-Off:

Microtus mordax mordax Merriam, (Rocky Mountain meadow mouse), North

Rim, Grand Canyon, Coconino County, July 7, 1945, 2 males, 6 females.

IDAHO-Off:

- Peromyscus maniculatus artemisae Rhoads (Sagebrush deer mouse), Craigmont, Lewis County, July 21, 1945, 1 male.

Zapus princeps princeps Allen (Rocky Mountain jumping mouse), Craigmont, Lewis County, July 21, 1945, 1 female.

It is also reported from

UTAH-Off:

Microtus spp. (meadow mouse), Logan Canyon, Cache County.

MONTANA-Off:

Ochotona princeps (cony), Park County

Thomomys spp. (pocket gopher), Gallatin County

Tamiasciurus hudsonicus (pine squirrel), Flathead, Ravalli Counties

Rattus norvegicus (Norwegian rat), Fergus County

Neotoma cinerea (wood rat), Ravalli County

Marmota flaviventris (woodchuck), Park County

Glaucomys sabrinus (flying squirrel), Yellowstone National Park

Eutamias spp. (chipmunk), Beaverhead County

Citellus richardsoni subsp. (Richardson ground squirrel), Beaverhead, Madison, and Park Counties

Citellus columbianus (Columbian ground squirrel), Beaverhead, Deer Lodge, Granite, Jefferson, and Ravalli Counties

Citellus armatus (Uinta ground squirrel), Park County

Citellus spp. (ground squirrel), Madison County

Mustela spp. (weasels), Meagher and Ravalli Counties

Canis latrans (coyote), Glacier National Park.

CANADA-The specimens upon which the original description was based were recorded off:

Mustela longicaudatus (weasel), Canadian National Park, Alberta

Microtus pennsylvanicus drummondi A. and B. (Drummond meadow mouse), Okanagan Landing, British Columbia. 


\section{Megabothris asio orectus Jordan 1938}

1904 Ceratophyllus asio Baker, Proc. U. S. Nat. Mus., 27:338.

1906 Ceratophyllus asio Baker, Proc. U. S. Nat. Mus., 29:132.

1929 Ceratophyllus asio Jordan, Nov. Zool., 35:33.

1938 Megabothris asio orectus Jordan, Nov. Zool., 41:122.

1940 Megabothris asio I. Fox, Fleas of the Eastern United States, p. 67.

In the original description for this species, Baker says, "From Prof. A. P. Morse comes a single female specimen taken at Wellesley, Massachusetts, on Otus asio (screech owl). There can be little doubt that this occurrence is accidental and that the species is normally parasitic on some small rodent of that region." Wagner states in his Fleas of British Columbia, "A pretty rare species, but widely distributed in the Northern States. Lives, it seems, on mice. Spencer's collection (University of British Columbia) contains one male from a 'mouse nest', Salmon Arm, British Columbia, Canada."

Dr. Jordan illustrated the male in 1929.

In 1938 Dr. Jordan found enough difference in 2 males and $2 \mathrm{fe}-$ males sent him from the Spotted Fever Laboratory at Hamilton, Montana, to establish the above-named subspecies. Specimens were taken from a mouse nest in Ravalli County, Montana, during October, 1935. Of this material, Jordan says, "A western subspecies. In the male the apex of finger $\mathrm{F}$ more produced backwards than in $M$. a. asio Baker 1904, and the terminal margin between this nose and the anterior angle less rounded; the prominent ventral lobe of st. IX narrower, and st. VIII has fewer ventral bristles. In the female the upper lobe of st. VII is slightly longer than in the specimens from the states of New York and Massachusetts, and the distance of the third or fourth bristle of the posterior row of this segment from the one above it greater."

The writer prefers to describe finger of male as being leg- and footshaped, armed with a long pointed spiniform at the kneecap and 2 short, blunt, black spiniforms at toe position. Outline of VII st. of female consists of an upper lobe which is squarish and angular, then a graceful dip to ventral margin.

LENGTH: Original description carried no measurements, but a male in collection of the writer is about $2.50 \mathrm{~mm}$. long.

RANGE: The single specimen in collection of the writer from southcentral Oregon, close to the Nevada-Oregon-California junction line, and types from Ravalli County, Montana, would suggest a western range of west from Rocky Mountains into Washington, perhaps as far west as Columbia River, west into Oregon perhaps as far as Cascades, west into Nevada and possibly into northeastern California, in locations where meadow mice can live.

Seasonal Distribution: Too few specimens of this subspecies are in collections at this time to suggest a seasonal distribution. 
Host Preference: Types and paratypes are listed as being from a mouse nest, the kind of mouse not given. While the writer's specimen is from Microtus, data at hand are too meager to suggest a host preference.

RECORD: The writer's specimen comes from the high plateau region of south-central Oregon, off:

Microtus mordax mordax Merriam (Rocky Mountain meadow mouse), Lakeview-Adel Highway (summit, 5,555 ft. el), Lake County, Oregon, June 31, 1937, 1 male.

MONTANA-The specimens upon which original description was based came from the state of Montana where this subspecies is recorded off Microtus spp. (meadow mouse), Beaverhead County, and out of rodent nest Ravalli County.

The remaining 4 species of the genus Megabothris, found west of the 100th meridian, were described from Canada and to this date have not been reported from the United States. These 4 may be keyed as follows:

\section{MALES}

A. Finger somewhat boot-shaped with 2 black short spiniforms at toe position, and heavy bristle at knee position

M. atrox, p. 218

B. Finger less boot-shaped with 1 black short spiniform and a long bristle at toe position. Knee position well developed with heavy bristle and an auxillary one

M. lucifer, p. 217

\section{FEMALES}

VII st. with upper lobe long, narrow, apically rounded, lower lobe shorter, pointed

M. lucifer, p. 217

VII st. with upper lobe long, narrow, apically angulate, lower lobe shorter, pointed

M. megacolpus, p. 219

VII st. with upper lobe broad, well rounded and about as long as the lower pointed lobe

M. adversus, p. 219

VII st. with upper lobe tapering, lower one broader truncate-rounded

M. atrox, p. 218

\section{Megabothris lucifer \\ Rothschild 1905}

1905 Ceratophyllus lucifer Rothschild, Nov. Zool., 12:170.

1933 Megabothris lucifer Jordan, Nov. Zool., 39:77.

1936 Megatbothris lucifer Wagner, Zeit. fur Parasit., 8:656.

The original description of this species was made from 2 females taken by G. F. Dippie off Microtus drummondi (Drummond meadow mouse) at Red Deer, Alberta, during April and August of 1901. It was not until 1936 that Wagner released description of male based upon materials taken off Microtus August 30, 1934, at Kamloops, British Columbia. 


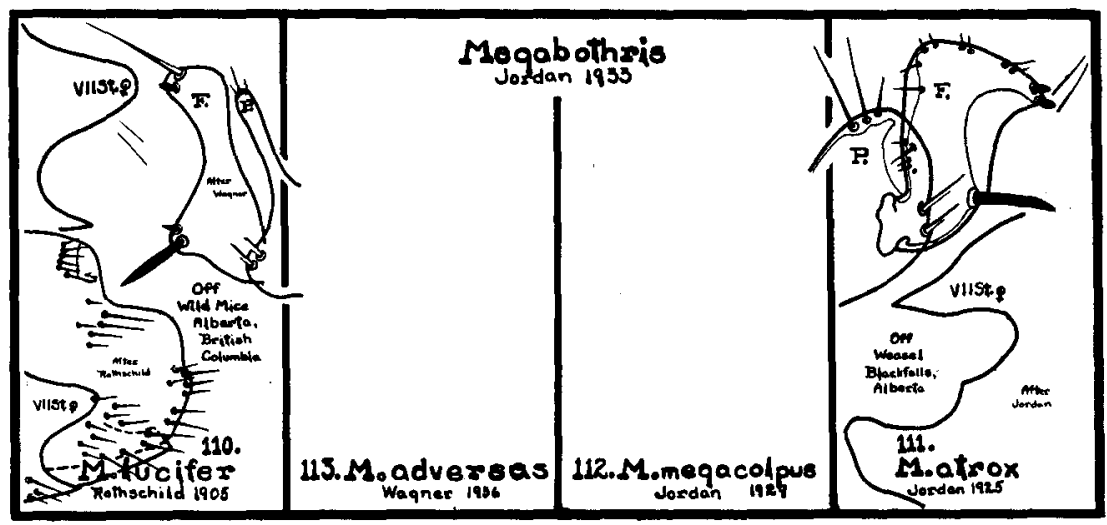

Modified SEgments are very characteristic. Of these the describers says, MaLE: Finger F long and constricted at middle. Posterior apical angle armed with a long spine-like bristle and slightly ventral to it a short black spiniform. At ventral angle of posterior face of finger a long spine-like bristle and above it a small blackish spiniform or bristle. Process $P$ is long and slender and armed apically with 3 bristles. FEMALE: VII st. with deep sinus. Upper lobe narrow, well rounded at apex, and much longer than lower pointed lobe. VIII t. bears 2 long and several short bristles at apex, besides 2 short stout ones. The patch of bristles situated near ventral edge contains 15 to 18 bristles.

LENGTH: Rothschild listed length of the female as $2.7 \mathrm{~mm}$. Wagner failed to include length for male.

RANGE: This flea is probably found in Canada throughout the Rocky Mountains and west.

\section{Megabothris atrox Jordan 1925}

1925 Ceratophyllus atrox Jordan, Nov. Zool., 32:112.

1933 Megabothris atrox Jordan, Nov. Zool., 39:77.

Jordan described this species from 2 males and 4 females taken off a weasel at Blackfalls, Alberta, by A. D. Gregson. While Jordan suggested the flea might be a bird flea, Wagner in 1936 doubted this.

The describer states that there are from 26 to 29 spines in pronotal comb, that stigma-cavity at $t$. VIII is very large. The following points also come from the original description: Five or 6 bristles on the metepisternum, 10 or more on metepimerum.

Modified Segments, Male: Finger $F$ of clasper resembling $M . c$. ciliatus Baker 1904, but much broader and shorter, broadest at apex, posterior margin angulate near middle, and here armed with long pointed spine, posterior apical angle produced and bearing 2 short obtuse spines. Ventral arm of st. IX narrowed basad and apicad, with 
a ventral row of small bristles from near base, and on each side one large apical bristle: membranous apical flap broad. FEMALE: VII st. with a very broad and deep sinus, which is deeper above than below, upper lobe tapering, lower one broader, truncate-rounded, margin in middle of sinus angulate, on 2 sides together more than 40 bristles. Head of spermatheca half as long again as broad, barrel-shaped, but narrowing towards tail, which is shorter than head.

Length: Original lengths given for this species were male and female from $2.8-3.0 \mathrm{~mm}$.

Range: Probably found throughout the Rocky Mountain area of Alberta, Canada.

\section{Megabothris megacolpus Jordan 1929}

1929 Ceratophyllus megacolpus Jordan, Nov. Zool., 35:33.

1933 Megabothris megacolpus Jordan, Nov. Zool., 39:77.

This species was described from a single female deposited in the National Museum. It was collected at Okanagan Landing, British Columbia, off Microtus drummondi (Drummond meadow mouse), September of 1912. Jordan states that this species is similar to $M$. asio Baker 1904, but VII st. is so deeply sinuate that row of long bristles is nearer apex of sinus than in M. asio. Pronotum with 2 rows of bristles. Bursa copulatrix with a long glandular continuation from which eminates the duct of the spermatheca.

\section{Megabothris adversus Wagner 1936}

1936 Megabothris adversus Wagner, Zeit. fur Parasit., 8:654.

This species was described by Wagner from a single female collected at Vancouver, British Columbia, on the 26th of May, 1935 off Peromyscus maniculatus (deer mouse). The great portion of Wagner's usual short German description is a comparison of this single female with females of other species of genus. Characteristics are, according to Wagner, very close to $M$. abantis Rothschild but duct of receptaculum seminis is not "chitinized." Pronotum with but a single row of bristles. VII st. as in $M$. asio and $M$. immitis but in outline broader and more evenly rounded. VIII t. has 1 or 2 bristles under stigma.

Length is not stated in original description and nothing is known about range of species.

\section{GENUS MONOPSYLLUS KOLENATI}

1857. Monopsyllus Kolenati. Wien. Entomol. Monatschr. 1:65.

Genotype: Monopsyllus scuirorum Schrank 1803

The eye in this genus is not reduced. Its longest diameter is longer than the distance of eye from angle of strongly chitinized portion of 
genal lobe. On occiput there are 2 medium bristles, upper one small. Comb with 22 or fewer spines. No bristles on hind tarsal segments I and II extend beyond segment following.

MALE: Bristles of segment II of antenna not reaching beyond the middle of club. One long antepygidial bristle and 2 minute ones. VIII t. without spiculose dorsal area on inner side. VIII st. narrow, with or without a membranous apical flap. Frontal margin of IX $t$. forming with manubrium of clasper an angle much smaller than $90^{\circ}$, the angle rounded off.

Female: Bristles of segment II of antenna reaching to or beyond apex of club. Stylet with 2 lateral bristles. Spermathecae of different types.

Jordan states that the above diagnosis of this genus permits placing into it some Nearctic species which are not very closely related to the genotype.

This genus as diagnosed by Jordan holds 8 species which are found west of 100th Meridian. Four of these have been broken into 2 or more subspecies. These fleas are found upon deer mice, chipmunks, pine squirrels and grasshopper mice.

When these species and subspecies are viewed side by side, it becomes apparent that fingers of claspers of males are quite distinct for each, and in female while marginal outline of VII st. is characteristic, shape of spermatheca is also taxonomically helpful. These characteristics bound into a key would result in:

Key to the Species of Monopsyllus West of the 100th Meridian

A. Three black spiniforms on posterior border of Finger

1. Finger somewhat ham-shaped, spermatheca somewhat barrelshaped, bursa copulatrix prominent and spirally rolled up (2 subspecies on chipmunks)

M. eumolpi, p. 236

2. Finger somewhat scythe-blade-shaped, spermatheca somewhat barrel-shaped

a. IX st. male long and slender, VII st. female with apical outline almost vertical and small triangular lobe at about middle

M. fornacis, p. 241

b. IX st. male broad, VII st. female with upper angular lobe and sinus below it

M. eutamiadis, p. 242

3. Finger not ham- or scythe-blade-shaped, spermatheca body veriform

a. Levers of the genital armature rolled into a spiral (3 subspecies on deer mice)

M. wagneri, p. 221

b. Levers of the genital armature not rolled into a spiral (1 species on deer mice)

M. thambus, p. 227 
B. Two black spiniforms at posterior dorsal angle of finger

1. Finger leg-shaped (knee and below) with 2 black blunt spiniforms at toe position, spermatheca with top-shaped body and a tail much longer and slightly bent (4 subspecies on chipmunks) M. ciliatus, p. 228

2. Finger not leg-shaped, the 2 spiniforms dark colored, small, spermatheca with body somewhat top-shaped ventral face flat-

tened, tail crooked (4 subspecies on grasshopper mice) M. exilis, p. 243

C. No black spiniforms on finger but armed with 5 bristles along posterior border, spermatheca with body somewhat top-shaped with dorsal face flattened, tail crooked (1 species on pine squirrels) M. vison, p. 234

\section{Monopsyllus wagneri Baker 1904}

1904 Ceratophyllus wagneri Baker, Proc. U. S. Nat. Mus., 27:405.

1929 Ceratophyllus wagneri Jordan, Nov. Zool., 35:35.

Dr. Karl Jordan says that this is a most interesting species because of its geographical variation, and that in some of subspecies female exhibits greater differences than do the males, that spermatheca is unique in its long subcylindrical head being narrower than tail, organ recalling a snake or certain Cipunculid worms, such as Aspidosiphora and Phascolosoma. The species is restricted to west of Mississippi River in United States, and Canada.

Subspecies of Monopsyllus wagneri Baker found in the West

1. Lower spiniform of the finger about five times as long as the upper 2, spermatheca without swollen outlet tip, and without swollen tail

M. wagneri wagneri, p. 221

As for above but with narrower finger and anterior margin more incurved. Duct of bursa copulatrix much shorter, Alberta, Canada, off deer mice

M. wagneri systaltus, p. 226

2. Lower spiniform of the finger about three times as long as the upper 2, spermatheca with swollen, globular outlet tip, tail much larger in diameter than body

M. wagneri ophidius, p. 226

\section{Monopsyllus wagneri wagneri Baker 1904}

1904 Ceratophyllus wagneri Baker, Proc. U. S. Nat. Mus., 27:405.

1928 Ceratophyllus peromysci Stewart, Can. Ent., 60:148.

1929 Ceratophyllus wagneri wagneri Jordan, Nov. Zool, 35:35.

1933 Monopsyllus wagneri wagneri Jordan, Nov. Zool., 39:78.

This, the parent subspecies of $M$. wagneri, was described by Baker from 2 males sent him by Professor Aldrich from Moscow, Latah County, Idaho, where one specimen was taken off Peromyscus leucopus (deer mouse), the other off Mus musculus (house mouse). Stewart described 


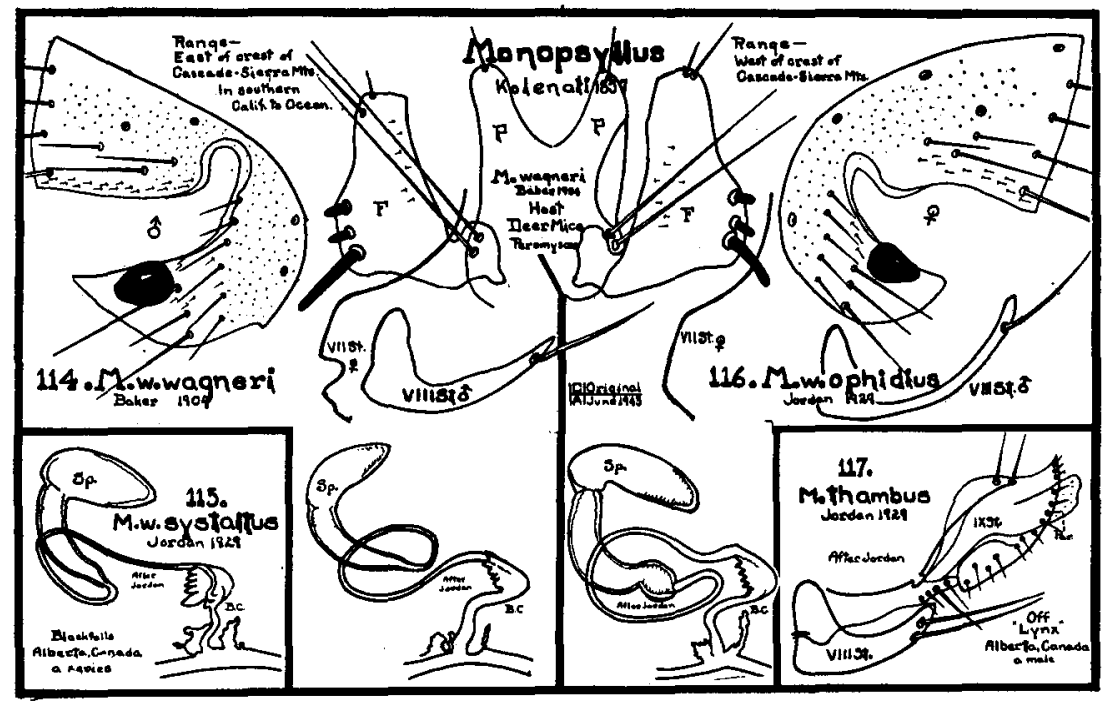

female in 1929 under designation Ceratophyllus peromysci from material taken at Cortez, Montezuma County, Colorado, off Peromyscus spp. (deer mouse).

Modified SeGments: Distinctly characteristic for this subspecies. MALE: Process of clasper is nicely rounded apically and bisymetrically. Finger $\mathrm{F}$ is characteristically shaped and armed posteriorly with 3 black spiniforms, upper 2 short, blunt and about the same length, lower one, long and slender, about 5 times as long as upper ones. Female: VII st. with apical outline sinuate. Above sinus, which is fairly low down, is an angular upper lobe which is shallow but broad. Spermatheca is unique in having body of a smaller diameter than tail. Body diminishes in diameter gradually to tip at outlet duct. Tail is slightly larger in diameter than body.

LeNGTH: Original length of male was given as $2.20 \mathrm{~mm}$. Specimens in collection of the writer average $2.00 \mathrm{~mm}$. in male and $2.40 \mathrm{~mm}$. in female.

Color of this flea was originally listed as light brown. Type material is in the United States National Museum under No. 6911.

RANGE: This subspecies ranges east of crest of Cascade-Sierra-Nevada Mountains, through Great Basin region and Rocky Mountains, thence through the Great Plains apparently as far as Mississippi River.

Host Preference: Preferred host of this flea is Peromyscus (deer mouse). It is also common on Reithrodontomys (harvest mice) and can occasionally be taken off other wild mice and other rodents. This flea can also be taken off carnivores of wild mice.

Abundance and Seasonal Distribution: Within its range this is 
the most common flea on deer mice. It is abundant during all seasons of year. Season of maximal abundance seems to be during mid spring, at which time large numbers of this flea can be taken off all deer mice. Relative abundance of this flea is well shown in a piece of field work carried on by the writer in northern Nevada during June and early July of 1944. Of 777 fleas collected during period, 627 were this subspecies. Remaining 150 fleas represented 12 other species from other rodents.

BroLogY: In northern portion of the Great Basin region in Walla Walla County, Washington, the writer has taken females with 4 oval eggs in abdominal cavity during middle of May.

Medical Importance: This flea has been experimentally infected with plague. Eskey and Haas fed 17 of these fleas on plague-positive guinea pigs. Two of these became infected. These investigators did not find the flea capable of transmitting plague.

RECORDs typical from hundreds in the collection of the writer are:

\section{OREGON-Off:}

Peromyscus maniculatus gambeli Baird (Gambel's deer mouse), Sisters, Deschutes County, March 18, 1937, I male, 1 female

Peromyscus maniculatus artemisiae Rhoads (sagebrush deer mouse), Wallowa Lake, Wallowa County, July 14, 1939, 5 males, 5 females

Peromyscus maniculatus sonoriensis Le Conte (Sonora deer mouse), Jordan Valley, Malheur County, July 10, 1939, 2 males,

Accidental Occurrences, off:

Citellus leucurus leucurus Merriam (Antelope ground squirrel), Adel, Lake County, June 23, 1937, 1 male

Dipodomys ordi columbianus Merriam (kangaroo rat), Narrows, Harney County, July 18, 1937, 2 males

Lepus californicus wallawalla Merriam (Oregon jack rabbit), Adel, Lake County, June 22, 1937, 1 male

Marmota flaviventris avara Bangs (woodchuck), Summit Lakeview-Adel Highway, Lake County, June 20, 1937, I male

Mus musculus musculus Linnaeus (house mouse), Willowdale, Jefferson County, June 15, 1937, 2 males, 7 females

Neotoma lepida nevadensis Taylor (Nevada round-tailed wood-rat), Adel, Lake County, June 28, 1937, 3 males, 1 female

Neotoma cinerea occidentalis Baird (western bushy-tailed wood-rat), Summit Lakeview-Adel Highway, Lake County (5,555 ft. el.), June 20, 1937, 1 male, 1 female

Ochotona fenisex fumosa Howell (dusky cony), Spark's Lake, Deschutes County, July 24, 1936, 1 male

Onychomys leucogaster fuscogriseus Anthony (grasshopper mouse), Crane, Harney County, July $17,1937,1$ male

Reithrodontomys megalotis megalotis Baird (desert harvest mouse), Jordan Valley, Malheur County, July 9, 1939, 1 female; Mitchell, Wheeler County, July 12, 1937, 1 pair; Plush, Lake County, July 1, 1939, 6 males, 4 females

Sylvilagus nuttalli nuttalli Bachman (sagebrush cottontail), Terrebonne, Crook County, July 9, 1937, 1 male 
Eutamias amoenus amoenus Allen (Klamath chipmunk), Terrebonne, Crook County, July 10, 1937, 1 male

Eutamias minimus pictus Allen (sagebrush chipmunk), Crane, Harney County, July 16, 1937, 1 male.

\section{WASHINGTON-Off:}

Peromyscus maniculatus gambeli Baird (Gambel's deer mouse), Guler, Klickitat County, May 15, 1943, 1 pair; Mabton, Yakima County, May 29, 1938, 5 pairs; Plymouth, Benton County, February 14, 1942, a series

Peromyscus maniculatus artemisiae Rhoads (sagebrush deer mouse), Lowden, Walla Walla County, July 15, 1939, 8 pairs

Onychomys leucogaster fuscogriseus Anthony (Oregon grasshopper mouse), Attalia, Walla Walla County, May 11, 1939, 1 female

Reithrodontomys megalotis nigrescens Howell (dusky harvest mouse), Top. penish, Yakima County, January 29, 1942, 1 female.

\section{CALIFORNIA-Off:}

Peromyscus maniculatus gambeli Baird (Gambel's deer mouse), Fort Bidwell, Modoc County, June 25, 1937, I male; Tule Lake, Siskiyou County, April 19,1942 , a series

Peromyscus maniculatus sonoriensis Le Conte (Sonora deer mouse), Truckee, Nevada County, June 23, 1944, a series; Lake Tahoe, Eldorado County, June 21, 1944, 1 male; Augustson reports large numbers of this flea taken off this mouse during June, July and August of 1940 and 1941 at Mammoth Lakes, Mono County. He also reports it off:

Microtus mordax sierrae R. Kellogg (Sierra meadow mouse), Tully's Hole, Fresno County, August 23, 1941, pair

Ochotona schisticeps muiri G. and S. (Yosemite cony), Duck Pass, Mono County, August 22, 1941, 1 female; Tully's Hole, Fresno County, August 23, 1941, 1 male, 3 females

Sylvilagus nuttalli grangeri Allen (Black Hills cottontail), Mammoth Mountain, Mono County, August 15, 1940, 1 male

Eutamias quadrivittatus inyoensis Merriam (Inyo chipmunk), Cascade Valley, Fresno County, August 27, 1941, I male.

NEVADA-In this state the writer has collected this flea off:

Peromyscus maniculatus gambeli Baird (Gambel's deer mouse), State Line, Washoe County, June 27, 1937, 1 male, 6 females

Peromyscus maniculatus sonoriensis Le Conte (Sonora deer mouse), Vya, Washoe County, June 16, 1944, 6 males, 4 females; Reno, Washoe County, June 21, 1944, 8 pairs; Lake Tahoe, Douglas County, June 21, 1944, 1 male, 3 females; Carson City, Ormsby County, June 26, 1944, large series; Virginia City, Storey County, July 13, 1944, 4 pairs; Lovelock, Pershing County, June 27, 1944, 1 male, 8 females; McDermitt, Humboldt County, July 8, 1939, 3 pairs; Winnemucca, Humboldt County, June 28, 1944, 4 pairs; Battle Mountain, Lander County, June 29, 1944, large series; Austin, Lander County, July 10, 1944, 6 pairs; Wells, Elko County, July 2, 1944, 26 pairs; Ely, White Pine County, July 8, 1944, 29 pairs; Eureka, Eureka County, July 9, 1944, 4 pairs; Yerington, Lyon County, July 12, 1944, large series

Reithrodontomys megalotis megalotis Baird (desert harvest mouse), Reno, Washoe County, June 21, 1944, 1 male; Minden, Douglas County, June 24, 1944, 1 pair; Lovelock, Pershing County, June 27, 1944, 1 female

Mus musculus musculus Linnaeus (house mouse), Lovelock, Pershing County, June 27, 1944, 2 males, 1 female 
Eutamias speciosus frater Allen (Tahoe chipmunk), Lake Tahoe, Douglas County, June 21, 1944, 1 male

Perognathus nevadensis Merriam (Nevada pocket mouse), Vya, Washoe County, June 16, 1944, 1 female

Dipodomys microps aquilonius Willet (kangaroo rat), Vya, Washoe County, June 16, 1944, 1 female; and in

IDAHO-Off:

Peromyscus maniculatus sonoriensis Le Conte (Sonora deer mouse), Burley, Cassia County, July 4, 1944, 12 pairs

Reithrodontomys megalotis megalotis Baird (desert harvest mouse), Burley, Cassia County, July 4, 1944, 1 female; and in

ARIZONA-Off:

Peromyscus maniculatus rufinus Merriam (tawny deer mouse), Grand Canyon, Coconino County, July 3, 1945, 12 males, 6 females; and in

\section{UTAH-Off:}

Peromyscus maniculatus rufinus Merriam (tawny deer mouse), Rubys Inn, Bryce Canyon, Garfield County, July 10, 1945, 1 male.

From this state this flea also has been reported as follows:

Peromyscus maniculatus subspp. (deer mouse), Logan, Cache County; Yost,

Box Elder County; and Provo, Utah County

Peromyscus truei subspp. (deer mouse), Fillmore, Millard County

Microtus sp. (meadow mouse), Logan, Cache County

Neotoma sp. (wood rat), Etna, Salina, Henry Mountains

Ochotona princeps (cony), Logan Canyon, Cache County

Mustela arizonensis (weasel), Logan Canyon, Cache County.

MONTANA-Although the records coming from the state of Montana are designated only as $M$. wagneri the author is placing them under this subspecies:

Peromyscus spp. (deer mouse), Beaverhead, Gallatin, Park, Powder River, and Ravalli Counties

Lepus bairdi bairdi Hayden (Rocky Mountain snowshoe rabbit), Ravalli County

Ochotona princeps princeps Richardson (Rocky Mountain cony), Park County

Sylvilagus spp. (cottontail), Ravalli County

Citellus richardsoni subspp. (Richardson ground squirrel), Cascade, Gallatin, Park, and Valley Counties

Citellus columbianus subspp. (Columbian ground squirrel), Beaverhead, Missoula, and Silver Bow Counties

Citellus armatus Kennicott (Uinta ground squirrel), Gallatin and Park Counties

Citellus lateralis subspp. (golden-mantled ground squirrel), Granite County

Mustela spp. (weasel), Gallatin, Madison, and Park Counties

Speotyto cunicularia (burrowing owl), Beaverhead County.

WYOMING-From this state this flea has been reported off:

Peromyscus maniculatus, Teton Mountains and Pinedale.

COLORADO-The female of this subspecies was described by Stewart from:

Peromyscus sp. taken at Cortez, Montezuma County.

The writer has examined specimens from Fort Collins, Larimer County.

BRITISH COLUMBIA-Off:

Peromyscus and Mustela (deer mouse and weasel), Aspen Grove, and Monte Creek. 


\section{Monopsyllus wagneri systaltus Jordan 1929}

1929 Ceratophyllus wagneri systaltus Jordan, Nov. Zool,, 35:35.

This subspecies was described from specimens taken at Blackfalls, Alberta, by A. D. Gregson off a mouse (probably Peromyscus), and a series taken by F. G. Dippie off Peromyscus arcticus at Red Deer, Alberta, during May of 1901 .

The describer states, MALE: Finger somewhat narrower than in previous subspecies, and its anterior margin more incurved. FEMALE: Duct of bursa copulatrix much shorter than in $C$. w. wagneri, the sclerified portion of it about as long as tail of spermatheca is broad. Head of spermatheca vermiform as in previous subspecies.

To date nothing further has come to attention of writer about this Alberta, Canada, subspecies of $M$. wagneri.

\section{Monopsyllus wagneri ophidius Jordan 1929}

1929 Ceratophyllus wagneri ophidius Jordan, Nov. Zool., 35:35.

This subspecies was described from specimens taken at San Francisco and San Mateo, California, off Mustela xanthogenys Gray (weasel).

Modified Segments, Male: Process of clasper not bisymmetrically rounded at apex, posterior face somewhat incurved. Finger broader than in preceding subspecies. Arrangement of 3 black spiniforms about same but lower longer one only about 3 times as long as upper shorter ones. Female: VII st. without sinus, lobe angulate. Spermatheca with tail several times as broad as body and meeting it at an angle of about $90^{\circ}$, apex of body swollen into a small globular end.

LENGTH: Hundreds of this common western flea in the collection of the writer measure close to $2.00 \mathrm{~mm}$. in both sexes.

RANGE: While the author originally ranged this subspecies as west of crest of Cascade-Sierra-Nevada Mountains throughout their length, records for the flea are still lacking from Alaska, and during 1943 records of Augustson pushed the range as far east as Palm Springs, Riverside County, in southern California.

Preferred Hosts: This subspecies is a true Peromyscus (deer mouse) flea. It is occasionally taken off other wild mice and their predators.

Seasonal Distribution: This flea can be taken off deer mice during all seasons of year.

Biology: In the Willamette Valley of Oregon, the writer has seen eggs in females of this flea as early as March 5.

ReCORDs: The following are typical of the many records in the collection of the writer:

OREGON-Off:

Peromyscus maniculatus rubidus Osgood (ruddy deer mouse), Forest Grove, 
Washington County, April 6, 1936, 1 male, 4 females; Brookings, Curry County, June 14, 1939, 5 males, 6 females; Crown Point, Multnomah County, February 18, 1939, 1 male, 2 females; Detroit, Marion County, (Fish Lake), September 30, 1939, 1 male,

Accidental Occurrences, off:

Clethrionomys californicus obscurus Merriam (red-backed mouse), Estacada, Clackamas County (35 miles east), August 6, 1938, 1 male

Microtus townsendi Bachman (Townsend's meadow mouse), Forest Grove, Washington County, June 20, 1935, 1 female

Rattus norvegicus Erxleben (Norwegian rat), Forest Grove, Washington County, March 10, 1937, 1 female

Tamiasciurus douglasi douglasi Bachman (pine squirrel), Forest Grove, Washington County, February 21, 1938, 1 female

Sciurus griseus griseus Ord (silver gray squirrel), Gaston, Washington County, November 8, 1938, 1 male.

WASHINGTON-Off:

Peromyscus maniculatus oreas Bangs (Washington deer mouse), Cape Horn, Skamania County, October 29, 1933, 3 males, 2 females; Battle Ground Clarke County, February 1, 1941, 8 pairs.

CALIFORNIA-Off:

Peromyscus maniculatus rubidus Osgood (ruddy deer mouse), Smith River, Del Norte County, September 10, 1944, 2 pairs,

In southern California Augustson reports this fiea off:

Peromyscus maniculatus sonoriensis Le Conte (Sonora deer mouse), Cabazon and Palm Springs, Riverside County

Peromyscus maniculatus gambeli Baird (Gambel's deer mouse), Cabazon, Riverside County; San Gabriel Mountains, Los Angeles County; Point Arguello, Santa Barbara County

Peromyscus californicus insignis Rhoads (southern parasitic mouse), Cabazon, Riverside County

Reithrodontomys megalotis longicaudus Baird (California harvest mouse). Point Arguello and Santa Maria, Santa Barbara County.

\section{Monopsyllus thambus \\ Jordan 1929}

1929 Ceratophyllus thambus Jordan, Nov. Zool., 35:36.

1933 Monopsyllus thambus Jordan, Nov. Zool., 39:78.

1944 Monopsyllus thambus Holland, Can. Ent., 76:244.

This species was described from a single male taken off a lynx by A. D. Gregson at Red Deer, Alberta, Canada.

The flea is stated to be close to $M$. w. wagneri, differing principally in the nature of the levers of the genital armature. The original description reads, "Closely allied to $C$. wagneri, but the levers of the genital armature not rolled up in a spiral, very much shorter than $C$. wagneri, the longest lever only forming half a convolution, and the lamina of the penis being without a long wire-like lever. St. VIII about half as long as in $C$. wagneri and without apical membranous flap. Process $\mathbf{P}$ of clasper much longer and extending a little above the finger. The latter less dilated below middle and gradually rounded-oblique at the 


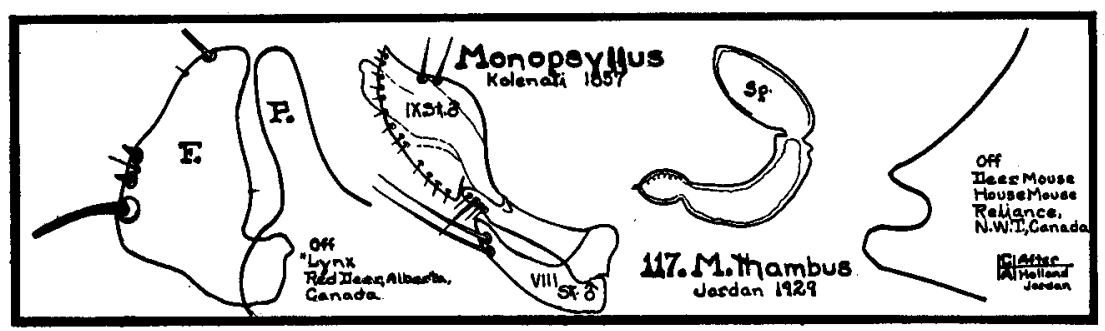

apex on posterior side; 3 spiniforms as in $C$. wagneri, but the lowest longer and thinner than in $C$. wagneri and the other 2 ending with a very thin point. Distal lobe of ventral arm of IX st. pointed, with the apex curved upward, not downward. Apex of paramere obtuse, thumb-like, its ventral apical margin rounded and its dorsal apical margin slightly incurved."

The describer states in the original description that he believes the true host of this flea to be a mouse.

Holland, during December of 1944, describes female of this species as follows: Female: Frontal row usually of 6 or 7 small setae rather than 4 or 5 as in $M$. wagneri.

St. VII with moderately deep sinus; upper lobe more or less acute. Spermatheca of same general vermiform shape as in $M$. wagneri except that tail is approximately same diameter as head instead of being broader as is the case in that species. Also, chitinous thickenings are pronounced in both head and tail regions. A constriction near proximal end of head of spermatheca is similar to that in $M$. wagneri ophidius (Jordan).

Holland examined the following materials collected at Reliance, North West Territory, Canada, off:

Peromyscus maniculatus borealis Mearns (northern deer mouse), July, 1936, 1 male, 2 females; April 15, 1944, 2 pairs

Mouse, "probably Mus musculus" (house mouse), May 21, 1937, 1 male (coll. W. J. G. Stewart, R.C.M.P.).

\section{Monopsyllus ciliatus \\ Baker 1904}

1904 Ceratophyllus ciliatus Baker, Proc. U. S. Nat. Mus., 27:397.

1929 Ceratophyllus ciliatus Jordan, Nov. Zool., 35:34.

Finger of the clasper of male of this species is long, apically dilated posticad until whole organ looks very much like a leg and foot, leg portion including a bent knee, but no part of leg above the knee. At toe position are 2 short obtuse spiniforms. Ventral arm of IX st. has no membranous apical flap. Body of spermatheca is almost globular, and much shorter than tail. VII st. of female is deeply sinuate, incrassate around apex of sinus. Surface ridges of basal abdominal sternite of 
female are much more strongly curved backwards in middle of segment than in any other allied species.

This species is a true chipmunk flea, although found constantly upon pine squirrels and at times upon silver gray squirrels, flying squirrels and other rodents.

The 4 subspecies of this species are all found west of 100th Meridian. They can be distinguished from one another by the following key and by their range.

Key to the Subspecies of Monopsyllus ciliatus Baker

1. Apex of finger not strongly dilated posticad, VII st. of female, upper lobe evenly rounded and broad, lower lobe truncate upper angle rounded off, sinus a narrow sharp incision $\quad M$. ciliatus ciliatus, p. 229

2. Apex of finger strongly dilated posticad, VII st. of female, upper lobe more or less triangular, and pointed

M. ciliatus protinus, p. 230

3. Finger typical but angle of anterior margin lower down, being placed below the middle, VII st. of female, upper lobe very much broader than the lower lobe, its apex rounded, the lower lobe subtriangular, dorsal margin rounded

M. ciliatus mononis, p. 233

4. Finger typically shaped but short and stout, VII st. of female with long finger-shaped lobe, spermatheca with rounded body rather than elliptical as in other subspecies

M. ciliatus kincaidi, p. 232

\section{SUBSPECIES BY RANGE}

Southern Subspecies

Coastal area south of San Francisco Bay, California

Sierra-Nevada Mountains of California and Nevada Northern Subspecies

Cascade Mountains through Alaska, west to Ocean M. c. ciliatus, p. 229 M. c. mononis, p. 233

Wallowa and Blue Mountains of Oregon and Washington east through Rocky Mountains

M. c. kincaidi, p. 232

Medical Importance: Eskey and Haas feeding 35 specimens of fleas designated only as Monopsyllus ciliatus upon plague-positive guinea pigs found that 9 became infected with plague. These investigators did not succeed in producing transmission from the 9 infected fleas to other guinea pigs.

\section{Monopsyllus ciliatus ciliatus Baker 1904}

1904 Ceratophyllus ciliatus Baker, Proc. U. S. Nat. Mus., 27:397.

1929 Ceratophyllus ciliatus Jordan, 4th Inter. Cong. Ent., II:497.

1929 Ceratophyllus ciliatus ciliatus Jordan, Nov. Zool., 35:34.

1933 Monopsyllus ciliatus Jordan, Nov. Zool., 39:77.

1936 Monopsyllus ciliatus ciliatus Wagner, Can. Ent., 68:200.

This subspecies was described from materials taken off Eutamias townsendi (chipmunk) a few miles south of San Francisco Bay at Moun- 


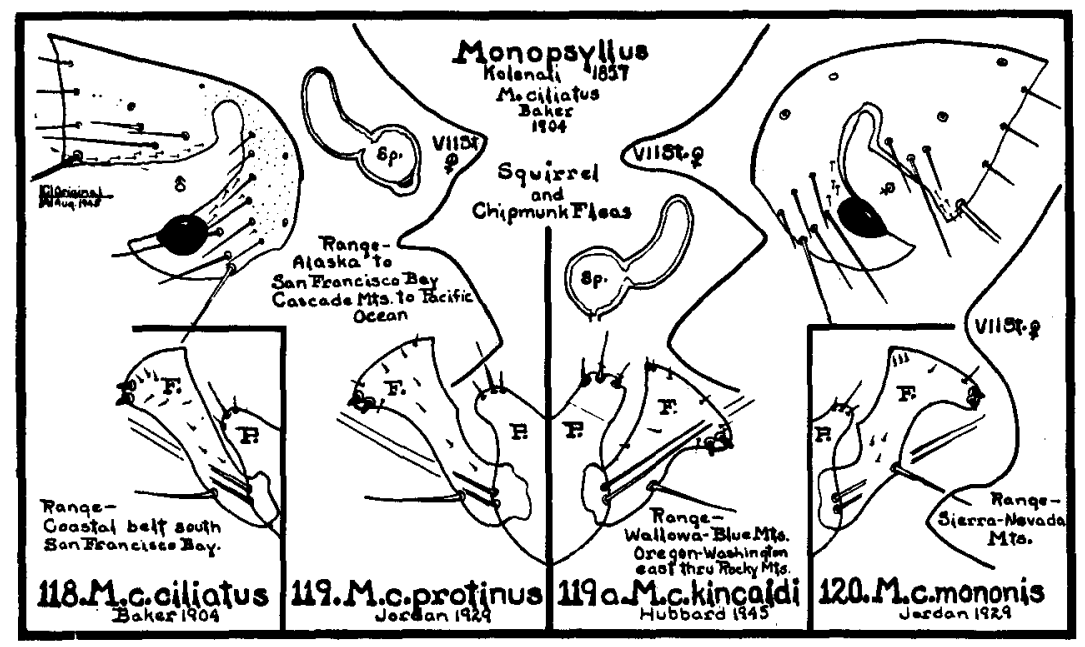

tain View by Ehrhorn. Of the finger Baker says, "Long and slender, upper end suddenly expanded, this latter portion being acute angled in front (heel) and rounded behind (toes), with 2 short, blunt, darkcolored teeth; near base of hind margin is a stout, straight bristle." The original description makes no mention of the spermatheca or apical outline of the VII st. of the female. Jordan adds these features in 1929 about which he says, "In male process $P$ of clasper is broader than in other 2 subspecies, and apex of exopodite (finger) less dilated posticad. Upper lobe of VII st. of female is evenly rounded and broad, but less broad than lower lobe, which is truncate with upper angle rounded off, the sinus a narrow sharp incision."

Type Material is deposited in the United States National Museum under No. 6906.

LENGTH: Original lengths are given as, male $2.3 \mathrm{~mm}$., female $2.5 \mathrm{~mm}$.

Range: This subspecies is known only from the San Francisco Bay area of California.

\section{Monopsyllus ciliatus protinus Jordan 1929}

1929 Ceratophyllus ciliatus protinus Jordan, Nov. Zool., 35:34.

1936 Monopsyllus ciliatus protinus Wagner, Can. Ent., 68:200.

In offering this as a new subspecies of $M$. ciliatus, Jordan states that process $\mathbf{P}$ of clasper is narrower than in M. c. ciliatus and apex of exopodite (finger), though variable, is always strongly dilated posticad. In female, upper lobe of VII st. is more or less triangular and pointed. The spermatheca is typical.

Original description was based on a series of specimens from vari- 
ous locations in British Columbia, Canada. Types came from Sumas off Eutamias townsendi (chipmunk) collected by Allan Brooks.

Wagner reports that the Spencer collection at University of British Columbia, Vancouver, and Kamloops Laboratory have specimens off Eutamias townsendi cooperi (Cooper's chipmunk) and Tamiasciurus douglasi cascadensis (Cascade pine squirrel). The Rocky Mountain Laboratory at Hamilton, Montana, has specimens off wood-rats, chipmunks, tree squirrels and ground squirrels from Oregon.

RANGE: From Alaska south throughout Cascade Mountains and west to Pacific Ocean.

Host Preference: Preferred host is doubtless the chipmunk, but the flea seems to be almost equally at home on pine squirrels. Those amoenus chipmunks which are found in Cascade Mountains are occasionally infested with this subspecies. Carnivores feeding upon chipmunks will also at times carry this flea.

Seasonal Distribution: In so far as chipmunks are in hibernation from 3 to 6 months of the year, this flea is generally only taken during spring, summer and fall. Occasionally this subspecies can be taken from squirrel nests in winter.

ABUNDANCE: Generally the number of this subspecies removed from any chipmunk is very small, 1 or 2 , but occasionally an animal may have as many as a dozen upon it.

RECORDs: The following records are representative of many in the collection of the writer:

OREGON-Off:

Eutamias townsendi townsendi Bachman (Townsend's chipmunk), Toledo, Lincoln County, August 4, 1936, 16 males, 16 females

Eutamias townsendi cooperi Baird (Cooper's chipmunk), Cloud Cap Inn, $6,500 \mathrm{ft}$.el., Mt. Hood, Hood River County, August 5, 1937, 4 males, 3 females

Eutamias townsendi ochrogenys Merriam (Redwood chipmunk), Port Orford, Curry County, August 23, 1937, 12 males, 15 females

Eutamias townsendi siskiyou Howell (Siskiyou chipmunk), Oregon Caves, Josephine County, June 16, 1939, 1 male, 1 female

Eutamias townsendi senex Allen (Allen's chipmunk), Frog Camp, 5 miles west summit Mckenzie Pass, Lane County, July 23, 1938, 1 male, 1 female

Eutamias amoenus amoenus Allen (Klamath chipmunk), New Pine Creek, Lake County, June 18, 1937, 1 male

Eutamias amoenus ochraceus (yellow chipmunk), Bolan Lake, Josephine County, June 17, 1939, 1 male

Tamiasciurus douglasi douglasi Bachman (pine squirrel), Florence, Lane County, August 20, 1937, 3 males, 4 females,

Accidental Occurrences, off:

Aplodontia rufa rufa Rafinesque (mountain beaver), Estacada, Clackamas County, July 19, 1931, I female

Glaucomys sabrinus oregonensis Bachman (Oregon flying squirrel), Gaston, Washington County, March 9, 1937, 2 males, 3 females (from nest) 
Microtus mordax abditus Howell (Tillamook longtailed meadow mouse), Forest Grove, Washington County, September 8, 1937, 2 females

Neotoma cinerea fusca True (dusky bushy-tailed wood-rat), Depoe Bay, Lincoln County, August 11, 1937, 1 male

Ochotona princeps brunnescens Howell (Cascade cony), Cloud Cap Inn, 5,500 ft. el., Rock Slide, Mt. Hood, Parkdale, Hood River County, August 3, 1935, 1 female

Peromyscus maniculatus gambeli Baird (Gambel's deer mouse), Cloud Cap Inn, 6,000 ft. el., Mt. Hood, Parkdale, Hood River County, October 5, 1935, 1 female

Sylvilagus bachmani ubericolor Miller (coast cottontail), Forest Grove, Washington County, March 7, 1932, 1 male

Thomomys bulbivorus Richardson (Willamette Valley pocket gopher), Cornelius, Washington County, May 24, 1935, 1 male

Thomomys monticola mazama Merriam (Mazama pocket gopher), Cooper Spur, Parkdale, Hood River County, August 5, 1935, 1 male

Sciurus griseus griseus Ord' (silver gray squirrel), Gaston, Washington County, October 9, 1938, 3 males, 5 females

Mephites occidentalis occidentalis Baird (common skunk), Gaston, Washington County, March 1, 1939, a series

Martes caurina caurina Merriam (Pacific martin), Summit Mckenzie Pass, Lane County, September 3, 1944, 2 males, 3 females.

CALIFORNIA-Off:

Eutamias amoenus amoenus Allen (Klamath chipmunk), Pine Creek, Modoc County, June 18, 1937, 1 male

Eutamias townsendi siskiyou Howell (Siskiyou chipmunk), Gasquet, Del Norte County, June 16, 1939, 1 male.

WASHINGTON-Off:

Eutamias townsendi townsendi Bachman (Townsend's chipmunk), Spirit Lake, Skamania County, July 7, 1938, 1 male, 2 females

Eutamias amoenus affinis Allen (Columbia chipmunk), Government Mineral Springs, 12 miles north of Carson, Skamania County, August 20, 1935, 1 male

Eutamias townsendi cooperi Baird (Cooper chipmunk), Goose Lake, Skamania County, August 22, 1935, 3 males, 4 females

Tamiasciurus douglasi cascadensis (Cascade pine squirrel), Goose Lake, Skamania County, August 22, 1935, 4 males, 7 females.

BRITISH COLUMBIA-Off:

Tamiasciurus douglasi cascadensis Allen (Cascade pine squirrel), Gambier Island.

ALASKA-Off:

Tamiasciurus hudsonicus hudsonicus Erxleben (red squirrel), Seward.

\section{9a. Monopsyllus ciliatus kincaidi}

Hubbard, 1946

A New Subspecies

There are before the writer at this time the holotype male, the allotype female and 2 paratype males and 2 paratype females from the Wallowa Mountains of Oregon and paratype male from Utah through the courtesy of Dr. J. S. Stanford.

Anatomy. Head. Well rounded in female, less so in male. Eye well developed, black- grape-seed shaped. Gena with 2 rows of bristles, 
lower row of 3 heavy ones, above eye level, upper row of 5 medium ones. Postantennal region with heavy bristle and several medium ones and marginal row of 1 heavy bristle at lower angle and 4 medium ones. Pronotal comb of about 20 heavy black teeth.

Modified Segment: Male. Characteristic ciliatus finger in this subspecies short and stout, being only about one-third longer than process which is broad, apically blunt and armed with three medium bristles. Armature of finger as in other ciliatus 2 blunt, black spiniforms at toe position and stout bristle below them. Female. The upper lobe of VII st. is as long or longer than lower and while somewhat triangular is drawn out into thumb-shaped terminal projection. Spermatheca is distinct, unlike that of other ciliatus in that body is almost spherical rather than elliptical.

LENGTH: Males and females $2.50 \mathrm{~mm}$.

RANGE: From Wallowa and Blue Mountains of Oregon and Washington east through Rocky Mountains.

TyPe Locality: Holotype and allotype taken at Wallowa Lake, Wallowa County, Oregon.

TyPe Host: Five of specimens before writer at this time were taken off Eutamias amoenus luteiventris Allen (Yellowbellied Chipmunk), sixth off Tamiasciurus hudsonicus richardsoni Bachman (Richardson pine squirrel). As with other ciliatus, this subspecies is probably as much at home on Pine, Red, and Gray squirrels as on chipmunks.

DePosit: Holotype male and allotype female, mounted on one slide bearing writer's number 2530 and dated July 30, 1945, are deposited in United States National Museum. Paratypes mounted, dated and numbered as types are sent to British Museum and California Academy of Sciences.

This flea was named for Professor Trevor Kincaid, who for 50 years headed the Department of Zoology at the University of Washington and was the author's major professor through several degrees.

MONTANA-Here, no doubt, belongs the flea listed from Montana as M. ciliatus which was taken off Eutamias spp. in Ravalli County, Montana, during 1922, 1930 , and 1931 .

UTAH-A record of the flea M. c. ciliatus from the state of Utah off Tamiasciurus $h$. ventorum Allen (red squirrel) should doubtless be shifted to this subspecies.

\section{Monopsyllus ciliatus mononis Jordan 1929}

1929 Ceratophyllus ciliatus mononis Jordan, Nov. Zool., 35:34.

This subspecies was described from materials collected by A. B. Howell at Pine City, California, off Eutamias frater (chipmunk) during July of 1922. The collector also secured material from Mustela arizonensis (weasel) but this infestation was without doubt accidental. 
Of this subspecies, Jordan says that process $\mathrm{P}$ of clasper of male is shorter and narrower than in both preceding subspecies; that finger $\mathbf{F}$ is as much widened at apex as in M. c. protinus, but angle of anterior margin is lower down, being placed below the middle. In the female the upper lobe of VII st. is very much broader than lower lobe, its apex rounded and oblique lower margin once feebly incurved; lower lobe subtriangular in lateral aspect, its dorsal margin rounded. Spermatheca is typical.

RANGE: This is apparently the subspecies of $M$. ciliatus found in Sierra-Nevada Mountains south of Tahoe Lake in California and Nevada. The writer has seen specimens from Mammoth Lakes and the original collections were made at Pine City.

Host Preference: Specimens collected at Mammoth Lakes, California, by G. F. Augustson during August of 1939 and 1940 seemed to be as much at home on pine squirrels as on chipmunks. This is characteristic of the other subspecies.

RECORDS are as follows:

CALIFORNA-Off:

Eutamias speciosus frater Allen (Tahoe chipmunk), Al Tahoe, Eldorado County, June 21, 1944, 2 males, 1 female,

Augustson's records for California are as follows, off:

Eutamias quadrivittatus inyoensis Merriam (Inyo chipmunk), Tully's Hole and Cascade Valley, Fresno County; Mammoth Lakes, Mono County

Eutamias alpinus Merriam (Alpine chipmunk), Tully's Hole, Fresno County

Tamiasciurus douglasi albolimbatus Allen (Sierra chickaree), Horse Heaven, Tully's Hole, and Cascade Valley, Fresno County; Mammoth Lakes, Mono County

Citellus beldingi beldingi Merriam (Belding ground squirrel), Mammoth Lakes, Mono County

Marmota flaviventris sierra Howell (Sierra marmot), Mammoth Lakes, Mono County

Eutamias quadrivittatus speciosus (chipmunk), near Big Bear Lake, San Bernardino County

Citellus chrysodeirus bernardinus Merriam (mantled ground squirrel), near Big Bear Lake, San Bernardino County.

NEVADA-Off:

Eutamias speciosus frater Allen (Tahoe chipmunk), Lake Tahoe, Douglas County, June 22, 1944, 1 male, 2 females, collected by author.

\section{Monopsyllus vison Baker 1904}

1904 Ceratophyllus vison Baker, Proc. U. S. Nat. Mus., 27:408.

1904 Ceratophyllus lucidus Baker, Proc. U. S. Nat. Mus., 27:410.

The original description of this species was made from materials collected by G. S. Miller, Jr., off Putorius vison (weasel) at Petersboro, New York, and a specimen taken by Prof. F. L. Harvey off Tamiasciurus hudsonicus (pine squirrel) at Orono, Maine. Baker personally took 


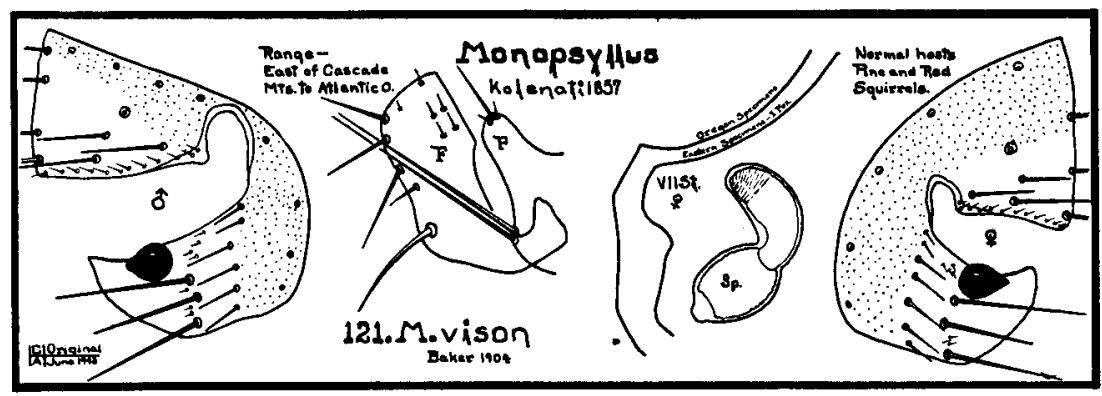

specimens of this species off "little spruce squirrels" that he found at the 9,000 ft. level on Pagosa Peak, southern Colorado, in 1899, which specimens he described as Ceratophyllus lucidus but which are now known to be $M$. vison.

Modified Segments: Characteristic, male having process $\mathbf{P}$ of clasper rather slender and fingerlike, while finger is broad and large, with posterior margin concave. Apically the finger is armed with 2 medium bristles and 1 stout one, lower angle bears a stout curved bristle. Some authorities consider the stout bristles mentioned to be spiniforms. Apical outline of VII st. of females must be variable. This outline as illustrated by Irving Fox from eastern specimens consists of an upper angulate lobe but specimens in the collection of the writer from the extreme western edge of the flea's range in Oregon have this outline represented in a single broad lobe somewhat angulate at the posterio-dorsal angle. Jellison and Kohls report VII st. of specimens from Alaska show considerable variation. Spermatheca has dorsal face of body flattened.

LENGTH: Original given as male, $2.5 \mathrm{~mm}$., female, $3.25 \mathrm{~mm}$.

RANGE: Sweeping across the United States and Canada from as far east as Maine, this species has come into Oregon and Washington, British Columbia, and Alaska with the pine squirrel. In Oregon it is confined to Wallowa and Blue Mountains where this pine squirrel is found; in Washington also, probably throughout the range of this squirrel.

Host Preference: This species seems to be a true pine squirrel flea. It can occasionally be found upon other rodents in its range.

ReCords: The author has collected this flea in

OREGON-Off:

Tamiasciurus hudsonicus richardsoni Bachman (Richardson pine squirrel), Wallowa Lake, Wallowa County, July 14, 1939, 2 pairs

Citellus columbianus columbianus Ord (red digger squirrel), Lostine, Wallowa County, August 6, 1938, 1 female; and in

IDAHO-Off:

Tamiasciurus hudsonicus ventorum Allen (Wind River Mountains pine squirrel), Smiths Ferry, Boise County, July 19, 1945, 1 female. 
MONTANA-In this state this flea has been reported off:

Tamiasciurus hudsonicus (pine squirrel), Ravalli County, 1922, 1930, 1931, and 1940

Ochotona princeps (Rocky Mountain cony), Park County, 1938

Citellus columbianus (Columbian ground squirrel), Ravalli County, 1922

Canis latrans (coyote), Ravalli County, 1922.

UTAH-This flea has been reported from Fish Lake Mountains, off:

Tamiasciurus hudsonicus ventorum Allen (Wind River Mountains red squirrel) .

BRITISH COLUMBIA-From Monte Creek and Kamloops, this flea is reported off: Tamiasciurus hudsonicus streatori Allen (Streator's pine squirrel)

Mustela arizonensis (weasel).

ALASKA-Small series of both sexes are reported from Lake Bennet, Seward, and Skilak Lake, June, 1937, off:

Tamiasciurus hudsonicus (pine squirrel)

Marmota monax (marmot), Fairbanks, July, 1937, a male.

\section{Monopsyllus eumolpi}

Rothschild 1905

1905 Ceratophyllus eumolpi Rothschild, Nov. Zool., 12:161.

In this species segments I and II of the mid-tarsus of male bears a characteristic fringe of long thin bristles. Finger is armed with 3 black blunt spiniforms, of which upper 2 are short, and lowest long. In female, bursa copulatrix is broad and rolled up. This species is found chiefly upon chipmunks. Specimens are almost jet black when collected. There are 2 subspecies west of the 100th meridian.

While the 2 subspecies west of the 100 th meridian have in the females marginal outlines of VII st. which check well with those of the 2 subspecies already described to date, males found with these females do not check apparently, with original descriptions, but seem to be just the reverse, eastern males having a wide ham-shaped finger, Great Basin, Cascade, and Siskiyou subspecies having finger narrow and somewhat rectangular. Thus it seems almost that the males of M. eumolpi eumolpi are associated with females of $M$. eumolpi cyrturus and vice versa.

Key to the Subspecies of Monopsyllus eumolpi Rothschild

1. Female with dorsal lobe of VII st. rounded, male with finger broad, somewhat ham-shaped, lower of shorter spiniforms closer to upper one

M. eumolpi eumolpi, p. 237

2. Female with dorsal lobe of VII st. angular, almost squarish, finger, narrow, somewhat rectangular, three spiniforms about equidistantly placed

M. eumolpi cyrturus, p. 238 


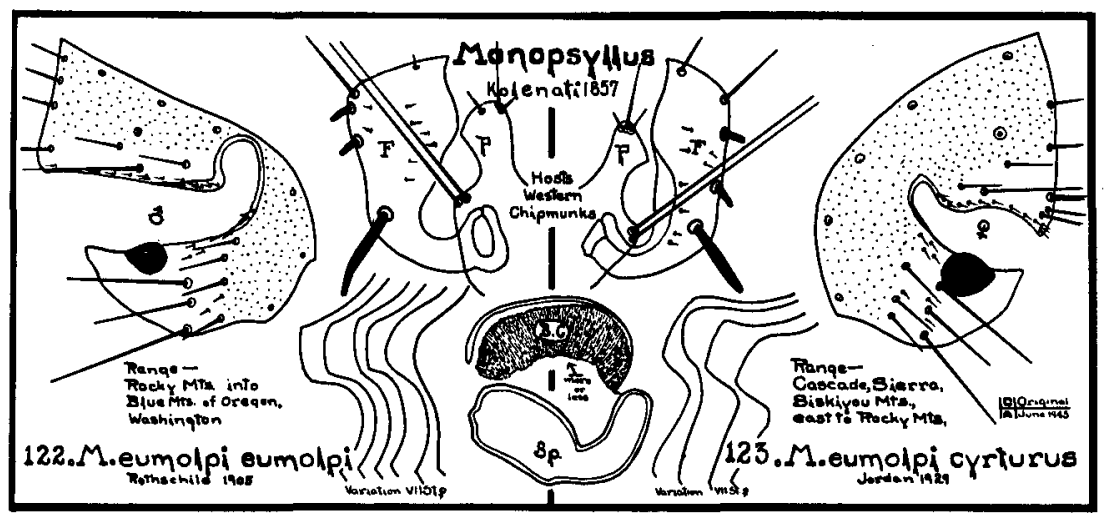

122. Monopsyllus eumolpi eumolpi

\section{Rothschild 1905}

1905 Ceratophyllus eumolpi Rothschild, Nov. Zool., 12:161.

1905 Ceratophyllus eumolpi Baker, Proc. U. S. Nat. Mus., 29:147.

1929 Ceratophyllus eumolpi eumolpi Jordan, Nov. Zool., 35:34.

1933 Monopsyllus eumolpi Jordan, Nov. Zool., 39:77.

1936 Monopsyllus eumolpi Wagner, Can. Ent., 68:200.

1940 Monopsyllus eumolpi Jellison, U. S. Pub. Health Repts., 55:12:491.

This subspecies was described from materials collected off Eutamias quadrivittatus affinis and Tamias borealis (chipmunks) taken in British Columbia and Alberta, Canada.

Modified Segments, Male: Original description states that VIII st. is long, narrow, and rod-like, bearing at its apex 2 long bristles and a number of shorter ones farther back. Finger is long (ham-shaped), bearing 3 blunt spines (lower shorter one much closer to upper shorter one than to longer one) and above them a bristle, another bristle standing at upper edge. Proximal portion of IX st. is short and rather narrow, bearing 2 bristles near sinus, distal portion is long and large, bearing proximally at ventral edge numerous short bristles, ventral portion, moreover, sinuate near apex. Female: It is said that VII st. is truncate, with upper angle produced as a broad rounded lobe. VIII t. bears 3 bristles at apex and 3 short spine-like ones proximally of them, besides a number of short and long bristles. The stylet is about twice as long as broad. Spine-like bristles on anal sternite are heavy and curved.

LeNGTH: Original given as male, $2.3 \mathrm{~mm}$., female, $2.8 \mathrm{~mm}$.

RaNGE: This is a Rocky Mountain subspecies. In Far West it seems to be migrating westward into northeastern Oregon and extreme eastern Washington from foothills of the Rocky Mountains. In Oregon the range is restricted to the Wallowa Mountains; in Washington, extreme portion of the state adjacent to Idaho wherever there are chipmunks.

Host Preference: While the writer has taken this flea only off Eutamias amoenus luteiventris Allen (yellow-bellied chipmunk), it is 
probable that it is just as at home on Eutamias amoenus canicaudus Merriam and as time goes on it will spread its range westward through those amoenus chipmunks which do not live in the desert regions.

Recoros: The writer's experience with this species is covered by the following:

\section{OREGON-Off:}

Eutamias amoenus luteiventris Allen (yellow-bellied chipmunk) (20 specimens), Wallowa Lake, Wallowa County, July 13, 1939, 8 males, 26 females

Tamiasciurus hudsonicus richardsoni Bachman (Richardson pine squirrel) (1 specimen), Wallowa Lake, Wallowa County, July 14, 1939, 1 female.

MONTANA-Although records from this state to this date are recorded only as Monopsyllus eumolpi, the writer feels that these fleas belong here. They have been recorded off:

Eutamias spp: (chipmunk), Beaverhead, Fergus, Gallatin, Missoula, Park, Ravalli, and Silver Bow Counties

Marmota flaviventris (woodchuck), Gallatin and Missoula Counties

Peromyscus spp. (deer mouse), Gallatin County

Tamiasciurus hudsonicus (pine squirrel), Ravalli County

Citellus richardsoni subspp. (Richardson ground squirrel), Gallatin and Madison Counties

Citellus columbianus (Columbian ground squirrel), Deer Lodge, Jefferson, Lake, Lewis and Clark, Missoula, and Ravalli Counties

Citellus armatus (Uinta ground squirrel), Park County

Ochotona princeps (Rocky Mountain cony), Ravalli County

Mustela spp. (weasel), Madison County

Canis latrans (coyote), Ravalli County.

In the Rocky Mountain area this flea is also reported off:

Eutamias spp. (chipmunk), Etna, Salina, and Logan Canyon, Utah; Teton, Wyoming; Red Deer and Banff, Alberta, Canada, and the interior of British Columbia.

\section{Monopsyllus eumolpí cyrturus Jordan 1929}

1929 Ceratophyllus eumolpi cyrturus Jordan, Nov. Zool., 35:34.

This subspecies was described from 1 male and 5 females taken off Mephitis (skunk) October, 1913, at Paradise, Arizona, by O. C. Duffner. The terse statement given in the original description of the female is, "The lobe of VII st. less rounded than in C. e. eumolpi, its lower angle usually distinct; spermatheca longer." This upper lobe in hundreds of specimens in the collection of the writer is distinctly angular, almost squarish. While original description of male finger and process reads, "Process $\mathrm{P}$ of clasper and exopodite (finger) broader than in C. e. eumolpi, the second spiniform much nearer to the long one than to the short subapical one." Finger of males associated with these females is much narrower than the preceding subspecies and the 3 spiniforms are almost equidistant from each other, except in the case of males 
collected in Siskiyou Mountains of Oregon and California. All specimens in the collection of the writer from Nevada, California, Oregon, and Washington are fairly constant in the shape and armature of the finger.

A letter received from Dr. Karl Jordan dated 26.X.1938 states that he believes this flea to be of this subspecies, but "... . perhaps a little different." It is quite possible that the Colorado River forms a natural barrier between these northern forms and the true M. e. cyrturus which was described from extreme southeastern Arizona at Paradise.

RANGE: Sweeping northward throughout the Great Basin region of Nevada, Oregon, and Washington, thence westward into the Cascade Mountains of Washington, Oregon, and California, and out into the Siskiyou Mountains of California and Oregon.

Host Preffrence: This flea is generally found upon the minimus and amoenus groups of chipmunks and those townsendi which are found in the Cascade, Siskiyou, and northern Sierra Nevada Mountains. It is not uncommon to find it upon pine squirrels and occasionally it is found upon other rodents of Great Basin and Cascade-Sierra-Nevada Mountains.

Seasonal Distribetion: This subspecies fades rapidly from collections after the chipmunks in its range go into hibernation during October or November, and appears again in spring with the spring appearance of their normal hosts.

The Rocky Mountain Laboratory reports specimens from Eutamias spp. (chipmunk) Harney and Douglas Counties, and Callospermophilus (golden mantled ground squirrel) from Harney County, Oregon.

Records: From several hundred records for this subspecies in the collection of the writer, the following are representative:

OREGON-Off:

Eutamias amoenus ludibundis Hollister (Hollister's chipmunk), Wamic, Wasco County, May 18, 1937, 6 males, 6 females

Eutamias amoenus amoenus Allen (Klamath chipmunk), Silvies, Harney County, July 15, 1937, 6 females

Eutamias minimus pictus Allen (Desert chipmunk), Crane, Harney County, July 16, 1937, 11 males, 20 females

Eutamias amoenus ochraceus Howell (yellow chipmunk), Bolan Lake, Josephine County, June 17, 1939, 3 males, 8 females

Eutamias townsendi senex Allen (Allen's chipmunk), Crater Lake, Klamath County, July 1, 1933, 1 male

Eutamias townsendi cooperi Baird (Cooper's chipmunk), Parkdale, Hood River County, May 17, 1936, I male, 5 females

Eutamias townsendi siskiyou Howell (Siskiyou chipmunk), Oregon Caves, Josephine County, June 16, 1939, 1 male, 2 females,

Accidental Occurrences off:

Reithrodontomys megalotis megalotis Baird (desert harvest mouse), Plush, Lake County, July 1, 1939, 1 male 
Neotoma cinerea occidentalis Baird (western bushy-tailed wood-rat), Wamic, Wasco County, May 18, 1937, 1 female

Ochotona fenisex fumosa Howell (dusky cony), Spark's Lake, Deschutes County $(5,437 \mathrm{ft}$. el. $)$, July 24, 1936, 1 male, i female

Peromyscus maniculatus gambeli Baird (Gambel's deer mouse), Sisters, Deschutes County, July 23, 1936, 1 male

Tamiasciurus douglasi douglasi Bachman (pine squirrel), Cooper Spur Junction, Hood River County, August 4, 1937, 1 female

Thomomy's quadratus quadratus Merriam (The Dalles pocket gopher), Sisters, Deschutes County, July 16, 1936, 1 male

\section{WASHINGTON-Off:}

Eutamias minimus pictus Allen (sagebrush chipmunk), Mabton, Yakima County (15 miles south), May 28, 1938, 3 males, 4 females

Eutamias townsendi cooperi Baird (Cooper's chipmunk), Goose Lake, Skamania County (west of Guler), August 23, 1935, 1 male.

NEVADA-Off:

Eutamias minimus pictus Allen (sagebrush chipmunk), Vya, Washoe County, June 16, 1944, 1 female; Contact, Elko County, July 2, 1944, 1 female; Wells, Elko County, July 6, 1944, 2 females

Eutamias sp., Minden, Douglas County, June 24, 1944, 1 male, 2 females; Lovelock, Pershing County, June 27, 1944, 2 pairs; Winnemucca, Humboldt County, June 28, 1944, 9 males, 16 females; Battle Mountain, Lander County, June 29, 1944, 7 males; Wells, Elko County, July 6, 1944, a large series; Austin, Lander County, July 10, 1944, 9 pairs

Reithrodontomys megalotis megalotis Baird, (desert harvest mouse), McDermitt, Humboldt County, July 8, 1939, 1 male.

IDAHO-Off:

Tamiasciurus hudsonicus richardsoni Bachman (Richardson pine squirrel), Bonner Ferry, Bonner County, July 24, 1945, 1 male.

Tamiasciurus hudsonicus ventorum Allen (Wind River Mountains pine squirrel), Smiths Ferry, Boise County, July 19, 1945, a pair.

Eutamias ruficaudus simulans Howell (Coeur d'Alene chipmunk), Smiths Ferry, Boise County, July 18, 1945, 9 males, 17 females.

ARIZONA-Off:

Eutamias dorsalis dorsalis Baird (Gila chipmunk), Grand Canyon, Coconino County, July 4, 1945, 1 male, 5 females.

\section{CALIFORNIA-Off:}

Eutamias townsendi siskiyou Howell (Siskiyou chipmunk), Happy Camp, Siskiyou County, June 17, 1939, 2 males, 5 females

Eutamias amoenus ochraceus Howell (yellow chipmunk), Happy Camp, Siskiyou County, June 17, 1939, 1 male, 2 females

Eutamias amoenus amoenus Allen (Klamath chipmunk), Pine Creek, Modoc County, June 18, 1937, I male, 3 females

Eutamias speciosus frater Allen (Tahoe chipmunk), Truckee, Nevada County, June 23, 1944, 1 male,

To the south in the central Sierra-Nevada Mountains, Augustson has taken this flea off:

Eutamias alpinus Merriam (Alpine chipmunk), Mammoth Meadows, Mono County, August 8, 1940, 1 male; Tully's Hole, Fresno County, August 24, 1941,1 female 
Eutamias quadrivittatus inyoensis Merriam (Inyo chipmunk), Benton Crossing, Casa Diablo, Mono County, August, 1940; Mammoth Lakes, Duck Pass, Mono County, July and August, 1941; Tully's Hole and Cascade Valley, Fresno County, August, 1941, in each case small series

Tamiasciurus douglasi albolimbatus Allen (California chickaree), Tully's Hole and Cascade Valley, Fresno County, August, 1941, 1 male, 1 female

Citellus lateralis chrysodeirus Merriam (mantled ground squirrel), Casa Diablo, Mono County, August, 1940, 1 female

Citellus beldingi beldingi Merriam (Belding ground squirrel), Mammoth Lakes, Mono County, August, 1939, 1 male

Sylvilagus nuttalli grangeri Allen (Granger cottontail), Mammoth Lakes, Mono County, July, 1940, 1 female.

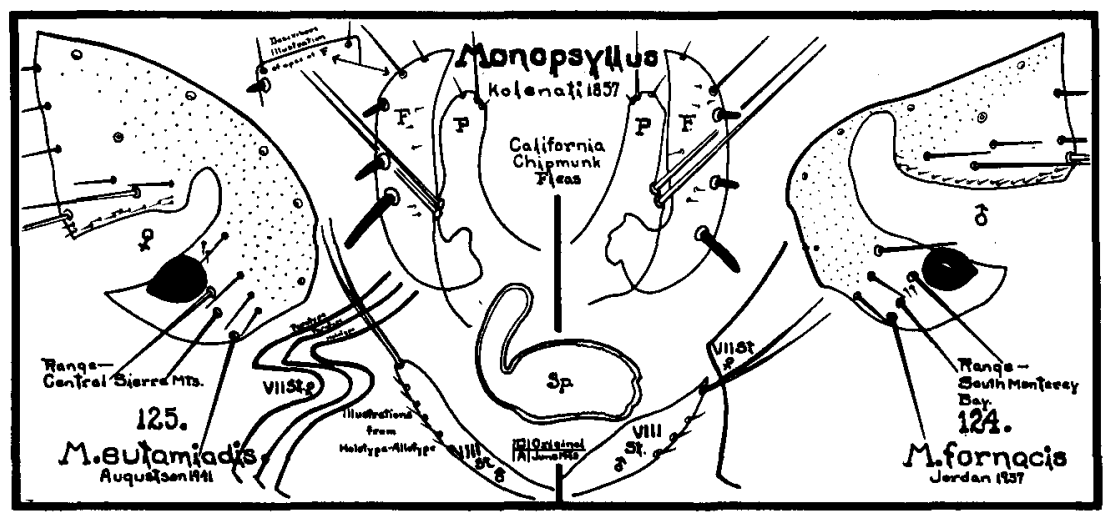

124. Monopsyllus fornacis

Jordan 1937

1937 Monopsyllus fornacis Jordan, Nov. Zool., 40:263.

1940 Monopsyllus fornacis Jellison, U. S. Pub. Health Repts., 55:12:491.

This species was described from 2 females taken off Sciurus griseus (silver gray squirrel) at Seven Oaks, San Bernardino County, California. The description of the male was made by Jellison during 1940 from a male taken off Eutamias merriami (chipmunk) at Jamesburg, Monterey County, on July 18, 1939.

This species is said to be close to Monopsyllus eumolpi Rothschild. Jellison states in his description of the male that in the males of both species the first segment of midtarsus is elongated and bears on its posterior side a very characteristic fringe of long thin bristles, and that this species differs from $M$. eumolpi mainly in modified abdominal segments.

This writer, in comparing the fingers of both species, prefers to describe the form of $M$. eumolpi as somewhat ham-shaped, that of $M$. fornacis as somewhat scythe-blade-shaped. Process $\mathrm{P}$ of clasper of this species is longer and broader than that of $M$. eumolpi. Spiniforms on finger are shorter, heavier, and straight, in contrast to slightly curved spines of $M$. eumolpi. 
Female: Apical outline of VII st. is fairly perpendicular and even with a small triangular lobe at its mid point, while VII st. of $M$. eumolpi cyrturus of Oregon and northern California has an upper lobe which is distinctly squarish, and VII st. of $M$. eumolpi eumolpi of northeastern Oregon has an upper lobe which is hooked or rounded.

RANGE: With the allotype male from just south of Monterey Bay and the holotype female from Seven Oaks, it appears that this species ranges throughout the southern half of California.

Host Preference: Jellison seems to feel that the preferred host of this species is Eutamias merriami (Merriam's chipmunk).

RECORDs: Holotype male was collected at Seven Oaks, San Bernardino County, California, allotype female at Jamesburg, Monterey County, California, and there are 5 males and 24 females in the collection of the Hastings Natural History Reservation, Jamesburg, Monterey County, California, where they were collected during April, June, and July of 1939 off 12 specimens of Eutamias merriami (chipmunk).

\section{Monopsyllus eutamiadis}

Augustson 1941

1941 Monopsyllus eutamiadis Augustson, Bul. S. Calif. Acad. of Sci., 40:141.

This flea was described off the Inyo chipmunk taken at Cascade Valley, Fresno County, California, by Rutherford and Augustson on August 27, 1941. The describer states that this species is close to $M$. eumolpi but the writer feels that it is close to $M$. fornacis and probably is a Sierra-Nevada Mountain variation of $M$. fornacis.

According to the original description this flea has 16 sharply pointed teeth in the pronotal comb.

Modified Segments, Male: T. VIII sharply rounded on its dorsoposterior angle, with 7 bristles on same area and 2 in the ventro-posterior area; clasper slender, half moon-shaped with a long, thumb-like process falling slightly short of the total length of the finger; finger very diagnostic, with 3 spiniforms; st. IX with a single lobe on ventral portion of free arm, upper portion long, slender; st. VIII long, with a few bristles along its lateral margin, and 2 terminal bristles. Female: VII st. with a very deep sinus high in free margin forming an acute upper lobe, fixed margin with numerous bristles, 7 long bristles in the posterior row and 12 smaller ones immediately anterior.

Range: While known only from Mono and Fresno Counties, California, this flea probably ranges throughout the southern half of the Sierra-Nevada Mountains.

Preferred Host: This flea is known only from 1 male and 4 females taken off Eutamias quadrivittatus inyoensis Merriam at Mammoth Lakes, Mono County and Cascade Valley, Fresno County, California. 


\section{Monopsyllus exilis \\ Jordan 1937}

1937 Megabothris exilis Jordan, Nov. Zool., 40:264.

1938 Monopsyllus exilis Jordan, Nov. Zool., 41:120.

The original description of this species was made from 2 males sent to Dr. Jordan by the staff of the Rocky Mountain Laboratory. Specimens were taken from a nest of Speotyto (burrowing owl) in Beaverhead County, Montana, during June, 1937. It is stated that this species is close to Monopsyllus ciliatus Baker. The finger which is quite characteristic and marks this male from all other western fleas, consists of a somewhat rectangular organ, posterior dorsal angle of which is armed with 2 small spiniforms and 2 medium bristles, a bristle above and one below spiniforms. Two apical spiniforms differ in shape but each is drawn out into a sharp point, the lower one especially resembling a thin bristle. Original description also states that female can be distinguished from female of $M$. ciliatus by shape of VII st.; margin is sinuate as in $M$. ciliatus but lobe above sinus is short, very broad and rounded, and sometimes projects very little. Spermatheca is larger than in $M$. ciliatus, tail shorter in proportion to its width, ventral surface of body flattened.

Host: The true host of these fleas is probably Onychomys (grasshopper mouse), and it seems possible that one of its subspecies will be found wherever there are grasshopper mice.

The species has been divided into 4 subspecies. These do not lend themselves readily to a key, and can more easily be separated by range, as follows:

Rocky Mountains of Montana and west

M. exilis exilis, p. 243

Central Rocky Mountains

Southwest United States

$M$. exilis triptus, p. 245

Great Plains

$M$, exilis opadus, p. 245

M. exilis kansensis, p. 245

\section{Monopsyllus exilis exilis \\ Jordan 1937}

1937 Megabothris exilis Jordan, Nov. Zool., 40:264.

1938 Monopsyllus exilis exilis Jordan, Nov. Zool., 41:120.

Through the kindness of Parker and Jellison of the Rocky Mountain Laboratory, Dr. Jordan received a second parcel of these fleas for study. The result was the breaking of the species into 3 subspecies. This subspecies is characterized below.

Modified Segments, Male: Process $P$ apically rounded, with one bristle. Finger, while somewhat rectangular, expanded at apex; anterior face flat, posterior face concave; posterio-dorsal angle with 2 spiniforms and 2 bristles, spiniforms, upper one short, heavy, pointed and 


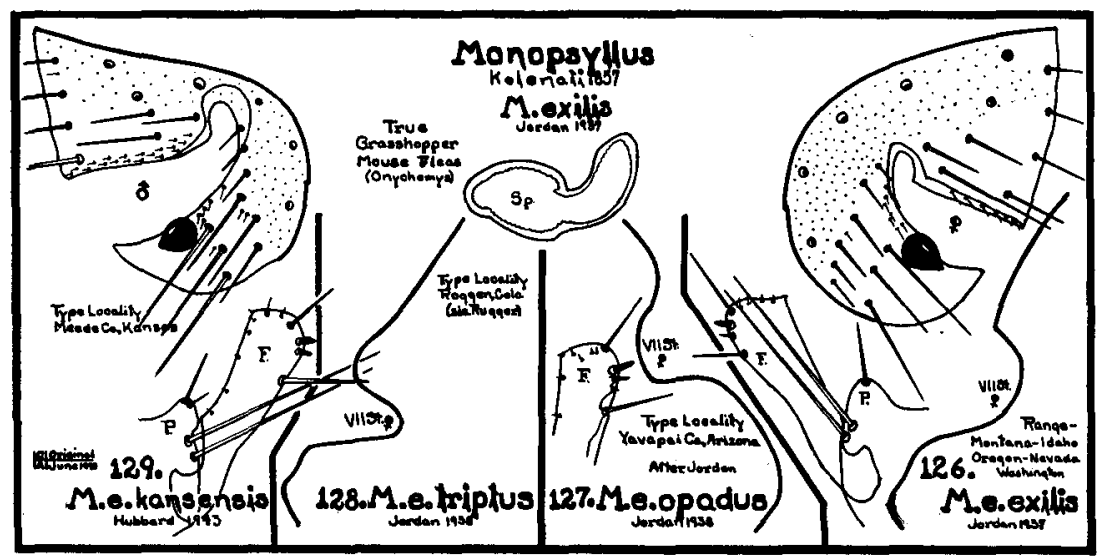

black, lower one short, weak, dark and bristle like, two about same length and close together. The two bristles are long and slender, one above and one below spiniforms. The angle which bears this armature is nicely rounded. FEMALE: VII st. with apical margin sinuate, sinus broad and not too deep. Upper and lower lobes weak. Spermatheca typical.

RANGE: Described from Montana and with two records of the writer's from southeastern Oregon, it seems probable that this subspecies at least is found between these two points and is probably increasing its range in the Great Basin region of Oregon and perhaps Nevada.

Host Preference: While the original description was made from the nest of Speotyto, the writer's records are all from grasshopper mice, and although 3 Microdipodops (gnome mice), 1 Perognathus (pocket mouse), 6 Perodipus (kangaroo rats), 10 Peromyscus (deer mice), 1 Microtus (meadow mouse), 2 Citellus (sage rats), and 1 amoenus (chipmunk) were collected the same morning, in immediate vicinity, none of these carried this subspecies. This writer feels that Onychomys (grasshopper mouse) is the preferred host of this flea.

RECORDS: The only records for this flea from west of the Rocky Mountains are from:

OREGON-Off:

Onychomys leucogaster fuscogriseus Anthony (Oregon grasshopper mouse), Pedro Springs, summit highway between Blitzen and Field, Harney County, Oregon, July 6, 1939, I male, I female; Blitzen and Steen Mountain Draw, Oregon, July $6,1939,2$ males. The author also collected it in

UTAH-Off:

Onychomys leucogaster melanophrys Merriam (dark-brown grasshopper mouse), Kanab, Kane County, July 9, 1945, 1 male. 


\section{Monopsyllus exilis opadus \\ Jordan 1938}

1938 Monopsyllus exilis opadus Jordan, Nov. Zool., 41:121.

This flea was described from material sent Dr. Jordan by Parker and Jellison from Yavapai County, Arizona.

The short description states that in VIII st. of male the distance of lower spiniform to long marginal bristle below it is the same as marginal bristle above spiniforms. Lower apical spiniform of finger $\mathbf{F}$ is narrower and much shorter than the upper, but not thin and bristle-like. Vertical arm of IX st. more strongly widened. VII st. of female has a short rounded upper lobe; lower lobe very broad, rounded-truncate, apical margin vertical.

RANGE: Although known only for Yavapai County, Arizona, this flea is probably found throughout the Pacific Southwest on grasshopper mice.

Host Preference: This flea is probably a true grasshopper mouse flea.

Records: Only the original records are available. These are from Yavapai County, April, 1937.

ARIZONA-Off:

Onychomys leucogaster capitalatus Hollister (Arizona grasshopper mouse), I male and 3 females

Dipodomys (olii sic.) ordi (kangaroo rat), 1 female.

\section{Monopsyllus exilis triptus Jordan 1938}

1938 Monopsyllus exilis triptus Jordan, Nov. Zool., 41:122.

This subspecies is known only from the female. Original short description reads as follows: Colorado: Roggen (Rugger sic.), June, 1937, on Dipodomys or Onychomys, 2 females.

In these $\mathbf{2}$ females, which are somewhat smaller than those from Arizona and Montana, sinus of VII st. is deeper and narrower, upper lobe projecting farther distad; lower lobe in one specimen nearly as in Arizona females, except that it is longer, in other specimen this lobe is narrow and its short apical margin oblique.

\section{Monopsyllus exilis kansensis Hubbard 1943}

1943 Monopsyllus exilis kansensis Hubbard, Pacific Univ. Bul., 39:10:1.

This subspecies was described from 2 males taken in Meade County, Kansas, during July of 1940 by Hill and Crowe. It can be distinguished from Monopsyllus exilis exilis Jordan 1937 by the difference in shape of clasper, both finger $\mathrm{F}$ and process $\mathrm{P}$. While finger in $M$. e. exilis is 
swollen posteriorly at apex, in this subspecies apex is more evenly rounded; anterior and posterior faces of finger are more parallel. Armature of the finger is similar to M. e. exilis, i.e., a bristle at apex, followed posteriorly by 2 small black spiniforms, lower one smaller than upper, then to ventral a bristle of about 3 times the weight of apical bristle. Apex of process $\mathbf{P}$ in $M$. e. exilis is dome shaped, in this subspecies rounded. VIII and IX sts. are similar and probably not of taxonomic value.

LENGTH: $2.30 \mathrm{~mm}$. and $2.50 \mathrm{~mm}$.

Type Host: The two known males are off Onychomys leucogaster articeps Rhoads (Great Plains grasshopper mouse).

Range: While known only from the type locality (Meade County, Kansas) this insect is probably found throughout the Great Plains on grasshopper mice.

\section{GENUS PLEOCHAETIS JORDAN}

1933. Pleochaetis Jordan. Nov. Zool. 39:77.

Genotype: Ceratophyllus mundus Jordan and Rothschild 1922

In this genus the preantennal region of head is armed with 2 or 3 rows of bristles; postantennal region with 2 or more bristles behind base of antennal groove and 3 or more in middle of region. Eye is well pigmented. Bristles on second segment of antenna are short, in female not reaching apex of club. In male, sternal plate VIII is slender, with 1 or more subapical bristles and sometimes with membranous flap. Stylet of female with 1 or 2 lateral bristles. Spermatheca with body subglobular to oblong.

This genus is represented in the West by but a single species.

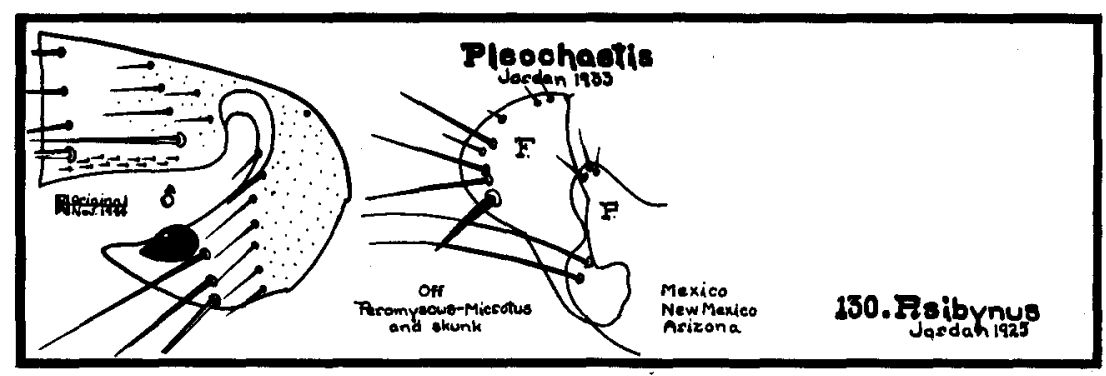

130. Pleochaetis sibynus

Jordan 1925

1925 Ceratophyllus sibynus Jordan, Nov. Zool., 32:110.

1933 Pleochaetis sibynus Jordan, Nov. Zool., 39:77.

1939 Pleochaetis sibynus I. Fox, Iowa State College Jour. of Sci., 13:336.

This species was described from a single male taken off a skunk collected at Paradise, Cochise County, Arizona, during December of 1913 by O. C. Duffner. 
Male, Head: Well rounded. Frontal tubercle small. Eye well developed, oval. Well above eye level a row of 3 stout bristles, middle one shortest. A second row of 4 medium bristles and a third row represented by a single medium bristle close to antennal groove. Postantennal region with 3 well developed rows of bristles, the numbers being 2, 4 , and 6 . There are a few setae along the antennal groove.

Pronotal Comb of about 20 teeth.

Modified Segments: Process of clasper fairly broad, rounded at apex, incurved posteriorly; armed apically with a few short bristles. Various descriptions of the finger vary. A specimen before the writer taken in the Grand Canyon of Arizona off a deer mouse possesses a finger which is broad apically and narrow at base. Front face for half its length is slightly concave, lower half incurved. From apex the posterior margin is nicely rounded to about one half the length, then incurved. In this specimen armature consists of 2 black spiniforms at posterio-ventral angle and above these 3 longer bristles evenly distributed along the upper margin. A few setae are scattered over the surface.

Ewing and Fox state of male specimen in collection of the United States National Museum, "This is a small flea. The movable finger of the clasper bears a row of 5 stout, darkened submarginal setae, the uppermost of which is the longest, the lowermost the shortest and stoutest while the other 3 are almost subequal in length, each being slightly longer than the lowermost." This specimen was taken in the Mogollon Mountains of New Mexico.

The original statement is, "The lowest bristle of the exopodite replaced by a stout, straight, obtuse, long spine; IX st. at some distance proximally of ventral sinus on each side with a cluster of 6 bristles, of which the 3 lateral ones are small and the 3 ventral, longish, the middle one of them being the longest."

The female of this species is unknown.

LENGTH: A male in the collection of the writer measures $2.00 \mathrm{~mm}$.

Range: This species is recorded only from Arizona and New Mexico.

Records: The original is off skunk, Paradise, Arizona, December, 1913; a specimen from Mogollon Mountains, New Mexico, with no host recorded in United States National Museum; and a single specimen in the collection of the writer off Peromyscus m. rufinus Merriam (Arizona wood mouse) taken in the Grand Canyon of Arizona during June of 1942.

I. Fox says in 1939 of "Records: Mexico-Ojo de Aqua, Craleano, Nuevo Leon, July 20, 1924, and August 10, 1938, on 'Peromyscus', 4 males; Cerro Potosi, Nuevo Leon, 12,500 ft., July 28, 1938, on 'Microtus', 1 male.

"Modified Segments: Movable finger variable in shape; of the 5 specimens at hand, 3 correspond with the figure published by Jordan in his original description while other 2 show marked similarity to Jor- 
dan's $P$. equatoris in structure of movable finger. Posterior margin of movable finger armed with 3 long bristles and a stout spiniform. Process of clasper more or less triangular in shape, its apex armed with 3 small bristles."

\section{GENUS CERATOPHYLLUS CURTIS}

1832. Ceratophyllus Curtis. British Entomology, 9:417.

Genotype: Ceratophyllus hirundinus Curtis 1832

Eye is well developed in this genus. The ocular bristle is placed on a level with or above upper margin of eye. Pre-antennal region of head with 2 rows of bristles of which upper consists of 3 to 6 , while lower consists of 3 much longer ones. Labial palpus not reaching beyond the apex of the forecoxa, usually about as long as maxillary palpus. Pronotal comb with 24 or more teeth. Male with 1 long and 2 minute antepygidial bristles, VIII $t$. with spiculose dorsal area (sometimes restricted to margin), VIII st. rod-like with apical bristles (often spiniforms) and apical flap. Apex of vertical arm of IX st. widened posteriorly, ventral arm with the antemedian rounded dilation and the proximal angle of apical lobe setiferous. In lateral aspect the anal sternite narrow, longer than tergite, with bristles dorsal and apical. Female with 1 long and 2 minute antepygidial bristles. Bursa copulatrix and spermatheca variable, body usually cylindrical, tube-like, several times as long as broad.

West of 100th meridian 11 species of this genus have so far been recorded. One of these is off a porcupine, the other 10 off birds. They do not readily fall into keys, but are much more easily studied through illustrations.

\section{Ceratophyllus niger niger \\ C. Fox 1908}

1908 Ceratophyllus niger C. Fox, Ent. News, 19:434.

This is the common western poultry flea. It can be found in large numbers during spring and summer in many western chicken houses where owners do not take control measures against it. The species was originally described off man from San Francisco, California.

The pronotal comb consists of from 26 to 28 teeth.

Modified Segments, Male: Process $P$ of clasper broad and apically rounded, armed at apex with 1 long bristle and 2 much shorter ones. Finger $F$ wide apically and broadly rounded. Upper half of posterior margin with 3 or 4 well developed bristles, and several weaker ones. Spiny area on the inner surface of VIII t. narrow. Apical flap of the VIII st. long, narrow, and tapering, leaning distad. Two ventral dilations of IX st. prominent, bristles numerous and spiniform. Female: VII st. with a single well rounded lobe. Spermatheca typical. 
LENGTH: Male $3.00 \mathrm{~mm}$., female $3.25 \mathrm{~mm}$.

RANGE: Western part of North America.

PREFERREd Host: This western chicken flea has been also reported off various wild birds, man, and barnyard animals.

Economic Importance: Unlike the sticktight hen flea this species

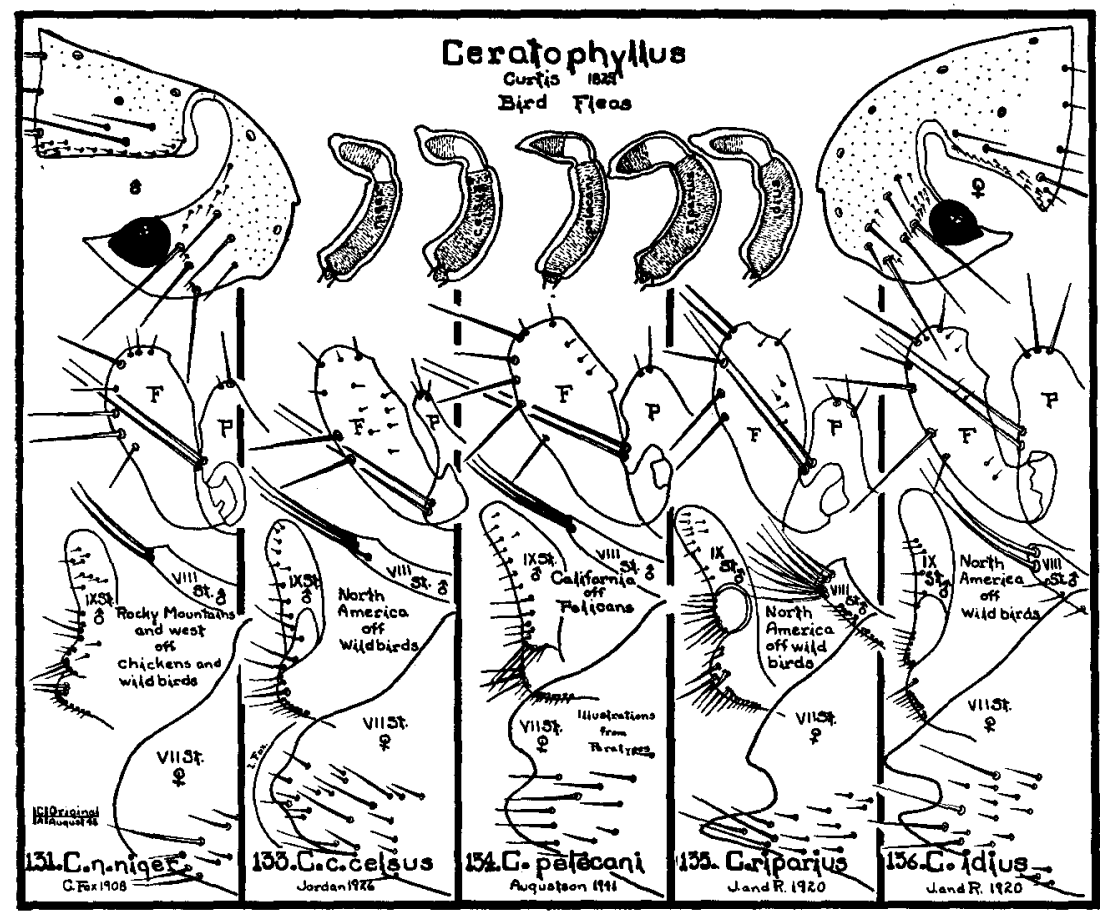

only contacts its host when it wishes to feed. At other times this flea is in nest boxes and cracks and crevices about the poultry houses. Uncontrolled infestation of poultry by this flea causes a marked drop in egg production.

CoNTRol measures call for periodic removal of all nesting materials and floor dressing which should be burned to kill the larvae. Application of kerosene to all crevices and cracks will kill the adults and larva.

Records: As early as 1909 this flea was reported from the San Francisco Bay area off man, house mouse, chickens and English sparrows.

During August of 1940 Augustson reported a male and 6 females of this flea from Benton Crossing, Mono County, California, off

Dryobates villosus orius Oberholser (Modoc woodpecker).

In Oregon the writer collected a large series from a chicken house at Cannon Beach, Tillamook County, during November of 1940, and in Seattle, King County, Washington, during June of 1920. 
In Canada there are many records of this flea from British Columbia and Alberta out of hen houses and off wild birds. To the north at Skilak Lake, Alaska, large numbers of this flea were reared from nests of Larus argentatus (herring gull), and Phalacrocorax auritus (cormorant) taken during June of 1937. In Beaverhead County, Montana, this species is reported off Pica pica hudsonia (magpie).

\section{Ceratophyllus niger inflexus Jordan 1929}

1929 Ceratophyllus niger inflexus Jordan, Nov. Zool., 35:37.

1936 Ceratophyllus niger inflexus Wagner, Can. Ent., 68:200.

The original description reads as follows: "Female: Only 2 specimens known. Both have apical margin of VII st. incurved above middle.

"Habit. Colorado: Custer Co., (T. D. A. Cockerell), no host mentioned, 1 female type, in United States National Museum; Colorado Springs, 1 female on Eutamias, xi 1909 (E. R. Warren), in Collection N. C. R."

In 1936 Wagner suggested that this subspecies was the same as $C$. niger niger.

\section{Ceratophyllus celsus celsus Jordan 1926}

1926 Ceratophyllus celsus Jordan, Nov. Zool., 33:387.

This flea was described off a bank swallow taken at Okanagan Falls, British Columbia.

Male can be distinguished from all other allied bird fleas by long and narrow process $\mathbf{P}$ of clasper. It is about 4 times as long as it is broad at middle. Finger is of type found in $C$. niger but longer and narrower. Armature consists of 2 strong bristles on posterior side in apical half, between them and apex 2 smaller ones of which the apical one is longer. Dilated portion of proximal half of IX st. of male longer and narrower than in $C$. niger. St. VIII of male with 7 long bristles at apex and 2 membranous projections which are directed distad. In female the outline of VII st. consists of a single broad lobe undulate along its entire border. Irving Fox illustrating this characteristic from eastern specimens depicts it as a well rounded single lobe.

Pronotal Comb consists of about 28 teeth.

RANGE: This bird flea seems to range from coast to coast in North America.

Preferred Host: A true bird flea which seems to be reported most often on cliff and bank swallows.

RECORD: West of the 100th meridian records for this flea are reported only from the type locality at Okanagan Falls, British Columbia and from Montana, off:

Petrochelidon albifrons (northern cliff swallow), Yellowstone

Riparia riparia (bank swallow), Beaverhead County. 


\section{Ceratophyllus pelecani}

Augustson 1942

1942 Ceratophyllus pelecani Augustson, Trans. San Diego Soc. of Nat. Hist., 9:37:437.

This species was described from 7 males and 3 females taken off a brown pelican collected on Los Coronados Islands, Lower California, Mexico, during September of 1937.

The following statements come from the original description:

Frontal notch prominent, acuminate; eye large, darkly pigmented; preantennal region with 2 rows of bristles, 3 medium bristles in upper row, 3 much longer ones in lower row; postantennal region with 3 short bristles and one very long bristle along posterior border of antennal groove; maxilla sharply acuminate; labial palpi falling slightly short of fore-coxa length. Pronotal comb of 25 teeth. Three antepygidial bristles in female, the middle one 4 times the length of the two equal, outer bristles; 1 long one in male. MALE: VIII st. a moderately thick, long arm with 5 long apical bristles in addition to a spike-like membranous extension, st. IX with a knob-like posterior basal portion well covered with setae, the dorsal portion weakly so; finger very characteristic, with 4 to 5 medium bristles along its outer edge; spring with 2 full turns. Female: VII st. with a sinus and sub-equal upper and lower lobes.

Length: Paratypes in the collection of the writer measure close to $3.00 \mathrm{~mm}$. in both sexes.

Range: This flea probably occurs throughout the range of Pelecanus occidentalis californicus R. (brown pelican) which is considered to be its true host.

Record: Besides the types off Brown Pelican this flea has also been taken off:

Peromyscus maniculatus elusus N. and G. (deer mouse) , Santa Barbara Island, Los Angeles County, March 22, 1940, 1 female, (Augustson).

\section{Ceratophyllus riparius}

Jordan and Rothschild 1920

1920 Ceratophyllus riparius Jordan and Rothschild, Ectoparasites, 1:71.

Although this species was described from materials taken out of the nests of Riparia riparia (bank swallow) at Milwaukee, Wisconsin, and Rosslyn, Virginia, the describers also had specimens from Okanagan Falls, British Columbia.

Pronotal Comb consists of about 32 teeth.

Modified Segments, Male: VIII t. forms a broad, prominent lobe posterior to the stigma. The distal margin is vertical. Armature of 60 bristles. Spinose inner area large, half as wide as long. VIII st. has 8 bristles on each side at apex and bears a hairy apical flap which has a sharply pointed triangular, short, vertical lobe. Finger $F$ is rounded on distal side, proximally incurved on anterior side and then excurved, 
about as broad at apex as below center. Posterior margin bears 5 or 6 bristles of nearly equal length. IX st. with bristles on dilated portions before and behind median sinus of ventral arm for most part spiniform. FEMALE: VII st. is deeply sinuate with upper lobe rounded and lower lobe pointed. Spermatheca is typical.

LENGTH: Specimens in collection of the writer measure, male 2.90 mm., female $3.00 \mathrm{~mm}$.

RANGE: This species is probably found from coast to coast in United States and Canada.

Records: The only western records for this flea are from Okanagan Falls, British Columbia.

\section{Ceratophyllus idius}

Jordan and Rothschild 1920

I920 Ceratophyllus idius, Jordan and Rothschild, Ectoparasites, 1:79.

This species was described from a series taken off Iridoprocne bicolor (tree swallow) collected by J. A. Monroe at Okanagan Landing, British Columbia, Canada, during July of 1913.

Pronotal Comb consists of about 32 teeth.

Modified Segments, MALe: VIII t. subangulate at the most anal point and bears behind stigma 7 to 9 marginal and submarginal bristles, on the sides 2 or 3 additional large ones and 1 to 3 small ones, besides one subventral bristle. Spiny inner area very narrow. St. VIII has on two sides together about 5 bristles, none of which are spiniform. Apical flap, which is large, is divided into a vertical lobe and a horizontal one, both fringed. Process $P$ of clasper broad and bluntly rounded at apex, and armed there with 3 bristles. Finger $F$ about 3 times as long as broad, widest in apical half; its anterior margin taken as a whole is nearly straight, whereas posterior margin is curved, slightly so in basal half and strongly in apical half. Beside some hairs at apex, there are 4 bristles in upper half of finger. Bristles on IX st. slender, not spiniform. Female: VII st. deeply sinuate, sinus rounded; upper lobe long and pointed, lower lobe shorter and strongly sclerotized. Spermatheca typically shaped.

LenGTH: Original lengths given as male $2.20 \mathrm{~mm}$., female 2.50 $3.00 \mathrm{~mm}$.

RaNGE: This flea seems to range from ocean to ocean in North America.

Preferred Host: A true bird flea which is more often reported off tree swallow but has been taken from nests of other birds.

REconds: From Tillamook, Tillamook County, Oregon, spring of 1942 out of nests of:

Sialia sialis (bluebird) and Iridoprocne bicolor (tree swallow).

At Okanagan Landing, British Columbia, this flea is reported off tree swallow and in New England states out of the nests of purple martins and house wrens. 


\section{Ceratophyllus garei \\ Rothschild 1902}

1902 Ceratophyllus garei Rothschild, Ent. Mon. Mag. 2nd Series, 13:225.

1919 Ceratophyllus utahensis Chapin, Bul. Brooklyn Ent. Soc., 14:60.

This species was described from nest of Gallinula chloropus (water hen) near Tring, England. Jordan and Rothschild in 1920 stated that this flea was common in Europe in nests built on ground. In their 1920 review of this species they state that apical area of metanotum is not reduced, a little under half as wide as rest of metanotum measured dorsally from long bristles forward. Clasper of male is very strongly curved and (apart from finger) narrower than the manubrium. Apex of VIII st. has a bundle of shortened stout spiniform bristles accompanied on each side by 1 or 2 longer bristles. The membranous apical flap of this sternite is very large and bears on proximal side a long narrow lobe. Chapin adds that process of clasper is enlarged near middle and is then contracted to a blunt apex; that finger is oblong, rounded at apex, nearly twice as long as process and bears at posterior apical angle 5 thin bristles. J. and R. state that head of spermatheca is twice as long as broad and much more excurved ventrally than it is incurved dorsally, two sides not parallel. Marginal outline of VII st. of female is truncaterotundate.

Pronotal comb consists of about 26 teeth.

LENGTH: Chapin gives measurements from Utah specimens as male $2.28 \mathrm{~mm}$., female $2.71 \mathrm{~mm}$.

RaNGE: Western part of North America.

Preferred Host: Reported off variety of western birds.

RECORDS: From

ALASKA-Off:

CANADA-Off:

Lagopus leucurus (ptarmigan, nest of) ;

Oidemia deglandi (white-winged scoter) and "goose," Edmonton, Alberta; Telmatodytes palustris (marsh wren), Shoal Wake, Manitoba;

UTAH-Off:

Steganopis tricolor, mouth of Bear River, MONTANA-Off:

Phasianus sp. (ringneck pheasant), Beaverhead County.

138. Ceratophyllus diffinis

Jordan 1925

1925 Ceratophyllus diffinis Jordan, Nov. Zool., 32:111.

1928 Ceratophyllus diffinis Jordan, Nov. Zool., 34:182.

1935 Ceratophyllus rileyi Liu, Ann. Ent. Soc. Amer., 28:123.

The male of this species was described from Colymbus grisegena holboelli taken at Okanagan Falls, British Columbia, female from nest of Dumetella carolinensis (cat bird) at Boston, Massachusetts.

Pronotal comb consists of about 24 teeth.

Modified Segments, Male: Process P of clasper prominent, broad and rounded at apex where it is armed with 2 short bristles and I long 


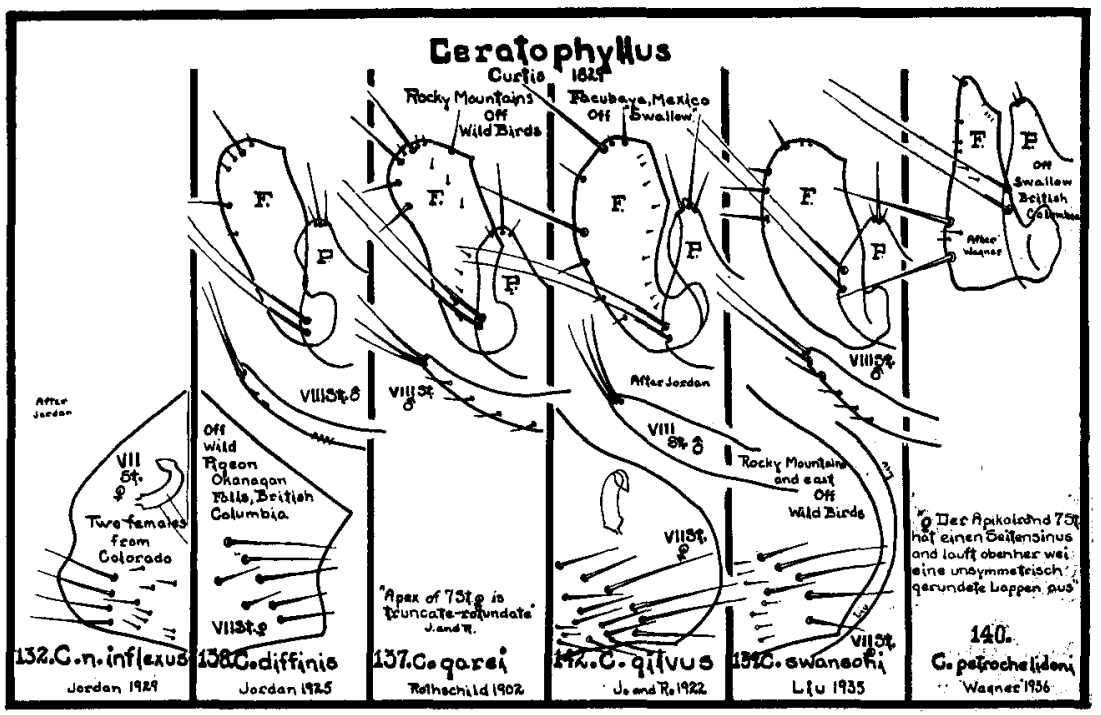

one. Finger $\mathrm{F}$ widest at middle where anterior border is not produced into a protuberance. Posterior border armed with 3 or 4 stout, long bristles and several smaller ones. VIII st. armed apically with 2 robust bristles to side. Female: VII st. with a broad sinus. Upper lobe pointed and extending slightly more distad than lower lobe. Body of spermatheca broad, about as long as tail.

LeNGTH: Original length of male is given as $2.6 \mathrm{~mm}$.

RANGE: Coast to coast in United States and Canada.

Host Preference: A true bird flea.

RECORDS: In West reported only from type locality but in East reported off ruffed grouse, catbird, ovenbird, veery, robin, bluebird and house wren from Minnesota, Massachusetts, New York, and New Hampshire.

\section{Ceratophyllus swansoni \\ Liu 1995}

1935 Ceratophyllus swansoni Liu, Ann. Ent. Soc. Amer., 28:121.

This species was described from Asio wilsonianus Sesson (long-eared owl) taken at Fertile, Minnesota.

Pronotal comb of about 28 teeth.

Modified Segments, Male: Process $P$ of clasper conical, apex blunt and armed with 3 bristles. Posterior margin of finger $F$ rounded and armed with 3 stout bristles and several weaker ones. VIII st. armed at apex with 2 or 3 stout bristles. Female: VII st. with a single well rounded lobe. Spermatheca with long slender body, much longer than the tail. 
Range: To date this flea is reported only from Montana and Minnesota.

Preferred Host: This flea is known only off Asio wilsonianus (longeared owl).

\section{Ceratophyllus petrochelidoni Wagner 1936}

1936 Ceratophyllus petrochelidoni Wagner, Zeit. f. Parasit., 8:655.

This flea was described from specimens taken off Petrochelidon albifrons (northern cliff swallow) at Chilcotin and Kamloops, British Columbia during 1934.

Monified Segments of this species are quite characteristic. MaLe: Process $\mathrm{P}$ of clasper, long and slender and reaching almost to apex of finger. Posterior border incurved. Finger unlike that of any other bird flea. Very narrow apically and very broad distally. Anterior-dorsal face, concave, short and terminating in small triangular prominence at about apex of process. Two strong bristles at slightly above posterio-ventral angle. Short bristles scattered along posterior margin. Female: Apical outline of VII st. sinuate, with an asymmetrically rounded upper lobe. Tail of spermatheca about half as long as body.

RANGE: While this flea has been recorded only from type locality, the writer believes he has material from eastern Colorado which will fall into this species.

\section{Ceratophyllus vagabundus Boheman 1865}

1865 Pulex vagabunda Boheman, Ofvers. af Finska Vetensk. Soc. Forhandl., 22:576.

This species was described from Spitsbergen. No host was mentioned. In 1932 Jordan listed species as not known from North America, but after examining materials off fledglings and from nest of Aquila chrysaetos (golden eagle) from Rapids, Alaska, he determined these specimens as this species. Collection was made on July 15, 1937. One male and 2 females in the material. Jellison and Kohls released the record during November of 1939.

\section{Ceratophyllus gilvus}

Jordan and Rothschild 1922

1922 Ceratophyllus gilvus Jordan and Rothschild, Ectoparasites, 1:270.

This species was described from a male and a female taken off a "swallow" at Facubaya, Mexico. Jellison and Good state in 1942, "The occurrence of this species on a migratory bird in Mexico suggests it may occur in the United States."

This species is a small pale bird flea in which the apical margin of 
metanotum is reduced as in other swallow fleas. Metanotum bears a short blunt spine in male and a thin pointed one in female, on each side. There is 1 long and 1 minute antepygidial bristle in male and a very short one in female.

Modified Segments, Male: VIII t. large and rounded; 9 or 10 bristles at dorsal margin, of which one is placed beyond denticulate area; this area small, elongate-triangular, dentition dense. VIII st. comparatively broad, with 3 long slender bristles at apex, and a broad flap nearly vertical to upper side of sclerite. Clasper is strongly curved down proximally to process $P$, being narrower at bend than at insertion of finger. Finger similar to $N$. fasciatus; its apical half much wider than lower half, posterior margin almost evenly curved; nearly one-third of finger extends above tip of process. Finger armed with 2 long bristles and a few short ones. IX st. complicated. $\mathrm{X}$ st. longer than $\mathrm{X}$ t., narrow, elongate-triangular, hairy at upper margin. FEMALE: VII st. rounded, with 17 bristles on each side. Spermatheca typical.

LENGTH: Male $2.00 \mathrm{~mm}$., female $2.50 \mathrm{~mm}$.

RANGE: Known only from type locality.

\section{Ceratophyllus adustus \\ Jordan 1932}

1932 Ceratophyllus adustus Jordan, Nov. Zool., 38:253.

Dr. Jordan states in the concluding paragraph of the description of this species, "The porcupine probably is the true host of this modified bird-flea, the peculiarities of the new species presumably being due to the change of host from bird to mammal. We have several instances of species of mammal flea types being parasitic on birds; in these cases the change of host from mammal to bird has likewise affected the development of the bristles."

This species was described from one female removed from Erethizon epixanthum (porcupine) at Atlin, British Columbia, by H. S. Swarth during 1931. The describer states, "A bird-flea parasitic on a mammal. Remarkable for the reduction in the number of bristles on the tibae, the presence of only 2 antepygidial bristles, one long, the other short and the short stylet."

"Modified Segments, Female: Apical margin of VII st. rounded truncate, slightly incurved above middle, 18 bristles on the two sides together. On each side of VII t. 2 or 3 bristles above stigma, 4 below it and 11 or 12 on ventral and apical areas. Stylet a little over twice as long as broad. Bursa copulatrix not very distinct, duct of spermatheca surrounded with glandular tissue, spermatheca typical, its head nearly 3 times as long as broad." 


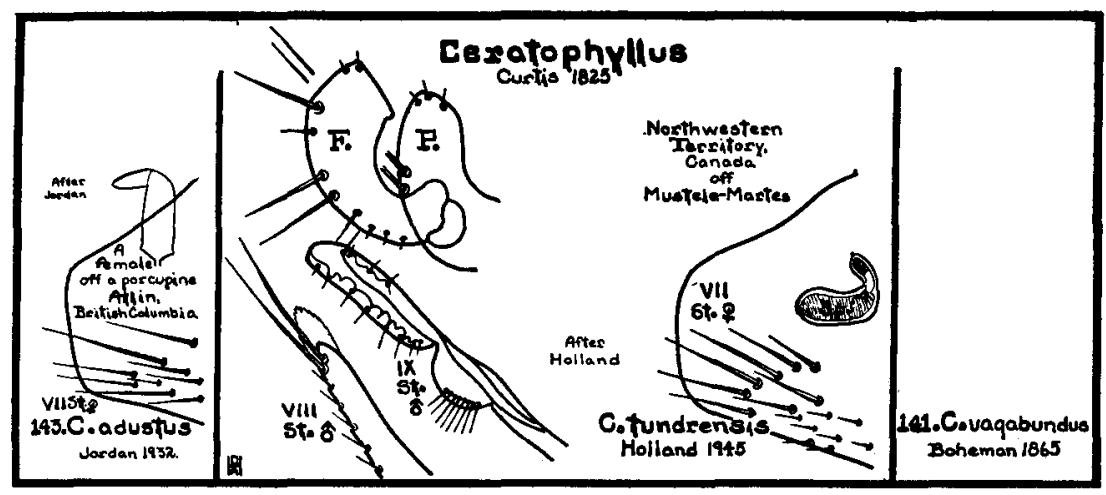

\section{Ceratophyllus tundrensis \\ Holland 1944}

1944 Ceratophyllus tundrensis Holland, Can. Ent., 76:242.

According to the describer, this species is characterized as follows:

"Male: Frontal tubercle prominent. Vestiture of head rather extensive for a Ceratophyllus. Upper frontal row with 7 setae of which the upper 3 border the anterior margin of the antennal groove. Lower or ocular row with 3 setae of which the first and third are very long. Four setae of varying lengths on the postantennal region of the head in addition to the marginal row. Posterior margin of antennal groove with a number of small hairs as shown. Labial palpus not quite reaching apex of fore coxa.

"Pronotal ctenidium of about 28 spines.

"Antepygidial bristles normally 3 of which the first and third are vestigial. Sometimes the third is lacking. Bristle II is much shorter than is usual in males of Ceratophyllus spp.

"T. VIII with about 12 marginal setae dorsally, and with about 3 on the lateral surface. Inner surface of dorsal margin of VIII t. bearing extensive spiculose area. Another patch of very sharp and slender spicules is located on the inner surface of the ventral margin. Clasper narrow and immovable process $P$ very broad. Movable process $F$ not extending much beyond $\mathrm{P}$, and shaped as shown in the figure. There are a number of marginal setae of which 3 are long, and 2 of these are particularly stout and heavily pigmented. Ventral arm of IX st. with a mid-ventral protuberance armed with about 8 setae. St. VIII more or less rod-shaped, with 2 or 3 long apical setae and a membranous appendage.

"Female: Chaetotaxy and general structure much as in male. Three well developed antepygidial bristles, of which the second is the longest.

"Sternite VII broadly rounded apically, with no trace of a sinus. Head of spermatheca cylindrical and about twice as broad and twice as long as the tail. 
"Holotype male and allotype female from Baker Lake, Northwest Territories, August 27, 1937, ex arctic weasel, Mustela arctica Merriam; No. 5544 in the Canadian National Collection, Ottawa.

"Paratypes: One male, same collection data; 1 male, 1 female (mounted together on one slide), Hanbury Portage, Clinton, Golden Lake, N. W. T., August 22, 1936, ex marten, Martes americana Kerr, coll. C. H. D. Clarke; 1 female, same data as above.

"Unfortunately, the spermathecae are missing in the two female paratypes.

"As Ceratophylli are typically bird fleas, it is highly probable that the true host of the present species is some ground-inhabiting bird, such as a ptarmigan or spruce grouse, which might be preyed upon by weasels and marten."

\section{GENUS DASYPSYLLUS BAKER}

1905. Dasypsyllus Baker. Proc. U. S. Nat. Mus., 29:129.

Genotype: Ceratophyllus gallinulae perpinnatus Baker 1904

In this genus frontal tubercle is minute. Preantennal and postantenal regions each have 3 rows of bristles. None of these are spiniform. Eye is large and heavily pigmented. The 5 segmented labial palpus does not reach apex of coxa I. Pronotal comb of 24 or more black teeth. No spinelets on inner surface of coxa III. Terminal segment of each tarsus with 6 pairs of lateral plantar bristles, the third pair shifted ventrally and replaced at this position by a pair of more slender ones. T. VII without posterior median process. Antepygidial bristles in both sexes a long median one and one very small one on both sides of long one.

Only one species of this genus is found in West. It is parasitic upon birds, but can occasionally be found upon burrowing rodents and probably upon bird and burrowing rodent carnivores.

\section{Dasypsyllus gallinulae perpinnatus Baker 1904}

1904 Ceratophyllus perpinnatus Baker, Proc. U. S. Nat. Mus., 27:391. 1905 Dasypsyllus perpinnatus Baker, Proc. U. S. Nat. Mus., 29:129. 1920 Ceratophyllus perpinnatus Jordan and Roths, Ectoparasites, 1:69. 1936 Dasypsyllus gallinulae perpinnatus Wagner, Can. Ent., 68:201.

Original description of this flea was made from a male specimen sent Baker from Queen Charlotte Islands, Canada, by the Rev. J. H. Keen. No host was given. comb.

In this species eye is large. There are about 34 teeth in pronotal

Modified Segments of abdomen characteristic, particularly finger 


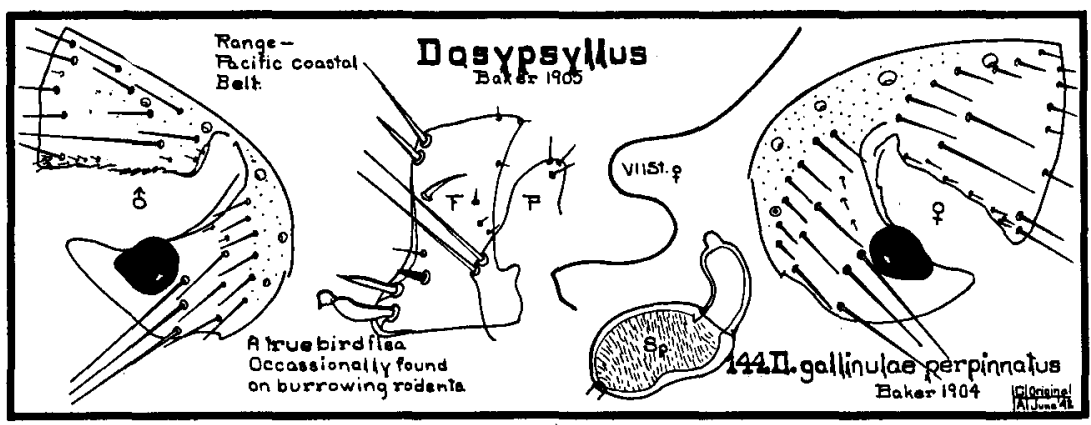

in male, which is armed at posterio-dorsal angle with long and short black bristle, two almost spiniforms, then below angle on posterior face a third heavy black bristle almost as long as upper one. At ventral lobe 3 black spiniforms, lowest being longest and curiously bent back upon itself ("distorted near this tip") at apex. In female apical outline of VII st. has a deep and fairly wide sinus, upper lobe shorter than lower lobe, and both narrow but somewhat rounded at apex. Spermatheca is not Ceratophyllus-like, but barrel shaped in body with ventral face somewhat concave, tail shorter than body, bent and with apical appendage.

LENGTH: Original length of male is given as $3.00 \mathrm{~mm}$., a female in the collection of the writer is slightly smaller.

TYPE: Deposited in United States National Museum under No. 6901.

RANGe: Described from Queen Charlotte Islands, Canada, Spencer Collection at University of British. Columbia has specimens off birds from many parts of British Columbia; the writer has specimens from northern and southern coastal belt of Oregon; San Francisco collections contain it from central California. Apparently, then, this flea is found over most of territory west of Cascade-Sierra-Nevada Mountains. It is not listed by I. Fox from eastern portion of United States.

Host Preference: While the only records for this flea in collection of the writer are from rodents, it is generally felt that this is a true bird flea. The Spencer collection contains 1 male taken off a Cascade pine squirrel.

RECORDS: The writer records from:

OREGON-Off:

Aplodontia rufa pacifica Merriam (coast mountain beaver), Brookings, Curry County, August 23, 1937, I female; Devil's Lake, Lincoln County, April 22, 1939, 1 male.

WASHINGTON-Off:

Eutamias townsendi townsendi Bachman (Townsend chipmunk), Spirit Lake, Skamania County, July 7, 1938, 1 female. 
BRITISH COLUMBIA-Off:

Thryomanes bewicki spp. (wren), Sumas.

"Off many migratory birds" Mail and Holland 1939. "From many avian hosts, British Columbia" Jordan 1929. Also reported off:

Sciurus douglasi (pine squirrel).

\section{GENUS AMPHIPSYLLA WAGNER}

1908. Amphipsylla Wagner. Mitteil. d. Kaukasisch. Museum 4:196.

Genotype: Amphipsylla schelkovnikovi Wagner 1908

In this genus frontal tubercle is vestigial. Gena with 3 rows of bristles one of which may be incomplete. Eyes small to vestigial. Labial palpus generally does not reach apex of coxa I. Although postantennal region is stated to be armed with 3 rows of bristles, paratypes of $A$. neotomae in collection of the writer possesses only a marginal row. Pronotal comb present. No spinelets on inner surface of coxa III. Tibia III with a comb-like row of 3 or 4 shorter outer setae between long middle and long apical bristles. Terminal segments of tarsus III with 5 pairs of lateral plantar bristles, first pair situated in between bristles of a second pair. VII t. plate without posterior median process. Three antepygidial bristles on both sides in both sexes. Broad VIII sternal plate of male not modified. IX st. male with modified posterior processes. Finger broad, flat, with 1 or more spiniforms.

This genus is represented in West by 3 species in which males can be separated by shape and armature of finger, females by apical margin of VII st.

Key to the Western Species of Amphipsylla

1. Finger paddle shaped, armed with two widely spaced spiniforms and between them 6 or more bristles, female unknown

A. ewingi, p. 261

2. Finger paddle shaped, armed with 2 spiniforms and between them 3

weak bristles, VII st. female a well rounded lobe A. sibirica pallionis, p. 262

3. Finger roughly triangular with 3 spiniforms, VII st. female undulate margin to angulate lobe

A. neotomae, p. 260

\section{Amphipsylla neotomae}

I. Fox 1940

1940 Amphipsylla neotomae I. Fox, Jour. Wash. Acad. Sci., 30:273.

1942 Amphipsylla neotomae Augustson, Bul. Southern Calif. Acad. Sci., 41:39.

This species was described from a male taken off Neotoma desertorum (wood rat) at Dos Palos, California, during March, 1934, by H. S. Gentry. Augustson described female from specimen taken off Spilogale gracilis arizonae Mearns (little spotted skunk) collected at Carrizo Creek, Riverside County, California.

Short description offered by Fox is as follows: MALE-Frontal tuber- 


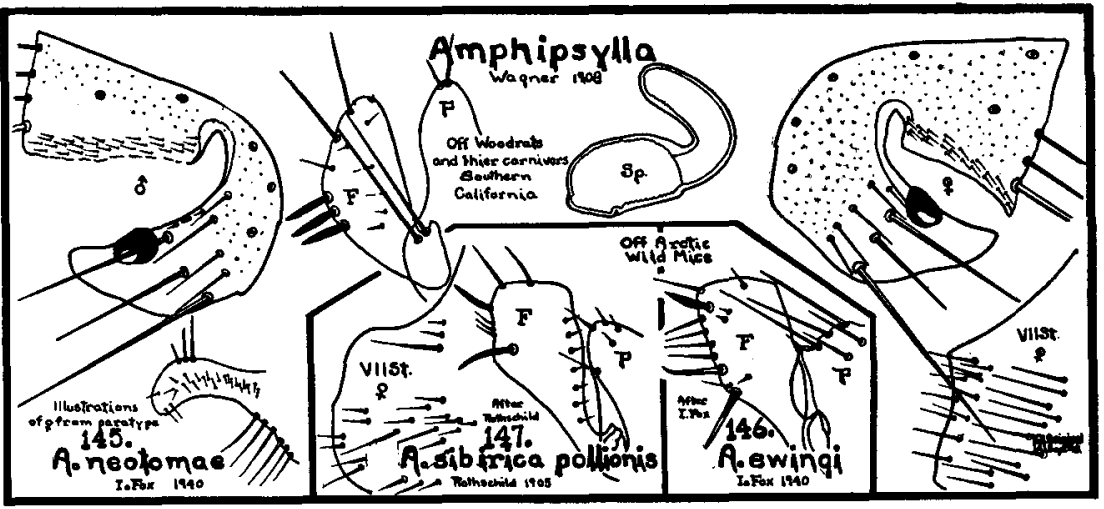

cle indistinct. Preantennal region of head armed with ocular row of 3 bristles, which lies below 2 bristles located near antennal groove. Postantennal region with single bristle in addition to marginal row of about 7. Eye vestigial, vestiges not pigmented. Labial palpus extending to about three-fourths length of fore coxa. Pronotal comb with about 13 teeth on a side. One long antepygidial bristle between 2 minute ones present on a side. Modified Segments: Process of clasper and finger as illustrated; latter armed on posterior margin with 3 prominent spiniform bristles in addition to several others. Spring short, not completing a single turn.

Augustson states of Female: Pronotal comb of 11 slender pointed spines on a side. Metanotum with 3 small tergal teeth, none on first abdominal tergite, 3 on second, 2 on third. Antepygidial bristles 3 . X st. angulate, thickly beset with bristles. VII st. broad, with a broad shallow sinus midway. Bursa copulatrix very diagnostic, prominent, a slightly undulate uniform tube with one end enlarged into bulb-like structure. Spermatheca barrel shaped, with sharply curved tail.

LENGTH: Specimens in collection of the writer measure male, 3.25 $\mathrm{mm}$., female $3.50 \mathrm{~mm}$.

RANGE: This species is known only from southern California.

RECORDS, off:

Brassariscus asutuus subsp. (ringtail cat), Riverside Mountains, Colorado River, Riverside County, California (Augustson).

\title{
146. Amphipsylla ewingi
}

\author{
I. Fox 1940
}

1940 Amphipsylla ewingi I. Fox, Proc. Ent. Soc. Wash., 42:64.

This species was described from a male holotype collected by E. C. Cushing from an "Alaska short-tailed mouse" at Golovin, Alaska, May 7, 1931, and a paratype male from Microtus sp. at Takotna, Alaska, collected by R. H. Twitchell May 29, 1932, in United States National Museum. 
The original description reads as follows:

MaLE: Head subangulate in front, preantennal region with 4 rows of bristles. Uppermost row consisting of 7 bristles, next row below this one reduced to but 1 bristle, remaining two rows consisting of 2 bristles each. Eye vestigial, but vestiges large and pigmented. Postantennal region with 3 rows of bristles. Uppermost row consisting of 2 bristles, middle row of 4 or 5 , and lowermost or submarginal row of 7. Labial palpus 5-segmented, reaching beyond one-half length of fore coxa. Pronotal ctenidium consisting of about 10 spines on a side. Three antepygidial bristles present on a side, the middle the longest, and the lowermost shorter than uppermost.

Modified Segments: Process of clasper not well set off from posterior abdominal tergites. Movable finger more or less subquadrate distally, bearing on dorsal margin a single bristle and on posterior margin about 9 bristles of which 1 is short, broad, heavily pigmented and spiniform. Spring of penis not completing a single turn.

LENGTH: Length was not included in original description.

RANGE: Not known but probably throughout northern North America on Microtus.

This species is known only from original type specimens.

\section{Amphipsylla sibirica pollionis \\ Rothschild 1905}

1905 Ceratophyllus pollionis Rothschild, Nov. Zool., 12:171.

1913 Amphipsylla pollionis Jordan and Rothschild, Zoologist No. 869:405.

1936 Amphipsylla sibirica pollionis Wagner, Can. Ent., 68:195.

This flea was described from 4 specimens taken off red-backed mice and meadow mouse collected at Red Deer, Alberta, Canada, during August, 1901, by G. F. Dippie.

Original description states that the head is peculiarly shaped, especially in male, front being rotundate-angulate.

Modified Segments, Male: VIII st. is long and almost completely divided in medial line, each lobe bearing 2 rows of long bristles ventrally at apex and a number of short ones at dorsal apical edge. Process of clasper is triangular, obtuse, bearing 1 bristle at apex, another further down, and a few short ones on back. There are no bristles at junction of clasper with finger. Finger is triangular (paddle shaped), being widest at apex. It bears 2 heavy long spiniforms in upper third, and between them several short bristles. At distal apical angle there is 1 long bristle, and at middle of upper edge a smaller second one. IX st. is slender and bears a number of short hairs. Female: Apex of VII st. is rounded. VIII $t$. bears a row of bristles above the stigma and a patch of bristles on lower half. At apical edge there are 2 bristles at lower corner, and obliquely above them 2 short ones. Stylet is long and slender, being at least 5 times as long as broad. At corner of anal tergite just below insertion of stylet there is a single bristle. In 1913, describer 
adds, bristles of second antennal segment are less than one-third length of club, and proportional width and length of stylet are 1:4.3.

LENGTH: Original lengths are given as male $2.20 \mathrm{~mm}$., female 2.80 $\mathrm{mm}$.

RANGE: While apparently only known from the original records, Wagner suggests in 1936 that this flea should also be found in British Columbia, Canada.

Preferred Host: Too little is known about this flea to suggest a true host. Wagner in 1936 states that all races of $A$. sibirica live on different Microtinae species (Microtus, Clethrionomys, etc.) and move temporarily from mice to martens and weasels.

RECORDS: Only the original are available. These are off:

Microtus pennsylvanicus drummondi A. and B. (Drummond meadow mouse), Red Deer, Alberta, Canada, August 21, 1901, 1 male,

Clethrionomys gapperi saturatus Rhoads (British Columbia red-backed mouse), Red Deer, Alberta, Canada, August 28, 1901, 3 females.

\section{GENUS TARSOPSYLLA WAGNER}

1927. Tarsopsylla Wagner. Konowia 6:108.

Genotype: Ctenonotus octodecimdentatus Kolenati 1863

This genus is characterized by having segment I of tarsus III longer than II, III and IV taken together. Segment V of tarsus II armed with 5 pairs of lateral plantar bristles, first pair shifted ventrally. Femur I with not more than a single lateral seta; coxa III without a row or patch of setae on inner surface.

Frontal tubercle which is angulate apically remains hidden in frontal notch. Eye present. Post- and preantennal regions with 3 rows of bristles. No genal comb. Five segmented labial palpi not reaching to apex of coxa I.

Pronotal Comb present. Abdomen without apical spinelets. Tergal plate VII without posterior median process.

This genus is represented in western North America by 1 species, found on squirrels in Rocky Mountains.

\section{Tarsopsylla coloradensis \\ Baker 1895}

1895 Pulex coloradensis Baker, Can. Ent., 27:110.

1904 Ceratophyllus coloradensis Baker, U. S. Nat. Mus. Proc., 27:417.

This species was described from a single male taken off a "Fremont's chickaree" collected at Georgetown, Clear Creek County, Colorado.

In this species head is well rounded, eye is oval and heavily pigmented. At eye level a row of 3 bristles, middle one short. Above this a second row of 3 medium bristles and a third row of 3 short bristles close to antennal groove. Postantennal region with 3 rows of bristles, first row a single medium bristle, second row of 2 bristles and marginal row of about 4 bristles. Short bristles all along antennal groove. 


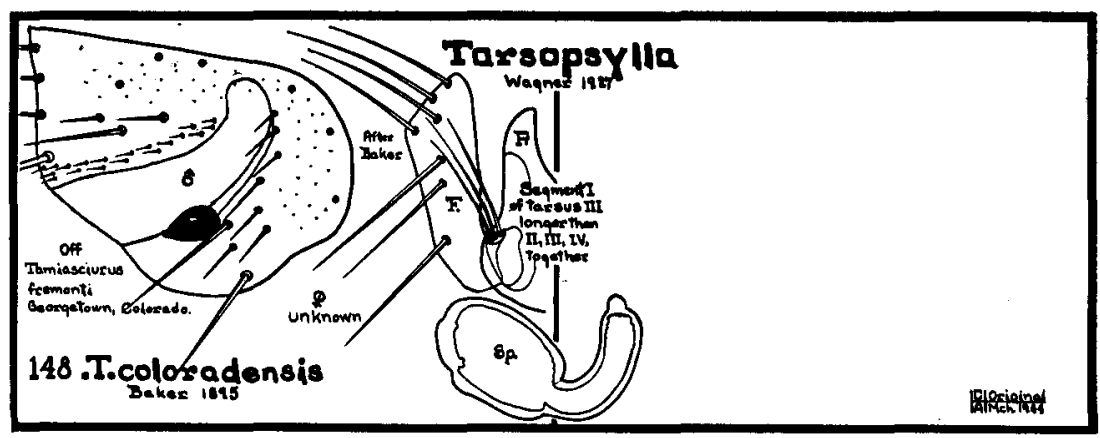

Modified Segments, Male: Process of clasper somewhat finger-like. Finger apically blunt, armed along this border with 4 long bristles. Ventral border armed with 3 long bristles. Female: Not yet described.

RANGE: This species seems to be known only from original type locality, specimens listed from British Columbia apparently being of another undescribed species.

\section{GENUS DOLICHOPSYLLUS BAKER}

1905. Dolichopsyllus Baker. Proc. U. S. Nat. Mus., 29:135.

Genotype: Ceratophyllus stylosus Baker 1904

In this genus eye is absent. Frontal tubercle is small. Both post- and preantennal regions of head have 2 rows of bristles. None of these are spiniform. There are small bristles all along posterior margin of gena. Pronotal comb of about 30 black teeth. Antepygidial bristles, 4 in female, 3 in male. No spinelets on inner surface of coxa III. Terminal segment of tarsus III with 5 pairs of lateral plantar bristles, first being shifted slightly ventrally. T. VII with a posterior median process. St. VIII of male produced posteriorly into a pair of lobes, each having a fimbriated ventral margin. St. IX male with inner vertical lobes crescentic.

This genus is represented by but a single species which is found upon Aplodontia rufa (mountain beavers) and their carnivores everywhere in Cascade-Sierra Mountains and west to ocean.

\section{Dolichopsyllus stylosus Baker 1904}

1904 Ceratophyllus stylosus Baker, Proc. U. S. Nat. Mus., 27:418.

1905 Ceratophyllus stylosus Baker, Proc. U. S. Nat. Mus., 29:135.

1905 Dolichopsyllus stylosus Baker, Proc. U. S. Nat. Mus., 29:155.

1914 Ceratophyllus stylosus C. Fox, U. S. Pub. Health Ser. Hyg. Lab. Bul., 97; pl. 19.

At time this species was described by Baker, $H$. schefferi had not yet been discovered. It was natural, then, for Baker to say, "This species is 
the largest of the Order in America." Specimens upon which description was based were collected by Dr. A. K. Fisher, of United States Biological Survey, at Astoria, Oregon, off Aplodontia rufa (mountain beaver). In West, size and host alone almost mark this species off from all other fleas. It is the largest flea without genal teeth in West, and is common species found upon Aplodontia rufa (mountain beavers). Male has characteristic caudad projection over one-third of pygidium and between two groups of antepygidial bristles a narrow triangular median prolongation of VII t. Finger is large obtriangular, upper face is armed with thick set row of rather numerous, quite uniform bristles. In female apical margin of VII st. is cut by a sinus which marks off wide up-

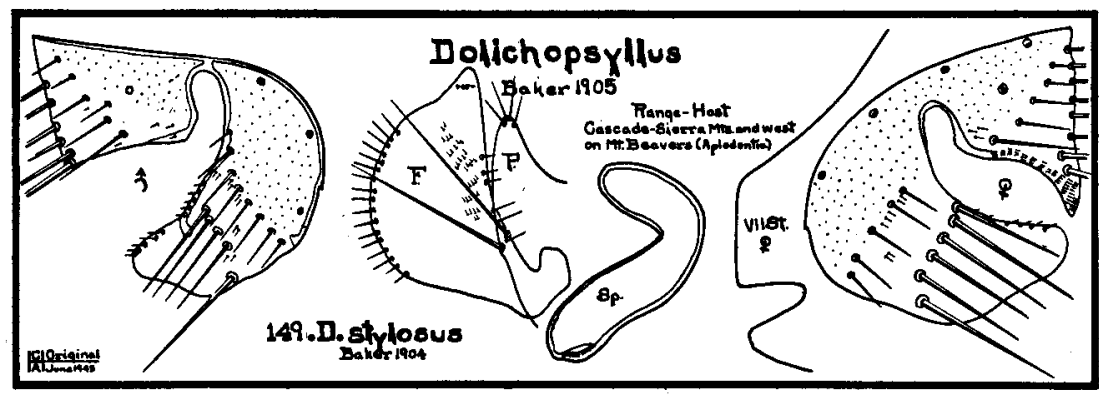

per lobe which is angular and a narrow lower lobe which is slightly triangular. Spermatheca is somewhat vermiform and it is with difficulty that tail can be distinguished from body.

LENGTH: Originals given as male, $5.50 \mathrm{~mm}$., female, $5.75 \mathrm{~mm}$.

Color is listed as clear brown, but considerable bleaching is necessary to clear these heavily pigmented giant fleas.

RANGE: This common mountain beaver flea can be found throughout the entire range of mountain beaver, which extends from Fraser River, British Columbia, south to San Francisco Bay, California, and west of crest of Cascade-Sierra Mountains to Pacific Ocean.

Preferred Host: Aplodontia rufa (mountain beaver) is true host of this flea, but it can occasionally be taken off such carnivores as mink, which apparently feast upon mountain beavers.

ABUNDANCE: Of records of 100 mountain beavers from West Coast collected by the writer since 1935, 40 per cent of the animals have been without fleas, remaining 60 per cent carried 25 males and 60 females of this species, or an average of about $1 \frac{1}{2}$ per host animal for those infested.

Seasonal Distribution: In much of their range, mountain beavers can be trapped throughout year, and regardless of season this species of flea is always present upon them.

RECORDS: The following records are representative of those in the collection of the writer: 
OREGON-Off:

Aplodontia rufa rufa Rafinesque (Cascade mountain beaver), Estacada, Clackamas County, July 19, 1931, l female; Crown Point, Multnomah County, April 14, 1939, 1 male, 4 females

Aplodontia rufa pacifica Merriam (coast mountain beaver), Devil's Lake, Lincoln County, April 22, 1939, 1 male, 1 female; Brookings, Curry County, June 14, 1939, 2 males, 1 female,

Accidental Occurrence, off:

Lutreola vison energumenos Bangs (western mink), Blodgett, Lincoln County, December 31, 1940, 1 male, 2 females.

WASHINGTON-Off:

Aplodontia rufa rufa Rafinesque (Cascade mountain beaver), Seattle, King County, July 1, 1922, 3 males, 6 females

Aplodontia rufa rainieri Merriam (Rainier Mountain beaver), Skamania, Skamania County, November 28, 1933, 1 male, 3 females

Aplodontia rufa olympica Merriam (Olympic Mountain beaver), Cathlamet, Wahkiakum County, November 12, 1933, 1 male.

CALIFORNIA-Off:

Aplodontia rufa humboldtiana Taylor (Humboldt Mountain beaver), Fort Dick, Del Norte County, June 15, 1939, 1 male.

BRITISH COLUMBIA-Although records for this flea are not yet available from this Canadian province, there is no doubt that mountain beavers taken south of Fraser River will carry this species. There is no natural barrier of any kind to separate the mountain beavers of British Columbia and those of Washington. Therefore, this flea should be as common in British Columbia as in Washington.

\section{GENUS ODONTOPSYLLUS BAKER}

1905. Odontopsyllus Baker. Proc. U. S. Nat. Mus., 29:129.

Genotype: Pulex multispinosus Baker 1898

Eye is very large and heavily pigmented at margins. Frontal tubercle is prominent and acuminate. Labial palpus reaches almost to apex of fore coxa. Pronotal comb bears from 28 to 40 teeth. Abdominal tergites with apical teeth. Female with 3 antepygidial bristles, shortest one on inside, longest one in middle, male with 2 , shortest one the inner one. Anterior margin of hind coxa armed with numerous small spinelets, which partly approach spiniforms.

This genus is represented in the west by one species, which parasitizes rabbits and by accident their carnivores.

\section{Odontopsyllus dentatus Baker 1904}

1904 Ceratophyllus dentatus Baker, Proc. U. S. Nat. Mus., 27:390.

1905 Odontopsyllus dentatus Baker, Proc. U. S. Nat. Mus., 29:131.

1923 Odontopsylla spenceri Dunn, U. S. Pub. Health Repts., 47:2765.

Original description of this species was based upon 1 male taken by Prof. J. M. Aldrich, who found it on Lynx canadensis at Moscow, 


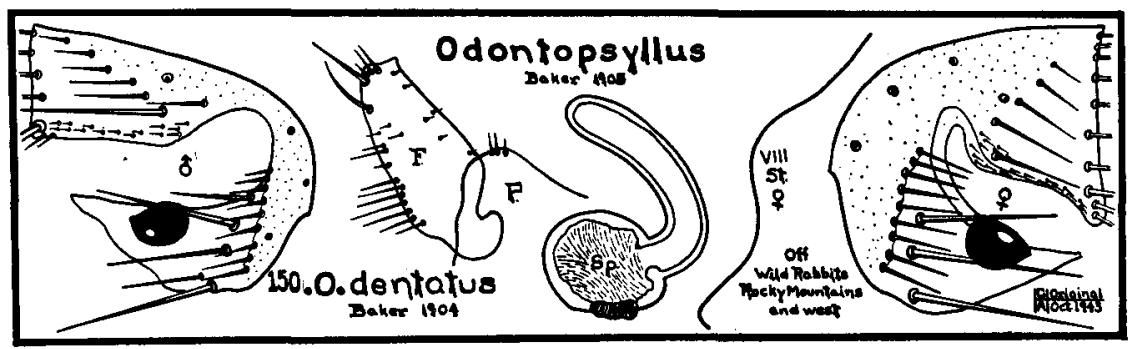

Idaho. As Baker suggested at the time, lynx was a carnivore, true host of species being rabbits. Pronotal comb consists of about 26 teeth. Male claspers twice longer, than wide, narrowed on apical half below to a truncate apex; margin with number of scattered bristles, and minute, weak hairs. In females, apical margin of VII st. has small rounded lobe at about mid point and below it a slightly concave bay. Spermatheca has large globular body, tail long, thin and crooked towards body dorsally.

LENGTH: Original given as male, $3.5 \mathrm{~mm}$., females in collection of the writer measure $3.75 \mathrm{~mm}$.

Type: Deposited in United States National Museum under No. 6900.

Color of this species is listed as dark brown, but it is almost black and considerable bleaching is necessary before mounting.

RANGE: While not as yet listed from British Columbia, this is common large rabbit flea found everywhere through Rocky Mountains and west to Pacific Ocean.

Seasonal Distribution: This species can be found during any month of year on rabbits. Season of abundance for them has not yet been found.

Abundance: This species is never abundant. One or 2 can be taken off individual jack rabbit or cottontail, but many a rabbit is examined without finding this big rabbit flea.

Host Preference:- A true rabbit flea, it can be found on wild rabbits and hares west of Rockies. It can also be found upon carnivores which feed upon rabbits.

The following are typical records of many in collection of the writer:

OREGON-Off:

Lepus californicus californicus Gray (California jack rabbit), Corvallis, Benton County, February 28, 1938, 1 male

Lepus californicus wallawalla Merriam (Oregon jack rabbit), Ontario, Malheur County, December 1, 1931, l male

Sylvilagus nuttalli nuttalli Bachman (sagebrush cottontail), Union, Union County, April 15, 1937, 2 females

Sylvilagus bachmani ubericolor Miller (coast cottontail), Gaston, Washington County, April 24, 1939, 4 males, 2 females, 
Accidental Occurrences, off:

Urocyon cinereoargenteus townsendi Merriam (gray fox), Blodgett, Benton County, December 22, 1940, 1 male.

\section{WASHINGTON-Off:}

Lepus townsendi townsendi Bachman (white-tailed jack rabbit), Donald, Yakima County, May 8, 1939, I male

Sylvilagus nuttalli nuttalli Bachman (sagebrush cottontail), Donald, Yakima County, May 8, 1939, I female.

\section{CALIFORNIA-Off:}

Sylvilagus bachmani ubericolor Miller (coast cottontail), Smith River, Del Norte County, June 15, 1939, 4 males, 1 female

Lepus californicus californicus Gray (California jack rabbit), Tule Lake, Siskiyou County, April 19, 1942, 1 male,

In southern California Augustson reports this flea off:

Sylvilagus bachmani cinerascens Allen (California brush cottontail), Glendale, Los Angeles County

Sylvilagus auduboni arizonae Allen (Arizona cottontail), Lancaster, Los Angeles County

Lepus californicus richardsoni Bachman (San Joaquin Valley jack rabbit), Moronga Valley, Riverside County

Neotoma fuscipes subsp. (round-tailed wood-rat), Moronga Valley, Riverside County

Urocyon cinereoargenteus californicus Mearns (California gray fox), Pasadena, San Gábriel Mountains, Los Angeles County.

MONTANA-This flea has been reported off:

Lepus bairdi bairdi Hayden (Rocky Mountain snowshoe rabbit), Ravalli County

Lepus californicus subsp. (black-tailed jack rabbit), Beaverhead County

Lepus townsendi subsp. (white-tailed jack rabbit), Custer, Gallatin, Powder River, Ravalli, and Wheatland Counties

Sylvilagus spp. (cottontail), Beaverhead, Ravalli, and Rosebud Counties and Yellowstone.

Other scattered reports from the West are:

Sylvilagus auduboni arizonae Allen (Arizona cottontail), Wilson Ranch, Nevada; City of Rocks, Idaho;

Lepus subsp. (jack rabbit), Logan, Cache County and Salina, Sevier County, Utah;

Lynx subsp. (bobcat), Tucson, Pima County, Arizona.

\section{GENUS AUGUSTSONIUS HUBBARD}

1941. Augustsonius Hubbard. Pacific Univ. Bul., $37: 8: 3$.

Genotype: Geusibia ashcrafti Augustson 1941

This genus is close to Odontopsyllus Baker 1905. Frontal tubercle present. Eye prominent, long and narrow. Frontal row of about 8 bristles, frequently as in Odontopsyllus 7, with the eighth dropped between the sixth and seventh. Three stout bristles in lower genal row, all longer than genal flap. Postantennal region with 3 rows of about 5 bristles each. Segment II of antennae with but a few short bristles. Pro- 
notum with a comb of bluntly rounded teeth, and a single row of bristles. Abdominal tergites with apical spinelets. Antepygidial bristles 3 to the side in both sexes. Stylet twice as long as wide. Shape of hind coxae as in Odontopsyllus, but armature of inner surface a series of small hairs rather than spiculose.

It has been suggested that this genus might be a synonym of Geusibia.

This genus is represented by but a single known species, the genotype, which appears to be a true flea of the Ochotona (cony).

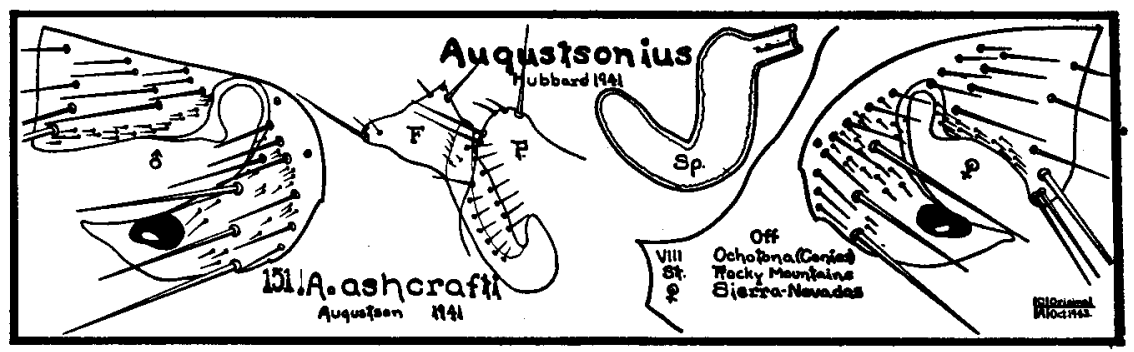

\section{Augustsonius ashcrafti \\ Augustson 1941}

1941 Geusibia ashcrafti Augustson, Bul. Southern California Acad. of Sci., 39:203. 1941 Geusibia ashcrafti Augustson, Bul. Southern California Acad. of Sci., 40:157. 1941 Augustsonius ashcrafti Hubbard, Pacific Univ. Bul., 37:8:3.

This species was described from 17 females taken off Ochotona schisticeps albatus (conies) at Dusky Lakes, Fresno County, California, August 23, 1938, by Gus Augustson. He did not secure the male until Auggust 27,1941 . On this date he removed the allotype from Ochotona schisticeps muiri (cony) at Cascade Valley, Fresno County, California.

HeaD: Well rounded in male, somewhat flattened in female. Frontal notch prominent. Eye black, elongated. Three strong bristles in lower genal row, well above eye. Seven or 8 medium bristles in upper genal row. Many setae scattered over area. Postantennal region with 3 rows of bristles totaling about 12 . Setae all along antennal groove.

ThORax: Pronotal comb consists of 18 black teeth.

Modified Segments, Male: Finger $F$ large, lower two-thirds thicker, more heavily pigmented than upper third, former rounded, latter flattened into a hoof-shaped structure with 1 medium posterior bristle and numerous small setae along entire anterior margin of finger. Process $\mathbf{P}$ of clasper prominent, broad and well rounded apically with armature of 3 bristles. IX st. with 2 posterior lobes, upper spoon-shaped, lower knob-like, both well clothed with setae. VIII st. very large, well rounded ventrally. FEMALE: Distinguished from all other American fleas by the shape of spermatheca which is hand-sickle-like, handle towards pos- 
terior. Apical margin of VII st. also very characteristic, consists of small pointed lobe close to ventral, followed by a long slanting undulate outline towards dorsal.

LENGTH: Specimens in collection of the writer average $3.00 \mathrm{~mm}$. for males and $3.10 \mathrm{~mm}$. for females.

RANGE: This species is probably found throughout Sierra-Nevada Mountains of California and in southern Rocky Mountains as far north as Colorado.

Host Preference: Some 45 specimens of this species known to date have all come off Ochotona (conies).

ReCoRDs: In central Sierra-Nevada Mountains of California, Augustson reports upon this flea as follows:

CALIFORNIA-Off:

- Ochotona schisticeps muiri G. and S. (Yosemite cony), Duck Pass, Mono County, August 22, 1941, 4 males, 3 females; August 27, 1941, 1 male; Tully's Hole, Fresno County, August 23, 1941, I pair; Horse Heaven, Fresno County, August 24, 1941, 1 male, 4 females; Cascade Valley, Fresno County, August 27, 1941, 3 males and 2 females

Ochotona schisticeps albata Grinnell (Mt. Whitney cony), Dusky Lakes, Fresno County, August 23, 1938, 17 females; Mammoth Meadows, Mono County, August 27, 1940, 3 females; Mammoth Lakes, Mono County, July 26, 1941, 3 females.

COLORADO-Off:

Ochotona princeps saxatalis Bangs (Colorado cony), San Juan County, June, 1939, 3 females.

\section{GENUS CTENOPHYLLUS WAGNER}

1927. Ctenophyllus Wagner. Konowia Bd. VI, Heft 2, p. 108.

Genotype: Ceratophyllus armatus Wagner 1901

Upper eye bristle at or near margin of antennal groove, above level of eye. On inside of genal area a rod-like sclerite. Lower genal row of 3 stout, long bristles, anterior row made up of spiniforms. Eye well devloped. Head rounded in female, not well rounded in male in which frontal tubercle is prominent and acuminate. Three rows of bristles on occiput. Pronotal comb with 22 teeth. Abdominal tergites with apical teeth.

This genus represented in West by but a single species found constantly but sparingly upon Ochotona (conies).

\section{Ctenophyllus terribilis \\ Rothschild 1903}

1903 Ceratophyllus terribilis Rothschild, Nov. Zool., 10:318.

1936 Ctenophyllus terribilis Wagner, Can. Ent., 58:195.

1941 Ctenophyllus terribilis Hubbard, Pacific Univ. Bul., 37:8:2.

This species was described from 4 males and 6 females collected by G. F. Dippie in the Canadian National Park, Alberta, Canada, July 26, 


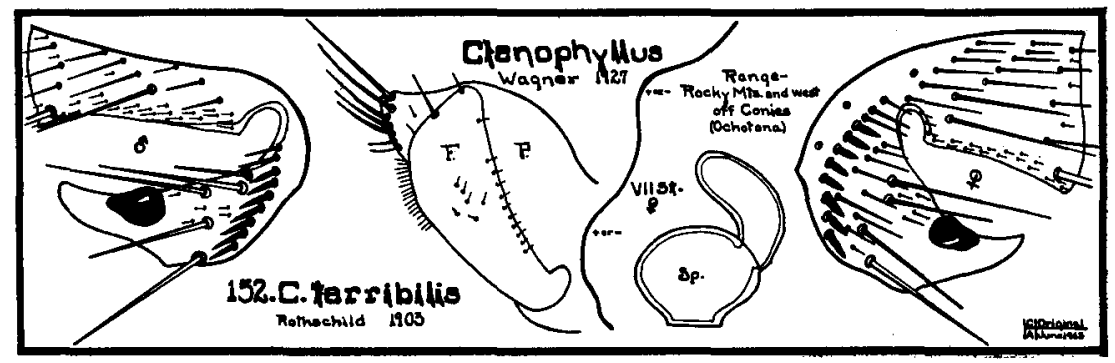

1899, off Lagomys (Ochotona) princeps (cony). In this species the modification of frontal row of 7 or 8 bristles into spiniforms is as characteristic as are modified segments. Head spiniforms, host and modified segments mark this species from all other western fleas. In MaLE finger $\mathbf{F}$ is a little shorter than the process $\mathbf{P}$ of clasper, and somewhat shaped like a half crescent, being convex on hinder and concave on anterior or upper side. Along this upper side finger is armed with 3 or 4 medium bristles, along most posterior section with a number of hairlike bristles. Female: VII st. has its apical margin rounded into one small lobe. Shape of spermatheca is, body somewhat rice-bowl-shaped, tail short and bent towards body.

LENGTH: Original given as $3.30 \mathrm{~mm}$.

RANGE: Described from Rocky Mountains of Alberta, Canada, this species is reported at least as far south as Montana in this range. To west it is found in practically all cony colonies of Washington and Oregon, westward limit of these being Cascade Mountains. California flea collecting agencies do not consider this species found in this state. It seems that California conies are infested with two other species of fleas not found in Oregon or Washington.

Host Preference: There is little doubt that Ochotona (cony) is the true host of this flea. Vernon Bailey states that conies are a source of Martes caurina (marten) food, and therefore in time this flea will doubtless be found upon martens as accidental occurrences.

Seasonal Distribution: The writer has specimens of this flea collected during each month from June through October. In most of their range conies cannot be collected during other months of the year because of the snow upon their rock slides.

Abundance: The few records of this flea in collection of the writer lead him to believe that either the seasonal maxima is during winter when conies cannot be collected, or that the flea is a nest flea which only by accident ventures from the cony nest, or that the flea is a rare species. From 100 conies collected in Oregon and Washington over a period of years, the writer has removed only 3 males and 7 females of this species. 


\section{RECORDS of these follow: \\ OREGON-Off: \\ Ochotona princeps brunnescens Howell (Cascade cony), Cooper Spur Junc- tion to Cloud Cap Inn, Parkdale, Hood River County, Rock Slide: at $5,500 \mathrm{ft}$. el., June 1, 1934, 1 female; at 4,000 ft. el., June 2, 1934, 1 male; at 4,500 ft. el., July 3, 1935, 1 female; at 5,500 ft. el., October 5, 1935, 1 male; at 4,000 ft. el., August 4, 1937, 1 female \\ Ochotona fenisex fumosa Howell (dusky cony), Fish Lake, Santiam Nat. For., Linn County, July 20, 1938, 1 female; Olallie Lake, Jefferson County, Mt. Hood Nat. For., August 7, 1938, 1 male \\ Ochotona schisticeps jewetti Howell (Jewett or Blue Mountain cony), Wall- owa Lake, Wallowa County, August 8, 1939, 1 female.}

\section{WASHINGTON-Off:}

Ochotona princeps brunnescens Howell (Cascade cony), Goose Lake, Skamania County (12 miles west of Guler), August 23, 1935, 1 female.

The largest other source of information on this flea comes from Jellison in his review on Ctenophyllus issued in Public Health Reports 56:49:6. In this 1941 issue Jellison reports this flea as follows:

BRITISH COLUMBIA-Off:

Ochotona princeps (cony), Reno Mountain, Salmon, May 29, 1936; Mt. Dunn, North Thompson Valley, August 1I, 1937; Salmon Arm, August 10, 1938; Robbins Range, October 3, 1939, 1 female; Tappen, March 31, 1940, 1 male, 1 female; Robbins Ridge, October 3, 1937, 1 male, 1 female; Reno Mine, May 29, 1936, 1 male

Ochotona princeps cuppes Bangs (Bangs cony), Okanagan, 1936, 1 female

Ochotona princeps brooksi Howell (Shuswap cony), Dunn Peak, August 11, 1937, 1 male.

\section{ALBERTA-Off:}

Ochotona princeps (cony), Banff, August 14, 1939, 2 females.

MONTANA-Off:

Ochotona princeps (cony), Beaverhead County, August 4, 1937, 1 female; Park County, June 29, 1938, 3 males, 2 females

Ochotona sp. (cony), Ravalli County, May 27, 1923, 1 male.

\section{UTAH-Off:}

Ochotona princeps uinta Hollister (Uinta cony), Provo (Mt. Timpanogos), Utah County, July 2, 1937, 11 females.

\section{COLORADO-Off:}

Ochotona princeps (cony), Silverlake, 32 miles west of Boulder, Boulder County, June 15 and 16,1939, from 4 separate hosts as follows: 3 males and 7 females; 3 males and 10 females; 2 females; 2 females. 


\section{FAMILY HYSTRICHOPSYLLIDAE TIRABOSCHI}

1904 Hystrichopsyllidae Tiraboschi, Archiv. de Parasit., 8:242.

1905 Hystrichopsyllidae Baker, Proc. U. S. Nat. Mus., 29:124.

1905 Ctenopsyllidae Baker, Proc. U. S. Nat. Mus., 29:124.

1909 Hystrichopsyllidae Oudemans, Nov. Zool., 16:155.

1915 Leptopsyllidae Rothschild, Ent. Mo. Mag., 51:80.

1915 Hystrichopsyllidae Rothschild, Ent. Mo. Mag., 51:83.

1926 Leptosyllidae Dampf, Ent. Mitt., 15:384.

1926 Hystrichopsyllidae Dampf, Ent. Mitt., 15:385.

1929 Hystrichopsyllidae Ewing, Manual External Parasites, p. 172.

1936 Ctenopsyllidae Wagner, Tierwelt Mitteleuropas, Bd. 6, Abt. 17, s. 14.

1940 Hystrichopsyllidae I. Fox, Fleas of Eastern U. S., p. 77.

Genera of this family of fleas characterized by presence of dorsal sulcus separating frons from posterior portion of head, which allows motion between two regions. Opinions differ as to what genera belong in this family.

To this date flea taxonomists have not agreed upon the generic content of this family or the generic sequence within it. While the writer well realizes that the following arrangement is not taxonomically sound, it does at least give a rapid and convenient method of distrubuting the genera.

NO GENAL TEETH
Atyphloceras
Callistopsyllus
Catallagia
Conorhinopsylla
Delotelis
Megarthroglossus
Trichopsylloides

2 GENAL TEETH

Epitedia

Meringis

Neopsylla

Peromyscopsylla

Phalacropsylla
3 GENAL TEETH

Carteretta

Ctenophthalmus

4 GENAL TEETH

Doratopsylla

Leptopsylla

Micropsylla

5 GENAL TEETH

Actenophthalmus

Micropsylla

Paratyphloceras

Rectofrontia
6-8 GENAL TEETH

Hystrichopsylla

12-14 GENAL TEETH

Stenoponia

HEAD WITH CREST

Corypsylla

Corypsylloides

Nearctopsylla 
Key to the Western Genera of HYSTRICHOPSTLLIDAE

I. Genal teeth absent

A. Segments I and II of hindtarsus hairy, with long dorsal bristles

B. Without hairy hindtarsus (Segments I and II)

Conorhinopsylla, p. 293

a. Genal spinelets present

Trichopsylloides, p. 307

b. Genal spinelets absent

1. Apical spinelets on abdominal tergites very prominent; spermatheca double

2. Apical spinelets on abdominal tergites normal

a. Finger finger-shaped with two black spiniforms; spermatheca without tail projecting into body

Callistopsyllus, p. 281

Finger rectangular with 2 black spiniforms; spermatheca barrel-shaped

Stenistomera, p. 304

b. Finger without black spiniforms

(1) Finger very large, somewhat fan-shaped; spermatheca very large, somewhat top-shaped Delotelis, p. 294

(2) Finger normal size

(a) IX st. male armed with black spiniforms, spermatheca with tail deeply imbedded in body

Catallagia, p. 283

(b) Both finger and IX st. male without black spiniforms; spermatheca, body small, with or without a collar, tail large Megarthroglossus, p. 296

II. Genal teeth present

A. 2 genal teeth present

a. Genal teeth not overlapping

b. Genal teeth overlapping at base

1. No apical spinelets on abdominal tergites

Peromyscopsylla, p. 328

2. Apical spinelets on abdominal tergites

Meringis, p. 317

Viniculum of the basal abdominal sternum present

Viniculum of the basal abdominal sternum absent

Neopsylla, p. 314

Epitedia, p. 309

B. 3 genal teeth present

California

Carteretta, p. 341

Rocky Mountains and east

Ctenophthalmus, p. 343

C. 4 genal teeth present

a. Genal teeth arranged horizontally

(On house mice)

(On wild native mice)

Leptopsylla, p. 346

b. Genal teeth arranged obliquely

1. Genal teeth curved

Micropsylla sectilis, p. 349

Doratopsylla, p. 344 
D. 5 genal teeth present

4 in row, the 5 th raised slightly along antennal groove

5 in row

Actenophthalmus, p. 352

Paratyphloceras, p. 353

a. Spermatheca with distinct apical hollow on tail; finger not tapering to apex

Micropsylla goodi, p. 351

b. Spermatheca without distinct apical hollow on tail; finger tapering gracefully to apex

E. 6 to 8 genal teeth (over $3 \mathrm{~mm}$. in length)

F. 12 or so genal teeth

Rectofrontia, P. 355

Hystrichopsylla, p. 357

Stenoponia, p. 362

III. Head with crest

A. Heavy incrassation on abdominal tergites absent

a. Crest with 5 teeth, all different lengths and 4 pointed

Nearctopsylla, p. 368

b. Crest with 6 teeth, all same length, 5 blunt Corypsylloides, p. 366

B. Heavy incrassation on abdominal tergites present Corypsylla, p. 363

\section{GENUS ATYPHLOCERAS J. AND R.}

1915. Atyphloceras Jordan and Rothschild. Ectoparasites Is p. 59.

Genotype: Ceratophyllus multidentatus C. Fox 1909

Genal comb absent but pronotal comb present. Eye reduced. Labial palpus is made up of from 5 to 8 segments. Abdominal tergites with heavy apical spinelets which are arranged on $t$. I to VI with 2 to 7 spinelets on side. Three antepygidial bristles to side in each sex. Fifth tarsal segment of each leg armed with 5 pairs of lateral plantar bristles. Females with 2 spermathecae.

This genus is represented in West by 4 species in United States and one from British Columbia. All are found on a variety of small rodents.

As one examines males and females of these species side by side, it is to be noticed at once that apical margin of VII st. in females is quite distinct, as are fingers and processes in claspers of males. A key based upon these characteristics will result in

\section{Key to the Western Species of Atyphloceras}

1. VII st. female with angular lower lobe; finger with both margins above pedicel slightly convex

Rocky Mountains

Central California

A. echis, p. 279

A. longipalpus, p. 280

2. VII st. female with undulate apical margin, male not yet described

British Columbia

A. artius, p. 279

3. VII st. female with lower angulate lobe and dorsal to sinus a small triangular lobe; finger long and narrow, posterior border convex, anterior flat

California

A. felix, p. 278 
4. VII st. female with narrow lower lobe not angulate, then deep sinus followed by rounded upper lobe; finger medium in length, posterior margin convex, anterior flat

Northern California and north

A. multidentatus, p. 276

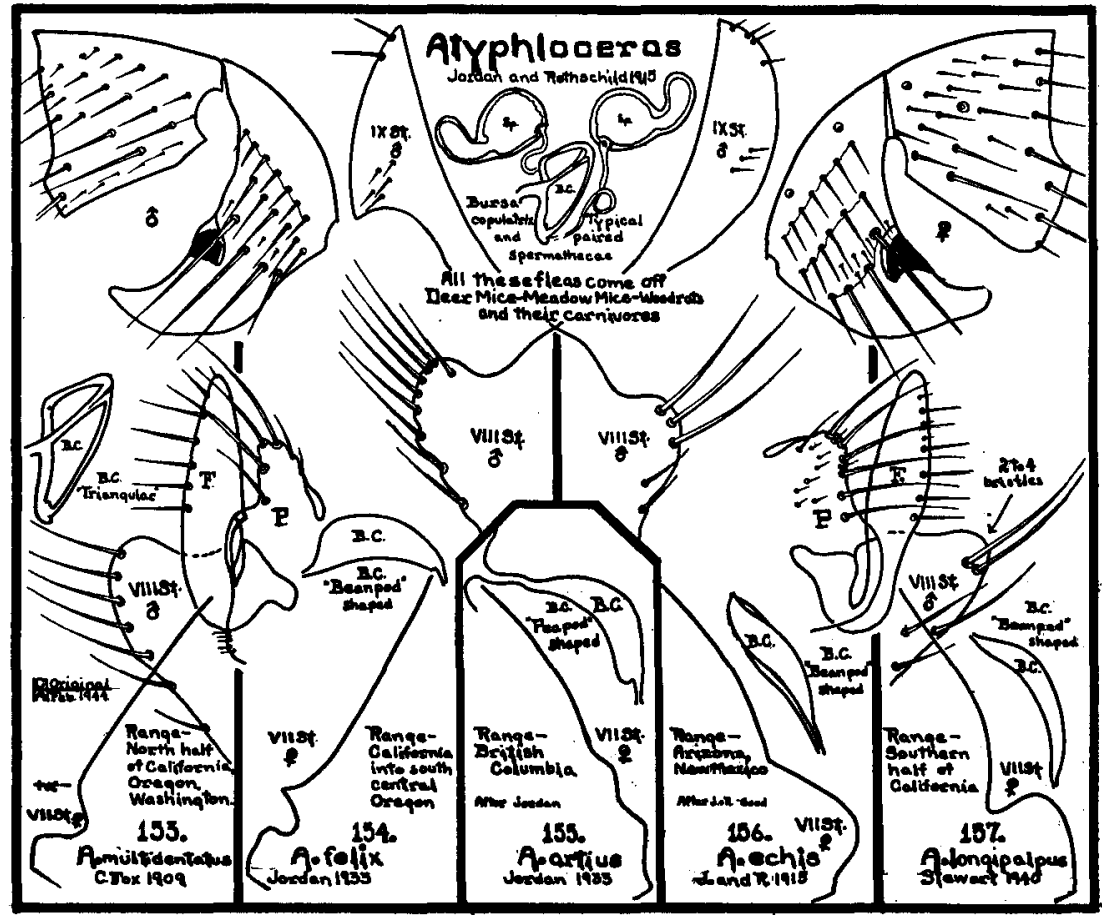

153. Atyphloceras multidentatus

C. Fox 1909

1909 Ceratophyllus multidentatus C. Fox, Ent. News, 20:107.

1914 Ceratophyllus multidentatus C. Fox, U. S. Pub. Health Ser. Hyg. Lab. Bul. No. 97, Fig. 51.

1915 Atyphloceras multidentatus Jordan and Rothschild, Ectoparasites I, p. 59.

1933 Atyphloceras multidentatus Jordan, Nov. Zool, 39:66 and 69.

1940 Atyphloceras multidentatus I. Fox, Fleas of Eastern U. S., p. 80.

This species was described from a small series of both sexes taken off Microtus californicus (California meadow mouse) and a female removed from nest of Neotoma (wood rat).

In common with other members of this genus, this species can be distinguished from members of other genera by prominent apical spinelets of abdominal tergites, and from other species of the genus by:

Modified Segments, Male: Apical portion of process narrowed down and armed with about 4 medium bristles; finger $\mathrm{F}$ with posterior 
border nicely rounded along entire length and armed along apical half with about 6 medium bristles; anterior border flat along upper twothirds, lower third incurved. VIII st. nicely rounded apically and armed along ventral border with 7 or so medium bristles. IX st. expanded apically into an axe-blade-shaped face which is apically pointed and armed close to apex with 2 small bristles. Female: VII st. with lower lobe small and angulate, sinus not large and upper face flat. Spermathecae 2 and bursa copulatrix which is said to be triangular.

LENGTH: Large series in collection of the writer average in males $2.60 \mathrm{~mm}$., in females $3.10 \mathrm{~mm}$.

RANGE: Central California and north, west of Great Basin.

Preferred Host: This species seems to be equally at home on Microtus (meadow mice), Peromyscus (deer mice), and Neotoma (wood rats) and can occasionally be taken off other small animals.

Seasonal Distribution: This species seems to be a fall, winter, and spring flea.

Abundance: Usually this flea is found on hosts singly, but if nest of host can be examined during the seasonal maxima of species many of them can be found in each nest.

Biology: Females frequently found during December and January with eggs. Eggs are very large for a flea and are generally found in pairs in abdomen. Presence of large numbers of these fleas in nests rather than on hosts would lead one to believe this species to be a nest flea.

MEdical IMPORTANCE: Eskey and Haas fed 2 specimens of this species upon plague-positive guinea pigs. One became infected. There is no record of the infected flea clearing itself of the infection or being able to transmit the disease.

Representative of many records for this species in collection of the writer are:

OREGON-Off:

Microtus townsendi Bachman (Townsend's meadow mouse), Forest Grove, Washington County, March 21, 1932, 1 male

Microtus canicaudus Miller (gray-tailed meadow mouse), Gaston, Washington County, December 5, 1940, 1 male, 4 females

Microtus oregoni oregoni Bachman (Oregon creeping mouse), Tillamook, Tillamook County, September 1, 1937, 2 males, 1 female

Peromyscus maniculatus rubidus Osgood (ruddy deer mouse), Gaston, Washington County, January 28, 1935, 1 female

Peromyscus maniculatus gambeli Baird (Gambel's deer mouse), The Dalles, Wasco County, March 1, 1940, 1 pair

Neotoma cinerea fusca True (dusky bushy-tailed wood-rat), Neskowin, Tillamook County, October 19, 1931, 1 male

Tamiasciurus douglasi douglasi Bachman (Douglas pine squirrel), Gaston, Washington County, October 10, 1938, 1 female

Tamiasciurus douglasi albolimbatus Allen (Sierra pine squirrel), Sisters, Deschutes County, March 20, 1937, 1 female

Mus musculus musculus Linnaeus (house mouse), Shaniko, Wasco County, November 8, 1940, 1 female. 
WASHINGTON-Off:

Peromyscus maniculatus gambeli Baird (Gambel's deer mouse), Grand Dalles, Klickitat County, January 28, 1942, I male.

CALIFORNIA-Off:

Peromyscus truei gilberti Allen (big-eared deer mouse), Elk Creek Forest Camp, Gasquet, Del Norte County, December 30, 1941, 1 female with eggs,

Augustson reports this flea from southern California off:

Peromyscus eremicus fraterculus Miller (San Diego desert mouse), San Gabriel Wash, Los Angeles County

Reithrodontomys megalotis longicaudus Baird (California harvest mouse), Santa Maria, Santa Barbara County.

\section{Atyphloceras felix Jordan 1933}

1933 Atyphloceras felix Jordan, Nov. Zool., 39:66.

1940 Atyphloceras felix Stewart, Pan-Pacific Ent., 16:22.

Male of this species was described from one specimen taken off Peromyscus truei (deer mouse) in Cuddy Valley, Ventura County, California, by A. B. Howell on May 20, 1922. Female was described by Dr. M. A. Stewart, who received a large series of this species from Jamesburg, Monterey County, California, where C. P. North collected the material off Peromyscus californicus subsp., Peromyscus truei subsp., and Microtus californicus subsp. from June 18, 1938, to January 11, 1939.

In this species, as well as others in this genus, the modified abdominal segments are characteristic. In female, apical outline of the VII st. with 2 well-defined lobes; lower one with more or less straight margin rounded at upper corner and separated by deep conspicuous sinus from small rather acutely pointed upper lobe, this latter extending posteriorly nearly as far as lower lobe. Margin of this sternite is, however, variable. In male, process is much longer than in $A$. multidentatus, with about 10 bristles, 4 long, other short, its anterior margin with a strongly projecting nose in middle. Finger longer and narrower than in $A$. multidentatus, apex of vertical arm of IX st. broader and triangular apical dilated portion of the ventral arm longer.

LENGTH: Male $2.30 \mathrm{~mm}$., female $2.50-3.00 \mathrm{~mm}$.

RANGE: Apparently this species ranges through entire length of state of California. Writer collected it in northern Siskiyou County. It was described from Monterey County, central California, and Augustson secured it in Los Angeles County.

RECORDs: The writer collected a male of this species from

CALIFORNIA-Off:

Peromyscus maniculatus gambeli Baird (Gambel's deer mouse), south shore Lake Meiss, Mcdoel, Siskiyou County, April 19, 1943. Augustson collected a series off this same host at Los Angeles on December 8, 1940, 
In central California the writer has examined specimens off:

Microtus californicus subsp. (California meadow mouse), taken on Hunter Ligget Reservation, Monterey County, April 18, 1942, 1 male

Peromyscus californicus subsp. (deer mouse), Santa Clara County, April 18, 1942, 2 males, 1 female,

Augustson also reports this species off:

Peromyscus boylii rowleyi Allen (Rowley deer mouse), San Gabriel Mountains, Los Angeles County

Peromyscus californicus insignis Rhoads (southern parasitic mouse), City of Tujuna and San Gabriel Mountains, Los Angeles County; Point Arguello, Santa Barbara County

Peromyscus eremicus fraterculus Miller (San Diego desert mouse), Santa Monica Mountains, Los Angeles County

Peromyscus maniculatus gambeli Baird (Gambel's deer mouse), San Gabriel Mountains and Santa Monica Mountains, Los Angeles County; and Point Arguello, Santa Barbara County

Neotoma fuscipes macrotis Thomas (large-eared wood rat), Santa Monica Mountains, San Gabriel Mountains, and city of Glendale, Los Angeles County

Neotoma lepida intermedia (wood rat), San Gabriel Mountains, Los Angeles County

Neotoma spp. (wood rat), Santiago Canyon, Orange County.

\section{Atyphloceras artius}

Jordan 1933

1933 Atyphloceras artius Jordan, Nov. Zool., 39:69.

1936 Atyphloceras artius Wagner, Can. Ent., 68:206.

This species was described from a female taken off Peromyscus at Kelowna, British Columbia, on October 4, 1908, by A. Tate.

FEMALE differs from other members of genus by having apical outline of VII st. undulate. MALE is undescribed.

This species seems to be only member of genus so far described from British Columbia. It is known only from the original description.

\section{Atyphloceras echis}

Jordan and Rothschild 1915

1915 Atyphloceras echis Jordan and Rothschild, Ectoparasites, 1:59.

1942 Atyphloceras echis Good. Pan-Pacific Ent., 18:87-89.

This species was described from single female taken off "Mus spec." at Paradise, Arizona, by O. C. Duffner during February of 1914. Dr. Newell Good described male from specimens taken off Peromyscus maniculatus spp. (deer mouse) in Greenlee County, Arizona, November 16, 1938, by F. J. Gonderman.

Process, finger, and IX st. of male are similar to same structures of A. longipalpus, but VIII st. of male is much broader and more evenly rounded. Apical margin of VII st. of female consists of a lower wellrounded lobe and above it a slightly convex outline without a sinus.

LENGTH: Male $2.30 \mathrm{~mm}$., according to Good.

RANGE: Known only from Arizona, but probably also from Utah.

RECORDS of this species are: 
UTAH-A flea listed as Atyphloceras (probably echis) is reported from Salina, Sevier County, off Neotoma desertorum Merriam (desert wood rat).

During April of 1942 Good described male as follows:

HeAD: Eye lightly pigmented, more degenerate than in $\mathrm{A}$. multidentatus. Labial palpus of 7 joints, reaching to or just short of apex of fore trochanter.

Thorax: Pronotal comb composed of 20 spines.

ABDomen: Number of apical spines on abdominal tergites (total of both sides) is as follows: $I=6, I I=11, I I I=8, I V=10, V=6$, $\mathrm{VI}=5$. Three antepygidial bristles on each side. Lengths of these are as follows: upper $=0.11 \mathrm{~mm}$., middle $=0.23 \mathrm{~mm}$., lower $=0.15 \mathrm{~mm}$.

Modified SEgments: Manubrium of clasper $(\mathrm{M})$ triangular, pointed, short, and broad at the base. Process of clasper $(\mathbf{P})$ short, bilobed, the apices rounded, armed with 7 bristles, 3 of which are large and are situated on apical margin of upper lobe. Movable finger $\mathrm{F}$ of clasper long with both margins convex on apical half, its rear margin provided with 3 long, thin bristles. Length of movable finger (apex to base of ventral bow), $0.29 \mathrm{~mm}$. Penis large, thick, club-shaped. External or postero-ventral arm of st. IX rounded ventrally, spoon-shaped or ladleshaped, not triangular. St. VIII moderately sinuate, with 3 large bristles near apex.

\section{Atyphloceras longipalpus \\ Stewart 1940}

1940 Atyphloceras longipalpus Stewart, Pan-Pacific Ent., 16:21.

This species was described from a male and a female taken off Spilogale gracilis subsp. (spotted skunk) near Jamesburg, Monterey, County, California, on November 19, 1938, by R. Holdenried.

In male, finger differs from male of other species of genus in that both margins above pedicel are slightly convex; apex bluntly rounded and posterior margin bearing 4 long bristles. Process is cone-shaped and bears 8 stout bristles. Horizontal arm of IX st. is shaped somewhat like a bean pod and bears 2 short, stout, sharply pointed bristles on posteroventral margin. In female apical margin of VII st. possesses a conspicuous ventral lobe broadly rounded at its upper angle and very slightly convex at its posterior margin.

Types are in the collection of the describer.

RANGE: Coastal belt of southern half of California and in southern California eastward. In southern California Augustson reports taking this flea off:

Peromyscus californicus insignis Rhoads (southern parasitic mouse)

Neotoma intermedia gilva Rhoads (yellow wood rat), Cabazon, Riverside County

Neotoma lepida intermedia (wood rat)

Spilogale gracilis microrhina (spotted skunk), San Gabriel Mountains, Los Angeles County. 
GENUS CALLISTOPSYLLUS J. AND R.

1915. Callistopsyllus Jordan and Rothschild. Ectoparasites I, p. 46.

Genotype: Ceratophyllus terinus Rothschild 1905

In this genus labial palpus consists of 4 segments. Eye is vestigial. Antennal groove does not continue upward across vertex. Second segment of antenna is widened on outside, covering one-third of club. No tuber centrale. Pronotal comb present. In metathorax, episternum is fused with sternum and epimerum with notum. Abdominal tergites with one row of bristles and some with apical spinelets. Antepygidial bristles 3 in both sexes. Femora without lateral bristles. Fifth segment of all tarsi with a proximal ventral pair of plantar bristles and 4 lateral pairs.

When cleared, members of this genus show distinct strengthing, thickened rod of chitin across gena at about eye position, rod bent anteriorly slightly in middle and from this point, anteriorly located thickening becomes almost a circle.

Modified Segments are very similar in 2 known species. Jordan holds that it is primarily the shape of spermatheca, and difference is slight, which separated females, VII st. outline of each is a simple slant from dorsal to ventral. Finger of male is finger-tip-shaped, armed at apex with 2, sometimes 3, blunt black spiniforms.

This western genus is represented by 2 species, one, smaller form, north of Lake Tahoe, California, in all Cascade Mountains and east into Great Basin region

C. terinus, p. 281

Second, larger, and almost identical with the first, but with range south of Lake Tahoe, throughout all of Sierra-Nevada Mountains of California and east C. deuterus, $p .283$ The two species come consistently off deer mice, occasionally off other rodents.

\section{Callistopsyllus terinus Rothschild 1905}

1905 Ceratophyllus terinus Rothschild 1905, Nov. Zool., 12:158.

1905 Ceratophyllus terinus Baker, Proc. U. S. Nat. Mus., 29:15I.

1915 Callistopsyllus terinus Jordan and Rothschild, Ectoparasites I, p. 46.

1936 Callistopsyllus terinus Wagner, Can. Ent., 68:197.

This species was described from 3 females taken at Mabel Lake, British Columbia, by Allan Brooks off Citellus columbianus (red digger squirrel) May 6, 1902.

Original description states that apex of VII st. of female is slanting and feebly emarginate. VIII t. bears no bristles above stigma and only one below it, patch of bristles ventrally at apex. VIII st. is sharply pointed, bearing a few extremely small hairs at apex. Anal tergite has comparatively few bristles which are slender, no spine-like ones. Finger $\mathbf{F}$ of male nicely rounded at apex, differing slightly in this re- 


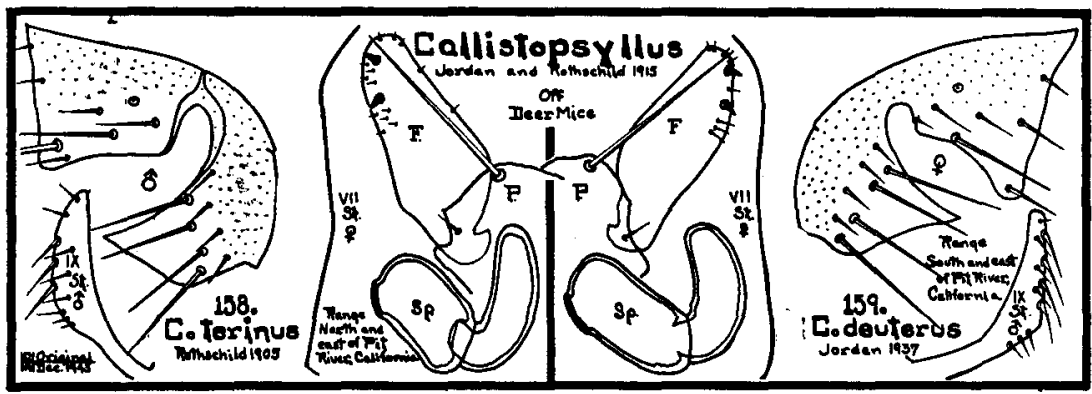

spect from following species which is more or less flattened at apex. Armature of finger 2 (occasionally 3 ) blunt black spiniforms and a clothing of weak bristles.

LENGTH: While original length of female is given as $2.40 \mathrm{~mm}$., this is somewhat longer than specimens in collection of the writer, which measure only $1.80 \mathrm{~mm}$. Males in collection of the writer average 1.60 mm.

Range: Described from Mabel Lake, British Columbia, this species must range southward through the Columbian Highlands and Cascade Mountains and Great Basin region of Washington and Oregon and on south as far at least as south end of Lake Tahoe in California and Nevada.

Abundance: In 1936, 31 years after description of this species appeared, Dr. Wagner stated, "Up to date there is known only a female." Obviously, then, this species must be rare.

Host Preference: Original type host was Columbian ground squirrel Citellus columbianus (red digger squirrel), but this writer feels that perhaps the true host is Peromyscus (deer mouse), although he has removed this species from a pine squirrel.

RECORDS: The few personal records in collection of the writer are:

OREGON-Off:

Peromyscus maniculatus gambeli Baird (Gambel's deer mouse), Sister, Deschutes County, July 18, 1936, 3 males, I female; Mitchell, Wheeler County, May 13, 1939, 1 male

Tamiasciurus douglasi albolimbatus Allen (pine squirrel), Sisters, Deschutes County, March 20, 1937, 1 female.

CALIFORNIA-Off:

Peromyscus maniculatus gambeli Baird (Gambel's deer mouse), Modoc Lava Beds, Siskiyou County, June 27, 1939, 1 male; Tule Lake, Siskiyou County, April 19, 1942, 1 male; Mcdoel, Siskiyou County, March 21, 1943, 1 female; Truckee, Nevada County, June 23, 1944, 1 male, 3 females.

NEVADA-Off:

Peromyscus maniculatus sonoriensis Le Conte (Sonora deer mouse), Lake Tahoe, Douglas County, June 21, 1944, 1 female. 


\section{Callistopsyllus deuterus Jordan 1937}

1937 Callistopsyllus deuterus Jordan, Nov. Zool., 40:266.

1941 Callistopsyllus deuterus Augustson, Bul. Southern Calif. Acad. Sci., 40:140.

Jordan described this species from single female taken off Peromyscus (deer mouse) at Big Bear Lake, San Bernardino County, California, May, 1936, by Glen M. Kohls, Gus Augustson described male from specimen taken off Peromyscus maniculatus sonoriensis Le Conte (Sonora deer mouse) collected at Mammoth Lakes, Mono County, August 10, 1941, by R. L. Rutherford.

Modified Segments, Male: Augustson states that VIII $t$. is reduced to short cone shaped structure with few scattered bristles; finger large, protruding well beyond rest of genitalia, two short well separated spiniforms at apex; IX st. with upper posterior portion blade-like, upper outer margin well covered with setae; VIII st. vestigial, a wing-like, weakly chitinized, veined structure remaining. Female: Jordan states that female agrees with female of $C$. terinus with exception of spermatheca and dark proximal portion of its duct. Spermatheca: its head longer than tail, being a little over twice as long as broad, in C. terinus head is very slightly shorter than tail, being much less than twice as long as broad. St. VII has straighter, less incurved posterior margin.

LENGTH: Somewhat larger than $C$. terinus, males measuring 1.80 mm., females $2.20 \mathrm{~mm}$.

RANGE: Sierra-Nevada Mountains south of Lake Tahoe, in California and Nevada.

Nothing is known about the seasonal distribution or abundance of this species.

RECORDS: With the exception of original female upon which description of species was based, only other records are those of Augustson. They follow:

Peromyscus maniculatus sonoriensis Le Conte (Sonora deer mouse), Mammoth Lakes, Mono County, August 3, 1939, 1 male, 2 females; June 1, 1941, 1 male, 4 females; August 2, 1941, 2 males, 13 females; August 10, 1941, 3 males, 1 female; August 15, 1941, 3 males, 6 females; August 28, 1941, 1 female

Microtus montanus dutcheri Bailey (Dutcher meadow mouse), Tully's Hole, Fresno County, August 25, 1941, 2 females

Microtus mordax sierrae R. Kellogg (Sierra meadow mouse), Tully's Hole, Fresno County, August 23, 1941, I female

Eutamias quadrivittatus inyoensis Merriam (Inyo chipmunk), Tully's Hole, Fresno County, August 23, 1941, 2 females.

\section{GENUS CATALLAGIA ROTHSCHILD}

1915. Catallagia Rothschild. Ectoparasites, I, p. 41.

Genotype: Pulex charlottensis Baker 1898

Frons with tubercle. Eye vestigial. Antennal groove is open. Bristles of segment II of antennae short. Labial palpus with 5 segments. 
Frons with 2 rows of bristles, occiput with 3 rows. No genal teeth. Pronotum armed with one row of bristles and comb of 14 teeth. Metanotum without apical spinelets. Pygidium convex. Fifth segment of the fore- and midtarsi with 4 lateral pairs of plantar bristles and a fifth pair in between first lateral pair; in hindtarsus, fifth segment with 4 lateral pairs, ventral pair absent or represented at most by one bristle.

This genus is represented in West by nine species, all from wild mice, distinguished from one another in males by armature of IX st. and in females by apical margin of VII st. Females are much more difficult to distinguish from one another than are males.

Key to the Species of Catallagia in the West

1. Spermatheca with tail not deeply projecting into lumen of bodymale not known
Oregon
C. motei, p. 290
Montana
C. moneris, p. 291

2. Spermatheca with tail deeply projecting into lumen of body

a. Apical margin VII st. female almost a flat surface; IX st. of male armed with 4 black spiniforms and several bristles at apex

C. charlottensis, p. 285

b. Apical margin VII st. female undulate; IX st. male armed apically with 4 black spiniforms and a group of bristles

Oregon

C. sculleni, p. 287

California

C. rutherfordi, p. 292

c. Apical margin VII st. female with rounded lobe dorsally situated;

IX st. male armed apically with 3 black spiniforms and 2 spiniform bristles

C. decipiens, p. 288

d. Apical margin VII st. female with small rounded prominence ventral of lobe; IX st. male armed apically with 4 or 5 black spiniforms, 3 short tack-like spiniform bristles and a series of bristles
Oregon
C. chamberlini, p. 289
California
C. von bloekeri, p. 292

e. Apical margin VII st. female slightly concave along lower twothirds of margin; IX st. male armed apically with hook-like spine and along posterior border with row of hairs giving appearance of comb

C. wymani, p. 291

WrITER's OpInion: Of the species of Catallagia described to this date the author believes 4 to be synonyms. $C$. motei Hubbard 1940 and $C$. moneris Jordan 1937 are known only in female. Their spermathecae are not typical. In examining hundreds of specimens of $C$. charlottensis from nests of mice the writer has always found a small per cent with spermatheca incompletely formed, tail not projecting into body. From this evidence the writer believes that $C$. mote $i$ to be the same as $C$. char- 


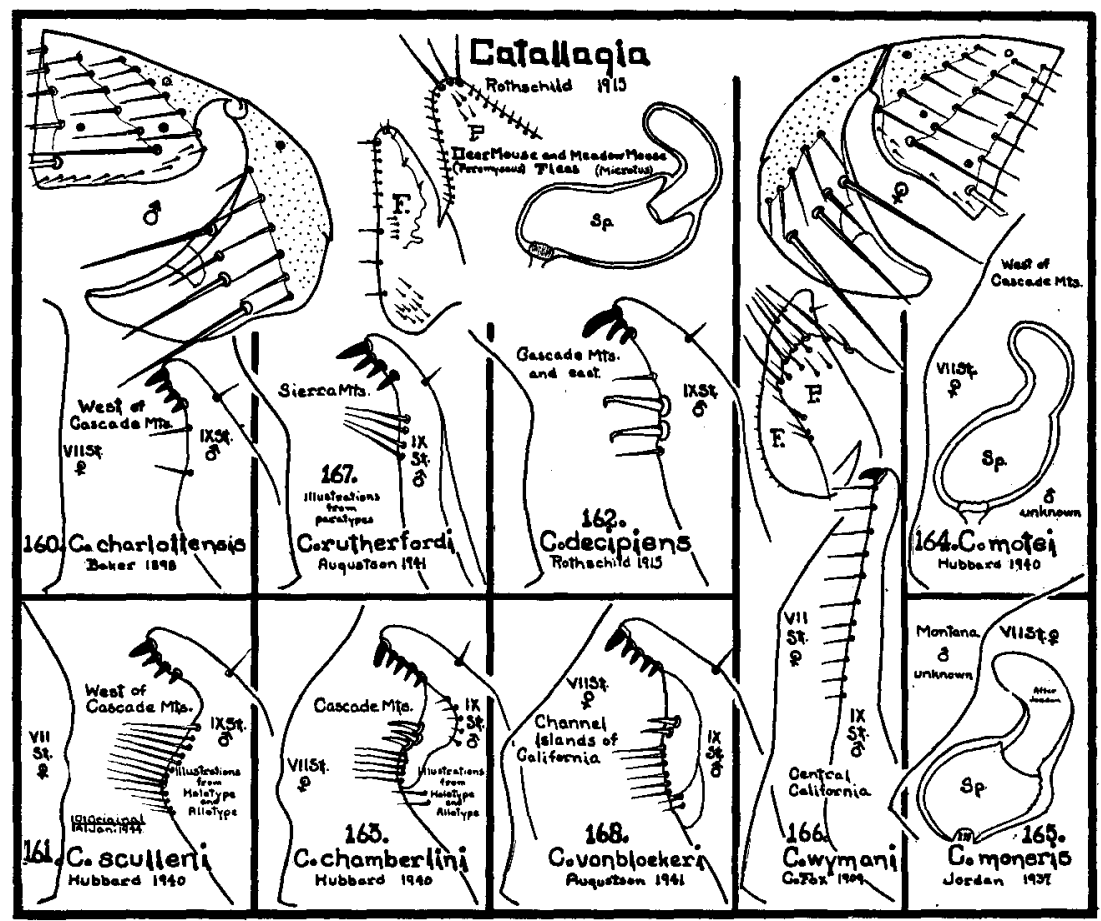

lottensis and $C$. moneris to be the same as $C$. decipiens. Study of paratypes leads the writer to believe $C$. rutherfordi the same as $C$. sculleni, and $C$. vonbloekeri the same as $C$. chamberlini.

\section{Catallagia charlottensis}

Baker 1898

1898 Pulex charlottensis Baker, Jour. N. Y. Ent. Soc., 6:56.

1904 Ceratophyllus charlottensis Baker, Proc. U. S. Nat. Mus., 27:390.

1905 Ceratophyllus charlottensis Rothschild, Nov. Zool., 12:174.

1905 Odontopsyllus charlottensis Baker, Proc. U. S. Nat. Mus., 29:145.

1915 Catallagia charlottensis Rothschild, Ectoparasites, 1:43.

1936 Catallagia charlottensis Wagner, Can. Ent., 68:202.

1940 Catallagia charlottensis Hubbard, Pacific Univ. Bul., 37:3:2.

This species was described from females taken from a mouse nest at Masset, Queen Charlotte Islands, by the Rev. J. H. Keen. During 1905 Rothschild described and pictured what he thought to be male of species but identification was in error and Jordan and Rothschild reported in $1915, "$. . . the material we had in 1905 , and which we thought was charlottensis, differs in various points and represents an unnamed species."

Modified SEgments of this species mark it off from all other fleas. 
Original description states that lower antepygidial bristle is scarcely half length of central one in both sexes. Clasper of male broad, finger incurved at base, hind margin, therefore, strongly elbowed beyond base; IX st. has 4 stout apical spiniforms and proximally to them a few slender hairs. VIII st. of male is sinuate subventrally and produced below narrow sinus into long, feebly chitinized, pointed flap. VII st. of female is said to be slightly incurved, but often this surface is almost flat. Spermatheca is typical for Catallagias, that is, tail projects deeply into lumen of body.

LENGTH: Specimens of both sexes in collection of the writer average $2.00 \mathrm{~mm}$.

RANGE: This species seems to have a limited range which extends westward from Cascade-Sierra Mountains in British Columbia, Washington, Oregon, and California. There is some indication that species also ranges in Warner Mountains of northeastern California.

Seasonal Distribution: February and March are months in which this species seems at its greatest abundance. At this time these fleas can be taken by dozens or even hundreds from meadow mouse nests and in less numbers from deer mouse nests. Can be taken singly or in twos or threes from mice themselves during cooler seasons of year.

Host Preference: Primarily a nest flea of meadow mice, although it seems equally at home in deer mouse nests. Taken consistently from meadow mice and deer mice and occasionally from other mammals, which play about on ground.

Abundance: This species is a common flea during spring months in its range, particularly if investigator can uncover meadow mouse nests.

RECORDS: Following are representative of many records in collection of the writer:

OREGON-Off:

Peromyscus maniculatus gambeli Baird (Gambel's deer mouse), New Pine Creek, Lake County, June 18, 1937, 1 male, 1 female

Peromyscus maniculatus rubidus Osgood (ruddy deer mouse), Cannon Beach, Tillamook County, March 28, 1937, I male

Microtus townsendi Bachman (Townsend meadow mouse), Forest Grove, Washington County, March 30, 1935, 2 females

Microtus richardsoni arvicoloides Rhoads (Cascade meadow mouse), Lookout Mountain, Mt. Hood, Hood River County, September 29, 1935, 1 male

Microtus oregoni oregoni Bachman (Oregon creeping meadow mouse), Tillamook, Tillamook County, August 20, 1937, 2 males

Clethrionomys californicus mazama Merriam (red-backed mouse), Crater Lake, Klamath County, August 29, 1933, 1 male,

Accidental Occurrences:

Eutamias townsendi cooperi Baird (Cooper's chipmunk), Parkdale, Hood River County, June 14, 1934, 3 females

Glaucomys sabrinus oregonensis Bachman (Oregon flying squirrel), Beaver, Tillamook County, September 15, 1937, 1 male 
Tamiasciurus douglasi douglasi Bachman (pine squirrel), Gaston, Washington County, December 20,1937, 1 male

Neotoma cinerea fusca True (dusky bushy-tailed wood rat), Cannon Beach, Tillamook County, March 29, 1937, 1 female

Thomomys bulbivorus Richardson (Willamette Valley pocket gopher), Cornelius, Washington County, July 2, 1935, 1 male.

\section{WASHINGTON-Off:}

Peromyscus maniculatus oreas Bangs (Washington deer mouse), Cape Horn, Skamania County, October 29, 1933, 1 male

Eutamias townsendi townsendi Bachman (Townsend chipmunk), Spirit Lake, Cowlitz County, July 7, 1937, 1 male.

\section{CALIFORNIA-Off:}

Peromyscus maniculatus rubidus Osgood (ruddy deer mouse), Smith River, Del Norte County, April 21, 1942, 1 female

Microtus mordax augusticeps Bailey (coast meadow mouse), Smith River, Del Norte County, April 21, 1942, 1 female.

\section{Catallagia sculleni Hubbard 1940}

1940 Catallagia sculleni Hubbard, Pacific Univ. Bul., 37:3:3.

This species is close to $C$. charlottensis from which it can be distinguished by armature of IX st. of male and apical margin of the VII st. of female. Apical portion of arm of IX st. of male is armed as in charlottensis with 4 black spiniforms but instead of a few bristles proximally to them there is a forest-like patch of bristles in this species. Apical margin of VII st. of female has 3 shallow rounded lobes which make outline undulate.

LENGTH: Male $2.20 \mathrm{~mm}$., female $2.25 \mathrm{~mm}$.

RANGe: This species ranges east from Pacific Ocean through coastal belt, Coast Range and into Puget Sound Trough of Oregon and Washington.

SeAsonal Distribution: This flea generally follows $C$. charlottensis in appearance, coming into collections during late spring and summer.

Host Preference: This insect seems to be primarily a deer mouse flea, but can occasionally be taken off other small rodents.

Abundance: This species does not seem as abundant as charlottensis.

Deposits: The types are in collection of Academy of Natural Sciences of Philadelphia.

RECORDS of the writer are:

\section{OREGON-Off:}

Peromyscus maniculatus rubidus Osgood (ruddy deer mouse), Forest Grove, Washington County, March 22, 1939, 4 males, 1 female; Alsea, Benton County, March 10, 1939, I male, 1 female; Gold Beach, Curry County, June 13, 1939, 2 males, 4 females; Brookings, Curry County, June 14, 1939, 1 male, 1 female

Neotoma cinerea fusca True (dusky bushy-tailed wood rat), Powers, Coos County, June 12, 1939, 1 male. 


\section{Catallagia decipiens \\ Rothschild 1915}

1915 Catallagia decipiens Rothschild, Ectoparasites, 1:43.

1936 Catallagia decipiens Wagner, Can. Ent., 68:203.

1940 Catallagia decipiens Hubbard, Pacific Univ. Bul., 37:3:4.

Original description was based upon series of both sexes taken in British Columbia and Alberta, Canada, during 1901 and 1903 off deer mice, red-backed mice and wood rats.

This species is said to differ from charlottensis as follows: Lower antepygidial bristle is more than half length of central one. Basal abdominal sternite has several small bristles, one behind the other, in front of postmedian pair. In male, process of clasper is narrower, the manubrium broader near apex, and finger $\mathbf{F}$ is proximally gradually rounded; IX st. armed apically with 3 short black spiniforms, and has farther proximally 2 spiniform bristles recurved at tip, one small bristle above, one below spiniform bristles. In female, spermatheca is typical, margin of VII st. has a well-rounded upper lobe.

LENGTH: Specimens in collection of the writer average male, 1.80 $\mathrm{mm}$., female $1.65 \mathrm{~mm}$.

RANGE: While this species may be found ranging in Cascade Mountains with charlottensis, its greater range is toward east. It is found in Columbian Highlands of Washington, Great Basin region of Washington, Oregon, Nevada, northeastern California, and to east into Rocky Mountains of Alberta, and Idaho and Montana.

Host Preference: This species seems to prefer wild mice.

RECORDS: Representative in collection of the writer are:

OREGON-Off:

Peromyscus maniculatus gambeli Baird (Gambel's deer mouse), Wamic, Wasco County, May 18, 1937, 1 male; Hampton, Deschutes County, October 6, 1940, 1 male

Peromyscus maniculatus artemisiae Rhoads (sagebrush decr mouse), Wallowa Lake, Wallowa County, July 14, 1939, 1 male and 1 female

Microtus mordax mordax Merriam (Rocky Mountain meadow mouse), Paulina Lake, Deschutes County, August 2, 1936, 1 male

Clethrionomys gapperi saturatus $\mathrm{Rhoads}$ (British Columbia red-back mouse), Mitchell, Wheeler County, August 25, 1940, 1 pair.

WASHINGTON-Off:

Peromyscus maniculatus oreas Bangs (Washington deer mouse), Rimrock, Yakima County, Washington, May 5, 1939, 1 male.

CALIFORNIA-Off:

Peromyscus maniculatus gambeli Baird (Gambel's deer mouse), Tule Lake, Siskiyou County, January 4, 1912, 1 pair; Fort Bidwell, Modoc County, June 25, 1937, 1 male

Peromyscus maniculatus sonoriensis Le Conte (Sonora deer mouse), Truckee, Placer County, June 23, 1944, 2 females; Truckee, Nevada County, June 23, 1944, 2 males. 
NEVADA-Off:

Peromyscus maniculatus gambeli Baird (Gambel's deer mouse), Vya, Washoe County, June 16, 1944, 1 male; Lake Tahoe, Douglas County, June 21, 1944, i female

Peromyscus maniculatus sonoriensis Le Conte (Sonora deer mouse), Eureka, Eureka County, July 9, 1944, 1 male

Reithrodontomys megalotis megalotis Baird (desert harvest mouse), Minden, Douglas County, June 24, 1944, 1 female.

ARIZONA-Off:

Microtus mordax mordax Merriam (Rocky Mountain meadow mouse), North Rim, Grand Canyon, Coconino County, July 7, 1945, a pair.

MONTANA-In this state this flea is reported off:

Peromyscus spp. (deer mice), Ravalli County, 1922

Eutamias spp. (chipmunk), Ravalli County, 1922

Neotoma cinerea subsp. (bushy-tailed wood rat), Ravalli County, 1926

Citellus columbianus subsp. (Columbian ground squirrel), Ravalli County, 1932.

UTAH-In this state this flea has been recorded off:

Microtus spp. (meadow mouse), Hyrum

Peromyscus maniculatus subsp., Logan, Cache County.

\section{Catallagia chamberlini}

Hubbard 1940

1940 Catallagia chamberlini Hubbard, Pacific Univ. Bul., 37:3:4.

This species is close to $C$. decipiens but can be distinguished from it by armature of IX st. in male and apical margin of VII st. of female. IX st. of male bears 4 or 5 stout, black, conical teeth at apex, most distal the longest and slightly recurved; slightly below a plateau upon which are 3 stout spiniform bristles, then slightly lower small patch of stout bristles; plateau fringed with shorter bristles. Apical margin of VII st. of female consists of a shallow bay ventrally and dorsally a shallow rounded lobe which is preceded by a small rounded prominence.

LENGTH: Males $2.00 \mathrm{~mm}$., females $2.10 \mathrm{~mm}$.

RANGE: This is a species of high Cascade and Siskiyou Mountains of Oregon. Range seems to be moving westward with encroachments into the Willamette Valley.

Host Preference: While specimens in collection of the writer are off Peromyscus (deer mice) and Clethrionomys (red-backed mice) there is little doubt that in time this species will be found upon other high altitude rodents.

Deposirs: Types are deposited in Academy of Natural Sciences of Philadelphia.

Type Locality: Rocky Point (north of Klamath Falls), Oregon.

Type Host: Holotype and allotype were taken off Peromyscus maniculatus gambeli Baird at Rocky Point, Oregon, June 26, 1939.

RECORDs: The following records are representative of those in collection of the writer: 


\section{OREGON-Off:}

Peromyscus maniculatus gambeli Baird (Gambel's deer mouse), Rocky Point, Klamath County, June 26, 1939, 3 males, 2 females

Peromyscus maniculatus rubidus Osgood (ruddy deer mouse), Fish Lake, Linn County, Detroit, July 10, 1938, 1 male

Peromyscus truei gilberti Allen (big-eared deer mouse), Oregon Caves, Josephine County, June 17, 1939, 3 males, 3 females

Clethrionomys californicus mazama Merriam (Mazama red-backed mouse), Rocky Point, Klamath County, June 26, 1939, 2 males

Microtus canicaudus Miller (gray-tailed meadow mouse), Odell, Hood River County, March 18, 1939, I male, 1 female.

\section{Catallagia motei \\ Hubbard 1940}

1940 Catallagia motei Hubbard, Pacific Univ. Bul., 37:3:4.

This species is known only in female, which resembles other Catallagia in all features except shape of spermatheca which has somewhat oval body and tail which does not project into lumen of body as is the case in other female Catallagias. VII st. has apical margin swollen into shallow lobe about midway along margin.

On the basis of findings to 1944, the writer believes this species to be a dimorphic form of $C$. charlottensis.

RaNGE: This species is known to writer only from about 15 specimens taken in Puget Sound Trough of Oregon and Washington.

Host Preference: Majority of specimens known to writer have come off deer mice.

Deposits: Type is deposited in Academy of Natural Sciences of Philadelphia.

TyPE Locality: Banks, Washington County, Oregon, where specimen was taken from a deserted meadow mouse nest on April 7, 1937.

ORIGINAL LeNGTH: $2.10 \mathrm{~mm}$.

RECORDs: The following are representative of those in collection of the writer:

OREGON-Off:

Microtus townsendi Bachman (nest) (Townsend meadow mouse), Banks, Washington County, April 7, 1937, 1 female; Corvallis, Benton County, March 24, 1939, 3 females, from 3 nests

Peromyscus maniculatus rubidus Osgood (ruddy deer mouse), Banks, Washington County, April 7, 1937, 1 female; Buell, Polk County, March 11, 1939, 2 females; Crown Point, Multnomah County, March 19, 1939, 1 female; St. Paul, Yamhill County, March 27, 1939, I female; Powers, Coos County, June 12, 1939, 1 female.

\section{WASHINGTON-Off:}

Peromyscus maniculatus oreas Bangs (Washington deer mouse), Washougall, Clark County, February 24, 1940, 1 female

Eutamias townsendi townsendi Bachman (Townsend chipmunk), Spirit Lake, Cowlitz County, July 7, 1938, 1 female. 


\section{Catallagia moneris \\ Jordan 1937}

1937 Catallagia moneris Jordan, Nov. Zool., 40:267.

This species was described from a single female taken off Marmota flaviventris subsp. (woodchuck) in Ravalli County, Montana, by the staff of Rocky Mountain Laboratory.

The writer believes this flea to be a dimorphic specimen of Catallagia decipiens.

In the short original description Jordan states that this species "Agrees in all details with $C$. decipiens Roths 1915, from Alberta and British Columbia, except in the size and shape of the spermatheca." In this female spermatheca does not have tail projecting into lumen of body. Body is not widened towards tail and is longer than latter.

This species is known only from the original specimen.

\section{Catallagia wymani}

$$
\text { C. Fox } 1909
$$

1909 Odontopsyllus wymani C. Fox, Ent. News, 20:6.

1914 Odontopsylla wymani C. Fox, Pub. Health Ser. Hyg. Lab. Bul., No. 97, fig. 58. 1915 Catallagia wymani Rothschild, Ectoparasites, 1:42.

This species was described from 3 males and 10 females taken off Microtus californicus subsp. (California meadow mouse) during summer of 1908. Like other members of genus, IX st. of male and apical margin of VII st. of female are characteristic. In male, IX st. is extended posteriorly into a slender upward and backward projecting process which is armed apically with single black spiniform and along posterioventral margin with series of slender bristles which have been likened to teeth of comb. Finger F is broader than in other Catallagias. In female apical margin of VII st. is slightly concave along lower two-thirds.

LENGTH: Although original lengths were given as female $2.14 \mathrm{~mm}$., male $2.08 \mathrm{~mm}$., specimens before the writer are females $2.40 \mathrm{~mm}$., males $1.90 \mathrm{~mm}$.

RANGE: This species ranges north and south of San Francisco Bay in California.

SEAsonal Distribution: Specimens before the writer were collected during April and September.

Host Preference: Most known records for this species have been removed from Microtus (meadow mice), but other ground dwelling mice are probably also occasionally infested.

MEdical IMPORTANCE: Thirty-eight specimens of this flea were fed upon plague-positive guinea pigs by Eskey and Haas. Thirteen became plague infected. This was 33 per cent. There is no record that these plague-infected fleas cleared themselves of infection or were able to transmit disease to healthy guinea pigs. 
RECORDS made available to the writer for this central California species are:

Microtus sp. (meadow mouse) by F. M. Prince, Plague Supp. M. Lab., San Francisco, September 23, 1938, 1 male; San Francisco, April 4, 1940, ] female from nest.

\section{Catallagia rutherfordi Augustson 1941}

1941 Catallagia rutherfordi Augustson, Bul. So. Calif. Acad. of Sci., 40:142.

This species was described from a male collected off Peromyscus maniculatus sonoriensis Le Conte (Sonora deer mouse) taken at Mammoth Lakes, Mono County, California, on August 14, 1940, by Augustson and a female collected off Microtus montanus dutcheri Bailey (Dutcher meadow mouse) taken at Tully's Hole, Fresno County, California, on August 15, 1941, by Rutherford and Augustson.

A study of paratypes in collection of the writer leads him to believe this flea is same as Catallagia sculleni Hubbard 1940.

Modified Segments of this species (Augustson): Male: IX st. with 4 stout black teeth at apex, most terminal very blunt, spatulate, twice as thick as pointed, lower 3, immediately below a cluster of bristles of 3 long medial and 4 much smaller outer. Female: VII st. as in $C$. decipiens but with deeper sinus forming more acute lobe on free margin; bursa copulatrix roughly " $S$ " shaped; spermatheca as in $C$. decipiens and related species but somewhat narrower, and with neck of appendix extending much deeper into body.

LeNGTH: Paratypes in collection of writer measure, male $1.80 \mathrm{~mm}$., female $2.50 \mathrm{~mm}$.

RANGE: Probably Sierra-Nevada Mountains of California.

TyPe Host: Reported as Microtus montanus dutcheri Bailey.

Type Locality: Tully's Hole, Fresno County, California.

Records: Augustson reports this flea also off:

Tamiasciurus douglasi albolimbatus Allen, Mammoth Lakes, Mono County, California.

\section{Catallagia vonbloekeri Augustson 1941}

1941 Catallagia vonbloekeri Augustson, Bul. So. Calif. Acad. of Sci., 40:102.

This species was described from materials collected on Santa Rosa Island of Channel Islands of Santa Barbara County, California, off Peromyscus maniculatus sanctaerosae von Bloeker (Santa Rosa Island deer mouse) by von Bloecker on August 8, 1939.

Specimens in collection of the writer as a gift of describer lead him to believe this flea is same as Catallagia chamberlini Hubbard.

Modified Segments (Augustson): Male: St. IX close to $C$. cham- 
berlini, differing in blunt, not curyed, first tooth of apical group, presence of spine-like bristle in this first group, and small plateau area. Female: St. VII close to that of $C$. decipiens, differing in weaker upper lobe and in number of bristles on a side-C. decipiens having 6-7 large bristles in posterior row, 12-14 small bristles in anterior row, C. von bloekeri with 5-6 in posterior row, and only 3-4 in anterior row.

LeNGTH: Original lengths are given as male $1.70 \mathrm{~mm}$., female 2.20 $\mathrm{mm}$.

Range: Probably Channel Islands of Santa Barbara County, California.

\section{GENUS CONORHINOPSYLLA STEWART}

1930. Conorhinopsylla Stewart. Canad. Ent. 62:178.

Genotype: Conorhinopsylla stanfordi Stewart 1930

In establishing this genus Stewart characterizes it as follows:

There is no frontal notch on head. At antero-ventral angle there is prominent cone-shaped protuberance. Genal process extends slightly posterior to eye and is subacutely pointed. Bristles of second antennal segment are very short and fine. Club of antenna distinctly segmented all around. Two rows of bristles on frons. Eyes present but only lightly pigmented. Rostrum about equals fore trochanter in length. Labial palpi 5-jointed. Some investigators count as many as 8 segments. No genal comb. Comb of about 12 teeth and single transverse row of bristles on pronotum. Two rows of bristles arm meso- and metanotum. Metepisternum very small. Two rows of bristles on each of second to seventh abdominal tergites. Three antepygidial bristles in female, one in male. Four pairs of lateral plantar bristles and proximal ventral pair on fifth tarsal segment of each leg.

Single species in this genus which in West has been reported only from Utah.

\section{Conorhinopsylla stanfordi Stewart 1930}

1930 Conorhinopsylla stanfordi Stewart, Can. Ent., 62:178.

This species was described from 3 males and 2 females collected at Ithaca, New York, October 28, 1927, off Tamiasciurus hudsonicus (red squirrel) by Dr. J. S. Stanford.

Head, thorax, abdomen and leg characteristics were set down in generic consideration.

Modified Segments: The process of the clasper is very inconspicuous. There are no acetabular bristles. Manubrium short and stout; acutely pointed at its upturned tip. Finger very large and roughly diamond-shaped. At upper apex a small group of minute bristles and 


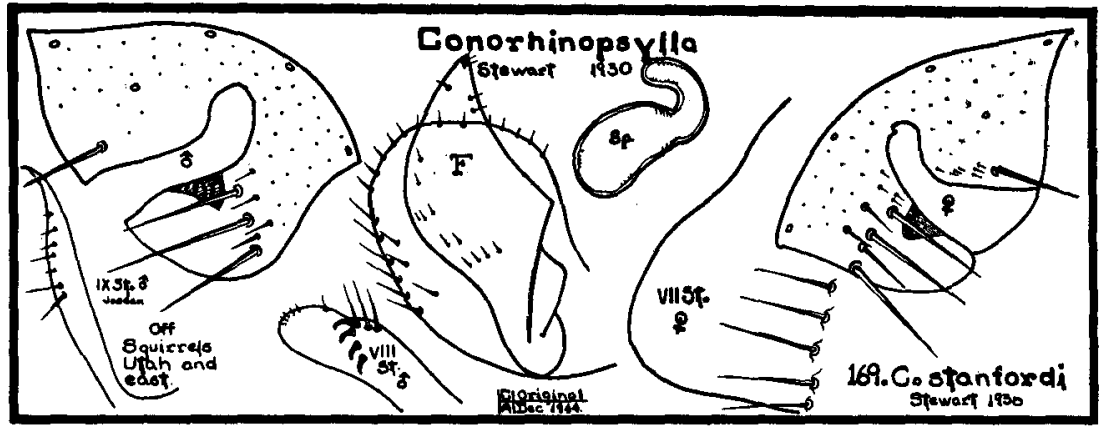

just below posterior angle a group of considerably larger bristles. VIII st. long and club-shaped at distal extremity, where there are 3 prominent stout teeth, dorso-anterior to which are 2 much smaller teeth. Between these two groups of teeth are about 4 bristles. IX st. is gradually curved upwards toward distal end and subacutely pointed; there are numerous bristles along ventral margin. Female: VII st. with posterior margin not incurved. Spermatheca large and characteristically shaped and proportioned.

LENGTH: Original lengths, male $1.78 \mathrm{~mm}$, female $2.25 \mathrm{~mm}$.

Range: Apparently this flea ranges from Rocky Mountains east to Atlantic coast.

RECORDS: In West this flea is known only from single record recorded as off Citellus $t$. mollis (soft-haired sage squirrel) collected at Salina, Sevier County, Utah.

\section{GENUS DELOTELIS JORDAN}

1937. Delotelis Jordan. Nov. Zool., 40:

\section{Genotype: Ceratophyllus telegoni Rothschild 1905}

Similar to Catallagia, but with 3 genal rows of bristles, a greatly expanded finger in male, and a very large characteristic spermatheca in female, which does not have tail projecting into the body. Eye vestigial. Pronotal comb of about 14 teeth.

Single species in genus is found in West primarily in nests of $\mathrm{Mi}$ crotus (meadow mice) and Peromyscus (deer mice).

\section{Delotelis telegoni Rothschild 1905}

1905 Ceratophyllus telegoni Rothschild, Nov. Zool., 12:172.

1905 Odontopsyllus telegoni Baker, Proc. Nat. Mus., 29:146.

1915 Catallagia telegoni Rothschild, Ectoparasites I, p. 42.

1936 Catallagia telegoni Wagner, Can. Ent., 68:203.

1937 Delotelis telegoni Jordan, Nov. Zool., 40:267.

At time of describing, Rothschild had before him 3 males and 3 females of this species, all collected by G. F. Dippie; 2 females off Evotomys gapperi (red-backed mouse), in Alberta, Canada, on October 
6,1903 , the rest of the specimens off Microtus drummondi (meadow mouse) in eastern British Columbia, Canada, October 14, 1903.

This species is probably one of most characteristic of the Catallagialike fleas, as far as modified abdominal segments are concerned. No other flea yet known even closely approaches their shape.

Modified Segments: Original description states: MALE: VIII t. very short, sternite enlarged bearing at apical edge a row of bristles of which those standing near the angle are very long. Process of clasper triangular, bears very long bristles along its distal edge. Finger is enormously elongated. It bears numerous fine long hairs along its edge. Manubrium is nearly straight. Vertical and horizontal portion of IX st. bent toward each other, forming acute angle, which, however, is rounded off. Right and left halves quite separate from each other, except at angle, each side of body having its own "boomerang." This sternite bears at its apex one short stout spine, and below it some fine

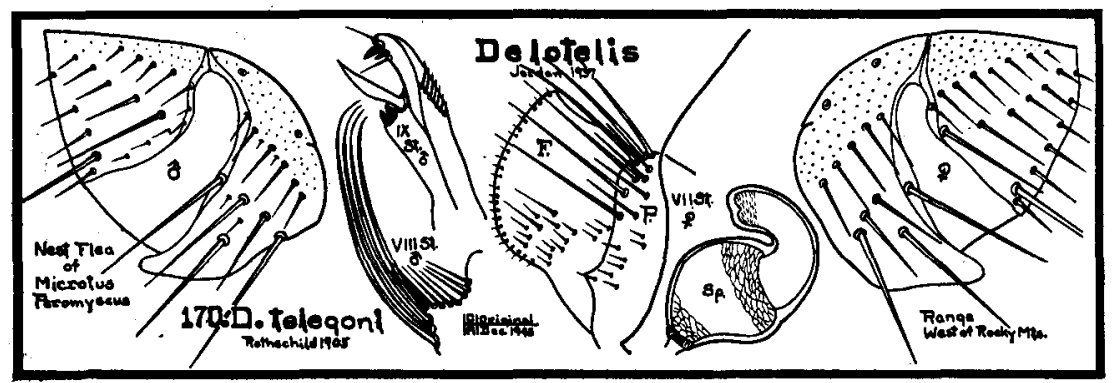

hairs, and further proximad 2 peculiar curved bristles, which are very pale, being apparently flat. Still further toward body a membranous flap projects from sternite, bearing at apex some variable spines, which are curved toward each other like bent fingers of hand. At and near upper edge sternite bears row of hairs. FeMALE: VII st. is shallowly biemarginate. VIII t. bears a row of short bristles from dorsal edge down ward and an apical ventral patch of bristles. VIII st. is pointed and bears a few extremely small hairs at upper edge. Spermatheca is very characteristic and very large.

RANGE: So few records of this flea are available in American collections that it is difficult to range species, but with specimens from western Alberta and eastern British Columbia, coupled with 20 specimens personally collected by writer in northwestern Oregon, it seems likely, that range should extend westward from Rocky Mountains to Pacific Ocean in Canada, Washington, and Oregon, and perhaps California.

Host Preference: Of 20 specimens in collection of writer, only 3 were taken from host animals, other 17 from nests. Ten were taken from one meadow mouse nest, 2 from another, 3 from one deer mouse nest, one from another nest. Preference seems to be meadow mice.

Original Length: Listed as male and female, $2.20 \mathrm{~mm}$. 
Abundance: Apparently this species is a nest flea of Microtus and Peromyscus with chance distribution during almost any month of year. This rare species seems more abundant in nests of above-mentioned mice than upon hosts themselves, but even in nests they are not found consistently.

RECORDS: Original records from Canada and those of writer and one by Augustson, seem to be only records of this flea from North America. The writer's personal records are:

OREGON-Off:

Microtus townsendi Bachman (Townsend meadow mouse), Newberg, Yamhill County, April 1, 1934, 1 female

Peromyscus maniculatus gambeli Baird (Gambel's deer mouse), Odell, Hood River County, September 30, 1938, 1 female

Neurotrichus gibbsi gibbsi Baird (Gibb's shrew mole) (accidental), Gaston, Washington County, December 22, 1940, 1 female

Peromyscus maniculatus rubidus Osgood (ruddy deer mouse) (nest), Newberg, Yamhill County, Feb. 22, 1939, 2 males, 7 females; Gaston, Washington County, February 14, 1940, 1 male, 2 females

Microtus townsendi Bachman (Townsend meadow mouse) (nest), Newberg, Yamhill County, Oregon, February 22, 1939, 2 males, 7 females; Gaston, Washington County, February 14, 1940, 1 male, 2 females.

CALIFORNIA-Augustson reports this flea from Mammoth Lakes, Mono County, off:

Peromyscus maniculatus sonoriensis Le Conte (Sonora deer mouse), August, 1941, 1 female.

\section{GENUS MEGARTHROGLOSSUS J. AND R.}

1915. Megarthroglossus Jordan and Rothschild. Ectoparasites, I, p. 46.

Genotype: Megarthroglossus procus Jordan and Rothschild 1915

Labial palpus consisting of 5 segments, last one very long, slightly curved, apex posteriorly much more produced than anteriorly, quite asymmetrical. Frons with tubercle. No tuber centrale. Eye vestigial. Antennal groove continued across vertex by very thin suture in male, but absent in female. Apex of genal lobe is obtuse. Pronotum possesses comb. In metathorax episternum is partly fused with sternum, and epimerum with notum. Abdominal tergites with but one row of bristles. Mid- and hind-femora with a lateral row of bristles on inside. Tibiae without lateral bristles on inner surface. Fifth segment in all tarsi with a proximal ventral pair of plantar bristles and 4 lateral pairs. Eighth abdominal segment of male large, in general appearance similar to seventh, apart from outline of apical margin. Anal segment of male long and separated from pygidium by suture. Stylet of female short.

This western genus is represented by the following series of species and subspecies:

Megarthroglossus divisus divisus Baker 1895 from Rocky Mountains. Megarthroglossus divisus exsecatus Wagner 1936 from British Columbia. 
Megarthroglossus divisus bisetis J. and R. 1915 from New Mexico. Megarthroglossus divisus wallowensis Hubbard 1946 from Oregon. bia.

Megarthroglossus procus procus J. and R. 1915 from British Colum-

Megarthroglossus procus oregonensis Hubbard 1946 from Oregon. Megarthroglossus sicamus J. and R. 1915 from British Columbia. Megarthroglossus similis Wagner 1936 from British Columbia.

Megarthroglossus spenceri Wagner 1936 from British Columbia.

Megarthroglossus pygmaeus Wagner 1936 from British Columbia.

It is quite possible that British Columbia forms might range southward into Columbian Highlands of Washington, but no records substantiate this.

It seems impracticable to key genus Megarthroglossus at this time because 4 of the representatives are known from females only and 2 only from males. Of 4 species so far described with females, each has distinctly shaped spermatheca. In each case this organ is much more easily illustrated than described. In case of species described with males, processes of claspers are not particularly diagnostic, apical portion of IX st. and shape of finger seeming much more so.

\section{Megarthroglossus procus procus Jordan and Rothschild 1915}

1915 Megarthroglossus procus Jordan and Rothschild, Ectoparasites I, p. 47. 1936 Megarthroglossus procus Wagner, Can. Ent., 68:196.

This species was described from a small series of both sexes from Chilliwack, British Columbia, where Allan Brooks took specimens off Spilogale (little spotted skunk) during September of 1899 and off Peromyscus (deer mouse) during December of 1899.

Frons bears an eye-row of 4 bristles, first and third of which are small, second and fourth large. Row of 4 small bristles in front of this row. Eye is vestigial but slightly pigmented. Maxillary palpus reaches beyond apex of forecoxa. Pronotal comb of 12 teeth, rather far apart. Posterior apical sinus of hind coxa rather deep and lobe above it acutely pointed. In clasper of male process $P$ is large and compact, about as broad as long. It bears a number of marginal bristles, 3 of which are long. Finger $\mathbf{F}$ projects beyond apical angle of $\mathbf{P}$. Broadest near base, slightly narrower toward the apex. Bristles of finger thin, 3 considerably longer than others. IX st. broad at base of horizontal arm. Arm narrows at apex, curving upward and bearing beyond center on outer side a ventral row of 6 or 7 slender bristles, and on inner side a few small ones. In female marginal outline of VII st. strongly slanting in dorso-ventral direction, apex of segment narrow, truncate-rotundate and slightly bisinuate. Spermatheca posteriorly dilated on dorsal side of head; its broad tail, which is ventrally not separated from head, is about as long as head. 


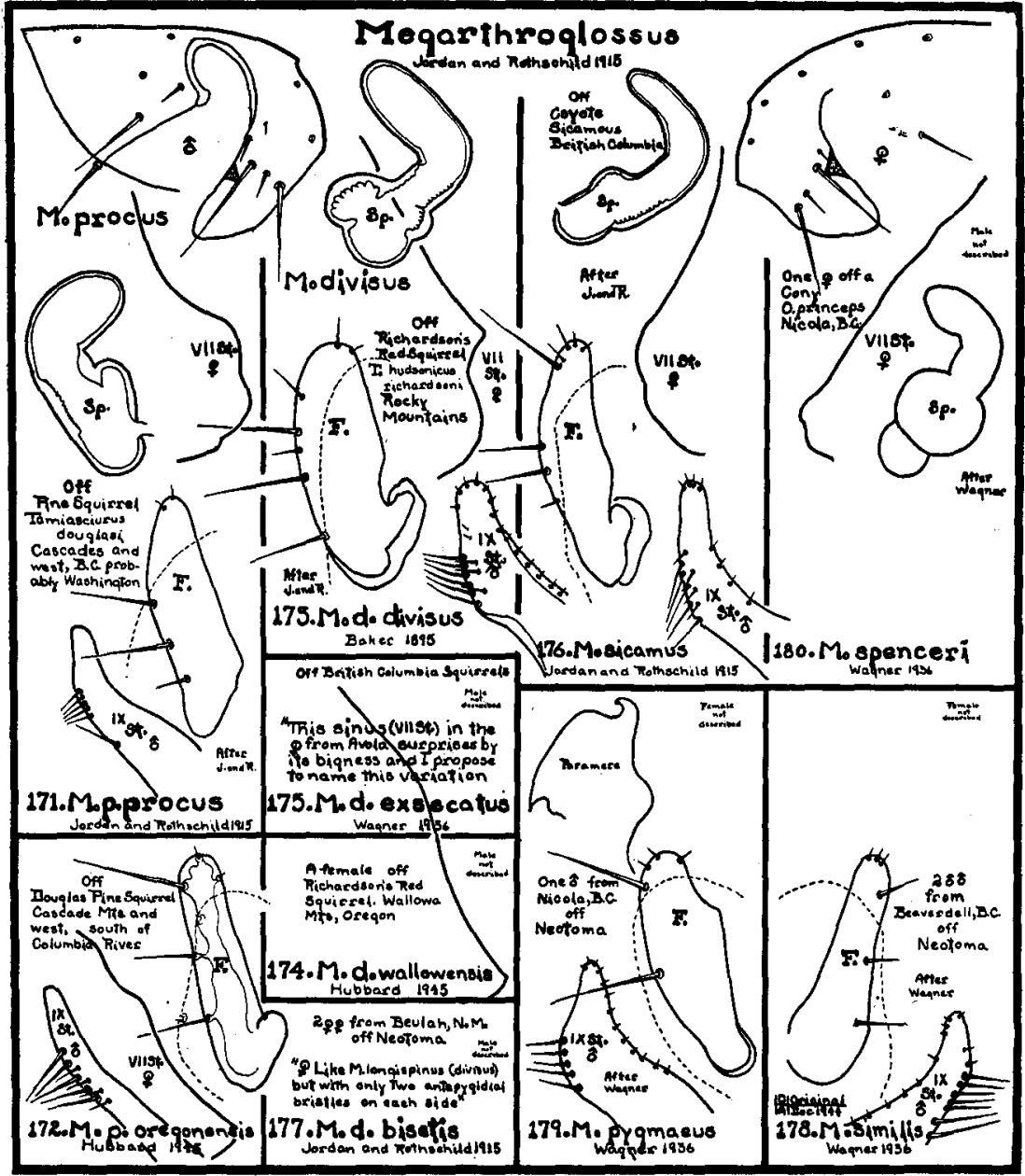

LENGTH: Not given in original description.

RANGE: From region of Chilliwack, British Columbia, the type locality, this species ranges southward probably into Washington. It is not listed from Montana.

Host Preference: Author is inclined to believe that this flea is customarily found upon Tamiasciurus douglasi (Douglas pine squirrel), that collections originally made by Brooks off Spilogale and Peromyscus were accidental occurrences.

Seasonal Distribution: Few records available lead writer to believe this insect to be a winter flea. 


\section{Megarthroglossus procus oregonensis Hubbard 1946}

A New Subspecies

There are before the writer at this time the 37 specimens listed below. Of these, 14 are males and 23 females.

This new subspecies is nearest Megarthroglossus procus $\mathrm{J}$. and $\mathrm{R}$. 1915, from which it can be distinguished by modified segments.

Head: Tubercle present. One row of 4 bristles on gena, short one alternating with very long one, these bristles not always in a straight row. A few small bristles above this row. Post-antennal region with a strong bristle half way up antennal groove and another at posterior angle.

Thorax: Pronotum with a pronotal comb of 12 well separated heavy black teeth.

Modified Segments, Male: Finger long and slender with edges about parallel and apex well rounded, whereas in $M$. procus the finger is thicker and the edges not parallel. Armature of 3 long slender bristles on posterior border and a few small bristles at apex. Apical arm of IX st. long, slender, finger-like, whereas in $M$. procus this sternite broadens considerably at base. Armature of this sternite consists of a group of 4 to 6 or more medium bristles and some smaller ones at apical bend. Female: VII st. with slanting undulate apical margin, without lobe or sinus. Females before writer do not vary in this respect. Apical outline of VII st. of $M$. procus is represented as being a large lobe, somewhat undulate in outline. Spermatheca is procus-like.

Deposits: Types are deposited in United States National Museum.

LENGTH: Specimens in collection of writer average male, $1.60 \mathrm{~mm}$., female $2.00 \mathrm{~mm}$.

Range: Throughout Cascade Mountains and west. South of Columbia River.

Host Preference: Great majority of specimens of this flea in collection of this writer are off Tamiasciurus douglasi (pine squirrels).

Seasonal Distribution: This species seems to be a distinct winter flea, coming into collections during December, January, February, and early March.

RECORDs: Typical of records in collection of writer are:

\section{OREGON-Off:}

Tamiasciurus douglasi douglasi Bachman (Douglas pine squirrel), Gaston, Washington County, March 1, 1931, 8 males, 14 females

Tamiasciurus douglasi cascadensis Allen (Cascade pine squirrel), Parkdale, Hood River County, December 11, 1938, 1 male, 3 females

Tamiasciurus douglasi albolimbatus Allen (Sierra pine squirrel), Sisters, Deschutes County, March 20, 1937, 1 male, 4 females

Glaucomys sabrinus oregonensis Bachman (flying squirrel), Forest Grove, Washington County, March 30, 1937, 1 female 
Neotoma cinerea fusca True (dusky bushy-tailed wood rat), Gaston, Washton County, January 29, 1933, 2 males

Neotoma cinerea occidentalis Baird (western bushy-tailed wood rat), Parkdale, Hood River County, October 10, 1937, 1 pair

Peromyscus maniculatus rubidus Osgood (ruddy deer mouse), Gaston, Washington County, February 13, 1938, 1 male

CALIFORNIA-On July 31,1939 , G. A. Augustson removed 1 female of this flea from Tamiasciurus douglasi albolimbatus (Sierra chickaree) at Mammoth Lakes, Mono County. He also reports it off:

Ochotona schisticeps muiri G. and S. (Yosemite cony), Duck Pass, Mono County, August 22, 1941, 1 pair; August 27, 1941, 1 male; Tully's Hole, Fresno County, August 23, 1941, 3 females; Cascade Valley, Fresno County, August 27, 1941, 4 males

Peromyscus maniculatus sonoriensis Le Conte (Sonora deer mouse), Tully's Hole, Fresno County, California, August 23, 1941, 1 female

Neosorex palustris navigator Baird (Rocky Mountain water shrew), Tully's Hole, Fresno County, August 24, 1941, 1 pair.

Augustson's records are reported as $M$. procus.

\section{Megarthroglossus divisus divisus}

Baker 1895

1895 Pulex longispinus Baker, Can. Ent., 27:132.

1898 Pulex divisus Baker, Jour. N. Y. Ent. Soc., 6:54.

1904 Ceratophyllus divisus Baker, Proc. U. S. Nat. Mus., 27:416.

1914 Ceratophyllus divisus Fox, U. S. Hygienic Lab. Bul., 97:24.

1915 Megarthroglossus longispinus Jordan and Rothschild, Ectoparasites I, p. 52.

1936 Megarthroglossus longispinus Wagner, Can. Ent., 68:195.

This species was described from material taken off a Fremont's chickaree (pine squirrel) at Georgetown, Colorado, by Professor Bruner. Jordan and Rothschild elaborated upon the description in 1915 from materials that were collected at Red Deer, Rocky Mountains, of Alberta, by A. D. Gregson off Tamiasciurus richardsoni baileyi (Richardson's pine squirrel).

This species differs from preceding in having a pronotal comb of 14 teeth. In male, finger $\mathbf{F}$ is shorter and broader than in preceding species and horizontal arm of IX st. broader; subventral lobe of VIII st. less rounded. In female, VII st. often has a very distinct apical sinus; VIII t. bears on lower portion 11 to 14 bristles on outer surface and 6 to 9 on inner. Spermatheca has a swollen collar, tail is long and hooked.

LENGTH: Female, $2.50 \mathrm{~mm}$.

RANGE: This is a Rocky Mountain species.

PreferRed Host: Rocky Mountain pine squirrels seem to be favored hosts of this insect.

Nothing is known about seasonal distribution or abundance of this flea.

Medical Importance: Eskey and Haas fed 19 specimens of this flea on plague-positive guinea pigs. Six of these became infected, one of which cleared itself of infection. There is no record of this species being found able to transmit plague. 
RECORDS: Typical records are:

CALIFORNIA-Augustson reports this flea from central Sierras off:

Tamiasciurus douglasi albolimbatus Allen (Sierra chickaree), Tully's Hole, Fresno County, August 25, 1941, 1 male.

MONTANA-This flea is reported from this state off:

Glaucomys sabrinus subsp. (flying squirrel), Ravalli County, 1935

Marmota flaviventris subsp. (woodchuck), Park County, 1938

Neotoma cinerea subsp. (wood rat), Beaverhead County, 1936, 1937, 1938;

Madison County, 1941; Park County, 1938; Ravalli County, 1932

Ochotona princeps subsp. (cony), Ravalli County, 1930.

UTAH-This species has been reported from Logan Canyon, Cache County, off: Neotoma cinerea cinerea Ord (bushy-tailed wood rat) .

ALBERTA-Jordan and Rothschild examined it off:

Tamiasciurus richardsoni baileyi Allen (Bailey's pine squirrel), Red Deer River, Rocky Mountains of Alberta, 3 males, 4 females.

\section{Megarthroglossus divisus wallowensis \\ Hubbard 1946 \\ A New Subspecies}

There is before the writer at this time only one female taken off Tamiasciurus hudsonicus richardsoni Bachman (Blue Mountain Richardson red squirrel) at Wallowa Lake, Wallowa County, Oregon, on August 6, 1938.

Spermatheca of new subspecies is divisus-like, therefore closely related to $M$. d. divisus. While the apical outline of VII st. of $M$. d. divisus is with a lobe and may be sinuate, and this outline is deeply and broadly sinuate in $M$. d. exsecatus, in new subspecies this outline is without sinus or lobe, being only slightly undulate.

LENGTH: The holotype female measures $2.50 \mathrm{~mm}$.

RANGE: Probably represents variation of $M$. d. divisus found west and south of Snake River in Blue and Wallowa Mountains of Washington and Oregon.

The holotype female bears the writer's number 1223 and is deposited in United States National Museum.

\section{Megarthroglossus divisus exsecatus Wagner 1936}

1936 Megarthroglossus divisus exsecatus Wagner, Can. Ent., 68:196.

Wagner's words on this subspecies read: "The collection of the Kamloops Laboratory contains one female from British Columbia (Avola, 2.IX.32) from Sciurus douglasi. Jordan and Rothschild point out that 'in the female (of $M$. divisus divisus) the seventh sternite often has a very distinct apical sinus.' This sinus in the female from Avola surprises by its bigness and I propose to name this variation Exsecatus var. nov. The type is No. 4112 in the Canadian National Collection, Ottawa." 


\section{Megarthroglossus sicamus Jordan and Rothschild 1915}

1915 Megarthroglossus sicamus Jordan and Rothschild, Ectoparasites I, p. 50. 1936 Megarthroglossus sicamus Wagner, Can. Ent., 68:196.

Described from Eagle River, Sicamous, British Columbia, where G. F. Dippie during September of 1903 took several males and females off Canis latrans (coyote).

Pronotal comb made up of 15 or 16 teeth with pronotum somewhat longer than in $M$. procus. In male, VIII st. is almost evenly rounded laterally instead of being produced into subventral lobe. Clasper is slightly longer, manubrium proximally broader, and finger more convex on hind side than in $M$. procus. Second long bristle of clasper is considerably shorter than upper one; horizontal arm of IX st. is broader; X st. bears on each side 3 long and 1 or 2 shorter bristles; and dorsal apical hook of paramere of penis is sharply pointed. In female VII st. has 9 or 10 bristles on each side; slanting portion of apical margin is less incurved than in $M$. procus. VIII t. bears 4 to 6 bristles above stigma, 2 or 3 long ones below it, 12 to 14 on lower portion of outer surface, and 13 to 15 on inner surface. Spermatheca has a swollen collar on the head, tail is very long and bent.

Although Sicamous, British Columbia, is almost 200 miles north of northern boundary of Washington, there is a possibility that this flea might be found in the northern Columbian Highlands of Washington, but there are no records to substantiate this range.

\section{Megarthroglossus divisus bisetis Jordan and Rothschild 1915}

1915 Megarthroglossus bisetis Jordan and Rothschild, Ectoparasites I, p. 54.

The original statements for this species are:

"FeMaLE. Like M. longispinus (divisus), but with only 2 antepygidial bristles on each side, the upper bristle being a little (one-fifth or onesixth) longer than the lower one. The pronotal comb contains 16 spines. The spermatheca, which, unfortunately, is collapsed in both our specimens, is similar to that of $M$. longispinus (divisus), but the head is more regularly rounded, and the tail apparently somewhat shorter.

"We have 2 females from Beulah, New Mexico, obtained by Professor T. D. A. Cockerell on Neotoma spec. in August, 1900."

\section{Megarthroglossus similis \\ Wagner 1936}

1936 Megarthroglossus similis Wagner, Can. Ent., 68:196.

The description of this species reads as follows:

"According to the structure of genitalia $M$. similis occupies a position between $M$. procus and $M$. longispinus (divisus). Acetabular- 
bristle well developed. The form of gonopod, as in $M$. divisus, but finger located as in M. procus. Posterior margin of gonopod slightly concave. IX st. as in $M$. procus, but the horizontal part comparatively longer and the apical end, bent up, wider. Fifth segment of the fore tarsi with 3 , of the hind tarsi with 2 plantar bristles anterior to the claws. Spencer's collection contains 2 males from Neotoma cinerea occidentalis (Beaverdell, B. C. 23, XI. 30) .

This species with type locality at Beaverdell, British Columbia, only about 50 miles north of Washington's north boundary, could easily range south in to Washington, but to this date no records are available for United States.

\section{Megarthroglossus pygmaeus Wagner 1936}

1936 Megarthroglossus pygmaeus Wagner, Can. Ent., 68:196.

The following statements appear in the original description of this species:

"The Kamloops collection contains one male from Neotoma cinerea (wood rat) (Nicola, B. C., 25. VIII.32.). Very near to $M$. divisus and $M$. sicamus, but differs from them in certain details of structure of genitalia. (Wagner stated that he was not sure whether this species was distinct, as there is a named species, known only by 2 females, $M$. bisetis Jordan and Rothschild 1915, found also on Neotoma-in New Mexico which is also stated to be near $M$. divisus.) Apical margin of VIII st. with a lateral ventral rounded salience less protruding than in $M$. $d i$ visus. Finger with distinct angle on the anterior margin approximately on level between apex and middle third. Apex of horizontal arm of IX st. more narrow than in $M$. divisus and $M$. sicamus. Paramere with dorsal hook as in $M$. sicamus, but in addition at ventral margin there is a sharp claw shaped salience, directed towards base of penis. Holotype is No. 4113 in Canadian National Collection, Ottawa."

In so far as type locality, Nicola, British Columbia, is only about 100 miles north of Washington border, this species could be found in northern Washington, but it has not yet been so recorded.

\section{Megarthroglossus spenceri \\ Wagner 1936}

1936 Megarthroglossus spenceri Wagner, Can. Ent., 68:196.

The short description of this species reads as follows:

"Differs from $M$. similis as follows. The occiput of the head with 1 bristle only, corresponding on anglebristle (i.e., the inferior of posterior margin row). Metanotum very short with only 4 bristles on each side, 
VI t. with 5, the VII with 3 bristles on each side. On the outer surface of the hind femora in their proximal half no bristles. One of the apical bristles of the II segment of the hind tarsi reaches to $2 / 3$, the other to $1 / 3$ of the $\mathrm{V}$ segment. The last tarsal segment of the fore legs bears 4 , of the hind legs 3 subapical plantar bristles, placed in one cross-row. VII st. considerably narrower backwards with a rounded apical angle near the ventral middle line. Spermatheca as in $M$. divisus, but the distal half of the reservoir spheric. Holotype, 1 female from Ochotona princeps Bangs, Nicola, British Columbia (26.VIII.32) in Coll. Spencer."

Although the type locality for this species is not much over 100 miles north of the Washington border, this species has not yet been recorded from this state.

\section{GENUS STENISTOMERA ROTHSCHILD}

1915. Stenistomera Rothschild. Nov. Zool., 22:307.

Genotype: Typhlopsylla alpina Baker 1895

During October of 1942 Dr. Newell E. Good released in Proceedings of the Entomological Society of Washington, Vol. 44, p. 131, an interesting article on the reevaluation of the genus Stenistomera. Following are characteristics which he enumerates for this interesting genus: It seems to combine characteristics of Peromyscopsylla and Callistopsyllus. Deep, usually oblique sulcus connecting antennal grooves. Eyes absent or vestigial. No genal comb but bristles of preantennal region as well as those of occiput and fore coxa numerous and usually enlarged toward their bases. Head helmet-shaped. Scape of antenna broad and extends as semi-transparent sheath over flagellum. Labial palpus, 4 segmented. Pronotal comb of 17 to 21 teeth. Along anterior margin of mesonotum, under pronotal comb, there are a number of small spinulets or minute teeth. Legs long and slender, hind coxa very narrow and first hind-tarsal joint nearly or quite as long as hind tibia. Bristles on second hind-tarsal joint do not extend past apex of third joint. Fifth joint of hind tarsi bears 5 pairs of plantar bristles, of which first pair is set downward and inward between second pair. Three antepygidial bristles in both sexes.

The genus holds 2 species which can be separated in following key.

Key to the Species of Stenistomera

A. Head bristles abnormally swollen

S. alpina, p. 305

B. Head bristles about normal in size

S. macrodactyla, p. 306 


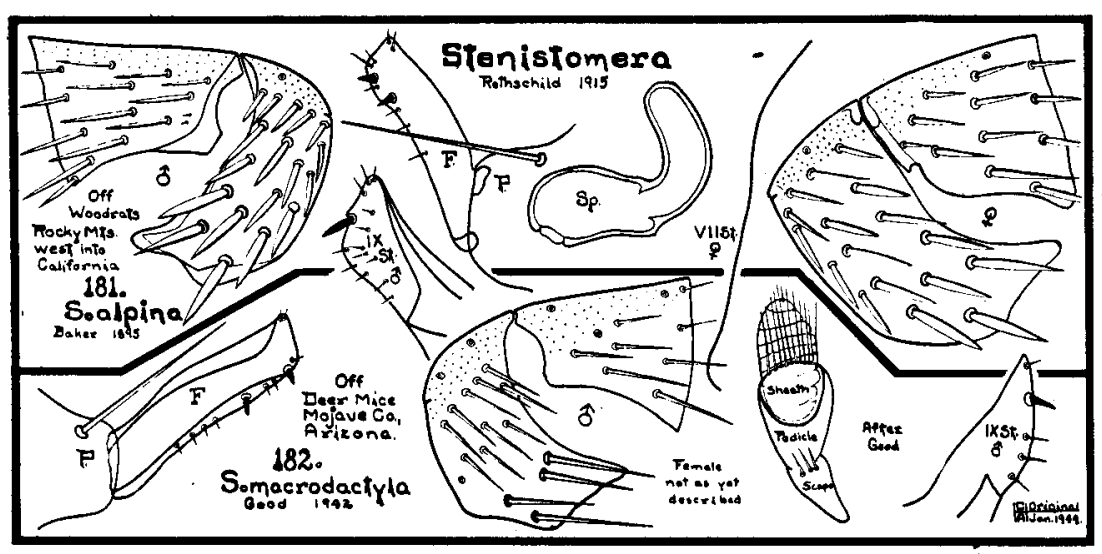

181. Stenistomera alpina

Baker 1895

1895 Typhlopsylla alpina Baker, Can. Ent., 27:189, 191.

1904 Ctenopsyllus alpinus Baker, Proc. U. S. Nat. Mus., 27:427.

1915 Stenistomera alpina Rothschild, Nov. Zool., 22:307.

1941 Delotelis mohavensis Augustson, Bul. So. Calif. Acad. of Sci., 40:138.

1942 Stenistomera alpina Good, Proc. Ent. Soc. Wash., 44:133.

This species was described from specimens taken off a "mountain rat" (probably Neotoma cinerea) collected at Georgetown, Clear Creek County, Colorado.

Enlarged bristles on bullet shaped head of this blind flea mark it from all other species. There are 5 rows of these on the pre-antennal region and 3 on the post-antennal region in both sexes.

Modified Segments, Mare: Process of clasper inconspicuous but finger $\mathrm{F}$ conspicuous and characteristically shaped and armed. Somewhat rectangular but slightly bent. Two short black spiniforms at posterio-ventral angle and a few short bristles along posterior border. IX st. is apically triangular with a black spiniform near apex and a number of short bristles over this surface. Female: VII st. with posterior face practically straight. Spermatheca not characteristic but as in many fleas with somewhat barrel-shaped body and tail crooked.

Range: Until Augustson reported this flea from the Mojave Desert of Kern County, California, off a wood rat this species was considered to be a Rocky Mountain species. It now appears that this flea must range south from Montana in Rocky Mountains, then west through Arizona, Nevada, and into southern California.

PReferred Host: While most of known specimens of this species are off Neotoma (wood rat), an occasional specimen is reported off Peromyscus (deer mouse). 
Records: Thirty-one specimens in collection of Plague Suppressive Measures Laboratory are reported by Good as follows:

MONTANA-Off:

Neotoma cinerea subsp. (western bushy-tailed wood rat), Miles City, Custer County, March 28, 1939, 9 females; Jeffers, Madison County, May 18, 1938, 2 females.

COLORADO-Off:

Neotoma micropus micropus Baird (Bairds wood rat), Walsenburg, Huerfano County, June 29, 1940, 1 female

Neotoma cinerea subsp. (wood rat), Meeker, Rio Blanco County, June 28, 1938, 1 female

Neotoma albigula warreni Merriam (Warren wood rat), Delhi, Las Animas County, June 20, 1941, 1 male, 3 females.

WYOMING-Off:

Neotoma cinerea subsp. (bushy-tailed wood rat), Green River, Sweetwater

County, August 23, 1938, 1 male.

NEW MEXICO-Off:

Neotoma albigula subsp. (wood rat), Glorieta, Santa Fe County, May 27, 1939, 2 pairs.

ARIZONA-Off:

Neotoma lepida stephensi Goldman (Stephens' wood rat), Springerville, Apache County, September 26, 1938, 2 females; Williams, Coconino County, April 20, 1939, I female; Holbrook, Navajo County, May 10 , 1939, 2 pairs

Peromyscus maniculatus subsp. (deer mouse), Red Lake, Coconino County, April 30, 1938, 1 male; Holbrook, Navajo County, May 10, 1939, 1 female.

UTAH-This species is reported from Salina, Sevier County, off:

Neotoma c. cinerea Ord (gray bushy-tailed wood rat)

Neotoma desertorum Merriam (desert wood rat)

Peromyscus maniculatus spp. (deer mouse).

CALIFORNIA-Under the designation Delotelis mohavensis Augustson reports this flea from 10 miles southwest of Mojave, Kern Couvty, off:

Neotoma lepida lepida Thomas (Thomas' wood rat), October 5, 1941, 1 pair.

\section{Stenistomera macrodactyla \\ Good 1942}

1942 Stenistomera macrodactyla Good, Proc. Ent. Soc. Wash., 44:135.

This species was described from 3 males taken off Peromyscus eremicus (deer mouse) collected 21 miles south of St. George, Utah, in Mojave County, Arizona, on April 27, 1938. This locality is north of Colorado River.

Bristles of head are almost normal, not so swollen as in S. alpina. Head bullet-shaped, frons projecting. Frontal tubercle very small, frontal notch shallow. Eye absent. Frontal row contains 5 or 6 bristles; 8 or 9 others on preantennal region slightly enlarged and irregularly placed. Three rows of bristles on postantennal region.

Modified Segments: Process of clasper inconspicuous; finger F somewhat rectangular but not noticeably curved, large, about twice as 
long and broad as finger of S. alpina. Two short black spiniforms at posterio-ventral angle. A few small bristles between and below spiniforms. IX st. is broad at base, curved upward and tapering evenly to pointed apex. Posterio-ventral face with a sharp black spiniform and several short bristles.

This species is known only from original 3 male specimens. Female is unknown. Nothing is known about range or seasonal distribution of species.

\section{GENUS TRICHOPSYLLOIDES EWING}

1938. Trichopsylloides Ewing. Proc. Ent. Soc. Wash., 40:49.

1939. Phaneris Jordan. Nov. Zool., October, 41:317.

Genotype: Trichopsylloides oregonensis Ewing 1938

Generic characteristics as amended here by the writer are: Head rather short. Frons has an evenly and broadly out-curved margin. Frontal tubercle small, notch missing. Eyes absent. Palpus 5-segmented, not reaching apex of coxa I. Maxilla produced ventrally into a long spinelike process. Antennal club short, segmentation more distinct on posterior than on anterior side; bristles on end of second antennal segment minute.

Armature of Head: Gena with 2 to 4 small apical spinelets-omitted in original description-(these are not genal teeth and do not make up a genal comb). Preantennal region with 2 rows of bristles, post antennal region with 3 rows.

Pronotum shorter than mesonotum, with a single transverse row of bristles. Pronotal comb occupying only part of posterior margin of pronotum. Mesepisternum separated from mesepimeron by an inner chitinous ridge. Upper sclerite of metepisternum fused with metanotum; metepimeron fused along upper part of anterior end with metepisternum.

Abdomen well clothed with exceptionally long bristles. Abdominal tergites with marginal spinelets (said to be absent in original description). Antepygidial bristles, absent in males, 2 in females (said to be absent in original description). Sternal plate VIII of male large, broad, practically unmodified; sternal plate IX of male produced posteriorly into a long pair of conspicuous lobes, each of which bears a ventral, subapical tuft of small bristles; movable finger of clasper an upturned hook. Spermatheca somewhat similar to Rectofrontia and Micropsylla.

Legs slender. Coxa III without a row or patch of spinelets on inside. Last segment of each tarsus with 4 pairs of lateral plantar bristles, none of them displaced toward middle line of segment.

Ewing in erecting this genus stated that it was nearest to Trichopsylla Kolenati but Jordan in erecting the genus under the name Phaneris 
believes it to be near Rectofrontia and Micropsylla. This writer is inclined to believe as Jordan does.

Trichopsylloides is represented by but one known species which is found only upon Aplodontia (mountain beaver). This rodent ranges in Far West of North America.

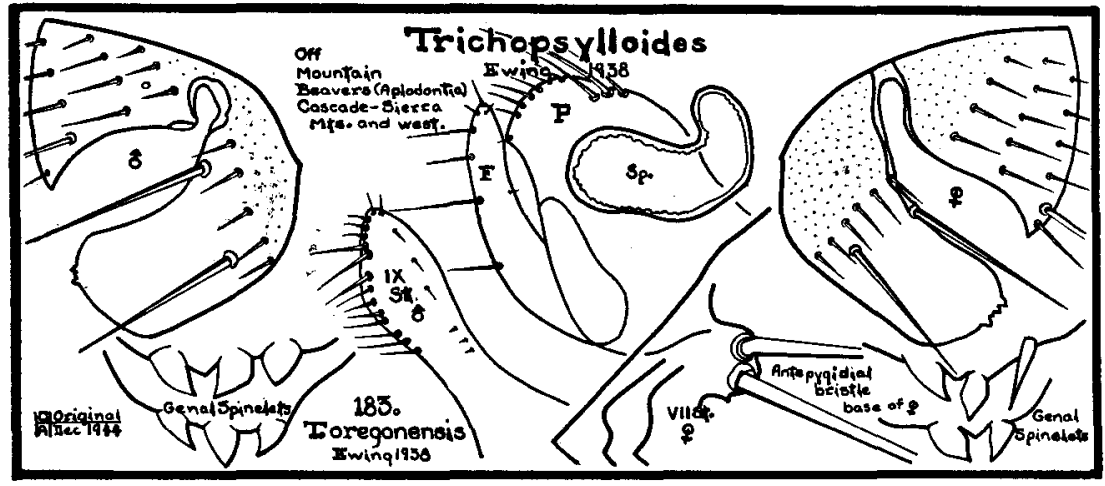

183. Trichopsylloides oregonensis

$$
\text { Ewing } 1938
$$

1938 Trichopsylloides oregonensis Ewing, Proc. Ent. Soc. Wash., 40:94.

1939 Phaneris hubbardi Jordan, Nov. Zool., October, 41:317.

1941 Trichopsylloides oregonensis Holland, Proc. Ent. Soc. B. C., No. 37.

This species was described from material collected at Delake, Oregon, off Aplodontia rufa pacifica by Stanley Jewett, Jr., June 24, 1933, and off Aplodontia rufa rainieri in Columbian National Forest, Washington, by Andy Roth on March 26, 1936. Dr. Karl Jordan described the species as Phaneris hubbardi from material collected by this writer as early as 1922 off Aplodontia rufa rufa at Seattle, Washington.

This flea is made distinct from other fleas by the extremely hairy condition of abdomen. This marks it off from all other fleas. Head is distinct from all other known western fleas because of presence of 2 or 3 apical spinelets on gena. In some cases it is necessary to remove front legs to see these apical genal spinelets. Pronotal comb with 12 teeth, decreasing in length from top downward. Typical abdominal segments each with long dorsal and ventral bristles and apical spinelets. Antepygidial bristles 2 in female, none in male. Finger $F$ of clasper of male hook-shaped. Spermatheca described as, head cylindrical, about 11/2 times as long as wide and a sausage-shaped tail of about same length. Apical margin of VII st. of female with bay toward ventral, followed dorsally by a high rounded lobe.

Original Length: Given as male, $1.80 \mathrm{~mm}$., female, $2.70 \mathrm{~mm}$.

RANGE: Apparently this flea occurs throughout the entire range of the various subspecies of Aplodontia (mountain beaver), which is south 
of Fraser River, British Columbia, and west of Great Basin region of Washington, Oregon, and California to Pacific Ocean and north of San Francisco Bay; in Sierra-Nevada Mountains to southern portion of Yosemite National Park, California.

Abundance and Seasonal Distribution: Unless a collector takes this flea during season of maximal distribution, it is very scarce. The writer's experience with this species is unique-20 years to collect 4 females and 1 male-but on April 22, 1939, he removed from 15 specimens of Aplodontia rufa pacifica at the type locality, Delake, Oregon (about sea level) 85 males and 135 females of this flea. Two weeks later these fleas had disappeared off this host at this location. Mid April and early May seems to be the season of greatest abundance for this species. At other seasons it is rare.

Host Preference: This species is a true Aplodontia (mountain beaver) flea.

RECORDS: Typical records in collection of writer for this species are: OREGON-Off:

Aplodontia rufa rufa Rafinesque (Cascade mountain beaver), Estacada, Clackamas County, July 30, 1931, 1 female

Aplodontia rufa pacifica Merriam (Coastal mountain beaver), Devil's Lake, Lincoln County, March 11, 1939, 1 female

WASHINGTON-Off:

Aplodontia rufa rufa Rafinesque (Cascade mountain beaver), Seattle, King County, June 30, 1921, 1 female

Aplodontia rufa rainieri Merriam (Rainier Mountain beaver), Skamania, Skamania County, October 29, 1933, 1 female

Aplodontia rufa olympicus Merriam (Olympic Mountain beaver), Cathlamet, Wahkiakum County, May 10, 1938, 1 female.

CALIFORNIA-Off:

Aplodontia rufa humboldtiana Taylor (Humboldt Mountain beaver), Fort Dick, Del Norte County, June 15, 1939, 1 female; Smith River, Del Norte County, August 16, 1943, 1 female.

BRITISH COLUMBIA-Holland reports a male of this species off:

Aplodontia carnivore (mink), Cultis Lake, British Columbia, November 9, 1940 , by $D$. Leavens.

\section{GENUS EPITEDIA JORDAN}

1938. Epitedia Jordan. Nov. Zool. $41: 124$.

Genotype: Ctenophthalmus wenmanni Rothschild 1904

Jordan states that this genus is like Catallagia Rothschild 1915, but with genal teeth as in Neopsylla Wagner 1903. It differs from the latter genus in that vinculum of basal abdominal sternum is absent, in that segment $\mathrm{V}$ of fore- and midtarsus bear 4 lateral pairs of plantar bristles and a proximal ventral pair, whereas this segment of hindtarsus has only the 4 lateral pairs. Spermatheca Catallagia-like with tail deeply projecting into lumen of body, or somewhat modified. Upper margin of 
propleurum with sinus where posterior end of (internal) vinculum between head and prosternite touches it; this sinus absent in Neopsylla. Abdominal terga II to III with 2 rows of bristles; VIII st. of male without bristles at or near apical margin. Marginal incrassation of metasternum longer than broad, in Neopsylla broader than long or vestigial. Pointed endoskeleton of metasternite directed straight upward, placed in between meral rods, whereas in Neopsylla it has a slightly more forward position, in mounted specimens, generally more or less directed obliquely upward-forward.

Three species of this genus are found in West. These can be distinguished from each other by:

\section{Key to the Species of Epitedia}

1. Spermatheca Catallagia-like, tail deeply projecting into lumen of body; IX st. male with about 12 black short spiniforms, E. wenmanni, p. 310 Like above but with process beside antepygidial br.

E. stanfordi, p. 312

2. Spermatheca not Catallagia-like, IX st. male armed with 4 or 5 short black spiniforms. VII st. female with rounded knob dorsal to bay

E. jordani, p. 312

\section{Epitedia wenmanni}

Rothschild 1904

1904 Ctenophthalmus wenmanni Rothschild, Nov. Zool., 11:642.

1919 Neopsylla similis Chapin, Bul. Brooklyn Ent. Soc., 14:50.

1938 Epitedia wenmanni Jordan, Nov. Zool., 41:124.

1940 Epitedia wenmanni I. Fox, Fleas of the Eastern U. S., p. 97.

This species was described from a male taken off Peromyscus leucopus (deer mouse) and a female taken off Neotoma cinerea (bushytailed wood rat) from British Columbia, Canada.

Modified SEGMENTs are distinct. IX st. of male has posterior arm wider basally than apically, and is armed with about 12 sharp, black, short spiniforms of various lengths. In female, spermatheca is Catallagia-like, tail projecting deeply into body. VII st. of female is divided by a wide sinus into 2 lobes of which upper is more acuminate and extends further distad than rounded lower one.

LENGTH: Specimens in collection of writer average male, $1.80 \mathrm{~mm}$., female $2.60 \mathrm{~mm}$.

RANGE: Apparently this flea has a very wide range in North America, listed as far east as New England States and New Brunswick. Writer has taken it at crest of Cascade Mountains in Oregon. It is reported from central California and described from British Columbia. These points would indicate a range represented by a wide swath across entire continent, this swath stopping in West at crest of Cascade Mountains.

Seasonal Distribution: While Fox states that this flea has been 


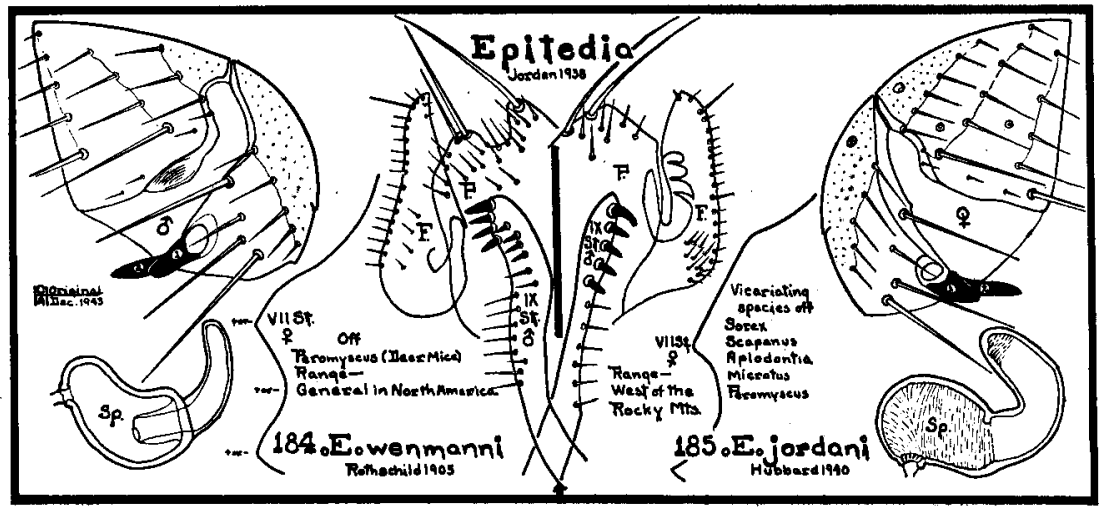

taken in eastern United States during all parts of all months of year, data of this writer for West leads him to believe this species is primarily a cool weather flea. In Great Basin region this species is seldom taken after March, but in high Cascades collections have been made in June.

Host Preference: While this species can be collected off wide variety of small rodents, it seems to distinctly prefer deer mice.

ABUNDANCE: The writer's records indicate that this species is not abundant west of Rocky Mountains.

Biology: Five females of this species collected at Mcdoel, California, March 15, 1943, all with eggs in abdominal cavity.

RECORDS: The writer records from the West:

OREGON-Off:

Peromyscus maniculatus gambeli Baird (Gambel's deer mouse), Cloud Cap Inn, Hood River County, June 7, 1934, 1 male; Summer Lake, Lake County, June 16, 1937, 1 male; Terrebonne, Deschutes County, March 4, 1940, 1 pair; Mitchell, Wheeler County, March 5, 1940, 2 females

Tamiasciurus douglasi albolimbatus Allen (pine squirrel), Sisters, Deschutes County, March 20, 1937, 1 male

Thomomys quadratus quadratus Merriam (Dalles pocket gopher), Sisters, Deschutes County, March 20, 1937, 1 male.

\section{CALIFORNIA-Off:}

Peromyscus maniculatus gambeli Baird (Gambel's deer mouse), Mcdoel, Siskiyou County, March 15, 1943, 5 females; Tule Lake, Siskiyou County, April 19, 1942, 1 female,

Augustson reports removing a male of this species off:

Peromyscus maniculatus sonoriensis Le Conte (Sonora deer mouse), Mammoth Lakes, Mono County, June 21, 1940, 1 male.

MONTANA-Off:

Citellus columbianus subsp. (Columbian ground squirrel), Silver Bow County, 1936

Citellus richardsoni subsp. (Richardson ground squirrel), Beaverhead County from host and nest, 1936; Fergus County, 1936

Peromyscus spp. (deer mouse), Ravalli County, 1938. 
UTAH-Off:

Peromyscus maniculatus subsp. (deer mouse), Logan canyon, Cache County.

NEW MEXICO-During 1919 Chapin described $N$. similis from a male taken off:

Peromyscus sp. at Lake Burford. This species proved a synonym of $E$. wenmanni.

NORTH DAKOTA-In 1937 Jordan recorded this species off:

Mustela longicauda longicauda Bonaparte (long-tailed weasel), Round Lake, McHenry County, 1 female.

\section{4a. Epitedia stanfordi \\ Traub 1944}

1944 Epitedia stanfordi Traub, Field Museum of Natural History, Zoology, 29:15:214

The original manuscript and unpublished illustrations of this species are in the hands of the author. In editing, the description was cut from 6 typewritten pages to a printed page, the illustrations were not featured. Therefore, the illustrations appear here for the first time.

According to the describer, this

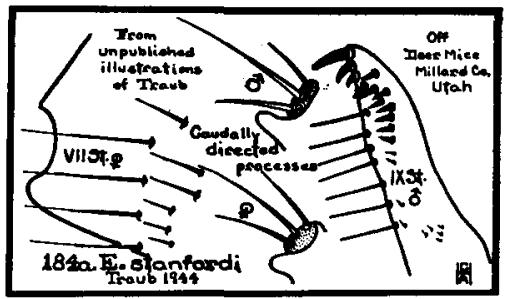
species is separated from all known Epitedia by the prominent caudally directed process immediately ventral to each group of antepygidial bristles, but is closest to $E$. wenmanni.

Two males and three females were gathered off Peromyscus truei at Fillmore, Millard County, Utah, by Leatham and Stanford on October 21, 1939.

According to the illustrations in the hands of the author, this species differs from specimens of wenmanni from Oregon, California, and Washington in collections of the author primarily only in presence of caudally directed processes adjacent to antepygidial bristles. P/2 seems a trifle broader in stanfordi, but finger, IX st. in shape and armature, spermatheca and VII st. female seem about same in both species. Range, length not discussed. Types in Field Museum Natural History.

\section{Epitedia jordani \\ Hubbard 1940}

1940 Epitedia jordani Hubbard, Pacific Univ. Bul., 37:2:10.

1940 Epitedia stewarti Hubbard, Pacific Univ. Bul., 37:2:11.

Considerable difference of opinion prevails on the validity of this species. Good and Holland without specimens at hand considered it to be a synonym of Epitedia scapani Wagner. Ewing and Fox, however, with paratypes at hand, did not so suggest. According to Dr. Karl Jordan, who advised this writer upon this species before the writer de- 
scribed it as new, it differs from Epitedia wenmanni in the modified abdominal segments and from $N$. scapani Wagner in the armature of the legs.

The species is a vicariating species which seems at home on almost any mammal it can contact. MoDIFIED SEGMENTS are quite characteristic. In male posterior arm of IX st. is armed with 5 or 6 short black sharp spiniforms located in a row posteriorly and apically. Apex is not noticeably swollen. In female, spermatheca is characteristic and apical margin of VII st. has, just dorsal to ventral bay, a small rounded prominence.

LENGTH: Average for male $2.00 \mathrm{~mm}$., for female $2.15 \mathrm{~mm}$.

RANGE: West of Great Basin region. Not known from desert region of West.

Seasonal Distribution: While there seems to be a preference for cool fall, winter and spring months, also taken in cool locations throughout summer. Large number of specimens taken off moles at Cannon Beach, Oregon, during late March of 1940 might indicate species to be a nest flea of moles, with seasonal maxima during March.

Host Preference: While this species is distinctly vicariating, records in possession of writer seem to show a slight preference to moles and shrews.

ABUNDANCE: This flea is apparently not abundant, usually coming off hosts singly, occasionally in twos and threes.

Types are deposited in Academy of Natural Sciences of Philadelphia.

RECORDS: Representative of many personal records in collection of writer are:

\section{WASHINGTON-Off:}

Peromyscus maniculatus oreas Banks (Washington deer mouse), Washougal, Clark County, March 9, 1940, 1 female

Aplodontia rufa rainieri Merriam (Rainier Mountain beaver), Skamania, Skamania County, October 29, 1933, 1 female

Aplodontia rufa rufa Rafinesque (Cascade Mountain beaver), Seattle, King County, July 1, 1921, 1 male

Eutamias townsendi townsendi Bachman (Townsend's chipmunk), Spirit Lake, Cowlitz County, July 6, 1938, 1 male

Sorex trowbridgi trowbridgi Baird (Trowbridge shrew), Pigeon Springs, Cowlitz County, July, 1938, 1 female

Neurotrichus gibbsi Baird (Gibb's shrew mole), Vancouver (Hockinson), Clark County, March 14, 1940, 3 females.

OREGON-Off:

Peromyscus maniculatus rubidus Osgood (ruddy deer mouse), Cannon Beach, Tillamook County, March 22, 1940, 1 male; Brookings, Curry County, August 28, 1937, I female

Peromyscus maniculatus gambeli Baird (Gambel's deer mouse), Cultus Lake, Deschutes County, July 28, 1936, 1 female

Microtus townsendi Bachman (Townsend's meadow mouse), St. Paul, Yamhill County, March 27, 1939, 1 female

Microtus mordax abditus A. B. Howell (Tillamook long-tailed meadow mouse), Cannon Beach, Tillamook County, March 23, 1940, 1 pair

Microtus oregoni oregoni Bachman (Oregon creeping meadow mouse), Tillamook, Tillamook County, August 30, 1937, 1 female 
Microtus canicaudus Miller (gray-tailed meadow mouse), Gaston, Washington County, February 29, 1940, 2 females

Aplodontia rufa pacifica Merriam (coastal mountain beaver), Devil's Lake, Lincoln County, April 28, 1938, 1 female

Sorex palustris navigator Baird (water shrew), Cannon Beach, Tillamook County, April 8, 1939, 5 males, 1 female

Sorex obscurus bairdi Merriam (Baird's shrew), Cannon Beach, Tillamook County, March 29, 1937, 4 males, 1 female

Sorex trowbridgi trowbridgi Baird (Trowbridge shrew), Newberg, Yamhill County, April 18, 1937, 1 male, 2 females

Sorex pacificus yaquinae Jackson (Yaquina shrew), Nashville, Lincoln County, March 25, 1939, 1 female

Sorex vagrans vagrans Baird (vagrant shrew), Cannon Beach, Tillamook County, March 29, 1939, 1 male

Neurotrichus gibbsi gibbsi Baird (Gibb's shrew mole), Gaston, Washington County, March 7, 1940, 1 pair

Scapanus townsendi Bachman (Townsend mole), Cannon Beach, Tillamook County, March 21, 1940, 7 males, 4 females

Mustela cicognani streatori Merriam (Puget Sound weasel), Cannon Beach, Tillamook County, October 12, 1940, 1 male.

\section{CALIFORNIA-Off:}

Sorex pacificus pacificus Coues (Pacific shrew), Smith River, Del Norte County, June 16, 1939, 1 pair

Aplodontia rufa pacifica Merriam (Pacific Mountain beaver), Smith River, Del Norte County, August 8, 1943, 5 females.

\section{GENUS NEOPSYLLA WAGNER}

1903. Neopsylla Wagner. Horae Soc. Ent. Ross., 36:138.

Genotype: Typhlopsylla bidentatiformis Wagner 1893

In this genus there are 2 genal teeth which overlap, outer one shorter and broader. Three stout bristles in lower genal row, in upper about 5 medium ones. Eye vestigial. Occiput with 3 rows of bristles. Pronotal comb of about 20 teeth. Anterior 4 abdominal tergites with apical spinelets and 2 rows of bristles. Both male and female with 3 antepygidial bristles.

The single species of this genus found in the West can be consistently taken off ground squirrels. A second species has been described from eastern Texas off a rat.

\section{Neopsylla inopina \\ Rothschild 1915}

1915 Neopsylla inopina Rothschild, Ectoparasites, 1:30.

1936 Neopsylla inopina Wagner, Can. Ent., 68:202.

1940 Neopsylla inopina Holland, Ent. Soc. B. C., No. 36.

This species was described from 3 males taken at Calgary, Alberta, off Citellus richardsoni (Richardson's ground squirrel), April 11, 1907, by C. Garret, and 3 females taken at the same place by G. Dippie off Putorius longicaudatus (weasel) and Evotomys saturatus (red-backed mouse). It can be distinguished from other ground squirrel fleas by 


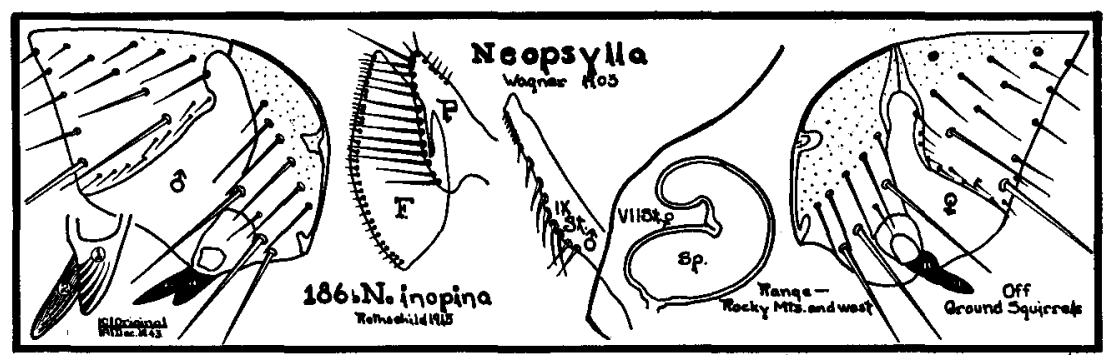

presence of two overlapping genal teeth and from other fleas generally by modified abdominal segments and long first segment of male antenna.

Modified Segments, Male: Lower apical corner of VIII st. produced into a membranaceous triangular lobe; clasper divided into short bristly dorsal lobe and larger lower one acuminate, bears fairly long bristles on ventral margin, shorter ones on the dorsal margin; finger $\mathbf{F}$ projecting beyond apex of process $\mathrm{P}$, elongate-ovate shape with apex pointed and proximal margin angulate, small bristles placed at posterior margin are much more numerous ventrally than at apex; IX st. also as characteristic, ventral arm being nearly straight, slightly curved upward beyond center and bearing a ventral row of spines from middle to apex, proximal spines long and distal ones quite short. Female: Apical margin of VII st. is broadly rounded and ventrally slightly incurved. Spermatheca is distinctly characteristic.

Range: Throughout Rocky Mountains of United States and Canada, thence west into British Columbia and into Great Basin region of Washington, Oregon, and Nevada.

Seasonal Distribution: In so far as this species seems to be a ground squirrel flea, it comes into collections only while these are out of hibernation, that is, from March through July.

Host Prefrerence: There is little doubt that this species is a true ground squirrel flea which at times can be taken off carnivores of these squirrels.

ABUndance: In comparison with other ground squirrel fleas, this species seems to be relatively scarce, except in Rocky Mountain area.

Medical Importance: This species is generally considered to be a vector of plague. Under laboratory conditions Eskey and Haas working with 2 specimens found that they became infected with plague after being fed upon plague-positive guinea pigs. No mention was made of fleas' ability to rid themselves of infection or their ability to transmit plague to healthy guinea pigs.

RECORDS in collection of the writer are: OREGON-Off:

Citellus columbianus columbianus Ord (red digger squirrel), Canyon City, Grant County, July 14, 1937, 1 female 
Citellus beldingi oregonus Merriam (Oregon ground squirrel), Silvies, Grant County, July 15, 1937, 1 female.

NEVADA-Off:

Citellus beldingi oregonus Merriam (Oregon ground squirrel), Franklin's Ranch (15 miles southeast of Denio, Oregon), Humboldt County, July 7, - 1939, 1 male.

From the Rocky Mountain area this flea is reported from

MONTANA-Off:

Citellus armatus Kennicott (Uinta ground squirrel), Beaverhead, Gallatin, Madison, and Park Counties

Citellus columbianus Ord (Columbian ground squirrel), Beaverhead, Deer Lodge, Jefferson, Lewis and Clark, Lincoln, Missoula, Powell, Ravalli, Sanders, and Silver Bow Counties

Citellus richardsoni subsp. (Richardson ground squirrel), general throughout the state

Cynomys ludovicianus Ord (black-tailed prairie dog), Blaine County

Marmota flaviventris subsp. (woodchuck), Madison, Park, and Ravalli Counties

Lepus bairdi bairdi Hayden (Rocky Mountain snow-shoe rabbit), Ravalli County

Speotyto cunicularia (burrowing owl), nest and burrows, Beaverhead County.

UTAH-Off:

Citellus armatus Kennicott (Uinta ground squirrel), Logan, Cache County.

BRITISH COLUMBIA-G. P. Holland reports (194l) this species off:

Citellus columbianus columbianus Ord (Columbian ground squirrel), Kimberly, May 14, 1938, by J. B. Poole.

NORTH DAKOTA-Jordan in 1937 reports this species off:

Citellus (Spermophilus) franklini Sabine (Franklin ground squirrel), Towner, 1 female.

\section{Neopsylla texana \\ Stewart 1930}

1930 Neopsylla texanus Stewart, Can. Ent., 62:179.

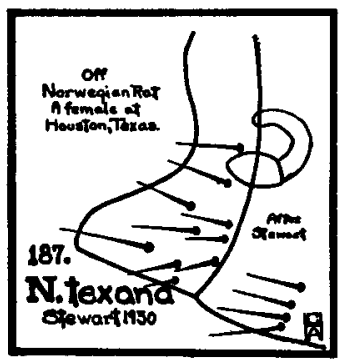

This species was described from a single female taken off Rattus norvegicus (Norwegian rat) at Houston, Texas, on January 30 , 1928 by Dr. A. C. Chandler. It has not again been recorded.

Frons broadly rounded and possesses a small frontal notch. Two genal teeth cross one another. Lower genal row of 3 bristles, middle one short. Upper genal row consists of 6 bristles.

Pronotal comb is made up of about 18 teeth.

Three antepygidial bristles on each side of abdomen.

Modified SEGments: Body of spermatheca oval, nearly twice as thick as tail and more than one-half as long. VII st. has a posterior margin somewhat incurved. VIII st. is finger-shaped. VIII t. has 4 short spine- 
like bristles and 3 longer ones. Stylet about 3 times as long as broad at base; its truncate tip possesses 1 long apical bristle and 2 smaller lateral bristles. The substylar flap is very inconspicuous but it is normally bristled.

LENGTH: Original length given as $1.96 \mathrm{~mm}$.

Range: Known only from original specimen taken at Houston, Texas.

\section{GENUS MERINGIS JORDAN}

1937. Meringis Jordan. Nov. Zool., 40:286.

1940. Atheropsylla Stewart. Pan-Pacific Ent., 16:18.

Genotype: Meringis arachis Jordan 1929

Rostrum reaches at most to three-fourths of forecoxa. Head well rounded. The 2 genal teeth overlap at base, outer shorter and broad, inner, narrow, more pointed and about one-half again as long as outer. Two rows of bristles on gena, anterior row of 3 medium and a lower row of 4 heavy ones, 3 extending slightly beyond genal teeth, second from antennal groove extending only about half way down shorter genal tooth. Post-antennal region with 3 rows of about 5 bristles each and along antennal groove some minute bristles.

Pronotal comb with 14 teeth.

Abdomen: No apical spinelets on tergites. Bristles on tergites a row of major, posterior, a row of medium, anterior, and between the major bristles a minor bristle.

Nine species of this genus are all western fleas which are found upon kangaroo rats, pocket mice, gnome mice, and as strays upon other desert mice.

As one views species side by side, it is at once noticeable that IX sts. of males are distinctly characteristic and in most cases apical margin of VII st. of females. A key based upon these characteristics will result in:

\section{Key to the Species of Meringis}

1. IX st. of male without proximal ventral lobe

a. Apex of IX st. male rounded, posterio-ventral border with 2 spiniforms dorsally, and below these 4 hair bristles evenly spaced.

VII st. female slanting, somewhat undulate, a shallow bay some distance above ventral angle

M. arachis, p. 318

b. Apex of IX st. male pointed, 2 or 3 spiniforms at posterio-dorsal angle, a gap and then several bristles below and evenly spaced.

VII st. female with angular upper lobe and a shallow bay towards ventral

M. dipodomys, p. 320

c. Apex IX st. male rounded, evenly spaced along posterio-ventral border 2 spiniforms and 5 bristles

VII st. female somewhat undulate with shallow bay at ventral 
d. Apex IX st. male flat, just below posterio-dorsal angle 1 black spiniform, then 2 fine curved bristles, then 4 hair bristles, then a stout bristle; female not described to date

M. walkeri, p. 322

2. IX st. male with proximal ventral lobe

a. Apex IX st. male rounded, above posterio-dorsal angle a black spiniform, below angle about 5 bristles evenly spaced and at proximal ventral lobe a stout bristle; female not described to date

M. jewetti, p. 322

b. Apex of IX st. male rounded, at posterio-dorsal angle a black spiniform, below it 4 bristles evenly spaced and at proximal ventral lobe a claw-like spiniform; VII st. female almost straight

$$
\text { M. parkeri, p. } 323
$$

c. Apex of IX st. male pushed over posteriorly, armed with a black spiniform and below 2 fang-like bristles; VII st. female undulate

M. jamesoni, p. 325

d. Apex of IX st. male flat, below posterio-dorsal a black spiniform and 2 spike-like bristles and below 3 bristles, proximal ventral lobe swollen and armed with a claw-like spiniform; VII st. female above a flat lobe, below it a shallow bay to ventral

M. shannoni, p. 325

e. Apex of IX st. male flattened, at posterio-dorsal angle a black spiniform, below it about 6 evenly-spaced bristles, proximal ventral lobe swollen and armed with claw-like spiniform; VII st. female with triangular lobe M. hubbardi, p. 326

\section{Meringis arachis \\ Jordan 1929}

1929 Phalacropsylla arachis Jordan, Nov. Zool., 35:37.

1937 Meringis arachis Jordan, Nov. Zool., 40:268.

1938 Meringis arachis Kohls, U. S. Pub. Health Repts., 53:1219.

1940 Meringis arachis Hubbard, Pacific Univ. Bul., 37:5:2.

Described from material taken off Dipodomys spectabilis (kangaroo rats) 30 miles south of Tucson, Arizona, by Vernon Bailey on January 30,1921 . In original description species is similar to $M$. cummingi $\mathrm{C}$. Fox, but in male bristles of VIII st. more distal; clasper with fewer bristles; finger narrower, without any bristles in lower two-fifths; apex of IX st. without proximal ventral lobe, more pointed and spiniforms nearer the point. In female apical margin of VII st. slanting, somewhat undulate, with a shallow bay at some distance above ventral angle, which is rounded off; apex of VIII t. pointed. Spermatheca similar to $M$. dipodomys Kohls but different from other Meringis, shape described originally as: ". . . as broad anteriorly as posteriorly, but thinner in the middle." In this species both male and female have 3 antepygidial bristles.

Length: Males $1.75-2.00 \mathrm{~mm}$., females $2.25 \mathrm{~mm}$.

RANGE: More eastern of the species of Meringis. Its range extends 
from southern Arizona east past Rio Grande River and on into Texas.

Host PReference: True kangaroo rat flea, but can be found occasionally as strays upon other desert mice.

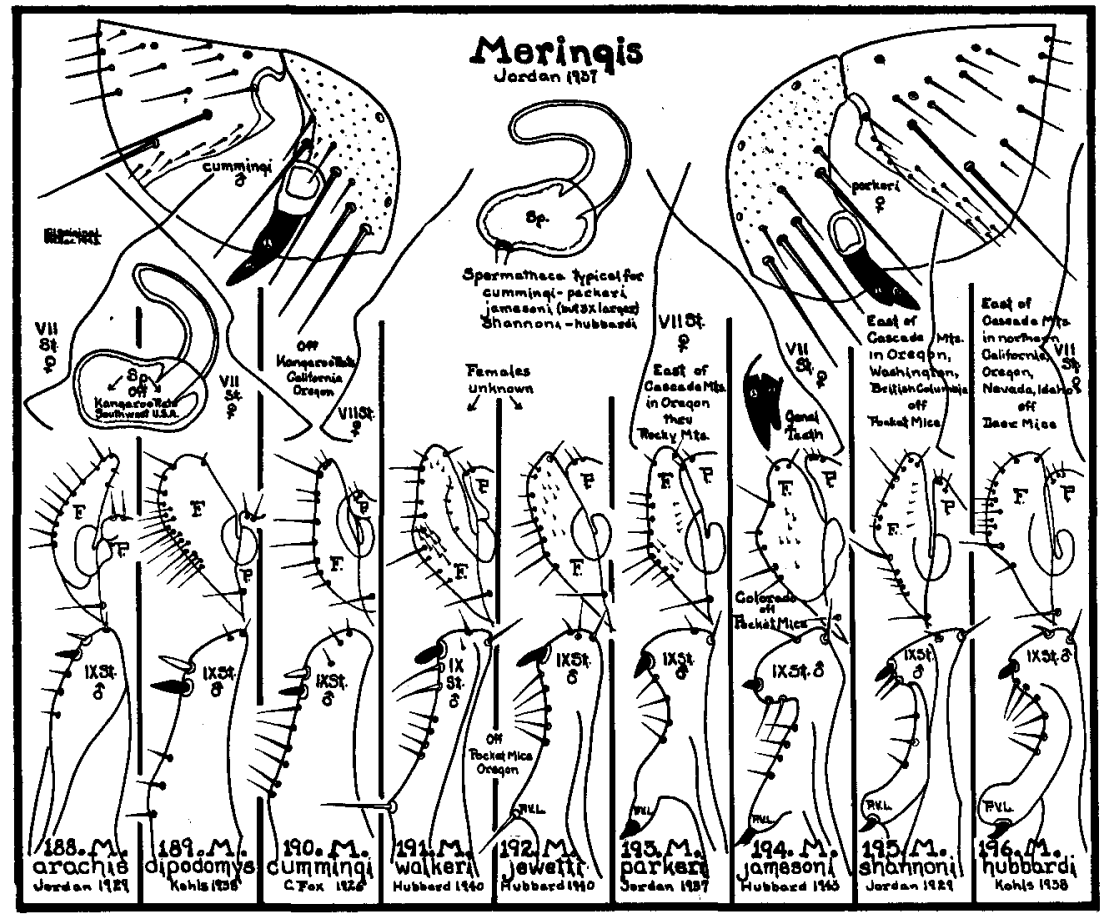

RECORDs: The writer can list only the following specimens in his collection which have been presented him by other collectors:

\section{ARIZONA-Off:}

Dipodomys spectabilis perblandis (kangaroo rat), Organ Pipe National Monument, Pima County, April 19, 1942, 1 male, 3 females

Neotoma lepida harteri (wood rat), Organ Pipe National Monúment, Pima County, April 20, 1942, 1 male.

NEW MEXICO-Off:

Dipodomys ordi subsp. (kangaroo rat), Sierra County, April 20, 1939, 1 female.

\section{TEXAS-Off:}

Neotoma sp. (wood rat), El Paso, El Paso County, February 12, 1944, I female.

The Plague Suppressive Measures Laboratory at San Francisco, California, has several hundred records of this flea from southeastern Arizona and New Mexico. One of these in collection of the writer is a male from Hidalgo county,

NEW MEXICO-Off:

Onychomys leucogaster subsp. (grasshopper mouse), April 14, 1939. 


\section{Meringis dipodomys \\ Kohls 1938}

1938 Meringis dipodomys Kohls, U. S. Pub. Health Repts., 53:1219.

1940 Meringis dipodomys Hubbard, Pacific Univ. Bul., 37:5:2.

Said to be close to $M$. arachis Jordan. Materials from which description was made came off kangaroo rats and a wood rat collected by field service of Plague Suppressive Measures Laboratory of San Francisco in Imperial and Inyo Counties, California, during the years 1935 and 1936.

Both male and female carry 3 antepygidial bristles on side. Female agrees with $M$. arachis but apex of VIII $t$. is truncate not pointed as in: $M$. arachis. VII st. has upper shallow angular lobe, followed ventrally by angular bay. Spermatheca similar to that of $M$. arachis, but different from other Meringis. In male posterior margin of process $\mathbf{P}$ of clasper is nearly straight, and is very short in relation to finger $F$, which is long, much broader than in $M$. arachis, and with apex broadly rounded. IX st. without a proximal ventral lobe and apical portion similar to $M$. arachis; very small pale cone-shaped spine and hair situated at apex; 2 or 3 spiniforms, more distal smaller, are just below ventral apical angle.

TyPes: Holotype male and allotype female in collection of Rocky Mountain Laboratory.

RANGE: Through Inyo to Imperial Counties, California, thence east throughout Arizona and into southwest New Mexico. During October of 1944 the writer discovered this southwestern flea far to north in extreme northeastern corner of California at Cedarville.

LENGTH: Males 1.75-2.00 mm., females $2.50-2.75 \mathrm{~mm}$.

Host Preference: True kangaroo rat flea, but can occasionally be found as strays on other desert mice and rats.

RECORDS of this species are:

CALIFORNIA-The writer removed from 10 specimens of

Dipodomys ordi columbianus Merriam (Columbian five-toed kangaroo rat), Cedarville, Modoc County, October 17, 1944, 13 males, 8 females,

Augustson reports this flea as follows:

Dipodomys deserti deserti Stephens (big desert kangaroo rat), Borego Desert, San Diego County

Dipodomys merriami simiolus Rhoads (allied kangaroo rat)

Onychomys torridus pulcher Elliot (desert grasshopper mouse)

Peromyscus maniculatus sonoriensis Le Conte (Sonora deer mouse), Palm Springs, Riverside County

Dipodomys sp. (kangaroo rat), Santa Rosa Mountains, Riverside County.

ARIZONA-Off:

Dipodomys merriami merriami Mearns (Merriam kangaroo rat), Organ Pipe National Monument, Pima County, April 20, 1942, 1 male; Mohave County, April 13, 1938, a pair by P.S.M.L.

Dipodomys deserti deserti Stephens (big desert kangaroo rat), Yuma County, April 9, 1938, a pair by P.S.M.L. 


\section{Meringis cummingi \\ C. Fox 1926}

1926 Phalacropsylla cummingi C. Fox, Pan-Pacific Ent., 11:182.

1937 Meringis cummingi Jordan, Nov. Zool., 40:268.

1938 Meringis cummingi Kohls, U. S. Pub. Health Repts., 53:1219.

1940 Atheropsylla bakeri Stewart, Pan-Pacific Ent., 16:19.

1940 Meringis cummingi Hubbard, Pacific Univ. Bul., 37:5:2.

Described from 1 male specimen taken off Dipodomys agilis (kangaroo rat) at Los Angeles, California, during 1925. Nothing more was heard of species until Hubbard described female in 1940 from about 50 specimens taken off Dipodomys heermanni californicus Merriam (Northern California kangaroo rat) captured in Modoc Lava Beds, Tule Lake, Siskiyou County, California, and Swan Lake Valley, Klamath County, Oregon, during June of 1939.

Both male and female have 3 antepygidial bristles on side. IX st. of male is without proximal ventral lobe and bears on posterior border at apex 2 spiniforms, lower one stoutest and blackest, and below these about 5 bristles. In female VII st. is somewhat undulate along upper two-thirds, lower third a shallow bay to ventral. Spermatheca unlike $M$. dipodomys and $M$. arachis but similar to other species of genus, and is described as being inverted pyriform (pear-shaped).

LENGTH: Original given as $1.80 \mathrm{~mm}$. in male, female $2.25 \mathrm{~mm}$.

TyPE: Holotype male in United States National Museum No. 28918.

Range: From type locality, Los Angeles, this species ranges north through California and into Oregon where its northern range and that of its northern host, Northern California kangaroo rat, is stopped by Sprague River and Klamath and Sycan marshes to north, Quartz and Winter Mountains to east, and Cascade Mountains to west.

Host Preference: A true kangaroo rat flea, but can probably be found as strays occasionally upon other desert mice.

ABUNDANCE: In spite of the fact that no specimens of this species were reported for over 15 years after the description appeared, the flea seems rather common, the writer having removed 16 from an old male kangaroo rat in Modoc Lava Beds of California and 8 from a male and 9 from a female at Swan Lake Valley, Oregon.

Recoros: The writer has taken off

Dipodomys heermanni californicus Merriam (Northern California kangaroo rat):

OREGON-Entrance of Swan Lake Valley (east of Klamath Falls), June 29, 1939, 10 males, 15 females,

CALIFORNIA-Modoc Lava Beds, Tule Lake, Siskiyou County, June 27, 1939, 12 males, 12 females.

Dipodomys microps aquilonius Willet (Suprise Valley kangaroo rat), Cedarville, Modoc County, June 5, 1945, 1 male. 
In central California under the designation Atheropsylla bakeri, Stewart recorded this flea from Jamesburg, Monterey County, off:

Dipodomys venustus subsp. (kangaroo rat), and

Neotoma fuscipes subsp. (round-tailed wood rat).

In southern California Augustson reports it from Pt. Arguello, Santa Inez Mountains, Santa Barbara County, off:

Dipodomys agilis agilis Gambel (Gambel's kangaroo rat)

Perognathus californicus ochrus Osgood (Kern pocket mouse)

Peromyscus maniculatus gambeli Baird (Gambel's deer mouse).

\section{Meringis walkeri}

Hubbard 1940

1940 Meringis walkeri Hubbard, Pacific Univ. Bul., 37:5:3.

This species was described from a single male taken off Perognathus paruus parous Peale (Oregon pocket mouse) at a point in the central Oregon desert about 15 miles south of Boardman on May 12, 1939. It is like the preceding species in that IX st. of male has no proximal ventral lobe, but resembles $M$. shannoni and $M$. hubbardi in that there are but 2 antepygidial bristles to side. Female has not yet been described.

This species differs from other Meringis in that the posterior face of IX st. is armed with 1 black spiniform at apex, followed ventrally by 2 long curved bristles, then at about middle of face and evenly spaced 4 hair-like bristles and finally at ventral a long, straight, stout bristle.

LENGTH: Large for a male Meringis, original given as $2.40 \mathrm{~mm}$.

TYPE: In United States National Museum bearing describer's No. 1398a.

RANGE: Known only from the type locality.

Host Preference: Type host listed as Oregon pocket mouse.

\section{Meringis jewetti \\ Hubbard 1940}

1940 Meringis jewetti Hubbard, Pacific Univ. Bul., 37:5:3.

This species was described from materials taken off Perognathus paruus parvus Peale (Oregon pocket mice) captured at south city limits of Baker, Oregon, on July 12, 1939. On IX st. of male it seems that proximal ventral lobe becomes expressed in its simplest condition, and unlike the other Meringis which have this lobe, it is armed with a long, straight, stout bristle rather than a black claw-like spiniform. On upper half of rather flat surface of posterior margin are about 5 evenly spaced bristles and slightly above the posterio-dorsal angle a single black spiniform. Apex of sternite well rounded and bears at tip several bristles. Female has not yet been described.

LENGTH: Original given as $2.20 \mathrm{~mm}$. 1616. 
RANGE: Known only from type locality.

Host Preference: Type host listed as Oregon pocket mouse.

Records: The writer can record only the specimens upon which the original description was based. These are from:

Perognathus parvus parvus Peale (Oregon pocket mouse), Baker (south city limits), Baker County, Oregon, July 12, 1939, 3 males.

\section{Meringis parkeri \\ Jordan 1937}

1937 Meringis parkeri Jordan, Nov. Zool., 40:269.

1938 Meringis parkeri Kohls, U. S. Pub. Health Repts., 53:1217.

1940 Meringis parkeri Hubbard, Pacific Univ. Bul., 37:5:4.

Described from material collected by field men of Dr. R. R. Parker of Rocky Mountain Spotted Fever Laboratory at Hamilton, Montana. Specimens were secured off Dipodomys sp. at Powderville, Montana.

Common kangaroo rat flea in Pacific northwest. Both male and female have 2 antepygidial bristles. In male IX st. is distinct, proximal ventral lobe which is not swollen and armed with a claw-like black spiniform. Deeply incurved posterior face of sternite is armed with about 4 bristles evenly spaced and at posterio-dorsal angle a black spiniform and at apex 2 short bristles. Female can be told from other Meringis by apical outline of VII st. which is an almost flat surface. Spermatheca is similar to $M$. cumming $i$ and body is said to be inverted pyriform broadest toward tail.

LENGTH: Average length of specimens in collection of the writer is male $2.00 \mathrm{~mm}$., female $2.30 \mathrm{~mm}$.

TyPEs: Not recorded but probably in N. C. Rothschild collection.

RANGE: South from Snake River in Washington and Columbia River in Oregon, thence throughout Great Basin region of Oregon, Nevada, Arizona, and New Mexico, and apparently through Rocky Mountain belt where there are kangaroo rats. Species not found in Klamath River drainage area of Oregon in range of Dipodomys heermani, the Northern California kangaroo rat, but in California it appears east of Warner Mountains in Modoc County.

Host Preference: True kangaroo rat flea but at times can be taken off other desert mice and pack rats.

SEAsonal Distribution: Because kangaroo rats do not hibernate, the writer has been able to take this species during every month of the year.

Abundance: Regardless of time of year kangaroo rats are examined, this flea seems to be fairly abundant upon them. While many kangaroo rats do not carry fleas when examined, the writer has removed often as many as 18 or 20 from a single individual, but by far the greater majority of those carrying fleas have only 3 or 4 . 
REcords: The author has collected this flea as follows:

OREGON-Off:

Dipodomys ordi columbianus Merriam (five-toed kangaroo rat), Hampton, Deschutes County, July 18, 1937, 5 males, 11 females,

Accidental Occurrences:

Peromyscus maniculatus gambeli Baird (Gambel's deer mouse), Terrebonne, Deschutes County, March 4, 1940, 1 male

Citellus townsendi canus Merriam (gray sage rat), Terrebonne, Deschutes County, July 10, 1937, 1 male

Neotoma cinerea occidentalis Baird (bushy-tailed wood rat), Bridge Creek School, Mitchell, Wheeler County, July 12, 1937, I male

Onychomys leucogaster fuscogriseus Anthony (grasshopper mouse), Crane, Harney County, July 17, 1937, 1 male, 1 female

Perognathus parvus parvus Peale (Oregon pocket mouse), Adel, Lake County, June 28, 1937, 1 male, I female.

WASHINGTON-Off:

Dipodomys ordi columbianus Merriam (five-toed kangaroo rat), Attalia-Two Rivers, Walla Walla County, May 11, 1939, 1 male.

CALIFORNIA-Off:

Peromyscus maniculatus gambeli Baird (Gambel's deer mouse), Eagleville, Modoc County, October 16, 1944, 1 male.

NEVADA-Off:

Dipodomys ordi columbianus Merriam (five-toed kangaroo rat), Coleman's Ranch, Washoe County (25 miles southeast of Adel, Oregon), June 27, 1937, 1 male, 3 females; Franklin's Ranch, Humboldt County (I5 miles south of Denio, Oregon), July 5, 1939, 2 males, 3 females; McDermitt, Humboldt County (15 miles south), July 8, 1939, 2 males

Dipodomys ordi subsp. (kangaroo rat), Pyramid Lake, Washoe County, June 19, 1944, 2 males; Carson City, Ormsby County, June 26, 1944, a series; Minden, Douglas County, June 26, 1944, 3 males; Yerington, Lyon County, July 12, 1944, 1 pair; Wells, Elko County, July 6, 1944, 1 male, 3 females

Perognathus parvus parvus Peale (Oregon pocket mouse), Coleman's Ranch, Washoe County, June 27, 1937, 1 female

Peromyscus maniculatus sonoriensis Le Conte (Sonora deer mouse), Coleman's Ranch, Washoe County, June 27, 1937, 1 male

Onychomys leucogaster fuscogriseus Anthony (grasshopper mouse), Frank. lin's Ranch, Humboldt County, July 5, 1939, 1 male

Citellus beldingi oregonus Merriam (Oregon ground squirrel), Franklin's Ranch, Humboldt County, July 5, 1939, 1 female.

IDAHO-Off:

Dipodomys ordi columbianus Merriam (Columbian five-toed kangaroo rat), Rogerson, Twin Falls County, July 15, 1945, 5 males, 26 females; King Hill, Gooding County, July 17, 1945, 10 males, 14 females.

UTAH-The author collected this flea off:

Onychomys leucogaster melanophrys Merriam (dark-brown grasshopper mouse), Kanab, Kane County, July 9, 1945, 1 male.

Dipodomys ordi spp. (kangaroo rat), Rubys Ranch, Bryce Canyon, Garfield county, July 10, 1945,2 pair.

Perognathus apache apache Merriam (Apache pocket mouse), Rubys Ranch, Bryce Canyon, Garfield County, July 10, 1945, I female. 


\section{Meringis jamesoni \\ Hubbard 1943}

1943 Meringis jamesoni Hubbard, Pacific Univ. Bul., 39:9:2.

This species was described from 2 males and 4 females collected in Alamosa County, Colorado, (type locality) off Perognathus flavus flavus Baird (type host) by J. E. Hill and P. E. Crowe during August, 1940.

The monstrosic appearance of IX st. of male immediately marks males of this species from other Meringis. In both male and female 2 genal teeth differ in arrangement from most other Meringis, that is roots instead of being one under other are not superimposed but long slender tooth has its root anterior to broad shorter tooth. Spermatheca is very large. VII st. of female is suggestive of $M$. parkeri Jordan.

Head: As in other Meringis lower genal row of 4 stout bristles, upper row of 3 or 4 medium bristles, genal teeth 2 arranged as stated above. Postantennal region with 3 rows of bristles but with more bristles to the row than in other Meringis.

Modified Segments, Male: IX st. seems monstrosic in that apex looks crushed down against body; apical black spiniform small, below and under it 2 fang-like curved bristles, then on posterior 4 short bristles evenly spaced; posterior-ventral lobe not swollen, armed with thumb and nail-shaped black spiniform. Finger of clasper broader than other Meringis. Female: Posterior face of VII st. almost flat, VIII st. has upper lobe projecting well beyond lower lobe, valley between. Spermatheca as in $M$. parkeri, shannoni and hubbardi but 3 times as large.

Length: Male $2.00 \mathrm{~mm}$., female $2.50 \mathrm{~mm}$.

SeAsonal Distribution and Range for this species are unknown.

TyPE: Holotype male and allotype female are deposited in United States National Museum.

\section{Meringis shannoni Jordan 1929}

1929 Phalacropsylla shannoni Jordan, Nov. Zool., 35:38.

1937 Meringis shannoni Jordan, Nov. Zool., 40:269.

1938 Meringis shannoni Kohls, U. S. Pub. Health Repts., 53:1217.

1940 Meringis shannoni Hubbard, Pacific Univ. Bul., 37:5:4.

1941 Meringis shannoni Holland, Pro. Ent. Soc. B. C., No. 37.

Described from material gathered during last half of 1920 by Shannon and Lane off various desert mice around Lind and Ritzville, Washington.

Differs from the preceding species in that male has a swollen proximal ventral lobe on IX st. Lobe is armed with a black claw-like spiniform. Along concave surface of posterior face of this sternite are about 3 bristles evenly spaced and to dorsal at posterior dorsal angle 2 stout spike-like bristles and above them a black spiniform. There are 2 bristles at apex of sternite. In female apical margin of VII st. is nearly 
vertical, its upper angle rounded and slightly projecting. Body of spermatheca is of inverted pyriform type. Male has 2 antepygidial bristles, female 3 , to side.

LENGTH: Specimens in collection of the writer average, male 2.00 mm., female $2.30 \mathrm{~mm}$.

Type: Deposited in United States National Museum.

Range: Throughout British Columbia, Washington, Oregon, and probably Nevada, where there are Perognathus (pocket mice), with exception of Klamath drainage basin of Oregon.

Host Preference: This species is a true Perognathus (pocket mouse) flea but can also be taken from other desert mice as strays.

Seasonal Distribution: In so far as pocket mice seem to hibernate or at least keep to their burrows during the cold months of winter, this species of flea can generally be taken only during spring and summer. The season of greatest abundance seems to be in May.

ABUndanCE: During May large numbers of this species can be taken off practically all pocket mice, and grasshopper mice, the grasshopper mice probably use pocket mice for food, thus carry fleas as strays. After May through summer, numbers of this flea coming into collections become less and less, and finally disappear altogether to show up again when pocket mice come out of hibernation in spring.

Following are representative records of many in collection of the writer:

WASHINGTON-Off:

Perognathus parvus parvus Peale (Oregon pocket mouse), 10 males, 15 females Onychomys leucogaster fuscogriseus Anthony (grasshopper mouse), 8 males, Peromyscus maniculatus gambeli Baird (Gambel's deer mouse), 1 male, Mabton, Yakima County (15 miles south), May 28, 1938.

OREGON-Off:

Perognathus parvus parous Peale (Oregon pocket mouse), 18 males, 22 females Onychomys leucogaster fuscogriseus Anthony (grasshopper mouse), 9 males, Peromyscus maniculatus gambeli Baird (Gambel's deer mouse), I male, Boardman, Morrow County (15 miles south), May 12, 1939

Dipodomys ordi columbianus Merriam (five-toed kangaroo rat), Mitchell, Wheeler County, May 13, 1939, 2 males, 2 females.

BRITISH COLUMBIA-G. P. Holland reports (1941) this species off:

Perognathus lordi lordi (pocket mouse)

Peromyscus maniculatus artemesia (deer mouse), Okanagan Landing, August $10,1940$.

\section{Meringis hubbardi \\ Kohls 1938}

1938 Meringis hubbardi Kohls, U. S. Pub. Health Repts., 53:1217.

1940 Meringis hubbardi Hubbard, Pacific Univ. Bul., 37:5:4.

Described from a male taken off a cottontail rabbit (accidental occurrence) captured at Mayfield, Idaho, June 25, 1932, and a female collected off a kangaroo rat in Elko County, Nevada, during September of 
1936, and a series of 12 paratypes handed describer by this writer for study. Species is described as being close to M. shannoni.

Original description states that apical portion of IX st. of male is like that of $M$. parkeri, but having, however, 6 or 7 bristles instead of 5 along ventral margin posterior to ventral apical spiniform. Two stout spike-like bristles immediately posterior to this spiniform in $M$. shannoni are absent. Proximal ventral lobe of this sternite has a stout clawlike spiniform, and margin of lobe immediately posterior to spiniform dilated ventrally and smoothly rounded. Male has 2 antepygidial bristles to side. In female, apical margin of VII st. is developed into a distinct triangular lobe. Spermatheca has body of inverted pyriform type. Three antepygidial bristles to side in female.

LENGTH: Average about $1.80 \mathrm{~mm}$. for males, females $2.20 \mathrm{~mm}$.

Types: Holotype male and allotype female deposited in collection of Rocky Mountain Laboratory.

RANGE: At least in the north, coincides very closely with that of $M$. parkeri, that is, south of Columbia and Snake Rivers in Oregon and Washington, east of east base of Cascade Mountains, through Oregon, Idaho, south at least into northern Nevada, and northeastern California.

Host Preference: Records of writer covering almost 100 specimens seem to show no host preference, fleas coming off deer micè, pocket mice, gnome mice, and kangaroo rats with equal regularity.

SEASONAL Distribution: Writer has records for every month of year. No month or season in which they are most abundant.

Abundance: When compared to $M$. parkeri and $M$. shannoni, this species is relatively scarce, comes by ones and twos off hosts. Generally desert mice are without them.

RECORDs: Representative of the large number of records in the collection of the writer are:

OREGON-Off:

Dipodomys ordi columbianus Merriam (five-toed kangaroo rat), Adel, Lake County, June 21, 1937, 2 males

Peromyscus maniculatus sonoriensis Le Conte (Sonoran deer mouse), Narrows, Harney County, July 18, 1937, 1 male, 1 female

Peromyscus maniculatus gambeli Baird (Gambel's deer mouse), Baker, Baker County, July 12, 1939, 1 male

Peromyscus crinitus crinitus Merriam (canyon deer mouse), Narrows, Harney County, July 18, 1937, 1 male, 1 female

Microdipodops megacephalis oregonus Merriam (gnome mouse), Blitzen, Harney County, July 3, 1939, 1 male, 1 female

Onychomys leucogaster fuscogriseus Anthony (grasshopper mouse), Steen Mountains, Harney County, July 6, 1939, 2 males, 1 female

Perognathus parvus parvus Peale (Oregon pocket mouse), Baker, Baker County, July 12, 1939, 4 males, 1 female.

WASHINGTON-Off:

Perognathus lordi columbianus Merriam (Columbian pocket mouse), Lowden, Walla Walla County, July 15, 1939, 6 pairs. 
CALIFORNIA-On July 25, 1942 the writer discovered a large concentration of these fleas at Dorris, Siskiyou County, in a small pocket of sagebrush a mile south of the town on the highway. Sixteen pairs were taken off:

Peromyscus maniculatus gambeli Baird (Gambel's deer mouse).

NEVADA:

Peromyscus maniculatus sonoriensis Le Conte (Sonoran deer mouse), Coleman's Ranch, Washoe County, June 27, 1937, 2 males; McDermitt, Humboldt County, July 8, 1939, 2 males, 1 female; Wells, Elko County, July 2, 1944, 2 males, 1 female

Perognathus nevadensis Merriam (Nevada pocket mouse), McDermitt, Humboldt County, July 8, 1939, 1 pair

Perognathus paruus olivaceus Merriam (Great Basin pocket mouse), Austin, Lander County, July 10, 1944, 2 males, I female

Peromyscus maniculatus gambeli Baird (Gambel's deer mouse), Vya, Washoe County, June 16, 1944, 3 males, 1 female

Eutamias minimus pictus Allen (sagebrush chipmunk), Wells, Elko County, July 7, 1944, 1 pair.

IDAHO-Oft:

Peromyscus manucilatus sonoriensis Le Conte (Sonoran deer mouse) Rogerson, Twin Falls County, July 16, 1945, 1 male.

\section{GENUS PEROMYSCOPSYLLA I. FOX}

1939. Peromyscopsylla I. Fox. Proc. Ent. Soc. Washington, $41: 47$.

Genotype: Ctenopsyllus hesperomys Baker 1904

Head well rounded but subangulate at vertex making shape steel jacket bullet-like. Frontal-genal angle is said to be acute. Anterior margin of head armed with a series of bristles, 2, 3, or 4 at vertex thickened, heavily pigmented and modified into spiniforms. Genal teeth 2 in number, not overlapping, more or less horizontal. Genal process prominent and variable in length. Eye is vestigial. Metanotum and abdominal tergites armed with apical spinelets. Spermatheca eliptical, with tail bent over body. Finger $\mathrm{F}$ roughly triangular. Three antepygidial bristles in male, 4 in female.

This genus is represented in West by 7 species which are commonly found upon wild mice and wood rats.

If one examines these 7 species side by side, it will at. once be noted that armature and shape of apical region of VIII st. of male is characteristic as is marginal outline of VII st. of female. An additional characteristic is length of transparent genal lobe. These 3 characteristics built into a key will result in:

Key to the Species of Peromyscopsylla West of Rocky Mountains

1. Transparent genal lobe as long as inner genal tooth

a. VIII st. male armed apically with 4 bristles all of different lengths, VII st. female deeply sinuate, upper lobe triangular

P. hesperomys, p. 329 
b. VIII st. male rounded or pointed apically and armed with 2 or 3 long bristles and 1 or 2 hair-like bristles, VII st. female with a shallow sinus, upper lobe hook-like

$P$. ravalliensis, p. 332

c. VIII st. male split apically into 2 pointed lobes, upper armed with 3 long bristles and a hair-like one, lower lobe with 3 bristles, VII st. female with semi-rounded lower lobe, deep sinus then prominent evenly rounded upper lobe

P. hemisphaerium, p. 331

2. Transparent genal lobe very short

a. VIII st. male with four bristles along posterio-dorsal border at apex a spine-like bristle and two fine bristles, VII st. female fairly well rounded with shallow bay towards ventral P. selenis, p. 333

b. VIII st. male produced laterally into a rounded lobe at apex of which are two fairly long and one or two shorter bristles, VII st. of female slightly incised ventrally with a shallow bay, then to dorsal an angular lobe P. ebrighti, p. 335

\section{Peromyscopsylla hesperomys \\ Baker 1904}

1904 Ctenopsyllus hesperomys Baker, Proc. U. S. Nat. Mus., 27:428.

1905 Ctenopsyllus hesperomys Baker, Proc. U. S. Nat. Mus., 29:136.

1914 Ctenopsyllus hesperomys C. Fox, U. S. Pub. Health Ser. Hyg. Lab., Bul: 97, Pl. XX.

1915 Leptopsylla hesperomys Rothschild, Nov. Zool., 22:304.

1928 Leptopsylla hesperomys Stewart, Cornell Univ. Agr. Exp. Sta., Mem. 101, p. 869.

1929 Leptopsylla hesperomys Jordan, Nov. Zool., 35:177.

1933 Leptopsylla hesperomys Stewart, Jour. N. Y. Ent. Soc., 41:260.

1933 Leptopsylla hesperomys Jordan, Nov. Zool., 39:62.

1939 Peromyscopsylla spinifrons I. Fox, Proc. Ent. Soc. Wash., 41:48.

1940 Peromyscopsylla hesperomys I. Fox, Fleas of East. U. S, p. 84.

Baker states that the description of this species was based upon “. . . a Ctenopsyllus taken at Franconia, New Hampshire, on Peromyscus, by Mrs. A. T. Slosson, which represents a very distinct species in that it possesses a ctenidium (comb) of 2 spines on either side of the head." Of 10 or 11 bristles along anterior margin of head, 2 or 3 closest to vertex are spiniform. Genal comb consists of 2 teeth, upper shorter than lower and closely associated with long spatulate genal process which extends well beyond it. Transparent lobe of gena below teeth is as long as shorter tooth. Pronotal comb of about 30 teeth.

Modified SEgments also characteristic. VIII st. is armed apically with 4 bristles all of different lengths. Finger $F$ is not so characteristic since all western Peromyscopsyllas have roughly triangular fingers. VII st. of females is deeply sinuate, upper lobe prominent, more or less triangular, lower lobe wider. Body of spermatheca oval and gradually merges into tail, which bends back over body.

LENGTH: Original given as $2.50 \mathrm{~mm}$.

TyPE: Deposited in United States National Museum as No. 6924. 


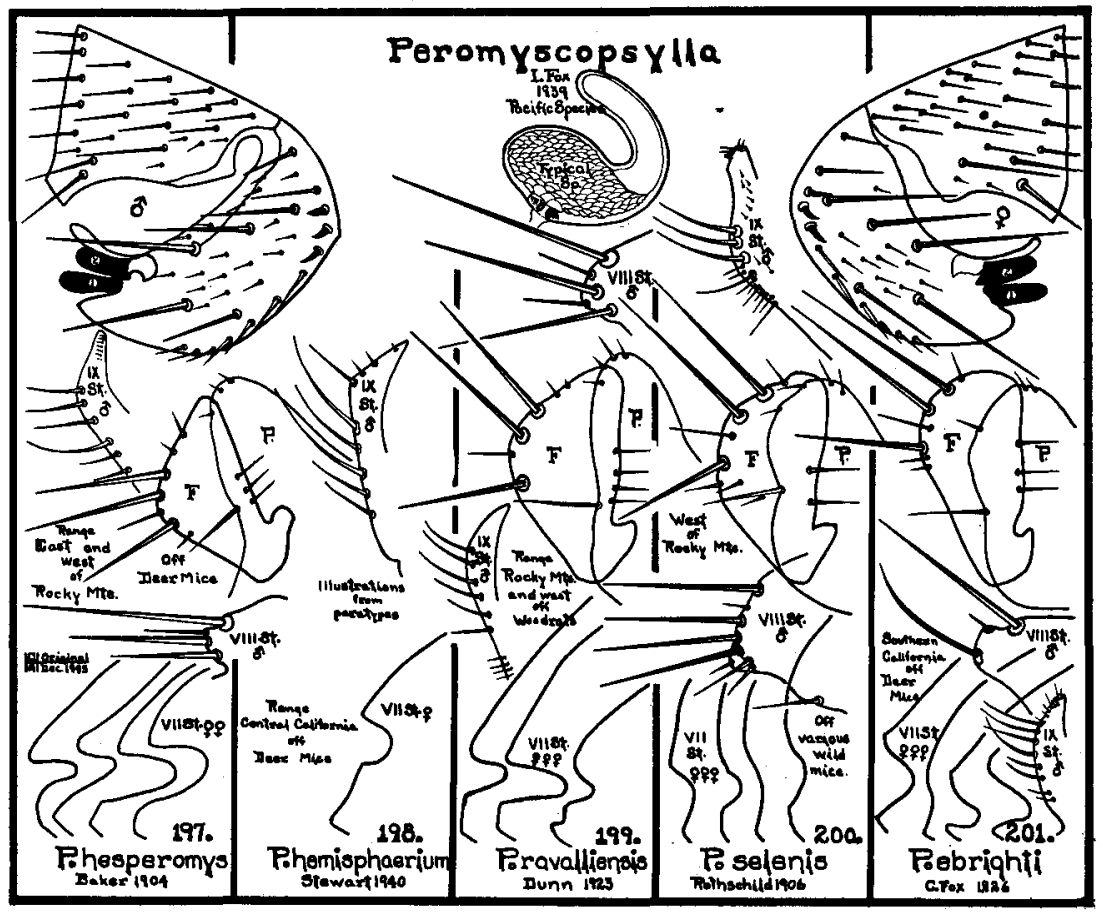

Range: Described from New Hampshire and listed by I. Fox from New York, Pennsylvania, and Tennessee, this flea should be found in territory between these records and northwest United States where it is fairly abundant. However, there seem to be no Mississippi Valley records, nor does staff of Rocky Mountain Laboratory seem to feel it is in Montana. In 1936 Wagner did not record the species found in southwest Canada. The writer has records from all over Cascade Mountains and west to Pacific Ocean in Washington, Oregon, and northern California, and to east in these states in such regions where distinctly desert conditions do not exist.

Host Preference: Found commonly upon Peromyscus (deer mice), Microtus (meadow mice), and Clethrionomys (red-backed mice), preference seems to be toward deer mice.

Seasonal Distribution: This flea begins to show up in collections after June 1 of any year and becomes abundant during August, then falls off in numbers but persists through winter months;

RECORDs: The writer has several hundred records of this species, of which the following are typical:

OREGON-Off:

Peromyscus maniculatus rubidus Osgood (ruddy deer mouse), Brookings, Curry County, August 23, 1937, 3 males, 4 females 
Peromyscus maniculatus gambeli Baird (Gambel's deer mouse), Crater Lake, Klamath County, August 29, 1933, 1 male, 2 females; Paulina Lake, Deschutes County, August 2, 1936, 2 males; Summer Lake, Lake County, June 16, 1936, 1 male, 1 female; Sisters, Deschutes County, July 14, 1940, 1 female

Clethrionomys californicus mazama Merriam (Mazama red-backed mouse), Crater Lake, Klamath County, August 20, 1933, 1 male, 2 females

Clethrionomys californicus californicus Merriam (California red-backed mouse), Sutton Lake, Lane County, August 19, 1937, 1 male

Microtus richardsoni arvicoloides Rhoads (Cascade meadow mouse), Frog Lake, Wasco County, October 4, 1931, 1 male

Microtus mordax mordax Merriam (Rocky Mountain meadow mouse), Davis Lake, Klamath County, July 30, 1937, 3 males, 4 females

Microtus oregoni oregoni Bachman (Oregon creeping meadow mouse), Tillamook, Tillamook County, August 30, 1937, 4 males, 1 female

Microtus townsendi Bachman (Townsend's meadow mouse), Newberg, Yamhill County, December 1, 1933, 2 females.

\section{WASHINGTON-Off:}

Peromyscus maniculatus oreas Bangs (Washington deer mouse), Carson, Skamania County, August 20, 1935, 1 male, 3 females.

\section{CALIFORNIA-Off:}

Peromyscus maniculatus rubidus Osgood (ruddy deer mouse), Fort Dick, Del Norte County, August 22, 1937, 2 males, 1 female

Peromyscus maniculatus gambeli Baird (Gambel's deer mouse), Modoc Lava Beds, Tule Lake, Siskiyou County, June 27, 1939, 1 male; Nevada County, (6 miles west of Truckee), June 23, 1944, 1 male.

NEVADA-Off:

Peromyscus maniculatus gambeli Baird (Gambel's deer mouse), Wells, Elko County, July 2, 1944, 1 male.

UTAH-A flea listed as Peromyscopsylla, probably hesperomys, has been recorded from Salina, Sevier County, off:

Peromyscus sp. (deer mouse)

Neotoma desertorum Merriam (desert wood rat) .

\section{Peromyscopsylla hemisphaerium \\ Stewart 1940}

1940 Peromyscopsylla hemisphaerium Stewart, Pan-Pacific Ent., 16:25.

Described from materials off Peromyscus truei subsp. (deer mice) taken at Jamesburg, California, during January, 1939. At vertex of head 3 or 4 spiniforms. Inner genal tooth slightly shorter than outer. Transparent genal lobe is as long as inner genal tooth. Pronotal comb bears about 26 teeth. Finger of male is still roughly triangular. Spermatheca of female typical. VIII st. of male is split apically into 2 pointed lobes, upper bearing 3 long bristles and a hair-like one, lower lobe armed with 3 bristles. Apical margin of VII st. of female is variable but most specimens have a semi-rounded ventral lobe and a deep regularly concave sinus separating it from a prominent evenly rounded upper lobe.

Range: Probably central California. 
RECORDs with original description are from Jamesburg, Monterey County, California, January, 1939, collected by Holdenried and North off following hosts:

Peromyscus truei subsp. (True's deer mouse)

Peromyscus boylii subsp. (Boyle's deer mouse)

Peromyscus californicus subsp. (California deer mouse)

Microtus californicus subsp. (California meadow mouse)

Reithrodontomys megalotis subsp. (California harvest mouse).

\section{Peromyscopsylla ravalliensis Dunn 1923}

1923 Ctenopsyllus ravalliensis Dunn, U. S. Pub. Health Repts., 38:2768.

1936 Ctenopsyllus ravalliensis Wagner, Can. Ent., 68:205.

Described from 11 specimens taken off 2 Neotoma (pack rats) captured at southern end of Ravalli County, Montana. It bears name of this county. The collections were made in August, 1922. Similar to preceding 2 species. At vertex of the head, 3, 4, or 5 black spiniforms and above them 2 bristles, below them along margin 4, 5, or 6 bristles, depending on number of spiniforms, whole row generally numbering 11. Of 2 genal teeth the inner is slightly shorter than outer. Transparent genal lobe is as long as inner genal tooth. Pronotal comb bears 24 teeth.

Modified SEgments in part are characteristic. Finger roughly triangular. Spermatheca typical with perhaps slightly bulkier tail. VIII st. in male is characteristic, rounded or somewhat pointed at apex and armed apically with 2 or 3 long bristles and 1 or 2 hair-like ones. Apical margin of VII st. of female variable, a shallow to deep sinus producing an upper somewhat rounded to triangular lobe and a lower lobe which is somewhat angulate.

Types: Deposited in United States Public Health Service Hygienic Laboratory at Washington, D. C.

RANGE: Described from Darby, Montana, this species is listed from Vavenby, British Columbia, Canada, by Wagner. It appears then that the range of this species must be north and west in Rocky Mountains, western boundary reaching through the Columbian Highlands of southwestern Canada, through mountainous portions of southeastern Washington and northeastern Oregon and on into Great Basin region of Oregon as far at least as Hart Mountain.

Host Preference: The writer's records of a few pairs and other records available have all been off the western bushy-tailed wood rat which seems to be the favored host for this species.

ReCoRDs: The majority of the writer's records are from a wood rat infested rock slide at Wallowa Lake, Oregon. The records are:

OREGON-Off:

Neotoma cinerea occidentalis Baird (bushy-tailed wood rat), Wallowa Lake, Wallowa County, July 14, 1939, 7 males, 4 females 
Microtus mordax mordax Merriam (Rocky Mountain meadow mouse), Adel, Lake County, June 30, 1939, 1 female.

CALIFORNIA-Augustson reports this flea from central Sierra-Nevadas off:

Peromyscus maniculatus sonoriensis Le Conte (Sonoran deer mouse), Mammoth Lakes, Mono County, August 10, 1941, 1 male, 3 females; August 29, 1941, 1 male; Tully's Hole, Fresno County, August 23, 1941, 2 pairs.

MONTANA-Although Jellison, Kohls, and Mills failed to include this species in their "Montana Fleas," probably as an oversight, the flea was described in 1923 from this state. Original specimens were taken off:

Neotoma cinerea occidentalis Baird (western bushy-tailed wood rat), Tin Cup Creek, Bitterroot Mountains, Darby, Ravalli County, August 31, 1922, holotype male; Spoon Creek, Bitterroot Mountains, Darby, Ravalli County, August 16, 1922, allotype female.

BRITISH COLUMBIA-Wagner reports this flea from Vavenby, off:

Neotoma cinerea occidentalis Baird (western bushy-tailed wood rat) .

\section{Peromyscopsylla selenis}

Rothschild 1906

1906 Ctenopsyllus selenis Rothschild, Can. Ent., 38:322.

1933 Ctenopsyllus selenis Stewart, Jour. N. Y. Ent. Soc., 41:259.

1936 Ctenopsylla selenis Wagner, Can. Ent., 68:205.

1940 Peromyscopsylla selenis I .Fox, Fleas of Eastern U. S., p. 110.

Described from material collected by Gregson and Dippie off deer mouse, meadow mouse, red-backed mouse, and jumping mouse in British Columbia and Alberta, during fall months of 1901, 1903, 1904. Species is said to be similar to hesperomys. At apex of head 3 spiniforms, below 4 bristles, above 2 bristles. In genal teeth, however, inner tooth is longer and transparent lobe of gena is very short. Pronotal comb bears 26 teeth.

Modified Segments in part are characteristic. Finger is roughly triangular, but a trifle broader than in hesperomys, spermatheca is as before, but tail is trifle longer. VIII st. in male is characteristic, there being along its posterio-dorsal border 4 bristles and at apex a spine-like bristle and 2 fine bristles. In female, apical margin of VII st. is characteristic, being fairly well rounded with shallow bay toward the ventral.

LENGTH: Originals given as male $1.30 \mathrm{~mm}$., female $2.00 \mathrm{~mm}$., but specimens in collection of writer are much larger, measuring $2.00 \mathrm{~mm}$. male, $3.00 \mathrm{~mm}$. female.

RANGE: Described from Rocky Mountains of Alberta and British Columbia, this species probably ranges along Columbian Highlands of southwest Canada then down the Cascades to at least northern California and west to Pacific Ocean.

Host Preference: Fifty pairs of this flea have been collected by the writer off red-backed mice, meadow mice, and deer mice, great majority taken off gray-tailed meadow mice.

Seasonal Distribution: This species, like preceding, seems to be a fall, winter, and spring flea. 
ReCORDS: Following records are representative of those in writer's collection:

OREGON-Off:

Microtus canicaudus Miller (gray-tailed meadow mouse), Sunnyside, Marion County, December 18, 1938, I male; Odell, Hood River County, March 18, 1939, 1 pair; Forest Grove, Washington County, March 22, 1939, 2 males; Gaston, Washington County, December 5, 1940, 2 males, 3 females

Clethrionomys californicus obscurus Merriam (dusky red-backed mouse), Estacada, Clackamas County (35 miles east), August 6, 1938, 8 males, 8 females

Peromyscus maniculatus rubidus Osgood (ruddy deer mouse), Sunnyside, Marion County, October 9, 1938, I male; Bridal Veil, Multnomah, March 17, 1939, I male; St. Paul, Marion County, March 27, 1939, 1 male

Peromyscus maniculatus gambeli Baird (Gambel's deer mouse), Fish Lake, Linn County, July 10, 1938, 1 female.

WASHINGTON-Off:

Microtus richardsoni arvicoloides Rhoads (Cascade meadow mouse), Guler, Klickitat County, May 15, 1943, 1 female,

CALIFORNIA-Off:

Microtus californicus californicus Peale (California meadow mouse), Fort Dick, Del Norte County, June 15, 1939, 1 male

Microtus montanus montanus Peale (Peale's meadow mouse), Tule Lake, Siskiyou County, April 19, 1942, 4 males, 9 females,

Sorex pacificus pacificus Coues (Pacific shrew), Smith River, Del Norte County, June 15, 1939, I male (accidental)

Augustson, reporting from central Sierra-Nevada Mountains of California, lists this flea taken at Tully's Hole, Fresno County, off:

Microtus mordax sierrae Kellogg (Sierra meadow mouse)

Microtus montanus dutcheri Bailey (Dutcher's meadow mouse)

Tamiasciurus douglasi albolimbatus Allen (California pine squirrel)

Citellus lateralis chrysodeirus Merriam (mantled ground squirrel) .

IDAHO-Off:

Peromyscus maniculatus artemesia Rhoads (sagebrush deer mouse), Craigmont, Lewis County, July 21, 1945, 1 male. (Col. C.A.H.)

This species was described from a series of specimens off various wild mice from British Columbia and Alberta, Canada.

\section{0a. Peromyscopsylla duma}

Traub 1944

1944 Peromyscopsylla duma Traub, Field Museum of Nat. Hist. Zoo., 29:15:217

The author has before him at this time the original manuscript in which this flea was described and unpublished illustrations which accompanied it. Original description of this species covered 6 doublespaced typewritten pages and illustrations covering a comparison between duma and selenis were 2 full pages. While Traub was in Burma, editors cut the description to a single printed page and failed to use the illustrations. Therefore the illustrations appear here for the first time. 
Author's Opinion: A very careful examination of 30 pairs of $P$. selenis collected in Oregon and California by the writer, the determination of some being verified by Dr. Karl Jordan, lead the writer to believe that there is enough individual variation in these to completely cover characteristics of duma. P. duma may then be selenis.

According to the original manu-

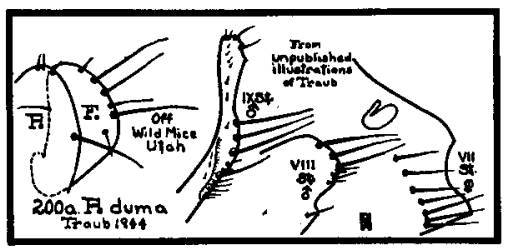
script the describer had before him a male and 10 female specimens, taken off deer mice, meadow mice, and red-backed mice at Logan and Hyrum, Cache County, Utah, during August and September, 1938, by Dr. J. S. Stanford. The species is said to be close to P. selenis.

Modified Segments: VIII st. male which is characteristic for this genus is illustrated as being apically blunt and armed with 3 medium bristles and cluster of about 4 much shorter ones; somewhat below these to ventral and anterior a medium bristle, the margin between cluster and single bristle being incurved. The VII st. female is cut with broad shallow sinus and is armed with 7 bristles in a row. Size of species is not discussed. Types in Field Museum Natural History.

\section{Peromyscopsylla ebrighti \\ C. Fox 1926}

1926 Leptopsylla ebrighti C. Fox, Pan-Pacific Ent. II, No. 4, 182.

Described from a series of males and females taken off Neotoma fuscipes (wood rat) near Los Angeles, California, during July, 1925. At vertex of head 2 spiniforms. Two genal teeth are about same length but transparent lobe of gena is very short. Pronotal comb bears 24 teeth.

Modified SEgments in part are characteristic. Finger is roughly triangular, spermatheca typical. VIII st. in male is characteristic in that it is produced laterally into a rounded lobe at apex of which are 2 fairly long and 1 or 2 shorter bristles. In female, apical margin of VII st. is variable. Generally it is sinuate with a dorsal angular lobe.

Types: Deposited in United States National Museum as No. 28919.

LENGTH: Originals given as male $1.80 \mathrm{~mm}$., female $2.80 \mathrm{~mm}$.

RANGE: Probably southern California.

Augustson states that this is a flea commonly encountered on whitefooted mice (deer mice) particularly from chaparral areas of Pacific Southwest and presents the following records:

CALIFORNIA-Off:

Peromyscus boylii rowleyi Allen (Rowley deer mouse), San Gabriel Mountains, Los Angeles County

Peromyscus californicus insignis Rhoads (southern parasitic deer mouse), City of Glendale and Santa Monica Mountains, Los Angeles County 
Peromyscus eremicus fraterculus Miller (San Diego desert mouse), San Gabriel Wash, Los Angeles County

Peromyscus eremicus eremicus Baird (western desert mouse)

Peromyscus crinitus stephensi Mearns (Stephens canyon mouse), Palm Springs.

Key to the Rocky Mountain Peromyscopsylla

1. VIII st. male rounded apically, VII st. female with upper lobe not hooked-Arizona

P. adelpha, p. 336

2. VIII st. male angular apically, VII st. female with upper lobe hooked

$P$. hamifer, p. 337

a. VIII st. male somewhat boot-shaped apically and armed with 4 bristles, VII st. female with an upper short, apically rounded distinctly hooked lobe -Alberta

$P$. h. hamifer, p. 337

b. VIII st. male apically angulate but not boot-shaped, armed with 2 heavy bristles, and several very short ones, VII st. female with upper lobe a distinct small triangular hooked lobe-Montana

P. h. vigens, p. 337

c. Male unknown, VII st. female with a long finger-like lobeAlaska

P. h. longiloba, p. 337

d. VIII st. male pointed posterio-ventrally, VII st. shallowly sinuateUtah

P. duma, p. 334

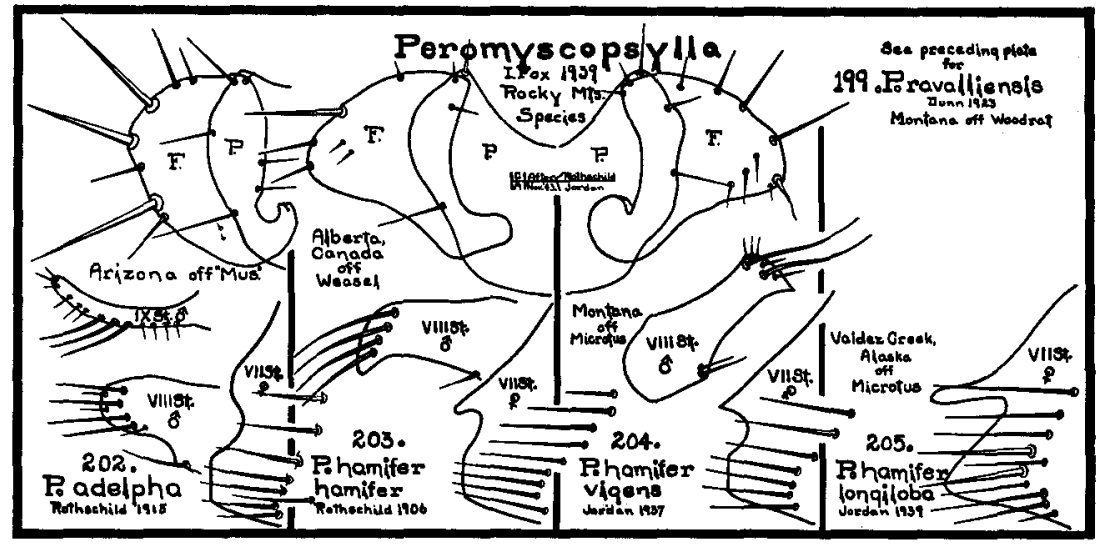

202. Peromyscopsylla adelpha

Rothschild 1915

1915 Leptopsylla adelpha Rothschild, Nov. Zool., 22:304.

Both male and female described from specimens of "Mus" collected at Paradise, Cochise County, Arizona, by O. C. Duffner during February, 1914.

This species is stated by the describers to be close to $P$. selenis.

As is case in most other species of this genus modified segments are distinctive. In male, process of clasper is broader apically and not so rounded; finger is not so triangular, armature, however, about the same. VIII st. is apically rounded and armed with about 4 medium bristles 
and as many short ones, all crowded toward the apex. IX st. long, narrow, almost finger-like with 3 medium bristles and above and below them a series of shorter bristles all along the ventral margin. In female the VII st. is shallowly sinuate, with lower lobe somewhat angulate, upper lobe rounded.

RANGE: Southeastern Arizona and probably adjacent New Mexico.

\section{Peromyscopsylla hamifer hamifer \\ Rothschild 1906}

1906 Ctenopsyllus hamifer Rothschild, Can. Ent., 38:324.

1937 Leptopsylla hamifer hamifer Jordan, Nov. Zool., 49:265.

This subspecies was described from a male taken off Mustela (weasel) at Blackfalls, Alberta.

It is marked off from male of other species so far described by shape of finger and VIII st. and in female by outline of margin of VII st. In male, process is apically angulate with posterior border broadly convex. Finger expanded apically, suggestive of a stalked puffball. However, anterior expanded portion of apex is angulate while posterior is nicely rounded. A stout bristle and several shorter ones arm apical margin. VIII st. is somewhat boot-shaped apically and armed terminally with 4 well developed bristles. In female, apical margin of VII st. is distinctly hooked, hook formed by small apically rounded lobe about onethird up margin.

RANGE: Known only from Canadian province of Alberta.

$$
\begin{aligned}
& \text { 204. Peromyscopsylla hamifer vigens } \\
& \text { Jordan } 1937
\end{aligned}
$$

1937 Leptopsylla hamifer vigens Jordan, Nov. Zool., 45:265.

This subspecies was described from materials collected in Ravalli County, Montana, off Microtus (meadow mouse).

In this subspecies process of clasper is similar to preceding subspecies but posterior border is undulate. Finger is stalked-puffballshaped with apical expanded portion bisymmetrical. About 6 bristles of varying lengths arm the apical margin. VIII st. in male characteristically shaped and armed apically with 2 well developed bristles and about 6 short ones. In female, VII st. is made hook-like by presence of small sharply pointed triangular lobe followed by small shallow sinus.

RANGE: Apparently this flea is known only from the type locality.

$$
\begin{aligned}
& \text { 205. Peromyscopsylla hamifer longiloba } \\
& \text { Jordan } 1939
\end{aligned}
$$

1939 Leptopsylla hamifer longiloba Jordan, Nov. Zool., 41:319.

This subspecies was described from 2 females, 1 taken off Microtus sp. (meadow mouse) at Valdez Creek, Alaska, September 23, 1937, the 
other off Lepus americanus (varying hare) at Fairbanks, Alaska, September 11, 1937. Male has not yet been described.

Apical outline of VII st. marks it off from other members of this genus. Single lobe as "longiloba" suggests is long, narrow and fingerlike.

Range: At this time this flea is known only from type localities in Alaska.

\section{GENUS PHALACROPSYLLA ROTHSCHILD}

1915. Phalacropsylla Rothschild. Ectoparasites I, p. 39.

Genotype: Phalacropsylla paradisea Rothschild 1915

Original description of this genus states that it combines in male and female characteristics of Ctenophthalmus and Neopsylla, and differs from both these genera in absence of a frontal tubercle.

Remainder of description is: "Antennal groove open, continued on to the propleurum, in male reaching nearly as far as the stigma. Eye vestigial. Two genal spines crossing each other as in Neopsylla. Hindcoxa with small bristles on inner surface. Fifth segment of all the tarsi with 4 lateral pairs of plantar bristles and a fifth pair in between the lateral pair. Genitalia of the Neopsylla type." Other characteristics are Head: Angulate in male, well rounded in female. Lower row of genal bristles, 4, stout, well above eye position. Upper row of medium bristles. Postantennal region with 3 incomplete rows of bristles. Labial palpus reaching to apex of coxa I. Pronotum with comb. Apical spinelets on anterior abdominal tergal plates. Three antepygidial bristles to the side. Ventral arm of IX st. with spiniforms. Finger long, narrow. Process broad, apically rounded. VII st. female sinuate.

The 3 species of this genus so far described are all found in West. Each has for its true host a western rodent, cony, wood rat, or mouse.

When these 3 species are viewed side by side it becomes apparent that distinctive features are in IX st. of male and apical outline of the VII st. of females. These features bound into a key will result in

\section{Key to the Species of Phalacropsylla}

1. IX st. male expanded apically

a. Armed with 4 black spiniforms, 2 bent; VII st. female with well rounded upper lobe

P. paradisea, p. 339

b. Armed with a row of 8 or more sharp, black spiniforms, VII st.

female with upper lobe narrow and somewhat triangular P. allos, p. 340

2. IX st. male not expanded, armed with 3 black, sharp spiniforms, VII

st. female with upper lobe rounded but shorter than lower lobe

P. monticola, p. 339 


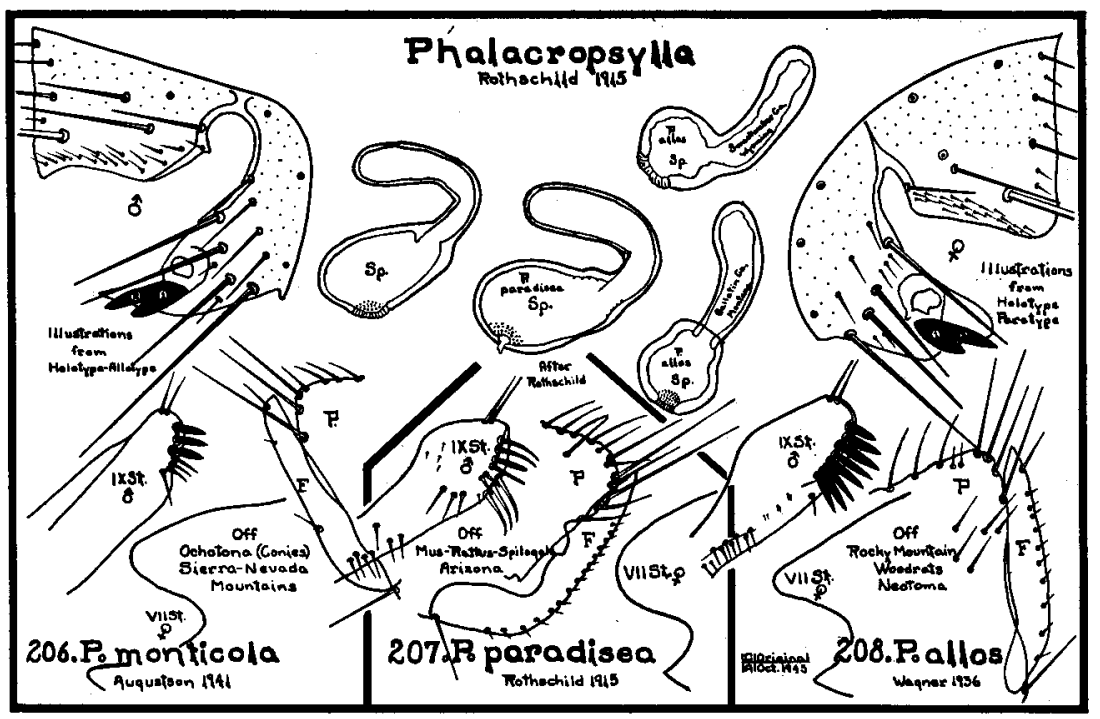

206. Phalacropsylla monticola Augustson 1941

1941 Phalacropsylla monticola Augustson, Bul. So. Calif. Acad. of Sci., 40:144.

Described from male and female taken off Ochotona schisticeps muiri G. and S. (Yosemite cony) by Augustson and Rutherford at Tully's Hole, Fresno County, California, on August 23, 1941. Augustson was kind enough to lend writer the types for study and from which to make illustrations.

Pronotal comb is made up of 12 long, rather blunt pointed spines.

Modified Segments, Male: Process is prominent and apically rounded. Finger long, slender, apically pointed, armed on posterior border with about 3 short bristles. IX st. characteristic, not expanded apically, armed at posterio-ventral angle with a row of 3 short stout, black spiniforms and a few weak bristles. Female: VII st. sinuate. Upper rounded lobe much shorter than lower narrow triangular lobe. Spermatheca with pear-shaped body and long slender finger-like tail which is bent back over body.

Range: Known only from the type locality, Tully's Hole, Fresno County, California.

\section{Phalacropsylla paradisea Rothschild 1915}

1915 Phalacropsylla paradisea Rothschild, Ectoparasites, 1:39.

Described from a series of specimens taken by O.C. Duffner during the months of September, October, November, and December of 1913 
at Paradise, Cochise County, Arizona. Hosts were given as "off 'Epimys' spec., 'Mus' spec. and civet cat." Epimys and Mus would be interpreted today as meaning house rats and mice; civet cat would represent a carnivore; therefore the writer doubts if true host of this flea is represented in these hosts.

Pronotal comb is made up of about 14 teeth.

Modified Segments, Male: Process prominent, broad and apically rounded. Finger long, narrow and apically pointed with short bristles along posterior margin. IX st. characteristic; expanded apically, armed at posterio-ventral angle with a row of short stout spines and 3 long, pointed, curved ones. FEMALE: VII st. with apical outline sinuate. Upper lobe broad, well rounded, and much longer than lower small somewhat triangular lobe. Spermatheca with body pear shaped and tail finger-like and crooked over body.

LENGTH: Original lengths, male $2.50 \mathrm{~mm}$., female $2.80 \mathrm{~mm}$.

RANGE: Little has been heard about this flea since the release of its description. It probably ranges throughout southeastern Arizona and adjacent New Mexico.

Host Preference: The writer does not believe that hosts from which this flea is reported are its natural hosts. It has been reported off "Epimys" (rattus?), "Mus" (house mouse), and Spilogale? (civet cat).

\section{Phalacropsylla allos \\ Wagner 1936}

1936 Phalacropsylla allos Wagner, Zeit. f. Parasit., 8:654.

Described from materials sent Wagner by Professor J. S. Stanford of Utah State Agricultural College, Logan, Utah. Stanford was kind enough to loan type materials to author for study and from which to make illustrations. Material came off Neotoma cinerea cinerea Ord (gray bushy-tailed wood rat).

Modified Segments, Male: Process prominent and broadly rounded apically. Finger long, slender and-apically pointed, armed along posterior border with short bristles. IX st. characteristic, expanded apically and armed at the posterio-ventral angle with a row of about 8 short, heavy black spiniforms. FEMALE: VII st. sinuate, upper lobe much longer than lower, narrow and rounded apically. Lower lobe small triangular. Spermatheca with body round to pear-shaped and tail long, slender but not bent back over body.

LENGTH: Specimens measured by writer varied in male from 3.25 to $3.50 \mathrm{~mm}$., in female from 4.00 to $5.25 \mathrm{~mm}$.

RANGE: This flea ranges through Rocky Mountains of United States but has not yet been reported from these mountains in Canada.

PREFERRed Host: All records to come to the attention of the writer have come from Neotoma (wood rats), either off them, from their nests 
or in vicinity of nests. This species, then, is probably a true wood rat flea.

Seasonal Distribution: All specimens to come to attention of writer were collected during fall months of year.

RECORDS of this species are:

MONTANA-Off:

Neotoma cinerea subsp. (bushy-tailed wood rat), Gallatin County, 1942, from nest; Jefferson County, 1941, from nest; Madison County, 1941.

UTAH-Off:

Neotoma cinerea cinerea Ord (gray bushy-tailed wood rat), Logan Canyon, Cache County.

WYOMING-Off:

Neotoma cinerea subsp. (bushy-tailed wood rat), Sweetwater County, August 17, 1938, 1 female.

\section{GENUS CARTERETTA C. FOX}

1927. Carteretta C. Fox. Trans. Amer. Ent. Soc., 53:209.

1940. Trirachipsylla Stewart. Pan-Pacific Ent., 16:23.

Genotype: Carteretta carteri C. Fox 1927

This genus is easily distinguished from all others known of the fracticipate fleas by the 3 genal teeth, the more anterior 2 of which overlap one another. Two rows of frontal bristles with large single bristle in between. Frontal tubercle present. Three rows of bristles on occiput. Eye but lightly pigmented. Bristles on segment II of antenna are short. Maxilla are very acutely pointed. Last 4 segments of labial palpi are short. First 5 abdominal tergites with apical spinelets. Antepygidial bristles 3 to the side. Hind coxae heavily armed with fine hairs in apical half. Bristles on posterior margins of tibiae arranged in groups of twos and threes. Four pairs of lateral plantar bristles and 1 median pair between first lateral pair on fifth tarsal segments of all legs.

There is but one representative of this genus which is found in West upon various wild mice.

\section{Carteretta carteri}

c. Fox 1927

1927 Carteretta carteri, C. Fox, Trans. Am. Ent. Soc., 53:209.

1940 Trirachipsylla digitiformis Stewart, Pan-Pacific Ent., 16:24.

1940 Carteretta carteri Jellison, U. S. Pub. Health Repts., 55:489.

The male of this species was described by $\mathrm{C}$. Fox from a single specimen taken off Neotoma fuscipes (wood rat) at Los Angeles, California, during 1925. Male and female were described by Stewart in January, 1940, as Trirachipsylla digitiformis, and during March, 1940, Dr. William Jellison from materials that came from the same source, that is, 


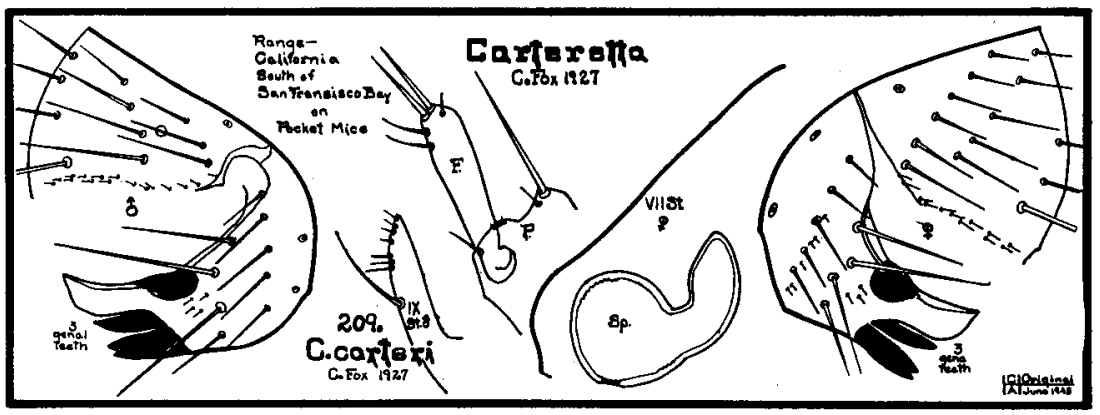

Hastings Natural History Reservation, Jamesburg, California, described the female as Carteretta carteri.

Arrangement of the 3 genal spines is quite characteristic. Posterior genal spine much narrower than 2 which overlap one another. Pronotal comb of 16 teeth. Modified Segments, Male: Finger F long and symmetrically digitate, armed with 4 conspicuous bristles at ventroposterior angle, upper 2 stoutest. Process $P$ bilobed, lower lobe bearing 3 very fine bristles, upper lobe bearing a very long stout bristle with a smaller bristle and hair above it and a smaller bristle below it. Female: Spermatheca large; head subspherical and tail stout, obliquely cut at tip. VII st. with apical margin not incised, sloping regularly toward the anterior.

LENGTH: Males average $2.20 \mathrm{~mm}$., females $2.30 \mathrm{~mm}$.

RANGE: With holotype male described from Los Angeles and a large series of specimens from Jamesburg, California, the range for this species is probably west of Sierra-Nevada and San Bernardino Ranges and south of San Francisco Bay in California.

Seasonal Distribution: Records available are for months of October to February.

RECORDs are from:

CALIFORNIA-Off:

Neotoma fuscipes subsp? (round-tailed wood rat), Los Angeles, 1925. (Holotype),

And from Jamesburg (Hastings Natural History Reservation) during fall and winter of 1938 and 1939, off:

Peromyscus maniculatus subsp? (deer mouse)

Peromyscus truei subsp? (True's deer mouse)

Perognathus californicus subsp? (California pocket mouse),

In southern California Augustson reports this flea off:

Perognathus californicus bernardinus (San Bernardino pocket mouse), Cabazon, Riverside County

Perognathus californicus dispar Osgood (Allen pocket mouse), Santa Monica Mountains, Los Angeles County

Perognathus californicus ochrus Osgood (Kern pocket mouse), Santa Maria, Santa Barbara County 
Perognathus fallax fallax Merriam (short-eared California pocket mouse), Cabazon, Riverside County

Peromyscus californicus insignis Rhoads (southern parasitic mouse), San Gabriel, Los Angeles County

Microtus californicus californicus Peale (California meadow mouse), Santa Monica, Santa Barbara County

\section{GENUS CTENOPHTHALMUS KOLENATI}

1856. Ctenophthalmus Kolenati. Die Parasiten der Chiropteren, p. 33.

Genotype: Ctenophthalmus bisoctodentatus Kolenati 1863

Head well rounded. Eyes vestigial. Three sharp genal teeth. Frontal tubercle prominent. Labial palpus not longer than apex of fore coxa; apical segment with curved apical bristle. Tarsal segment $\mathrm{V}$ of fore and middle legs armed with 4 pairs of lateral plantar bristles and basal and distal submedian pair. Same segment of hind legs armed with 3 pairs of lateral plantar bristles and a basal and distal submedian pair. Three antepygidial bristles.

In West this genus is represented by a single species which has been reported only from Montana.

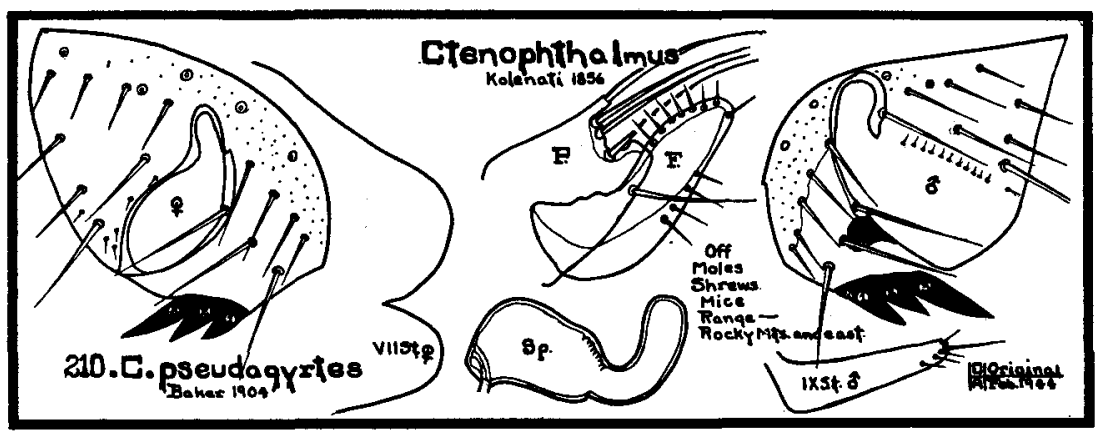

210. Ctenophthalmus pseudagyrtes

\section{Baker 1904}

1904 Ctenophthalmus pseudagyrtes Baker, Proc. U. S. Nat. Mus., 27:421.

Described from male and female off Geomys bursarius (gopher) taken at Agricultural College, Michigan.

HeAD: Three genal teeth, lower row of 3 genal bristles, upper row of about 5 medium bristles. Postantennal region with 3 rows of bristles.

Pronotum with comb of about 14 teeth and a single row of bristles, weak alternating with strong.

Modified Segments, Male: Process of clasper with 2 lobes apically, armature consisting of about 6 stout bristles. Finger $F$ longer than process, broad and finger-shaped; armed with medium bristles around perimeter. Female: VII st. with 2 well rounded lobes, between them a sharp wedge-shaped sinus. Spermatheca characteristically shaped. 
RANGE: A well known flea in East but only reported from Montana in West.

ReCoRds: Off Microtus spp. (meadow mouse), Big Horn County, Montana, 1940.

GENUS DORATOPSYLLA J. AND R.

1912. Doratopsylla Jordan and Rothschild. Nov. Zool., 19:62.

Genotype: Typhlopsylla dasycnemus Rothschild 1897

Frontal tubercle absent and eye is vestigial. There are 4 teeth in genal comb. Labial palpus composed of 4 segments. Frons rounded, and armed with 2 rows of conspicuous bristles. Fifth tarsal segment of all tarsi armed with 4 pairs of lateral plantar bristles and a basal median pair. In both sexes there are 3 antepygidial bristles on each side.

Represented in West by 2 species which are usually found upon shrews. Species may be separated from one another by the shape of finger and VII st. of female.

Key to the Species of Doratopsylla in the West

1. Finger pointed apically, VII st. female with upper triangular lobe much longer than lower angulate lobe D. jellisoni, p. 344

2. Finger blunt apically, VII st. female with upper, small triangular lobe about as long as lower rounded one D. c. curvata, p. 346

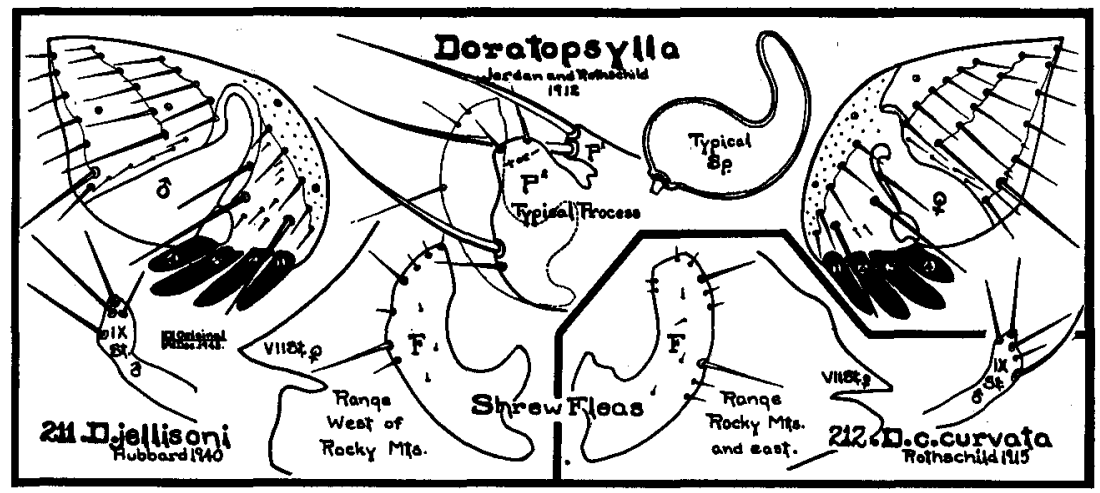

211. Doratopsylla jellisoni

Hubbard 1940

1940 Doratopsylla jellisoni Hubbard, Pacific Univ. Bul., 37:2:8.

Described from materials taken by author off Sorex trowbridgi (Trowbridge shrew) captured under a hay cock at Forest Grove, Oregon, June 25, 1935. It differs from others of genus primarily in modi- 
fied segments. Head well rounded, without frontal tubercle. Four genal teeth. Pronotal comb of about 20 teeth. VII t. produced into a rather strongly chitinized process between 2 sets of antepygidial bristles. Apical edges of abdominal segments scalloped, but no teeth on tergites.

Modified Segments: Characteristic. Clasper is divided into 2 processes, between which there is a very small lobe. Upper process $\mathbf{P}^{1}$ is slender and bears 2 long bristles at apex. Lower process $\mathbf{P}^{2}$ is shorter than $\mathrm{P}^{1}$ and wider, armed with up to several hairs. At insertion of finger $F$ there is a long stout bristle and a thin bristle. Finger is somewhat sickle-blade-shaped and longer than both $\mathrm{P}^{1}$ and $\mathrm{P}^{2}$. St. IX swollen at apex and armed with 2 heavy bristles and 2 medium ones. In female, apical margin of VII st. cut by shallow sinus which divides margin into squarish lower short lobe and upper much longer triangular lobe. Spermatheca has somewhat elliptical body with tail gradually diminishing in size.

Types: Deposited in Academy of Natural Sciences of Philadelphia.

LENGTH: Average size of male $1.90 \mathrm{~mm}$., female $2.15 \mathrm{~mm}$.

Range: West of Great Basin to Pacific Ocean.

It has been suggested that this species is same as D. c. obtusata Wagner 1929.

Host Preference: This species is a true shrew flea which at times will find its way onto meadow mice running same burrows.

Seasonal Distribution: Seems to be entirely a summer flea, being well represented in writer's collection from shrews during June, July, August, and September.

RECORDs: The author has collected this flea in

\section{OREGON-Off:}

Sorex trowbridgi trowbridgi Baird (Trowbridge shrew), Cornelius, Washington County, July 2, 1936, large series

Sorex obscurus bairdi Merriam (Baird's shrew), Tillamook, Tillamook County, August 12, 1937, series

Sorex vagrans vagrans Baird (vagrant shrew), Cannon Beach, Tillamook County, March 29, 1937, 1 male

Microtus townsendi Bachman (Townsend's meadow mouse), Forest Grove, Washington County, June 25, 1935, I male

Microtus oregoni oregoni Bachman (Oregon creeping meadow mouse), Tillamook, Tillamook County, August 30, 1937, 1 female.

\section{WASHINGTON-Off:}

Sorex trowbridgi trowbridgi Baird (Trowbridge shrew), Vancouver, Clark County, April 10, 1943, 2 females.

\section{CALIFORNIA- Off:}

Sorex pacificus pacificus Coues (Pacific shrew), Smith River, Del Norte County, June 16, 1940, 6 males, 4 females.

NEVADA-Off:

Peromyscus maniculatus sonoriensis Le Conte, (Sonoran deer mouse), Reno, Washoe County, June 21, 1944, 1 male. 


\section{Doratopsylla curvata curvata \\ Rothschild 1915}

1915 Doratopsylla curvata Rothschild, Ectoparasites, 1:25.

Described from materials off Blarina órevicauda (shrew) collected by Wickham at Iowa City, Iowa, June 19, 1910, and off Zapus? (kangaroo mouse) and Sorex (shrew mouse) collected by Gregson at Blackfalls, Alberta.

Head well rounded and without frontal tubercle. Armature consists of comb of 4 genal teeth and 2 rows of bristles on preantennal region and 3 rows on postantennal region. Pronotal comb consists of about 18 teeth. Apical edges of abodminal segments denticulate. T. VII produced into a heavy process which extends between the 2 sets of antepygidial bristles.

Modified Segments, Male: Process of clasper as in preceding species made up of 2 processes between which there is a very small lobe. Upper process slender with 2 long apical bristles. Lower process as long as upper, much wider and armed with 2 hairs at apex and below one long stout bristle and a small one. Finger $\mathrm{F}$ is strongly curved and of nearly even width throughout, apex blunt. Posterior margin bears 2 thin fairly long bristles and several short ones. Female: Apical margin of VII st. slants in a dorso-ventral direction and is divided by sinus into 2 lobes, upper sharply angulate, lower rounded. Spermatheca is typical.

LeNGTH: Original lengths are given as male $2.50 \mathrm{~mm}$., female 2.80 $\mathrm{mm}$.

RANGE: Reported from all over eastern portion of United States and in Rocky Mountains from Montana and Alberta, Canada. Its range probably is everywhere east of Great Basin.

Host Preference: This species is doubtless a true shrew flea.

Records: On October 20, 1935, a pair of these fleas was taken from a "shrew nest" in Ravalli County, Montana. Types came from Blackfalls, Alberta, Canada, off Sorex and Zapus.

\section{GENUS LEPTOPSYLLA J. AND R.}

1911. Leptopsylla Jordan and Rothschild. Nov. Zool., 18:85.

Genotype: Pulex segnis Schonherr 1811

Characteristics are very similar to those of Peromyscopsylla, that is, head is subangulate in front, bullet-shaped, frontal tubercle absent. Frons armed with 9 bristles of which 2 or 3 at vertex are spiniforms. Eye is vestigial. Genal comb consists of 4 genal teeth. Three or 4 antepygidial bristles to side. Posterior margin of the hind tibia armed with series of about 14 medium-sized bristles, among which there are 3 or 4 long ones. Tarsal segment $\mathrm{V}$ of each leg armed with 4 pairs of lateral plantar bristles and a basal sub-medium pair. Spermatheca body not elliptical, but more rectangular with rounded corners. 
Only representative of this genus in West is European mouse flea which has been introduced into port towns through trade channels.

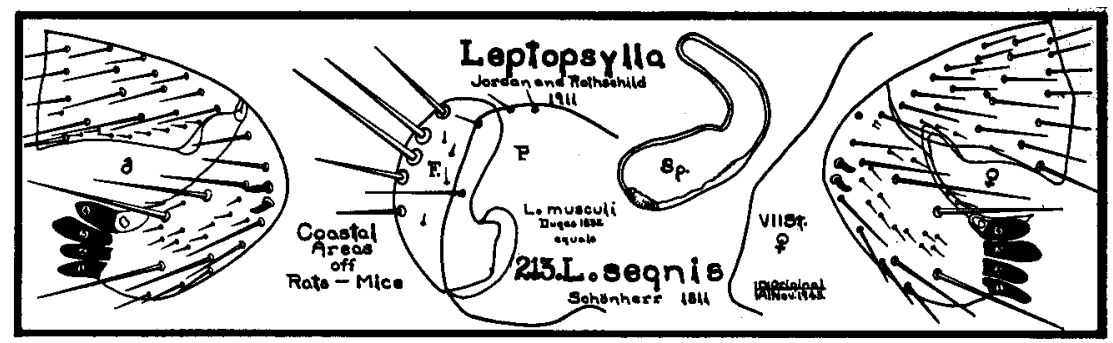

\section{Leptopsylla segnis}

Schonherr 1811

1811 Pulex segnis Schonherr, Kogl, Svenska Vetenskakad. Nya. Handl. (2nd s.) , 32:98, Pl. V, figs. A, B.

1832 Pulex musculi Duges, Ann. d. Sci. Nat. (lst s.), 27:163.

1936 Leptopsylla musculi Fricks, U. S. Pub. Health Bul., No. 232.

1940 Ctenopsyllus segnis I. Fox, Fleas of Eastern U. S., p. 88.

This is the common European mouse flea. Head well rounded (bullet-shaped) with slightly pointed tip at apex of female. Directly posterior to apex are 2 heavy spiniforms and below them on the anterior margin 5 bristles, above them 2 bristles. Genal comb consists of 4 teeth, most dorsal broadest, the third the longest. Eye is vestigial. Host and head characteristics mark this species from all others, but MoDIFiEd SeGments are also characteristic. In MALE, finger $F$ rounded at posterior margin and armed with 5 or 6 .bristles, of which 3 are longer than others. Distal end of posterior arm of IX st. is expanded, posterior margin bearing a number of hair-like setae. Three antepygidial bristles to the side, shortest one inner, medium one outer. In FEMALE, VII st. is not sinuate, single lobe having a somewhat undulate slant. There are 4 antepygidial bristles on each side. Spermatheca with body somewhat rectangular, corners rounded off, tail broader at base than at apex and curved.

Range: This flea has been introduced into Pacific port towns and cities on commerce routes by means of rats from boats. Range does not extend much beyond original ports of entry. Not reported from inland portions of United States.

Host Preference: A true domestic rat and mouse flea. I. Fox reports accidental occurrence upon cotton rat and white-footed mouse in East; the writer has a specimen off a shrew.

Medical Importance: While this flea is generally considered a vector of plague, Eskey and Haas found that only 5 out of 28 fed upon plague-positive guinea pigs became infected. There is no record of any of the 5 infected fleas having freed themselves of infection or succeeding in transmitting plague. 
RECORDS in the collection of the writer are:

OREGON-Off:

Rattus norvegicus Erxleben (Norwegian rat), Portland, Multnomah County, (water front), May 2, 1936, 1 male, 2 females

Prince reports this flea off this rat from Marshfield, Coos County

Rattus rattus rattus Linnaeus (black rat), Portland, Multnomah County, (water front), April 6, 1939, 1 female, collected by the author.

\section{CALIFORNIA-Off:}

Sorcx pacificus pacificus Coues (Pacific shrew), Smith River, Del Norte County, June 15, 1939, 1 female, collected by the author,

As early as January, 1909, Carroll Fox reports in Entomological News as follows: "Ctenopsyllus musculi (Duges) Wagner. Hosts: Mus norvegicus, Mus rattus, Mus musculus. Once found on Microtus californicus."

Augustson reports this flea off domestic rats and mice taken in the city of Los Angeles.

Prince offers the following records for this species:

Rattus rattus rattus Linnaeus (black rat), Costa Mesa, Jamu, and San Diego Rattus norvegicus Erxleben (Norwegian rat), Palm City, Chula Vista, Berkeley, Williams, and Nicolaus.

WASHINGTON-L. D. Fricks, reporting upon fleas collected at Seattle, during 1927 , 1928, 1929, states that Carroll Fox, who made the determinations, estimated the number of $L$. musculi to be 10.6 per cent of the rat flea population of this city.

Prince reports this flea taken off Norwegian rat in Seattle.

NEW MEXICO-Off:

Rattus rattus alexandrinus Geoffroy (Alexandrine rat), Lordsburg, (reported by Prince).

BRITISH COLUMBIA-G. P. Holland reports (1941) that C. D. Mail took this species off Mus musculus musculus (house mouse) at Kelowna, on October 4, 1939.

\section{GENUS MICROPSYLLA DUNN}

1923. Micropsylla Dunn. U. S. Pub. Health Repts., 38:2767.

Genotype: Micropsyilla sectilis Jordan and Rothschild 1923

The original statement of this genus says that it was founded on an extremely small male flea taken off a field mouse; that it is near Neopsylla and Rhadinopsylla, differing from former mainly by having 4 pairs of spines on each fifth tarsal segment, and from latter by overlapping of some of genal spines. Seventy-five specimens in collection of the writer that represent 2 species of this genus, some of which have been viewed by Dr. Karl Jordan who has verified the generic and specific placement, present the following characteristics. Head pointed (tubercle present). Genal teeth 4 or 5, fairly constant but not overlapping and of about same color. Genal bristles, lower row of 3 stout bristles high above eye position, upper row of 5 medium bristles. No eyes. Three rows of bristles on occiput. Pronotal comb of about 16 teeth. Abdominal tergites with apical spinelets. Antepygidial bristles absent in male, 2 in female.

This genus is western North American and seems to be represented by 2 species which are taken mostly from wild mice. 
Key to the Species of Micropsylla

A. 4 genal teeth on both sides of head

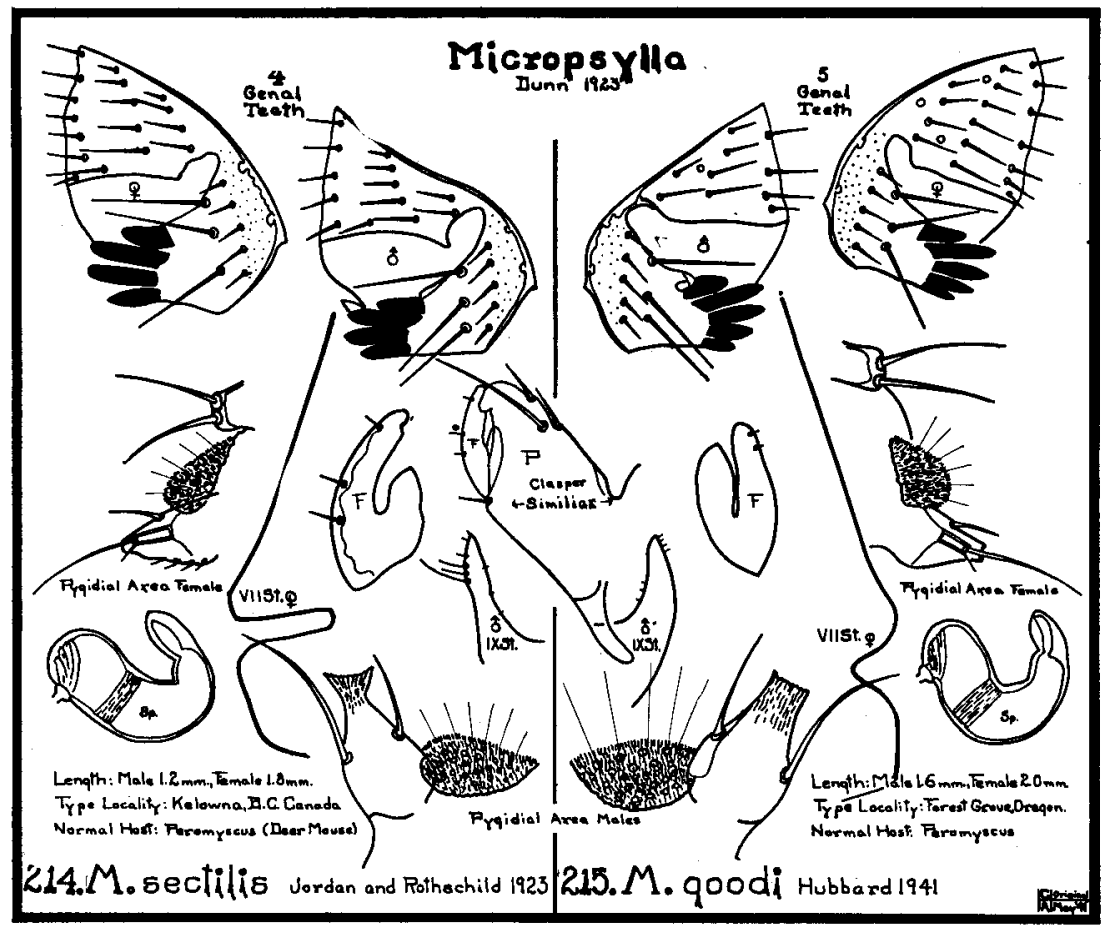

214. Micropsylla sectilis

Jordan and Rothschild 1923

1923 Rhadinopsylla sectilis Jordan and Rothschild, Ectoparasites I, p. 314.

1923 Micropsylla peromyscus Dunn, U. S. Pub. Health Repts., 38:27:67.

1936 Rectofrontia sectilis Wagner, Can. Ent., 68:203.

1941 Micropsylla sectilis Hubbard, Pacific Univ. Bul., 37:10:1-4.

Described from 3 females taken during October, 1908, and March, 1909, off Peromyscus (deer mouse) and Mus spec. by Tate at Kelowna, British Columbia. Presence of 4 genal teeth on both sides of head coupled up with structure of modified abdominal segments marks this species from all other known fleas. In female, spermatheca differs from that of all other fleas, with exception of following species, and was originally described as gradually narrowed, apex of tail concave on anal side.

Modified Segments, Male: Process of clasper somewhat triangular but apically rounded, not characteristic. Finger F scythe-blade-shaped and armed on posterior margin with 3 short bristles. IX st. expanded 
slightly short distance below apex and armed posteriorly along swollen apical portion with small series of bristles of different lengths. Female: VII st. deeply sinuate. Lower angular lobe much larger than upper angular lobe.

LENGTH: Specimens in collection of writer average males $1.20 \mathrm{~mm}$., females $1.80 \mathrm{~mm}$.

Range: East of Cascade-Sierra-Nevada Mountains to Great Plains.

Host Preference: One hundred personally collected specimens of this flea, which is rather rare in American collections, seem to have come off deer mice and ground squirrels in about equal proportions.

Seasonal Distribution: Seems to be a winter flea, but in higher elevations in cooler locations a few specimens can occasionally be taken during mid summer. Greatest single collection made by the writer occurred on November 29, 1943, at Dorris, Siskiyou County, California, where he took 13 males and 34 females off 7 specimens of Peromyscus maniculatus gambeli Baird. Twenty specimens were also taken at Wasco, Wasco County, Oregon, March 13, 1942, off sage and ground squirrels that had just come out of hibernation.

BIOLOGY: Females taken off ground squirrels (when they come out of hibernation during March) often have in their abdomen 2 or 3 eggs large for a flea.

RECORDS for this species personally collected by the writer are from:

CALIFORNIA-Off:

Peromyscus maniculatus gambeli Baird (Gambel's deer mouse),

Tule Lake, Siskiyou County, April 19, 1942, 1 male; Mcdoel, Siskiyou County, March 21, 1943, 3 males, and 8 females with eggs; April 17, 1943, I male, 2 females; April 18, 1943, 1 male, 4 females; Dorris, Siskiyou County, November 29, 1943, 13 males, 34 females.

OREGON-Off:

Peromyscus maniculatus gambeli Baird (Gambel's deer mouse),

Shaniko, Wasco County, December 8, 1940, 2 females; Sisters, Deschutes County, March 19, 1937, 1 female; Mitchell, Wheeler County, March 5, 1940, I female.

Citellus townsendi canus Merriam (gray sage squirrel), Shaniko, Wasco County, March 3, 1941, 2 females; Wasco, Wasco County, March 13, 1942, 2 males, 8 females

Citellus beldingi oregonus Merriam (Oregon ground squirrel), Grass Valley, Wasco County, March 13, 1942, 3 males, 6 females

Thomomys quadratus quadratus Merriam (Dalles pocket gopher), Sisters, Deschutes County, March 19, 1937, 1 male

Dipodomys heermanni californicus Merriam (Northern California kangaroo rat), Swan Lake Valley, Klamath County, April 18, 1942, 1 male

Onychomys leucogaster fuscogriseus Anthony (grasshopper mouse), Narrows, Harney County, December 11, 1936, 1 female.

NEVADA-Off:

Perognathus nevadensis Merriam (Nevada pocket mouse), Elko County, April 10, 1940, 1 male

Peromyscus maniculatus gambeli Baird (Gambel's deer mouse), Vya, Washoe County, June 16, 1944, 2 females. 
Other specimens to come under the study of the writer are:

ARIZONA-Off:

Onychomys leucogaster capitalatus Hollister (Arizona grasshopper mouse), Coconino County, April 22, 1939, 1 female

Peromyscus spp. (deer mouse), Yavapai County, April 20, 1938, 1 male.

IDAHO-Off:

Citellus townsendi mollis Kennicott (little gray sage squirrel), Canyon County, January 14, 1941, 1 female; Ada County, April 18, 1941, 1 male.

MONTANA-Off:

Citellus columbianus (Columbian ground squirrel), Ravalli County, May 3, 1940, 1 female

Peromyscus maniculatus artemesia Rhoads (sagebrush deer mouse), Rosebud County, April 12, 1940, 1 female.

UTAH-Off:

Peromyscus maniculatus artemesia Rhoads (sagebrush deer mouse), Millard County, April 10, 1940, 1 male.

WASHINGTON-Svihla reports this flea off:

Peromyscus maniculatus artemesia Rhoads (sagebrush deer mouse), Whitman County.

\section{Micropsylla goodi \\ Hubbard 1941}

1941 Micropsylla goodi Hubbard, Pacific Univ. Bul., 37:10:3.

Very similar to the preceding, differing from it mainly in presence of 5 genal teeth on each side of head. In female, spermatheca similar to preceding species, but sinus in margin of VII st. not so deeply or narrowly sinuate, but relative size of lower and upper lobes are about same. Although male is larger than preceding species, clasper is smaller, yet very similar in shape. Finger much shorter and broader than in preceding; apex not notched. IX st. distinctly different from preceding, being in shape of a stout hook.

LeNGTH: This species is somewhat larger than preceding, males measuring about $1.50 \mathrm{~mm}$., females about $2.00 \mathrm{~mm}$.

RANGE: Ranges west of crest of Cascade Mountains in Oregon, Washington, and northern California and southern British Columbia.

Host Preference: Taken generally from deer mice, occasionally from other small rodents.

Seasonal Distribution: Like preceding species, this flea is generally found only during winter and early spring months.

RECoRDs: Representative of 70 specimens of this species in the collection of the writer are:

OREGON-Off:

Peromyscus maniculatus rubidus Osgood (ruddy deer mouse), Huber, Washington County, March 2, 1935, 1 male; Gaston, Washington County, February 9, 1935, 6 males, 9 females (from nest) ; Gold Beach, Curry County, June 13, 1939, 1 female 
Peromyscus maniculatus gambeli Baird (Gambel's deer mouse), Cooper Spur, Hood River County, May 17, 1936, 1 male; Odell, Hood River County, January 15, 1939, l pair

Microtus canicaudus Miller (gray-tailed meadow mouse), Forest Grove, Washington County, March 23, 1939, 1 male,

Microtus townsendi Bachman (Townsend meadow mouse), Newberg, Yamhill County, April 18, 1937, 1 pair (from nest); Boyer (Willamina), Polk County, February 24, 1939, 3 pairs (from nest).

Accidental Occurrence:

Tamiasciurus douglasi douglasi Bachman (Douglas pine squirrel), Tualatin, Washington County, February 2, 1935, 1 female

Neotoma cinerea fusca True (dusky bushy-tailed wood rat), Gaston, Washington County, February 18, 1937, 1 female

Citellus beecheyi douglasi Richardson (gray digger), Wheatland, Yamhill County, March 6, 1939, 1 female.

WASHINGTON-Off:

Peromyscus maniculatus oreas Bangs (Washington deer mouse), Government

Mineral Springs, Carson, Skamania County, August 17, 1935, I male; Vancouver, Clark County, February 1, 1940, 1 female; Washougal, Clark County, February 23, 1940, 1 female.

CALIFORNIA-Off:

Microtus mordax augusticeps Bailey (Coast meadow mouse), Smith River, Del Norte County, April 21, 1942, 1 pair

Peromyscus maniculatus rubidus Osgood (ruddy deer mouse), Gasquet, Del Norte County, December 30, 1941, I female.

\section{GENUS ACTENOPHTHALMUS C. FOX}

1925. Actenophthalmus C. Fox. Ent. News 36:121.

Genotype: Ctenophthalmus heiseri McCoy 1911

Frontal notch distinct. Eyes absent. Gena armed with comb which consists of 5 teeth, 4 of which are line and apical, fifth rooted at about eye position on antennal groove margin. Labial palpus 5 segmented. Coxa III with spinelets on inner surface. Tarsal segment $V$ of all legs armed with 6 pairs of lateral plantar bristles. Pronotal comb present. Apical spinelets on some of the abdominal tergites. Two antepygidial bristles to the side.

Represented by a single species found in Mojave desert of southern California on ground squirrels.

\section{Actenophthalmus heiseri McCoy 1911}

1911 Ctenophthalmus heiseri McCoy, Ent. News, 22:445.

Described from single female taken at Mojave, California. Host not mentioned. Male not yet described.

Genal comb characteristic. It consists of 4 teeth in a row and apically situated, and a fifth tooth rooted above the 4 at about eye position. Occiput is gently rounded and forms distinct angle with front of head. 
Lower genal row of bristles, 2 or 3, heavy and extending far beyond genal teeth. Upper genal row with 5 strong bristles. Postantennal region with 3 rows of bristles.

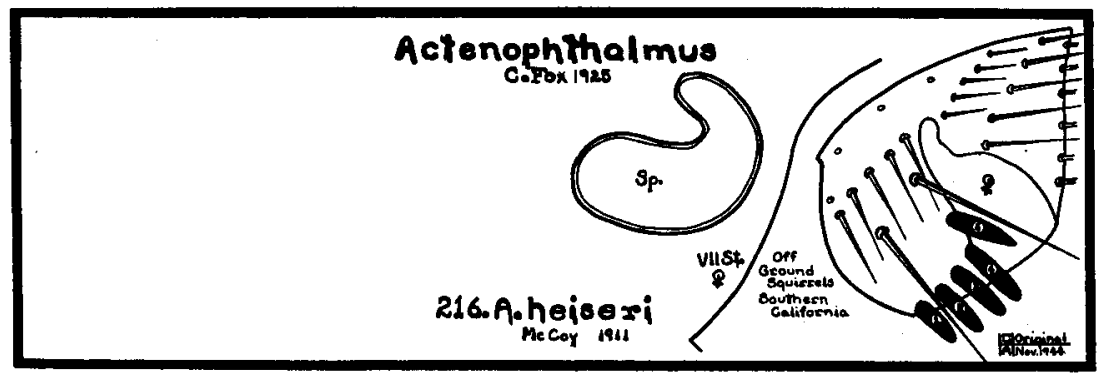

Pronotum with comb of 20 teeth, and single row of bristles. Some abdominal tergites with apical spinelets.

Modified Segments: Original drawing illustrates VII st. of female as long slanting slightly convex face; spermatheca as gradually diminishing from end to end without line of demarcation between body and tail.

LENGTH: Original length given for female $2.40 \mathrm{~mm}$.

RANGE: Known only from Mojave Desert of southern California in area about Mojave, Kern County.

Both males and females of this little known species were taken off Citellus leucurus (antelope ground squirrels) by plague investigating agencies between 1936 and 1938 in south central California but individual records have not yet been made public.

\section{GENUS PARATYPHLOCERAS EWING}

1940. Paratyphloceras Ewing. Wash. Biol. Soc. Proc. 53:35.

Genotype: Paratyphloceras oregonensis Ewing 1940.

Frontal tubercle small and apically angulate. Gena truncate apically and broad. Genal comb consists of 5 or 6 sharply pointed teeth. Eyes absent. Labial palpi with 8 segments. Pronotum with comb. Fifth segment of tarsus II with 5 pairs of lateral plantar bristles; fifth segment of tarsus III with 6 pairs of lateral plantar bristles. Abdominal tergal plate VII of female produced into a short process between two groups of antepygidial bristles.

According to Ewing, this genus is nearest to Typhloceras Wagner, from which it differs in having labial palpi composed of 8 segments rather than 5 .

This genus includes single species described from a mink taken at Mercer Lake, Oregon. 


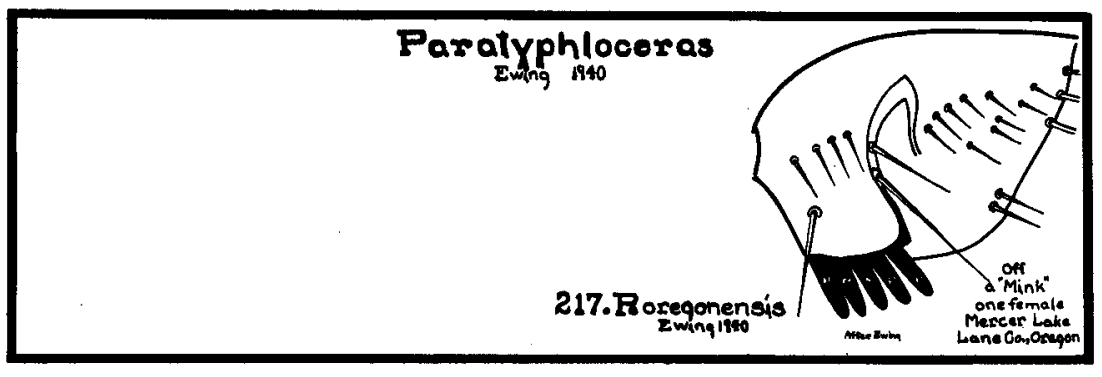

\section{Paratyphloceras oregonensis \\ Ewing 1940}

1940 Paratyphloceras oregonensis Ewing, Wash. Biol. Soc. Proc., 53:35.

Described from single female taken off Mustela vison energumenos Bangs (mink) collected at Mercer Lake, coastal strip of Lane County, Oregon, on March 12, 1933 by H. H. Stage. According to describer this species seems, at first glance, to belong to one of genera of Hystrichopsyllinae, but the presence of a frontal tubercle and less than 7 spines in the genal comb immediately separate it from members of that sub-family.

HEaD: Well rounded with genal comb of 5 teeth. Frontal tubercle present. Eyes absent. At about eye level a row of 2 long bristles and above these a second row of 4 medium bristles; midway between 2 rows a lone medium bristle at antennal groove. Postantennal region with 3 rows of bristles. Maxillary palpus reaches to about apex of Coxa I. Maxillary lobe is long, dagger-like, reaching to middle of segment III of maxillary palpus.

Pronotal comb with 18 teeth. Mesonotum about equal in length and width to pronotum. The metanotum is shorter but broader than mesonotum. The upper sclerite of metepisternum is subtriangular, with a large, posterior, marginal bristle, a large, ventral submarginal bristle, and 2 much smaller distal setae.

Abdomen is large, somewhat swollen and clothed with long setae dorsally and ventrally, but not laterally. Abdominal t. I armed with a transverse row of 8 apical spines; t. III with 6 apical spines; t. IV with 2 apical spines; other abdominal tergites without apical spines. There are 3 antepygidial bristles to side. These are long, subequal. Stylet long, slender and curved, and armed subterminally with dorsally placed large bristle, and a much smaller terminal bristle and an outer subterminal one. Spermatheca made up of a medium sized, subspherical body and a short, strongly curved, truncate tail.

LENGTH: Original length of female is given as $5.10 \mathrm{~mm}$.

RANGE: This species is known only from original specimen taken at Mercer Lake, Lane County, Oregon. 
GENUS RECTOFRONTIA W. AND A.

1934. Rectofrontia Wagner and Argyropolo. Zeitschr. Parasit., 7:230.

Genotype: Typhlopsylla pentacanthus Rothschild 1897.

According to I. Fox, anterior border of head is produced into a prominent tooth. Eye vestigial. Genal teeth variable, 4 to 6 . Genal bristles, 1 or 2 heavy ones above eye position, and 5 or 6 medium ones to anterior. There are 5 segments to labial palpi. Males possess no antepygidial bristles, females 2 . Fifth tarsal segment of each leg armed with 4 pairs of lateral plantar bristles, basal submedium pair missing.

Represented in North America by but one known species which seems to be sparingly distributed from coast to coast, and which apparently is a vicariating species found upon a variety of smaller mammals.

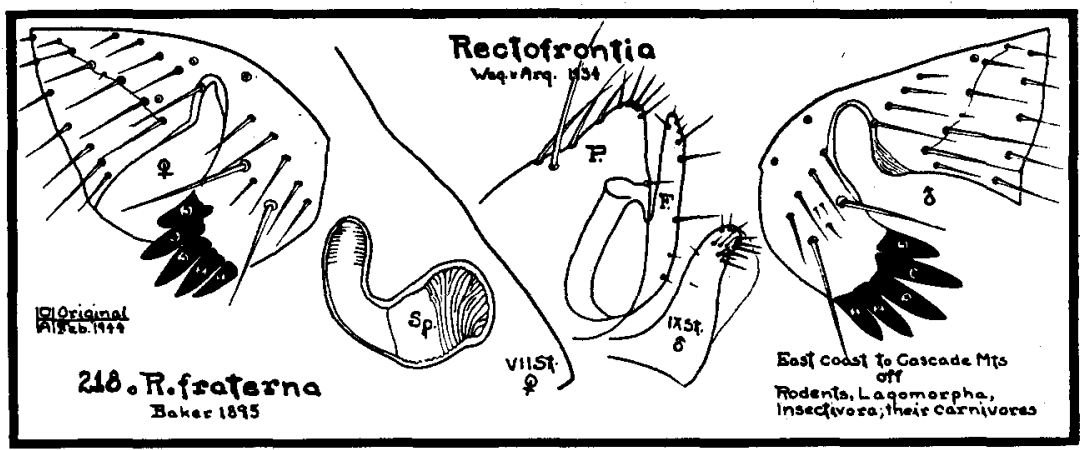

218. Rectofrontia fraterna

Baker 1895

1895 Typhlopsylla fraterna Baker, Can. Ent., 27:189.

1904 Ctenophthalmus fraternus Baker, Proc. U. S. Nat. Mus., 27:423.

1905. Ctenophthalmus fraternus Baker, Proc. U. S. Nat. Mus., 29:135.

1913 Rhadinopsylla fraterna Rothschild, The Entomologist, 46:297.

1923 Rhadinopsylla fraternus J. and R., Ectoparasites 1, p. 314.

1923 Neopsylla hamiltoni Dunn, U. S. Pub. Health Repts., 38:2770.

1936 Rectofrontia fraternus Wagner, Can. Ent., 68:203.

1937 Rectofrontia fraterna Jordan, Nov. Zool., 40:270.

1940 Rectofrontia fraterna I. Fox, Fleas of the Eastern U. S., p. 38.

Described from single female which Professor Aldrich collected at Brookings, South Dakota. Host was not given but Baker thought it might have been a mole. As late as $1940 \mathrm{I}$. Fox gives a description of male, specimen in United States National Museum, collection made off Microtus at Kensington, Maryland.

Armature of head consists of 2 rows of bristles on gena, 2 stout below, 5 or 6 weak ones above, postantennal region with 3 rows. Genal teeth 4 or 5 in number. Pronotal comb of 20 to 22 teeth. Some abdominal tergites with apical spinelets. These characteristics are similar in female. 
Modified Segments: According to Fox, process $\mathrm{P}$ wide and heavy, somewhat triangular. Finger $\mathbf{F}$ narrower, outer margin convex, inner concave. VII st. of female may be variable. The writer's only specimen, which was studied by Dr. Jordan, has distinct apical margin consisting of fairly wide sinus toward ventral, and dorsal to it a lobe somewhat triangular. Female loaned the writer by Dr. M. A. Stewart possesses a margin distinctly not sinuate. Spermatheca characteristic.

LeNGTH: Female in Dr. Stewart's collection measures $2.80 \mathrm{~mm}$., the writer's female measures only $2.30 \mathrm{~mm}$., and male in Dr. Stewart's collection measures $2.30 \mathrm{~mm}$.

RANGE: This flea apparently ranges from coast to coast in North America. Records from Maryland, South Dakota, Montana, Wyoming, Alberta, Canada, and the writer's record from Oregon.

Host Preference: This seems a vicariating species, the writer's record off a cony, other records from meadow mice, ground squirrels, and other small rodents.

Abundance: From few specimens of this flea in collections, it should be considered rare. It could be a nest species.

Records: The writer's only record from west of the Rocky Mountains is:

Ochotona fenisex fumosa Howell (dusky cony), Summit McKenzie Pass, Oregon, July 24, 1938, 1 female.

Although the writer has trapped this cony rock slide at various seasons of various years, and has taken all types of mountain rodents from it, this species has never again been taken here or elsewhere west of Rockies of United States.

G. P. Holland reports taking this species off Citellus columbianus columbianus Ord (red digger) at Waterton Lakes, British Columbia, June 27, 1938, and off Citellus richardsoni (Richardson ground squirrel) at Hanna, 7 miles south of Watts on June 1, 1939, and High River on August 28, 1938, both localities in Alberta.

MONTANA-From this state this flea is reported off:

Mustela nigripes subsp. (black-footed ferret), Powder River County

Mustela spp. (weasel), Flathead County

Citellus armatus Kennicott (Uinta ground squirrel), Madison County

Citellus columbianus subsp. (Columbian ground squirrel), Jefferson, Powell, and Ravalli Counties

Citellus richardsoni subsp. (Richardson ground squirrel), Beaverhead and Valley Counties

Cynomys ludovicianus (prairie dog), Garfield County

Neotoma cinerea subsp. (wood rat), Madison and Ravalli Counties.

SOUTH DAKO'TA-From this state the writer has seen specimens off:

Peromyscus maniculatus subsp. (deer mouse), collected in Potter County, May 26, 1942. 


\section{GENUS HYSTRICHOPSYLLA TASCHENBERG}

1880. Hystrichopsylla Taschenberg. Die Flohe, p. 83.

Genotype: Pulex talpae Curtis 1826

Eye is vestigial. Labial palpus consists of 5 segments. Both genal and pronotal comb present. Apical spinelets on abdominal tergites II, III, and IV. Each tergite armed with 3 rows of bristles. Females with 2 spermatheca. Three antepygidial bristles in male, 4 in female, on each side. Anterior tibia armed with a comb of robust heavily pigmented bristles on posterior border. Fifth tarsal segment of each leg armed with 5 pairs of lateral plantar bristles, basal submedian pair missing.

Represented in West by two species, smaller from 4 to $5 \mathrm{~mm}$. in length with about 36 pronotal teeth and found generally on wild mice H. gigas dippiei, p. 357 and the larger from 6 to $8 \mathrm{~mm}$. in length with about 46 pronotal teeth, and found generally only on Aplodontia H. schefferi, p. 359

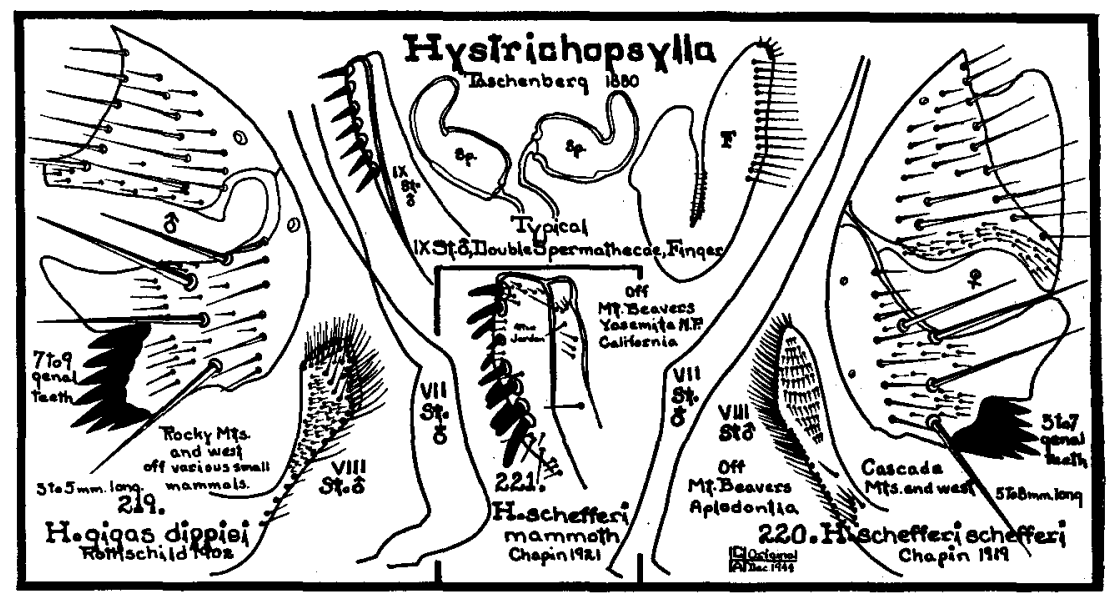

219. Hystrichopsylla gigas dippiei

\section{Rothschild 1902}

1895 Pulex gigas Baker, Can. Ent., 27:163.

1902 Hystrichopsylla dippiei Rothschild, Ent. Record, 14 (3) :63.

1914 Hystrichopsylla dippiei C. Fox, U. S. Pub. Health Serv. Hyg. Lab. Bul., 97, fig. 52.

1919 Hystrichopsylla dippiei Chapin, Bul. Brooklyn Ent. Soc., 14:52.

1921 Hystrichopsylla dippiei Chapin, Proc. Ent. Soc. Wash., 23 No. 2.

1936 Hystrichopsylla dippiei Wagner, Can. Ent., 68:205.

This subspecies was described from materials gathered off Lutreola vison energumenos Bangs (western mink) at Chilliwak, British Columbia and off Putorius longicaudatus (weasel) at Alberta. To this writer both of these occurrences seem accidental. The true hosts of this species are without doubt various small wild rodents. 
With exception of the following species from which it can be distinguished by size, host, and number of pronotal teeth, this flea can be told from all other known western fleas by the presence of the 6 to 9 slender pointed genal teeth. Pronotal comb with about 36 teeth. Upper half of finger concave on either border while in following species borders of upper half slightly convex. VII st. of female of this species has an apical outline almost identical with the following. There are 2 spermatheca.

LENGTH: This species varies a great deal in length in both sexes, some as small as $3.50 \mathrm{~mm}$., others as long as $5.50 \mathrm{~mm}$.

RANGE: Described from Rocky Mountains of Alberta, and from western British Columbia, this species seems to sweep south through Rocky Mountains, Cascade-Sierra Mountains and territory west to $\mathrm{Pa}$ cific Ocean. Reported as far south as San Francisco Bay. This species seems to avoid desert regions of Great Basin.

Preferred Host: This species seems more or less vicariating, making itself at home on almost any wild mouse. It can occasionally be found upon house mice living in fields and upon pine squirrels and other small rodents.

Seasonal Distribution: A large series of this species in collection of the writer has been collected in all months of year except May, June, and July.

Abundance: Not abundant upon host itself, occasionally I, sometimes 2, but if nests of meadow mice or deer mice can be located in spring, sometimes they give up half a dozen or more. This would lead one to believe this species to be a nest flea.

Medical Importance: Eskey and Haas fed 5 specimens of this species upon plague-positive guinea pigs. Two of these became infected. There is no record of infected fleas being able to transmit the disease or of clearing themselves of infection.

RECORDS: Representative of many records for this species in the collection of the writer are:

\section{OREGON-Off:}

Peromyscus maniculatus rubidus Osgood (ruddy deer mouse), Silver Creek Falls, Silverton, Marion County, September 3, 1935, 1 male

Microtus townsendi Bachman (Townsend's meadow mouse), Gaston, Washington County, March 12, 1935, 1 male, 1 female

Microtus oregoni oregoni Bachman (Oregon creeping mouse), Tillamook, Tillamook County, September 1, 1937, 1 male

Microtus canicaudus Miller (gray-tailed meadow mouse), Gaston, Washington County, March 25, 1940, 1 male, 1 female

Microtus richardsoni arvicoloides Rhoads (Cascade meadow mouse), Bridal Veil, Multnomah County, April 1, 1939, 1 female

Mus musculus musculus Linnaeus (house mouse), Nashville, Lincoln County, March 25, 1939, 1 female

Tamiasciurus douglasi douglasi Bachman (Douglas pine squirrel), Gaston Washington County, December 20, 1937, 1 female 
Tamiasciurus douglasi cascadensis Allen (Cascade pine squirrel), Detroit Marion County, September 30, 1939, 1 female

Neotoma fuscipes fuscipes Baird (round-tailed wood rat), Salem, Marion County, September 10, 1940, 1 male.

NEVADA-Off:

Peromyscus maniculatus sonoriensis Le Conte (Sonoran deer mouse), Charleston Park, Las Vagas, Clark County, June 25, 1945, 1 female.

WASHINGTON-Off:

Microtus richardsoni arvicoloides Rhoads (Cascade meadow mouse), Carson, Skamania County, August 20, 1935, 1 female.

CALIFORNIA-As early as February, 1921, Dr. A. E. Chapin states in Vol. 23, No. 2 of Proc. Ent. Soc. of Wash. that he was "indebted to S. O. Martin of Berkeley, who collected this species in nests of Neotoma fuscipes" (round-tailed wood rat).

On April 21, 1942 the writer removed 2 males and 1 female from:

Microtus mordax augusticeps Bailey (coast meadow mouse), nest, adult, and 1 young, Smith River, Del Norte County,

Augustson reports this species as far south as Point Arguello, Santa Barbara County, where on March 14, 1942 he took a male off:

Peromyscus maniculatus gambeli Baird (Gambel's deer mouse).

MONTANA-Off:

Tamiasciurus hudsonicus subsp. (pine squirrel), Ravalli County, 1922

Microtus spp. (meadow mouse), Powder River County, 1916

Eutamias spp. (chipmunk), Ravalli County, 1922

Citellus richardsoni subsp. (Richardson's ground squirrel), Beaverhead County, 1938

Citellus armatus Kennicott (Uinta ground squirrel), Gallatin County, 1938

Canis latrans Say (northern coyote), Toole County, 1936.

UTAH-Reported off:

Microtus spp. (meadow mouse), Etna

Tamiasciurus spp. (red squirrel)

Clethrionomys (red-backed mouse), Logan Canyon, Cache County.

ARIZONA-In this state the author has collected this flea off:

Microtus mordax mordax Merriam (Rocky Mountain meadow mouse), North Rim, Grand Canyon, Coconino County, July 7, 1945, 1 male.

Peromyscus maniculatus rufinus Merriam (tawny deer mouse), North Rim, Grand Canyon, Coconino County, July 7, 1945, 1 male.

BRITISH COLUMBIA-Off:

Peromyscus maniculatus austerus Baird (Puget Sound deer mouse), Vancouver, B. C.

Eutamias amoenus affinis Allen (Columbian chipmunk)

Spilogale gracilis phenax Merriam (little spotted skunk).

\section{Hystrichopsylla schefferi schefferi Chapin 1919}

1919 Hystrichopsylla schefferi Chapin, Bul. Brooklyn Ent. Soc., 14:50.

1921 Hystrichopsylla schefferi Chapin, Proc. Ent. Soc. Wash., 23, No. 2.

Described from single female taken from nest of Aplodontia rufa (mountain beaver) at Puyallup, Washington, by T. H. Scheffer.

Distinguished from all other American fleas by its large size, it is 
conceded to be largest flea known. Number of genal teeth is fairly constant at 6, although occasionally 7 can be found. Pronotal comb bears about 46 teeth. In male, finger $\mathbf{F}$ has borders of apical half slightly convex, thus differing from preceding species. In female, apical margin of VII st. is very similar to preceding, but there is recorded a difference in size of spermatheca. Size of spermatheca is relatively unimportant when the size, host, and number of genal teeth act as distinguishing features.

LENGTH: Of 5 males and 30 females in this relatively rare flea in the collection of the writer, there are all stages of contraction in the mounted specimens. The largest male measures a full $6.00 \mathrm{~mm}$., the largest female a full $8.00 \mathrm{~mm}$. This subspecies is listed as the largest known flea in the world.

RANGE: The writer has collected this giant flea from mountain beavers throughout their entire range; therefore, the range of this spe- cies is south of the Frazer River in British Columbia, north of San Francisco Bay, California, throughout Cascades and west to the Pacific Ocean.

Preferred Host: A true flea of Aplodontia (mountain beaver) in all its subspecies. Occasionally it can be taken off the carnivores of mountain beavers.

Seasonal Distribution: So few of these fleas come to hand that it is difficult to establish a seasonal distribution. Single specimens have been taken during every month of year. An exception deserving of note was removal of 1 male and 6 females from a single mountain beaver at Cannon Beach, Oregon, March 22, 1940. This record suggests a sex ratio of about 6 females to 1 male and a seasonal maxima possibly during March.

ABUNDANCE: This flea seems rare. Collection records for 100 mountain beavers trapped by the writer reveal only 5 males and 24 females taken, or about 1 specimen to every 4 hosts. It is quite possible that this species is a nest flea which would be more easily found in nests of host than upon hosts themselves. Mountain beaver nests are rather difficult to locate.

RECORDS: Representative of the 35 specimens of this species in collection of the writer are:

WASHINGTON-Off:

Aplodontia rufa rufa Rafinesque (Cascade mountain beaver), Seattle, King County, July 3, 1921, 1 female

Aplodontia rufa rainieri Merriam (Rainier mountain beaver), Skamania, Skamania County, October 29, 1933, 1 female; Amboy, Clark County, November 12, 1933, 1 female

Aplodontia rufa olympica Merriam (Olympic mountain beaver), Cathlamet, Wakiakum County, June 15, 1934, 1 female.

OREGON-Off:

Aplodontia rufa rufa Rafinesque (Cascade mountain beaver), Estacada, Clackamas County, July 20, 1931, 1 female 
Aplodontia rufa pacifica Merriam (coast mountain beaver), Toledo, Lincoln County, September 4, 1936, 1 female.

Accidental Occurrence:

Lutreola vison energumenos Bangs (western mink), Blodgett, Lincoln County, (from mountain beaver burrow), July, 1939, 1 female.

CALIFORNIA-Off:

Aplodontia rufa humboldtiana Taylor (Humboldt Bay mountain beaver), Fort Dick, Del Norte County, June 15, 1939, I female; Smith River, Del Norte County, August 10, 1943, 5 females.

\section{Hystrichopsylla schefferi mammoth Chapin 1921}

1921 Hystrichopsylla mammoth Chapin, Proc. Ent. Soc. Wash., 23, No. 2. 1937 Hystrichopsylla mammoth Jordan, Nov. Zool., 40:270.

Described from material taken off Aplodontia californica Peters (mountain beaver) at Mammoth, Mono County, California, July, 1917, by A. B. Howell and at Indian Canyon, Yosemite National Park, California, probably off Aplodontia by Dr. G. F. Ferris.

Original description states that upper genal row of bristles consists of 7 , but this is not necessarily a point of distinction since preceding subspecies has also at times 7 instead of 8 , and while original description calls for 7 genal teeth, in preceding often it has 6 , same number listed originally for this subspecies. Pronotal comb, if correctly diagnosed, is a distinct feature; its description follows: "The pronotum bears on its posterior margin a ctenidium of about 36 spines or pairs of spines. That is, commencing with the fourteenth spine from either side, the dorsal spines are very irregular but appear to be grouped in pairs, one superimposed upon the other." While original description calls attention to apical spinelets on tergites, these are seldom constant in number. Of modified segments, it is said that VIII st. of male is produced posteriorly into a scoop-shaped process, thick-set with fine short hairs. IX st. club shaped. Finger of clasper is elongate, thickest slightly beyond middle. On either side, toward posterior margin there is a straight row of about 15 hairs, reaching from apex to about basal third. VIII $t$. trapezoidal in shape. In female, body of spermatheca is nearly square instead of rectangular as in $H$. schefferi Chapin.

LENGTH: Original given as male $7.38 \mathrm{~mm}$., female $7.53 \mathrm{~mm}$.

This subspecies is known only from original description.

Jordan states in 1937, "The various Nearctic fleas described as distinct species of Hystrichopsylla Taschenb. 1880 are possibly all forms of one species, $H$. gigas Kirby 1837. But the material we have in the collection, or I have examined in U. S. A., is insufficient for the thorough revision of the genus. I have made notes, but have to wait for more specimens, the usual complaint in systematics.

"We figure here sternum IX of the type of mammoth, in U. S. Nat. Mus., Washington, D. C. The specimen is much larger than any of our specimens of $H$. gigas dippiei Roths. 1900." 
While studying this flea in the National Museum Jordan failed apparently to compare it with $H$. schefferi, the most closely allied species. The author feels that $H$. schefferi and $H$. mammoth are very closely allied, both being set off from $H$. gigas dippiei in structure of VIII st. of male. From this evidence the writer is reducing mammoth to a subspecies of schefferi.

\section{GENUS STENOPONIA J. AND R.}

1911. Stenoponia Jordan and Rothschild. Proc. Zool. Soc. London 1911, p. 391. Genotype: Hystrichopsylla tripectinata Tiraboschi 1902.

Genal comb of many long slender black teeth. Eyes absent. Labial palpus short and consisting of 1 segment (Ewing and Fox maintain that there are 2 segments). Club of antenna short. Pronotal comb present. First abdominal tergite with a comb of teeth which are as prominent as those of pronotal comb. Apical spinelets short and stout on abdominal tergites 2 to 5 . Antepygidial bristles number 4 to 6 on each side in the female; 3 to 4 in male. Tarsal segment $V$ with 4 pairs of lateral plantar bristles and a basal median pair. Spermatheca usually one. Size large.

Represented in West by but a single species which has been recorded from Montana off Peromyscus (deer mouse).

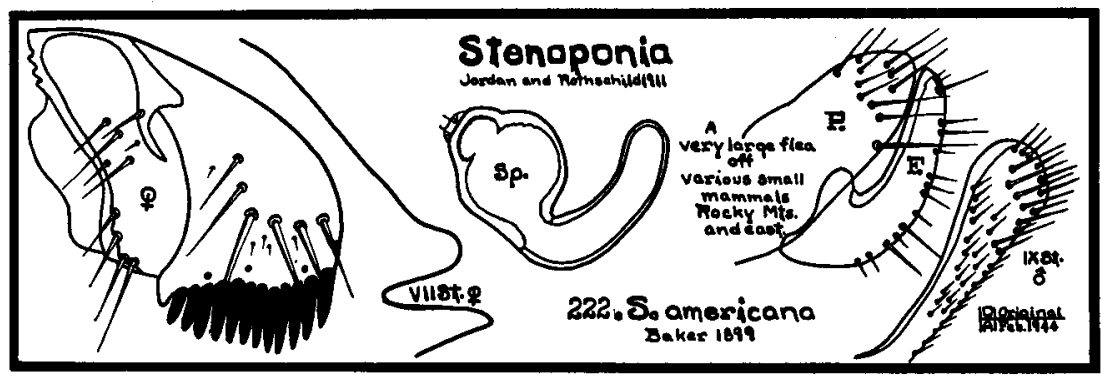

\section{Stenoponia americana \\ Baker 1898}

1899 Hystrichopsylla americana Baker, Ent. News, 10:37.

1919 Stenoponia wetmorei Chapin, Bul. Brook. Ent. Soc., 14:52.

Described from material off a red-backed mouse taken at Orono, Maine.

Head: Genal comb of about 26 teeth. Six bristles on gena; about 6 on postantennal region. No eyes. Genal process wide, postantennal region narrow.

Pronotum with a comb of about 26 teeth to side. In front of comb about 4 rows of bristles.

Abdomen: Abdominal tergites each with 3 rows of bristles. First 
tergite with comb of 42 teeth. T. II to IV with a series of short stout apical spinelets.

Modified Segments, Male: Process of clasper is broad, apically rounded and armed with a series of medium bristles. Finger F curved and a little longer than process; armed all along posterio-ventral border with short and medium bristles. IX st. expanded apically, paddle shape, armed with numerous bristles. Female: VII st. with deep sinus close to ventral. Lower lobe narrow, triangular, upper lobe also weak, apically rounded. Head of spermatheca spherical; tail very long, crooked.

LENGTH: This large species varies between 4.00 and $5.00 \mathrm{~mm}$. in both sexes.

RANGE: In West this flea is reported only from Montana. It is a common flea in east of United States. Only western record is off Peromyscus spp. (deer mouse), Rosebud County, Montana, 1916.

\section{GENUS CORYPSYLLA G. FOX}

1908. Corypsylla C. Fox. Ent. News 19:452.

Genotype: Corypsylla ornatus C. Fox 1908

Simple statements listed for the genus at time of its erection were: "Spines on head, structure of head, spines on back of abdomen, mesothorax not divided by a vertical surture, episternum of metathorax fused with the metanotum. Hind coxae with a patch of bristles on inside. All tarsi with 4 pairs of lateral bristles on fifth segments."

Additional characteristics common to the 3 known species are: Genal comb of 6 spatulate teeth (the crest). Eyes absent. Bristles of post-antennal region constant. Antepygidial bristles 1 in male, 2 in female, to the side. Pronotal comb with all teeth normal in male, but in female lower 8 or 9 "indistinct pseudo spines." Abdominal tergites from first to sixth have in median line of dorsal surface a distinct saddle-shaped chitinous patch (called by present writers "heavy transverse incrassation") and a set of short stout teeth (apical spinelets) which overhang chitinous patch of next posterior segment.

This western genus is represented by 3 known species which regularly infest Insectivora (moles and shrews), and which can be distinguished from one another by arrangement of teeth of crest.

\section{Key to the Species of Corypsylla}

1. Third genal tooth from ventral longest, pointed but not bisymmetrical C. ornata, p. 364

2. Third genal tooth from ventral longest, pointed and symmetrical C. jordani, p. 365

3. Third genal tooth from ventral longest, greatly enlarged at tip which terminates in an acute angle C. setosifrons, p. 366 


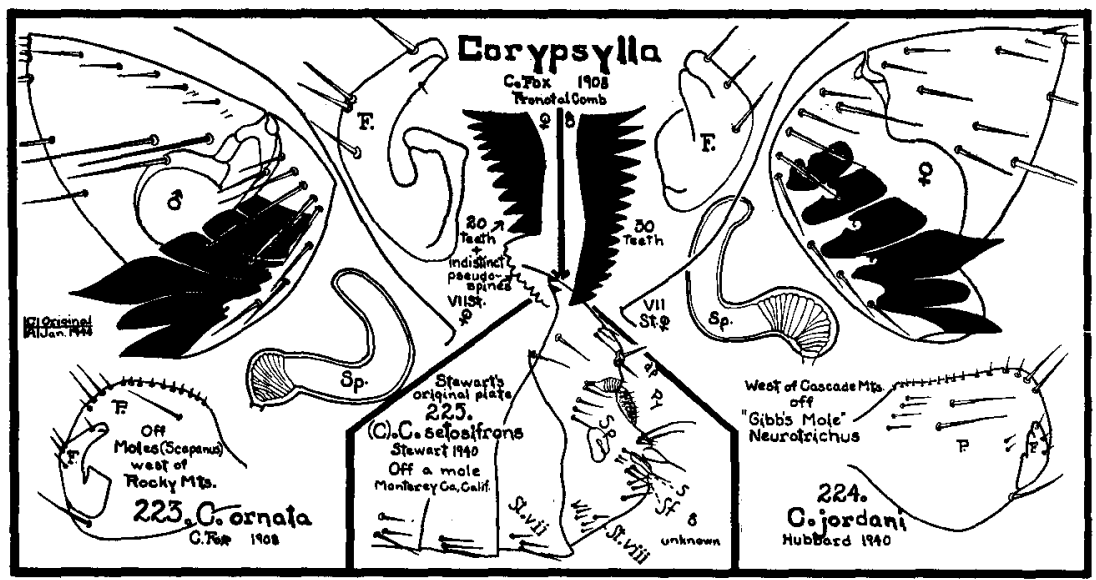

\section{Corypsylla ornata}

C. Fox 1908

1908 Corypsylla ornatus C. Fox, Entomological News, 19:452.

1940 Corypsylla ornatus Hubbard, Pacific Univ. Bul., 37:1:6.

1940 Corypsylla ornatus Hubbard, Pacific Univ. Bul., 37:2:7.

This species was described from materials taken off Scapanus californicus (mole) at San Francisco, California. The species bears a genal crest of 6 spatulate teeth of which third from ventral is characteristic in shape, thus distinguishing it from other 2 species. This tooth is longest, pointed, but not bisymmetrical in shape, swelling on upper lateral margin much greater than swelling on lower lateral margin. Head is pointed. Pronotal comb, in male 36 normal teeth, in female 36 teeth of which the lower 8 or 9 are modified, reduced, plate-like ("indistinct pseudospines"). Abdominal tergites with transverse incrassation and apical spinelets. In male process of clasper large and finger $\mathrm{F}$ small. Finger somewhat hook-shaped and armed with 4 bristles. Body of sper: matheca tiny, globular, tail long, hooked.

Length: Male $2.00 \mathrm{~mm}$., female $2.30 \mathrm{~mm}$. Variable.

RANGE: South of Fraser River of British Columbia, west of east foothills of Cascade-Sierra Mountains in Washington, Oregon, and California.

Preferred Host: A true western mole flea.

Seasonal Distribution: Can be taken from moles whenever they can be trapped, but larger numbers seem present during spring.

Abundance: Moles are seldom without this species, a host carrying from a few up to a hundred.

RECORDS: Representative of several hundred records in collection of the writer are: 
WASHINGTON-Off:

Scapanus townsendi Bachman (Townsend's mole), Washougal, Clark County, March 8, 1940, 1 male, 1 female.

OREGON-Off:

Scapanus townsendi Bachman (Townsend's mole), Forest Grove, Washington County, May 1, 1937, 1 male, 5 females; Cannon Beach, Tillamook County, March 21, 1940, 25 males, 67 females; Salem, Marion County, June 25, 1938, 3 males, 3 females

Scapanus latimanus alpinus Merriam (Mazama mole), Little Lava Lake, Bend, Deschutes County, July 27, 1936, 3 males, 4 females

Scapanus latimanus dilatus True (silver mole), Tygh Valley, Wasco County, May 22, 1937, 3 males, 14 females

Scapanus orarius orarius True (coast mole), Cannon Beach, Tillamook County, March 23, 1940, 6 males, 12 females,

Accidental Occurrences:

Peromyscus maniculatus rubidus Osgood (ruddy deer mouse), nest, Gaston, Washington County, March 16, 1935, 1 female; Forest Grove, Washington County, March 18, 1936, 1 female

Thomomys bulbivorus Richardson (Camas pocket gopher), Forest Grove, Washington County, July 8, 1932, 1 male, 1 female.

\section{CALIFORNIA-Off:}

Scapanus orarius orarius True (coast mole), Fort Dick, Del Norte County, April 21, 1942, 2 pairs.

BRITISH COLUMBIA-G. J. Spencer collected this species off Scapanus orarius schefferi Jackson (Scheffer's mole) during 1938 at Vancouver.

\section{Corypsylla jordani \\ Hubbard 1940}

1940 Corypsylla jordani Hubbard, Pacific Univ. Bul., 37:1:9.

Although this species was described from a male and a female taken from nest of deer mouse, the writer feels that there is no doubt that this occurrence was accidental. True host of species Neurotrichus gibbsi gibbsi Baird (Gibb's shrew mole).

Distinguished from $C$. ornata by rounded head and shape of third tooth from ventral on crest, which is longest, pointed and bisymmetrical. Pronotal comb in male with about 30 normal teeth, in female about 32 teeth of which the lower 8 or 9 are "indistinct pseudospines." Abdominal tergites with transverse incrassation and apical spinelets. In male process $\mathbf{P}$ somewhat rounded but flattened dorsally; finger $\mathrm{F}$ characteristic in shape and armed with 3 bristles. Spermatheca much larger than in $C$. ornata, body seeming to be mere enlargement of tail which is long and hooked.

LENGTH: Male $1.60 \mathrm{~mm}$., female $2.00 \mathrm{~mm}$.

RANGE: Range of this species is probably that of Gibb's shrew mole, that is, west of Cascade Mountains in British Columbia, Washington, Oregon, and northern California.

Host Preference: True host of this species is Neurotrichus gibbsi gibbsi Baird which is known commonly as shrew mole or Gibb's mole.

Seasonal Distribution and Abundance: Where definitely known to 
range, it can be taken off its true host, Gibb's mole, whenever host can be trapped. The writer removed 29 males and 36 females off 25 of these small moles captured between January 15 and February 15, 1940.

Deposits: Holotype and allotype are mounted on one slide which bears the writer's number 238 and are deposited in the Academy of Natural Sciences of Philadelphia.

Records: Typical of many records from type locality are: OREGON-Off:

Neurotrichus gibbsi gibbsi Baird (Gibb's mole), Gaston, Washington County, January 15, 1940, 4 males, 5 females

Peromyscus maniculatus rubidus Osgood (ruddy deer mouse), nest with young, Gaston, Washington County, March 16, 1935, 1 pair.

The author has also taken this flea in

WASHINGTON-Off:

Neurotrichus gibbsi gibbsi Baird (Gibb's mole) (10 specimens), Vancouver, Clark County, January and February, 1940, clean

Neurotrichus gibbsi gibbsi Baird (Gibb's mole) (I specimen), Battle Ground, Clark County, September 16, 1941, 1 male, 1 female.

CALIFORNIA-Off:

Neurotrichus gibbsi gibbsi Baird (Gibb's mole), Elk Creek Forest Camp, Gasquet, Del Norte County, April 21, 1942, l female.

\section{Corypsylla setosifrons \\ Stewart 1940}

1940 Corypsylla setsifrons Stewart, Pan-Pacific Ent., 16:23.

Described from a single female which was taken off Scapanus latimanus subsp. (mole) near Jamesburg, California, July 9, 1938, by C. P. North.

Distinguished from 2 preceding in that third tooth of crest, from ventral is longest and has tip greatly enlarged and terminates in acute angle. Pronotal comb consists of 16 normal teeth and below these a continuation composed of 9 "indistinct pseudospines." No mention is made in description of transverse incrassation, but apical spinelets are present on abdominal tergites. The modified segments are characterized as follows: A vertical row of 4 bristles below antepygidial bristles. VIII t. bears a vertical row of 5 bristles. Two horizontally arranged bristles on dorsal margin of VIII st. Posterior margin of VII st. curved concavely. Spermatheca slightly veriform and with tail longer than body. Stylet long and cylindrical in shape.

Known only from holotype which is deposited in collection of describer.

\section{GENUS CORYPSYLLOIDES HUBBARD}

1940. Corypsylloides Hubbard. Pacific Univ. Bul., 37:2:7.

Genotype: Corypsylla kohlsi Hubbard 1940.

Similar to Corypsylla but without transverse incrassation on abdominal tergites and no "indistinct pseudospines" in pronotal comb of 
female. Differs, from Nearctopsylla Rothschild which has in common with it the crest, by structure of thorax which is: Mesopleuron not divided by a vertical rodlike sclerotization into a mesoepisternum and a mesepimeron; line of division between metepisterna and metepimeron not distinct. Eyes absent.

Represented by but 1 known species, the genotype, which is found upon various shrews but can occasionally be taken off meadow mice which associate closely with shrews.

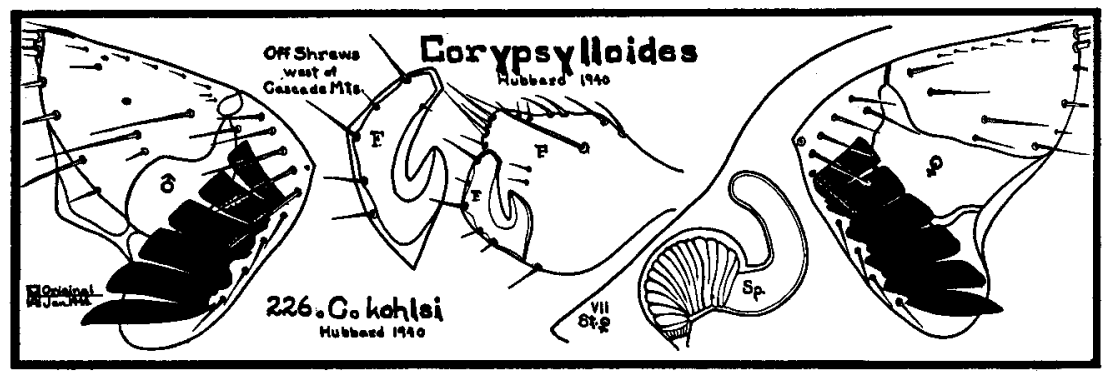

\section{Corypsylloides kohlsi \\ Hubbard 1940}

1940 Corypsylla kohlsi Hubbard, Pacific Univ. Bul., 37:1:10.

1940 Corypsylloides kohlsi Hubbard, Pacific Univ. Bul., 37:2:7.

1940 Corypsylloides spinata I. Fox, Jour. Wash. Acad. of Sci., 30:273.

Described from materials taken off Sorex obscurus bairdi Merriam (Baird's shrew) at Cannon Beach, Tillamook County, Oregon, March 29, 1937.

Distinguished instantly from all other known crested fleas, that is, Corypsylla and Nearctopsylla, by fact that all 6 spatulate teeth of crest are about same length and 2nd, 3rd, 4th, and 5th teeth of crest are apically blunt. Pronotal comb of about 26 normal teeth in both sexes. Apical spinelets present on abdominal tergites but transverse incrassation absent.

Modified Segments, Male: Process of clasper large, armed dorsally with medium bristles, finger characteristic in shape and armed with several bristles. Spermatheca large, body larger in diameter than tail, the 2 parts of about equal length.

LENGTH: Male $1.30 \mathrm{~mm}$., female $1.50 \mathrm{~mm}$.

RANGE: West of Cascade Mountains in northern California, Oregon, and probably Washington and British Columbia.

Host Preference: Although I. Fox lists 8 specimens from Townsend's meadow mouse at Portland, Oregon, which is more specimens than this writer has seen, this writer is inclined to believe the true host of this species is Sorex (shrews) because at both locations where he secured his specimens many meadow mice were also taken, but these did 
not carry this species, and many meadow mice taken by the writer at Portland did not carry them either.

Deposits: Holotype and allotype are mounted on one slide bearing the writer's number 659, and are deposited in the Academy of Natural Sciences of Philadelphia.

RECORDS: The writer's records for this species are:

OREGON-Off:

Sorex obscurus bairdi Merriam (Baird's shrew), Cannon Beach, Tillamook County, March 29, 1937, 1 pair; Cannon Beach, Tillamook County, February, 22, 1940, 1 male, 3 females; Forest Grove, Washington County, April 11, 1940, 1 female

Fox reports this flea off:

Microtus townsendi Bachman (Townsend's meadow mouse) (Jewett), Portland, Multnomah County, December 24, 1931, 5 males, 3 females (Type material described by I. Fox as C. spinata).

\section{CALIFORNIA-Off:}

Sorex pacificus pacificus Coues (Pacific shrew), Fort Dick, Del Norte County, January 6, 1942, 1 male, 2 females.

\section{GENUS NEARCTOPSYLLA ROTHSCHILD}

1915. Nearctopsylla Rothschild. Nov. Zool., 22:307.

Genotype: Ctenopsyllus brooksi Rothschild 1904.

Frontal tubercle absent. Both genal and pronotal comb present. Genal comb vertical and composed of 5 spatulate spines. Eyes absent. Labial palpus composed of 5 segments. Antepygidial bristles, 1 in male, 2 in female, to the side. Fifth tarsal segment of fore and middle legs with 5 pairs of lateral plantar bristles; fifth tarsal segment of hind legs with 4 pairs of lateral plantar bristles.

Represented in West by 4 species. Moles seem favored host, but specimens are reported off carnivores.

\section{Key to the Species of Western Nearctopsylla}

1. IX st. male elbow-shaped, apically pointed with large number of curved bristles at elbow; VII st. female with well developed upper lobe

N. brooksi, p. 371

2. IX st. male curved, borders parallel, apically blunt with about 3 medium bristles, VII st. female with weak nicely rounded upper lobe

$$
\text { N. hyrtaci, p. } 370
$$

3. IX st. male narrowly hook-shaped, apically pointed, medium bristles all along ventral border, VII st. female with angulate upper lobe

N. jordani, p. 369

4. IX st. male broadly hook-shaped, stout bristles along ventral border, VII st. female with small upper rounded lobe and lower face undulate 


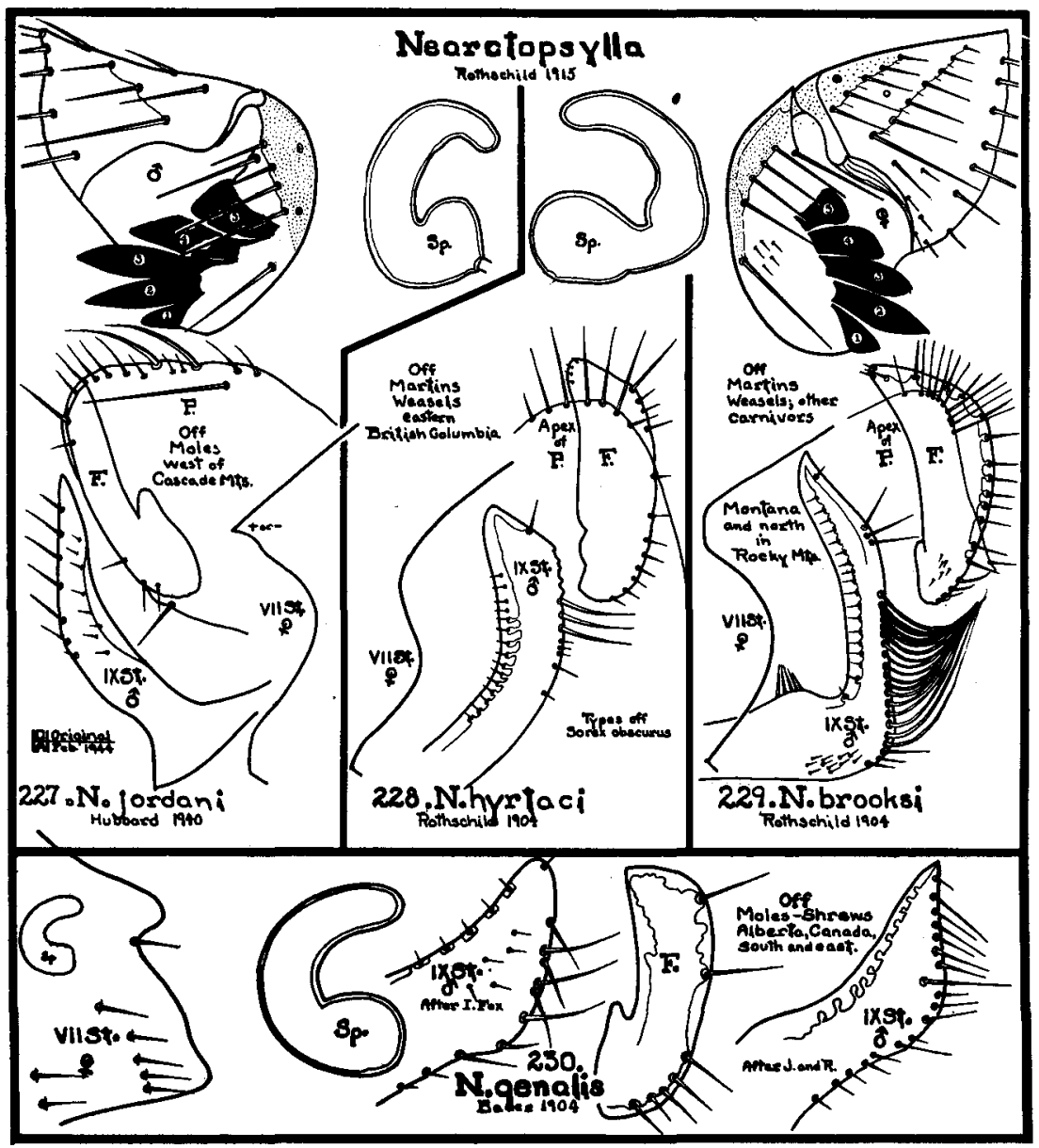

227. Nearctopsylla jordani

Hubbard 1940

1940 Nearctopsylla jordani Hubbard, Pacific Univ. Bul., 37:1:5.

1940 Nearctopsylla hygini columbiana Wagner, Zeit. fur Para., 11 (4) .

Described from a small series of specimens off Scapanus townsendi (Townsend's mole) taken in northwestern Oregon during the spring months of 1937.

In both male and female head is well rounded and armed with a genal comb of 5 spatulate teeth, outer ones shorter, inner ones longer. Pronotal comb of about 26 teeth in male and about 24 in female.

Modified Segments, Male: Process $P$ of clasper large and well rounded, armed with several stout bristles on margin and one of equal weight to side. A bristle below junction with finger. Finger $F$ long and slender, shorter than process, armed with about $\mathbf{5}$ short bristles. IX st. 
hook-shaped, apically pointed, armed with evenly spaced short bristles on ventral border. FEMALE: VII st. with shallow but broad sinus. Upper lobe pointed. Spermatheca with squat body and tail several times as long, heavy and hooked over body.

LENGTH: Male $2.50 \mathrm{~mm}$., female $3.00 \mathrm{~mm}$.

RANGE: Where there are moles in California, Oregon, Washington, and British Columbia.

Host Preference: This species seems to be a true mole flea.

Seasonal Distribution and Abundance: Specimens in collection of writer have been collected during spring months. Generally only 1 or 2 specimens come off a host, many hosts are without them.

Deposits: Holotype and allotype are deposited in Academy of Natural Sciences of Philadelphia and bear writer's number 685.

RECORDs: Representative of records in the collection of writer are: OREGON-Off:

Scapanus townsendi Bachman (Townsend's mole), Forest Grove, Washington County, May 1, 1937, 1 pair; Cannon Beach, Tillamook County, March 21, 1940, 1 male.

CALIFORNIA-Off:

Scapanus orarius orarius True (coast mole), Fort Dick, Del Norte County, April 21, 1942, 1 female.

WASHINGTON-Off:

Scapanus townsendi Bachman (Townsend's mole), Vancouver, Clark County, May. 21, 1943, 1 female.

Wagner reports this flea from

BRITISH COLUMBIA-Off:

Scapanus orarius schefferi Jackson (Scheffer's mole), Vancouver, British Columbia, December 9, 1938, a series.

\section{Nearctopsylla hyrtaci \\ Rothschild 1904}

1904 Ctenopsyllus hyrtaci Rothschild, Nov. Zool., 11:652.

1915 Nearctopsylla hyrtaci Rothschild, Nov. Zool., 22:307.

Described from male and female off Sorex obscurus subsp. (shrew) from British Columbia and male off Mustela vison energumenos Banks (western mink), from Cariboo, B. C.

Similar to preceding but differs in:

Modified Segments, Male: Process of clasper prominent and well rounded apically; armed at apex with series of medium bristles. Finger $F$ with sides parallel, longer than process, armed on posterio-ventral border with a long bristle and a series of shorter ones. IX st. curved with edges parallel; armed on posterio-ventral angle with 3 or so stout bristles and lower down some shorter ones. Fem.aLE: VII st. with shallow broad sinus and a not very well developed rounded upper lobe. Spermatheca similar to $N$. brooksi.

RANGE: Known only from British Columbia.

RECORDS: Specimens examined by the writer through the courtesy 
of Holland were from Cultus Lake, British Columbia, collected January 22, 1941 off martin and weasel.

\section{Nearctopsylla brooksi \\ Rothschild 1904}

1904 Ctenopsyllus brooksi Rothschild, Nov. Zool., 11:649.

1915 Nearctopsylla brooksi Rothschild, Nov. Zool., 22:307.

Described from series of specimens taken as follows: males and females off Mustela cigognani richardsoni Bonaparte (Richardson's weasel) and Mustela longicauda longicauda Bonaparte (long-tailed weasel) from Calgary, Alberta; female off Mustela cogognani richardsoni Bonaparte from Neresall, British Columbia, and male and female off Martes americana americana Turton (American martin) from Mabel Lake, British Columbia.

Heads not so well rounded as in preceding, slightly flattened at frons. Five genal teeth are spatulate, outer one shorter, inner ones longer.

Modified Segments, Male: Process of clasper somewhat triangular, apically rounded and armed there with a series of slender bristles. Finger F plough-share-shaped, longer than process, armed with a series of short bristles all along posterio-ventral border. IX st. elbow shaped, pointed apically, armed above elbow with a number of strong, curved bristles, above these 3 shorter straight bristles. Female: VII st. with a shallow broad sinus, upper lobe not broad, apex probably depending upon amount of wear upon it. In specimens examined by writer apex blunt. Spermatheca with subglobular body and long heavy tail which arches over body; tail with swollen basal portion.

RANGE: Known from as far south in Rocky Mountains as Montana, thence north and west in Alberta and eastern British Columbia.

RECORDs are not numerous for this species. MONTANA-Off:

Mustela spp. (weasel), Flathead and Ravalli Counties

Canis latrans (coyote), Glacier National Park.

BRITISH COLUMBIA-George Holland was kind enough to loan the writer specimens off:

Martes americana americana Turton (American martin) from Beaver Mouth, taken January 29, 1941.

\section{Nearctopsylla genalis \\ Baker 1904}

1904 Ctenophthalmus genalis Baker, Proc. U. S. Nat. Mus., 27:424.

1904 Ctenopsyllus hygini Rothschild, Nov. Zool., 11:650.

1923 Nearctopsylla hygini J. and R., Ectoparasites, 1:315.

1940 Nearctopsylla genalis I. Fox, Fleas of Eastern U. S., p. 91.

1943 Nearctopsylla g. genalis Ewing and Fox, Misc. Pub. 500, Dept. of Agr., p. 94.

This flea seems to have been described by Baker from materials taken at Michigan Agricultural College off either pocket gopher or mole. During the same year Rothschild described a flea as C. hygini 
from materials off a weasel from Red Deer, Alberta. In 1942 Jellison and Good did not suggest that the two fleas were same, but as early as 1940 I. Fox suggests the fleas are the same and in 1943 Ewing and Fox still list hygini as a synonym of genalis.

I. Fox characterizes this species about as follows: MaLE: Front of head flattened, more or less vertical. Genal row of 5 bristles. Frons with long bristle. Genal comb (crest) with 5 spatulate teeth, the first shortest, middle 3 longest, fifth truncate, others more or less acuminate. Postantennal region of head with 3 rows of from 4 to 6 bristles each.

Pronotum with a comb of from 26 to 28 teeth.

One long antepygidial bristle in male, 2 in female.

Modified Segments, Male: Process of clasper armed apically with a number of bristles of various sizes, and on inner surface many small setae. Finger armed on posterior margin with 4 or 5 long bristles and a few short ones. IX st. broadly hook-shaped and apically rounded, according to I. Fox, but apically pointed according to Jordan and Rothschild. There are 7 or 8 bristles on the posterior margin. Female: Apical margin of VII st. made up of 2 small lobes separated by a wide sinus which is undulate. Spermatheca characteristic.

RANGE: Widely distributed in eastern United States, but in West it is reported only from type locality for hygini which is Red Deer, Alberta.

Only original records are available.

Preferred Host: While author is inclined to call this flea a shrew and mole flea, there are records of it off pocket gophers and weasels. 


\title{
FAMILY ISCHNOPSYLLIDAE WAHLGREN
}

1907 ISCHNOPSYLLIDAE Wahlgren, Ent. Ttdsk., 28:89.

The western North American members of this family are characterized by presence of pair of highly scleotized preoral plates on each side of head. These vary in size and shape and represent modified genal teeth. Head is divided into anterior and posterior parts by a frontoepicranial groove. Eyes may be reduced, vestigial or absent. True or false abdominal combs may be present. Fifth tarsal segment of each leg is armed with 4 pairs of lateral plantar bristles and a basal submedian pair. There may also be an apical pair of small bristles.

Members of this family are normally parasitic on bats.

In West bats carry fleas of 4 genera of this family. These genera can be separated by the following key:

Key to the Genera of Western ISCHNOPSYLLIDAE

1. Maxilla truncate

Abdomen with false combs

Abdomen without false combs

2. Maxilla acuminate

Antepygidial bristles present

Antepygidial bristles absent

\author{
Myodopsylla, p. 373 \\ Myodopsylloides, p. 376 \\ Sternopsylla, p. 379 \\ Eptescopsylla, p. 378
}

\section{GENUS MYODOPSYLLA J. AND R.}

1911. Myodopsylla Jordan and Rothschild. Nov. Zool., 18:88.

Genotype: Ceratophyllus insignis Rothschild 1903.

In this genus of bat fleas the maxilla is truncate. Near position of vestigial eye at anterior border of antennal groove, a long stout bristle on gena. Pronotal comb made up of long slender spines. A false comb made up of thickened dorsal bristles, is located on metanotum and abdominal tergites I to VII. In both sexes there is but one antepygidial bristle to the side. bats.

Represented in West by 2 species, which are common on western

\section{Key to the Western Species of Myodopsylla}

1. Females similar

2. IX st. male without 2 apical black spiniforms $\quad M$. gentilis, p. 374

IX st. male with 2 apical black spiniforms

M. collinsi, p. 375 


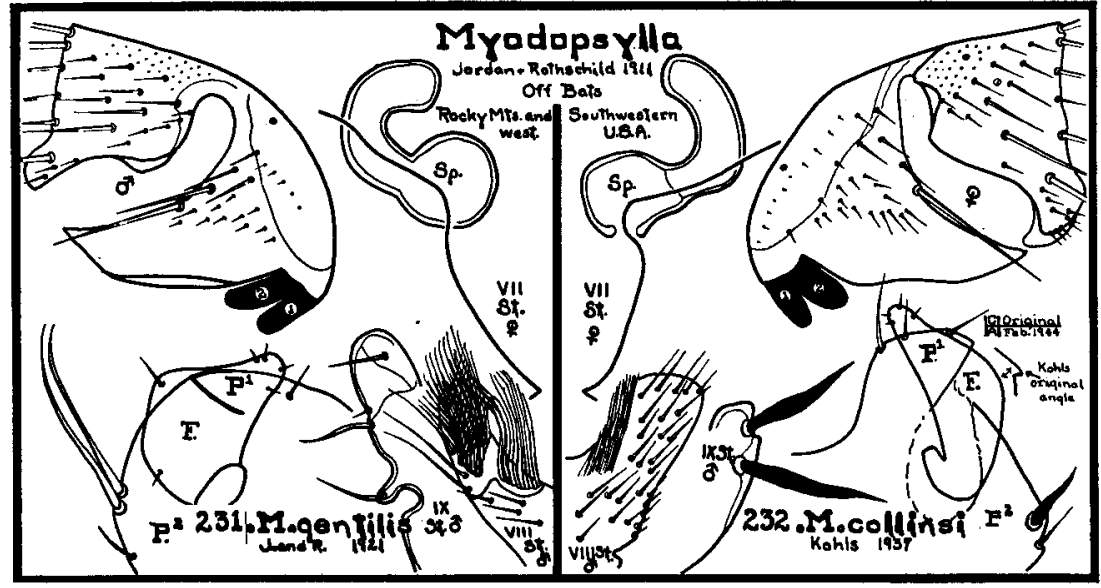

231. Myodopsylla gentilis

Jordan and Rothschild 1921

1921 Myodopsylla gentilis Jordan and Rothschild, Ectoparasites I, p. 152.

Described from a small series of both sexes which were removed from a bat at Okanagan Landing, British Columbia, by J. A. Munroe during September, 1912.

Distinguished from other bat fleas by structure of modified abdominal segments. Original statements for these are: Clasper less produced below finger than above it, bears only 2 long ventral bristles and a short one. Finger is not quite twice so long as it is broad, being triangular with posterior angle broadly and irregularly rounded off. Upper prong of lobe of paramere is slender and gradually curved inward at apex, lower prong of fork has apex resembling neck and head of a bird. In female, apical margin of VII st. consists of rounded upper lobe, but no lower lobe; spermatheca has a somewhat globular body and a hooked tail.

LENGTH: The writer's specimens average male $2.10 \mathrm{~mm}$., female $2.60 \mathrm{~mm}$.

RANGE: From records in the collection of the writer and those from adjacent areas, it seems likely that range of species is through Rocky Mountains west to Pacific Ocean.

Host Preference: Western bats are true host.

Seasonal Distribution: In so far as bats go into hibernation or migrate in West during winter, this species can generally be collected only during spring, summer and early fall months.

BIOLOGY: Females have been taken with eggs in abdomen as late as July 4 in vicinity of California-Oregon state line south of Klamath Falls. 
ReCORDs for this species in the collection of the writer are:

OREGON-Off:

Myotis yamanensis sociabilis Grinnell (Tejon bat), Narrows, Harney County, July 18,1937 , a series

Myotis lucifugus alascensis Miller (little brown bat), Forest Grove, Washington County, February 20, 1940, a series

Myotis yamanensis saturatus Miller (dusky bat), Tillamook, Tillamook County, August 8, 1938, a series.

WASHINGTON-Off:

Myotis lucifugus alascensis Miller (little brown bat), Vancouver, Clark County, August 24, 1942, 1 male

Corynorhinus rafinesqui townsendi Cooper (jack-rabbit bat), Kalama, Cowlitz County, July 8, 1940, a series.

CALIFORNIA-Off:

Myotis yamanensis sociabilis Grinnell (Tejon bat), Lower Klamath Lake, Siskiyou County, June 10, 1944, a pair, Augustson reports this flea from southern California off:

Myotis occulatus Hollister, (Hollister's bat), Blythe, Riverside County.

In the Rocky Mountain area this flea has been reported from

MONTANA-Off:

Myotis lucifugus carissima Thomas (Yellowstone bat), Beaverhead County, 1936, and off "Bat", Ravalli County, 1938.

UTAH-Off:

"Bat", Logan, Cache County.

The writer has examined specimens from

COLORADO-Off:

"Bat", from Fort Collins, Larimer County.

\section{Myodopsylla collinsi \\ Kohls 1937}

1937 Myodopsylla collinsi Kohls, Parasitology 23:300.

Described from 3 males and 4 females taken off 3 bats collected by describer in an abandoned mine tunnel located in Madera Canyon, Santa Rita Mountains, Santa Cruz County, Arizona, May 9, 1933.

Of Modified Segments Kohls says: Male: Clasper is more produced below finger than above, bears a bristle on apical margin of lower process $\mathrm{P}^{2}$. General configuration of finger similar to $M$. gentilis, the taper of the dorso-proximal prolongation being, however, more abrupt. Three small bristles near apex of this prolongation, and one slightly distad on dorsal margin. IX st. is evenly rounded ventrally; dorsal margin straight except for a low protuberance apically. Apex rounded. Strong spine-like bristle near lower distal margin of process, another about two diameters proximad, and a third, which is somewhat shorter and submarginal, situated about twice this distance proximad. No ventral processes are discernable. Upper prong of lobe $\mathrm{L}^{1}$ of paramere curved resembling claw of a bird. Lower lobe is one-third as long and is evenly rounded. Ventral process $\mathrm{L}^{2}$ of paramere strongly curved, dilated apically, posterior margin of dilation serrate. FEMALE: VII st. similar to $M$. gentilis but upper posterior margin more sharply produced. Spermatheca as in M. gentilis. 
Length: The original lengths are given as male $2.00 \mathrm{~mm}$., female $2.20 \mathrm{~mm}$.

RANGE: Probably throughout southwestern part of United States.

Preferred Host: This species is a true bat flea.

Records: Since Kohls described this species from Arizona, Augustson has reported it from the Riverside Mountains of Riverside County, California, off Myotis velifer velifer Allen (cave bat).

\section{GENUS MYODOPSYLLOIDES AUGUSTSON}

1941. Myodopsylloides Augustson, Bul. S. Calif. Acad. Sci. 40:104.

Genotype: Ceratopsylla palposus Rothschild 1904.

In establishing this genus Augustson made the following statements: "Head like that of Myodopsylla; differing in slightly attenuate frons with a weak indentation above oral flaps, single row of 4 bristles in the postantennal region and fewer number of small bristles in the preantennal region. Maxilla truncate. Labial palpi 6 segmented. Metaepimerum longer than high, with only 2 stout bristles and 1 medium bristle on posterior margin, making a total of 7 bristles in all on side; with only a single vertical bar. Metanotum with 6 minute teeth on its dorsal, posterior margin. Six similar teeth on first abdominal tergite, 4 on second, and 2 on third. Other vestiges of ctenidia lacking. Abdominal tergites with internal incrassations particularly evident in segments 2 and 3 of females and 1 to 7 inclusive in males. Abdominal sternites without incrassations. Clasper of males knob-like posterior to manubrium. Spermatheca of females with globular head not much thicker than curved tail."

On July 15, 1943, Dr. Karl Jordan wrote the author as follows: "The bat flea which Wagner transferred to Rhinophopsylla does not belong to that genus at all. I have lately revised the classification of the bat fleas and find that $M$. palposus is really a Myodopsylla with none of the rows of bristles modified into false combs."

Should Jordan's contentions hold true, then Myodopsylloides Augustson will fall as a synonym of Myodopsylla $\mathrm{J}$. and R. Jordan did not state that he had considered Augustson's Myodopsylloides.

This genus is represented in West by but a single species which is found upon bats.

\section{Myodopsylloides palposa \\ Rothschild 1904}

1904 Ceratopsylla palposus Rothschild, Nov. Zool., 11:652.

1936 Rhinolophopsylla palposus Wagner, Can. Ent., 68:206.

1940 Rhinolophopsylla palposus Wagner, Zeit. f. Parasit., 11 (4) :463.

1941 Myodopsylloides piercei Augustson, Bul. So. Calif. Acad. Sci., 40:104.

Described from a female taken off a brown bat at Cowichan (Duncans), Vancouver Island, British Columbia. It was not until 1940 that 


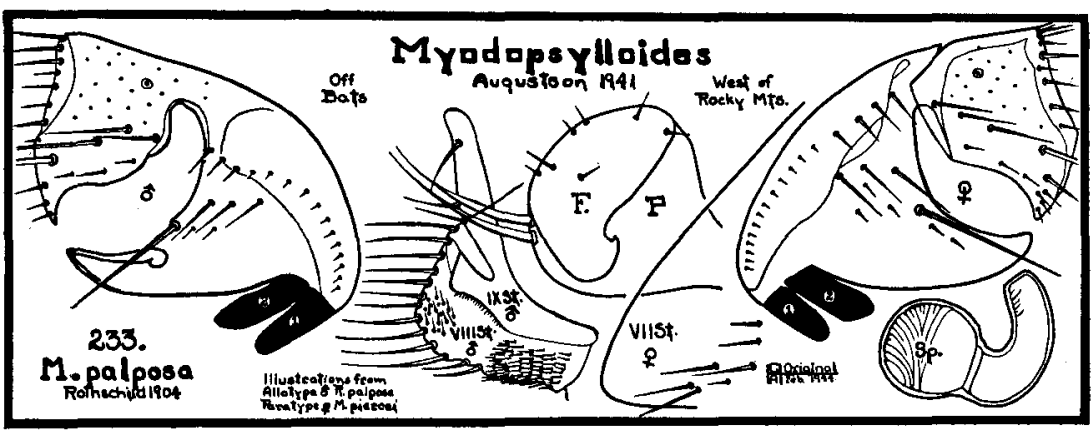

Wagner described male from materials taken by Holland at Kamloops off a bat.

During 1941 Augustson described this fiea as Myodopsylloides piercei from materials collected off bats taken on Channel Islands of Santa Barbara County, California.

Eye is vestigial. Prenantennal region armed with 1 long bristle just above eye position, 3 medium bristles continuing row obliquely towards outer angle of frons and anterior to this row 4 or 5 scattered small bristles. Two prominent black genal teeth. Postantennal region is armed with 1 row of 4 bristles and a marginal row of quite a few medium bristles. Also a few short bristles along antennal groove. Genal process is sharply pointed and heavily pigmented. Oral flaps large and subequal, inner slightly longer and more pointed than outer.

Pronotum bears a comb of 20 teeth.

Modified Segments, Male: Process of clasper well rounded throughout, greatly constricted at its union with manubrium. Armed posteriorly with 2 stout curved bristles. Finger weak, somewhat triangular in shape and entirely hidden by process. Base of IX st. weak and fused with that of VIII. Divided into 2 posterior processes, ventral short with outer row of many short bristles, upper long with single normal bristle. Base of VIII st. very broad; outer portion acutely rounded, with many long bristles curved at ends, 2 patches of small stout bristles along outer ventral border. Female: St. VII with flat receding outline. Spermatheca with globular body and hooked tail.

LENGTH: Augustson gives following measurements for this species, male $2.50 \mathrm{~mm}$., female $3.20 \mathrm{~mm}$.

RANGE: This species probably ranges all along the Pacific Slope of United States and Canada.

Host Preference: A true bat flea.

RECORDs: This species is reported as follows:

"Female from brown bat," Cowichan, Vancouver Island, British Columbia. "Female from Eptesicus fuscus fuscus," Vancouver, British Columbia. Holland collected both sexes off bats at Kamloops, British Columbia. 
Augustson reports the following occurrences from CALIFORNIA, southern and central,-Off:

Corynorhinus rafinesqui (intermedius) townsendi Cooper (jack-rabbit bat), Santa Cruz Island, Santa Barbara County

Antrozous pallidus pacificus Merriam (Pacific pale bat), San Gabriel Mountains, Los Angeles County; San Jose, Santa Clara County; Santa Cruz Island, Santa Barbara County.

\section{GENUS EPTESCOPSYLLA I. FOX}

1940. Eptescopsylla I. Fox. Fleas of Eastern U. S., p. 107.

Genotype: Nycteridopsylla chapini Jordan 1929.

Maxilla acuminate. Ocular bristle absent. Vestigial eye distinct and more or less oval. Besides genal and pronotal comb this genus has a false comb on VII t. consisting of thickened dorsal bristles. Apical border of metanotum and abdominal tergites I, II, and III with apical spinelets. Antepygidial bristles absent in both sexes.

This genus is represented in West by a single known species which is found sparingly upon bats.

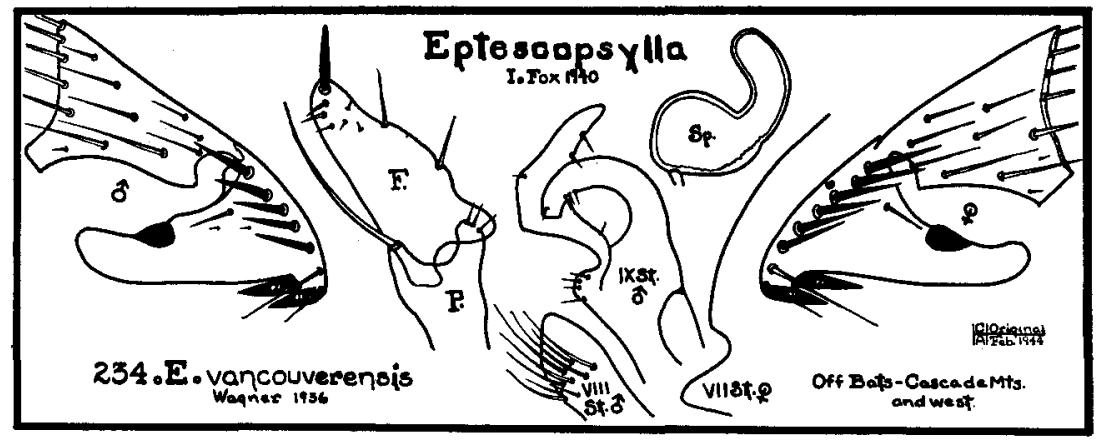

\section{Eptescopsylla vancouverensis \\ Wagner 1936}

1936 Nycteridopsylla vancouverensis Wagner, Zeit. f. Parasit, 8:654.

Described from 4 males and 4 females in Spencer collection at University of British Columbia, Canada. Materials had apparently come off a bat at Vancouver.

Shape of head, shape and armature of finger of male, and shape of spermatheca and apical outline of VII st. of female are all so characteristic that they sharply distinguish this species. All of these characteristics, because of their complexity, are more easily drawn than described.

LENGTH: A dozen specimens collected by the writer average, male $2.00 \mathrm{~mm}$., female $1.40 \mathrm{~mm}$.

RANGE: May be far more extensive than records reveal. At present the writer's specimens are listed as far south as Corvallis, Oregon; type 
locality is Vancouver, British Columbia; area between must surely be included.

Very little is known about this relatively scarce western bat flea.

RECORDs for this species are:

OREGON-Off:

Myotis lucifugus alascensis Miller (little brown bat), Forest Grove, Washington County, March 22, 1939, 2 males; Corvallis, Benton County, April 6, 1939, 1 female.

\section{GENUS STERNOPSYLLA J. AND R.}

1921. Sternopsylla Jordan and Rothschild. Ectoparasites I, p. 158.

1940. Aptilopsylla Ewing. Wash. Biol. Soc. Proc. 53:36.

Genotype: Ischnopsyllus texanus C. Fox 1914

No dorsal incrassations on head. There may or may not be a frontal tubercle. Ventral flaps long, slender, and curved tapering to acuminate apex. Posterior flap longer than anterior. Genal process acuminate. Eye vestiges large. There is an ocular bristle. Maxillae acuminate. True comb on pronotum. No combs on abdominal terga. Antepygidial bristles present. Tarsi long. First segment of mid and hind tarsi armed with numerous small, hair-like setae, particularly in male. Fifth tarsal segment of each leg has 5 pairs of plantar bristles, first pair ventral, others lateral.

Although 2 species have so far been assigned to this genus, considerable amounts of variation in specimens and uncertainty as to which males belong to which females has led to much confusion.

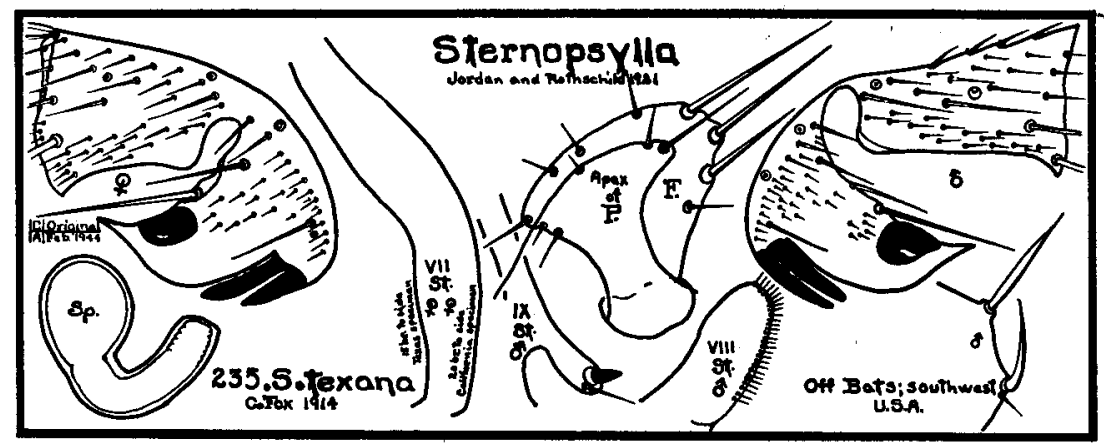

235. Sternopsylla texana

C. Fox 1914

1914 Ischnopsyllus texanus C. Fox, U. S. Pub. Health Serv. Hyg. Lab. Bul., 97:16.

Described from a female taken off a Mexican free-tailed bat collected at Pecos, Texas. Male was described off same host but taken at Thomasville, Georgia on June 26, 1936. 
Prenantennal region of head armed with a row of bristles on frons extending from base of genal spines to antennal groove. These bristles are mixed in size. Along antennal groove, besides long ocular bristle there may be from 1 to 3 medium bristles. Two genal teeth, long, black, curved and pointed. Very short labial palpus is 5 segmented. Postantenregion armed with two or three rows of setae along antennal groove and about 4 rows of bristles.

Pronotum with a comb of about 26 teeth in male and about 20 in female.

Modified Segments, Male: Process of clasper markedly incurved dorsally. Finger roughly triangular and armed at posterior angle with 3 stout bristles and several shorter ones at other points. Penis broad and blunt. Manubrium finger-shaped. IX st. with a ventral process which is armed with a stout spiniform. Posterior end of abdomen armed with 4 large bristles situated on conical protuberances. FEMALE: VII st. with well rounded margin in California specimens and armed with 20 bristles to the side. Texas specimens with somewhat undulate outline and armed with 15 bristles to side. Spermatheca with subglobular body and crooked tail.

LENGTH: Specimens in collection of writer measure $2.10 \mathrm{~mm}$. for male and $3.00 \mathrm{~mm}$. for female.

Range: Augustson's report of this species from Los Angeles, California, stretches range across entire southern portion of United States.

Preferred Host: A true bat flea.

ReCORDs: Augustson reports this species from Los Angeles off:

Eumops perotis californicus Merriam (California mastiff bat)

Tadarida mexicana Saussure (Mexican free-tailed bat) .

The writer has specimens in his collection off this latter bat from Hondo, Median County, Texas.

\section{Sternopsylla carlsbadensis Ewing 1940}

1940 Sternopsylla carlsbadensis Ewing, Wash. Biol. Soc. Proc., 53:36.

Described from material taken in Carlsbad Cavern, New Mexico.

Describer remarks as follows: "The genus is remarkable in that the females of the 2 species and their varieties appear to be identical, except that in one situation, Carlsbad Cavern, New Mexico, some of the females possess a very distinct frontal tubercle and the others not so much as a vestige of such a tubercle. The males corresponding to the 2 kinds of females in this cavern are so nearly alike that they cannot be separated except for the presence and absence of the frontal tubercle. While the females from other localities appear to be alike, the males show slight differences in the shape of posterior process of clasper, in shape of movable finger, and especially in chaetotaxy of latter."

In the clasper of "Those from Carlsbad Cave, N. Mex., the movable 
finger is about as broad as long and the anterior margin is very broadly incurved, the 2 lower, posterior, marginal, spine-like setae of the movable finger are situated at a distance from each other, and the seta adjacent to the third posterior, marginal, spine-like seta is large and longer than the third seta itself."

RaNGE: "The typical form (with frontal tubercle) known only from Carlsbad Cavern, New Mexico."

Host Preference: A true bat flea. 


\section{GEOGRAPHICAL INDEX TO WESTERN FLEAS}

LEGEND: $T$-type locality within state. $R$-records personally collected and identified by the author. $\mathrm{X}$-published records not verified by the author. ?-record questioned by author or other western flea students. *-Known vector of plague. *? - Suspected vector of plague. **-Known vector of murine typhus. ***-Known vector of plague and murine typhus. Totals-right hand, number of states flea has been recorded in by end of 1945; bottom, number of different fleas recorded from state by end of 1945 .

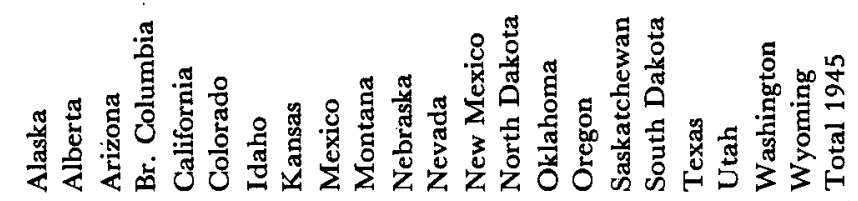

abantis, $M \ldots \ldots \ldots$
act.

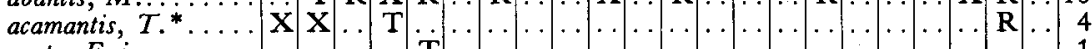

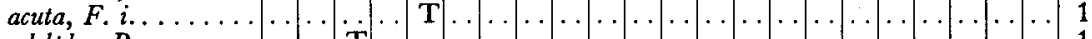

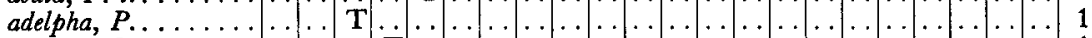

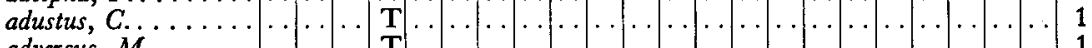

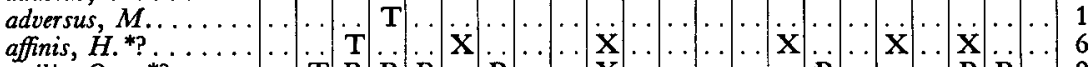

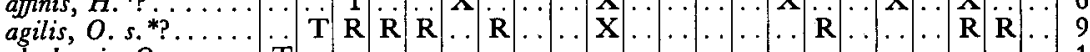

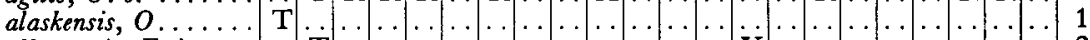

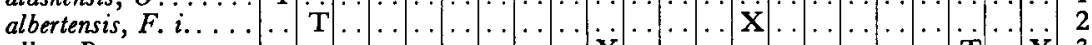
allos, $P \ldots \ldots \ldots \ldots$.

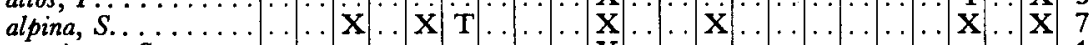

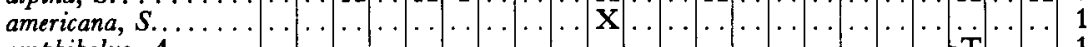

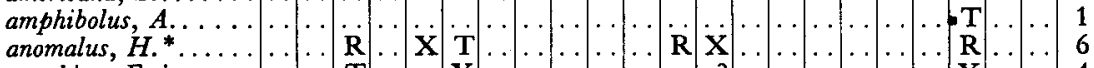

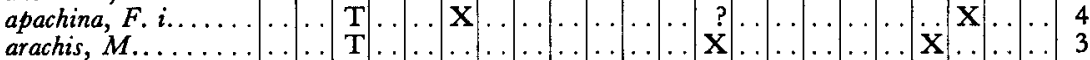

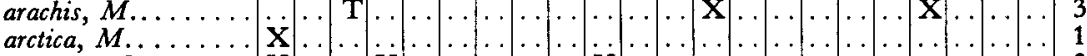

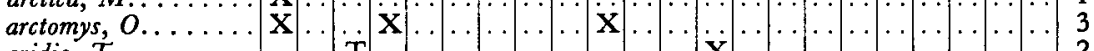

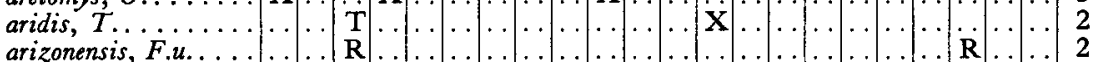

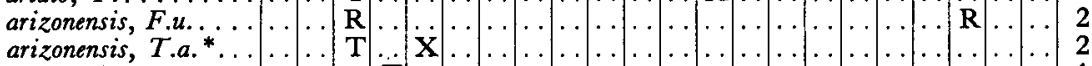

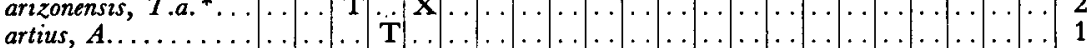

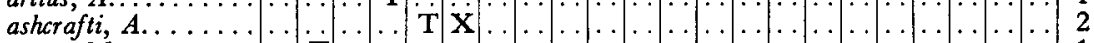

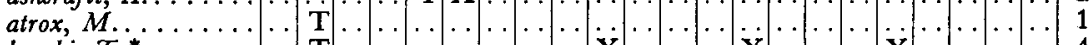

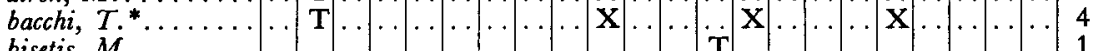

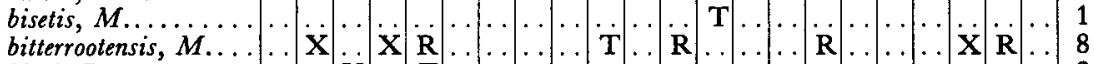

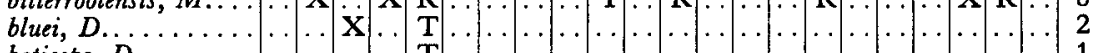

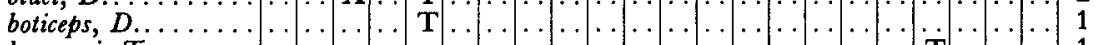

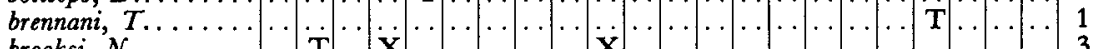
brooksi, $\mathcal{N} \ldots \ldots \ldots$
bruneri, $0, \ldots \ldots$

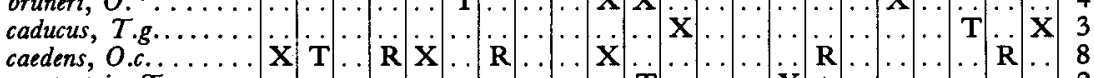

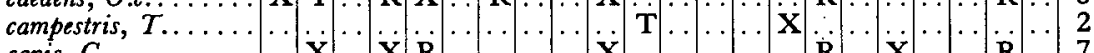

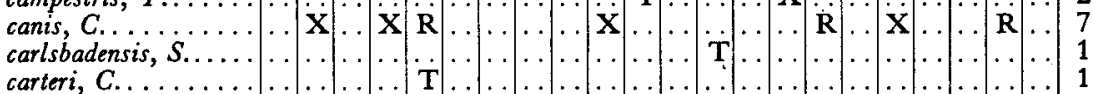

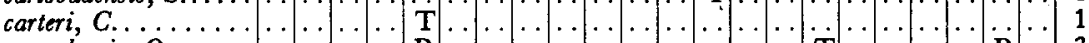

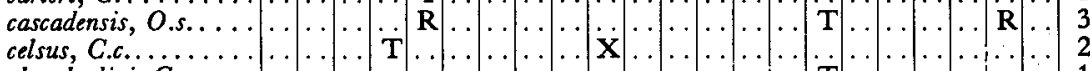

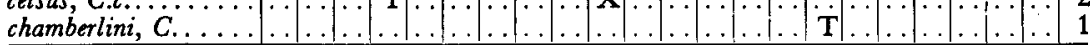




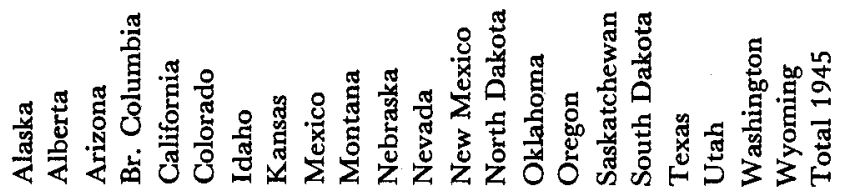

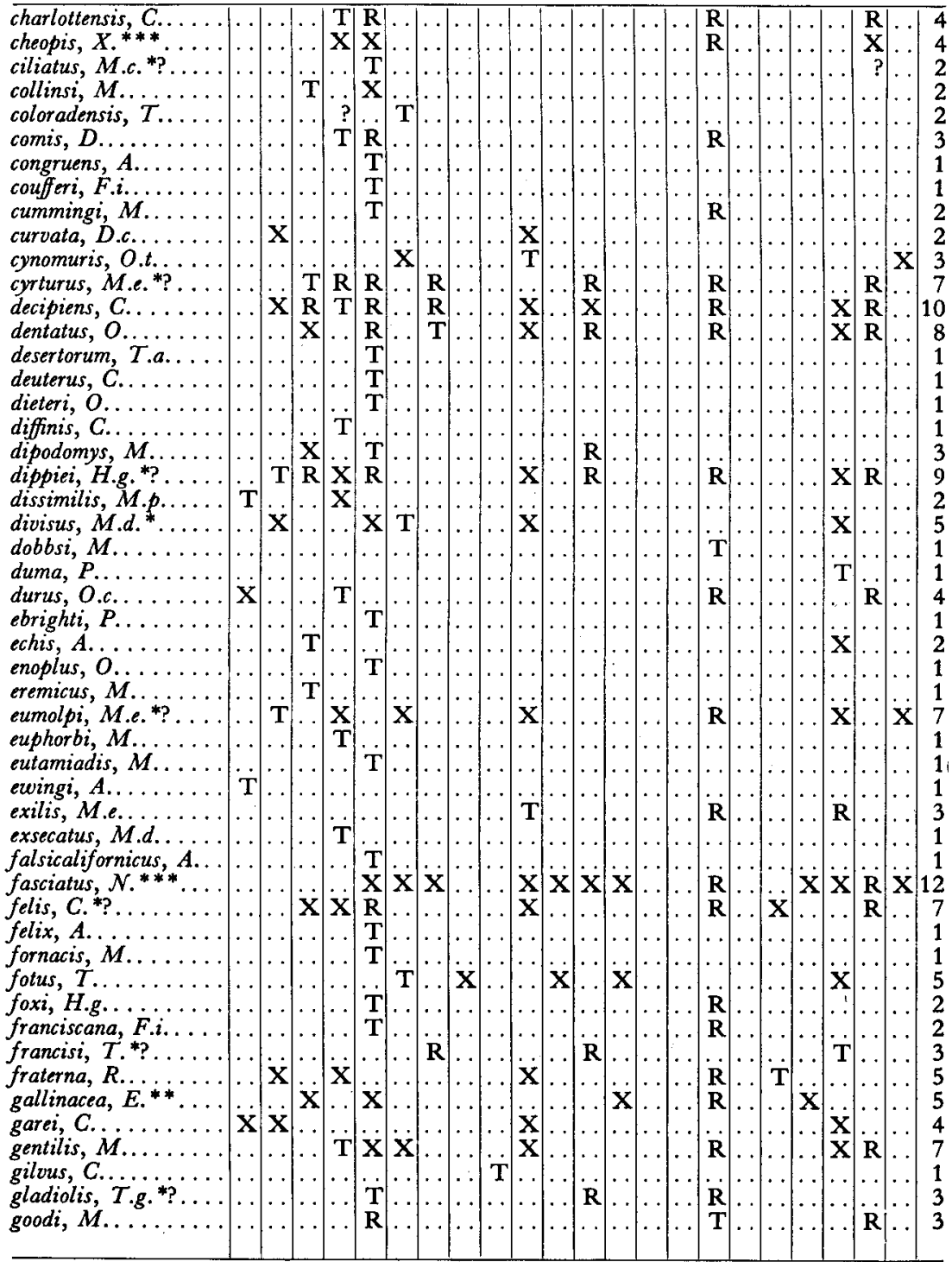


GEOGRAPHICAL INDEX-Continued

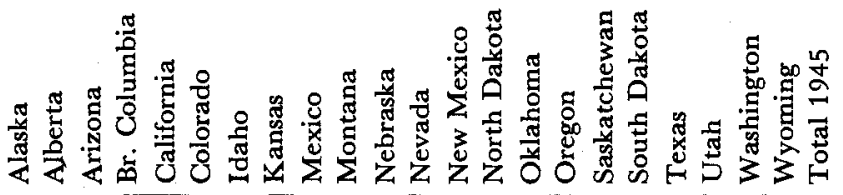

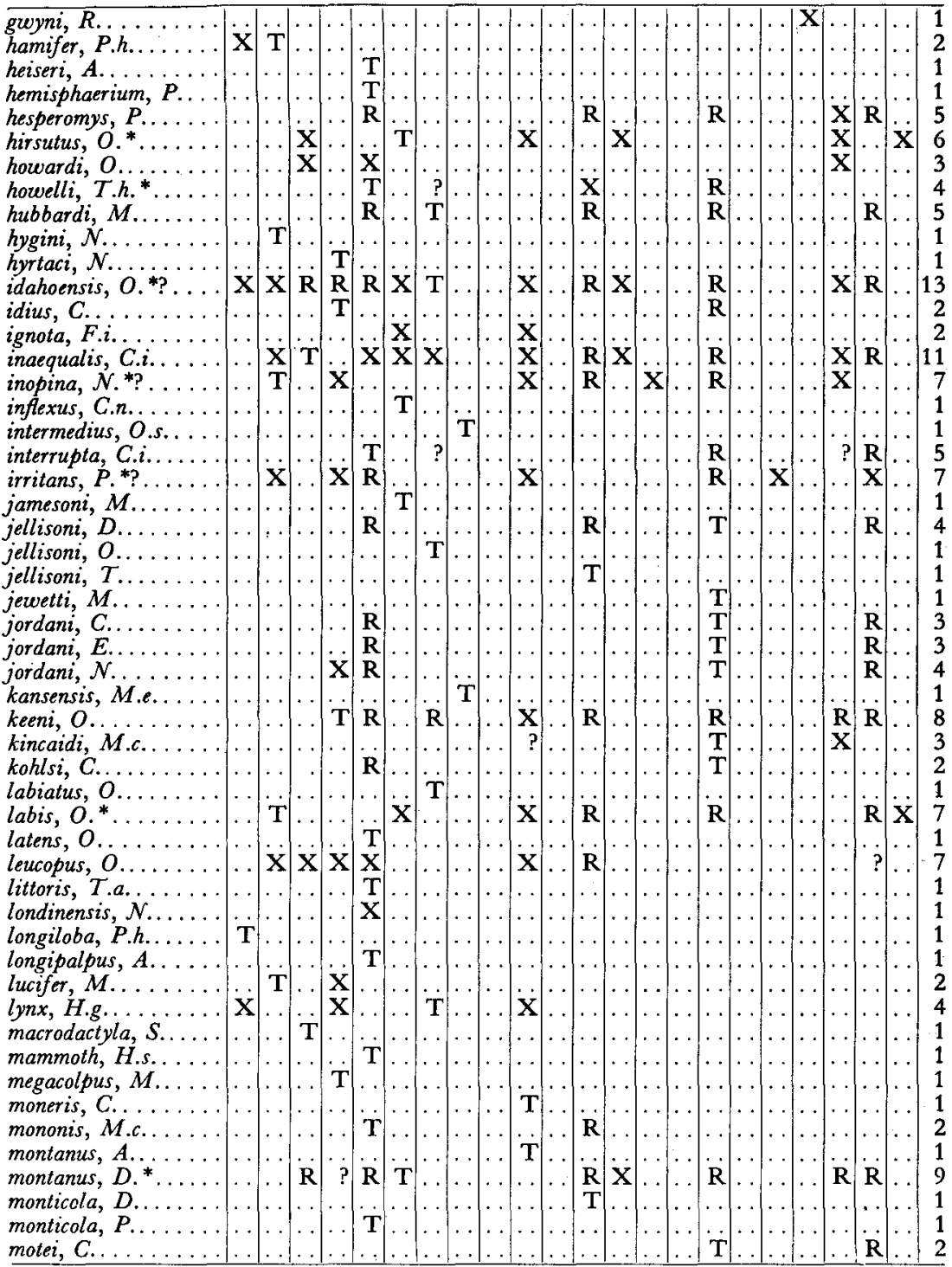




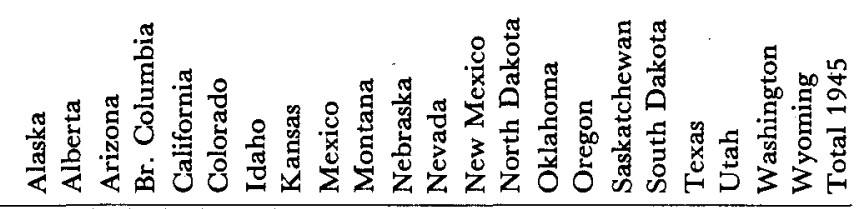

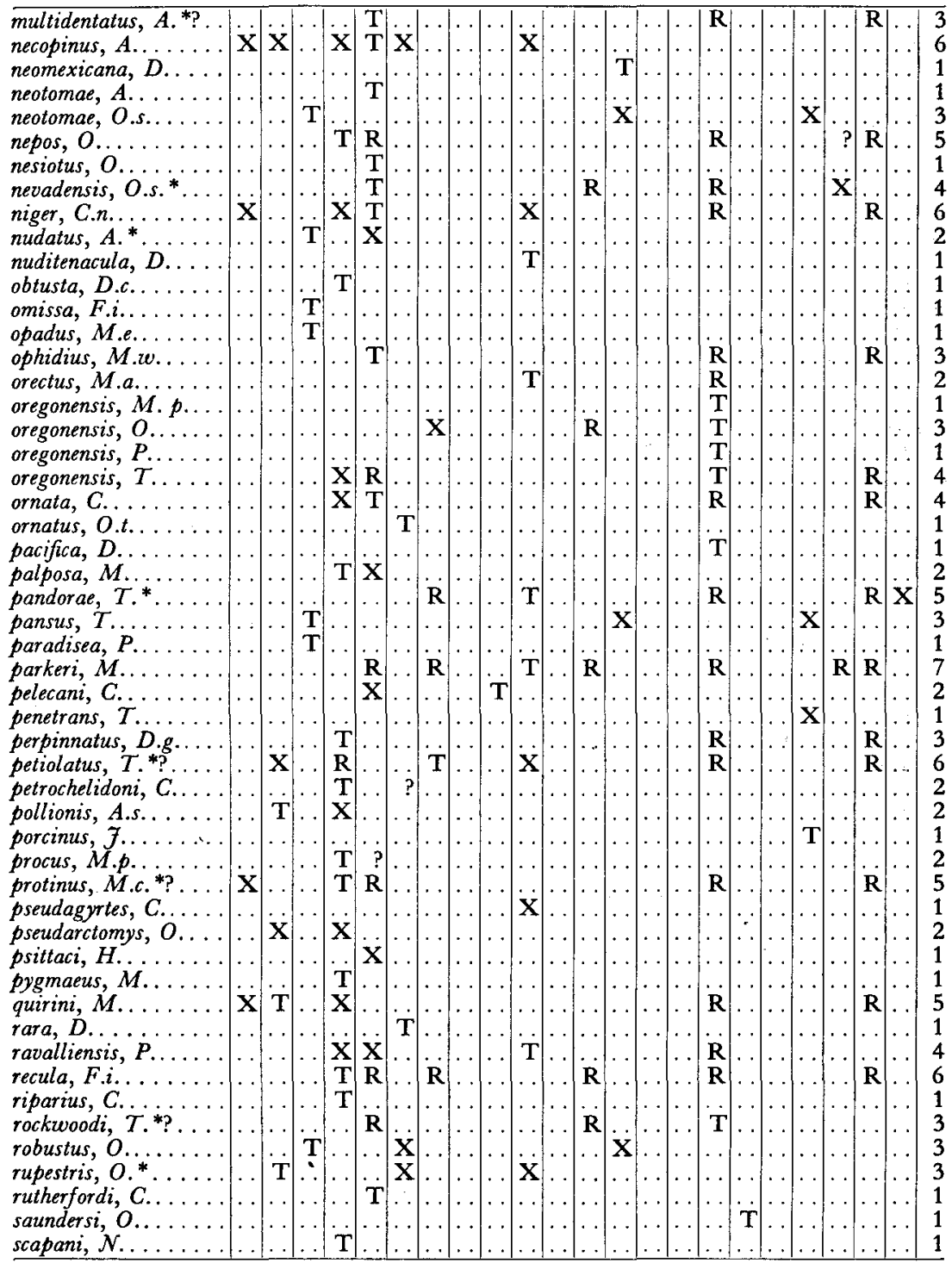




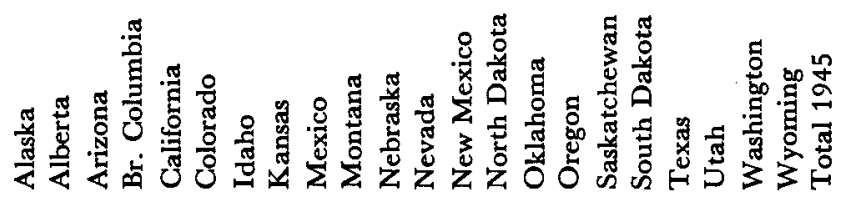

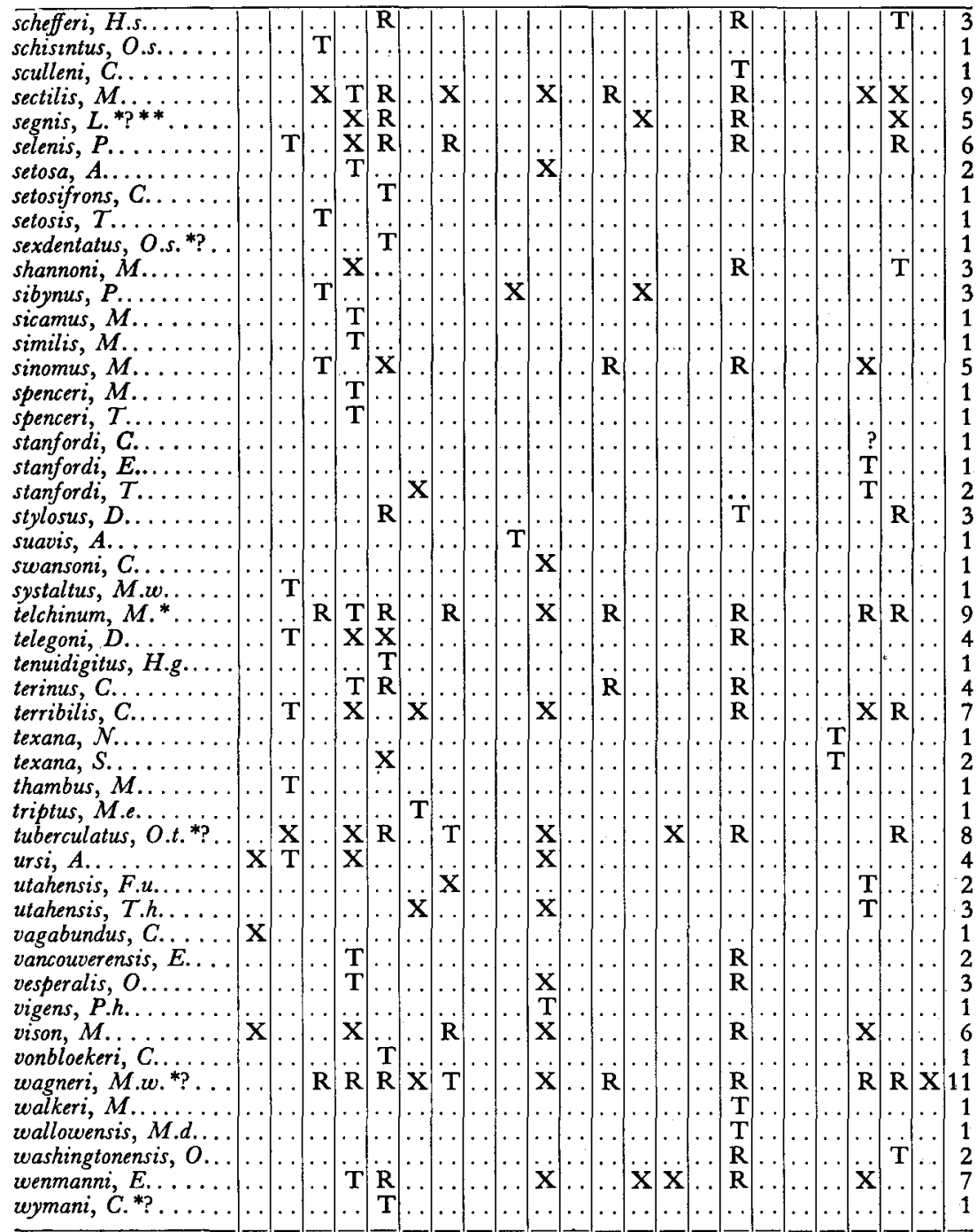

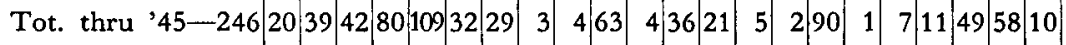




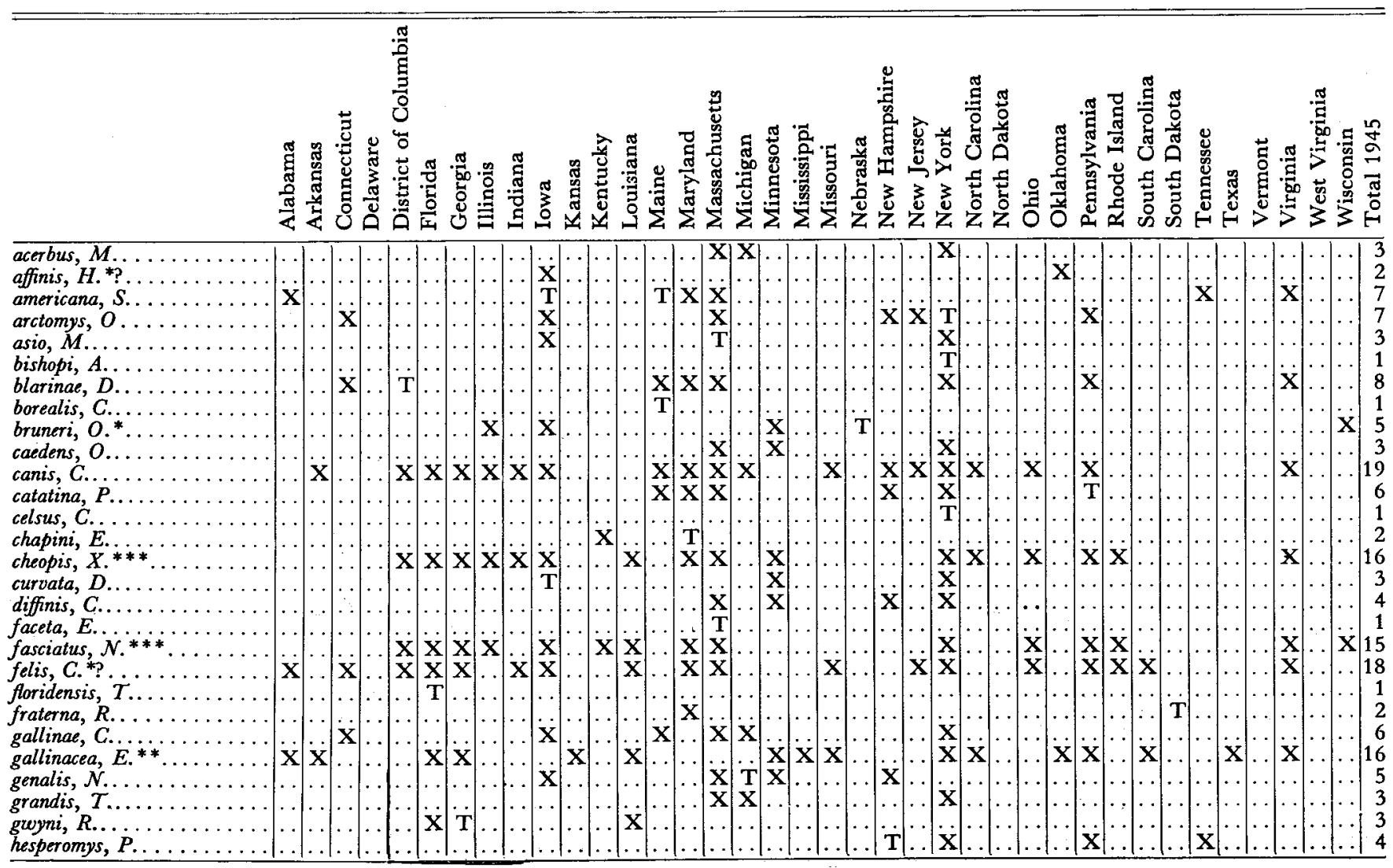




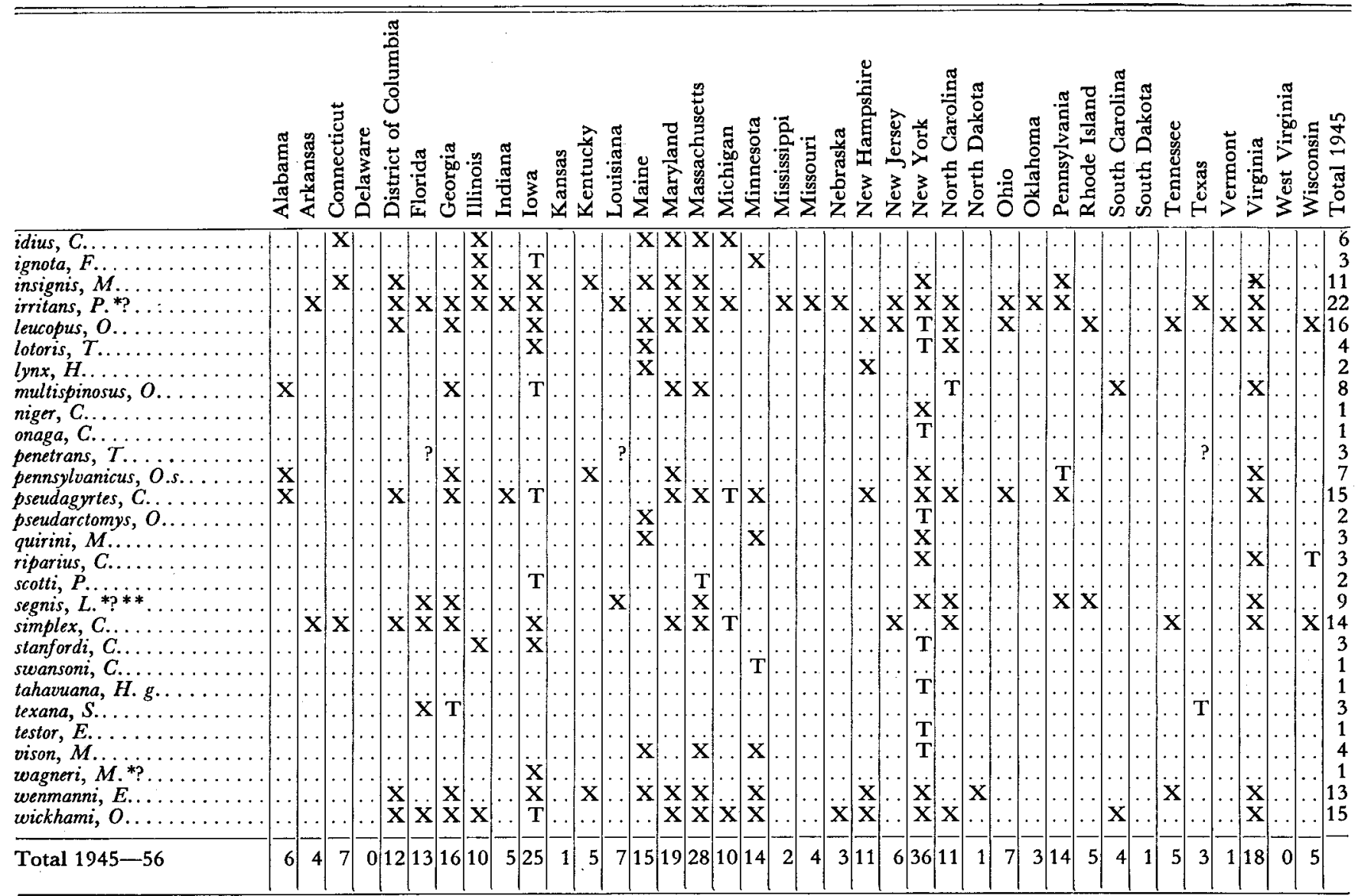




\section{SUMMARY AND CONCLUSIONS}

\section{Fleas East And West Of The 100Th Meridian-}

Of the 302 fleas listed here 10 have a range extending from coast to coast. Seven of these are introduced: $C$. canis, X. cheopis, $N$. fasciatus, C. felis, E. gallinacea, P. irritans, L. segnis; three are native: P. hesperomys, M. quirini, C. niger. The author questions the presence of C. niger in New York but this western chicken flea could have become widely distributed through chicken shipments from the west. Two widely distributed eastern deermouse fleas, O. leucopus and E. wenmanni, are found as far west as the Cascade Mountains.

\section{Fleas West of The 100Th Meridian-}

The flea which has the widest published distribution in the west is $O$. idahoensis, found on all types of western ground squirrels. It is recorded from 13 of the 22 western states. $N$. fasciatus follows second, being recorded from 12 states; $M$. wagneri wagneri and $C$. inaequalis inaequalis third from 11 states.

Of the 246 fleas recorded from the west 106 are known only from the type state. This is 43 per cent.

The western locations in which the smallest amount of flea research has been accomplished seem to be Saskatchewan, with 2 published record, Oklahoma with 2, Kansas with 3, South Dakota and Mexico with 4, North Dakota with 5. Students who wish to work fleas in the most fertile fields west of the 100th meridian should locate in these states.

The best worked locations on the Pacific coast are California with 109 recorded fleas, Oregon with 90, British Columbia with 80 . In the Rocky Mountains Montana records show 63 different fleas, Utah 49.

\section{Fleas East of the 100Th Meridian-}

The flea which has the widest published distribution in the east is $P$. irritans, the human flea. It is recorded from 22 states. Other interesting fleas of wide distribution in the east are $C$. canis, 19 states; $C$. felis, 18 states; $O$. leucopus and $E$. gallinacea, 16 states; $O$. wickhami (howardi), C. pseudagyrtes and $N$. faciatus, 15 states.

Of the 56 fleas recorded from the east 9 are known only from the type state. This is 16 per cent.

The eastern localities in which the smallest amount of flea research has been accomplished seems to be Delaware and West Virginia with no published records; Kansas, North and South Dakota, and Vermont with 1 published record each; Mississippi with 2; Nebraska, and Oklahoma with 3; Arkansas, Missouri, and South Carolina with 4; Kentucky, Rhode Island and Wisconsin with 5. Students wishing to work fleas in the east should settle in these localities. 
It should be noted at this time that the 100th meridian cuts North and South Dakota and Nebraska in half, Kansas and Texas about a third, and Oklahoma through its very narrow western portion. These states therefore appear in both divisions.

The best worked eastern states are New York with 36 recorded fleas, Massachusettes with 28, and lowa with 25. 
PART III

\section{THE HOSTS}

$\mathrm{OF}$

WESTERN RODENT FLEAS

AND

\section{WESTERN LAGOMORPHA FLEAS}

Their Relation to Plague,

Tularemia, Murine Typhus 

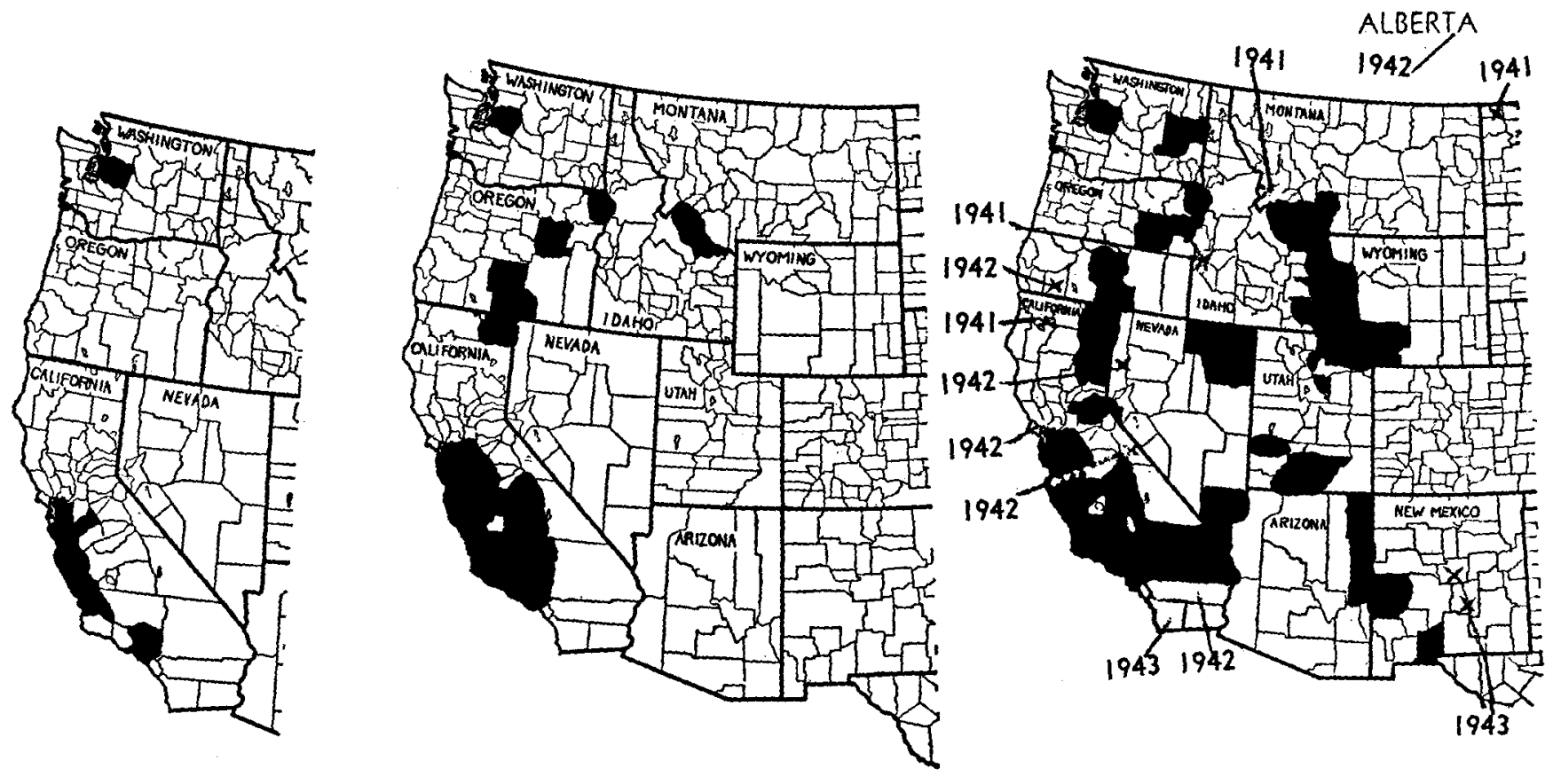

1939

1935

1910

Fig. 4. Extension of known a 1147.)

Public Heath Service 


\section{RODENT PLAGUE IN NORTH AMERICA*}

The idea that plague is primarily a disease of rodents is well founded in North America. Whether government research bureaus suspected the presence of plague in this country prior to its outbreak in San Francisco in 1900 is a question. There could be no doubt after this first epidemic. Immediately the United States Public Health Service and the health agencies of the State of California began war on San Francisco rats. Since that time there has been no ceasing of the endeavor to trace out plague areas in this country, and Canada has followed suit in its suspected provinces.

Up to 1944, health agencies had found plague manifest in 18 of the some 30 different genera of North American rodents and lagomorpha. The chronological order of the discoveries is as follows:

\begin{tabular}{|c|c|c|c|}
\hline Host & Genus & Year & Location \\
\hline Rats & (Rattus) & 1902 & San Francisco, Calif. \\
\hline Ground Squirrels & (Citellus) & 1908 & $\begin{array}{l}\text { Contra Costa Co., and } \\
\text { Los Angeles, Calif. }\end{array}$ \\
\hline Woodrats & (Neotoma) & 1909 & Alameda Co., Calif. \\
\hline Field Mice & (Microtus) & 1935 & Modoc Co., Calif. \\
\hline Chipmunks & (Eutamias) & 1936 & Eldorado Co., Calif. \\
\hline Marmots & (Marmota) & 1936 & Beaverhead Co., Montana \\
\hline Prairie Dogs & (Cynomys) & 1936 & Garfield Co., Utah \\
\hline Flying Squirrels & (Glaucomys) & 1937 & Fresno Co., Calif. \\
\hline Pine Squirrels & (Tamiasciurus) & 1937 & Fresno Co., Calif. \\
\hline Deer Mice & (Peromyscus) & 1938 & Catron Co., New Mexico \\
\hline Kangaroo Rats & (Dipodomys) & 1939 & Dona Ana Co., New Mexico \\
\hline Cottontails & (Sylvilagus) & 1939 & Lincoln Co., Washington \\
\hline Golden Mantles & (Callospermophilus) & 1940 & San Bernardino Co., Calif. \\
\hline Jack Rabbits & (Lepus) & 1941 & Baker Co., Oregon \\
\hline \multicolumn{4}{|c|}{ Antelope Ground } \\
\hline Squirrel & (Ammospermophilus) & 1942 & San Bernardino Co., Calif. \\
\hline Meadow Mice & (Microtus) & 1942 & Marin Co., Calif. \\
\hline Pocket Gophers & (Thomomys) & 1942 & San Luis Obispo Co., Calif. \\
\hline Grasshopper Mice & e(Onychomys) & 1943 & Lincoln Co., New Mexico \\
\hline Harvest Mice & (Reithrodontomys) & 1943 & Monterey Co., Calif. \\
\hline
\end{tabular}

* In the following pages all references to plague in animals have come from various issues of "Public Health Reports," published by the U. S. Public Health Service. 
Two views are expressed upon rodent plague in North America. One holds that plague has been on the continent for long periods of time and the slowness in its discovery is due primarily to lack of research. The other view holds that plague in America started in West Coast port towns through imported rats and their fleas, and from these ports of entry plague has gradually spread through the West's rodent population.

\section{SOURCE LITERATURE}

In the following pages on the fleas of the rodents and lagamorpha found west of the 100th meridian, the following sources have been used.

"List of North American Recent Mammals 1923," Gerrit S. Miller, Jr., United States National Museum Bulletin 128.

"Provisional List of Land Mammals of the State of Washington," Taylor and Shaw, Occasional Papers of the Conner Museum, No. 2, December, 1929, State College of Washington.

Field Book of North American Mammals, H. E. Anthony, 1928, G. P. Putnam's Sons.

"The Mammals and Life Zones of Oregon," Vernon Bailey, North American Fauna No. 55, Washington, D. C., 1936.

Due to the large importance played by ground squirrels in the spread of plague in the west, "Revision of the North American Ground Squirrels," A. H. Howell, North American Fauna No. 56, Washington, D. C., 1938 is frequently referred to in that section.

Many articles on California mammals found in the University of California Publications in Zoology have been found useful.

In the southwest a volume of great help has been Mammals of New Mexico," Vernon Bailey, North American Fauna No. 53, Washington, D. C., 1931. For work far to the north in the Great Plains region, "A Biological Survey of North Dakota," Vernon Bailey, North American Fauna No. 49, Washington, D. C. 1926.

The various works of Ernest Thompson Seton have been found excellent.

In the rodents and lagamorpha taxonomists have not agreed entirely upon generic synonomy, and therefore the number of genera of rodents found in the West varies to some extent, depending upon the source used. For practical purposes the number can be placed at 32 genera. In the following pages these genera will be considered alphabetically. 


\section{HOST INDEX}

1. Ammospermophilus-antelope ground squirrels . . . . . . p. 396

2. Aplodontia-mountain beavers . . . . . . . . . . . p. 397

3. Brachylagus-Idaho pygmy rabbits . . . . . . . . . p. 398

4. Callospermophilus - golden mantled ground squirrels . . . . p. 399

5. Castor-Canadian beavers . . . . . . . . . . . . p. 401

6. Citellus - gray and red diggers, ground squirrels, sage rats . . . p. 401

7. Clethrionomys-red-backed mice . . . . . . . . . . p. 419

8. Cynomys—-prairie dogs . . . . . . . . . . . . . p. 421

9. Dipodomys (Perodipus)-kangaroo rats ' . . . . . . . p. 422

10. Erethizon-porcupines . . . . . . . . . . . . . p. 425

11. Eutamias-chipmunks . . . . . . . . . . . . . p. 426

12. Fiber-muskrats . . . . . . . . . . . . . . . p. 431

13. Glaucomys-flying squirrels . . . . . . . . . . . . p. 432

14. Lepus-rabbits . . . . . . . . . . . . . . . p. 433

15. Marmota-marmots, groundhogs, woodchucks . . . . . . p. 434

16. Microdipodops-gnome mice . . . . . . . . . . . p. 436

17. Microtus-meadow mice . . . . . . . . . . . . . . p. 437

18. Mus-house mice . . . . . . . . . . . . . . . p. 447

19. Neotoma-wood-rats, pack rats . . . . . . . . . . . p. 448

20. Ochotona-conies, pikas, little chief hares, rock rabbits . . . . p. 453

21. Onychomys-grasshopper mice . . . . . . . . . . . p. 456

22. Perognathus-pocket mice . . . . . . . . . . . . p. 458

23. Peromyscus-deer mice, white footed mice . . . . . . . p. 461

24. Phenacomys-tree mice . . . . . . . . . . . . . p. 475

25. Rattus-rats . . . . . . . . . . . . . . . . p. 476

26. Reithrodontomys-harvest mice . . . . . . . . . . p. 480

27. Sciurus-gray squirrels . . . . . . . . . . . . . . p. 482

28. Sigmodon-cotton rats . . . . . . . . . . . . . . . . . . p. 483

29. Sylvilagus—cottontails . . . . . . . . . . . . . . . . p. 484

30. Tamiasciurus—red squirrels, pine squirrels . . . . . . . p. 487

31. Thomomys-pocket gophers . . . . . . . . . . . p. 490

32. Zapus-jumping mice . . . . . . . . . . . . . . . . 4.494 
(Ammospermophilus)

Citellus

The Antelope Ground SQuirrels

Howell lists 9 types of antelope ground squirrels in the United States. These animals are about chipmunk size, coarse-haired and cinnamon brown in color. They are rapid movers and upon the slightest alarm dart into their burrows or under a bush of sagebrush. They are diurnal in habits.

Unless one is an excellent shot, these squirrels are hard to shoot because of their quick movements. A .410 gauge shotgun is effective. Box trapping can be successful if the traps are constructed heavy enough to prevent the savage little squirrels from wrecking the doors. Rolled oats is a good bait. The animals should be removed from the traps with gloves-they bite severely.

In the Pacific Northwest, antelope ground squirrels have a very limited range. They have apparently migrated into south central and southeastern Oregon from California and Nevada, and are found throughout Warner Valley with records also from the Owyhee and Malheur Valleys. As indicated by this range, these animals are desert dwellers.

OREGON-This rodent is the special host of the flea:

58. Thrassis gladiolis gladiolis Jordan 1925.

ACcidental. OccurRence:

114. Monopsyllus wagneri wagneri Baker 1904 is found occasionally on this rodent where it comes in close contact with Peromyscus (deer mice).

CALIFORNIA-Although Miller listed 4 subspecies of antelope ground squirrels, Howell declared 2 of these synonyms, so at the present time C. l. leucurus (whitetailed ground squirrel) ranges in the southeastern and northeastern portions of the state and C. nelsoni (San Joaquin antelope squirrel) ranges in the San Joaquin Valley of California.

Although the San Joaquin antelope squirrel is hemmed in on all sides by plague infected ground squirrels, it has not been found plague-positive. The whitetailed antelope ground squirrel, however, was found plague-positive during April, 1942, in specimens secured on the Helendale Airport and at Needles in San Bernardino County. In this region these squirrels carry:

58. Thrassis gladiolis gladiolis Jordan 1925

60. Thrassis arizonensis arizonensis Baker 1898

62. Thrassis arizonensis desertorum Stewart 1937

61. Thrassis arizonensis littoris Jordan 1929

216. Actenophthalmus heiseri McCoy 1911.

How far north along the California-Nevada line these fleas are carried is not known, but by the time the squirrels are ranging in Oregon they are carrying only the first above-named flea which seems to be a true parasite of this squirrel.

This squirrel also ranges throughout Nevada, western Utah, northwestern Arizona and southeastern Idaho. Through this range they seem to carry no other fleas than those already mentioned.

- The 5 types of Rocky Mountain antelope ground squirrels have not been found plague-positive. 
ARIZONA-The writer has specimens of:

59. Thrassis gladiolis caducus Jordan 1930 off $C$. harrisi harrisi (gray-tailed antelope squirrel), Tucson

64. Thrassis setosis Prince 1944 off $C$. harrisi saxicola (Yuma antelope squirrel), Yavapia County.

UTAH:

59. Thrassis gladiolis caducus Jordan 1930, described off C. l. cinnamomeus (rusty antelope squirrel), Vernal.

NEVADA:

14. Hoplopsyllus anomalus Baker 1904. During June, 1944, the writer removed this flea off antelope ground squirrels taken all along west side of Pyramid Lake, Washoe County.

\section{Aplodontia \\ The Mountain Beavers}

Mountain beavers are strictly western rodents. Their range extends from crest of Cascade-Sierra Mountains westward to Pacific Ocean, from Fraser River in British Columbia south to San Francisco Bay. The range of these animals is gradually extending eastward.

These animals are burrowers. Underground systems have all doors left open. The foot-long, stubby-tailed animals can be found in almost any part of their range where there are running creeks bordered by sword fern and sallal. Securing specimens for examination is simple. Place a No. 1 steel trap in runway and stake it securely. Do not bait or cover. The animals readily step into the sets, seldom gnaw out. Where sets are made in runways in which water is flowing, it is advisable to visit traps very early in the morning, because under these conditions the animals shortly die of exposure and fleas soon leave body.

This study of fleas of Aplodontia is the report on 100 animals trapped by writer in 40 localities in Washington, Oregon, and northwestern California, from which were removed 350 fleas. Ten per cent of the animals were without fleas at time of examination. This average of 4 fleas to the host is too large due to the presence of the gray digger flea upon the mountain beaver as an accidental occurrence.

OREGON-There are 2 subspecies of Aplodontia, the Coastal form, Aplodontia rufa pacifica Merriam, and the Cascade form, Aplodontia rufa rufa Rafinesque. Both are generally only moderately infested with fleas; often specimens can be taken which are clean.

Aplodontia is consistently and commonly infected with:

149. Dolichopsyllus stylosus Baker 1904 for which it forms the true and apently only host. This flea is large, $5.00 \mathrm{~mm}$. long, active and dark colored. The second most common flea upon Aplodontia in Oregon is:

220. Hystrichopsylla schefferi schefferi Chapin 1919, a huge flea measuring close to $8.00 \mathrm{~mm}$. This flea has been found by the writer only occasionally. It seems rare.

More often during the spring months than at other times,

183. Trichopsylloides oregonensis Ewing 1938 (= Phaneris hubbardi Jordan 1939) can be taken from the various Oregon Aplodontia. 
185. Epitedia jordani Hubbard 1940 also infests Aplodontia generally but slightly during the spring months. It is a vicariating species which is more often found upon shrews, moles, and mice.

The mountain beaver has about the same western range as Citellus beecheyi douglasi (gray digger) and frequently this large gray ground squirrel takes over for exploring or for nesting purposes the burrows of the mountain beaver. At such times the mountain beavers may become moderately or heavily infested with the gray digger flea,

69. Diamanus montanus Baker 1895.

This infestation is shown by records from 1 male Aplodontia rufa pacifica Merriam, Devil's Lake, Oregon, February 24, 1939, 15 males, 40 females; 1 female Aplodontia rufa pacifica Merriam, Smith River, California, June 15, 1939, 1 male, 1 female. In the state of Washington the range of the two animals does not coincide. Although many gray diggers have been trapped out of mountian beaver burrows by the writer, in no case has he ever taken the mountain beaver fleas off the gray diggers.

\section{Accidental Occurrences:}

OREGON-Although many of the smaller animals of the vicinity can be trapped out of mountain beaver burrows, few stray fleas can be found upon Aplodontia. The following strays are recorded by the writer:

119. Monopsyllus ciliatus protinus Jordan 1929 from Eutamias, Estacada, July 19, 1931

144. Dasypsyllus gallinulae perpinnatus Baker 1904 a bird-flea, Brookings, August 23, 1937

160. Catallagia charlottensis Baker 1898 from Peromyscus, Devil's Lake, April 20, 1938.

WASHINGTON-Has Aplodontia rufa rufa Rafinesque (Brown mountain beaver) in the lower ranges of Cascade Mountains; Aplodontia rufa rainieri Merriam (Rainier mountain beaver) around Mt. Rainier and south to Skamania; and Aplodontia rufa olympica Merriam (Olympic mountain beaver) in the coastal belt and throughout Olympic Mountains.

Throughout their range these Aplodontia of Washington are infested lightly but consistently with:

149. Dolichopsyllus stylosus Baker 1904

183. Trichopsylloides oregonensis Ewing 1938 (=Phaneris hubbardi Jordan 1939)

185. Epitedia jordani Hubbard 1940.

220. Hystrichopsylla schefferi schefferi Chapin 1919

CALIFORNIA-At Fort Dick and Smith River, during June of 1939, the writer removed from Aplodontia rufa humboldtiana Taylor:

69. Diamanus montanus Baker 1895.

149. Dolichopsyllus stylosus Baker 1904

183. Trichopsylloides oregonensis Ewing 1938

220. Hystrichopsylla schefferi schefferi Chapin 1919

221. Hystrichopsylla schefferi mammoth Chapin 1921 was described off Aplodontia rufa californicus (Peters) from Sierra Nevada Mountains in Yosemite National Park.

\section{Brachylagus \\ IDAHO Pygmy RABbits}

Brachylagus idahoensis Merriam (Idaho pygmy rabbit), is a dweller in the Great Basin Region of Oregon and Washington, with scattered 
reports from northwestern California. It has a scattered range throughout the Great Basin, thence eastward into Idaho. This very small rabbit has short legs and ears and can be distinguished from cottontails by the all-gray tail. While the rabbit constructs a definite underground den, no trace has ever been found of a nest. Nestless animals are generally not very heavily infested with fleas.

The one record of the writer, doubtless accidental, is:

6. Ctenocephalides felis Bouche 1935 (domestic cat flea), Summer Lake, Oregon, June 17, 1937, 1 female, a stray from a dog, cat, or coyote.

A May, 1943, report from Beaverhead, Montana, gives this rabbit carrying:

15. Cediopsylla inaequalis inaequalis Baker 1895.

The absence of any other conclusive data on this rabbit up to this time makes it necessary to name only possibilities. It seems probable that the fleas of Brachylagus would be the same as for the jack rabbits and cottontails of the same environment. These would be:

15. Cediopsylla inaequalis inaequalis Baker 1895

150. Odontopsyllus dentatus Baker 1904.

\section{(Callospermophilus)}

\section{Citellus}

\section{Golden-Mantled Ground SQuirRels}

Howell recognizes 15 types of mantled ground squirrels north of Mexico. These mantled ground squirrels, sometimes called lava squirrels or big chipmunks, are strictly daylight animals which hibernate through the long mountain, or Great Basin winters. Nothing is known about the type of nest they build for themselves, but it is probably a good warm home for the squirrel and also for its ectoparasites.

Specimens can easily be taken in strong box traps baited with oatmeal, in No. 0 steel traps set in their burrow openings, or shot with a .410-gauge shotgun. These savage little squirrels should be handled with gloves.

Mantled ground squirrels are generally only moderately infested with fleas, the numbers on any one animal are usually few, and at times many of the squirrels can be examined and found without them.

OREGON-Citellus (Callospermophilus) lateralis chrysodeirus Merriam (goldenmantled ground squirrel) ranges over most of Oregon east of crest of Cascade Mountains and to a slight extent, in favorable localities, west of crest. South and west of Grants Pass, in a limited area in Oregon and California Citellus (Callospermophilus) lateralis trinitatis Merriam is found. In the northeast corner of state, Citellus (Callospermophilus) lateralis connectens Howell makes its home. Evidence at hand for the 3 subspecies in Oregon and for most of their range leads writer to believe that their only true flea parasite is:

79. Oropsylla idahoensis Baker 1904.

Accidental OccurRences: In spite of the fact that golden-mantled ground squirrel is unafraid and will enter any crevice or burrow, the animal picks up very few stray fleas. Perhaps the unusually tough skin of this spermophile makes it an unprofitable host for most fleas, thus causing them to leave as soon as possible. The following stray fleas have been taken from these squirrels: 
26. Orchopeas sexdentatus agilis Rothschild 1904. Proper host Neotoma (wood rats) . Cooper Spur Junction, Parkdale, August, 1935

53. Thrassis howelli howelli Jordan 1925. Proper host Marmota (groundhogs). One occasion at Sisters, July, 1936

69. Diamanus montanus Baker 1895. Proper host Citellus douglasi (gray digger). Biggs, March 2, 1940

119. Monopsyllus ciliatus protinus Jordan 1929. Proper host Eutamias (chipmunks). Two occasions at Parkdale, August, 1937.

WASHINGTON-In this state is found Citellus (Callospermophilus) saturatus Rhoads (Washington's Cascade golden-mantled ground squirrel). The writer has records for this form from Peterson's Prairie, west of Guler, and Rimrock. The only fleas obtained from these were:

79. Oropsylla idahoensis Baker 1904.

In the extreme southeast corner of the state lives Citellus (Callospermophilus) lateralis chrysodeirus Merriam (golden-mantled ground squirrel). This form also has for its chief flea parasite:

79. Oropsylla idahoensis Baker 1904

\section{CALIFORNIA-}

About the checking station on the Redwood Highway and south of Bolan Lake, Oregon, Citellus (Callospermophilus) lateralis trinitatus Merriam is found. Specimens secured at these points yielded only:

79. Oropsylla idahoensis Baker 1904.

Somewhat to the south of the range of $C$. l. trinitatus in a small local patch the Yolla Bolly mantled ground squirrel is found. It is confined to the coast ranges of northern California from Glenn County north to southern Siskiyou County. This squirrel is technically Citellus (Callospermophilus) lateralis mitratus Howell. It is paler than other forms, more grayish. Plague infection has not yet been found in this squirrel. Like other members of the western golden mantleds it probably carries only:

79. Oropsylla idahoensis Baker 1904.

Far to the south in another small isolated patch is Citellus (Callospermophilus) la* teralis bernardinus Merriam, the San Bernardino mantled ground squirrel which is found in San Bernardino Mountains of county by same name. As early as 1937 these squirrels were found infected with plague and a 1938 check proved infection still in them, and they are still found infected. It is known that these squirrels carry:

69. Diamanus montanus Baker 1895

79. Oropsylla idahoensis Baker 1904

120. Monopsyllus ciliatus mononis Jordan 1929.

In the Cascade-Sierra-Nevada Mountains of California the golden mantled ground squirrel Citellus (Callospermophilus) lateralis chrysodeirus Merriam ranges. It is the most brightly colored member of the western group. In 1937 it was found plaguepositive in Eldorado and Fresno Counties, 1938 in Plumas County, 1941 in Shasta County, 1942 in Mono and Siskiyou Counties. These squirrels carry:

69. Diamanus montanus Baker 1895

123. Monopsyllus eumolpi cyrturus Jordan 1929

known vectors of plague, and the following suspected flea:

79. Oropsylla idahoensis Baker 1904.

A flea occasionally found on these squirrels is:

200. Peromyscopsylla selenis Rothschild 1906.

MONTANA-Along western edge of Montana Citellus (Callospermophilus) lateralis tescorum Howell (Hollister's mantled ground squirrel) ranges. This squirrel has not been found plague-infected. It is known to carry the following fleas in this state:

79. Oropsylla idahoensis Baker 1904

122. Monopsyllus eumolpi eumolpi Rothschild 1905. 
Other types of mantled ground squirrels have not yet been found plague-infected. They probably all carry Oropsylla idahoensis mantled ground squirrel flea and such other stray fleas they may pick up off their neighboring rodents. As far north as. Salina, Utah, these squirrels are known to carry:

14. Hoplopsyllus anomalus Baker 1904, an efficient vector of plague.

\section{Castor}

\section{Canadian Beavers}

The Canadian beaver of the northwest is one of the most valuable fur bearers. Due to the fact that extinction threatened, all taking of the animals has been prohibited by state laws for several years. Such being the case, no ectoparasitological work has been possible on these forms. Their water habits promise to give an interesting phase to ectoparasitological work when time arrives to make collection of sufficient specimens possible.

Epizootics in beaver populations in North America have been noted for some period of time; but it seems that the first account of tularemia in these animals was recorded by Dr. John W. Scott in an animal autotopsied during April, 1939, in Sheridan County, Wyoming. Since that time, many dead beavers have been examined in southern half of Montana by staffs of Rocky Mountain Laboratory and veterinary department of Montana. Findings of these investigations are: that tularemia may become epidemic in beavers, that it seems likely these animals may become infected by injestion of contaminated water or infected animal tissue. Beavers seem not to harbor fleas or other blood sucking ectoparasites; therefore, the ectoparasite, as a vector of the transmission of the disease seems impossible in these animals. It seems highly probable that human beings skinning infected beavers or coming in contact with stagnant or still waters in which tularemia-positive animals have died and decomposed, could contract the disease through abrasions on hands. It has also been suggested that land animals which play about the water ways, such as meadow mice, may be responsible for carrying the disease to beavers. Meadow mice seem very susceptible to tularemia, and the disease has been found in muskrats.

While beavers are not known to carry fleas, there are limited records of tick infestation, and Platypsyllus castoris (parasitic beetle) is known to be a constant parasite of beaver. This beaver beetle is without sucking mouth parts. It must have a very wide distribution since the writer has a good supply of specimens, sent him, during 1939, by a lad in Kristiansand, Norway.

\section{Citellus}

\section{Gray Diggers, Red Diggers, Sage Rats, Ground Squirrels}

In the following pages on Citellus the "Revision of the North American Fround Squirrels" by A. H. Howell (North American Fauna 
No. 56, April, 1938) is referred to constantly. In this Revision, Howell sunk to subgenera of Citellus, Ammospermophilus (antelope ground squirrels) and Callospermophilus (the golden mantled ground squirrels). The writer in no way means to dispute this action of Howell's, but since both antelope ground squirrels and golden mantled ground squirrels are easily told from other ground squirrels, he has handled them in previous pages under Ammospermophilus and Callospermophilus.

In handling the American ground squirrels, Howell has used the following order: Citellus townsendi, $C$. washingtoni, $C$. richardsoni, $C$. armatus, C. beldingi, C. columbianus, C. tridecemlineatus, C. franklini, $C$. variegatus, $C$. beecheyi, and $C$. tereticaudus. This order is taxonomically sound, but it gives no indication of the plague importance of these squirrels. In the following pages the plague importance is paramount, and when these squirrels are listed from this aspect they fall in the order which is here used.

There are various species or subspecies of Citellus in practically all parts of the West. The sage rats are generally small, the rock squirrels medium, the ground squirrels, gray diggers and red diggers fairly good sized. All are squirrel-like. They build their warm nests in the ground at the end of burrow systems. All hibernate, some spending more than half the year in the sleeping condition. The nature of their nests and the texture of their fur make these ground squirrels excellent hosts for large numbers of fleas.

These ground squirrels have carried plague infection all through the West and are the hosts of some dozen species of fleas known to be efficient vectors of plague.

\section{PLAGUE IN GROUND SQUIRRELS}

Early in the plague investigations in North America, ground squirrels were found infected with plague. It is reported that large numbers of ground squirrels died in the vicinity of San Francisco during 1903, but it was not determined that the cause was plague. Five years later plague was proved in Citellus b. beecheyi (California ground squirrel) in the county of Contra Costa. During the year also, a boy contracted plague in Los Angeles County after being bitten by a ground squirrel. Plague was found in the squirrels in the vicinity. During 1909 infected C. b. beecheyi were found in Santa Clara and Santa Cruz Counties. By the end of 1910 the infection had also been located in Alameda, Monterey, San Benito, San Luis Obispo and Stanislaus Counties. In 1911 infected ground squirrels were found in Fresno, Merced, Santa Barbara and San Joaquin Counties. In 1916 the infection was located in San Mateo County and in 1918 in the county of San Francisco. During 1928 Ventura County was added to those known to have infected ground squirrels. In 1934 California ground squirrels were found infected in Kern and Tulare Counties. 
While above areas in the range of $C . b$. beecheyi were being located, other ground squirrels in California were found infected. During 1934 in the northeast corner of the state, in Modoc County, C. b. oregonus (Oregon ground squirrel) was found infected and in 1936 the same squirrel was found plague-infected in Lassen County. During this year in the extreme southern part of the state, in San Bernardino County, C. b. parvulus (Lesser California ground squirrel) was found infected. In 1937 C. b. beldingi (Belding's ground squirrel) proved plague-positive in Placer and Eldorado Counties. Ground squirrels proved plague-infected in Plumas County during 1938.

On August 19, 1941, plague was proved for the first time in $C . b$. douglasi (gray digger), the infected squirrels being found in Siskiyou County, and on December 2 of the same year these squirrels were found infected in Shasta County.

During $1942 C$. b. fisheri (Fisher's ground squirrel) was found infected in Mono and Riverside Counties-the first plague infection records for these counties-and in Los Angeles and San Diego Counties. During 1943 infection was found in $C$. b. nudipes (Juarez ground squirrel) at Delmar in San Diego County. By the close of 1943 plague-infested ground squirrels had been found in 30 of the 57 counties of California.

During 1935 infected squirrels were found in Lake, Grant, and Wallowa Counties in Oregon, and in Beaverhead County, Montana. In Oregon the involved squirrels were $C . b$. oregonus (Oregon ground squirrel) and C. c. ruficaudus (red digger).

During 1936 infection was found in ground squirrels from Bonneville County, Idaho; Elko County, Nevada; Beaver County, Utah. The next year added Bannock County, Idaho; Madison County, Montana; Ormsby County, Nevada; and Morgan and Wasatch Counties, Utah. These finds of 1936 and 1937 pushed plague-infection in the ground squirrels across the Great Basin into and through the Rocky Mountains. The year 1938 brought to light plague-infected ground squirrels in Bear Lake County, Idaho; Gallatin County, Montana; Catron County, New Mexico; and Rich County, Utah. The same year brought to attention the first infected squirrels to be found in the state of Washington in the counties of Adams and Lincoln. In this year also the first plague was found in Wyoming in infected squirrels taken in Lincoln, Sublette, and Uinta Counties. Fremont County, Idaho, was added in 1939. During 1941 it was revealed that plague had crossed the Rocky Mountains and entered the Great Plains. Richardson's ground squirrels taken at Crosby in Divide County, North Dakota, were found plague-infected. Infected squirrels were also found in San Miguel County, Colorado; Canyon, Payette, and Ada Counties, Idaho; Ravalli County, Montana; and Stevens County, Washington. In 1942 plagueinfected squirrels were discovered in Washoe County, Nevada. The thirteen-lined ground squirrel in Torrence County, New Mexico, was found infected in May, 1943. 
During these investigations to the north and east of California, the following ground squirrels were found plague-infected:

\author{
Oregon ground squirrel \\ Belding ground squirrel \\ Piute ground squirrel \\ Columbian ground squirrel \\ Red Digger \\ Gray digger \\ Richardson ground squirrel \\ Wyoming ground squirrel \\ Uinta ground squirrel \\ Say's rock squirrel \\ Striped ground squirrel
}

\author{
(Citellus beldingi oregonus Merriam) \\ (Citellus belding beldingi Merriam) \\ (Citellus townsendi mollis Kennicott) \\ (Citellus columbianus columbianus Ord) \\ (Citellus columbianus ruficaudus Howell) \\ (Citellus beecheyi douglasi Richardson) \\ (Citellus richardsoni richardsoni Sabine) \\ (Citellus richardsoni elegans Kennicott) \\ (Citellus armatus Kennicott) \\ (Citellus variegatus grammurus Say) \\ (Citellus tridecemlineatus Mitchill)
}

It was discovered early in 1942 that plague in ground squirrels was spreading north from California on the west side of the Cascade Mountains. Citellus beecheyi douglasi (gray diggers) taken March 21 in the vicinity of Brownsboro and on March 23 at Ruch, Jackson County, Oregon, were found infected. About 30 miles due west of Ruch at Selma, Josephine County, Oregon, the gray digger was also found infected on March 23. The gray digger with its huge north and south range from San Francisco Bay north to the Simcoe Mountains of Washington forms one of the main western channels of plague distribution through all western California, western Oregon, and south central Washington.

Plague was found in the Richardson's ground squirrels of Alberta, Canada, in several localities during 1942.

\section{Citellus beecheyi beecheyi (Richardson) \\ The California Ground SQuirrel}

The California ground squirrel is the common form found ranging all along the coastal belt from San Francisco Bay south into northern San Diego County. To the east it crosses the Coast Range and the San Gabriel Mountains. The squirrel seems not particular about its home range, although it is seldom found in dense woods or chaparral. In size this squirrel is between medium and large. The general color of the fur is pinkish buff. The sides of the shoulders and neck are dull white, this color extending backward as two divergent stripes that fade out about the middle of the back. Sides are white-flecked.

Although plague was discovered in rats in the range of this squirrel as early as 1902, the squirrels were not found plague-positive until 1908. During that year this California ground squirrel was found plague-infected at the extreme ends of its range in Contra Costa County to the north and Los Angeles County in the south. These plague records are the first established for native rodents in North America. During 1909 this infection was found to have spread about the Bay Region. Squirrels in Santa Clara and Santa Cruz Counties being found plague-positive. Evidence in 1910 showed the infection to be spreading southward, for during this year plague was found in these squirrels in Alameda, Stantislaus, San Benito, Monterey, and 
San Luis Obispo Counties. During 1911 plague in squirrels was found farther south in Merced, Fresno, and Santa Barbara Counties, and to the east in San Joaquin County. In 1916 plague in squirrels was found to the west in San Mateo County and in 1918 in San Francisco County. In 1928 infection was found in these squirrels in Ventura County and in 1941 in Kern County. Wherever one finds the California ground squirrel, plague infection is likely to be present in them, and as they spread their range to the east they carry the infection with them.

As early as 1910 Tularemia was discovered in these squirrels by McCoy, but as far as is known, no human cases of the disease in this part of the country have ever been traced to the infection in these squirrels.

In spite of the fact that plague has had a rapid spread in the ground squirrels of California, the California ground squirrel seems to be the normal host of only 2 known vectors of plague, in comparison with the some 8 or 10 carried by northwest ground squirrels.

These 2 fleas are:

14. Hoplopsyllus anomalus Baker 1904.

69. Diamanus montanus Baker 1895 (Ceratophyllus acutus Baker)

The following rat and mouse fleas, also known or suspected vectors of plague, have been reported occasionally off this squirrel about the Bay Area.

9. Xenopsylla cheopis Rothschild 1903

105. Nosopsyllus fasciatus Bosc 1801

213. Leptopsylla segnis Schonherr 1811.

The sticktight hen flea,

1. Echidnophaga gallinacea Westwood 1875 has been taken off this squirrel in Los Angeles County. Since this flea has been taken off Citellus beecheyi douglasi in large numbers, 1,000 miles to the north at the Columbia River in Oregon, the writer believes Citellus beecheyi may be infested with this flea throughout its range.

In the southern portion of its range, this squirrel has been found carrying occasionally the following rabbit fleas:

10. Hoplopsyllus foxi Ewing 1924

16. Cediopsylla inaequalis interrupta Jordan 1929.

166. Catallagia wymani C. Fox 1909, the central California meadow mouse flea, has been reported off this squirrel.

\section{Citellus beecheyi douglasi (Richardson)}

\section{The Gray Digger or Douglas Ground Squirrel}

The gray digger, or Douglas ground squirrel, is found in California, Oregon, and Washington. It generally avoids high elevations and densely forested areas. It is a large coarse-haired dirty gray squirrel that can be seen on almost every fence post throughout its range. It is the squirrel which should have been wiped out of existence long ago by the various rodent control campaigns, but which seems to nicely hold its own in spite of man's strychnined oats and barley. The squirrel is of danger to man, not only because of the huge amount of damage it does to grain crops, but also because it is the normal host of one of the most efficient vectors of bubonic plague.

In spite of the fact that much of the range of these big gray ground squirrels is along the coastal area, they do hibernate, perhaps not so much because of cold as of the dampness. Their winter sleep, however, terminates on almost any sunny day during the winter and out they come for a look around.

Gray diggers can be secured for study and for their fleas by shooting with rifle or shotgun or by trapping with a well staked No. 1 steel trap placed in their burrow or runs. They are vicious biters, so should be handled with care. Poisoned grain 
could be used to collect the squirrels but not too much time should elapse between death of the squirrel and its examination for fleas, since the fleas will leave as the animal cools off.

CALIFORNIA-This ground squirrel is common along the coastal belt north of San Francisco Bay and diagonally across the state to the northeast corner. During July of 1941 these squirrels were first found plague-infected in Siskiyou County, during December in Shasta County, and by the end of 1943 in practically all parts of these 2 northern California counties. Throughout most of its California range the gray digger seems to carry but 1 flea:

69. Diamanus montanus Baker 1895 (California ground squirrel flea) known to students for a number of years as Ceratophyllus acutus Baker. Its importance has been great in California studies of bubonic plague.

At times the infestation of the gray digger by this flea becomes so great that as many at 200 can be taken off a single squirrel and about their runways the ground may be teeming with fleas. Citellus b. douglasi seems to be the favored host, and even when it is present in great numbers, few of the other rodents associated with the gray digger become infested with it.

The writer has collected these squirrels at the ocean around Fort Dick in Del Norte County and on the east side of the range in the Modoc Lava Beds, at Tule Lake. In both locations he secured only large numbers of:

69. Diamanus montanus Baker 1895.

OREGON-The gray digger is found in this state from Deschutes River west to Pacific Ocean, and in southern Oregon they are found as far east as Goose Lake. But in the Deschutes River country these big ground squirrels have crossed this river and are migrating eastward, so are slowly encroaching upon the range of Citellus townsendi canus (gray sage rat), Citellus beldingi oregonus (Oregon ground squirrel), and the golden mantled ground squirrel. The danger zone is in this encroachment area, for here the gray digger becomes the host for some 8 known vectors of plague carried by the other ground squirrels and the other ground squirrels are soon carrying the gray digger's flea.

By 1942 it was pretty well known that these ground squirrels were heavily infected with plague in Siskiyou County, California, and during March of that year plague was demonstrated across the state line in Oregon, found in that month in these squirrels at Selma, Josephine County, and at Brownsboro and Ruch in Jackson County.

Throughout the greater portion of its Oregon range the writer has found on this squirrel only:

69. Diamanus montanus Baker 1895.

Occasionally this squirrel will pick up a stray flea. During June of 1934 gray diggers trapped by the writer from under a deserted chicken house at Dufur, Wasco County, were found infested with the small:

1. Echidnophaga gallinacea Westwood 1875 the tropical hen or sticktight flea.

Since that time the writer has traced this flea to the banks of the Columbia River, carried either by the gray digger or mice. So it seems, then, that the tropical hen flea has become a definite parasite of the gray digger in Oregon.

Accidental OccurRences: Few stray fleas can be reported from the gray digger. At Sparks Lake, 5,500 feet up in Cascade Mountains on Century Drive out of Bend, an old gray digger was taken by the writer, far from range of his kind. This specimen was running the rocky environment of the yellow-bellied groundhog. The only fleas on the squirrel were 3 males and 2 females of:

53. Thrassis howelli howelli Jordan 1925 (western marmot flea).

A gray digger shot by the writer at Wheatland, Yamhill County, March 6, 1937, was carrying a female, 
215. Micropsylla goodi Hubbard 1941.

On the eastern border of the range of the gray digger where it mingles with other ground squirrels of Oregon the writer has found it carrying the following known vectors of plague:

47. Thrassis petiolatus Baker 1904

69. Diamanus montanus Baker 1895 (its own flea)

70. Opisocrostis tuberculatus tuberculatus Baker 1904

79. Oropsylla idahoensis Baker 1904.

WASHINGTON-Originally this squirrel did not range in this state. Somewhere around 1910, however, a few seemed to have made their way into this state from across the Columbia River from Oregon. It is possible that they were taken across as pets. First noticed near White Salmon, they can now be seen from Underwood all along the Evergreen Highway to Maryhill and as far north as the Simcoe Mountains. So these squirrels now range throughout the greater portion of Klickitat County and into the southern portion of Yakima County. This squirrel is not known to be plague-infected in Washington to date. The only flea the writer has been able to recover from these squirrels in Washington has been:

69. Diamanus montanus Baker 1895.

When one realizes that plague has been found in the gray digger in northern. California and southwestern Oregon, it is easy to see the dangerous channel for plague infection that this squirrel makes possible from San Francisco Bay north throughout California, throughout Oregon west of Deschutes Rivers into south central Washington as far north as the Simcoe Mountains.

\section{Citellus beecheyi fisheri (Merriam) \\ Fisher's Ground SQuirReL}

CALIFORNIA-This ground squirrel seems to range through much of central California. It is found as far north as Lassen County and as far south as Kern and Santa Barbara Counties. It has also been recorded from Douglas and Washoe Counties, Nevada. It is said to be quite similar to its close relative the California ground squirrel but the hind feet are shorter, coloration paler, both above and below, light markings on shoulders more prominent and clearer white.

Fisher's ground squirrel was found plague-infected during 1940 in San Bernardino County and during 1942 in Mono, Riverside, Los Angeles, and San Diego Counties.

This squirrel is known to carry:

14. Hoplopsyllus anomalus Baker 1904

53. Thrassis howelli howelli Jordan 1925

69. Diamanus montanus Baker 1895,

all efficient vectors of plague, and

1. Echidnophaga gallinacea Westwood 1875 , the sticktight or tropical hen flea.

\section{Citellus beecheyi nudipes (Huey) \\ Juarez Ground SQuirreL}

CALIFORNIA-This Lower California fair sized ground squirrel ranges north into most of the western half of San Diego County. The head is wood brown, the upper and under parts grayish white and snuff brown, heavily flecked. The feet are cartridge buff, the tail black. This squirrel is very similar to the California ground squirrel, but smaller.

During 1943 specimens of this squirrel collected at Del Mar, San Diego County, were found plague-positive. 
This squirrel is known to carry:
1. Echidnophaga gallinacea Westwood 1875
7. Ctenocephalides canis Curtis 1826
14. Hoplopsyllus anomalus Baker 1904, a vector of plague
33. Orchopeas latens Jordan 1925
69. Diamanus montanus Baker 1895, a vector of plague.

\section{Citellus beecheyi nesioticus (Elliot) Catalina Ground Squirrel}

CALIFORNIA-This ground squirrel is found on Catalina Island, Los Angeles County. It is not known to be infected with plague, but it carries:

14. Hoplopsyllus anomalus Baker 1904, and

69. Diamanus montanus Baker 1895, 2 known native vectors of the disease.

\section{Citellus beldingi oregonus (Merriam) \\ The Oregon Ground SQuirrel}

The Oregon ground squirrel is medium-sized and the most abundant and widespread species of ground squirrels in Oregon. It occurs in practically all open parts east of Cascades. It is also found in northeastern California, northern Nevada, and southwestern Idaho. It is plain gray in color but when closely examined, the short tail has a rufus red cast, distinguishing it from all other ground squirrels with which it may be associated.

For study, these squirrels are best secured with rifle, shotgun or poisoned grain. They resent presence of steel traps in their burrows, skillfully covering them up and abandoning tunnels in which sets are made.

As early as summer of 1934 the Oregon ground squirrel was found infected with plague in Modoc County in extreme northeastern corner of California. Records revealed as high as 5 per cent plague infection in the squirrels examined. During April of 1935, 7 per cent of squirrels collected in this county were found plagueinfected. In May of 1937 these squirrels were found infected in Wallowa County, Oregon, a good 300 miles to the north of the foci in Modoc County, California. Since that time a practically solid foci has been found in these squirrels between these two points, to involve the Oregon counties of Malheur, Lake, Grant, Baker, and Union. There seems nothing to stop the spread of infection into Nevada from northeastern California or from southeastern Oregon into southwestern Idaho. To date, however, plague in Oregon ground squirrels is not reported from Nevada or Idaho, but both states do have plague reported in other ground squirrels.

OREGON-The Oregon ground squirrel was found tularemia-positive in Baker County during April, 1940. The writer has never found this squirrel very heavily infested with fleas. He reports by far the most common flea found on this squirrel is:

79. Oropsylla idahoensis Baker 1904. The infestation seems to be throughout its entire range.

48. Thrassis pandorae Jellison 1937 follows second with infestations rather general throughout the Great Basin. This flea has been taken from Union, Silvies, and Canyon City, during 1937.

The following are also recorded:

47. Thrassis petiolatus Baker 1904, Silvies, July 15, 1937

56. Thrassis rockwoodi Hubbard 1942, Sisters, Summer Lake, Lakeview,

69. Diamanus montanus Baker 1895, Denny Creek, north of Klamath Falls, June 26, 1939 
70. Opisocrostis tuberculatus tuberculatus Baker 1904, Union, April 1, 1937

77. Opisocrostis oregonensis G. and P 1939, Baker, July 12, 1939

78. Opisocrostis washingtonensis G. and P. 1939, Lexington, March 15, 1940

186. Neopsylla inopina Rothschild 1915, Silvies, July 15, 1937. All of these fleas are known or suspected vectors of plague. "

Accidental OccurRences: The inquisitive nature and the strong build of this squirrel makes it practically unafraid to enter and explore all cavities and burrows; thus it becomes a favorite for stray fleas. The following list of strays is recorded by the writer:

86. Foxella ignota recula Jordan and Rothschild 1915 (pocket gopher flea), 1 male, Summer Lake, June 17, 1937

92. Dactylopsylla comis Jordan 1929 (giant pocket gopher flea), 1 male, Little Lava Lake, Century Drive out of Bend, July 26, 1936

123. Monopsyllus eumolpi cyrturus Jordan 1929 (Great Basin chipmunk flea), 1 female, Adel, June 25, 1937 (a known vector of plague)

214. Micropsylla sectilis Jordan and Rothschild 1923, host uncertain, 1 female, Grass Valley, March 15, 1942.

NEVADA-Several specimens of this squirrel examined at Coleman's Ranch (20 miles southeast of Adel, Oregon), June 26, 1937 were without fleas, but 3 specimens examined at Franklin's Ranch (15 miles southeast of Denio, Oregon), July 5, 1939 yielded:

49. Thrassis jellisoni Hubbard 1940, 8 males, 10 females

79. Oropsylla idahoensis Baker 1904, 2 males, 3 females

186. Neopsylla inopina Rothschild 1915, 1 male.

CALIFORNIA-Ten specimens of this squirrel examined north of Fort Bidwell, June 25, 1937 were infested with:

53. Thrassis howelli howelli Jordan 1925, 1 female (a marmot flea)

123. Monopsyllus eumolpi cyrturus Jordan 1929, 1 female (a chipmunk flea), both known vectors of plague.

Twelve speçimens of this squirrel examined at Dorris, April 20, 1942 were infested with:

56. Thrassis rockwoodi Hubbard 1942, 4 males, 3 females

69. Diamanus montanus Baker 1895, 1 male

70. Opisocrostis tuberculatus tuberculatus Baker 1904, 10 males, 7 females

79. Oropsylla idahoensis Baker 1904, 20 males, 30 females.

Six specimens of this squirrel examined in the Modoc Lava Beds, April 19, 1942 yielded only:

56. Thrassis rockwoodi Hubbard 1942, 5 males.

\section{Citellus beldingi beldingi (Merriam) \\ Belding's Ground SQuirrel}

CALIFORNIA-Belding's ground squirrel ranges through a narrow strip of California bordering on Nevada. The squirrels are found as far north as Nevada County and as far south as Inyo County. They are found to some extent in Tuolumne and Fresno Counties and there is some evidence pointing to their presence in western Nevada.

Belding's ground squirrel is a very close relative to the Oregon ground squirrel and resembles it very much in appearance, and as the former spreads its range north and the latter south the distance between the 2 subspecies becomes yearly less. At the present time the intervening space seems to be about 20 miles.

During 1942 Belding's ground squirrel was found plague-positive in Eldorado and Mono Counties. 
It is not definitely known just what fleas this squirrel carries but from its range it is quite possible that in the south it might be infested with:

14. Hoplopsyllus anomalus Baker 1904

69. Diamanus montanus Baker 1895.

Through the central and northern portion of its range it might be infested with:

79. Oropsylla idahoensis Baker 1904

120. Monopsyllus ciliatus mononis Jordan 1929

123. Monopsyllus eumolpi cyrturus Jordan 1929.

\section{Citellus columbianus columbianus (Ord)}

The Columbian Ground SQuirrel

and

\section{Citellus columbianus ruficaudus (Howell) \\ The Red Digger or Blue Mountain Ground Squirrel}

The red digger has a limited range, that of the Blue Mountains of Oregon and Washington. The Columbian ground squirrel has a huge range extending from Burns, Harney County, Oregon, eastward and thence northward through Idaho, western Montana, eastern Washington and far to north through western Alberta and eastern British Columbia, Canada.

These two squirrels can easily be handled as one "since they are the same build, color, habit, and carry generally the same fleas. Both are large and heavy in body, coarse-haired and rufus red. They are efficient diggers. While they prefer open country, sparsely timbered and brushy areas are not shunned. They readily and clumsily step into bare steel traps placed in their burrows. The traps, numbers I or 2, should be securely staked. These squirrels are easily shot with a rfle or shotgun.

The red digger was first found plague-infected in June, 1987, in Wallowa County, Oregon, and has been plague-positive in that county ever since. There is not so much as a creek to prevent the spread of the infection into the red diggers of Walla Walla, Columbia, Garfield, and Asotin Counties of Washington. Plague infection in 1935 in Beaverhead County, Montana, may have covered the Columbian ground squirrel; if not, they were definitely known to be infected by 1941 and during July of that year this squirrel was found infected in Stevens County, Washington.

OREGON-The writer has taken the following known vectors of plague from these squirrels:

47. Thrassis petiolatus Baker 1904, 1 male, Canyon City, July 14, 1937; 1 male, 1 female, Lostine, August 6, 1938

48. Thrassis pandorae Jellison 1937, 1 male, Canyon City, July 14, 1937; 1 male, 1 female, Lostine, August 6, 1938

69. Diamanus montanus Baker 1895, 8 males, 2 females, Umapine, May 12, 1939

70. Opisocrostis tuberculatus tuberculatus Baker 1904, 1 female, Canyon City, July 14, 1937; 1 male, Lostine, August 5, 1938

77. Opisocrostis oregonensis G. and P. 1939, 2 males, 3 females, Umapine, July 15, 1939; 1 male, 2 females, Lostine, July 13, 1939

79. Oropsylla idahoensis Baker 1904, 1 female, Canyon City, July 14, 1937; 1 female, Lostine, August 6, 1938

186. Neopsylla inopina Rothschild 1915, 1 female, Canyon City, July 14, 1937,

And not yet condemned as a vector of plague:

121. Monopsyllus vison Baker 1904, 1 female, Lostine, August 5, 1938. 
WASHINGTON-The following known vectors of plague have been taken:

47. Thrassis petiolatus Baker 1904

69. Diamanus montanus Baker 1895

77. Opisocrostis oregonensis Good and Prince 1939

79. Oropsylla idahoensis Baker 1904

105. Nosopsyllus fasciatus Bosc 1801, Lowden, Walla Walla County, May 12, 1939.

MONTANA-The following ground squirrel fleas have been reported taken off the Columbian ground squirrel:

47. Thrassis petiolatus Baker 1904

48. Thrassis pandorae Jellison 1937

70. Opisocrostis tuberculatus tuberculatus Baker 1904

75. Opisocrostis labis Jordan and Rothschild 1922

79. Oropsylla idahoensis Baker 1904

80. Oropsylla rupestris Jordan 1929

186. Neopsylla inopina Rothschild 1915, all being vectors of plague.

The following stray fleas have been found on this squirrel:

15. Cediopsylla inaequalis inaequalis Baker 1895, a rabbit flea.

51. Thrassis acamantis (probably Th. h. utahensis Wag.), a marmot fleaa known vector of plague

108. Megabothris abantis Rothschild 1905, a mouse flea

114. Monopsyllus wagneri wagneri Baker 1904, a deer mouse flea-a known vector of plague

121. Monopsyllus vison Baker 1904, a squirrel flea

122. Monopsyllus eumolpi eumolpi Rothschild 1905, a chipmunk flea-a known vector of plague

184. Epitedia wenmanni Rothschild 1904, a deer mouse flea

162. Catallagia decipiens Rothschild 1915, a deer mouse flea

218. Rectofrontia fraterna Baker 1895, normal host uncertain.

CANADA-These squirrels are reported carrying the following fleas:

47. Thrassis petiolatus Baker 1904

69. Diamanus montanus Baker 1895

70. Opisocrostis tuberculatus tuberculatus Baker 1904

79. Oropsylla idahoensis Baker 1904

80. Oropsylla rupestris Jordan 1929

186. Neopsylla inopina Rothschild 1915, all known vectors of plague, and

160. Catallagia charlottensis Baker 1898

218. Rectofrontia fraterna Baker 1895

158. Callistopsyllus terinus Rothschild 1905, which have not as yet been condemned as vectors of plague.

\section{Citellus richardsoni richardsoni (Sabine) Richardson's Ground SQUIRREL}

Richardson's ground squirrel covers a rather large territory in Montana, North Dakota, South Dakota, Alberta, Saskatchewan, Manitoba, and extreme western Minnesota. These medium-sized ground squirrels are nearly uniform buff with slight dapplings above and below deep buff. They are lovers of the plains and open prairies, and are abundant on lake shores and river banks.

During July, 1941, these squirrels were found plague-infected in North Dakota, 6 miles south of the Canadian boundary line near Crosby in Divide County. This is the first plague record east of the Rockies in the Great Plains. During 1942 plague 
infection was found in these squirrels in the Canadian province of Alberta near Youngstown, Hanna, Suffield, Sunnybrook, and Stanmoore.

MONTANA-The following ground squirrel fleas, all known to be vectors of plague, have been reported off Richardson's ground squirrel:

47. Thrassis petiolatus Baker 1904

48. Thrassis pandorae Jellison 1937

51. Thrassis acamantis (probably Th. h. utahensis Wagner), a marmot flea

65. Thrassis bacchi Rothschild 1905

70. Opiscocrostis tuberculatus tuberculatus Baker 1904

75. Opisocrostis labis Jordan and Rothschild 1922

79. Oropsylla idahoensis Baker 1904

80. Oropsylla rupestris Jordan 1929

114. Monopsyllus wagneri wagneri Baker 1904, a deer mouse flea

122. Monopsyllus eumolpi eumolpi Rothschild 1905, a chipmunk flea

186. Neopsylla inopina Rothschild 1915, and the following strays, also vectors of plague:

219. Hystrichopsylla gigas dippiei Rothschild 1902, a mouse flea, and the following fleas that as yet are not known to transmit plague:

15. Cediopsylla inaequalis inaequalis Baker 1895, a rabbit flea

108. Megabothris abantis Rothschild 1905, a mouse flea

218. Rectofrontia fraterna Baker 1895, host uncertain.

NORTH DAKOTA-The following vectors of plague have been taken off these squirrels:

65. Thrassis bacchi Rothschild 1905

70. Opisocrostis tuberculatus tuberculatus Baker 1904

75. Opisocrostis labis Jordan and Rothschild 1922

80. Oropsylla rupestris Jordan 1929.

SOUTH DAKOTA:

65. Thrassis bacchi Rothschild 1905

73. Opisocrotis bruneri Baker 1895.

CANADA-In January of 1933 Dr. Karl Jordan described from Saskatchewan:

74. Opisocrostis saundersi, the host being the Richardson ground squirrel.

The writer has specimens of:

218. Rectofrontia fraterna Rothschild Baker 1895 off these ground squirrels taken in Alberta.

Dr. Jordan described:

80. Oropsylla rupestris Jordan 1929 off this squirrel from this province.

\section{Citellus richardsoni, elegans (Kennicott) \\ Wyoming Ground SquirRel}

This medium-sized ground squirrel is found in southwestern Montana, southeastern Idaho, southern Wyoming, and northwestern Colorado. It is said to be smaller than Richardson's ground squirrel and has shorter hind feet. General tone of the upper parts is light drab, head and shoulders frequently marked with smoky gray, under parts cartridge buff. Feet are pinkish buff or ivory yellow. Tail is cinnamon buff below, color of back changing to black edged with pale buff.

During June, 1938, the unusually high mortality of squirrels about Cokeville, Lincoln County, Wyoming, brought investigation which revealed the Wyoming ground squirrel plague-positive to the extent of 17.3 per cent of the animals examined. Although the infected squirrels were taken very close to the Idaho and Utah state lines, infection does not seem to have spread to these states through these squirrels. 
MONTANA-In this state this squirrel is known to carry:

48. Thrassis pandorae Jellison 1937, and in

COLORADO:

71. Opisocrostis tuberculatus cynomuris Jellison 1939

75. Opisocrostis labis Jordan and Rothschild 1922

79. Oropsylla idahoensis Baker 1904.

\section{Citellus richardsoni nevadensis (Howell) \\ Nevada Ground Squirrel}

The Nevada ground squirrel has a limited range in northern Nevada, southeastern Oregon and southwestern Idaho, frequently associated with the Oregon ground squirrel. When seen side by side, however, the Nevada is a size larger than the Oregon and upper parts are paler and more buff, tail paler and less red beneath.

Ground squirrels were found plague-positive in Elko County, Nevada, as early as 1936.

During July, 1939, late for collecting ground squirrels in this area, the writer did secure a few specimens of fleas off a few squirrels which had not yet gone into hibernation.

The fleas taken were:

49. Thrassis jellisoni Hubbard 1940

56. Thrassis rockwoodi Hubbard 1942

79. Oropsylla idahoensis Baker 1904

186. Neopsylla inopina Rothschild 1915.

\section{Citellus variegatus grammurus (Say)}

\section{SAY's Rock SQuirReL}

This rock squirrel has an extended range in the Rocky Mountains and west, in the mountain valleys and foothills of Colorado, Arizona, New Mexico, Utah, Nevada, the Province Mountains of California, and southern Texas. Throughout this range these squirrels seem to show a decided preference for inhabiting rocky canyons and rocky mountain slides, thus their name "rock squirrel." As is the case of many of the other ground squirrels, these climb trees readily to obtain green buds and juniper berries for storage purposes. They are distintt hoarders. It is not definitely known that they hibernate, but through their cold range the inclement winters probably keep them in their nests.

These fairly large squirrels are pinkish buff in head regions, with back and rump cinnamon buff. Under parts and legs run to pinkish white.

NEW MEXICO-The writer has removed from this squirrel in Grant County:

1. Echidnophaga gallinacea Westwood 1875

69. Diamanus montanus Baker 1895

It is known that they also carry:

14. Hoplopsyllus anomalus Baker 1904. in their southern range.

ARIZONA-In this state they carry:

64. Thrassis setosis Prince 1944.

As early as August, 1938, Say's ground squirrel was found plague-infested about Cokeville, Catron County, New Mexico. Earlier in the year unusual mortality was noted in the prairie dogs of the vicinity. The prairie dogs collected and examined were found plague-infected, as were the ground squirrels of the vicinity. During July, 1941, this rock squirrel was found plague-positive in San Miguel County, Colorado. 


\section{Citellus variegatus utah (Merriam) \\ The Utah Rock SQuirrel}

Howell states that the Utah rock squirrel appears to be a recognizable race, but it is difficult to define limits of its range. The squirrel is said to be similar to $C$. $v$. grammurus but head and posterior back darker, more tawny. This squirrel, where it is better recognized, ranges through central Utah, from the Wasatch Mountains south to the Beaver Mountains.

As early as 1936 ground squirrels were found infected with plague in Beaver County, Utah. During 1937 squirrels were found plague-positive in Morgan and Wasatch Counties. Rich County was added in 1938.

Throughout the range of this squirrel the following vectors of plague are probably found:

47. Thrassis petiolatus Baker 1904

57. Thrassis francisi C. Fox 1927

69. Diamanus montanus Baker 1895

75. Opisocrostis labis Jordan and Rothschild 1922

79. Oropsylla idahoensis Baker 1904

80. Oropsylla rupestris Jordan 1929

186. Neopsylla inopina Rothschild 1915.

UTAH-The following fleas have been definitely reported off this squirrel:

14. Hoplopsyllus anomalus Baker 1904, general in state

69. Diamanus, montanus Baker 1895 , general in state Orchopeas sexdentatus subsp., Tory (one occasion).

\section{Citellus armatus (Kennicott) \\ The Uinta Ground SQuirrel}

The medium sized Uinta ground squirrel ranges through eastern Idaho, south central Montana, western Wyoming and north central Utah. As early as 1935 ground squirrels were found plague-infected in Beaverhead County, Montana. The Uinta ground squirrel in this county was doubtless infected with plague at that time. During 1936 plague was demonstrated in these squirrels in Bonneville County, Idaho. In June, 1938, an epidemic was noted in these squirrels at Cokeville, Lincoln County, Wyoming. Specimens taken the next month were found plague-positive to the extent of 55.3 per cent. During June, 1939, these squirrels were found plaguepositive in Fremont County, Idaho.

MONTANA-The following common ground squirrel fleas, all vectors of plague, are found on this squirrel:

48. Thrassis pandorae Jellison 1937

70. Opisocrostis tuberculatus tuberculatus Baker 1904

75. Opisocrostis labis Jordan and Rothschild 1922

79. Oropsylla idahoensis Baker 1904

80. Oropsylla rupestris Jordan 1929

186. Neopsylla inopina Rothschild 1915.

The following stray fleas are also known to have been found on this squirrel. Of these, suspected vectors of plague are:

51. Thrassis acamantis (probably 54. Th. h. utahensis Wag), a marmot flea

114. Monopsyllus wagneri wagneri Baker 1904, a deer mouse flea

122. Monopsyllus eumolpi eumolpi Rothschild 1905, a chipmunk flea

219. Hystrichopsylla gigas dippiei Rothschild 1902, a mouse flea.

The following fleas which have not as yet been condemned as vectors of plague:

90. Foxella ignota (probably albertensis J. and R. 1915), a pocket gopher flea 
108. Megabolhris abantis Rothschild 1905, a mouse flea

218. Rectofrontia fraterna Baker 1895, normal host uncertain.

Throughout the southern portion of its range this squirrel is also infested with:

57. Thrassis francisi C. Fox, a true ground squirrel flea-a known vector of plague.

There is little doubt that this squirrel also carries:

47. Thrassis petiolatus Baker 1904, a common northwest ground squirrel flea and a known vector of plague.

UTAH-This squirrel has been found carrying:

57. Thrassis francisi C. Fox 1927, Salina

Thrassis arizonensis subsp., Logan

69. Diamanus montanus Baker 1895, Logan

Opisocrostis tuberculatus subsp., Logan

79. Oropsylla idahoensis Baker 1904, Logan

186. Neopsylla inopina Rothschild 1915, Logan.

\section{Citellus tridecemlineatus (Mitchill)}

\section{The Thirteen-Lined Ground SQuirrels}

Howell recognizes 8 races of these small striped ground squirrels. One type or another ranges all through the Rocky Mountain area and thence east to around the Great Lakes. It is interesting to note that Rothschild in 1905 described the known plague vector:

65. Thrassis bacchi off these squirrels from Red Deer, Alberta, Canada.

The possible vector of plague:

66. Thrassis fotus was described off these squirrels by Jordan in 1925 from specimens taken at Colorado Springs, Colorado.

Specimens of this squirrel collected at Moriarty, Torrence County, New Mexico, on May 8, 1943, were found to be plague-positive.

\section{Citellus tereticaudus teréticaudus (Baird) \\ Round-Tailed Ground SQuirrel}

This ground squirrel is found in southeastern California, southern Nevada, and northwestern Arizona. It is a desert squirrel resembling Citellus townsendi (sage rats) to the north, being light drab above, creamy. white below. While these squirrels have never been reported as carrying plague, they are infested with the following known vectors:

60. Thrassis arizonensis arizonensis Baker 1898

61. Thrassis arizonensis littoris Jordan 1929.

\section{Citellus tereticaudus chlorus (Elliot) Palm Springs Ground SQuirrel}

This squirrel resembles the preceding race very much. It is said to be more drab, less pink. Its range is a small area about Palm Springs, Riverside County, California. It is known to carry:

1. Echidnophaga gallinacea Westwood 1875

60. Thrassis arizonensis arizonensis Baker 1898

61. Thrassis arizonensis littoris Jordan 1929. 


\section{Citellus washingtoni washingtoni (Howell) \\ The Washington Ground SQuirrel}

Prior to Howell's revision of the ground squirrels in 1938 this squirrel was known as Citellus townsendi (Townsend's ground squirrel) but Howell changed the popular name to the Washington ground squirrel with technical name of Citellus washingtoni washingtoni. The squirrel ranges in southeastern Washington and northern Oregon; north to southern Adams County, Washington; east at least to the Idaho boundary; south to Heppner, Oregon; west to Willows, Oregon. The squirrel is medium-sized and short-tailed. The general color is grayish, with back distinctly spotted. Estivation is entered early, during June and July; hibernation may be over as early as February or early March.

During 1939 these squirrels were found plague-positive in Adams County, Washington. They do not as yet seem to be have proved plague-positive in Oregon.

This squirrel and the following race are found in the open sagebrush or grass land country where the soil is sandy and easy to dig. The slightest disturbance sends the squirrels scurrying for their burrow entrances, where they hesitate momentarily, probably through curiosity. If they are shot with a .410-gauge shotgun with 3-inch shells or with a rifle, they must be killed instantly and blown away from their burrow or their last kicks send them sliding down out of reach.

OREGON-The writer has removed the following vectors of plague from these squirrels:

47. Thrassis petiolatus Baker 1904

48. Thrassis pandorae Jellison 1937

70. Opisocrostis tuberculatus tuberculatus Baker 1904.

WASHINGTON-The writer has removed from this squirrel:

47. Thrassis petiolatus Baker 1904

78. Opisocrostis washingtonensis G. and P. 1939.

\section{Citellus washingtoni loringi (Howell) \\ LORING'S GROUND SQUIRREL}

Slightly to north of range of Washington ground squirrel but south of Columbia and Snake Rivers, Loring's ground squirrel is found. It is similar in all respects to Washington ground squirrel but is smaller. This squirrel carries the same fleas and was found plague-positive at same time as Washington ground squirrel. Infection was discovered in Lincoln County, Washington.

\section{THE SAGE RATS OR SAGE SQUIRRELS}

The sage rats which have been known for years as belonging to the species of Citellus mollis are, under Howell's revision, all subspecies of the species Citellus townsendi. Of various sage rats, Citellus townsendi mollis (Kennicott) (Citellus mollis mollis) sage squirrel has the greatest range. This squirrel can be found all through Nevada, western Utah, southern Idaho, southeastern Oregon, and at some points in eastern California. These squirrels are small, short and plump, with short tails, short legs and minute ears. Their fur is short and soft. They are plain buff-gray above and fulvous below. Like the others of the townsendi group, they dart for their burrows at the slightest alarm. At the opening they hesitate, reach high on their back legs to see what is wrong, then scramble into their retreats.

Too often, when shot, they simply tumble into their burrows, where they slide down out of reach. The technique of shooting involves blowing the squirrels out of and ąway from the burrow openings. Even if instantly killed, unless blown away 
from the burrow entrance, the final muscular contractions before death cause the animals to slide down their burrows out of sight. A .410-gauge shotgun chambered for 3-inch shells is ideal for securing specimens of the sage rats.

The sage rats must be collected before July 15 , since by that date practically all of them have gone down under to escape the summer heat. They do not again appear until the following February.

During 1941 plague was found in these squirrels in Ada County, Idaho, during 1942 in Canyon County, Idaho, and Washoe County, Nevada, and Malheur County, Oregon. On the west side of their range these squirrels are the normal host of:

56. Thrassis rockwoodi Hubbard 1942, and on the east side:

57. Thrassis francisi C. Fox 1927. Both are vectors of plague.

UTAH-Specimens of this squirrel taken at Salina are reported as carrying:

57. Thrassis francisi C. Fox 1927

Opisocrostis tuberculatus subsp.

169. Conorhinopsylla stanfordi Stewart 1930.

\section{Citellus townsendi canus (Merriam) (Citellus mollis canus) \\ The Gray Sage Squirrel}

These are small, soft-furred gray ground squirrels which range the sagebrush plains and high ridges between the Deschutes and John Day Rivers, thence south down through the Lake Region of the Great Basin of Oregon.

OREGON-A series of these squirrels collected along the Sherman County Highway between Wasco and Grass Valley on February 28, 1992, and June 5, 1934, netted the writer only:

47. Thrassis petiolatus Baker 1904, but 5 specimens taken over the same route March 2, 1940 netted the writer:

47. Thrassis petiolatus Baker 1904, 15 males, 30 females

70. Opisocrostis tuberculatus tuberculatus Baker 1904, 10 males, 11 females

69. Diamanus montanus Baker 1895, Wasco, 2 males, and 1 specimen taken Shaniko, March 3, 1940:

56. Thrassis rockwoodi Hubbard 1942, 2 males

70. Opisocrostis tuberculatus tuberculatus Baker 1904, 1 male.

Twelve of the squirrels collected at the colony about the 117-mile post DallesCalifornia Highway, 2 miles north of Terrebonne, July 10, 1937, netted the writer 25 fleas:

47. Thrassis petiolatus Baker 1904

56. Thrassis rockwoodi Hubbard 1942

79. Oropsylla idahoensis Baker 1904.

A series of the squirrels collected along the highway between Antelope and Maupin on May 13, 1939, were without fleas.

Accidental Occurrences:

86. Foxella ignota recula J. and R. 1915, pocket gopher flea, Grass Valley, March 2, 1940, 1 male

114. Monopsyllus wagneri wagneri Baker 1904, deer mouse flea, Grass Valley, March 2, 1940, 1 male; Shaniko, March 3, 1940, 1 male, 1 female

193. Meringis parkeri Jordan 1937, kangaroo rat flea, Terrebonne, July 10, 1937, 1 male

214. Micropsylla sectilis J. and R. 1923, true host not known, Shaniko, March $3,1940,2$ females. 


\section{Citellus mollis vigilis (Merriam) SPECkLed Sage SQuirrel}

These little soft-furred and smooth brown-gray squirrels inhabit the valley of the Owyhee and Malheur Rivers in extreme east-central Oregon. They like the low, hot desert country.

These squirrels were found tularemia-positive at Ontario, Malheur Countý, Oregon, in"1938.

The writer's records are from Ontario, Oregon, during April, 1932, and the same vicinity July, 1939. Specimens were taken which were infested only with:

70. Opisocrostis tuberculatus tuberculatus Baker 1904.

\section{Citellus townsendi townsendi (Bachman) \\ (Citellus mollis yakimensis Merriam) \\ YAKIMA GROUNd SQUiRREL}

This ground squirrel or sage rat is, as the name suggests, a resident of the Yakima district of Washington. The writer has specimens from most of its range, scuth of Ellensburg almost to Columbia River, east to Yakima River, but with specimens taken ten miles farther east, beyond Donald, Washington, west to foothills of the Cascade Mountains.

Fleas taken from this squirrel during extensive search by the writer during May, 1939, were:

47. Thrassis petiolatus Baker 1904 (by far the most common)

70. Opisocrostis tuberculatus tuberculatus Baker 1904

75. Opisocrostis labis Jordan and Rothschild 1922

78. Opisocrostis washingtonensis Good and Prince 1939

79. Oropsylla idahoensis Baker 1904.

\section{Citellus franklini (Sabine) . \\ FrankLin's Ground SQuirRel}

It is the general consensus of opinion that it will be the lot of Franklin's ground squirrel to spread plague infection out of the Rocky Mountains, across the Great Plains, over the Mississippi River and into the United States east of this great waterway. This squirrel has a vast range which runs from north to south through Alberta, Saskatchewan, Manitoba, North Dakota, South Dakota, Minnesota, Nebraska, Iowa, Kansas, Missouri, Wisconsin, Illinois, and Indiana. In the northwest portion of its range the squirrel mingles everywhere with Citellus richardsoni richardsoni on the west border. Richardsoni has been found plague-positive in Montana, North Dakota, and Alberta. The vectors of plague found on Richardson's ground squirrel are also found on Franklin's ground squirrel. It is only a matter of time, then, until Franklin's ground squirrel becomes infected with plague and carries it across the Great Plains and into the area across the Mississippi.

Franklin's ground squirrel is a medium-sized squirrel often referred to as the "gray gopher." It is said that the squirrels prefer to dig their burrows where there is tall grass cover and should the grass be harvested, as in the case of hay, the squirrels move to new locations. It is the custom of the squirrel to live in colonies. During October they hole up for the winter, coming out again during April.

In these squirrels the back is from olive to clay color. The sides are pinkish buff, mixed with grayish white. The thighs are pale smoke-gray, feet pinkish buff, tail blackish.

In the western portion of the range of this squirrel the following known vectors of plague are found: 
65. Thrassis bacchi Rothschild 1905

70. Opisocrostis tuberculatus tuberculatus Baker 1904

73. Opisocrostis bruneri Baker 1895

75. Opisocrostis labis Jordan and Rothschild 1922

80. Oropsylla rupestris Jordan 1929.

Gradually towards the east the Rocky Mountain ground squirrel plague vectors fade out, and by the time the Mississippi River is reached the squirrels are carrying only:

73. Opisocrostis bruneri Jordan 1929.

\section{Clethrionomys \\ The Red-BACKed Mice}

Little is known about the red-backed mice or their homes. As far as trapping records are concerned, these mice always seem to be scarce. Under normal conditions they are taken more or less by accident in live or dead traps which are just set for anything that will go into them. Records are scarce-the following are those of the writer.

\section{Clethrionomys californicus mazama Merriam}

\section{The Mazama Red-backed Mouse}

These mice are found generally through the higher Cascade Mountains in Oregon.

OREGON-One male and 1 female taken at Crater Lake, elevation 7,200 feet, August 29, 1933 were infested with:

98. Malaraeus telchinum Rothschild 1905. 1 male, 4 females

163. Catallagia chamberlini Hubbard 1940. 1 male

200. Peromyscopsylla selenis Rothschild 1906, I male, 2 females.

One male taken at Frog Lake, Wapinitia Cut-off, Mt. Hood National Forest, 12 miles east of Government Camp, elevation 4,000 feet, October 10, 1935 was infested with:

200. Peromyscopsylla selenis Rothschild 1906, 2 females.

One female, taken at West Lava Forest Camp, slightly west of the summit of McKenzie Pass, elevation 5,100 feet, July 24, 1937, was dead in trap. No fleas were on this mouse at time of examination.

One male was taken at the summit of the Cascade Range, Medford-Lake of the Woods Highway, elevation 5,500 feet, June 25, 1939. The fleas on this specimen were:

163. Catallagia chamberlini Hubbard 1940, 2 females

200. Peromyscopsylla selenis Rothschild 1906, 2 males, 1 female

Four females taken at Lake of the Woods, elevation 5,000 feet, June 24, 1939 netted the writer only:

200. Peromyscopsylla selenis Rothschild 1906, 1 female.

Three females taken at Cold Springs Camp, Rocky Point (north of Klamath Falls), elevation 6,000 feet, June 26,1939 were infested with:

163. Catallagia chamberlini Hubbard 1940, 2 males, 1 female

200. Peromyscopsylla selenis Rothschild 1906, 3 males,.2 females

\section{Clethrionomys californicus californicus Merriam \\ The California Red-backed Mouse}

These mice are found in the coastal belt of Oregon and northern California.

One female was taken at Sutton Lake, Florence, Oregon, elevation 15 feet, August 19, 1937. The single flea on this specimen was:

200. Peromyscopsylla selenis Rothschild 1906, 1 female. 


\section{Clethrionomys californicus obscurus Merriam}

\section{The Dusky Red-backed Mouse}

These mice range along the western slope of the Cascade Mountains. OREGON-One female, taken at High Rock Forest Camp, Mt. Hood National Forest, 35 miles east of Estacada, elevation 4,500 feet, August 6, 1938, was infested with:

116. Monopsyllus wagneri ophidius Jordan 1929, 1 male

200. Peromyscopsylla selenis Rothschild 1906, 8 males, 8 females.

One female was taken at Humbug Forest Camp, Willamette National Forest, 6 miles east of Detroit, elevation 2,500 feet, August 8, 1938. No fleas were on this mouse at the time of examination.

\section{- Clethrionomys gapperi saturatus Rhoads The British Columbia Red-Backed Mouse}

These mice are the forms which are found in the Blue Mountains of Oregon and range to the east and to the north.

OREGON-Two specimens of this mouse, taken at Lostine, elevation 6,000 feet, August 8, 1938, yielded:

108. Megabothris abantis Rothschild 1905, 1 male, 2 females.

ALBERTA-The personal records of the writer listed above for red-backed mice are augmented by those of Jordan and Rothschild far to the north at Red Deer. In this province these men reported:

37. Orchopeas leucopus Baker 1904

107. Megabothris quirini Rothschild 1905

147. Amphipsylla sibirica pollionis Rothschild 1905

162. Catallagia decipiens Rothschild 1915

200. Peromyscopsylla selenis Rothschild 1906

210. Ctenophthalmus pseudagyrtes Baker 1904,

And at Calgary:

186. Neopsylla inopina Rothschild 1915.

BRITISH COLUMBIA-These investigators found on this mouse at Kicking Horse:

98. Malaraeus telchinum Rothschild 1905

170. Delotelis telegoni Rothschild 1905

200. Peromyscopsylla selenis Rothschild 1906.

\section{Clethrionomys dawsoni dawsoni Merriam}

\section{Dawson ReD-Backed Mouse}

ALASKA-Farther to the north at Rapids, the following fleas were taken off Dawson red-backed mouse:

102. Malaraeus pencilliger dissimilis Jordan 1938

107. Megabothris quirini Rothschild 1905.

Because of the scarcity of records from the red-backed mouse the writer here adds eastern occurrences for comparison.

184. Epitedia wenmanni Rothschild 1904 from Ashburnham, Massachusetts

210. Ctenophthalmus pseudagyrtes Baker 1904 from eastern part of United States without exact data

222. Stenoponia americana Baker 1899 from Orono, Maine, the holotype female and from Martha's Vineyard, Massachusetts. 


\section{Cynomys}

The Prairie Dogs

Prairie-dogs range through the Great Plains and Rocky Mountains. They are said to resemble a small woodchuck or marmot, and live in colonies or "towns." The mouth of their burrow is a miniature model of a volcano. A conical mound of bare earth a foot or so high and several feet in diameter surrounds the round 4-inch crater in the center. The dogs roam about in their town, barking with their neighbors and nibbling the plant life within reach. At the slightest alarm they all dart to their own doorway, hesitate a moment and if the disturbance still persists tumble into their burrows, barking as they go.

Like many of the western ground squirrels these "dogs" have proved a nuisance in range and agricultural lands but in spite of man's attempts for years to put an end to them, they are still plentiful and cover wide areas.

To add to the difficulties of the prairie-dogs large numbers of them were noticed to be dying in Garfield County, Utah, during 1935. In 1936 these Cynomys parvidens (Utah prairie-dogs) were found to be infected with bubonic plague. This was the first record of plague in prairie-dogs. The realization of this caused further search and it was found in 1938 that Cynomys gunnisoni zuniensis (prairie-dogs) were infected in Apache County, Arizona; in Catron County, New Mexico; and $C$. leucurus in Loncoln and Uinta Counties, Wyoming. During 1939 the infection was found in Sweetwater County, Wyoming, and in 1941 in Valencia County, New Mexico. During 1943 prairie-dogs were found plague-positive in Lincoln County, New Mexico, Huerfano County, Colorado (C. gunnisoni), and Garfield County, Montana (C. ludovicianus).

Throughout their range prairie-dogs are known to act as the true host of: (76.) Opisocrostis hirsutus Baker 1895, a known vector of plague and they are very often found to be carrying the human flea (4.) Pulex irritans Linnaeus 1758.

Several other stray fleas have been taken off these animals.

\section{Cynomys ludovicianus ludovicianus (Ord) \\ The Black-tailed Prairie-dog}

This is the prairie-dog of the Great Plains and east side of the Rocky Mountains. In the northwestern portion of its range it is known to carry:

51. Thrassis acamantis Rothschild 1905 (probably Th. howelli utahensis Wag.)

65. Thrassis bacchi Rothschild 1905

75. Opisocrostis labis Jordan and Rothschild 1922

76. Opisocrostis hirsutus Baker 1895

80. Oropsylla rupestris Jordan 1929

186. Neopsylla inopina Rothschild 1915, all vectors of plague. 
The following strays which as yet have not been condemned as vectors:

4. Pulex irritans Linnaeus 1758

71. Opisocrostis tuberculatus cynomuris Jellison 1939

218. Rectofrontia fraterna Baker 1895.

$$
\begin{aligned}
& \text { Cynomys parvidens (Allen) } \\
& \text { UTAH PRAIRIE-DOG }
\end{aligned}
$$

The Utah prairie-dog is known to carry the following vectors of plague:

14. Hoplopsyllus anomalus Baker 1904

57. Thrassis francisi C. Fox 1927

76. Opisocrostis hirsutus Baker 1895.

\section{Cynomys leucurus (Merriam) \\ White-TAIled Prairie-dog}

The white-tailed prairie-dog of Wyoming carries the following fleas:

48. Thrassis pandorae Jellison 1937

70. Opisocrostis tuberculatus tuberculatus Baker 1904

75. Opisocrostis labis Jordan and Rothschild 1922

76. Opisocrostis hirsutus Baker 1895

79. Oropsylla idahoensis Baker 1904, all known or suspected vectors of plague.

Cynomys gunnisoni zuniensis (Hollister)

\section{Zuni Pratrie-dog}

The Zuni prairie-dog of Arizona and New Mexico carry:

4. Pulex irritans Linnaeus 1758 , the human flea

69. Diamanus montanus Baker 1895

76. Opisocrostis hirsutus Baker 1895, known vectors of plague and

89. Foxella ignota apachina C. Fox 1914, a pocket gopher flea.

\section{Cynomys gunnisoni gunnisoni (Baird) \\ Gunnison Pratrie-dog}

This prairie-dog of southeastern Colorado carries the following fleas:

71. Opisocrostis tuberculatus cynomuris Jellison 1939

75. Opisocrostis labis Jordan and Rothschild 1922

76. Opisocrostis hirsutus Baker 1895

79. Oropsylla idahoensis Baker 1904, all known vectors or suspected vectors of plague.

During 1940 I. Fox described:

72. Opisocrostis tuberculatus ornatus I. Fox 1940 from these prairie dogs collected in Saguache County on June 26, 1926.

\section{Dipodomys (Perodipus) \\ Kangaroo Rats}

Grinnell as early as June, 1922, stated that the generic term Perodipus could not even be used as a subgenus to separate 4-toed from 5toed kangaroo rats. So many writers have abandoned it in favor of Dipodomys.

Kangaroo rats are silky little animals that hop over the sandy desert wastes at night. Their back legs are long, fitted to send the animals 
over the sand in long bounds. The front feet are small, like little hands and are used primarily for the purpose of handling things. The tail is very long and ends in a tassel; it seems to be used as a rudder and perhaps a brake. These little animals, with body sometimes as big as a fist, may be sandy colored or dark brown with white markings. At dawn, they retire to their burrows, closing the doors as they enter. During the day they sleep beneath the sand in a warm nest made of shredded sagebrush bark.

Kangaroo rats can be trapped in small box traps baited with oatmeal. Since these rodents close all their doorways upon retiring for the day, burrows generally cannot be found. Sets should be made at the base of likely sage bushes, or better still, along the animals' trails. These can usually be spotted because kangaroo rats seem always to drag their long tails across the sand, making a tiny trough between their foot prints.

To what extent kangaroo rats are infected with plague is not known at the present time, but during April, 1939, 10 miles west of Las Cruces, Dona Ana County, New Mexico, these animals were found plague-positive. In the intervening 5 years no new foci of plague have been uncovered in these rodents. However, if one race of kangaroo rats is susceptible to plague it is probable that they are all subject to its ravages.

OREGON-Kangaroo rats are found east of the Cascade Mountains in all the sagebrush country, and in the southwest portion of the state as far west, perhaps, as Grants Pass, Josephine County.

\section{Dipodomys heermanni gabrielsoni Goldman Gabrielson's Kangaroo Rat}

This rat has a small range in the upper Sonoran area of the Rogue River Valley from Grants Pass to Ashland. This form is commonly known at Gabrielson's kangaroo rat.

The writer has the following records for this rodent:

Two specimens taken from the hillside (type locality) facing the service station at Brownsboro, June 21, 1939, were without fleas. These kangaroo rats are scarce. The old time settlers had seen them in years gone by, but none recently. The writer trapped for more specimens, but secured no others. Being but a subspecies of the following, these kangaroo rats should probably carry their fleas, but the Siskiyous on the south and the Cascade Range on the east completely separate the ranges of the 2 subspecies.

\section{Dipodomys heermanni californicus Merriam \\ The Northern California Kangaroo Rat}

These, the largest of the kangaroo rats in Oregon, range south from the Klamath Valley in south central Oregon to San Francisco Bay, California.

OREGON-The writer records from 12 specimens taken at the entrance of Swan Lake Valley, east of Klamath Falls, June 29, 1939:

190. Meringis cummingi Fox 1926, 10 males, 15 females. 


\section{Dipodomys ordi columbianus Merriam Columbian Kangaroo Rat}

This Columbian 5-toed kangaroo rat ranges over the sagebrush portions of the Great Basin.

\section{Dipodomys microps preblei Goldman Preble's Kangaroo Rat}

This Preble's kangaroo rat ranges around Harney Lake and south. This subspecies differs from the preceding one primarily in its mound building habit. Both of these subspecies are commonly infested with:

193. Meringis parkeri Jordan 1937, and occasionally with:

196. Meringis hubbardi Kohls 1938.

ACCidental OCcurRences: Kangaroo rats quite frequently pick up:

114. Monopsyllus wagneri wagneri Baker 1904 (Great Basin deer mouse flea) and where the range coincides with that of the antelope ground squirrel, its flea,

58. Thrassis gladiolis gladiolis Jordan 1925 is occasionally picked up.

195. Meringis shannoni Jordan 1927 (common pocket mouse flea) is also found occasionally upon kangaroo rats.

WASHINGTON-In this state kangaroo rats have only a very limited range, south and east of Pasco in the sagebrush country. This form is Dipodomys ordi columbianus Merriam, which has probably migrated into this section from Oregon. The only fleas taken by the writer in this region from kangaroo rats have been:

193. Meringis parkeri Jordan 1937.

CALIFORNIA-As one leaves the northwest and ventures into the southwest in search of kangaroo rats the races multiply by leaps and bounds. Almost every patch of sagebrush, sand, and chaparall has its own race or races of kangaroo rats. Grinnell lists 33 races from the thousand-mile-long state of California. One of the major kangaroo rat fleas of this state is:

190. Meringis cummingi C. Fox 1926

which the writer has taken off Dipodomys heermanni californicus Merriam, the northern California kangaroo rat in the Modoc Lava Beds at Tule Lake, Siskiyou County in the extreme northeastern corner of the state. This flea was described by C. Fox far to the south in Los Angeles where it was taken off Dipodomys agilis. Augustson took the flea off the same race at Point Arguello, Santa Barbara County, and Stewart had specimens of it, removed from Dipodomys venustus at Jamesburg, Monterey County.

Surprise Valley lies in northeastern Modoc County and northwestern Washoe County, Nevada. Here the author has taken:

Dipodomys ordi columbianus Merriam (five-toed kangaroo rat) and

Dipodomys microps aquilonius Willet (Surprise Valley kangaroo rat) off which he collected:

189. Meringis dipodomys Kohls 1938.

193. Meringis parkeri Jordan 1937.

196. Meringis hubbardi Kohls 1938.

On the eastern border of the state in the region adjacent to Nevada is found: 189. Meringis dipodomys Kohls 1938.

Ie was described off kangaroo rats in Imperial and Inyo Counties. Augustson records this flea off Dipodomys deserti deserti in San Diego County and off Dipodomys merriami simiolus at Palm Springs in Riverside County. The writer removed this flea from kangaroo rats at Cedarville, Modoc County, October, 1944. 
The following stray fleas have been reported by Augustson off these animals in the Santa Ynex Mountains of Santa Barbara County:

85. Foxella ignota acuta Stewart 1940 (probably $F$. i. franciscana), a pocket gopher flea

98. Malaraeus telchinum Rothschild 1905, a deer mouse flea.

NEVADA-The kangaroo rats of northern Nevada carry, according to the records of the writer, only:

189. Meringis dipodomys Kohls 1938

193. Meringis parkeri Jordan 1937.

In the southern portion of the state they are known to carry:

189. Meringis dipodomys Kohls 1938.

ARTZONA-It is thought that:

189. Meringis dipodomys Kohls 1938 ranges throughout this state and that in the southern portion of the state the range of this flea overlaps that of:

188. Meringis arachis Jordan 1929, which seems to have its center of concentration farther to the east. Augustson reports this latter flea off Dipodomys spectabilis perblandis from the Pipe Organ National Monument, Pima County.

In the northern part of the state the kangaroo rats also carry:

193. Meringis parkeri Jordan 1937.

67. Thrassoides aridis Prince 1944, has recently been described off Dipo. domys merriami taken at Nogales, Santa Cruz County.

NEW MEXICO-The following 4 kangaroo rat fleas are known to be in New Mexico:

193. Meringis parkeri Jordan 1937

67. Thrassoides aridis Prince 1944

188. Meringis arachis Jordan 1929

189. Meringis dipodomys Kohls 1938.

Of these the 2 latter are found on kangaroo rats in Dona Ana County and adjacent territory but although these animals were found plague-positive in this county in 1939 their fleas have not yet been condemned as vectors of plague. It is possible the kangaroo rats became infected through stray infestation by prairie-dog or rock squirrel fleas, known to be infected a small distance to the northwest.

COLORADO-The writer has examined specimens of:

193. Meringis parkeri Jordan 1937 from Alamosa County, and it seems likely that the kangaroo rats in this vicinity also carry:

194. Meringis jamesoni Hubbard 1943, which the writer described off pocket mice in this county.

MONTANA-The type locality of:

193. Meringis parkeri Jordan 1937 is at Powder River, Custer County.

NEBRASKA-In the western portion of this state there has recently been described a new kangaroo rat flea. It comes off Dipodomys ordi and is named:

68. Thrassoides campestris Prince 1944.

\section{Erethizon}

\section{Porcupines}

Erethizon epixanthum epixanthum Brandt (yellow-haired porcupine) is found in almost all parts of Oregon. The very nature of their wandering habits, together with their custom of sleeping during the day in trees, the apparent absence of any nest or retreat habitually used, make them very unsuitable hosts for fleas. 
While the writer has a series of records for porcupine captures and examinations, he has never taken fleas from them.

The roving ground habits of the porcupines might make them good targets for stray fleas, but the hide of the animal is so thick and tough that fleas probably do not linger long on them, even if contact is made.

Dr. Karl Jordan states that a series of materials sent from Atlin, British Columbia, contained a flea taken from a porcupine. It was a new species. Jordan described it in 1932 as (143) Ceratophyllus adustus and stated, "A bird-flea parasitic on a mammal. The porcupine is probably the true host of this modified bird-flea."

Dunn in 1923 reported as follows: "Erethizon epixanthum epixanthum (yellow-haired porcupine), 1 ; (38) Ceratophyllus wickhami, 2."

The record comes from Page 2775, Nov. 23, 1923, Public Health Reports No. 47. The material was probably gathered in the Bitterroot Valley of Montana.

In so far as the above 2 records are the only ones to come to the attention of the writer, and since Irving Fox in his Fleas of the Eastern United States presents no records for this rodent east of the Rocky Mountains, the porcupine should be a good field for flea investigation. Therefore, the writer offers the following suggestions.

In spite of the fact that it is generally thought that porcupines sleep in trees, many of them do find their way into caves. The amount of manure sometimes found in these caves leads one to believe that perhaps the animals habitually use them for permanent homes. The close examination of such caves and crevices might be a starting place for investigation.

In the field, porcupines seem to have well-traveled highways. These trails can be distinguished from the trails of other animals by presence of dragged quill marks of the tail, and, of course, by the large and characteristic foot prints. While the porcupine is conceded to be rather unintelligent, it does not step readily into steel traps. A set which is very successful can be made by setting a No. 2 steel trap, then making a ball of horse hair and placing this under the pan. Excavate a hollow in a porcupine trail, place the trap and hair ball in it, then cover with soil. The hair ball prevents the soil from getting under the pan. Stake the trap securely and cover the chain with soil. Smooth the entire set over with a bough. Porcupines can be shot at night with a shotgun or from trees during the day with a rifle.

\section{Eutamias \\ The Western Chipmunks}

Chipmunks are so familiar to everyone that little need be said about their ways or habits. They can readily be trapped in small box traps 
baited with oatmeal or apple. In passing through territories where they are to be collected, a .410-gauge shotgun using $21 / 2^{-i n c h}$ shells is very effective.

This study of the fleas of the western chipmunks is based on the capture and examination of 450 of the animals in 250 locations in Washington, Oregon, northern California, and northern Nevada. From these animals 1,000 fleas were secured. One quarter of the animals were without fleas at the time of examination and the average fleas per chipmunk was 3 .

So, chipmunks are only moderately infested with fleas, but occasionally one will come under examination which may have upon it as many as 25.

As early as 1936 the chipmunks of the high Sierras were found infected with plague in Eldorado County, California. During 1937 plague was found in these animals in Douglas and Ormsby Counties, Nevada, and Placer, San Bernardino, and Fresno Counties, California. In 1942 plague-positive chipmunks were found in Mono, Alpine, Eldorado, Kern, and Modoc Counties, California.

Of the several fleas known to be carried by chipmunks, only Monopsyllus eumolpi has been condemned to date as a vector of plague.

\section{Eutamias townsendi townsendi Bachman}

\section{The Townsend Chipmunk}

This is the big, brown chipmunk found in the Willamette Valley and westward to the Pacific. It has for its main flea parasite throughout its range:

119. Monopsyllus ciliatus protinus Jordan 1929.

\section{Eutamias townsendi ochrogenys Merriam The Redwood Chipmunk}

This orange-tinted-bellied chipmunk inhabits southwestern Oregon. Specimens taken at Port Orford and on the Chetco River during August of 1937 were infested only with:

119. Monopsyllus ciliatus protinus Jordan 1929.

\section{Eutamias townsendi siskiyou Howell \\ The Siskiyou ChipMunk}

This chipmunk is found in southwestern Oregon, east of the range of the preceding subspecies. Specimens taken at Oregon Caves and to the east during June, 1939, were infested only with:

119. Monopsyllus ciliatus protinus Jordan 1929.

Specimens taken in the higher elevations around Bolan Lake, Oregon, particularly where they come in contact with Eutamias amoenus ochraceus Howell, were infested sparingly with:

123. Monopsyllus eumolbi cyrturus Jordan 1929. 


\section{Eutamias townsendi cooperi Baird}

\section{The Cooper Chipmunk}

This chipmunk lives in the Cascade Range north of Mt. Jefferson, Oregon. While its true flea parasite is:

119. Monopsyllus ciliatus protinus Jordan 1929

it continually associates with Eutamias amoenus ludibundis Hollister, the small Hollister's chipmunk, from which it becomes infested occasionally and mildly with:

123. Monopsyllus eumolpi cyrturus Jordan 1929.

\section{Eutamias townsendi senex Allen \\ The Allen Chipmunk}

These dull-colored, grayish chipmunks range over the east slopes of the Cascades and to some extent into the Great Basin. Location of the catch plays a great part in the flea infestation of these chipmunks; high up, in the Cascades, the infestation may be all:

119. Monopsyllus ciliatus protinus Jordan 1929

while on the east slopes of the Cascades the infestation includes:

123. Monopsyllus eumolpi cyrturus Jordan 1929

and the farther east the specimens are taken the more of the latter and the less of the former are to be noted, until in the Great Basin Region the former entirely disappears.

\section{Eutamias amoenus}

These small bright-colored chipmunks are found east of the crest of the Cascade Mountains, with 1 subspecies in the Siskiyou Mountains.

\section{Eutamias amoenus ludibundis Hollister The Hollister Chipmunk}

This chipmuk ranges north of O'Leary Mountain in the Cascades. In so far as this chipmunk is in almost constant association with the townsendi group of chipmunks of the high Cascades, it is commonly infested with:

119. Monopsyllus ciliatus protinus Jordan 1929

123. Monopsyllus eumolpi cyrturus Jordan 1929.

\section{Eutamias amoenus amoenus Allen}

\section{The Klamath Chipmunk}

This chipmunk ranges over the Great Basin region and southwest into the Cascades about Crater Lake and south. Where these chipmunks mingle with the townsendi group in the high Cascades they will be infested with:

119. Monopsyllus ciliatus protinus Jordan 1929 and

123. Monopsyllus eumolpi cyrturus Jordan 1929, but the farther east the specimens are taken the more of the latter and the less of the former are noted, until in the Great Basin regions the former entirely disappear.

\section{Eutamias amoenus luteiventris Allen}

\section{The Yellow-bellied Chipmunk}

This chipmunk ranges in the northeastern portion of the state of Oregon and southeastern portion of Washington. The fleas of this chipmunk are a light but constant infestation of: 
122. Monopsyllus eumolpi eumolpi Rothschild 1904

with an occasional:

119a. Monopsyllus ciliatus kincaidi Hubbard 1946, and

121. Monopsyllus vison Baker 1904.

These data come from 20 specimens examined by the writer at Wallowa Lake, Oregon, July, 1939.

\section{Eutamias amoenus ochraceus Howell \\ The Yellow Chipmunk}

This chipmunk ranges in the Siskiyou Mountains of southwestern Oregon and northern California. In so far as the range of this chipmunk is about the same as that of Eutamias townsendi siskiyou Howell, it is little wonder that it carries:

119. Monopsyllus ciliatus protinus Jordan 1929,

where it associates with siskiyou, but in the higher elevations where siskiyou does not range, there ochraceus carries only:

123. Monopsyllus eumolpi cyrturus Jordan 1929.

\section{Eutamias minimus pictus Allen \\ SAgebrush or Desert Chipmunk}

This pygmy of Oregon chipmunks makes its home in all the sagebrush parts of the Great Basin. It may have some slight contact with Eutamias townsendi senex but these townsendi are so far east that they do not carry the flea Monopsyllus ciliatus protinus Jordan 1929. Therefore, the only flea found on these desert chipmunks is: 123. Monopsyllus eumolpi cyrturus Jordan 1929.

\section{ACCIDENTAL OCCURRences:}

Chipmunks spending most of their time on the ground, as they do, probably pick up many stray fleas: The following are in the collection of the writer.

OREGON-The most common of these strays, recorded upon 5 occasions, is:

160. Catallagia charlottensis Baker 1898 from around Parkdale, in the Mt. Hood National Forest during the years 1932, 1934, 1935, 1937. This flea has for its true hosts Peromyscus (deer mice), and Microtus (meadow mice)

114. Monopsyllus wagneri wagneri Baker 1904 (Great Basin deer mouse flea) from E. amoenus amoenus Allen (Klamath chipmunk), 1 female, Terrebonne, July 10, 1937; from E. minimus pictus Allen (desert chipmunk), 1 male, Crane, July 16, 1937

32. Orchopeas nepos Rothschild 1905 (tree squirrel flea), from E. townsendi townsendi Bachman (Townsend's chipmunk), 1 male, Dodge Park, July 26, 1934

40. Opisodasys keeni Baker 1896 (deer mouse flea), from E. townsendi townsendi Bachman (Townsend's chipmunk), 1 female, Boyer, April 24, 1937

108. Megabothris abantis Rothschild 1905 (mouse flea), from E. townsendi townsendi Bachman (Townsend's chipmunk), 1 male, Coaledo, August 21, 1937.

WASHINGTON-Various species and subspecies of chipmunks are infested with fleas which range very similarly to the forms in Oregon. West of the crest of the Cascade Mountains the chief flea of the chipmunks is:

119. Monopsyllus ciliatus protinus Jordan 1929. 
In the Cascade Mountains where both the townsendi and the amoenus group of chipmunks are found side by side:

119. Monopsyllus ciliatus protinus Jordan 1929, and

123. Monopsyllus eumolpi cyrturus Jordan 1929, parasitize these chipmunks.

East of the base of the Cascade Mountains, in the Great Basin region, the only flea of the chipmunks is:

123. Monopsyllus eumolpi cyrturus Jordan 1929

while in the extreme eastern portion of the state

122. Monopsyllus eumolpi eumolpi Rothschild 1905 is found.

119a. Monopsyllus ciliatus kincaidi Hubbard 1946, is found in Blue Mountains.

CALIFORNIA-In the western portion of northern California the chief flea of the chipmunks is:

119. Monopsyllus ciliatus protinus Jordan 1929

while in the Cascades both:

119. Monopsyllus ciliatus protinus Jordan 1929 and

123. Monopsyllus eumolpi cyrturus Jordan 1929

infest them. This mixed infestation reaches as far east as Pine Creek.

118. Monopsyllus ciliatus ciliatus Baker 1904 was described from materials taken off a chipmunk at Mountain View.

120. Monopsyllus ciliatus mononis Jordan 1929 was described from material taken off chipmunks in Mono County.

124. Monopsyllus fornacis Jordan 1937 is found on chipmunks in central California and south.

125. Monopsyllus eutamiadis Augustson 1941 was described off chipmunks from the central Sierra Mountains around Mammoth Lakes, Mono County.

In California the following stray fleas have been reported off chipmunks:

69. Diamanus montanus Baker 1895

79. Oropsylla idahoensis Baker 1904

114. Monopsyllus wagneri wagneri Baker 1904

159. Callistopsyllus deuterus Jordan 1937.

NEVADA-In northern Nevada the chief flea of the chipmunks is:

123. Monopsyllus eumolpi cyrturus Jordan 1929, a known vector of plague.

In the Sierra Nevada Mountains along the boundary line of Nevada and California the chipmunks carry:

120. Monopsyllus ciliatus mononis Jordan 1929, and probably

125. Monopsyllus eutamiadis Augustson 1941.

MONTANA-The following are carried by chipmunks:

119. Monopsyllus ciliatus protinus Jordan 1929

119a. Monopsyllus ciliatus kincaidi Hubbard 1946

122. Monopsyllus eumolpi eumolpi Rothschild 1905

and the following strays:

35. Orchopeas caedens caedens Jordan 1925 (pine squirrel flea)

51. Thrassis acamantis (54. Th. h. utahensis?) (marmot flea),

and the following ground squirrel fleas:

47. Thrassis petiolatus Baker 1904

48. Thrassis pandorae Jellison 1937

75. Opisocrostis labis Jordan and Rothschild 1922

79. Oropsylla idahoensis Baker 1904

and the following mouse fleas:

108. Megabothris abantis Rothschild 1905

162. Catallagia decipiens Rothschild 1915, and

219. Hystrichopsylla gigas dippiei Rothschild 1902. 
BRITISH COLUMBIA-ALBERTA-From these provinces of Canada the following fleas have been removed from chipmunks:

119. Monopsyllus ciliatus protinus Jordan 1929

122. Monopsyllus eumolpi eumolpi Rothschild 1905

219. Hystrichopsyllus gigas dippiei Rothschild 1902.

\section{Fiber-Ondatra}

The Muskrats

Muskrats inhabit practically all the waterways of the Northwest. Interesting professional trappers in securing live animals for ectoparasitological work is not a very successful business. The few muskrats which come into the writer's hands each year are generally dead and the fleas, if any were present at the time of the catch, have had plenty of time to leave as the host cooled.

The writer has but one record of a flea from Fiber and this might have been an accidental occurrence. The record is:

105. Nosopsyllus fasciatus Bosc 1801 (common European and American rat flea), from Fiber zibethicus occipitalis Elliot (Oregon coast muskrat), Forest Grove, Oregon, October 3, 1931, captured alive in a creek running by a stable, 1 female.

Irving Fox offers only the name of the muskrat under his caption of "Eastern Hosts" for the vicariating flea:

210. Ctenophthalmus pseudagyrtes Baker 1904, actual record not given.

The muskrat needs more study as a flea host. To secure them alive for this study does offer a problem. Generally, because they do gnaw their legs off and escape from traps, muskrats are taken in sets which drown them. These drowned animals are of little use to the flea student. It is the understanding of the writer that muskrats can be taken alive by planting a barrel in waters where they are abundant. The barrel is partially filled with water and fitted with a tilting head. The hinged head is baited with vegetables or fruit and as the animals climb upon the head to secure the food, they fall in the water and the tilting head, which immediately swings back into the closed positon, prevents the animals from escaping. The idea is worth trying by some student who is anxious to find a host which has been inadequately worked to date.

During April, 1942, muskrats taken on the shores of Klamath Lake, Lake County, Oregon, were found tularemia-positive. This lake, and its extension into northern California, and Tule Lake in northern California form one of the most natural harbors for muskrats and their trapping. The writer has been unable so far to secure fleas off the muskrats from this region. It seems likely, therefore, that fleas do not play a part in the spread of tularemia in these animals. Muskrats examined by the writer have carried several different types of mites-mites which resemble very much the types carried by Aplodontia (mountain beavers) which live in very damp burrows. While the writer knows of no re- 
searches carried out on tularemia and the mite as a vector, such a study might be worth-while in conjunction with this disease.

A disease commonly referred to in northeastern Nevada as "muskrat fever" may upon more study prove to be tularemia. Muskrat trappers about Ruby Lake develop the disease during the trapping season and after the skinning of the animals begins. No fatal cases have been reported in man.

\section{Glaucomys \\ FLYING SQUIRRELS}

Flying squirrels are well distributed over most of the wooded portions of the West. They are probably far more common than is suspected. Their night-gliding habits keep them from being seen and only occasionally is one actually discerned. They are not of ten taken in traps even though they do become a nuisance in winter as they attempt to secure the baits from traps set for fur bearers. Only a few are generally taken over considerable periods of time, and then only by accident. In nut orchards bordering timber tracts flying squirrels can be caught in small steel traps set' on boards leaning against the trunks of the nut trees.

Occasionally large numbers of these squirrels can be chased from hollow trees, and then easily shot as they come to rest dazed by the daylight. Woodpecker holes and deserted bird nests also seem favorite retreats and homes, and once in a while nests are built in deserted cabins. When driven from their homes during daylight and shot, the squirrels are found to be heavily infested with feeding fleas.

In 1937 plague-positive flying squirrels were taken in Fresno County, California.

OREGON-Flying squirrels are generally infested with:

43. Opisodasys vesperalis Jordan 1929

sometimes the infestation becoming very heavy as is indicated by 43 males and 27 females from a specimen of:

Glaucomys sabrinus oregonensis Bachman, collected as it was chased from its nest at Gaston, February 12, 1938.

The flying squirrel is thought to be the true host of this flea.

Accidental Occurrences: The writer has taken the following fleas other than opisodasys vesperalis Jordan from the nests of flying squirrels.

119. Monopsyllus ciliatus protinus Jordan 1929 on several occasions, and on 1 occasion:

172. Megarthroglossus procus oregonensis Hubbard 1946, and

160. Catallagia charlottensis Baker 1898.

IDAHO-Off a flying squirrel at Boise, the following flea was described:

41. Opisodasys jellisoni I. Fox 1941.

MONTANA-The following fleas have been reported off flying squirrels:

43. Opisodasys vesperalis Jordan 1929

108. Megabothris abantis Rothschild 1905

173. Megarthroglossus divisus divisus Baker 1895. 
BRITISH COLUMBIA-The following are reported:

43. Opisodasys vesperalis Jordan 1929

42. Opisodasys pseudarctomys Baker 1904

148. Tarsopsylla coloradensis Baker 1895.

\section{Lepus \\ Jack Rabbits-Snowshoe RabBits}

Jack rabbits are fairly well distributed over the West. The California jack extends throughout the open country of the Willamette, Rogue, and Umpqua River Valleys; the Oregon jack, throughout the sagebrush portions of the Great Basin; the white-tailed jack everywhere east of the Cascades.

Jack rabbits are best secured for study by shooting with rifle or shotgun and can be more generally found at dusk and daybreak.

Naturalists are of the opinion that these big rabbits do not build nests. Such being the case, they should form poor hosts for fleas, because the flea must rely purely upon chance to find its rabbit host.

This condition seems to bear out the data of the writer, for during June, 1937, 15 jack rabbits taken in central and southcentral Oregon had no fleas; 10 taken about Sister, Oregon, during June, 1936, had:

15. Cediopsylla inaequalis inaequalis Baker 1895 upon only 1 specimen.

Specimen after specimen examined during early 1939 in Oregon, Washington, and Nevada deserts were also without fleas. However, there is little doubt that, as is the case in the Willamette Valley of Oregon, all jack rabbits of the Northwest are infested with:

150. Odontopsyllus dentatus Baker 1904

and east of the Cascade with:

15. Cediopsylla inaequalis inaequalis Baker 1895, and

16. Cediopsylla inaequalis interrupta Jordan 1925

and west of the Cascades with:

16. Cediopsylla inaequalis interrupta Jordan 1925.

In southwestern Oregon the jack rabbit is also infested with:

10. Hoplopsyllus foxi Ewing 1924.

ACCIDENTAL OCCURRENCES: Jack rabbits seem to pick up only a few of their own fleas; strays, therefore, are rarely found. The writer has in his records:

114. Monopsyllus wagneri wagneri 1904 from Lepus californicus wallawalla Merriam, Adel, Oregon, June 22, 1936, 1 female

4. Pulex irritans Linnaeus 1758 from Lepus californicus wallawalla Merriam, Grass Valley, Oregon, March 27, 1932, 1 female.

The writer has records for:

150. Odontopsyllus dentatus Baker 1904, and

15. Cediopsylla inaequalis inaequalis Baker 1895. from jack rabbits in.eastern Washington and northwestern Nevada.

CALIFORNIA-Jack rabbits carry the following fleas:

10. Hoplopsyllus foxi Ewing 1924

16. Cediopsylla inaequalis interrupta Jordan 1929

150. Odontopsyllus dentatus Baker 1904,

and the following strays:

1. Echidnophaga gallinacea Westwood 1875

4. Pulex irritans Linnaeus 1758. 
In the Southwest jack rabbits carry:

13. Hoplopsyllus affinis Baker 1904

15. Cediopsyllus inaequalis inaequalis Baker 1895.

To the north in the Rocky Mountains the following are added to the list of jack rabbit fleas:

12. Hoplopsyllus glacialis lynx Baker 1904

150. Odontopsyllus dentatus Baker 1904.

\section{Lepus bairdi}

\section{The SNowshoe Rabiit}

MONTANA-By far the best records for this rabbit come from this state where the following fleas have been taken off it:

12. Hoplopsyllus glacialis lynx Baker 1904

13. Hoplopsyllus affinis Baker 1904

15. Cediopsylla inaequalis inaequalis Baker 1895

150. Odontopsyllus dentatus Baker 1904, all true rabbit fleas,

and the following strays:

26. Orchopeas sexdentatus agilis Rothschild 1905

114. Monosyllus wagneri wagneri Baker 1904

186. Neopsylla inopina Rothschild 1915.

ALASKA-This rabbit is known to carry:

12. Hoplopsyllus glacialis lynx Baker 1904.

Occasionally, here and there, a cat flea:

6. Ctenocephalides felis Bouche 1835 is found on a jack rabbit.

Plague-positive jack rabbits were found in Baker County, Oregon in 1941, and during 1942 in Kern, Los Angeles, and San Luis Obispo Counties, California.

Tularemia had been noted in rabbits long before tularemia-positive fleas were recorded from them. During 1935, snowshoe rabbits in Minnesota were found to be tularemia-positive, and fleas which were pooled from them were found to be carrying the bacillus. During June and July, 1937, tularemia-positive snowshoe rabbits were taken in south central Alaska. Both fleas and ticks were very few on the 172 animals examined. A tularemia-positive tick was removed from 1 animal; but no mention is made of the fleas. It is known, however, that this rabbit carries:

12. Hoplopsyllus glacialis lynx Baker 1904 in this northern range.

\section{Marmota \\ MARMOTS-WOODGHUCKS-GROUNDHOGS}

Groundhogs are one of the traditions of American peoples and Groundhog Day brings out every pair of human eyes to watch the actions of this animal on February 2; he is supposed to be America's No. 1 ace weather prophet. Groundhogs are found in most of North America. They are a good-sized rodent, almost 2 feet long. Their home is generally in a burrow, but in the West they also build their nests in rock slides and hollow trees. In the high mountains where they seldom see man, they are very wary; where they see much human activity, not so much so.

Woodchucks, are brown, or reddish brown animals with a very characteristic call, a loud piercing whistle. The animals are not social 
in the way that prairie dogs are colonial. Each seems to have its own range which it defends against others. These animals are distinct hibernators, spending from October to March down under. In the high mountains marmots hibernate for a much longer period.

Where marmots live in burrows they can easily be trapped in a No. 1 steel trap. No cover is necessary, but the traps should be securely staked. In rock slides the animals are best shot, either with rifle or shotgun.

When these animals are caught they are generally found heavily infested with fleas. Their burrow and soft warm nest both tend to keep their fleas concentrated. Their coarse hair also favors flea infestation.

While marmots in Asia have long been known to be the reservoirs of plague in that region, it was not until 1936 that these animals were found plague-positive in this country. During 1936 woodchucks in Beaverhead County, Montana, and Beaver County, Utah, were found plague-infected. Infection was discovered in Lincoln County, Wyoming, and Bannock County, Idaho, during 1938. In 1941 infected marmots were found in Malheur County, Oregon, and San Miguel County, Colorado. During 1942 plague-positive marmots were found in Grant, Harney, and Lake Counties, Oregon, Lassen County, California, and Ada County, Idaho.

Four true marmot fleas are known in the West:

51. Thrassis acamantis Rothschild 1905, north of the Columbia River

53. Thrassis howelli howelli Jordan 1925, south of the Columbia River, both vectors of plague, and

54. Thrassis howelli utahensis Wagner 1936, in the central Rocky Mountains

52. Thrassis spenceri Wagner 1986, of western. British Columbia, against which no experiments have as yet been carried on to test their effectiveness as vectors of plague.

81. Oropsylla arctomys Baker 1904 (eastern marmot flea), has been reported from British Columbia and Alaska, and

55. Thrassis stanfordi Wagner 1936 is reported off marmots from Salina, Utah, but they are not of common occurrence in the West and neither has been associated with plague.

WASHINGTON-Three forms of marmots are found in Washington: Marmota flaviventris avara Bangs in the lowlands of the Cascades and east; Marmota caligata cascadensis Howell (Cascade hoary marmot) in the high Cascades; and Marmota olympus Merriam (Olympic marmot) in the higher levels of the Olympic Mountains. All these marmots have for their common flea:

51. Thrassis acamantis Rothschild 1905.

There are reports that:

53. Thrassis howelli howelli Jordan 1925 is found in the state, but this investigator has never found this flea in Washington. It is quite possible that this flea might be found on marmots south of the Snake River in this state.

OREGON-In this state the only marmot flea is:

53. Thrassis howelli howelli Jordan 1925, which is found upon Marmota flaviventris flaviventris A. and B. in the high Cascades and also upon Marmota flaviventris avara Bangs in the lowlands to the east. 
The writer has removed from marmots in the Cascades these strays:

32. Orchopeas nepos Rothschild 1905 (tree squirrel flea)

197. Peromyscopsylla hesperomys Baker 1904 (mouse flea).

CALIFORNIA-In northern California the writer has taken off Marmota flaviventris avara Bangs:

53. Thrassis howelli howelli Jordan 1925, described off Marmota flaviventris sierrae Howell taken at Pine City, Mono County. This is the only marmot flea in California. The writer has also taken this flea off marmots in Nevada.

UTAH-The writer has in his collection, through the courtesy of Prof. J. S. Stanford of Utah State Agricultural College, paratype specimens of:

54. Thrassis howelli utahensis Wagner 1936

55. Thrassis stanfordi Wagner 1936, taken off Marmota flaviventris englehardti Allen at Fish Lake and Logan, the type localities.

COLORADO-The following 2 vectors of plague are reported off marmots in this state:

75. Opisocrostis labis Jordan and Rothschild 1922

80. Oropsylla rupestris Jordan 1929.

MONTANA-Extensive work on marmots has resulted in the recording of the following fleas from this animal. The known vectors of plague are:

51. Thrassis acamantis (utahensis?) (marmot flea)

47. Thrassis petiolatus Baker 1904 (ground squirrel flea)

48. Thrassis pandorae Jellison 1937 (ground squirrel flea)

70. Opisocrostis tuberculatus tuberculatus Baker 1904 (ground squirrel flea)

75. Opisocrostis labis Jordan and Rothschild 1922 (ground squirrel flea)

76. Opisocrostis hirsutus Baker 1895 (prairie dog flea)

80. Oropsylla rupestris Jordan 1929 (ground squirrel flea)

122. Monopsyllus eumolpi eumolpi Rothschild 1905 (chipmunk flea)

186. Neopsylla inopina Rothschild 1915 (ground squirrel flea),

and the following fleas which have as yet not been condemned as vectors of the disease:

79. Oropsylla idahoensis Baker 1904 (ground squirrel flea)

81. Oropsylla arctomys Baker 1904 (eastern marmot flea)

108. Megabothris abantis Rothschild 1905 (mouse flea)

165. Catallagia moneris Jordan 1937, off a marmot

173. Megarthroglossus divisus divisus Baker 1895 (squirrel flea).

Records from the Southwest reveal that 2 additional known vectors of plague are occasionally taken off marmots in that region:

14. Hoplopsyllus anomalus Baker 1904, and

69. Diamanus montanus Baker 1895.

From this review it is evident that marmots in the West carry 11 of the most efficient known. vectors of plague. It will be necessary to watch them more closely, perhaps even plan for their rigid control.

\section{Microdipodops \\ The GNome Mice}

The writer trapped for this quaint, big headed little creature in the Oregon desert for sèveral years without success, then during July, 1939, succeeded in securing 12 specimens without difficulty. These little gray mice, appropriately called gnome mice because of their seemingly big 
heads, are said to be found in the extremely arid Upper Sonoran Zone valleys of southeastern Oregon and northern Nevada. Like their relatives the kangaroo rats and pocket mice, these little fellows burrow in the sand and close their holes in after them when they retire for the day. The writer's specimens were for the most part without fleas, which might indicate that the repeated dustings of these little mice make them poor subjects for fleas.

It has generally been presumed by naturalists that the scarcity of these little mice in collections was due to inability to tempt them with bait, and their small size failing to make traps spring. The specimens listed below were all taken in small box traps baited with oatmeal and set under likely bushes. The writer and many collecting naturalists have had fine success in setting traps along a long mark made in the sand with a stick or heel.

\section{Microdipodops megacephalus oregonus Merriam}

\section{Oregon GNome Mouse}

OREGON-The writer records the following:

196. Meringis hubbardi Kohls 1938 from 2 specimens examined at Blitzen, (10 miles west) July 3, 1939, 2 males, 1 female; 3 specimens examined at Fields (south end Alvord Lake), July 4, 1939, were without fleas.

NEVADA-Three specimens examined in Nevada 3 miles south of Denio, Oregon, July 5, 1939, were without fleas; two specimens examined in Nevada 15 miles south of McDermit, July 8, 1939, were without fleas. One specimen examined on the east shore of Pyramid Lake, Washoe County, July 18, 1944, clean. Two specimens examined at Big Bear Farm, Washoe County, June 5, 1945, carried a male

196. Meringis hubbardi Kohls 1938.

CALIFORNIA-Three specimens examined at Cedarville, Modoc County, October 22, 1944, clean. Three specimens examined at Eagleville, Modoc County, June 9, 1945 , carried 2 pairs

196. Meringis hubbardi Kohls 1938.

\section{Microtus \\ Meadow Mice-Field Mice}

Of the even 100 races of meadow mice listed by Miller from North America, 65 are found west of the 100th meridian. Eighteen of these are from Alaska, 20 from California. Bailey lists 13 types from Oregon. Taylor and Shaw record 14 types from Washington. All of these meadow mice have about the same ways and habits. They live underground to a great extent, coming up out of their burrows to feed upon vegetation of one type or another. The openings of the burrows are seldom closed. Somewhere along the underground runways are built several all-grass nests. It is the belief of the writer that the mice use the nests alternately to starve out their ectoparasites. The nests seldom have many fleas in them; the mice, too, often are entirely without them. 
Meadow mice are at home from sea level to high mountain valleys. While they are generally meadow lovers and push their trails through the sheltering grass, many of the races are woods mice and take to the shelter of down logs or rocks. Other races make their homes along rapid-running, cold mountain streams.

From time to time pestilence strikes these mice, but it was not until 1935 that plague was discovered in them in Modoc County, California. Seven years later in September, 1942, Microtus californicus examined at Fort Cronkhite, Marin County, California, were found plague-positive, as were mice of San Luis Obispo County. These mice were also found infected in 1943 on the Fort Ord Military Reservation, Monterey - County, California.

Meadow mice in any great numbers are difficult to take in live traps, but over periods of time enough are obtained for fairly conclusive records. Nothing one can place in traps as bait can take the place of the ever-present grasses and roots upon which they live. Under old hay cocks is an excellent place to secure the mice and their nests. Far more fleas can be taken from the nests than off the mice. Meadow mice taken from under new hay cocks are seldom infested with many fleas,

Meadow mouse signs consist of their midden heaps, their small stacks or piles of grass cuttings, their above-ground trails. Trap settings with oatmeal bait will frequently succeed if placed beside such signs.

The following records of the fleas of western meadow mice is the result of personal trapping of 200 specimens from 90 localities in the West. From these mice the writer removed 185 fleas. Forty per cent of the 200 recorded mice were without fleas. The average number of fleas per mouse was less than 2, but from 25 meadow mouse nests collected over Oregon and Washington, the writer recovered 345 fleas.

The flea parasites of Microtus are first listed here according to their frequency and abundance on the host.

\section{OREGON:}

159. Atyphloceras multidentatus Fox 1909 from $M$. townsendi Bachman (Townsend's meadow mouse); $M$. oregoni oregoni Bachman (Oregon creeping mouse), northwest Oregon

185. Epitedia jordani Hubbard 1940 from M. townsendi Bachman (Townsend's meadow mouse), northwest Oregon; M. mordax abditus A. B. Howell (Tillamook long-tailed meadow mouse), Forest Grove, March 12, 1937; $M$. oregoni oregoni Bachman (Oregon creeping mouse), Tillamook, August 30, 1937

160. Catallagia charlottensis Baker 1898 from $M$. townsendi Bachman (Townsend's meadow mouse), northwest Oregon; $M$. richardsoni arvicoloides Rhoads (Cascade meadow mouse), Lookout Mountain, Mt. Hood National Forest, September 29, 1935

219. Hystrichopsylla gigas dippiei Rothschild 1902 from $M$. townsendi Bachman (Townsend's meadow mouse), northwest Oregon; $M$. oregoni oremoni Bachman (Oregon creeping mouse), Tillamook, August 30, 1937 . 
197. Peromyscopsylla hesperomys Baker 1904 from $M$. richardsoni arvicoloides Rhoads (Cascade meadow mouse), Frog Lake, Mt. Hood National Forest, October 4, 1931; Davis Lake, Century Drive out of Bend, July 30, 1936; $M$. townsendi Bachman (Townsend's meadow mouse), Newberg, December 1, 1933; $M$. oregoni oregoni Bachman (Oregon creeping mouse), Tillamook, August 30, 1937

108. Megabothris abantis Rothschild 1905 from $M$. townsendi Bachman (Townsend's meadow mouse), Newberg, April 18, 1937; M. richardsoni arvicoloides Rhoads (Cascade meadow mouse), High Rock Forest Camp, 4,750 feet elevation, 35 miles southeast of Estacada, September 25, 1938; $M$. mordax mordax Merriam (Rocky Mountain meadow mouse), Lostine, August 8, 1938; $M$. montanus montanus Peale (Peale's meadow mouse), Hart Mountain, July 2, 1939

200. Peromyscopsylla selenis Rothschild 1906 from M. canicaudus Miller (gray-tailed meadow mouse), Odell, March 18, 1939; Salem, December 18, 1938; Gaston, February 15, 1940; Forest Grove, March 22, 1939

199. Peromyscopsylla ravalliensis D. 1923 from M. mordax mordax (Rocky Mountain meadow mouse), Adel, June 30, 1939,

Accidental Occurrences: Microtus frequently becomes temporarily inhabited by a number of stray fleas belonging rightfully to other rodents or insectivora running in the burrows of the meadow mouse. The writer records the following:

116. Monopsyllus wagneri ophidius Jordan 1929. True host Peromyscus (deer mouse) from M. townsendi Bachman, 3 occasions around Forest Grove,

Where shrews abound, frequently their chief flea:

211. Doratopsylla jellisoni Hubbard 1940 makes its way on to $M$. townsendi Bachman, Forest Grove; $M$. oregoni oregoni Bachman, Tillamook

109. Megabothris asio orectus Jordan 1988. True host not known. From $M$. mordax mordax, Summit Adel-Lakeview Highway, June 21, 1937

98. Malaraeus telchinum Rothschild 1905. True host Peromyscus (deer mouse) from $M$. richardsoni arvicoloides Rhoads, Lookout Mountain, Mt. Hood National Forest, September 29, 1935

162. Catallagia decipiens Rothschild 1915. True host Peromyscus (deer mouse) from M. montanus montanus Peale, Paulina Lake, out of Bend, August 2, 1936

170. Delotelis telegoni Rothschild 1905. True host not known. From $M$. townsendi Bachman, Newberg, April 1, 1934

40. Opisodasys keeni Baker 1896. True host Peromyscus (deer mouse) from $M$. townsendi Bachman, Newberg, July 15, 1935

119. Monopsyllus ciliatus protinus Jordan 1929. True host Eutamias townsendi, from M. mordax abditus A. B. Howell, Forest Grove, September 8, 1937

107. Megabothris quirini Rothschild 1905. True host not known. From $M$. mordax abditus A. B. Howell, Forest Grove, March 12, 1937.

Fleas of western meadow mice are listed below as to species and subspecies of the host.

\section{Microtus montanus montanus Peale \\ Peale's Meadow Mouse}

This mouse is general throughout the southeast quarter of the state of Oregon, northeastern California and northern Nevada. From it the writer records:

108. Megabothris abantis Rothschild 1905, Hart Mountain, Oregon, July 2, 1939 , 5 males, 4 females

162. Catallagia decipiens Rothschild 1915, Paulina Lake, Newberry Crater, out of Bend, Oregon, August 2, 1936, 1 male. 


\section{Microtus canicaudus Miller}

\section{Gray-tailed Meadow Mouse}

This mouse is general but scarce in the northwest quarter of the state of Oregon and southwestern Washington.

OREGON-The records of the writer are:

160. Catallagia charlottensis Baker 1898, Forest Grove, March 24, 1939, 1 male, I female

163. Catallagia chamberlini Hubbard 1940, Detroit, May 21, 1938, 1 male; Odell, March 18, 1939, 2 màles

200. Peromyscopsylla selenis Rothschild 1906, Salem, December 18, 1938, 1 male; Forest Grove, March 22, 1939, 2 males; Odell, March 18, 1939, 1 male, 1 female; Gaston, February 15, 1940, 2 males, 2 females

215. Micropsylla goodi Hubbard 1941, Forest Grove, March 23, 1939, 1 male.

\section{Microtus townsendi Bachman \\ Townsend's Meadow Mouse}

This is the common meadow mouse west of the west base of the Cascade Mountains in Oregon and Washington. The writer's rceords for this species are:

NORTHWEST OREGON AND SOUTHWEST WASHINGTON:

153. Atyphloceras multidentatus Fox 1909

160. Catallagia charlottensis Baker 1898

185. Epitedia jordani Hubbard 1940

219. Hystrichopsylla gigas dippiei Rothschild 1902.

\section{OREGON:}

40. Opisodasys keeni Baker 1896, Newberg, July 15, 1935, 1 male

108. Megabothris abantis Rothschild 1905, Newberg, April 18, 1937, 1 female 116. Monopsyllus wagneri ophidius Jordan 1929, Forest Grove, July 8, 1936, 1 male, 2 females

170. Delotelis telegoni Rothschild 1905, Newberg, April 1, 1934, 1 male

197. Peromyscopsylla hesperomys Baker 1904, Newberg, December 1, 1933, 2 males

211. Doratopsylla jellisoni Hubbard 1940, Cornelius, June 8, 1936, 1 male

215. Micropsylla goodi Hubbard 1941, Gaston, February 18, 1987, 2 males, 3 females; Newberg, April 18, 1937, 1 male, 1 female.

\section{Microtus mordax mordax Merriam \\ Rocky Mountain Meadow Mouse}

These mice range in that portion of Oregon south of a line drawn from Pendleton through Grants Pass; in Washington east of the crest of the Cascades; and Trinity Mountains, northern California. They are mountain mice living generally where there is an abundant supply of water throughout the summer. The writer's records for this mouse are:

108. Megabothris abantis Rothschild 1904, Lostine, Oregon, July 8, 1938, 1 female

109. Megabothris asio orectus Jordan 1938, Summit Adel-Lakeview Highway, Oregon, June 21, 1937, 1 male

199. Peromyscopsylla ravalliensis Dunn 1923, Adel, Oregon, June 30, 1939, 1 male.

163. Catallagia chamberlini Hubbard 1940, Bickleton, Washington, June 18, 1938 , 4 females 


\section{Microtus mordax abditus A. B. Howell \\ Tillamook Long-Tailed Meadow Mouse}

These mice are thought to have a limited range around Tillamook, Oregon, but the writer has his records from the Willamette water shed slightly west of Forest Grove, and from Cannon Beach and Florence, Oregon.

OREGON-The records are:

107. Megabothris quirini Rothschild 1905, 2 occasions, Forest Grove, March 12,1937

119. Monopsyllus ciliatus protinus Jordan 1929, Forest Grove, March 12, 1937, 2 females

185. Epitedia jordani Hubbard 1940, Forest Grove, March 12, 1937, 1 male; Cannon Beach, March 22, 1940, 2 males, 1 female.

\section{Microtus mordax augusticeps Bailey}

\section{Coast Meadow Mouse}

This mouse is found in the marshes and fields along the coast only slightly above high tide, in northwest California and southwest Oregon.

CALIFORNIA-The writer records off these mice:

200. Peromyscopsylla selenis Rothschild 1906, Fort Dick, Del Norte County, June 15, 1939, 1 male, and from a female with 4 young and their nest taken from under a wire spool at same place but on April 22, 1942:

153. Atyphloceras multidentatus C. Fox 1909, 1 pair

160. Catallagia charlottensis Baker 1898, 1 female

185. Epitedia jordani Hubbard 1940, 3 males, 1 female

215. Micropsylla goodi Hubbard 1941, 1 pair

219. Hystrichopsylla g. dippiei Rothschild, 2 pair,

A single specimen trapped at this location and on this date was carrying:

84. Foxella i. franciscana Rothschild 1910, 1 female

108. Megabothris abantis Rothschild 1905, 1 male

160. Catallagia charlottensis Baker 1898, 1 female

200. Peromyscopsylla selenis Rothschild 1906, 2 females.

-

\section{Microtus richardsoni arvicoloides Rhoads}

\section{Cascade Meadow Mouse}

This large meadow mouse inhabits the Cascade Range of Washington and Oregon south to Crater Lake. It is rarely found far from water. The writer records from these mice:

98. Malaraeus telchinum Rothschild 1905, Lookout Mountain, 12 miles southeast of Mt. Hood, Oregon, September 29, 1935, 1 female

108. Megabothris abantis Rothschild 1905, High Rock Forest Camp, east of Estacada, Oregon, September 25, 1938, 1 male; Government Mineral Springs, Washington, September 21, 1935, 1 male

160. Catallagia charlottensis Baker 1898, Lookout Mountain, 12 miles southeast of Mt. Hood, Oregon, September 29, 1935, 1 female

197. Peromyscopsylla hesperomys Baker 1904, Frog Lake, 12 miles east of Government Camp, Oregon, October 4, 1931, I female; Government Mineral Springs, Washington, August 21, 1935, I male; Davis Lake, Century Drive, out of Bend, Oregon, July 30, 1936; a small series of both sexes 
219. Hystrichopsylla gigas dippiei Rothschild 1902, Bridal Veil, Oregon, April 1, 1939, 1 female; Government Mineral Springs, Washington, August 31, 1935, 1 male.

\section{Microtus oregoni oregoni Bachman}

\section{Oregon Creeping Mouse}

This small mouse is said to range all over Oregon and Washington west of the crest of the Cascade Range. The writer's records are all from the coastal belt of Oregon.

OREGON-A series taken on August 30, 1937 at Tillamook were infested with:

101. Malaraeus dobbsi Hubbard 1940, 5 males, 6 females

153. Atyphloceras multidentatus Fox 1909, 2 females

160. Catallagia charlottensis Baker 1898,2 females

185. Epitedia jordani Hubbard 1940, 4 females

200. Peromyscopsylla selenis Rothschild 1906, 4 males, 1 female

211. Doratopsylla jellisoni Hubbard 1940, 1 female

219. Hystrichopsylla gigas dippiei Rothschild 1902, 1 male.

- Microtus californicus californicus Peale

\section{California Meadow Mouse}

This mouse is found in the dry upland meadows of southwestern Oregon and northwestern California.

OREGON-A specimen examined at Takilma, June 18, 1939, carried only:

79. Oropsylla idahoensis Baker 1904, 1 male-doubtless a stray from a golden-mantled ground squirrel.

CALIFORNIA-From this species in central California have been collected and described:

154. Atyphloceras felix Jordan 1933

166. Catallagia wymani Fox 1909

198. Peromyscopsylla hemisphaerium Stewart 1940.

\section{FLEAS FROM THE NESTS OF MICROTUS}

The nests of meadow mice are generally all-grass structures which sometimes have coarse grasses to the outside and finer grasses as a lining. These can sometimes be found on top of the ground as large bulky structures, but more often below the surface in small cavities. Frequently the nests can be found under boards or other sheltering objects which have rested on the ground for periods of time and under which the mice have burrowed. Many new nests can be found under new hay and grain shocks, but these, due to their newness, are seldom infested with fleas. Old haycocks which have been left in the field over winter are ideal places to find flea infested meadow mice nests. Nests can also be found under fallen logs, within rotten logs and sometimes in tree cavities. While the nests are generally all-grass structures, a more definite determination of the type of nest can be made by taking the occupant with the nest. 
The writer's records of 25 meadow mouse nests with 345 fleas, from Oregon and Washington, follow.

OREGON:

No. 237. All-grass nest with 1 Townsend meadow mouse from under a plank at Gaston, March 12, 1935. Eight fleas were recovered, as follows:

153. Atyphloceras multidentatus Fox 1909, 3 males, 3 females

215. Micropsylla goodi Hubbard 1941, 1 male, 1 female.

No. 405, Townsend meadow mouse nest, under a board at Newberg, February 2, 1936. No fleas.

No. 406. Nest under an old door which had fallen to the ground. The nest contained but 1 flea, a male:

219. Hystrichopsylla gigas dippiei Rothschild 1902.

No. 622. At a deserted rock crusher beside a lake at Dilley, February 10, 1937, beneath old timbers fallen to ground 3 Townsend meadow mouse nests. The records are:

A. With 8 fleas:

153. Atyphloceras multidentatus Fox 1909, 2 males, 3 females

160. Catallagia charlottensis Baker 1898, 1 male, 2 females,

B. With 8 fleas:

153. Atyphloceras multidentatus Fox 1909, 2 males, 1 female

215. Micropsylla goodi Hubbard 1941, 1 male, 1 female

219. Hystrichopsylla gigas dippiei Rothschild 1902, 2. males, 1 female,

C. With 6 fleas:

160. Catallagia charlottensis Baker 1898, 1 male, 2 females

185. Epitedia jordani Hubbard 1940, 1 male

219. Hystrichopsylla gigas dippiei Rothschild 1902, 1 male, 1 female,

No. 629. Nest from under a plank at Gaston, February 18, 1937. Fleas removed from it were:

219. Hystrichopsylla gigas dippiei Rothschild 1902, 1 male, 1 female.

No. 669. Nest from beneath haycock that had been left in field over winter. In it were 5 half-grown Townsend meadow mice. The record is from Chehalem Mountains, Newberg, April 18, 1937. The following 28 fleas were removed:

40. Opisodasys keeni Baker 1896, I female

108. Megabothris abantis Rothschild 1905, 1 male

153. Atyphloceras multidentatus Fox 1909, 2 females

160. Catallagia charlottensis Baker 1898, 7 males, 7 females

215. Micropsylla goodi Hubbard 1941, 1 male, 3 females

219. Hystrichopsylla gigas dippiei Rothschild 1902, 3 males, 3 females.

\section{WASHINGTON:}

No. 1077. Nest found under well cover at Bickleton, Washington June 15, 1938. The 4 hairless young were too small to identify, but the range was that of Microtus mordax mordax (Merriam). From the nest were removed:

163. Catallagia chamberlini Hubbard 1940, 4 females.

No. 1078. Nest removed from under the same well cover as No. 1077 and at the same time. From it were recovered:

163. Catallagia chamberlini Hubbard 1940, 2 females.

No. 1186. Nest, containing 4 half-grown Townsend meadow mice, taken from under an old haycock at Kalama, August 22, 1938. The 1 female flea in the nest was: 108. Megabothris abantis Rothschild 1905.

\section{OREGON:}

No. 1241. Three nests of Townsend meadow mice from under old haycocks at Laurel, December 28, 1938. The nests were not kept separate; a total of 26 fleas were removed from the 3 . These were: 
108. Megabothris abantis Rothschild 1905, 8 males, 1 female

160. Catallagia charlottensis Baker 1898, 8 males, 6 females

219. Hystrichopsylla gigas dippiei Rothschild 1902, 2 males, 1 female.

No. 1269. Nest collected under an old haycock where it had probably been for many months and used often, perhaps, as a nursery. At the time of taking there were 7 half-grown Townsend meadow mice about it. The collection date was February 22, 1939, the location Chehalem Mountain, Newberg. There were no fleas on the 7 young mice, but from the nest were removed the following 42 fleas:

116. Monopsyllus wagneri ophidius Jordan 1929, 1 male, 3 females

153. Atyphloceras multidentatus Fox 1909, 3 males, 4 females

160. Catallagia charlottensis Baker 1898, 10 males, 10 females

170. Delotelis telegoni Rothschild 1905, 1 male, 6 females

215. Micropsylla goodi Hubbard 1941 1, male, 1 female

219. Hystrichopsylla gigas dippiei Rothschild 1902, 2 females.

No. 1271. Nest from under a haycock not 10 feet away from item No. 1269. Haycocks were tumbled over one after the other. The following 39 fleas were removed from the nest:

116. Monopsyllus wagneri ophidius Jordan 1929, 3 females

153. Atyphloceras multidentatus Fox 1909, 2 males, 4 females

160. Catallagia charlottensis Baker 1898, 10 males, 11 females

215. Micropsylla goodi Hubbard 1941, 3 males, 4 females

219. Hystrichopsylla gigas dippiei Rothschild 1902, 2 females.

No. 1727. Two nests taken from same field, same day and time as 2 preceding were without occupants and seemed not to have been used recently. From them were removed but 5 fleas, as, follows:

160. Catallagia charlottensis Baker 1898, 2 males, 3 females.

No. 1274. This nest taken from under old haycock at Boyer, Oregon, February 24, 1939. Sole occupant was a female Microtus oregonus oregonus (Bachman). The mouse was without fleas but the nest contained 8 . These were:

215. Micropsylla goodi Hubbard 1941, 3 males, 3 females

219. Hystrichopsylla gigas dippiei Rothschild 1902, 2 -females.

No. 1309. Five nests removed from under old haycocks which had been standing in field at least 8 months were not kept separate for checking. The nests were taken at Corvallis, Oregon, March 24, 1939. The nests were of Townsend meadow mice, and contained 152 fleas:

153. Atyphloceras multidentatus Fox 1909, 6 males, 8 females

160. Catallagia charlottensis Baker 1898, 60 males, 75 females

164. Catallagia motei Hubbard 1940, 3 females.

No. 1552. On June 20,1939, 12 miles west of Adel, Oregon, on a high plateau on the Plush Road, a swale was trapped by the writer. From an old zinc water canteen found in the swale a nest of Microtus mordax mordax was removed. In it were a mother and 5 young, but neither the mice nor the nest produced fleas. The same swale gave up 10 other nests from under boards and tussocks, but in no case were there fleas on the mice or in the nests.

No. 1640. This nest was removed from under a plank at Gaston, Oregon, February 14, 1940. The Townsend meadow mouse gathered with it was without fleas but the nest contained 10 , as follows:

153. Atyphloceras multidentatus Fox 1909, 2 males, 6 females 170. Delotelis telegoni Rothschild 1905, 1 male, 1 female.

If one compares the number of fleas found upon the meadow mice themselves with the number found in their nests, it seems apparent that some fleas found in nests commonly are scarce upon the hosts when they are roaming about. While 215 Catallagia charlottensis were taken 
from 8 nests, only 39 of these fleas were removed from 11 of the 200 mice examined. And while 8 nests gave 51 Atyphloceras multidentatus, 3 of the 200 mice carried only 10 specimens. Six of the 200 mice carried 8 Hystrichopsylla gigas dippiei but 9 of the nests examined had in them 23 specimens. While 6 of the 25 nests gave up 23 specimens of Micropsylla goodi, 4 of the 200 mice carried only 4 . These data might suggest that these fleas were what might be called nest fleas-fleas which prefer to live in the nest of the host, contacting the host only at meal times, then withdrawing from the host at the end of the meal or when the host becomes restless prior to leaving the nest. The relative scarcity of certain fleas from collections might be accounted for in this way, and what might be considered a rare flea could be far less scarce in the nest of the host.

The above data for Microtus list 18 species and subspecies of fleas from the mice themselves and 11 species and subspecies from their nests. Of the 18 species and subspecies off the mice 4 are distinct strays:

79. Oropsylla idahoensis Baker 1904. True host ground squirrels 119. Monopsyllus ciliatus protinus Jordan 1929. True host chipmunk 199. Peromyscopsylla ravalliensis Dunn 1923. True host wood-rat 211. Doratopsylla jellisoni Hubbard 1940. True host shrew.

WASHINGTON-In this state the writer has taken the following fleas off Microtus richardsoni arvicoloides (Cascade meadow mouse) :

98. Malaraeus telchinum Rothschild 1905

108. Megabothris abantis Rothschild 1905

114. Monopsyllus wagneri wagneri Baker 1904

163. Catallagia chamberlini Hubbard 1940

200. Peromyscopsylla selenis Rothschild 1906

219. Hystrichopsylla gigas dippiei Rothschild 1902,

Off Microtus townsendi (Townsend's meadow mouse) :

153. Atyphloceras multidentatus C. Fox 1909

160. Catallagia charlottensis Baker 1898

197. Peromyscopsylla hesperomys Baker 1904

219. Hystrichopsylla gigas dippiei Rothschild 1902.

CALIFORNIA-In the northwestern corner of this state in Del Norte County, the writer has taken off Microtus mordax augusticeps (coast meadow mouse) the following fleas: .

84. Foxella ignota franciscana Rothschild 1910

108. Megabothris abantis Rothschild 1905

153. Atyphloceras multidentatus C. Fox 1909

160. Catallagia charlottensis Baker 1898

185. Epitedia jordani Hubbard 1940

197. Peromyscopsylla hesperomys Baker 1904

200. Peromyscopsylla selenis Rothschild 1906

215. Micropsylla goodi Hubbard 1941

219. Hystrichopsylla gigas dippiei Rothschild 1902.

And in the northeastern part of the state in Modoc County off Microtus montanus montanus (Peale meadow mouse), the following:

40. Opisodasys keeni Baker 1896

98. Malaraeus telchinum Rothschild 1905

108. Megabothris abantis Rothschild 1905 
162. Catallagia decipiens Rothschild 1915

184. Epitedia wenmanni Rothschild 1904

200. Peromyscopsylla selenis Rothschild 1906.

In the central portion of the state off Microtus californicus californicus (California meadow mouse) the following have been reported:

95. Dactylopsylla bluei C. Fox 1909

98. Malaraeus telchinum Rothschild 1905

153. Atyphloceras multidentatus C. Fox 1909

157. Atyphloceras longipalpus Stewart 1940

166. Catallagia wymani C. Fox 1909

168. Catallagia vonbloekeri Augustson 1941

201. Peromysçopsylla ebrighti C. Fox 1926

213. Leptopsylla segnis Schonherr 1811

219. Hystrichopsylla gigas dippiei Rothschild 1902.

In the central Sierra-Nevada Mountains and south, Gus Augustson reports off meadow mice:

1. Echidnophaga gallinacea Westwood 1875

98. Malaraeus telchinum Rothschild 1905

108. Megabothris abantis Rothschild 1905

114. Monopsyllus wagneri wagneri Baker 1904

159. Callistopsyllus deuterus Jordan 1937

200. Peromyscopsylla selenis Rothschild 1906.

Of some 22 fleas listed to date as being taken off Microtus in California, only 1 (98.) Malaraeus telchinum has been condemned as a vector of plague. However, the following are known to have become infected with plague, but were apparently unable to transmit the disease:

114. Monopsyllus wagneri wagneri Baker 1904

153. Atyphloceras multidentatus C. Fox 1909

166. Catallagia wymani C. Fox 1909

213. Leptopsylla segnis Schonherr 1811

219. Hystrichopsylla gigas dippiei Rothschild 1902.

There are few records of fleas from' meadow mice through the southwest and up the Rocky Mountains until one comes to the state of:

MONTANA-where following fleas have been taken off Microtus spp.:

37. Orchopeas leucopus Baker 1904

98. Malaraeus telchinum Rothschild 1905

109. Megabothris asio orectus Jordan 1938

204. Peromyscopsylla hamifer vigens Jordan 1937

210. Ctenophthalmus pseudagyrtes Baker 1895

219. Hystrichopsylla gigas dippiei Rothschild 1902.

However, on July 7, 1945, the author collected at North Rim, Grand Canyon, ARIZONA-off;

Microtus mordax mordax Merriam

108. Megabothris abantis Rothschild 1905, 2 males, 6 females

162. Catallagia decipiens Rothschild 1915, 1 pair

219. Hystrichopsylla gigas dippiei Rothschild 1902, I male, and in

UTAH-At Logan, meadow mice have been found infested with:

100. Malaraeus bitterrootensis Dunn 1928

108. Megabothris abantis Rothschild 1905

114. Monopsyllus wagneri wagneri Baker 1904

162. Catallagia decipiens Rothschild 1915, at Hyrum

219. Hystrichopsylla gigas dippiei Rothschild 1902, at Etna. 
ALBERTA-Reported off Microtus drummondi A. and B. the following fleas:

110. Megabothris lucifer Rothschild 1905

147. Amphipsylla sibirica pollionis Rothschild 1905

210. Ctenophthalmus pseudagyrtes Baker 1904.

BRITISH COLUMBIA-From the same mouse:

107. Megabothris quirini Rothschild 1905

108. Megabothris abantis Rothschild 1905

110. Megabothris lucifer Rothschild 1905

112. Megahothris megacolpus Jordan 1929

122. Monopsyllus eumolpi eumolpi Rothschild 1905

170. Delotelis telegoni Rothschild 1905

200. Peromyscopsylla selenis Rothschild 1906.

ALASKA-Reported off meadow mice:

102. Malaraeus pencilliger dissimilis Jordan 1938

107. Megabothris quirini Rothschild 1905.

It is quite possible that plague is far more common in meadow mice than is suspected. The recent drive to clean the vicinity of military camps of plague bearing rodents has resulted in many new finds as far as plague is concerned. It seems likely that much more work should be directed towards meadow mice to find if perchance they form a natural reservoir for the disease.

During September, 1942, a dead Microtus pennsylvanicus (meadow mouse) picked up at Newell, North Dakota, was found tularemia-positive.

\section{Mus \\ The House Mouse}

In the West, Mus musculus musculus Linnaeus (house mice) are to be found generally wherever there are inhabited parts. They usually stay close to houses, barns, towns, farms, and ranches, but can at times be taken in fields and meadows. They can be caught in small live-catch box traps baited with rolled oats and cheese.

These domestic mice never carry many fleas, and very often are taken without them.

Where the house mouse is in the range of the domestic rats the chief flea found upon it is (105.) Nosopsyllus fasciatus Bosc 1801. This is the common European or American rat flea. Where the house mouse takes up residence in fields and meadows, away from the common rats and where it has plenty of chance to lose the rat fleas, it then collects the fleas of the mice of the field in which it is living. A house mouse taken by the writer in a field at Willowdale, Wasco County, Oregon, June 15, 1937, had 2 males, 7 females: (114.) Monopsyllus wagneri wagneri Baker 1904, (Great Basin deer mouse flea) and a specimen taken at Mitchell, Wheeler County, Oregon, July 11, 1937, was carrying only 1 flea, a male of the above subspecies.- The writer removed from a house mouse taken from under a long-deserted barn at Nashville, Lincoln County, Oregon, March 25, 1939, the following deer mouse fleas: 
40. Opisodasys keeni Baker 1896, 1 male

116. Monopsyllus wagneri ophidius Jordan 1929

219. Hystrichopsylla gigas dippiei Rothschild 1902.

One of these mice taken from under a deserted desert house at Shaniko, Wasco County, Oregon, on November 8,1940 , was carrying only a female of:

153. Atyphloceras multidentatus C. Fox 1909, a native mouse flea.

The European mouse flea:

213. Leptopsylla segnis Schonherr 1811 does not seem to be carried by rural house mice, but there are records of this mouse flea being taken off house mice in port towns where the house mice run the ranges of the domestic rats.

NEVADA-A house mouse secured by the writer in a field close to Lovelock, Pershing County, on June 27, 1944 was carrying:

114. Monopsyllus wagneri wagneri Baker 1904, 2 males, 1 female.

\section{Neotoma \\ WOOD RATS-PaCk RATS}

Wood rats live in well-constructed, warm nests in trees, buildings, rock crevices-almost anywhere where they can build and heap up their collected trash. Their nests are excellent incubators for fleas; their many jaunts away from it form excellent collecting tours. These features of the wood rat make it possible at times to collect as many as $\mathbf{5 0}$ fleas from I animal. It is quite unusual to collect wood rats without fleas.

Wood rats can be found in almost every deserted cabin in the woods, every rock slide, rock cliff and hollow juniper tree in their range. An empty food can placed upon its side with a small bit of oatmeal thrown in the back and a No. 0 steel trap set at or in the opening will catch them every time. They will also enter any box trap, but will force their way out if there is any chance. Most of the wood rats of the West are vicious and should be handled with gloves.

Plague was discovered early in wood rats in California. A specimen taken in Alameda County during October, 1909, was discovered to be plague-positive. Wood rats examined in San Luis Obispo County, California, in 1935 were found plague-infected. During 1937 plaguepositive wood rats were found in Placer and San Bernardino Counties, California. In 1938 were added Clarke County, Nevada, and Kane County, Utah, to the list of states in which plague-infected wood rats were known. During 1942 plague-positive wood rats were located in Alpine, Monterey, and Los Angeles Counties, California, and during May, 1943, the infection was found in wood rats as far east as Quay County, New Mexico.

Study of plague in wood rats during these years reveals that plague may become 'epidemic in these animals and that they are doubtless rodents in which plague reservoirs can exist. It has also been found that their 2 major western fleas (26.) Orchopeas sexdentatus agilis Roths- 
child 1905 and (25.) Orchopeas sexdentatus sexdentatus Baker 1904 are capable of transmitting plague, at least in the laboratory.

Of the some 95 races of wood rats listed by Miller in 1923, 33 are found west of the 100th meridian. While these animals are likely to be less abundant than ground squirrels, they probably are far more common than suspected. Being roamers of the night, they become known only when they race about dwellings in wooded districts or on the outside edges of cities. Deserts generally have an individual in each hollow juniper tree or every rock ledge. They are in no way social, driving their neighbors from their domains. In captivity the writer has known wood rats to keep certain individuals in their nests until they starved to death. Wood rats do not hibernate but nearly all of them do store. In most of their range only 1 brood a year is raised, but occasionally 2 or more families may be attempted.

This study of the fleas of the wood rats of the Northwest is from the personal capture of 100 of the animals in 65 localities in northern California, northwestern Nevada, Oregon, and Washington. The writer personally removed from these 100 animals 1,000 fleas.

OREGON-Four subspecies of wood rats are found in Oregon. Two of these are bushy-tailed, 2 round-tailed. The coastal form, which also extends throughout the Willamette Valley, is Neotoma cinerea fusca True (dusky bushy-tailed wood rat) ; the Great Basin form, which also extends through the Rogue River Valley, is Neotoma cinerea occidentalis Baird (western bushy-tailed wood rat). The round-tailed wood rats are much more limited in their range. Neotoma fuscipes fuscipes Baird (dusky-footed round-tailed wood rat), is limited to the Willamette and Rogue River Valleys. Neotoma lepida nevadensis Taylor (Nevada round-tailed wood rat), is limited to southeastern Oregon and northern Nevada.

Regardless of what subspecies of wood rat or in what part of the state of Oregon the rats are taken, by far the most common flea is:

Orchopeas sexdentatus,

27. Orchopeas sexdentatus nevadensis Jordan 1929 in the southeastern portion of the state, on all wood rats,

26. Orchopeas sexdentatus agilis Rothschild 1905 in the Cascade Mountains and northeastern portion of the state, on all wood rats, and

28. Orchopeas sexdentatus cascadensis Jordan 1929 everywhere west of the crest of the Cascade Mountains on all wood rats,

ACcidental OccurRences:

The very wandering, inquisitive nature of the wood rat makes it subject to collecting large numbers of stray fleas. The following have been collected by the writer at various times, either from the animals or from their nests:

OREGON:

79. Oropsylla idahoensis Baker 1904. Proper host Callosperomphilus or Citellus (ground squirrel) on 2 occasions at Sisters, off Neotoma cinerea occidentalis Baird

114. Monopsyllus wagneri wagneri Baker 1904. Proper host Peromyscus (deer mouse) on 6 occasions in 3 localities-Adel, Lakeview, Sisters, off Neotoma cinerea occidentalis Baird and Neotoma lepida nevadensis Taylor

153. Atyphloceras multidentatus C. Fox 1909. Proper host Microtus (meadow mouse) or Peromyscus (deer mouse) on $\mathbf{3}$ occasions in northwestern Oregon off Neotoma cinerea fusca True 
172. Megarthroglossus procus oregonensis Hubbard 1946. Proper host Tamiasciurus douglasi douglasi Bachman (pine squirrel) on 3 occasions from 2 localities, Gaston and Parkdale, off Neotoma cinerea fusca True and Neotoma cinerea occidentalis Baird

193. Meringis parkeri Jordan 1937. Proper host Dipodomys ordi columbianus Merriam (kangaroo rat) on 2 occasions at Sisters and Mitchell, off Neotoma cinerea occidentalis Baird.

The following on single occasions:

53. Thrassis howelli howelli Jordan 1925. Proper host Marmota (groundhog), Adel, June 21, 1937, off Neotoma cinerea occidentalis Baird

69. Diamanus montanus Baker 1895. Proper host Citellus b. douglasi (gray digger), Wamic, May 18, 1937, off Neotoma cinerea occidentalis Baird

86. Foxella ignota recula Jordan and Rothschild 1915. Proper host Thomomys (pocket gopher), Adel, June 20, 1937, off Neotoma cinerea occidentalis Baird

98. Malaraeus telchinum Rothschild 1905. Proper host Peromyscus (deer mouse), Wamic, May 18, 1987, off Neotoma cinerea occidentalis Baird

119. Monopsyllus ciliatus protinus Jordan 1929. Proper host Eutamias townsendi (Townsend's chipmunk), Depoe Bay, August 11, 1937, off Neotoma cinerea fusca True

123. Monopsyllus eumolpi cyrturus Jordan 1929. Proper host Great Basin Eutamias (chipmunk), Wamic, May 18, 1937, off Neotoma cinerea occidentalis Baird

160. Catallagia charlottensis Baker 1898. Proper host Peromyscus (deer - mouse), Cannon Beach, March 29, 1937, off Neotoma cinerea fusca True

200. Peromyscopsylla selenis Rothschild 1906. Proper host Peromyscus (deer mouse), Cloud Cap Inn, Mt. Hood, off Neotoma cinerea occidentalis Baird

215. Micropsylla goodi Hubbard 1941. Proper host Peromyscus (deer mouse), Gaston, February 18, 1937, off Neotoma cinerea fusca True.

WASHINGTON-Only Neotoma cinerea occidentalis Baird (western bushy-tailed wood rat) is found in this state. The records say that it seems to be somewhat more common in the eastern portion than in the western portion of the state. From the Cascades and east the writer has been able to take only:

26. Orchopeas sexdentatus agilis Rothschild 1905, off wood rats.

From a few of these animals taken west of the Cascades he has removed:

28. Orchopeas sexdentatus cascadensis Jordan 1939.

CALIFORNIA-Emmet T. Hooper, in University of California Publications in Zoology for 1938, lists 11 subspecies of round-tailed wood rats alone from California. In northern California the writer has taken:

26. Orchopeas sexdentatus agilis Rothschild 1905 off bushy-tailed wood rats in the California portion of the Cascade Mountains

27. Orchopeas sexdentatus nevadensis Jordan 1929 in Modoc County off round-tailed wood rats

28. Orchopeas sexdentatus cascadensis Jordan 1939 off round-tailed wood rats all through the Siskiyous, west to the ocean.

In the central portion of the state and on to the south the following fleas are reported off various California wood rats:

25. Orchopeas sexdentatus sexdentatus Baker 1904 from the Bay Region south throughout the entire state 
105. Nosopsyllus fasciatus Bosc 1801 from the Bay Region, a stray off rats

219. Hystrichopsylla gigas dippiei Rothschild 1902 from round-tailed wood rat nest in central California.

About the Los Angeles area the following were described from wood rats:

18. Anomiopsyllus falsicalifornicus C. Fox 1929

201. Peromyscopsylla ebrighti C. Fox 1925

209. Carteretta carteri C. Fox 1937. the state:

Gus Augustson reports the following off wood rats in the southern portion of

1. Echidnophaga gallinacea Westwood 1875 off N..l. lepida, Riverside County

17. Anomiopsyllus nudatus Baker 1898 off $N$. l. intermedia, N. f. macrotis, Los Angeles County

18. Anomiopsyllus falsicalifornicus C. Fox 1929 off $N$. f. macrotis, Los Angeles County

35. Orchopeas caedens caedens Jordan 1925 off $N$. f. macrotis, Los Angeles County

44. Opisodasys nesiotus Augustson 1941 off $N$. $f$. macrotis, Santa Barbara County

69. Diamanus montanus Baker 1895 off $N$. f. macrotis, Los Angeles County

98. Malaraeus telchinum Rothschild 1905 off $N$. f. macrotis, N. l. intermedia, Los Angeles County

150. Odontopsyllus dentatus Baker 1904 off $N$. fuscipes sp., Riverside County 154. Atyphloceras felix Jordan 1933 off N. l. macrotis, Los Angeles County, 157. Atyphloceras longipalpus Stewart 1940 off $N$. l. intermedia, Los Angeles County, $N$. l. gilva, Riverside County

And in the Mojave Desert of Kern County:

181. Stenistomera alpina Baker 1895 off $N$. lepida lepida.

NEVADA-The following suspected vectors of plague have been taken off wood rats in this state:

27. Orchopeas sexdentatus nevadensis Jordan 1929

58. Thrassis gladiolis gladiolis Jordan 1925

114. Monopsyllus wagneri wagneri Baker 1904.

ARIZONA-The' fbllowing fleas have been taken off wood rats in this state:

17. Anomiopsyllus nudatus Baker 1898

29. Orchopeas sexdentatus schisintus Jordan 1929

31. Orchopeas (sexdentatus) neotomae Augustson 1943

64. Thrassis setosis Prince 1944

67. Thrassoides aridis Prince 1944.

NEW MEXICO:

177. Megarthroglossus bisetis J. and R. 1915 was described off a wood rat taken at Beulah.

UTAH-Off wood rats the following fleas have been reported:

17. Anomiopsyllus nudatus Baker 1898

21. Anomiopsyllus amphibolus Wagner. 1936

32. Orchopeas nepos Rothschild 1905

38. Orchopeas howardi (wickhami) Baker 1895

99. Malaraeus sinomus Jordan 1925

114. Monopsyllus wagneri wagneri Baker 1904

181. Stenistomera alpina Baker 1895

197. Peromyscopsylla hesperomys Baker 1904

208. Phalacropsylla allos Wagner 1936. 
MONTANA-In this state, where a great deal of work has been done on fleas, the following are reported off wood rats:

20. Anomiopsyllus montanus Collins 1936

26. Orchopeas sexdentatus agilis Rothschild 1905

47. Thrassis petiolatus Baker 1904

51. Thrassis acamantis (h. utahensis?)

100. Malaraeus bitterrootensis Dunn 1923

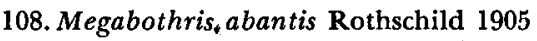

162. Catallagia decipiens Rothschild 1915

181. Stenistomera alpina Baker 1895

208. Phalacropsylla allos Wagner 1936

218. Rectofrontia fraterna Baker 1895.

BRITISH COLUMBIA-The following wood rat fleas are reported:

26. Orchopeas sexdentatus agilis Rothschild 1905:

176. Megarthroglossus sicamus J. and R. 1915

178. Megarthroglossus similis Wagner 1936

179. Megarthroglossus pygmaeus Wagner 1936

184. Epitedia wenmanni Rothschild 1904

199. Peromyscopsylla ravalliensis Dunn 1923.

\section{THE NESTS OF WOOD RATS}

Wood rats, commonly, known as pack rats, gain the latter name from their habit of collecting trash of all kinds which they build into piles or sometimes about their nests. Round-tailed pack rats build regular fortresses of small twigs, which may cover old stumps, may be up in the crotches of trees, in fence rows, or just on the ground. In these piles of twigs are the warm lichen nests. The bushy-tailed wood rats build in rock cliffs, rock slides, deserted buildings, hollow trees, almost anywhere a small bit of protection is found. The nest of this type of wood rat is like a bird's nest-cup-shaped to almost flat, but the structures are probably so constructed that they can be topped over for winter protection. The writer has examined the following wood rat nests:

Sisters, Oregon, March 18, 1937, Neotoma cinerea occidentalis Baird

This nest of a western bushy-tailed wood rat was taken from beneath an old tent base. Its construction was of intermingled burlap, red sweater yarn, string, and other soft cloths, collected from a nearby farm. The following 70 fleas were removed from the nest:

26. Orchopeas sexdentatus agilis Rothschild 1905, 25 males, 35 females

114. Monopsyllus wagneri wagneri Baker 1904, 1 female

153. Atyphloceras multidentatus C. Fox 1909, 1 female

158. Callistopsyllus terinus Rothschild 1905, 1 female

172. Megarthroglossus procus oregonensis Hubbard 1946 I male, 4 females 193. Meringis parkeri Jordan 1937, I male.

Cannon Beach, Oregon, March 29, 1937, Neotoma cinerea fusca True

The female wood rat which was taken with this nest had made her nest of cotton linter gathered from the mattresses of the beach cottage in the attic in which she had built. There were no fleas in the nest but on the rat were the following 25:

28. Orchopeas sexdentatus cascadensis Jordan 1939, 10 males, 15 females. 
Wamic, Oregon, May 18, 1937, Neotoma cinerea occidentalis Baird

This nest was an open structure built between the walls of a deserted house. The fermale was taken. The crying of her young led the writer to the nest. Six halfgrown young were in it. From the 7 rats were removed the following 30 fleas: 26. Orchopeas sexdentatus agilis Rothschild 1905, 10 males, 16 females 69. Diamanus montanus Baker 1895, 1 male, 2 females

98. Malaraeus telchinum Rothschild 1905, 1 male, And from the nest the following 18 fleas:

26. Orchopeas sexdentatus agilis Rothschild 1905, 5 males, 4 females

69. Diamanus montanus Baker 1895, 3 males, 5 females

123. Monopsyllus eumolpi cyrturus Jordan 1929, 1 female.

Summit Lakeview-Adel Highway, Oregon, June 20, 1937, Neotoma cinerea occidentalis Baird

From 8 young and 2 adult females with their 2 nests made of burlap, taken from the same attic of a deserted house, were removed:

26. Orchopeas sexdentatus agilis Rothschild 1905, 28 males and 33 females

86. Foxella ignota recula J. and R. 1915, 1 male

114. Monopsyllus wagneri wagneri Baker 1904, I male, $\mathbf{I}$ female.

Adel, Oregon, June 24, 1937, Neotoma lepida nevadensis Taylor

A female Nevada round-tailed wood rat with 1 young and 5 nests taken from under the floor of a garage gave the writer only 2 fleas for the trouble of sorting over these birdnest-shaped nests of sheep wool. The fleas were:

27. Orchopeas sexdentatus nevadensis Jordan 1929, 1 male, 1 female.

\section{Ochotona \\ Pikas-Conies-Rock Rabbits}

The conies are small, rabbit-like animals which live in the rock slides of the higher mountain elevations. In the West they are seldom found below 3,000 feet. Little is known about their habits or their homes. While they are generally thought to be plentiful, their numbers are limited and their families small. A bit of persistent trapping or shooting soon brings a colony to an end.

Four things in a rock slide mark the presence of conies. First is the little animal's call. This is like a toy whistle; second, their hay stacks, under protected rocks; third, their little round manure pellets about the size of BB shot; and fourth, the urine pinnacles, favored sharp rocks to which regular visits are made to urinate and at which place a snow white to yellowish deposit is always found. After one is certain conies are present in a slide, they can be shot. The collector sits in the middle of the slide, shooting the animals as they appear on their favorite rock to sun themselves. A .410-gauge shatgun is best. The fine shot causes little bleeding. The animals must be killed instantly or they roll down into the rocks out of sight. Conies will enter small box traps baited with apple, and if their under rock highways can be located, many of them can be taken from one location with No. 0 steel traps.

Conies are generally very clean, being more often than not quite free from fleas. On the other hand, when fleas are present, they are liable to be in the nature of strays, the conies picking up the fleas of the other inhabitants of the rock slides. 
Because of the early and late snows in the elevations above 2,500 feet in the West, conies can be collected only from June 1 to November 1 in favorable years.

From 80 conies personally collected by the writer in Washington and Oregon in 40 localities, 70 fleas were recovered. Fifty per cent of the animals were without fleas at the time of examination. By far the most common flea was the true western cony flea:

100. Malaraeus bitterrootensis Dunn 1923, with 29 specimens, 17 males and 12 females.

26. Orchopeas sexdentatus agilis Rothschild 1905 was second with 12 specimens, 5 males and 7 females; this flea is a stray off wood rats which always live in the rock slides of the conies.

Then the second true cony flea:

152. Ctenophyllus terribilis Rothschild 1903 was third with 9 specimens, 3 males and 6 females.

Accidental Occurrences include the following:

32. Orchopeas nepos Rothschild 1905, I male, stray off a pine squirrel

79. Oropsylla idahoensis Baker 1904, 3 males, this a stray from golden. mantled ground squirrel

108. Megabothris abantis Rothschild 1905, 1 male, 5 females, this being a mouse flea

114. Monopsyllus wagneri wagneri Baker 1904, 2 males, 1 female, stray from deer mice

119. Monopsyllus ciliatus protinus Jordan 1929, 1 female, stray off chipmunk

123. Monopsyllus eumolpi cyrturus Jordan 1929, 1 male, 1 female, stray from chipmunks

163. Catallagia chamberlini Hubbard 1940, 1 male, 1 female, stray off deer mice

218. Rectofrontia fraterna Baker 1895, 1 female, true host not known.

OREGON-In the Cascade Mountains of Oregon there are 2 conies, Ochotona fenisex fumosa Howell around McKenzie Pass, and Ochotona princeps brunnescens Howell to the north and to the south of the range of the first. According to the records of the writer, both meet and mingle at Fish Lake, Santiam National Forest. In the Blue Mountains is Ochotona schisticeps jewetti Howell, and south to Burns and in the Great Basin Lakes region is Ochotona schisticeps taylori Grinnell.

Regardless of species or subspecies, Oregon conies are regularly but lightly infested with 2 fleas which seem to have these rock rabbits for their true host. These are:

100. Malaraeus bitterrootensis Dunn 1923

152. Ctenophyllus terribilis Rothschild 1903.

\section{Accidental Occurrences:}

As above stated, the conies become the temporary host of many of the fleas of the rock slides. The following are listed, the true hosts being other rodents of the slides. Unless otherwise stated, these fleas are from Ochotona princeps brunnescens Howell.

On 3 occasions:

79. Oropsylla idahoensis Baker 1904. Proper host Callospermophilus (golden-mantled ground squirrel), Frog Lake and Cloud Cap Inn, Mt. Hood National Forest. At site of old fish hatchery, Lakeview-Adel Highway, July 1, 1939, off Ochotona schisticeps taylori Grinnell 
163. Catallagia chamberlini Hubbard 1940. Proper host Peromyscus (deer mouse), Cooper Spur Road, Mt. Hood National Forest,

114. Monopsyllus wagneri wagneri Baker'1904. Proper host Peromyscus (deer mouse), Spark's Lake, Century Drive out of Bend, July 24, 1936; Summit McKenzie Pass, July 20, 1937 off Ochotona fenisex fumosa Howell; Fish Lake, Santiam National Forest, July 21, 1938

On one occasion the following:

123. Monopsyllus eumolpi cyrturus Jordan 1929. Proper host Eutamias (chipmunk), Spark's Lake, Century Drive out of Bend, July 24, 1936

119. Monopsyllus ciliatus protinus Jordan 1929. Proper host Eutamias (chipmunk), Cloud Cap Inn, Parkdale, July 3, 1935

218. Rectofrontia fraterna Baker 1895. True host not known. Summit McKenzie Pass, July 24, 1938, off Ochotona fenisex fumosa Howell.

35. Orchopeas caedens caedens Jordan 1925. Proper host Tamiasciurus hudsonicus richardsoni, Wallowa Lake, July 14, 1939, off Ochotona schisticeps jewetti Howell, and off same cony August 2, 1945, Wallow Lake

108. Megabothris abantis Rothschild 1905

197. Peromyscopsylla hesperomys Baker 1904

WASHINGTON-Three conies are reported: Ochotona princeps cuppes Bangsnortheastern portion of state; Ochotona princeps fenisex Osgood-northern Cascades; Ochotona princeps brunnescens A. H. Howell in Cascades. From these the writer has collected:

152. Ctenophyllus terribilis Rothschild 1903

32. Orchopeas nepos Rothschild 1905 (accidental occurrence)

108. Megabothris abantis Rothschild 1905 (accidental occurrence).

CALIFORNIA-Five conies are listed: Ochotona taylori Grinnell-northern Cascades; Ochotona schisticeps albata Grinnell-Inyo County; Ochotona schisticeps schisticeps Merriam-Placer County; Ochotona schisticeps muiri G. and S.-Yosemite National Park; Ochotona schisticeps sheltoni Grinnell-Mono County.

During July, 1922, A. B. Howell removed from Ochotona schisticeps muiri at Pine City, a series of fleas which Dr. Karl Jordan described as:

83. Amphalius necopinus Jordan 1925.

In so far as there is no natural barrier to conies between the Cascade Mountains of Oregon and California, there is little doubt that extreme northern California conies are also infested with:

100. Malaraeus bitterrootensis Dunn 1923

152. Ctenophyllus terribilis Rothschild 1903.

In the central Sierra-Nevada Mountains in Mono County, Gus Augustson reports off Ochotona schisticeps albata Grinnell:

83. Amphalius necopinus Jordan 1925

151. Augustsonius ashcrafti Augustson 1941

both true cony fleas, and the following stray from a ground squirrel:

69. Diamanus montanus Baker 1895

off Ochotona schisticeps muiri G. and S.

83. Amphalius necopinus Jordan 1925

151. Augustsonius ashcrafti Augustson 1941,

And the following stray fleas:

32. Orchopeas nepos Rothschild 1905, a squirrel flea

53. Thrassis $h$. howelli Jordan 1925, a marmot flea

114. Monopsyllus w. wagneri Baker 1904, a mouse flea

171. Megarthroglossus procus J. and R. 1915, squirrel flea, and from Fresno County, the true cony flea:

206. Phalacropsylla monticola Augustson 1941. 
MONTANA-In this state where considerable collecting has been done, the following 9 fleas have been reported off Ochotona princeps:

83. Amphalius necopinus Jordan 1925

100. Malaraeus bitterrootensis Dunn 1923

152. Ctenophyllus terribilis Rothschild 1903, all considered,by the writer to be true cony fleas, and the following strays:

26. Orchopeas s. agilis Rothschild 1905, a wood rat flea

108. Megabothris abantis Rothschild 1905, a mouse flea

114. Monopsyllus w. wagneri Baker 1904, a mouse flea

121. Monopsyllus vison Baker 1904, a squirrel flea

122. Monopsyllus e. eumolpi Rothschild 1905, a chipmunk flea

173. Megarthroglossus d. divisus Baker 1895, a squirrel flea.

COLORADO-Two true cony fleas have been reported taken from this state:

83. Amphalius necopinus Jordan 1925, off Ochotona sp., Boulder County

152. Ctenophyllus terribilis Rothschild 1903, off Ochotona princeps saxitalis, San Juan County.

UTAH-The records known to date from conies of this state are:

114. Monopsyllus w. wagneri Baker 1904, Logan

152. Ctenophyllus terribilis Rothschild 1903, off Ochotona sp., Beaver County, July 1936; Mt. Timanogus, July, 1937.

ALBERTA-Reported off conies from Banff, are:

26. Orchopeas s. agilis Rothschild 1905, a wood rat flea

83. Amphalius necopinus Jordan 1925, a cony flea

152. Ctenophyllus terribilis Rothschild 1903, a cony flea.

BRITISH COLUMBIA-The following fleas have been reported off conies from this Canadian province:

83. Amphalius necopinus Jordan 1925

152. Ctenophyllus terribilis Rothschild 1903

173. Megarthroglossus d. divisus Baker 1895

180. Megarthroglossus spenceri Wagner 1936.

ALASKA-Off Ochotona collaris taken at Red Mountain, Mt. Hayes Section:

83. Amphalius necopinus Jordan 1925.

\section{Onychomys}

\section{GrasshopPER Mice}

Miller lists 20 types of grasshopper mice north of Mexico. These are found through the Great Plains area and west. They are dwellers of the plains, open stretches, deserts, and waste places. They generally shun forests. The writer has found them savage little brutes, much more apt to severely bite a hand thrust into a trap than to try to avoid it. They are murderous little carnivores that rob and kill all mice they are able to contact. Taken in a small live trap, they will defy anything to come and get them. They seem to chip their characteristic little chip, chip, chip in utter rage of the confinement. These mice, when they are handled, are found to be very soft furred, subdued colored on the back, and spotless white on the belly. The tail is short. Their marauding habits tell in their fleas, for upon them can be found all the desert species, fleas picked up from their victims as they pommel and kill them. Meat in 
traps does not seem to attract these mice; they seem to enter box traps primarily to investigate the smells left by other mice. It is generally thought that these mice do not have permanent homes, but females expecting a family do build themselves a warm, cup-shaped nursery. If they can steal a nest, this probably does just as well. They appreciate their meat, and deftly sink their teeth into the bases of the skulls of their victims.

All grasshopper mice examined by the writer have been taken in small box traps baited with oatmeal, the traps being set for other mice.

'It was not until April, 1943, that grasshopper mice were found plague-infected; then during April, May, and June plague-positive specimens were found in Lincoln, Quay, Sandoval, and Union Counties, New Mexico. It is quite possible that plague in these mice is far more prevalent than suspected; they do pick up a great many known vector fleas from ground squirrels. But the mice are hard to catch, so little plague research has been carried out on them.

There is but 1 grasshopper mouse in the Oregon country. It ranges over the entire sagebrush plains of the Pacific Northwest. It is Onychomys leucogaster fuscogriseus. Considerable time spent in the northwest deserts in search of hosts of fleas has produced for the writer only a few grasshopper mice. These have proved their freebooting habits by being infested with practically all of the other rodents' fleas of the desert.

The records are:

\section{Onychomys leucogaster fuscogriseus Anthony \\ Oregon Grasshopper MOUSE}

OREGON-From 1 male taken at Crane, July 17, 1937:

114. Monopsyllus wagneri wagneri Baker 1904, deer mouse flea, I male,

193. Meringis parkeri Jordan 1937, kangaroo rat flea, 1 male, 1 female

From 1 female taken at Broadman (15 miles south), May 12, 1939: •

47. Thrassis petiolatus Baker 1904, ground squirrel flea, 3 females,

195. Meringis shannoni Jordan 1929, pocket mouse flea, 9 males, 6 females

From 2 specimens examined at summit Steen Mountain Pass, Blitzen-Fields Highway, July 6, 1939:

48. Thrassis pandorae Jellison 1937, ground squirrel flea, 1 male, 1 female

86. Foxella ignota recula J. and R. 1915, pocket gopher flea, 2 males, 1 female

114. Monopsyllus wagneri wagneri Baker 1904, deer mouse flea, 1 female

126. Monopsyllus exilis exilis Jordan 1938, grasshopper mouse flea, 3 males, 1 female

196. Meringis hubbardi Kohls 1938, kangaroo rat flea, 3 males, 1 female,

From 2 specimens examined at Narrows, December 11, 1936:

75. Opisocrostis labis Jordan and Rothschild 1922, ground squirrel flea, 2 males

86. Foxella ignota recula J. and R. 1915, pocket gopher flea, 1 male, 1 female 193. Meringis parkeri Jordan 1937, kangaroo rat flea, 2 males, 1 female

214. Micropsylla sectilis J. and R. 1923, true host not known, 1 female. 
WASHINGTON-From 2 specimens taken at Mabton (12 miles south), May 28, 1938:

114. Monopsyllus wagneri wagneri Baker 1904, deer mouse flea, 2 males, 3 females,

195. Meringis shannoni Jordan 1929, pocket mouse flea, 8 males, 16 females

From 2 specimens taken at Two Rivers (Casey-Attalia), May 11, 1939:

47. Thrassis petiolatus Baker 1904; ground squirrel flea, 1 male, 5 females

114. Monopsyllus wagneri wagneri Baker 1904, deer mouse flea, 1 female.

NEVADA-From 1 specimen examined 3 miles south of Denio, Oregon, July 5, 1939:

48. Thrassis pandorae Jellison 1937, ground squirrel flea, 1 female

99. Malaraeus sinomus Jordan 1925, true host not known, 2 females

114. Monopsyllus wagneri wagneri Baker 1904, deer mouse flea, 2 males, 1 female

196. Meringis hubbardi Kohls 1938, kangaroo rat flea, 1 female.

A grasshopper mouse taken by the author at Searchlight, Clark County, on July 1, 1945, carried

14. Hoplopsyllus anomalus Baker 1904, 5 males, 3 females

58. Thrassis g. gladiolis Jordan 1925, 3 males.

CALIFORNIA-Gus Augustson reports the following fleas off California grasshopper mice. From Riverside County off Onychomys torridus pulcher:

60. Thrassis a. arizonensis Baker 1898

99. Malaraeus sinomus Jordan 1925

189. Meringis dipodomys Kohls 1938.

During 1937 and 1938 Dr. Karl Jordan described from materials sent him by the staff of the Rocky Mountain Laboratory:

126. Monopsyllus exilis exilis Jordan 1937, off grasshopper mouse from Powder River, Montana

127. Monopsyllus exilis opadus Jordan-1938, off grasshopper mouse from Yavapai County, Arizona, and

128. Monopsyllus exilis triptus Jordan 1938, off grasshopper mouse from Roggen (sic. Rugger), Colorado.

During July, 1943, the writer described off Onychomys leucogaster articeps taken in Meade County, Kansas:

129. Monopsyllus exilis kansensis Hubbard 1943. carried

A specimen examined by author at Kanab, Kane County, Utah, July 9, 1945,

126. Monopsyllus e. exilis Jordan 1938, 1 male

193. Meringis parkeri Jordan 1937, 1 male.

During January, 1944, Frank Prince of the Plague Suppressive Measures Laboratory described:

67. Thrassoides aridis Prince 1944, off Onychomys leucogaster from Mohave County, Arizona, and Hidalgo County, New Mexico; and

68. Thrassoides campestris Prince 1944, off Onychomys leucogaster from Hooker and Cherry Counties, Nebraska.

\section{Perognathus}

\section{Pocket Mice}

Pocket mice are silky little animals which live for the most part in the western desert wastes. They are found west of the Mississippi River to the Pacific Ocean, south of Ashcroft, British Columbia, to. Tlalpam, Mexico. Their external fur-lined cheek pouches are characteristic. Their soft fur runs to sandy grays, light browns, and buffs. They seem 
gentle creatures, practically defenseless. These mice spend the hot desert days down under the sand in their burrows. All burrows are plugged during the day as a precáution, perhaps, against heat, snakes, and light. Often, however, their tunnels can be found because it seems that the mice can never quite get the plug at the entrance, always back a little ways. The writer has on several occasions dug these mice out of their burrows after excavating with the fingers only a few inches. This would seem to suggest that during the summer, when there were no family cares, the mice might burrow in anywhere for the day. During nursery cares, and when winter calls for a warm nest, such a structure is doubtless built.

Miller, in 1923, listed 93 forms of pocket mice in North America. Almost every patch of desert west of the Mississippi has 1 or more of its own forms of these mice.

From April to July, many of these mice can be taken in small box traps baited with oatmeal. After July the numbers trapped taper off sharply since the mice hole up to escape the summer heat and continue holed up for the winter.

Pocket mice have 3 fleas for which they seem the true host. These are (195.) Meringis shannoni, (209.) Carteretta carteri, and (194.) Meringis jamesoni.

Apparently, these mice have learned to dust themselves well, since few taken are infested with fleas except during the maxima of: (195.) Meringis shannoni Jordan 1927, and (196.) Meringis hubbardi Kohls 1938, even though they run the same territory with the deer mice and kangaroo rats, which are usually infested, and should drop fleas to be picked up by the pocket mice.'

The writer has records of many taken from Oregon with flea infestation light or even absent except during the above-mentioned maxima.

The writer's records for pocket mice are:

\section{Perognathus parous parvus Peále \\ Oregon Pocket Mouse}

OREGÓN-Ranges over most of the desert east and south of the Deschutes River, with a few records to prove it is found as far west as The Dalles.

The writer secured from specimens taken at Adel (12 miles southeast), June 28, 1937:

193. Meringis parkeri Jordan 1937, kangaroo rat flea, 1 female.

From 10 specimens, Boardman (15 miles south), May 12, 1989:

191. Meringis walkeri Hubbard 1940, true host not known, 1 male

195. Meringis shannoni Jordan 1929, pocket mouse flea, 18 males, 22 females.

From 4 specimens, Blitzen (10 miles west), July 3, 1939:

196. Meringis hubbardi Kohls -1938 , deer mouse flea, 3 males, 2 females.

From 6 specimens taken at south city limits of Baker, July 12, 1939:

192. Meringis jewetti Hubbard 1940, 3 males

196. Meringis hubbardi Kohls 1938, deer mouse flea, 8 males, 4 females. 
NEVADA-From 2 specimens taken at Coleman's Ranch (25 miles southeast of Adel, Oregon), June 28, 1937:

193. Meringis parkeri Jordan 1937, kangaroo rat flea, 1 female.

WASHINGTON-This mouse ranges in Washington west and north of the Columbia River to the Cascade Mountains and Yakima. From 6 specimens taken at Mabton (12 miles south), May 29, 1938:

195. Meringis shannoni Jordan 1929, pocket mouse flea, 2 males, 1 female.

From 17 specimens taken at Prosser (10 miles south), May 10, 1939:

195. Meringis shannoni Jordan 1929, pocket mouse flea, 20 males, 18 females.

\section{Perognathus parvus mollipilosus Coues Coues' Pocket Mouse}

Extends northward into the Klamath Valley from northeastern California. From 6 specimens taken at the entrance of Swan Lake Valley, east of Klamath Falls, June 29, 1939:

190. Meringis cummingi Fox 1926, kangaroo rat flea, 1 female.

\section{Perognathus lordi columbianus Merriam Columbia Pocket Mouse}

WASHINGTON-This mouse ranges south of Pasco in the sagebrush country. From 20 specimens taken at Lowden, May 12, 1939:

195. Meringis shannoni Jordan 1929, pocket mouse flea, 3 males, 10 females 196. Meringis hubbardi Kohls 1938, deer mouse flea, 6 males, 6 females.

\section{Perognathus nevadensis Merriam Nevada Pocket Mouse}

This mouse ranges in extreme southeastern Oregon; thence into northern Nevada. Three specimens taken at Rome, Oregon, July 9, 1939, were without fleas; but 3 specimens taken at Jordan Valley, Oregon, July 10, 1939 were infested with: 196. Meringis hubbardi Kohls 1938, deer mouse flea, 1 male, 2 females.

NEVADA-From 1 specimen examined 15 miles south of McDermitt, July 8, 1939: 196. Meringis hubbardi Kohls 1938, deer mouse flea, 1 male, 1 female.

CALIFORNIA-Some 20 species and subspecies of pocket mice are listed by Miller from this state.

Reported off Perognathus californicus subsp. at Jamesburg is:

209. Carteretta carteri C. Fox 1927.

Augustson reports this California pocket mouse flea from the southern portion of the state off Perognathus californicus bernardinus, taken at Cabazon, Riverside County; off Perognathus californicus dispar, taken in the Santa Monica Mountains, Los Angeles County, and off Perognathus californicus ochrus taken at Santa Maria, Santa Barbara County. Augustson also reports as strays off southern California pocket mice:

38. Orchopeas howardi (=wickhami) Baker 1895, and

190. Meringis cummingi C. Fox 1926. 
In spite of the ease with which pocket mice are taken in the deserts, and the large numbers generally falling into the hands of collectors, there are few other records of their fleas. George Holland reports in British Columbia taking off pocket mice:

195. Meringis shannoni Jordan 1929

and the writer described off Perognathus flavus flavus:

194. Meringis jamesoni Hubbard 1943 from Alamosa County, Colorado.

To date (1944) pocket mice have not been found infected with plague.

\section{Peromyscus \\ Deer Mige-White-Footed Mice}

This study of the Peromyscus of the West is the result of the writer's personal capture and examination of 2,500 deer mice in 450 localities in Washington, Oregon, northern California, Arizona, Idaho, Nevada. From these mice were removed 5,000 fleas. Four per cent of the mice were without fleas at the time of examination.

Deer mice are found all over the West, and can easily be trapped in small box traps baited with oatmeal. They seem to be everywhere and always form the greatest bulk of any night's catch.

They are excellent subjects for flea study. Their warm, well-constructed nests are usually alive with fleas. As many as 100 are recorded by the writer from 1 nest, and single mice may have as many as 12 upon them while roaming about.

These mice run everywhere, explore every nook and cranny. Thus, they not only pick up many of their own fleas but also many strays from other rodents.

During August, 1938, while agencies were investigating an epizootic among the wild rodents in Catron County, New Mexico, a single specimen of Peromyscus truei truei (True's deer mouse) came under examination. This mouse was plague positive; this record is the first against deer mice. The mouse examined was in a vicinity where the Zuni prairie-dog was found, during the epidemic, to be 50 per cent plague positive and Citellus variegatus grammurus (rock squirrel) 16 per cent plague positive. Since ground squirrels and prairie-dogs have been found plague positive in many places, it is entirely probable that plague in deer mice in these areas is far more common than suspected. However, no new plague reports on deer mice were forthcoming until agencies on military reservations began extensive search for the disease in camp rodents as a protection to the military personnel. These searches revealed during March, April, and May, 1943, that the deer mice on the Fort Ord Military Reservation in Monterey County, California, were plague positive.

There is little doubt in the mind of the writer that Peromyscus is infested with more species of fleas than any other rodent in the West. In the records of the writer are 30 species or subspecies of fleas taken off 
this small mouse. Of these 30,20 seem to choose Peromyscus for their favored host. The list follows, the species or subspecies arranged according to prevalence.

114. Monopsyllus wagneri wagneri Baker 1904; this flea is found on all species or subspecies of deer mice east of the crest of Cascade Mountains.

116. Monopsyllus wagneri ophidius Jordan 1929; this flea is found on all species of deer mice west of crest of Cascade Mountains.

40. Opisodasys keeni Baker 1895; this flea seems to shun the greater portion of the desert region, but is found on all species or subspecies of deer mice west of the east base of Cascade Mountains. It is also found in lake region of southcentral Oregon, and non-desert regions east of CascadeSierra Range.

160. Catallagia charlottensis Baker 1898; fairly common on deer mice west of Cascades and scattered records from all West Coast.

197. Peromyscopsylla hesperomys Baker 1904; a flea very common west of the Great Basin on all deer mice during August and later.

153. Atyphloceras multidentatus C. Fox 1909; this flea is common enough, but seems to spend most of its time in the nest of the host, the numbers actually taken from the host itself are limited.

215. Micropsylla goodi Hubbard 1941; the writer's personal records for this flea do not extend farther east than the crest of Cascade Mountains.

98. Malaraeus telchinum Rothschild 1905; the writer's records for this flea are from the Cascade and Siskiyou Mountains in Oregon, and northern California, northwestern Nevada, and the Cascades of Washington.

163. Catallagia chamberlini Hubbard 1940; scattered records from the Cascade Mountains and as far east as the Great Basin.

219. Hystrichopsylla gigas dippiei Rothschild 1902; this flea is found only occasionally on the deer mice themselves, but more often in small numbers in their nests.

185. Epitedia jordani Hubbard 1940; this is a roaming flea attacking many of the smaller rodents and insectivora of the Northwest. It is more common on deer mice than other animals.

184. Epitedia wenmanni Rothschild 1904; this flea seems to be rare in the Northwest, the writer having only a few from the region.

162. Catallagia decipiens Rothschild 1915; the writer's records are scattered from crest of Cascades over the Great Basin region.

158. Callistopsyllus terinus Rothschild 1905; taken by the writer off Peromyscus maniculatus gambeli Baird only on 1 occasion each, at Sisters, and Burnt Ranch, Oregon, and from Modoc Lava Beds, California.

214. Micropsylla sectilis Jordan and Rothschild 1923; taken only at Sisters, Oregon, on 1 occasion off Peromyscus maniculatus gambeli Baird, and off same mouse at Dorris, Siskiyou County, California, November, 1943, 13 males and 84 females.

170. Delotelis telegoni Rothschild 1905; taken from Peromyscus maniculatus rubidus Osgood, at Newberg, Oregon, and off Peromyscus maniculatus gambeli Baird at Odell, Oregon.

108. Megabothris abantis Rothschild 1905; taken by the writer off Peromyscus maniculatus rubidus Osgood at Winchuck River, Harbor, Oregon (southwestern coastal belt).

99. Malaraeus sinomus Jordan 1925; taken by the writer off Peromyscus maniculatus gambeli Baird at Mitchell, Oregon.

161. Catallagia sculleni Hubbard 1940; taken from deer mice in western Oregon and Washington. 
164. Cataltagia motei Hubbard 1940; known by the writer only from 4 specimens taken from Peromyscus maniculatus rubidus Osgood, Oregon.

200. Peromyscopsylla selenis Rothschild 1906; known for deer mice from a specimen taken at Gladstone, Oregon, off Peromyscus maniculatus rubidus Osgood.

196. Meringis hubbardi Kohls 1938; Canyon deer mouse, Narrows, Oregon; Gambels' deer mouse, Dorris, California.

ACCiDEnTal OCCURRENCES:

OREGON-The following fleas have been taken from deer mice upon at least 1 occasion:

\section{Peromyscus maniculatus gambeli Baird \\ GaMbel's DeER MOUSE}

53. Thrassis howelli howelli Jordan 1925; proper host Marmota (marmot. groundhog), Lakeview, July 19, 1937

69. Diamanus montanus Baker 1895; proper host Citellus douglasi (gray digger), Parkdale, May 17, 1936

86. Foxella ignota recula Rothschild 1915; proper host Thomomys, (pocket gopher), Paulina Lake, out of Bend, August 2, 1936

119. Monopsyllus ciliatus protinus Jordan 1929; proper host Eutamias townsendi (chipmunk), Cloud Cap Inn, Mt. Hood, October 5, 1935

123. Monopsyllus eumolpi cyrturus Jordan 1929; proper host Eutamias amoenus (Klamath chipmunk), Sisters, July 23, 1936

193. Meringis parkeri Jordan 1937; proper host Dipodomys (kangaroo rat), Crane, July 16, 1937.

\section{Peromyscus maniculatus rubidus Osgood \\ Ruddy DeER Mouse}

28. Orchopeas sexdentatus cascadensis Jordan 1939; proper host Neotomba (wood rat), Gaston, March 16, 1935

105. Nosopsyllus fasciatus Bosc 1801; proper host Rattus norvegicus (Norwegian rat), Cherry Grove, November 22, 1933

223. Corypsylla ornata Fox 1908; proper host Scapanus (mole), Forest Grove, March 18, 1936

224. Corypsylla jordani Hubbard 1940; proper host Neurotrichus (Gibb's mole), Gaston, March 16, 1939:

\section{FLEAS OF WESTERN PEROMYSCUS}

\section{LISTED AS TO SPECIES AND SUBSPECIES OF THE HOST}

The writer's personal records for Oregon, Washington, northern California, northern Nevada, and southwestern Idaho follow:

Peromyscus maniculatus gambeli Baird

\section{GaMbel's DĖer Mouse}

This has the greatest range of any deer mouse in the Northwest, found almost everywhere east of crest of Cascade Sierra-Nevada Mountains. 
OREGON-In its entire Oregon range, by far the most common flea found upon it is: 114. Monopsyllus wagneri wagneri Baker 1904, Great Basin deer mouse flea

40. Opisodasys keeni Baker 1896, on the Cascade and desert fringe of its range

197. Peromyscopsylla hesperomys Baker 1904, on the Cascade fringe of its range are found constantly

98. Malaraeus telchinum Rothschild 1905, persistently found in small numbers in higher mountainous portions of its range.

196. Meringis hubbardi Kohls 1938

Other fleas found upon this mouse are of rare occasion or accidental:

99. Malaraeus sinomus Jordan 1925, Mitchell

158. Callistopsyllus terinus Rothschild 1905, Sisters and Mitchell

160. Catallagia charlottensis Baker 1898, New Pine Creek

162. Catallagia decipiens Rothschild 1915

163. Catallagia chamberlini Hubbard 1940, Cascade Mountains .

170. Delotelis telegoni Rothschild 1905, Odell

184. Epitedia wenmanni Rothschild 1904, both from the western mountainous and Great Basin ranges of this mouse

214. Micropsylla sectilis Jordan and Rothschild 1923, Sisters.

ACcidental Occurences-The following first three are from Cooper Spr, Parkdale:

119. Monopsyllus ciliatus protinus Jordan 1929, from Eutamias

123. Monopsyllus eumolpi cyrturus Jordan 1929, from Eutamias

69. Diamanus montanus Baker 1895, from Citellus douglasi

86. Foxella ignota recula Rothschild 1915, from Thomomys, Paulina Lake, Newberry Crater, Bend, August 2, 1936

53. Thrassis howelli howelli Jordan 1925, from Marmota, Lakeview, June 19,1937

193. Meringis parkeri Jordan 1937, from Perodipus Crane, Hampton, Adel, Willowdale, June, 1937

195. Meringis shannoni Jordan 1929, from Perognathus, Boardman (15 miles south), May 12, 1939.

WASHINGTON:

36. Orchopeas caedens durus Jordan 1929, occasionally on this mouse in the eastern portion of its range

40. Opisodasys keeni Baker 1896, and

98. Malaraeus telchinum Rothschild 1905, on the Cascade fringe of range of this mouse

114. Monopsyllus wagneri wagneri Baker 1904, general and abundant throughout the range of this mouse

160. Catallagia charlottensis Baker 1898, and

162. Catallagia decipiens Rothschild 1915, on specimens of this mouse from the Cascade Mountains,

ACcidental OCcURRENCES:

69. Diamanus montanus Baker 1895; where this mouse comes in contact with Citellus $b$. doublasi (gray digger)

195. Meringis shannoni Jordan 1926, in the desert regions where this mouse comes in contact with pocket mice.

\section{CALIFORNIA:}

37. Orchopeas leucopus Baker 1904, Cedarville, Modoc County

40. Opisodasys keeni Baker 1896; Pine Creek and west

98. Malaraeus telchinum Rothschild 1905, general

100. Malaraeus bitterrootensis Dunn 1923, Eagleville

114. Monopsyllus wagneri wagneri Baker 1904, general 
154. Atyphloceras felix Jordan 1933, Siskiyou County

158. Callistopsyllus terinus Rothschild 1905, Modoc County

160. Catallagia charlottensis Baker 1898, Pine Creek

162. Catallagia decipiens Rothschild 1915, Modoc County

184. Epitedia wenmanni Rothschild 1904, northeastern

189. Meringis dipodomys Kohls 1938, Eagleville, Modoc County

193. Meringis parkeri Jordan 1937, Eagleville, Modoc County

196. Meringis hubbardi Kohls 1938, Dorris, Siskiyou County

197. Peromyscopsylla hesperomys Baker 1904, Siskiyou County

214. Micropsylla sectilis J. and R. 1923, Siskiyou County.

NEVADA-From northern Washoe County:

37. Orchopeas leucopus Baker 1904

98. Malaraeus telchinum Rothschild 1905

100. Malaraeus bitterrootensis Dunn 1923

108. Megabothris abantis Rothschild 1905

114. Monopsyllus wagneri wagneri Baker 1904

162. Catallagia decipiens Rothschild 1915

193. Meringis parkeri Jordan 1937

196. Meringis hubbardi Kohls 1938

211. Doratopsylla jellisoni Hubbard 1940

214. Micropsylla sectilis J. and R. 1923.

\section{Peromyscus maniculatus rubidus Osgood \\ Ruddy Defr Mouse}

In the Northwest this mouse ranges from the Columbia River south to San Francisco Bay, and west of the west slopes of the Cascade Mountains.

OREGON-Throughout the entire range of this mouse, the most common flea is:

116. Monopsyllus wagneri ophidius Jordan 1929

Following closely as second in importance is:

40. Opisodasys keeni Baker 1896

Also very common in their season on this mouse throughout its entire range are:

108. Megabothris abantis Rothschild 1905, not common, but throughout western Oregon

153. Atyphloceras multidentatus C. Fox 1909

160. Catallagia charlottensis Baker 1898

161. Catallagia sculleni Hubbard 1940, and

164. Catallagia motei Hubbard 1940, general throughout the Willamette Valley and west.

170. Delotelis telegoni Rothschild 1905, Newberg

185. Epitedia jordani Hubbard 1940, a vicariating species, can be taken from mouse in very limited numbers during the spring months

197. Peromyscopsylla hesperomys Baker 1904

215. Micropsylla goodi Hubbard 1941, are also frequently taken during their season from this mouse in northwestern Oregon

219. Hystrichopsylla gigas dippiei Rothschild 1902

Accidental Occurences-

28. Orchopeas sexdentatus cascadensis Jordan 1939, wood rat flea, Gaston, March 15, 1935

105. Nosopsyllus fasciatus Bosc 1801, rat flea, Cherry Grove, November 22, 1933

223. Corypsylla ornata C. Fox 1908, mole flea, Forest Grove, March 18, 1996

224. Corypsylla jordani Hubbard 1940, Gibb's mole flea, Gaston. 
CALIFORNIA-From northern California the writer has these records:

98. Malaraeus telchinum Rothschild 1905

116. Monopsyllus wagneri ophidius Jordan 1929

160. Catallagia charlottensis Baker 1898

197. Peromyscopsylla hesperomys Baker 1904

\section{Peromyscus maniculatus sonoriensis Le Conte Sonoran DeER MOUSE}

Said to be abundant throughout practically all the southeast quarter of Oregon, all of Nevada, and extreme eastern and southern California.

OREGON-The chief flea of this mouse is:

114. Monopsyllus wagneri wagneri Baker 1904, with an occasional:

98. Malaraeus telchinum Rothschild 1905,

40. Opisodasys keeni Baker 1896, and

196. Meringis hubbardi Kohls 1938.

The above-mentioned fleas have also been taken from this mouse in northwestern Nevada.

\section{Peromyscus maniculatus artemesiae Rhoads \\ SAgebrush Deer Mouse}

Its range in Oregon is extreme northeast corner of state, and in Washington, the southeast corner. Bailey says about them, "They are more partial to a forest and brush country but adapt themselves to almost any habitat." The only records of this mouse in the possession of the writer come from 40 specimens personally secured at Lostine and Wallowa Lake, Oregon, August, 1938 and July, 1939, from which were taken:

40. Opisodasys keeni Baker 1896

108. Megabothris abantis Rothschild 1915.

114. Monopsyllus wagneri wagneri Baker 1904

162. Catallagia decipiens Rothschild 1905

\section{Peromyscus maniculatus oreas Bangs \\ Washington DeEr Mouse}

Ranges north of the Columbia River and west of Cascades in Washington. From it the writer records:

40. Opisodasys keeni Baker 1896

108. Megabothris abantis Rothschild 1905

116. Monopsyllus wagneri ophidius Jordan 1929

119. Monopsyllus ciliatus protinus Jordan 1929

197. Peromyscopsylla hesperomys Baker 1904

160. Catallagia charlottensis Baker 1898

161. Catallagia sculleni Hubbard 1940

164. Catallagia motei Hubbard 1940

215. Micropsylla goodi Hubbard 1941.

\section{Peromyscus crinitus crinitus Merriam \\ Idaho Canyon Deer Mouse}

This mouse lives in rocks, cliffs, and canyons throughout the Great Basin region of Oregon, eastern California, and northern Nevada. 
The writer has specimens from Adel and Narrows, Oregon and Coleman's Ranch, Nevada, from which were taken:

114. Monopsyllus wagneri wagneri Baker 1904

193. Meringis parkeri Jordan 1937

196. Meringis hubbardi Kohls 1938.

\section{Peromyscus truei gilberti Allen \\ GiLbert's White-FOOTED MOUSE}

Because of its very large ears it should probably be called the big eared deer mouse. It is found throughout upper Rogue River Valley in Oregon, the interior of California, and the Coast south of San Francisco Bay.

Specimens taken by the writer at Oregon Caves Junction, Kerby, Merlin, and Brownsboro, Oregon, had upon them only:

98. Malaraeus telchinum Rothschild 1905.

\section{Peromyscus truei preblei Bailey \\ Preble's White-Footed Mouse}

Thought to be a cliff dweller rather than a brush or timber dweller. Little is known about this mouse that has been collected a very few times in the Crooked River country of Oregon. The writer has no records for this mouse.

CALIFORNIA-Reported off the species truei in this state are:

198. Peromyscopsylla hemisphaerium Stewart 1940

209. Carteretta carteri C. Fox 1927

154. Atyphloceras felix Jordan 1933, from the Hastings Natural History Reservation near Jamesburg, Monterey County.

\section{Peromyscus californicus californicus Gambel}

\section{California Deer Mouse}

Reported infested with:

19. Anomiopsyllus congruens Stewart 1940

198. Peromyscopsylla hemisphaerium Stewart 1940, and

154. Atyphloceras felix Jordan 1933.

Off this mouse was described Ceratophyllus californicus Baker 1904, which is now known to have been a female of:

105. Nosopsyllus fasciatus Bosc 1801.

\section{Peromyscus boyli boyli Baird}

\section{BOYLE'S DeER MOUSE}

Reported infested with:

198. Peromyscopsylla hemisphaerium Stewart 1940.

In the southern half of California, Gus Augustson has reported 32 species and subspecies of fleas off deer mice:

17. Anomiopsyllus nudatus Baker 1898, off Peromyscus eremicus fraterculus from Los Angeles County

18. Anomiopsyllus falsicalifornicus C. Fox 1929, off Peromyscus crinitus insignis from Los Angeles County

25. Orchopeas s. sexdentatus Baker 1904, off Peromyscus eremicus eremicus from Riverside County; off Peromyscus maniculatus gambeli from Santa Barbara County; off Peromyscus crinitus insignis from Los Angeles County; off Peromyscus crinitus stephensi from Riverside County 
38. Orchopeas howardi Baker 1895, off Peromyscus crinitus dispar, Peromyscus crinitus insignis, Peromyscus eremicus fraterculus from Los Angeles County

37. Orchopeas leucopus Baker 1904, off Peromyscus eremicus fraterculus, Peromyscus crinitus insignis from Riverside County

32. Orchopeas nepos Rothschild 1905, off Peromyscus maniculatus sonoriensis from Mono County

35. Orchopeas caedens caedens Jordan 1925, off Peromyscus eremicus fraterculus from Los Angeles County; off Peromyscus crinitus insignis from San Diego County

40. Opisodasys keeni Baker 1896, off Peromyscus maniculatus sonoriensis from Mono County

44. Opisodasys nesiotus Augustson 1941, off Peromyscus maniculatus gambeli from Santa Barbara County

58. Thrassis g. gladiolis Baker 1925, off Peromyscus eremicus eremicus from Riverside County

60. Thrassis a. arizonensis Baker 1898, off Peromyscus crinitus insignis from Riverside County

98. Malaraeus telchinum Rothschild 1905, off Peromyscus maniculatus gambeli, general in southern California; off Peromyscus crinitus insignis, general in southern California; off Peromyscus eremicus fratercu. lus from Los Angeles County; off Peromyscus boyli rowleyi from Los Angeles County

99. Malaraeus sinomus Jordan 1925, off Peromyscus crinitus stephensi, Peromyscus eremicus eremicus, Peromyscus eremicus fraterculus, Peromyscus crinitus insignis, Peromyscus crinitus sanctidiegi, general in southern California

100. Malaraeus bitterrootensis Dunn 1923, off Peromyscus maniculatus sonoriensis from Mono County

108. Megabothris abantis Rothschild 1905, off Peromyscus maniculatus sonoriensis from Mono County

114. Monopsyllus w. wagneri Baker 1904, off Peromyscus maniculatus sonoriensis from Mono County

116. Monopsyllus w. ophidius Jordan 1929, off Peromyscus maniculatus gambeli, general in southern California; off Peromyscus maniculatus sonoriensis, Peromyscus crinitus insignis from Riverside County

199. Peromyscopsylla ravalliensis Dunn 1923, off Peromyscus maniculatus sonoriensis from Mono County

201. Peromyscopsylla ebrighti C. Fox 1926, off practically all deer mice in the chaparral areas of southern California

190. Meringis cummingi C. Fox 1926, off Peromyscus maniculatus gambeli from Santa Barbara County

189. Meringis dipodomys Kohls 1938, off Peromyscus maniculatus sonoriensis from Riverside County

209. Carteretta carteri C. Fox 1927, off Peromyscus crinitus insignis from Los Angeles County

184. Epitedia wenmanni Rothschild 1904, off Peromyscus maniculatus sonoriensis from Mono County

167. Catallagia rutherfordi Augustson 1941, off Peromyscus maniculatus sonoriensis from Mono County

168. Catallagia vonbloekeri Auguston 1941, off Peromyscus maniculatus sanctaerosae from Santa Rosa Island

170. Delotelis telegoni Rothschild 1905, off Peromyscus maniculatus sonori. ensis from Mono County 
159. Callistopsyllus deuterus Jordan 1937, off Peromyscus maniculatus sonoriensis from Mono County

171. Megarthroglossus procus J. and R. 1915, off Peromyscus maniculatus sonoriensis from Fresno County

153. Atyphloceras multidentatus C. Fox 1909, off Peromyscus eremicus fraterculus from Los Angeles County

157. Atyphloceras longipalpus Stewart 1940, off Peromyscus crinitus insignis from Riverside County

154. Atyphloceras felix Jordan 1933, off practically all species of deer mice found in southern California

219. Hystrichopsylla gigas dippiei Rothschild 1902, off Peromyscus maniculatus gambeli from Santa Barbara County.

ARIZONA-If the term "Mus", so often used by Jordan in designating hosts from Paradise, Arizona, can be interpreted as meaning Peromyscus, then the following deer mouse fleas can be listed from this state:

37. Orchopeas leucopus Baker 1904, off deer mice

64. Thrassis setosis Prince 1944, off Peromyscus leucopus arizonae from Yavapia County

99. Malaraeus sinomus Jordan 1925, off "Mus" from Paradise

104. Malaraeus eremicus Baker 1904, off Peromyscus eremicus from Santa Rita Mountains

130. Pleochaetis sibynus Jordan 1925, off Peromyscus maniculatus rufinus from the Grand Canyon

156. Atyphloceras echis J. and R. 1915, off "Mus" from Paradise

184. Epitedia wenmanni Rothschild 1904, off deer mice

202. Peromyscopsylla adelpha Rothschild 1915, off "Mus" from Paradise

207. Phalacropsylla paradisea Rothschila 1915, off "Mus" from Paradise

214. Micropsylla sectilis J. and R. 1923, off deer mice.

UTAH-Off Peromyscus truei (deer mouse) the following fleas have been reported:

35. Orchopeas caedens caedens Jordan 1925

197. Peromyscopsylla hesperomys Baker 1904

181. Stenistomera alpina Baker 1895, and off Peromyscus maniculatus

99. Malaraeus sinomus Jordan 1925

114. Monopsyllus wagneri wagneri Baker 1904

184. Epitedia wenmanni Rothschild 1904.

MONTANA-Off the various deer mice of this state the following fleas have been reported from Ravalli County:

40. Opișodasys keeni Baker 1898

51. Thrassis acamantis Rothschild 1905

98. Malaraeus telchinum Rothschild 1904

114. Monopsyllus w. wagneri Baker 1904

122. Monopsyllus e. eumolpi Rothschild 1905

184. Epitedia wenmanni Rothschild 1905

162. Catallagia decipiens Rothschild 1915

214. Micropsylla sectilis J. and R. 1923, and from Powder River:

37. Orchopeas leucopus Baker 1904, and from Rosebud County:

222. Stenoponia americana Baker 1899.

ALBERTA-From this Canadian province the following fleas are reported off Peromyscus articus from Red Deer and Blackfalds:

37. Orchopeas leucopus Baker 1904

115. Monopsyllus wagneri systaltus Jordan 1929

162. Catallagia decipiens Rothschild 1915. 
BRITISH COLUMBIA-Deer mice in this Canadian province have been found to carry:

40. Opisodasys keeni Baker 1896, off Peromyscus keeni from Queen Charlotte Islands

102. Malaraeus pencilliger dissimilis Jordan 1938, off Peromyscus maniculatus borealis from Atlin

103. Malaraeus euphorbi Rothschild 1905, off Peromyscus canadensis from Horse Creek

113. Megabothris adversus Wagner 1936, off Peromyscus maniculatus from Vancouver

114. Monopsyllus w. wagneri Baker 1904, off Peromyscus from Aspen Grove 155. Atyphloceras artius Jordan 1933, off Peromyscus from Kelowna.

160. Catallagia charlottensis Baker 1898, off Peromyscus macrorhinus from Inverness

162. Catallagia decipiens Rothschild 1915, off Peromyscus from Horse Creek

171. Megarthroglossus procus J. and R. 1915, off Peromyscus from Chilliwack

184. Epitedia wenmanni Rothschild 1904, off Peromyscus leucopus

200. Peromyscopsylla selenis Rothschild 1906, off Peromyscus canadensis from Horse Creek

214. Micropsylla sectilis J. and R. 1923, off Peromyscus

215. Micropsylla goodi Hubbard 1941, off Peromyscus from Vancouver

Up to this date there seems to be no data available on the fleas which deer mice carry in Alaska.

\section{THE NESTS OF WESTERN DEER MICE}

There is little doubt that the nests of deer mice are a far better criterion of the fleas of this mouse than is the mouse itself. While an average of 4 fleas may be removed from these mice, a nest will often produce 100 or more. Deer mice nests can be searched for almost anywhere in the country side. Under the fallen boards of fence rows, beneath old logs, fallen timbers and buildings, in deserted houses, barns and shanties, in rotten logs and hollow trees-almost anywhere a small bit of shelter is afforded.

Deer mice, it seems, build but 1 nest. If the nest is taken without its occupant, very often the mouse will quickly rebuild in the same place. The writer has taken as many as 4 nests in the same cavity at intervals of a month or so. Deer mouse nests may be large or small, depending upon the space available. Generally the mouse uses coarser materials in the outer layers of the nest, finer softer materials within-grasses, lichens, mosses to the outside; fur, burlap, cotton, thistle down, within. This warm lining is tightly woven, making almost a prison for the ectoparasites. The bottom becomes packed with debris, even wastes of the animals, this material being the food of the flea larvae and other forms which do not feed upon the mouse.

\section{No. 238 Peromyscus maniculatus rubidus Osgood}

On March 16, 1935, a deer mouse nest was discovered in an old empty grain bin in the barn of a long-deserted mill settlement 5 miles south of Gaston, Oregon, at the base of Chehalem Mountain. The nest was 8 inches in diameter, a perfect orb built up from a hub hoop of an old wagon hub. The nest contained a female mouse 
with her 3 three-quarter grown young of the first litter. With the nest were taken the 4 mice. Only 16 fleas were taken from the 4 mice, but the nest produce the following 100:

32. Orchopeas nepos Rothschild 1905, 1 male

40. Opisodasys keeni Baker 1896, 11 males, 14 females

116. Monopsyllus wagneri ophidius Jordan 1929, 13 males, 14 females

153. Atyphloceras multidentatus Fox 1909, 2 males, 3 females

160. Catallagia charlottensis Baker 1898, 12 males, 20 females

215. Micropsylla goodi Hubbard 1941, 3 females

219. Hystrichopsylla gigas dippiei Rothschild 1902, 1 male, 4 females

224. Corypsylla jordani Hubbard 1940, 1 male, 1 female.

No. 319. Peromyscus maniculatus rubidus Osgood

On August 15,1935, a deer mouse nest was again taken from the above-described grain bin (No. 238). Just 5 months had elapsed since the previous nest was collected. The present nest was built in the corner of the bin. Again burlap made a warm lining for the nest. The occupant of the nest was not taken. The following 26 fleas were removed from the mass of materials in the nest:

40. Opisodasys keeni Baker 1896, 7 males, 3 females.

116. Monopsyllus wagneri ophidius Jordan 1929, 8 males, 8 females.

\section{No. 414. Peromyscus maniculatus rubidus Osgood}

On March 18, 1936, in Duyck's Wood at Forest Grove, Oregon, a deer mouse nest was located under a board in a brush tangle. A single male deer mouse was in the nest, and taken with it. The nest was small, confined to a small hollow beneath the board. Almost the entire structure of the nest was made of cottontail rabbit fur, a structure with such packed walls that the ectoparasites found it impossible to leave except through the exit, an opening ectoparasites do not readily recognize. The nest with its occupant furnished the following 20 fleas:

40. Opisodasys keeni Baker 1896, 2 males, 1 female

116. Monopsyllus wagneri ophidius Jordan 1929, 3 males, 3 females

153. Atyphloceras multidentatus Fox 1909, 2 females

160. Catallagia charlottensis Baker 1898, 5 males, 3 females

223. Corypsylla ornata Fox 1908, 1 female.

\section{No. 623. Peromyscus maniculatus rubidus Osgood}

On February 9, 1937, again, but under the grain bin mentioned in No. 238, a deer mouse nest with 5 young l-inch long was taken. The mother of the young was not found. The nest was constructed of grass. The fine lining was of finely shredded cedar bark. Being located under the bin in a small hollow, the nest was not as large as those previously taken from within the bin. The following 40 fleas were taken from this nest.

40. Opisodasys keeni Baker 1896, 4 males, 6 females

116. Monopsyllus wagneri ophidius Jordan' 1929, 1 male

153. Atyphloceras multidentatus Fox 1909, 4 males, 7 females

160. Catallagia charlottensis Baker 1898, 1 male.

215. Micropsylla goodi Hubbard 1941, 6 males, 9 females

219. Hystrichopsylla gigas dippiei Rothschild 1902, 1 female.

\section{No. 623a. Peromyscus maniculatus rubidus Osgood}

On February 10, 1937, under a slightly elevated timber lying partially upon the ground at an old rock quarry on the Tualatin River at Dilley, Oregon, a sizable deer mouse nest was taken from the elevated end. The structure of the nest was characteristic, coarse grass nicely packed, making up the bulk of the outside, fine 
grass and some lichens and moss making up the lining. The following 40 fleas were in the nest:

116. Monopsyllus wagneri ophidius Jordan 1929, 15 males, 10 females

153. Atyphloceras multidentatus Fox 1909, 5 females

160. Catallagia charlottensis Baker 1898, 2 males, 3 females

215. Micropsylla goodi Hubbard 1941, 1 male

219. Hystrichopsylla gigas dippiei Rothschild 1903, 2 males, 2 females.

\section{No. 628. Peromyscus maniculatus rubidus Osgood}

Underneath a fallen door of a community of deserted lumber camp shanties, an all-grass deer mouse nest was taken on February 18, 1937, at Dewey, Gaston, Oregon. The following 21 fleas were removed from the nest:

40. Opisodasys keeni Baker 1896, 1 male, 2 females

116. Monopsyllus wagneri ophidius Jordan 1929, 2 males, 5 females

153. Atyphloceras multidentatus Fox 1909, 1 male, 2 females

160. Catallagia charlottensis Baker 1898, 1 male

215. Micropsylla goodi Hubbard 1941, 2 males, 3 females

219. Hystrichopsylla gigas dippiei Rothschild 1903, 1 male, 1 female.

\section{No. 651. Peromyscuis maniculatus rubidus Osgood}

On March 25, 1937, at Forest Grove, Oregon, a deer mouse nest with 1 inhabitant was located in the side of a grassy pasture lot under an old plank drag. The space being small, the nest was not large. The bulk of the building material was shredded burlap. A few leaves, dried, were used as filler. Forty-one fleas were removed from the nest:

116. Monopsyllus wagneri ophidius Jordan 1929, 8 males, 6 females

119. Monopsyllus ciliatus protinus Jordan 1929, 1 male

160. Catallagia charlottensis Baker 1898, 6 males, 20 females.

\section{No. 665. Peromyscus maniculatus rubidus Osgood}

Out of a prostrate stump with a hollow inside, an all-grass nest was taken at the edge of a swamp of the lake at Banks, Oregon, April 7, 1937. Only 4 fleas were found in the nest:

160. Catallagia charlottensis Baker 1898, 2 females

161. Catallagia sculleni Hubbard 1940, I female

164. Catallagia motei Hubbard 1940, 1 female.

No. 667. Peromyscus maniculatus rubidus Osgood

A deer mouse nest taken at Gaston, Oregon, April 8, 1937, was located under a large piece of bark. The nature of the building materials was almost all grass, with a few feathers as inside lining. Fifty-two fleas were taken from the nest immediately and 63 emerged during the next few days. The total adult fleas were then 115 , listed as follows:

40. Opisodasys keeni Baker 1896, 45 males, 49 females

116. Monopsyllus wagneri ophidius Jordan 1929, 7 males, 8 females

153. Atyphloceras multidentatus Fox 1909, 1 male, 2 females

160. Catallagia charlottensis Baker 1898, 2 males.

\section{No. 670. Peromyscus maniculatus rubidus Osgood}

A large deer mouse nest of all moss taken with 3 adults was situated in a ravine beside a creek under a large piece of corded wood at Hoffman's Ranch, Laurel, Oregon, April 20, 1937. The elevation was 1,200 feet on top of Chehalem Mountain. 
From the 3 mice, 8 fleas, as follows:

40. Opisodasys keeni Baker 1896, 2 males, 2 females.

116. Monopsyllus wagneri ophidius Jordan 1929, 4 males.

From the nest upon taking, 24 fleas as follows:

116. Monopsyllus wagneri ophidius Jordan 1929, 3 males, 3 females

153. Atyphloceras multidentatus Fox 1909, 1 male. 2 females

160. Catallagia charlottensis Baker 1898, 3 females

170. Delotelis telegoni Rothschild 1905, 1 male, 3 females

215. Micropsylla goodi Hubbard 1941, 1 male, 2 females

219. Hystrichopsylla gigas dippiei Rothschild 1903, 1 male, 4 females.

From the nest 1 week later:

40. Opisodasys keeni Baker 1896, 13 males, 23 females.

116. Monopsyllus wagneri ophidius Jordan 1929, 1 male, 2 females.

From the nest 2 weeks later:

40. Opisodasys keeni Baker 1896, 2 males, 2 females.

116. Monopsyllus wagneri ophidius Jordan 1929, 1 male, 1 female.

No. 671. Peromyscus maniculatus rubidus Osgood

This nest in same cavity as No. 651 was made by the same mouse. This deer mouse had a preference for shredded burlap. The present nest was taken just 29 days after 651; therefore a flea population had not yet been established. At this time under this drag the nest taken April 22, 1937, contained only ' 14 fleas and but little debris for scavengers to live upon. The fleas are listed here:

116. Monopsyllus wagneri ophidius Jordan 1929, 3 males, 4 females

160. Catallagia charlottensis Baker 1898, 1 male, 6 females.

\section{No. 672. Peromyscus maniculatus rubidus Osgood}

This deer mouse nest with its I occupant was taken in Duyck's Woods at Forest Grove, Oregon, April 22, 1937. The nest was situated under a $\log$ and was a rather bulky affair made up of dried leaves and dried grass. The nest could not have been over 2 months old, still it contained 64 fleas:

40. Opisodasys keeni Baker 1896, 1 female

116. Monopsyllus wagneri ophidius Jordan 1929, 1 male, 8 females

160. Catallagia charlottensis Baker 1898, 19 males, 35 females.

No. 679. Peromyscus maniculatus rubidus Osgood

This nest was taken at Boyer, Salmon River Cut-off, Willamina, Oregon, April 24, 1937. It was deserted, situated in a decayed log. Two fleas had maintained themselves therein. These were the only inhabitants.

219. Hystrichopsylla gigas dippiei Rothschild 1903, 2 females.

No. 686. Peromyscus maniculatus rubidus Osgood

This deer mouse nest was taken under the same drag as were Nos. 671 and 651, at Duyck's Woods, Forest Grove, Oregon, on May 5, 1937, and was taken just 13 days later. The nest was composed of all burlap. There were the following fleas in the nest:

40. Opisodasys keeni Baker 1896, 3 males, 3 females

116. Monopsyllus wagneri ophidius Jordan 1929, 1 male, 1 female

160. Catallagia charlottensis Baker 1898, 3 females.

No. 696. Peromyscus maniculatus gambeli Baird

This deer mouse nest was taken with a female and 4 young at Friend, Oregon, May 18, 1937. The nest was in an open box and was made of shredded paper and burlap. The fleas were:

40. Opisodasys keeni Baker 1896, I male (from mouse), 1 male, 1 female (from nest). 
No. 703. Peromyscus maniculatus gambeli Baird

This nest was taken at Wamic, Oregon, May 18, 1937. It was found in a decaying 12x12-inch timber under an old bridge. The nest was made of grass, wool, and paper. The following fleas were removed from it:

98. Malaraeus telchinum Rothschild 1905, 4 males, 2 females

163. Catallagia chamberlini Hubbard 1940, 1 male.

\section{No. 824. Peromyscus maniculatus gambeli Baird}

This nest contained a female and 5 newly-born young, and was situated on the floor in the corner of a school privy at Bridge Creek School, Mitchell, Oregon. The collection date was July 10, 1937. The nest was made up of newspaper, burlap, and cloth. The mice and nest were infested only with:

114. Monopsyllus wagneri wagneri Baker 1904, 2 male, 8 females.

\section{No. 1,000. Peromyscus maniculatus rubidus Osgood}

This nest was taken with a female and her 4 grown young, from the same grain bin as were Nos. $238,319,623$, February 12,1938 . The nest was a large warm structure constructed of grass, burlap, and moss. Forty-three feeding fleas were taken from the mice:

40. Opisodasys keeni Baker 1896, 13 males, 21 females

116. Monopsyllus wagneri ophidius Jordan 1929, 3 males, 3 females

215. Micropsylla goodi Hubbard 1941, I female

219. Hystrichopsylla gigas dippiei Rothschild 1902, 2 females.

From the nest 51 fleas were taken, as follows:

40. Opisodasys keeni Baker 1896, 1 female

116. Monopsyllus wagneri ophidius Jordan 1929, 1 male, 1 female

119. Monopsyllus ciliatus protinus Jordan 1929, 1 female

153. Atyphloceras multidentatus Fox 1909, 4 males, 5 females

160. Catallagia charlottensis Baker 1898, 6 males, 10 females

170. Delotelis telegoni Rothschild 1905, 1 female

215. Micropsylla goodi Hubbard 1941, 4 males, 10 females

219. Hystrichopsylla gigas dippiei Rothschild 1902, 4 males, 3 females.

\section{No. 1,001. Peromyscus maniculatus rubidus Osgood}

This nest was taken out from under a board at Gaston, Oregon, February 13, 1938, and was composed of grass, cedar bark, and burlap. From it were recovered:

40. Opisodasys keeni Baker 1896, 1 male, 5 females

172. Megarthroglossus procus oregonensis Hubbard 1946, 1 male.

\section{No. 1,027. Peromyscus maniculatus rubidus Osgood}

This nest was removed from above a door jam in a deserted cabin 15 miles east of Detroit, Oregon, on May 22, 1938. A mouse was taken with the nest. From the mouse was removed 12 fleas:

40. Opisodasys keeni Baker 1896, 7 males, 5 females.

From the nest were taken 23 fleas:

40. Opisodasys keeni Baker 1896, 7 males, 5 females

116. Monopsyllus wagneri ophidius Jordan 1929, 2 males, 9 females.

\section{No. 1,031. Peromyscus maniculatus gambeli Baird}

This nest with its 1 occupant was taken from under a shanty board in the desert region 12 miles south. of Mabton, Washington, May 28, 1938. The nest was made of shredded paper collected in the shanty. There were no fleas on the mouse or in the nest. 
No. 1,287. Peromyscus maniculatus rubidus Osgood

Six mice with 4 nests were taken from under old haycocks at Alsea, Oregon, March 10, 1939. The nests were constructed of grass and moss with feathers as lining. From the 6 mice was removed:

116. Monopsyllus wagneri ophidius Jordan 1929, 1 male.

From the nests were removed 17 fleas, as follows:

40. Opisodasys keeni Baker 1896, 1 male, 3 females

116. Monopsyllus wagneri ophidius Jordan 1929, 2 males, 4 females

153. Atyphloceras multidentatus Fox 1909, 1 female

161. Catallagia sculleni Hubbard 1940, 1 male, 5 females.

No. 1,441. Peromyscus maniculatus rubidus Osgood

This nest with 4 young and their mother was taken out of the oven of the range of a deserted CCC camp 8 miles up the Chetco River out of Brookings, Oregon, on June 14, 1939. The nest was a bulky structure built of trash gathered around the camp. One hundred four fleas were taken, 24 off the mice, and 80 from the nest. From the mice came:

40. Opisodasys keeni Baker 1896, 4 males, 9 females.

116. Monopsyllus wagneri ophidius Jordan 1929, 5 males, 6 females.

From the nest:

40. Opisodasys keeni Baker 1896, 18 males, 12 females

116. Monopsyllus wagneri ophidius Jordan 1929, 15 males, 22 females

161. Catallagia sculleni Hubbard 1940, 5 males, 3 females.

No. 1,845. Peromyscus truei gilberti Allen

This is probably the most interesting nest of the series. It was taken from under an apple box lying upon the floor of a deserted chicken house on a farm near Grants Pass, Josephine County, Oregon, December 31, 1941. The nest was taken about noon. A female had built a very large nest of burlap, feathers, and cotton linter. She had used it for a nursery and had maintained with her 5 young of the last litter. These were full grown. The family was doubtless nested down for winter warmth. The entire family was taken. Two hundred fifty fleas were feeding upon these 6 small mice. From the 6 mice were removed the following 120 fleas:

98. Malaraeus telchinum Rothschild 1905, 32 males, 32 females

153. Atyphloceras multidentatus C. Fox 1909, 10 males, 17 females, 10 of which were carrying a single large oval egg

162. Catallagia decipiens Rothschild 1915,17 males, 12 females.

From the nesting material the following 130 fleas were removed:

28. Orchopeas sexdentatus cascadensis Jordan 1939, 1 male

69. Diamanus montanus Baker 1895, 1 female

98. Malaraeus telchinum Rothschild 1905, 40 males, 30 females

153. Atyphloceras multidentatus C. Fox 1909, 24 males, 18 females, 10 of which were carrying a single large oval egg

162. Catallagia decipiens Rothschild 1915, 6 males, 5 females.

\section{Phenacomys \\ Tree Mice-Phenacomys}

The mice of this genus are of 2 habits; those that spend most of their lives up in forest trees, living in bird-like nests and feeding upon needles, and those which live upon the ground, running in burrows of their own or of other mice, nesting above ground in all-grass structures, or under ground in grass nests. The tree mice, as the tree-living forms 
are known, are seldom trapped. Records of these must come from taking the mice from their nests or from specimens captured by woodsimen as they fell trees. The ground forms are taken generally by accident in dead or live traps set for other mice.

The writer's records of these mice are few. They follow:

\section{Phenacomys intermedius olympicus Elliot}

One female captured by hand by the writer at the summit of McKenzie Pass, Oregon, July 20, 1937. The capture was made at noon as the mouse ventured from a burrow. No fleas.

Montana reports 3 species of fleas taken off Phenacomys intermedius, the Rocky Mountain Phenacomys, from Gallatin County during 1938. These fleas were:

Anomiopsyllus sp.

51. Thrassis acamantis Rothschild 1905, a marmot flea

79. Oropsylla idahoensis Baker 1904, a ground squirrel flea.

\section{Phenacomys silvicola A. B. Howell \\ Dusky Tree Mouse}

One female, Newberg, Oregon, February 11, 1938. Captured with its nest from a felled tree. Nest and mouse with but 1 flea, a female:

107. Megabothris quirini Rothschild 1905

One female with young male and their nest, Gaston, Oregon, August 1, 1938. Taken 35 feet up in a Douglas Fir crotch. No fleas.

Although A. B. Howell studied the life history and habits of tree mice in California before he wrote his revision of these mice in North American Fauna No. 48, 1926, there seems to be no records of his having taken fleas from the mice or their nests. If he took fleas in this study from these mice or their nests, the records of the fleas have become lost or were never published.

The difficulties in securing these mice, and the ease with which the ground forms can be confused with Microtus, is probably why there are so few flea records from this genus. Only those listed above have come to the attention of the writer.

\section{Rattus \\ Norwegian Rat-BLack Rat}

Over most of the West where man can live, there, too, will be found Rattus norvegicus Erxleben.(Norwegian rat). This rat is not a native of the country, but has been brought into port towns to be scattered inland as fast as man ventures there. Rat and man seem inseparable, until now this rat is almost considered one of the domestic animals. This gray, brown rat is crafty, dangerous, destructive, and prolific. Where they are not controlled in garbage dumps large numbers can be shot with a rifle. These rats do not readily step into steel traps but in places where steel traps can be used a No. 0 set covered with a piece of white cloth will catch the rat every time.

Rattus rattus rattus Linnaeus (black rat), is far less aggressive than the Norwegian rat. In the West it has not wandered far from the port towns and generally where there are large populations of Norwegian 
rats, the black rats are few. Black rats readily step into steel traps covered with white cloth.

These rats are of economic importance to man because of the damage they do to food stuffs and because they form natural pools for plague and murine typhus. When they were introduced into this country, these rats brought with them the following 3 Old World rat fleas:

9. Xenopsylla cheopis Rothschild 1903, oriental rat flea 105. Nosopsyllus fasciatus Bosc 1801, European rat flea 213. Leptopsylla segnis Schonherr 1811, European mouse flea.

In this trio of fleas, man has the most efficient of the known vectors of bubonic plague. It is these fleas which seem to have laid the way for plague in North America.

After the first epidemic of human plague in San Francisco in 1900, attention was turned to the city's rats, but it was not until 1902 that the port rats were found plague-positive. Continued samplings of these rats proved them plague-positive until 1908. From 1907 through 1917 the harbor rats were found plague-positive in Seattle, Washington. During 1907 and 1908, 1924 and 1925, infected rats were taken in Oakland, California. In 1912, 1914, through 1917, 1920, 1921, and 1925 infected rats were taken in New Orleans, Louisiana. Galveston, Texas, produced plague-positive rats during the years 1920, 1921, and 1922. Rats in Pensacola, Florida, were found plague-positive during 1920 and 1921. Plague-positive rats were picked up in Los Angeles during 1925, 1926, 1927, and 1932. During 1941 plague-positive rats were taken in Berkeley, Oakland, Richmond, and San Francisco, California. During 1942 infected rats were still found in Oakland; and at Fort Cronkhite, Camp Mendell, and Fort Baker in Marin County new plague pools were found in rats. It was during this year that a new foci of plague in rats was discovered at Tacoma, Washington. Three introduced rats were involvedthe Norwegian rat, the black rat, and the Alexandrian rat. The Norwegians were found plague-positive September 22, the blacks on December 16, and the Alexandrians on December 18. These rats continued to be plague-positive through 1943 .

Students of plague seem to feel that most of the human cases of this disease in this country could be traced directly to rats and that this is also the case in Europe.

Specialists are not in agreement as to whether the Old World typhus and the New World type, generally known as murine typhus, are one and the same. The points for and against the arguments are stated elsewhere. Here it is only necessary to say that the human body louse and perhaps the human head louse are considered to be the vectors of typhus in the Old World, but in North America extensive researches have proved that pools of the disease are in the domestic rats, thus the name murine typhus. The one vector is the rat flea, (9.)Xenopsylla cheopis. The work which led to condemning the flea Xenopsylla 
cheopis as a vector of murine typhus was carried out after infection was found among rats in Baltimore, Maryland. A series of human cases of the disease in this city led to the discovery of the infected rats.

Tularemia has been reported from white rats, and wild rats, but whether wild rat refers to Neotoma or Rattus the writer is unable to say.

OREGON-Away from the port town areas the only rat flea carried by rats is:

105. Nosopsyllus fasciatus Bosc 1801.

The infestation may be light or heavy, depending upon the time of year the collections are made.

About the waterfront of Portland the flea situation on rats changes markedly. Always in larger or smaller numbers:

105. Nosopsyllus fasciatus Bosc 1801, is present on the Norwegian and black rats and, in addition,

9. Xenopsylla cheopis Rothschild 1903, can be taken in small numbers off the majority of these rats.

213. Leptopsylla segnis Schonherr 1811, is picked off them occasionally by the investigator.

ACCIDENTAL OCcuRrencEs: While following reports will show many stray fleas off rats, the writer can mention but 2 from Oregon. These are:

6. Ctenocephalides felis Bouche 1835, the cat flea taken off a Norwegian rat at Portland, September 10, 1938

116. Monopsyllus wagneri ophidius Jordan 1929, a deer mouse flea taken off a Norwegian rat from a farm near Forest Grove, March 10, 1937.

WASHINGTON-From specimens of Norwegian rats taken at Kalama, September 15, 1938, the writer removed:

105. Nosopsyllus fasciatus Bosc 1801, 2 males, 3 females.

In a review of a rat flea campaign directed by Dr. L. D. Fricks in Seattle during the period between April, 1927, and August, 1929, Frick says, "One thousand five hundred and ninety-nine fleas were collected and sent to Dr. Carroll Fox for identification. He reported Nosopsyllus fasciatus, 67.3 per cent, Xenopsylla cheopis 22.1 per cent, Leptopsylla musculi ( $L$. segnis), 10.6 per cent." This report is to be found in "Review of Plague in Seattle (1907)," Public Health Bulletin No. 232, 1936.

CALIFORNIA-As early as 1909 Dr. Carroll Fox reports removing from rats taken in San Francisco:

9. Xenopsylla cheopis Rothschild 1903

105. Nosopsyllus fasciatus Bosc 1801

106. Nosopsyllus londinensis Rothschild 1903

213. Leptopsylla segnis Schonherr 1811,

Fox, in this report of 1909 on the fleas of the San Francisco area, lists from 14,273 Norwegian rats examined the following stray fleas:

4. Pulex irritans Linnaeus 1758 , the human flea

6. Ctenocephalides felis Bouche 1835, the cat flea

7. Ctenocephalides canis Curtis 1826, the dog flea

131. Ceratophyllus n. niger C. Fox 1908, the chicken flea.

The average collector seldom collects over a few rats a season, the data thus being insignificant beside that of Fox.

In recent years the most extensive paper to appear upon the fleas of rats was issued by Frank M. Prince of the Plague Suppressive Measures Laboratory of San Francisco. This paper appeared in Public Health Reports, Vol. 58, No. 18, April 30, 1943, p. 700. In it Prince lists the fleas to come into his laboratory from the 13 states 
west of the 102nd Meridian. Of the 21 fleas listed from rats, 4 are introduced species, 17 native species. Prince's list according to states, alphabetically arranged, follows:

ARIZONA:

9. Xenopsylla cheopis Rothschild 1903, from Phoenix, Nogales.

CALIFORNIA:

1. Echidnophaga gallinacea Westwood 1875, from Willows, Fresno

6. Ctenocephalides felis Bouche 1835, from Palm City

7. Ctenocephalides canis Curtis 1826, from San Diego

9. Xenopsylla cheopis Rothschild 1903, from Fresno, San Diego

14. Hoplopsyllus anomalus Baker 1904, from Costa Mesa

32. Orchopeas nepos Rothschild 1905, from Costa Mesa

69. Diamanus montanus Baker 1895, from Fresno, Stockton

84. Foxella ignota franciscana Rothschild 1910, from Palm City

105. Nosopsyllus fasciatus Bosc 1801, from Berkeley, Willows, San Diego

213. Leptopsylla segnis Schonherr 1811, from Berkeley, Fresno, San Diego.

\section{COLORADO:}

9. Xenopsylla cheopis Rothschild 1903, from Denver 105. Nosopsyllus fasciatus Bosc 1801, from Fort Collins 114. Monopsyllus w. wagneri Baker 1904, from Walensburg.

\section{IDAHO:}

47. Thrassis petiolatus Baker 1904, from St. Maries

105. Nosopsyllus fasciatus Bosc 1801, from Lewiston 114. Monopsyllus w. wagneri Baker 1904, from Lewiston.

MONTANA:

Orchopeas sexdentatus spp.?, from Lewiston

75. Opisocrostis labis J. and R. 1922, from Lewiston

80. Oropsylla rupestris Jordan 1929, from Lewiston

105. Nosopsyllus fasciatus Bosc 1801, from Sidney, Savage

108. Megabothris abantis Rothschild 1905, from Lewiston

110. Megabothris lucifer Rothschild 1905, from Lewiston

114. Monopsyllus w. wagneri Baker 1904, from Moore.

\section{NEBRASKA:}

66. Thrassis fotus Jordan 1925, from Alliance

105. Nosopsyllus fasciatus Bosc 1801, from Alliance.

NEVADA:

105. Nosopsyllus fasciatus Bosc 1801, from Reno, Sparks.

NEW MEXICO:

1. Echidnophaga gallinacea Westwood 1875, from Las Cruces, Albuquerque

9. Xenopsylla cheopis Rothschild 1903, from Albuquerque, Lordsburg

105. Nosopsyllus fasciatus Bosc 1801, from Los Lunas

213. Leptopsylla segnis Schonherr 1811, from Lordsburg.

OREGON-Prince lists 4 species of fleas here that have not already been reported from rats in the state. These are:

7. Ctenocephalides canis Curtis 1826, from McMinnville

Orchopeas sexdentatus spp.?, Baker, from Roseburg

69. Diamanus montanus Baker 1895, from Roseburg

98. Malaraeus telchinum Rothschild 1905, from Roseburg. 
TEXAS:

1. Echidnophaga gallinacea Westwood 1875, Newman

69. Diamanus montanus Baker 1895, from El Paso

105. Nosopsyllus fasciatus Bosc 1801, from Amarillo, Newman.

UTAH:

9. Xenopsylla cheopis Rothschild 1903, from Salt Lake City

105. Nosopsyllus fasciatus Bosc 1801, from Salt Lake Sity.

WASHINGTON-Besides the fleas already listed above as being on rats in this state, Prince lists the following additions:

6. Ctenocephalides felis Bouche 1835, from Seattle

114. Monopsyllus w. wagneri Baker 1904, from Spokane.

WYOMING:

Thrassis howelli subsp. Jordan 1925, from Fort McKenzie

105. Nosopsyllus fasciatus Bosc 1801, from Fort McKenzie.

BRITISH COLUMBIA-The report of Prince used above did not cover this Canadian province, but the work of George Holland about Vancouver reveals the presence of the following fleas on rats:

6. Ctenocephalides felis Bouche 1835

9. Xenopsylla cheopis Rothschild 1903

105. Nosopsyllus fasciatus Bosc 1801.

\section{Reithrodontomys \\ HaRvest Mice}

Harvest mice are inconspicuous drab little creatures which can easily be mistaken for house mice. The characteristic mouse smell is common to both. Harvest mice are dwellers of the grassy localities, chaparral wastes, and sagebrush country. Many of these mice can be taken from under hay cocks. Frequently an investigator takes one in a box trap baited with oatmeal.

The nests of harvest mice are small, all-grass, cup-shaped structures built on the ground or in low vegetation. There are records of the mice using deserted bird nests for quarters. Harvest mice seem not to hibernate. The writer has taken them occasionally on top of packed snow in midwinter. Under such conditions the small mice are distinctly out of place, look miserable, doubtless feel so, and are always looking for a hole to get down under. In comparison with other mice, harvest mice seem to be uncommon. Several hundred other mice may be taken for examination to every harvest mouse.

These little inoffensive mice were considered to be of no medical importance until late in March, 1943, when specimens of them taken on the Hunter Ligget Military Reservation at Jolon, Monterey County, California, were found plague-positive. The tests were made from a pool of 12 fleas off 32 of the mice. 


\section{Reithrodontomys megalotis nigrescens Howell \\ Dusky Harvest Mouse}

WASHINGTON-This harvest mouse is Washington's own. From this mouse, taken at Toppenish, Yakima County, the writer can record:

36. Orchopeas caedens durus Jordan 1929, I male, 1 female

98. Malaraeus telchinum Rothschild 1905, 1 male

114. Monopsyllus w. wagneri Baker 1904, 1 female,

From specimens of this mouse examined at Donald, Yakima County, the writer was able to secure only:

36. Orchopeas caedens durus Jordan 1929.

\section{Reithrodontomys megalotis longicaudus Baird California Harvest Mouse}

OREGON-The writer has taken the following fleas off this mouse in southwestern Oregon:

98. Malaraeus telchinum Rothschild 1905, Brownsboro, Jackson County, 2 males, 1 female; Williams, Josephine County, 1 female; Merlin, Josephine County, 1 male

162. Catallagia decipiens Rothschild 1915, Williams, Josephine County, 1 female.

CALIFORNIA-Gus Augustson reports the following fleas off this mouse:

98. Malaraeus telchinum Rothschild 1905, from Los Angeles County

99. Malaraeus sinomus Jordan 1925, from Los Angeles County

116. Monopsyllus w. ophidius Jordan 1929, from Santa Barbara County

153. Atyphloceras multidentatus C. Fox 1909, from Santa Barbara County.

Reithrodontomys megalotis megalotis Baird

\section{Desert Harvest Mouse}

This harvest mouse ranges over a great portion of the Great Basin region south of Columbia River. The writer has taken it in the following localities, carrying the following fleas:

OREGON-Mitchell, Wheeler County, July 12, 1937, 7 specimens from under hay cocks carrying only:

114. Monopsyllus w. wagneri Baker 1904, 2 males.

One female with 4 naked young in all-grass nest under hay cock, clean.

Plush, Lake County, July 1, 1939, 1 specimen carrying the following 20 fleas:

40. Opisodasys keeni Baker 1896, 5 males, 2 females

98. Malaraeus telchinum Rothschild 1905, 1 male

114. Monopsyllus w. wagneri Baker 1904, 6 males, 4 females

123. Monopsyllus e. cyrturus Jordan 1929, 1 male.

Jordan Valley, Malheur County, July 9, 1939, 1 specimen carrying:

114. Monopsyllus w. wagneri Baker 1904, 1 female.

Swan Lake Valley, Klamath County, January 4, 1942, 1 specimen taken on top crush of 18 inches of snow, clean.

Midlands, 8 miles south of Klamath Falls, Klamath County, June 9, 1944, 5 specimens, 1 flea on each of 3:

114. Monopsyllus w. wagneri Baker 1904, I male, 2 females.

Adel, Lake County, October 15, 1944, 1 specimen carrying:

114. Monopsyllus w. wagneri Baker 1904, 1 female. 
CALIFORNIA-Cedarville, Modoc County, October 22, 1944, 1 specimen carrying: 114. Monopsyllus w. wagneri Baker 1904, 2 males.

IDAHO-Burley, Cassia County, July 4, 1944, 2 specimens carrying: 114. Monopsyllus w. wagneri Baker 1904, 1 female.

NEVADA-Extreme northwestern Washoe County, July 3, 1937, 1 specimen carrying: 123. Monopsyllus e. cyrturus Jordan 1929, 1 male,

Reno, Washoe County, June 21, 1944, 2 specimens carrying:

114. Monopsyllus w. wagneri Baker 1904, 1 male,

Minden, Douglas County, June 26, 1944, 2 specimens carrying:

114. Monopsyllus $w$. wagneri Baker 1904, 1 pair

162. Catallagia decipiens Rothschild 1915, 1 female,

Lovelock, Pershing County, June 27, 1944, 2 specimens carrying:

114. Monopsyllus w. wagneri Baker 1904, 2 pair.

UTAH-To the east in this state it is reported that:

38. Orchopeas howardi Baker 1895, has been taken off Reithrodontomys megalotis spp. at Salina, Sevier County.

CALIFORNIA-Augustson reports taking:

35. Orchopeas caedens Jordan 1925, off Reithrodontomys catalinae and $\boldsymbol{R}$. m. limicola from Los Angeles County.

\section{Sciurus}

Gray Squirrels-FoX Squirrels-TufT-eared Squirrels

The genus Sciurus is represented in the West by the silver gray squirrel from lower California north through Washington, the black-footed gray squirrel of the coast section of central California, Anthony's gray squirrel of southern California; 4 tuft-eared squirrels of the Rocky Mountains and the southwest United States, the northern gray squirrel and the fox squirrel introduced into many parks from the eastern states.

Of these squirrels, Sciurus griseus griseus Ord (California silver gray squirrel), covers the greatest area in the West. It is found west of the east foothills of the Cascade Sierra-Nevada Mountain Range. Bailey says it is ". . . among the shyest of wild game, rarely seen except where given special protection, which they are quick to recognize and to which they respond with full confidence."

Collectors realize that this statement is only too true. These big tree squirrels lead a rangy life, moving far from their home nests. Only occasionally does the hunter come across one, then unless he is fully prepared, the squirrel has vanished before a shot can be taken.

So much time of these large squirrels is spent in the high tree tops and off the ground that they do not make good hosts for fleas. Generally they are only moderately infested with fleas but once in a while a specimen can be taken which may be carrying 15 or 20 fleas.

OREGON-Beginning at the east base of Całcade Mountains and working west, the writer has the following records from the California silver. gray squirrel: 
32. Orchopeas nepos Rothschild 1905, Sisters, Deschutes County, 1 female; Crater Lake National Park, 2 females; Brownsboro, Jackson County, 12 females; Portland, Multnomah County, 2 females; Holland, Josephine County, 4 males, 4 females

69. Diamanus montanus Baker 1895, a ground squirrel flea, Brookings, Curry County, 1 male

119. Monopsyllus ciliatus protinus Jordan 1929, Brookings, Curry County, 3 males, 2 females; Gaston, Washington County, many.

WASHINGTON-Four California silver gray squirrel nests were located at Vancouver, Clarke County, April 5, 1942. In 1 of these was a family of 3 small naked young. The writer wishing to photograph the young, returned the next day with camera, to find that the mother had moved them away. The nests, bulky structures of twigs, were lined inside with moss and lichens. After being removed from the high tree tops and examined, it was found that they contained only specimens of:

32. Orchopeas nepos Rothschild 1905, and

119. Monopsyllus ciliatus protinus Jordan 1929.

CALIFORNIA-At Gasquet, Del Norte County, the writer picked up a California silver gray squirrel which had been run over by an automobile. From it he removed 22 fleas as follows:

32. Orchopeas nepos Rothschild 1905, 8 males, 14 females.

124. Monopsyllus fornacis Jordan 1937, was described off this squirrel at Seven Oaks and Jamesburg.

33. Orchopeas latens Jordan 1925, was described from Santa Cruz County.

From Anthony's gray squirrel from Sunland, Los Angeles County, the following flea is reported:

34. Orchopeas dieteri C. Fox 1929.

It seems that the introduced eastern fox squirrel at Encino, Los Angeles County, carries:

38. Orchopeas howardi (=wickhami) Baker 1895.

NEW MEXICO-Off Sciurus aberti aberti (Abert tuft-eared squirrel) was described from a female flea taken at Riti de los Frijoles:

46. Opisodasys robustus Jordan 1925.

ARIZONA-Specimens of the tuft-eared squirrels taken in the San Francisco Mountaihs were carrying:

79. Oropsylla idahoensis Baker 1904.

COLORADO-At Fort Collins the tuft-eared squirrel was found carrying:

69. Diamanus montanus Baker 1895.

\section{Sigmodon \\ Cotron Rat}

Cotton rats are found in the West only along both sides of lower Colorado River, thence east through Arizona, New Mexico, Texas, and beyond. These rodents are medium-sized rats, with long, rough, harsh fur. The ears are nearly hidden by the fur. The tail is long, scaly and thinly haired. Above, the rats are rich brown, below grayish white to buff. They are active day and night, winter and summer. They are dwellers of grasslands and open places, and may burrow or seek the shelter of rocks and logs. 
In Riverside County, California, along the lower Colorado River Valley, Sigmodon hispidus eremicus Mearns (cotton rat), is known to carry:

37. Orchopeas leucopus Baker 1904.

Far to the east from specimens taken at Houston, Texas, off Sigmodon hispidus texianus $\mathbf{A}$. and $\mathbf{B}$. (Texas cotton rat) comes:

22. Polygenis gwyni C. Fox 1914.

\section{Sylvilagus \\ Cottontail Rabbits}

Two cottontail rabbits are found in Oregon. East of the Cascades, Sylvilagus nuttalli nuttalli Bachman (desert cottontail) ranges; west of the Cascades, Sylvilagus bachmani ubericolor Miller (coast cottontail) is found.

Cottontails can be shot or taken in steel traps set in their den ways. Dusk and dawn are the best shooting times, but on dark days these rabbits are out from under cover as long as the sun is hidden.

Cottontails build themselves warm fur nests, for their own use and for nursery use. This warm nest and the ground habits of the animal make it a tremendous incubator for fleas. These rabbits are at times so heavily infested with fleas that several hundred can be taken from a single animal and if such an animal is picked up, the fleas swarm onto the hands.

Through their range east of the Cascade Mountains cottontails are infested heavily with:

15. Cediopsylla i. inaequalis Baker 1895, and moderately with:

16. Cediopsylla i. interrupta Jordan 1925.

West of the Cascade Mountains the infestation is with:

16. Cediopsylla $i$. interrupta Jordan 1929 , and constantly but lightly everywhere with:

150. Odontopsyllus dentatus Baker 1904, and in southwestern Oregon also with:

10. Hoplopsyllus foxi Ewing 1924.

Accinental. Occurrences-Cottontail rabbits pick up their share of the stray fleas in their environment. The writer lists the following:

\section{Sylvilagus nuttalli nuttalli Bachman}

\section{SAgEBRUSH CotToNTAIL}

OREGON:

53. Thrassis h. howelli Jordan 1929, proper host groundhog, Silvies, July 15,1937

70. Opisocrostis $t$. tuberculatus Baker 1904, proper host sage rat, Union, April 15, 1937

79. Oropsylla idahoensis Baker 1904, proper host Callospermophilis, Union, April 15, 1937

114. Monopsyllus wagneri wagneri Baker 1904, proper host deer mouse, Terrebonne, July 8, 1937 . 


\section{Sylvilagus bachmani ubericolor Miller \\ Coast Cottontail}

119. Monopsyllus ciliatus protinus Jordan 1925, proper host Eutamias (chipmunk), Forest Grove, March 7, 1932

160. Catallagia charlottensis Baker 1898, proper host Peromyscus (deer mouse), Forest Grove, April 12, 1936.

A cottontail rabbit nest found by the writer beneath a box in a brush patch at Forest Grove, April 12, 1936, had in it 3 young, about to leave the nest. From the small rabbits and the nest 38 fleas were removed, as follows:

16. Cediopsylla i. interrupta Jordan 1925, 4 males, 3 females

150. Odontopsyllus dentatus Baker 1904, 1 female

160. Catallagia charlottensis Baker 1898, 12 males, 18 females.

WASHINGTON-East of the Cascade Mountains in Washington, the writer has removed the following fleas from:

\section{Sylvilagus nuttalli nuttalli Bachman}

\section{Desert Cottontail RabBit}

15. Cediopsylla inaequalis inaequalis Baker 1895

16. Cediopsylla inaequalis interrupta Jordan 1925

150. Odontopsyllus dentatus Baker 1904.

It is reported that introduced eastern cottontail rabbits on Whidby Island in Puget Sound carry the flea:

13. Hoplopsyllus affinis Baker 1904.

A large concentration of eastern cottontail rabbits around Vancouver, Clarke County, failed to bring into the hands of the writer any fleas.

CALIFORNIA-In the extreme northwestern portion of California at Fort Dick in Del Norte County from:

\section{Sylvilagus bachmani ubericolor Miller}

\section{Coast Cottontail Rabit}

the writer has removed the following fleas:

16. Cediopsylla inaequalis interrupta Jordan 1925

150. Odontopsyllus dentatus Baker 1904.

\section{Sylvilagus nuttalli nuttalli Bachman Desert Cottontall RabBit}

From specimens taken at Tule Lake, Siskiyou County in the northeastern part of the state:

10. Hoplopsyllus foxi Ewing 1924.

From central California off Sylvilagus auduboni subsp.

11. Hoplopsyllus tenuidigitus Stewart 1940, was described. From this portion of California these additional fleas are known to be carried by cottontail rabbits:

10. Hoplopsyllus foxi Ewing 1924

16. Cediopsylla inaequalis interrupta Jordan 1925

150. Odontopsyllus dentatus Baker 1904.

In the southern portion of the state in Los Angeles County, Gus Augustson re- 
ports in addition to those fleas already listed from California:

15. Cediopsylla inaequalis inaequalis Baker 1895, a western rabbit flea which should not be in this locality, and the following strays:

14. Hoplopsyllus anomalus Baker 1904, a wood rat flea

69. Diamanus montanus Baker 1895, a ground squirrel flea

114. Monopsyllus wagneri wagneri Baker 1904, a deer mouse flea.

ROCKY MOUNTAINS-East of the Pacific Coast states and through the Rocky Mountains cottontail rabbits are known to carry the following common rabbit fleas:

13. Hoplopsyllus affinis Baker 1904

15. Cediopsylla inaequalis inaequalis Baker 1895

150. Odontopsyllus dentatus Baker 1904.

MONTANA-The following stray fleas have been taken off cottontail rabbits in Ravalli County:

26. Orchopeas sexdentatus agilis Rothschild 1905, wood rat flea

47. Thrassis petiolatus Baker 1904, ground squirrel flea

51. Thrassis acamantis Rothschild 1905, marmot flea

98. Malaraeus telchinum Rothschild 1905, deer mouse flea

114. Monopsyllus wagneri wagneri Baker 1904, deer mouse flea.

Although the flea (196.) Meringis hubbardi Kohls 1938, was described off a cottontail taken at Mayfield, Idaho, this writer, who probably has the largest collection of these fleas today, feels that that occurrence was accidental, and that the true host of this flea is the deer mouse, from which the majority of his specimens have been taken.

BRITISH COLUMBIA-Records from this Canadian province for cottontail rabbits seem to include only:

12. Hoplopsyllus glacialis lynx Baker 1904, and

15. Cediopsylla inaequalis inaequalis Baker 1895.

\section{PLAGUE AND TULAREMIA IN COTTONTAIL RABBITS}

During 1939 a desert cottontail rabbit taken in Lincoln County, Washington, was found plague-positive. This is apparently the first record of plague in rabbits. It was not until March, 1942, that plague wàs again found in cottontails, in Sylvilagus bachmani (brush cottontail), taken near Bradley Road in Monterey County, California; the evidence came from a pool of fleas. During May, 1942, a brush cottontail examined at Alamo Creek, northeast of Santa Maria, San Luis Obispo County, California, was found plague-positive, the evidence in tissue. This seems to be the evidence to date regarding plague in cottontail rabbits.

The disease tularemia in man has long been known commonly as "rabbit fever." As early as 1936 the disease was known to have occurred in 46 states. Because of the plentifulness of cottontail rabbits, they have been considered everywhere in this country as fine small game and are hunted as a table food. If in skinning rabbits which may be infected, the blood comes in contact with abrasions on the hands of the hunter, the disease may be so transmitted from the rabbit to the hunter. Flies and ticks are known vectors of the disease and fleas have come under suspicion. 


\section{Tamiasciurus \\ Pine Squirrfels-Red Squirrels}

Pine squirrels, red squirrels, and chickarees are found in forests from coast to coast. There is no mistaking their identity. They form the most characteristic animal life in any forested area. There are lots of them, and they never miss the chance to bring their graceful and acrobatic climbing powers to the attention of anything that will watch their capers. Seemingly always looking for trouble or excitement, these squirrels are very easily shot, but the writer is of the opinion that when they fall far, most of their fleas are bounced off when the squirrels hit the ground. They can be trapped in box traps but unless the traps are lined with metal, the squirrels just gnaw out. If the investigator can find the nest of the animal, far more fleas can be secured than off the animals themselves. The nests may be topped over old bird nests, or found in cavities of trees or logs. The bulk of the nesting material consists of moss. It is common knowledge that female squirrels may have several nests and will move their young from one to the other if the little fellows are bothered.

Tamiasciurus douglasi douglasi Bachman (Douglas pine squirrel) ranges through the Puget Sound Trough and west. Tamiasciurus douglasi cascadensis Allen (Cascade pine squirrel) ranges throughout the Cascade Mountains and northern Sierras and the Siskiyous. Tamiasciurus douglasi albolimbatus Allen (Sierra pine squirrel) ranges west of the Great Basin to and into the foothills of the Cascades and Sierras. Tamiasciurus hudsonicus richardsoni Bachman (Richardson's pine squirrel) ranges in the Blue Mountains of Oregon and Washington and east and north into the Rockies.

It is the opinion of the writer that pine squirrels rank next to the deer mice in abundance of kinds and numbers of fleas. Their nests are warm and well constructed to hold ectoparasites. The squirrels play over the ground, run into every burrow, hole, and crevice they can find. They are inquisitive and not afraid. Everything about the pine squirrel makes it a fine subject for flea infestation.

The following study of the fleas of the pine squirrels of the West is the result of the personal trapping or shooting and examination of 150 specimens by the writer in 100 localities in Oregon, Washington, and northern California. Six hundred fifty fleas were removed from these squirrels; 8 per cent were without fleas. Usually only moderately infested with fleas, occasionally as many as 25 can be removed from 1 ani. mal, and upon 1 occasion the writer removed 75 fleas from 1 of these squirrels which died in a live-catch box trap.

Along the coastal belt the chief flea of the pine squirrel is:

119. Monopsyllus ciliatus protinus Jordan 1929, which it picks up from the chipmunk, with which it is closely associated. 
172. Megarthroglossus procus oregonensis Hubbard 1946 is common in winter.

East of the Coast Range and in the Cascade and northern Sierra Mountains:

119. Monopsyllus ciliatus protinus Jordan 1929, is still common on the pine squirrel, as are:

32. Orchopeas nepos Rothschild 1905, and

172. Megarthroglossus procus oregonensis Hubbard 1946.

East of the Cascades in the Blue Mountains the infestation is generally only of:

119a. Monopsyllus ciliatus kincaidi Hubbard 1946,

121. Monopsyllus vison Baker 1904,

35. Orchopeas caedens caedens Jordan 1925, and

36. Orchopeas caedens durus Jordan 1929.

OREGON-ACcidental Occurrences: The inquisitive habits of the pine squirrel make it a very good subject for stray fleas. The writer records:

\section{Tamiasciurus douglasi albolimbatus Allen}

Sisters, March 20, 1937:

79. Oropsylla idahoensis Baker 1904, proper host Callospermophilus or Citellus

184. Epitedia wenmanni Rothschild 1904, proper host Peromyscus (deer mouse)

153. Atyphloceras multidentatus Fox 1909, proper host Microtus.

Tamiasciurus douglasi cascadensis Allen

123. Monopsyllus eumolpi cyrturus Jordan 1929, proper host Eutamias amoenus (Klamath chipmunk), Parkdale, August 4, 1937.

Tamiasciurus douglasi douglasi Bachman

69. Diamanus montanus Baker 1895, proper host Citellus douglasi (gray digger), Port Orford, August 22, 1937

105. Nosopsyllus fasciatus Bosc 1801, proper host house rats and mice, Albany, May 7,1938

116. Monopsyllus wagneri ophidius Jordan 1929, proper host Peromyscus (deer mouse), Forest Grove, February 21, 1938

160. Catallagia charlottensis Baker 1898, proper host Peromyscus (deer mouse), Gaston, December 30, 1937.

215. Micropsylla goodi Hubbard 1941, proper host Peromyscus (deer mouse), Gaston, March 7, 1932.

\section{Tamiasciurus douglasi douglasi Bachman \\ Douglas Pine SQuirrel}

WASHINGTON-Specimens collected were infested with:

32. Orchopeas nepos Rothschild 1905

116. Monopsyllus wagneri ophidius Jordan 1929

119. Monopsyllus ciliatus protinus Jordan 1929

\section{Tamiasciurus douglasi cascadensis Allen}

\section{Cascade Pine Squirrel}

Specimens collected were infested with:

119. Monopsyllus ciliatus protinus Jordan 1929.

CALIFORNIA-While the writer has been able to remove from Tamiasciurus douglasi douglasi (pine squirrel) in Del Norte County only:

119. Monopsyllus ciliatus protinus Jordan 1929, 
Gus Augustson working in the Central Sierra-Nevada Mountains in Fresno and Mono

Counties removed from Tamiasciurus douglasi albolimbatus the following fleas:

32. Orchopeas nepos Rothschild 1905

45. Opisodasys enoplus Rothschild 1909

69. Diamanus montanus Baker 1895

79. Oropsylla idahoensis Baker 1904

108. Megabothris abantis Rothschild 1905

120. Monopsyllus c. mononis Jordan 1929

123. Monopsyllus e. cyrturus Jordan 1929

167. Catallagia rutherfordi Augustson 1941

171. Megarthroglossus procus J. and R. 1915

173. Megarthroglossus d. divisus Baker 1895

200. Peromyscopsylla selenis Rothschild 1906.

IDAHO-The author has taken off:

Tamiasciurus hudsonicus ventorum Allen at Smith's Ferry:

121. Monopsyllus vison Baker 1904

123. Monopsyllus eumolpi cyrturus Jordan 1929

and far to the north at Bonner's Ferry off Tamiasciurus hudsonicus richardsoni Bachman:

35. Orchopeas caedens caedens Jordan 1925.

COLORADO-Described off $T$. $f$. fremonti (Fremont chickaree) taken at Georgetown, is:

148. Tarsopsylla coloradensis Baker 1895, and recorded off the same squirrel from Pagosa Peak is:

121. Monopsyllus vison Baker 1904.

MONTANA-In Ravalli County the following fleas have been taken off Tamiasciurus hudsonicus:

12. Hoplopsyllus g. lynx Baker 1904

Orchopeas caedens Jordan 1925

47. Thrassis petiolatus Baker 1904

108. Megabothris abantis Rothschild 1905

121. Monopsyllus vison Baker 1904

122. Monopsyllus e. eumolpi Rothschild 1905

219. Hystrichopsylla gigas dippiei Rothschild 1903.

UTAH-From this state the following fleas are reported off red squirrels:

35. Orchopeas c. caedens Jordan 1929, Fish Lake Mountains

38. Orchopeas howardi Baker 1895, Manti

Monopsyllus ciliatus subsp., Utah

121. Monopsyllus vison Baker 1904, Fish Lake Mountains •

219. Hystrichopsylla g. dippiei Rothschild 1902, Utah.

BRITISH COLUMBIA-From pine squirrels and chickarees:

32. Orchopeas nepos Rothschild 1905

36. Orchopeas caedens durus Jordan 1929

121. Monopsyllus vison Baker 1904

144. Dasypsyllus gallinulae perpinnatus Baker 1904

175. Megarthroglossus divisus exsecatus Wagner 1936.

The author removed from these squirrels at Cranbrook:

35. Orchopeas caedens caedens Jordan 1925

47. Thrassis petiolatus Baker 1904

123. Monopsyllus eumolpi cyrturus Jordan 1929.

ALBERTA-Off Richardson's pine squirrel:

173. Megarthroglossus divisus divisus Baker 1895. 
ALASKA-Off Richardson's pine squirrel:

35. Orchopeas caedens caedens Jordan 1925, from Lake Bennet

36. Orchopeas caedens durus Jordan 1929, from Seward

119. Monopsyllus ciliatus protinus Jordan 1929, from Seward

121. Monopsyllus vison Baker 1904, from Lake Bennet.

\section{FROM THE NESTS OF PINE SQUIRRELS}

OREGON-Nests of pine squirrels are usually moss structures built up in trees, but these animals will take advantage of the protection offered by old buildings, timbers and boards upon the ground, hollow trees, in fact almost anywhere a position meets their fancy. The bulk of their structures is almost always bearded lichens and moss. The writer has examined the following nests of Tamiasciurus douglasi douglasi.

At Gaston, January 26, 1985: A bulky nest in shelter of deserted chicken house, nest in one of the nesting boxes, 142 fleas:

32. Orchopeas nepos Rothschild 1905, 2 males, 2 females

116. Monopsyllus wagneri ophidius Jordan 1929, 8 males, 5 females

119. Monopsyllus ciliatus protinus Jordan 1929, 30 males, 35 females

172. Megarthroglossus procus oregonensis Hubbard 1946, 25, males, 35 females.

At Newberg, February 18, 1937, nest under a collapsed building, 8 fleas:

32. Orchopeas nepos Rothschild 1905, 1 male

119. Monopsyllus ciliatus protinus Jordan 1929, 4 males, 3 females.

At Dilley, August 30, 1937: This nest was a large moss structure located in a fir tree, 7 fleas:

32. Orchopeas nepos Rothschild 1905, 3 males, 3 females

119. Monopsyllus ciliatus protinus Jordan 1929, 1 female.

At Gaston, December 20, 1937: Nest was a moss structure beneath a door which had fallen to the ground. Fifty-two fleas were recovered from the nest. These were:

32. Orchopeas nepos Rothschild 1905, 8 males, 8 females

116. Monopsyllus wagneri ophidius Jordan 1929, 1 female

119. Monopsyllus ciliatus protinus Jordan 1929, 12 males, 11 females

153. Atyphloceras multidentatus Fox 1909, 2 males, 7 females

160. Catallagia charlottensis Baker 1898, 1 male

215. Micropsylla goodi Hubbard 1941, 1 male

219. Hystrichopsylla gigas dippiei Rothschild 1902, 1 female.

At Newberg, February 25, 1940: Nest on ground under pile of lumber, 21 fleas:

32. Orchopeas nepos Rothschild 1905, 5 males, 3 females

119. Monopsyllus ciliatus protinus Jordan 1929, 3 males, 7 females

153. Atyphloceras multidentatus Fox 1909, 1 female

219, Hystrichopsylla gigas dippiei Rothschild 1902, 1 male, 1 female.

As early as 1937 the California State Board of Public Health found plague in $T . d$. albolimbatus? ("red squirrel") in the Sierra-Nevada Mountains of Fresno County, California. The report was based on 2 pooled inoculations of fleas and 2 inoculations of tissue. No other reports of plague-positive pine squirrels are known to the writer.

\section{Thomomys \\ Pocket Gophers}

Pocket gophers of one type or another range all over the West. Bailey enumerates 15 species and subspecies from Oregon. Briefly stated, these are: 
Thomomys bulbivorus Richardson (Willamette Valley pocket gopher), Willamette Valley west to foothills of Cascade Range

Thomomys townsendi townsendi Bachman (Townsend's pocket gopher), Malheur and Owyhee Valleys

Thomomys townsendi nevadensis Merriam (Nevada pocket gopher), Alvorad and Malheur Lake Valleys

Thomomys douglasi douglasi Richardson (Douglas' pocket gopher), around Scappoose, Oregon

Thomomys bottae leucodon Merriam (white-toothed pocket gopher), Rogue, Umpqua, and Klamath Valleys

Thomomys bottae laticeps Baird (Humboldt Bay pocket gopher), extreme southwestern Oregon, Chetco and Winchuck Rivers

Thomomys douglasi oregonus Merriam (Oregon pocket gopher), scattered through northwest Oregon

Thomomys hesperus Merriam (West Coast pocket gopher), northwest Oregop, particularly coastal belt

Thomomys niger Merriam (black pocket gopher), mouth of Umpqua River

Thomomys monticola mazama Merriam (Mazama pocket gopher), Cascade, Siskiyou, and Trinity Mountains

Thomomys monticola helleri Elliot (Heller's pocket gopher), mouth of Rogue River, north side

Thomomys monticola nasicus Merriam (Deschutes pocket gopher), south Deschutes Valley and Paulina and Yamsey Mountains

Thomomys fuscus fuscus Merriam (brown pocket gopher), Blue Mountains

Thomomys quadratus quadratus Merriam (Dalles pocket gopher), sagebrush plains of eastern Oregon

Thomomys columbianus Bailey (Columbia pocket gopher), sandy bottoms of Columbia River Valley, Umatilla to Willows.

OREGON-With the exception of Thomomys niger, the writer has records for all the pocket gophers of this state. Generally speaking, these records show that:

First. Pocket gophers in the Willamette and Tualatin Valleys-Thomomys bulbivorus, Thomomys douglasi douglasi, and Thomomys douglasi oregonus-are not infested with a flea of their own, but only with strays they pick up.

Second. Pocket gophers of southwest Oregon as far north as Rogue RiverThomomys bottae laticeps, Thomomys bottae leucodon-are infested only with:

84. Foxella ignota franciscana Rothschild 1910.

Third. All other pocket gophers of the state are infested at all times with large numbers of:

86. Foxella ignota recula J. and $\mathrm{R}$. 1915, and during the late summer and fall months with:

92. Dactylopsylla comis Jordan 1929, in very small numbers.

Fourth. Foxella ignota has not come into the Willamette Valley for some unknown reason, even though it is on all sides.

Fifth. Along the coastal belt of Oregon, pocket gophers also carry:

93. Dactylopsylla pacifica Hubbard 1943.

AcCidental Occurrences-Pocket gophers are subject to many stray fleas because of the fact that many of the smaller rodents of the vicinity run their burrows. The writer records the following:

27. Orchopeas sexdentatus nevadensis Jordan 1929, proper host Neotoma (wood rat), off T. q. quadratus, Silvies, Grant County, July 15, 1937

69. Diamanus montanus Baker 1895, proper host Citellus douglasi (gray digger), off T. m. mazama, Parkdale, Hood River County, August 5, 1935 
79. Oropsylla idahoensis Baker 1904, proper host Citellus or Callospermophilus, off T. m. mazama, Little Lava Lake, Deschutes County, July 27, 1936

119. Monopsyllus ciliatus protinus Jordan 1929, proper host Eutamias (chipmunk), off $T$. bulbivorus, Cornelius, Washington County, June 24, 1935; off T. m. mazama, Parkdale, Hood River County, August 5, 1935

123. Monopsyllus eumolpi cyrturus Jordan 1929, proper host E. amoenus (Klamath chipmunk), off T. q. quadratus, Sisters, Deschutes County, July 16, 1936

160. Catallagia charlottensis Baker 1898, proper host Peromyscus (deer mouse), off T. bulbivorus, Cornelius, Washington County, July 3, 1936

184. Epitedia wenmanni Rothschild 1904, proper host Peromyscus (deer mouse), off T. q. quadratus, Sisters, Deschutes County, March 19, 1937

185. Epitedia jordani Hubbard 1940, vicariating species, no true host, off T. d. oregonus, Forest Grove, Washington County, March 5, 1937

214. Micropsylla sectilis J. and R. 1923, proper host not known, off $T$. q. quadratus, Sisters, Deschutes County, March 19, 1937

215. Micropsylla goodi Hubbard 1941, proper host peromyscus (deer mouse), off T. m. mazama, Flag Point, Mt. Hood National Forest, August 11, 1935

223. Corypsylla ornata C. Fox 1908, proper host Scapanus (mole), off T. bulbivorus, Forest Grove, Washington County, July 8, 1932.

WASHINGTON-Specimens gathered at Government Mineral Springs, Bickleton, and Lowden and covering Thomomys columbianus Bailey, Thomomys douglasi douglasi Richardson and probably Thomomys quadratus quadratus Merriam were - all infested with:

86. Foxella ignota recula J. and R. 1915.

CALIFORNIA-Miller lists some $\mathbf{3 0}$ species and subspecies of pocket gophers:

Specimens of Thomomys bottae laticeps Baird (Humboldt Bay pocket gopher) taken by the author at Smith River and Fort Dick, Del Norte County, during all seasons of 1939, 1940, 1941 were infested with:

84. Foxella ignota franciscana Rothschild 1910, and

94. Dactylopsylla bottaceps Hubbard 1943.

Specimens of Thomomys monticola monticola Allen (California mountain pocket gopher) taken by the author on the west shore of Lake Donner, Nevada County, and the south shore of Lake Tahoe, Eldorado County during June, 1944, carried only:

86. Foxella ignota recula J. and R. 1915.

Reported from central California are:

84. Foxella ignota franciscana Rothschild 1910

85. Foxella ignota acuta Stewart 1940

95. Dactylopsylla bluei C. Fox 1909.

In southern California around Big Bear Lake in San Bernardino County Gus Augustson described off Thomomys altivallis Rhoads:

87. Foxella ignota coufferi Augustson 1942, and at Point Arguello, Santa Barbara County, he took during March, 1942:

84. Foxella ignota franciscana Rothschild 1910.

NEVADA-Specimens of Thomomys quadratus quadratus Merriam (Dalles pocket gopher) taken by the author at Coleman's Ranch and Vya, northwest Washoe County, during June, 1944, were infested with:

86. Foxella ignota recula J. and R. 1915, as were specimens of Thomomys townsendi nevadensis Merriam (Nevada pocket gopher) taken during July, 1944, at Winnemucca, Humboldt County, and Battle Moùntain, Lander County.

95b. Dactylopsylla monticola Prince 1945, was described off Thomomys monticola taken in Ormsby County. 
IDAHO-Pocket gophers of this state carry:

91. Foxella utahensis utahensis Wagner 1936, in southeastern portion of the state, and the author has taken

86. Foxella ignota recula J. and R. 1915, in other portions.

UTAH-The pocket gophers carry in northern half of the state:

91. Foxella utahensis utahensis Wagner 1936, and it seems quite likely that

91a. Foxella utahensis arizonensis Hubbard 1946, will be found in Southern half and adjacent to Arizona the pocket gophers will carry:

89. Foxella ignota apachina C. Fox 1914.

ARIZONA-Pocket gophers in this state carry the large pocket gopher flea:

95. Dactylopsylla bluei C. Fox 1909, and the small pocket gopher flea:

89. Foxella ignota apachina C. Fox 1914 (probably F. i. omissa Prince).

MONTANA-The following 5 fleas are reported off pocket gophers from Gallatin County:

94a. Dactylopsylla (F.) nuditenacula Prince 1945

Foxella ignota subsp.

70. Opisocrostis $t$. tuberculatus Baker 1904, a ground squirrel flea

79. Oropsylla idahoensis Baker 1904, a ground squirrel flea

108. Megabothris abantis Rothschild 1905, a mouse flea.

The various species of pocket gophers of the Great Plains all carry:

88. Foxella ignota ignota Baker 1895.

WYOMING-East of the Continental Divide the pocket gophers carry:

88. Foxella ignota ignota Baker 1895; west of the Divide:

91. Foxella utahensis utahensis Wagner 1936.

NEW MEXICO-West of the Continental Divide it seems likely that pocket gophers carry the small pocket gopher flea:

89. Foxella ignota apachina C. Fox 1914, and in San Miguel County pocket gophers are known to carry the large

95a. Dactylopsylla neomexicana Prince 1945

COLORADO-Pocket gophers carry the following 3 fleas, the giant:

96. Dactylopsylla rara I. Fox 1940, and the small gopher fleas:

89. Foxella ignota apachina C. Fox 1914, west of Continental Divide, and

88. Foxella ignota ignota Baker 1895, east of Continental Divide.

BRITISH COLUMBIA-Both the giant pocket gopher flea:

92. Dactylopsylla comis Jordan 1929, and the small pocket gopher flea:

86. Foxella ignota recula J. and R. 1915, were described from Okanagan Landing, the former from Thomomys fuscus, the latter off a weasel which had probably made a meal of the gopher which was carrying the fiea.

ALBERTA-Off Geomys from this Canadian province Jordan and Rothschild described:

90. Foxella ignota albertensis J. and R. 1915.

The only record of a plague-positive pocket gopher comes from a tissue pool of organs taken at Arroyo Grande, San Luis Obispo County, California, on May 27, 1942. Pocket gopher fleas have not as yet been condemned as vectors of plague.

Pocket gophers must be trapped with specially built traps which fit 
into the runway after it has been opened. The traps are sprung when the gopher attempts to plug the open runway. In so far as these traps kill by driving sharpened prongs into the body, frequent visits must be made to the sets to remove captured gophers before the fleas leave the body. For small gophers, up to 5 or 6 inch body length, the Macabee gopher trap is best. These small traps will not hold large gophers, which must be taken with Chinch gopher traps.

\section{Zapus \\ JUMPING MicE}

While jumping mice are mainly nocturnal, they are occasionally seen in daylight. Generally, this only happens when they have been frightened from their grass nests which in summer are built on the surface of the ground. The animals burrow into the soil to make their winter nests. In these they hibernate. Jumping mice seldom make their way into traps. Excellent places to set traps for chance catches are in amongst the bases of skunk cabbage plants or in culverts, the mice coming to the culverts from all directions to play in them because of the shelter they afford. Oatmeal should be the bait. In most cases, however, this bait cannot run competition with the ever present supply of natural greens upon which the mice live.

When a jumping mouse comes to hand it is found to be a beautiful, timid creature. The tail is long, slender, and without a tassel. Forefeet are small, hind ones well developed, for hopping. Fur is soft but with a tendency to be slightly coarse. The mice are fawn-brown above and immaculate white beneath.

Jumping mice seldom carry any ectoparasites. The great majority examined were free of them. Of the some dozen collected by the writer over a period of years, all were clean of fleas, with the exception of the following individuals:

OREGON:

108. Megabothris abantis Rothschild 1905, off Zapus trinotatus montanus Merriam (mountain jumping mouse), Cooper Spur Junction, Parkdale, Hood River County, August 5, 1997, 1 male; off Zapus princeps oregonus Preble (Blue Mountain jumping mouse), Lostine, Wallowa County, August 8, 1938, 2 males, 9 females; off Zapus princeps oregonus Preble, Wallowa Lake, Wallowa County, Oregon, July 14, 1939, 1 male, August 9, 1945, 3 males, 3 females.

107. Megabothris quirini Rothschild 1905, off Zapus trinotatus trinotatus Rhoads (Northwest jumping mouse), Golf Course, Devil's Lake, Lincoln County, August 10, 1937, 2 females.

IDAHO-The author collected at Craigmont off Zapus princeps princeps Allen 108. Megabothris abantis Rothschild 1905.

Other records of the fleas of Zapus are scarce. Those to come to the attention of the writer are: 
64. Thrassis setosis Prince 1944, reported from Yavapai County, Arizona, 107. Megabothris quirini Rothschild 1905, reported from British Columbia, 108. Megabothris abantis Rothschild 1905, reported from California, 200. Peromyscopsylla selenis Rothschild 1906, and 212. Doratopsylla c. curvata Rothschild 1915, reported from Alberta, Canada, 222. Stenoponia americana Baker 1898, reported from Gayhead, Massachusetts. 


\section{THE FLEAS OF WESTERN CARNIVORA}

In the following pages on the fleas of western Carnivora the hosts are listed in the alphabetical order of the genus:

1. Bassaricus-ring-tailed cat . . . . . . . . . . . . p. 496

2. Canis latrans-coyote . . . . . . . . . . . . . p. 497

3. Canis familiaris and Felis catus-domestic dog and cat . . . p. 497

4. Euarctos and Ursus-black and grizzly bears . . . . . . p. 497

5. Felis oregonus-cougar . . . . . . . . . . . . . . p. 497

6. Gulo-wolverine . . . . . . . . . . . . . . p. 498

7. Lutreola-mink . . . . . . . . . . . . . . . p. 498

8. Lynx-bob cat, lynx, wild cat . . . . . . . . . . . . . p. 498

9. Martes-martin . . . . . . . . . . . . . . . p. 499

10. Mephites-common skunk . . . . . . . . . . . . p. 499

11. Mustela-weasels . . . . . . . . . . . . . . p. 500

12. Spilogale-little spotted skunk . . . . . . . . . . . p. 501

13. Taridea-badger . . . . . . . . . . . . . . p. 502

14. Urocyon-gray fox . . . . . . . . . . . . . . p. 502

15. Vulpes—red fox, desert fox . . . . . . . . . . . . p. 502

After handling considerable of the wild materials above, it is the opinion of the writer that most of these Carnivora do not have fleas of their own, but at times become heavily or lightly infested with the fleas of the rodents upon which most of them live. During the struggles of the kill the rodent fleas are thrown from their proper host onto the Carnivora, where they are found by the collector. Their fleas then could very easily become an index of the various small animals which these carnivores use for food. With this in mind the writer will list after each flea its normal host. In case such a listing does not occur, the true host of the flea is not known or the carnivore is the true host of the flea.

\section{Bassaricus \\ Ring-TAILED Gat}

CALIFORNIA-Augustson reports off these animals from Riverside County:

1. Echidnophaga gallinacea Westwood 1875, hen flea

32. Orchopeas nepos Rothschild 1905, squirrel flea

37. Orchopeas leucopus Baker 1904, mouse flea

145. Amphipsylla neotomae I. Fox 1940, wood rat flea. 


\section{Canis latrans \\ Coyote}

CALIFORNIA-From Los Angeles County, Augustson reports off this animal:

4. Pulex irritans Linnaeus 1758, human flea

6. Ctenocephalides felis Bouche 1835, cat flea

7. Ctenocephalides canis Curtis 1826, dog flea.

ARIZONA-From Yuma County:

7. Ctenocephalides canis Curtis 1826, dog flea.

MONTANA-The largest study on coyote fleas comes from this state where these animals have been found to carry the following 14 fleas:

4. Pulex irritans Linnaeus 1758, human flea

12. Hoplopsyllus glacialis lynx Baker 1904, rabbit flea

15. Cediopsylla i. inaequalis Baker 1904, rabbit flea

24. Arctopsylla setosa Rothschild 1906, bear flea

51. Thrassis acamantis Rothschild 1905, marmot flea

75. Opisocrostis labis J. and R. 1922, ground squirrel flea

76. Opisocrostis hirsutus. Baker 1895, prairie-dog flea

79. Oropsylla idahoensis Baker 1904, ground squirrel flea

81. Oropsylla arctomys Baker 1904, marmot flea

108. Megabothris abantis Rothschild 1905, mouse flea

121. Monopsyllus vison Baker 1904, squirrel flea

122. Monopsyllus e. eumolpi Rothschild 1905, chipmunk flea

219. Hystrichopsylla g. dippiei Rothschild 1903, mouse flea

229. Neactopsylla brooksi Rothschild 1904, shrew flea.

UTAH-Off Canis lestis (coyote) at Kelton, the following rabbit fleas were taken:

15. Cediopsylla i. inaequalis Baker 1904

16. Cediopsylla i. interrupta Jordan 1929.

BRITISH COLUMBIA-The following fleas have been reported taken off coyotes:

51. Thrassis acamantis Rothschild 1905, marmot flea

176. Megarthroglossus sicamus J. and R. 1915.

\section{Canis familiaris and Felis catus \\ Domestic Dog and Cat}

In the West, cats and dogs are generally infested with:

6. Ctenocephalides felis Bouche 1835, the cat flea, and

7. Ctenocephalides canis Curtis 1825, the dog flea.

\section{Euarctos and Ursus \\ Black Bears-Grizzly Bears}

The American bear fleas:

23. Arctopsylla ursi Rothschild 1902, and

24. Arctopsylla setosa Rothschild 1906, have been reported off grizzly bears in British Columbia and Alberta, and off black bears in Alaska and Montana.

52. Thrassis spenceri Wagner 1936, is reported off grizzly bear from Eagle River, British Columbia.

\section{Felis oregonus \\ Cougar-Mountain Lion}

From Mineral County, Montana, the following flea is reported off this mountain lion:

24. Arctopsylla setosa Rothschild 1906. 


\section{Gulo \\ WOLVERINE}

From Eagle River, British Columbia, the following fleas are reported off the wolverine:

52. Thrassis spenceri Wagner 1936

69. Diamanus montanus Baker 1895, ground squirrel flea, the latter record questioned by some students.

\section{Lutreola \\ MinK}

OREGON-A specimen of this animal trapped out of a mountain beaver burrow at Blodgett, Lincoln County, July, 1939, was infested with:

220. Hystrichopsylla schefferi schefferi Chapin 1919, mountain beaver flea, 1 male, 2 females.

Mink trapped in Lincoln County during December, 1940, were carrying:

149. Dolichopsyllus stylosus Baker 1904, a mountain beaver flea. And from a mink examined from Mercer Lake, in the coastal belt of Lane County, Ewing described:

217. Paratyphloceras oregonensis Ewing 1940.

BRITISH COLUMBIA-Off a mink taken at Chilliwack:

219. Hystrichopsylla gigas dippiei Rothschild 1902.

183. Trichopsylloides oregonensis Ewing 1938, a mountain beaver flea, was taken off this animal at Cultis Lake.

The strange death of a mink farmer in southeastern Alberta in 1939 which involved ground squirrels, mink, and a scratched hand, has been attributed to plague. Whether the farmer received the infection through skinning the mink which had died after eating Richardson's ground squirrels in which there might have been plague infection, or whether the farmer was given the infection from a flea vector off an infected ground squirrel will probably never be known. At any rate, this case gives the first indication that mink might become victims of plague, the record stating, ". . . was believed to have been contracted from infected mink."

\section{Lynx \\ Bob Cat-LynX-Wild Cat}

The writer has taken off this animal in the southern Cascades of Oregon:

10. Hoplopsyllus foxi Ewing 1.924, a rabbit flea.

From Los Angeles, California, described off a bob cat is: 34. Orchopeas dieteri C. Fox 1929.

Augustson records from the southern part of California:

1. Echidnophaga gallinacea Westwood 1875, hen flea

4. Pulex irritans Linnaeus 1758 , human flea

6. Ctenocephalides felis Bouche 1835, cat flea

16. Cediopsylla i. interrupta Jordan 1929, rabbit flea. 
From Moscow, Idaho, off Lynx canadensis, Baker originally described the following fleas:

12. Hoplopsyllus glacialis lynx Baker 1904

39. Orchopeas labiatus Baker 1904

47. Thrassis petiolatus Baker 1904

150. Odontopsyllus dentatus Baker 1904.

From Alberta, the following fleas have been recorded off lynx:

4. Pulex irritans Linnaeus 1758 , human flea

90. Foxella i. albertensis J. and R. 1915, pocket gopher flea

117. Monopsyllus thambus Jordan 1929.

From a lynx taken at Tucson, Arizona, a pair of rabbit fleas:

150. Odontopsyllus dentatus Baker 1904.

From lynx examined in Utah the rabbit flea:

15. Hoplopsyllus i. inaequalis Baker 1895.

\section{Martes}

\section{Pine Martins-Martins}

In Ravalli County, Montana, the following fleas have been taken off the pine martin:

26. Orchopeas s. agilis Rothschild 1905, wood rat flea

35. Orchopeas c. caedens Jordan 1925, squirrel flea.

At the summit of McKenzie Pass, Deschutes County, Oregon, on September 8, 1944, Alex Walker, while hunting conies in the lava beds, secured a martin which was also apparently hunting conies. Walker removed the fleas from the animal and sent them to the writer:

32. Orchopeas nepos Rothschild 1905, a good series, and

119. Monopsyllus ciliatus protinus Jordan 1929,2 males, 3 femáles, the former being a pine squirrel flea, the latter a chipmunk flea.

\section{Mephitis \\ Common Skunk}

Records from this animal have generally come from those taken from steel traps, or picked upon highways after having been killed by automobiles. The records are:

51. Thrassis acamantis Rothschild 1905, stray from groundhog, Grand Dalles, Klickitat County, Washington, April 16, 1932, small series of both sexes.

69. Diamanus montanus Baker 1904, stray from gray digger, Fall Creek, Lane County, Oregon, September 2, 1981, 5 males, 4 females; Odell, Hood River County, Oregon, February 16, 1939, 6 males, 8 females.

119. Monopsyllus ciliatus protinus Jordan 1929, stray from chipmunk, Gaston, Washington County, Oregon, March 1, 1939, a small series of both sexes.

CALIFORNIA-As early as 1909 Carroll Fox reports that:

4. Pulex irritans Linnaeus 1758 ". . . seems to be a constant parasite of Mephitis occidentalis (skunk)" in the county of San Francisco.

Augustson reports off the common skunk taken in Los Angeles County:

4. Pulex irritans Linnaeus 1758 , human flea

25. Orchopeas s. sexdentatus Baker 1904, wood rat flea

69. Diamanus montanus Baker 1895, ground squirrel flea.

MONTANA-Off the common skunk:

51. Thrassis acamantis Rothschild 1905, marmot flea

81. Oropsylla arctomys Baker 1904, marmot flea. 
ARIZONA-Originally described off skunk from Paradise:

63. Thrassis pansus Jordan 1925

123. Monopsyllus eumolpi cyrturus Jordan 1929

130. Pleochaetis sibynus Jordan 1925.

BRITISH COLUMBIA-Off the common skunk:

51. Thrassis acamantis Rothschild 1905, marmot flea

219. Hystrichopsylla g. dippiei Rothschild 1902, mouse flea.

\section{Mustela •}

\section{Mustela longicauda arizonensis Mearns}

\section{Mountain WEASEL}

A male and a female of this large weasel were taken a short distance apart in small box traps used for deer mice, the smell of the mice probably attracting the weasels. The catches were made at Coleman's Ranch, Washoe County, Nevada (25 miles southeast of Adel, Oregon), June 27, 1937. From these specimens were secured:

86. Foxella ignota recula J. and R. 1915, pocket gopher flea, 18 pairs

114. Monopsyllus wagneri wagneri Baker 1904, Great Basin deer mouse flea, 2 males, 5 females.

A single specimen taken at Lostine, Wallowa County, Oregon, August 8, 1938, was infested with:

79. Oropsylla idahoensis Baker 1904, ground squirrel flea, 21 males, 8 females

86. Foxella ignota recula J. and R. 1915, pocket gopher flea, 3 males, 12 females

108. Megabothris abantis Rothschild 1905, 2 males.

From a specimen taken at Pine City, Mono County, California, in 1922 by A. B. Howell, the following fleas were originally described:

27. Orchopeas sexdentatus nevadensis Jordan 1929 .

53. Thrassis howelli howelli Jordan 1925.

\section{Mustela cicognani muricus Bangs \\ SIERRA LEAST WEASEL}

A specimen trapped in a gopher trap from a gopher burrow at Friend, Wasco County, Oregon, May 17, 1937 was infested with:

86. Foxella ignota recula $\mathrm{J}$. and R. 1915, pocket gopher flea, 2 females.

A specimen taken from $A$. r. rufa (mountain beaver) burrow at Fall Creek, Lane County, Oregon, January 10, 1932 was infested with:

98. Malaraeus telchinum Rothschild 1905, stray from a deer mouse, 1 male.

A specimen taken at Summer Lake, Lake County, Oregon, June 17, 1937 was infested only with:

114. Monopsyllus wagneri wagneri Baker 1904, deer mouse flea, 1 male, 1 female.

\section{Mustela cicognani streatori Merriam \\ Puget Sound Least Weasel}

A specimen of this weasel trapped in a burrow of $A$. $r$. pacifica (mountain beaver) was infested with:

86. Foxella ignota recula J. and R. 1915, pocket gopher flea, Devil's Lake, Lincoln County, Oregon, January 28, 1939, 1 male, 1 female. 


\section{Mustela longicauda saturata Merriam \\ Cascade Weasel}

Specimens of this weasel examined at Tillamook, Tillamook County, Oregon, November 23, 1939 were infested with:

28. Orchopeas sexdentatus cascadensis Jordan 1939, wood rat flea, 3 males, 4 females.

\section{OTHER WESTERN WEASELS}

MONTANA-The following 17 fleas have been taken off the various weasels in various parts of the state. The writer believes this is the largest listing off weasels from any source:

4. Pulex irritans Linnaeus 1758 , human flea

26. Orchopeas s. agilis Rothschild 1905, wood rat flea

35. Orchopeas c. caedens Jordan 1925, squirrel flea

43. Opisodasys vesperalis Jordan 1929, flying squirrel flea

48. Thrassis pandorae Jellison 1937, ground squirrel flea

70. Opisocrostis $t$. tuberculatus Baker 1904, ground squirrel flea

71. Opisocrostis t. cynomuris Jellison 1939, prairie-dog flea

- 75. Opisocrostis labis J. and R. 1922, ground squirrel flea

76. Opisocrostis hirsutus Baker 1895, prairie-dog flea

79. Oropsylla idahoensis Baker 1904, ground squirrel flea

80. Oropsylla rupestris Jordan 1929

Foxella ignota ssp., pocket gopher flea

94a. Dactylopsylla nuditenacula Prince 1945, pocket gopher flea

108. Megabothris abantis Rothschild 1905, mouse flea

114. Monopsyllus w. wagneri Baker 1904, deer mouse flea

122. Monopsyllus e. eumolpi Rothschild 1905, chipmunk flea

218. Rectofrontia fraterna Baker 1895

229. Nearctopsylla brooksi Rothschild 1904, shrew flea.

NORTH DAKOTA-The following fleas are reported off weasels from this state:

90. Foxella $i$. albertensis J. and R. 1915, pocket gopher flea

184. Epitedia wenmanni Rothschild 1904, mouse flea.

BRITISH COLUMBIA-Reported off weasels:

86. Foxella ignota recula J. and R. 1915, pocket gopher flea

114. Monopsyllus w. wagneri Baker 1904, deer mouse flea

229. Nearctopsylla brooksi Rothschild 1904, shrew flea.

\section{ALBERTA:}

26. Orchopeas s. agilis Rothschild 1905, wood rat flea

35. Orchopeas c. caedens Jordan 1925, squirrel flea

75. Opisocrostis labis J. and R. 1922, ground squirrel flea

108. Megabothris abantis Rothschild 1905, mouse flea

111. Megabothris atrox Jordan 1925

203. Peromyscopsylla h. hamifer Rothschild 1906

229. Nearctopsylla brooksi Rothschild 1904, shrew. flea

231. Nearctopsylla h. hygini Rothschild 1904

219. Hystrichopsylla g. dippiei Rothschild 1902, mouse flea.

\section{Spilogale}

\section{Littre Spotted Skunk}

OREGON-A male and a female specimen of this animal were taken from the same Aplodontia rufa pacifica (mountain beaver) burrow at Coaledo, Coos County, August 21, 1937. From them were secured: 
28. Orchopeas sexdentatus cascadensis Jordan 1939, stray from pack rat, 9 males, 9 females

160: Catallagia charlottensis Baker 1898, stray from Microtus, 1 male. with:

A specimen secured at Gaston, Washington County, March 5, 1932 was infested

28. Orchopeas sexdentatus cascadensis Jordan 1939, stray from pack rat, 3 males, 4 females.

CALIFORNIA-Off the California little spotted skunk have been reported:

17. Anomiopsyllus nudatus Baker 1904, wood rat flea, Claremont, Los Angeles County

18. Anomiopsyllus falsicalifornicus Fox 1929, wood rat flea, Jamesburg, Monterey County

19. Anomiopsyllus congruens Stewart 1940, Jamesburg, Monterey County

157. Atyphloceras longipalpus Stewart 1940, Jamesburg, Monterey County

145. Amphipsylla neotomae I. Fox 1940, wood rat flea, Riverside County.

ARIZONA-The original description of the following flea comes off a little spotted skunk taken at Paradise:

207. Phalacropsylla paradisea Rothschild 1915.

BRITISH COLUMBIA-The little spotted skunk is known to carry the following fleas in this Canadian province:

32. Orchopeas nepos Rothschild 1905, squirrel flea

52. Thrassis spenceri Wagner 1936

171. Megarthroglossus procus J. and R. 1915, squirrel flea.

\section{Taxidea}

BADGER

During July, 1942, a badger was examined southwest of Jordan Valley, Malheur County, Oregon. From it were removed 2 ticks. This pool of ticks was pronounced plague-positive by the Plague Suppressive Measures Laboratory at San Francisco and the record is the only known evidence of plague against this animal.

MONTANA-The following 2 fleas are recorded off the badger from this state:

4. Pulex irritans Linnaeus 1758 , human flea

51. Thrassis acamantis Rothschild 1905, marmot flea.

CALIFORNIA-Mr. Augustson reports off a badger taken in San Bernardino County.

1. Echidnophaga gallinacea Westwood 1875, hen flea.

\section{Urocyon and Vulpes}

\section{Gray Fox-Red Fox-Desert Fox}

OREGON-From the Oregon gray fox taken in Benton County during December, 1940, the writer has collected:

7. Ctenocephalides canis Curtis 1826, dog flea

16. Cediopsylla i. interrupta Jordan 1929, rabbit flea

150. Odontopsyllus dentatus Baker 1904, rabbit flea.

CALIFORNIA-Off the California gray fox, Gus Augustson reports the following fleas, from Los Angeles County:

1. Echidnophaga gallinacea Westwood 1875, hen flea

4. Pulex irritans Linnaeus 1758 , human flea

6. Ctenocephalides felis Bouche 1835, cat flea

7. Ctenocephalides canis Curtis 1826, dog flea

16. Cediopsylla i. interrupta Jordan 1929, rabbit flea

150. Odontopsyllus dentatus Baker 1904, rabbit flea. 
Off the California desert fox Augustson reports from San Bernardino County: 4. Pulex irritans Linnaeus 1758 , human flea.

ARIZONA-Augustson reports off the desert fox in Yuma County:

1. Echidnophaga gallinacea Westwood 1875 , hen flea.

MONTANA-Off a blue fox from a fox ranch in Park County:

7. Ctenocephalides canis Curtis 1826. 


\section{THE FLEAS OF WESTERN INSECTIVORA}

\section{The Moles}

The presence of moles can always be detected by their characteristic mounds which differ from those of pocket gophers in being round, with the soil flowing from the center, while the pocket gopher pushes the soil out of the burrow, generally building a crescent-shaped hill, the distinct burrow plug always being present. Moles are not easy to trap. The "Out of Sight Mole Trap" recommended by the Bureau of Biological Survey is probably the surest method of securing specimens, but even these the moles will avoid unless every care is used in setting the traps. A good string of these traps carefully set will bring satisfactory results.

Young moles are born about April first in the greater portion of their western range. By mid June these are shifting for themselves. At this time they may seem to burrow out of the ground and have difficulty re-entering the soil. Many of them die above ground and if one is alert, these can be picked up along highways and roads in good numbers. If they have not been dead too long, many fleas can be picked off them.

The writer's records for moles in the West follow:

\section{Scapanus latimanus alpinus Merriam Mazama Mole}

OREGON-Ranges north from Crater Lake to the Three Sisters. From a specimen taken at Little Lava Lake, July 27,1936 , the writer secured:

160. Catallagia charlottensis Baker 1898, 3 males

223. Corypsylla ornata Fox 1908, 4 males, 3 females.

\section{Scapanus latimanus dilatus True \\ Silver or Klamath Mole}

OREGON-Ranges throughout south central part according to the records, but the specimens collected by the writer are from a few miles south of The Dalles. From these he removed:

223. Corypsylla ornata Fox 1908, from 1 specimen collected at 8 Mile Creek, The Dalles, May 22, 1937, 1 male, 2 females; from 1 specimen collected at Tygh Valley, May 23, 1937, 3 males, 14 females.

Scapanus orarius orarius True

\section{COAST MOLE}

OREGON-This is the smaller mole ranging west of the crest of the Coast Range and in a limited way found in the Willamette Valley. The writer's records are from 2 specimens taken at Cannon Beach, March 28, 1937, from which were removed:

185. Epitedia jordani Hubbard 1940, 1 male

223. Corypsylla ornata Fox 1908, 2 males, 13 females 224. Nearctopsylla jordani Hubbard 1940, 1 male. 


\section{Scapanus townsendi Bachman TownSEND's Mole}

OREGON-Ranges everywhere west of the Cascade Mountains in Oregon. Records from numerous specimens throughout the Willamette Valley list:

223. Corypsylla ornata Fox 1908, as the chief flea, with

227. Nearctopsylla jordani Hubbard 1940, and

185. Epitedia jordani Hubbard 1940, occasionally found.

An interesting record for this mole is from 1 female taken at Cannon Beach, March 21, 1940, from which were removed 105 fleas, as follows:

223. Corypsylla ornata Fox 1908, 25 males, 67 females

227. Nearctopsylla jordani Hubbard 1940, 1 male, 1 female

185. Epitedia jordani Hubbard 1940, 7 males, 4 females.

WASHINGTON-In the southwestern portion of the state, west of the crest of the Cascade Mountains, is found the smaller Scapanus orarius orarius True (Coast mole), and the larger Scapanus townsendi Bachman (Townsend mole), both of which are infested with:

223. Corypsylla ornata Fox 1908, during the trapping year

185. Epitedia jordani Hubbard 1940, during the early spring

227. Nearctopsylla jordani Hubbard 1940.

In the northwestern portion of the state and in favorable locations in the eastern portion is found Scapanus orarius schefferi Jackson (Scheffer mole). West of the crest of the Cascades the flea infestation for this mole is the same as for the preceding Washington forms.

CALIFORNIA-In 1908 Carroll Fox described:

223. Corypsylla ornata

from Scapanus californicus Bangs taken at San Francisco. This flea infests all species and subspecies of moles from this point north to the British Columbia line, and probably as far north on the west coast as moles are found.

From a female flea taken off Scapanus latimanus ssp. at Jamesburg, Monterey County, during July, 1938, was described:

225. Corypsylla setosifrons Stewart 1940.

From a series of Scapanus orarius orarius True (Coast mole) taken by the writer during 1939-1940-1943 at Fort Dick, Del Norte County, the following fleas were secured:

223. Corypsylla ornata C. Fox 1908

227. Nearctopsylla jordani Hubbard 1940.

BRITISH COLUMBIA-From the moles about Vancouver, the following fleas have been removed:

Neopsylla scapani Wagner 1936

223. Corypsylla ornata C. Fox 1908

227. Nearctopsylla jordani Hubbard 1940.

\section{Neurotrichus gibbsi gibbsi Baird GiBb's SHREw Mole}

This small mole is about 2 inches in body length and jet black in color. It runs small burrows but seems to build no mounds. It is found west of the Cascades from northern California north to southwestern British Columbia. It is seldom seen and is considered rare. In vicinities where its burrows can be found under boards, many of the tiny moles can be taken in half-gallon' jars sunk under their burrows. The jars should not be baited; they act as simple pit-falls in which the animals fall and from which they or their fleas cannot escape. 
OREGON-At Gaston, the writer captured 40 specimens of this tiny mole in 4 jars during February and March, 1940. From the 40 animals, 95 fleas were removed. Gibb's shrew mole seems to carry but 1 flea of its own:

224. Corypsylla jordani Hubbard 1940, of which the writer secured 32 males and 46 females from the 40 specimens, besides 8 males and 9 females of

185. Epitedia jordani Hubbard 1940, a vicariating species found occasionally upon shrews, moles, and mice in the spring of the year.

A male of the flea:

170. Delotelis telegoni Rothschild 1905, was removed off these small moles during December, 1940. The mole carrying this flea was taken in a pitfall at Gaston, Washington County.

WASHINGTON-At Vancouver, Clark County, on September 5, 1941, 2 of these small moles were taken in a pit-fall placed under a log. A male and a female of the following flea were the only ones found upon the animals:

224. Corypsylla jordani Hubbard 1940.

CALIFORNIA-During April, 1942, the writer established a series of pit-falls about the forest camp at Elk Creek out of Gasquet, Del Norte County. Into these tumbled several of these small moles. The writer removed from them only several pairs of:

224. Corypsylla jordani Hubbard 1940.

\section{THE SHREWS}

Shrews are generally abundant about swales, waterways, and meadows. They can be trapped in small live-catch box traps baited with fried bacon and oatmeal. Half-gallon jar pit-falls placed under runways catch many. Snap traps can be used if they are visited frequently by the trapper. Shrews will play under old doors and planks that have - lain on the ground for long periods of time. The writer has taken many out from under such shelter in small box traps during all hours of the day. They soon die even in live-catch box traps; the sets should be visited often.

\section{Sorex bendirii palmeri Merriam \\ Palmer's Water Shrew}

OREGON-These are the largest of the Oregon shrews. The writer has occasionally taken them about waterways in live-catch box traps. They usually worry themselves to death in the trap and are cold and without fleas upon examination. At Cannon Beach, March 29, 1937 a specimen was taken alive. Upon it were found:

185. Epitedia jordani Hubbard 1940, and

160. Catallagia charlottensis Baker 1898.

\section{Sorex trowbridgi trowbridgi Baird}

\section{TROWBRIDGE SHREW}

This long-tailed medium sized, almost black shrew is at home west of the Cascades from British Columbia south to northern California. The writer has records from Washington, Oregon, and California. Its most common flea is:

211. Doratopsylla jellisoni Hubbard 1940.

Common in its season is:

185. Epitedia jordani Hubbard 1940. 
As strays, the writer records:

116. Monopsyllus wagneri ophidius Jordan 1929

160. Catallagia charlottensis Baker 1898

153. Atyphloceras multidentatus Fox 1909.

\section{Sorex obscurus bairdi Merriam}

BaIro's DUSKY SHREW

This medium sized all-brown shrew is found all over Oregon west of the Cascade Mountains. From many specimens the writer records:

211. Doratopsylla jellisoni Hubbard 1940

185. Epitedia jordani Hubbard 1940

226. Corypsylloides kohlsi Hubbard 1940.

\section{Sorex pacificus yaquinae Jackson Yaquina SHREW} only:

This shrew is found around Yaquina Bay, Oregon. From it the writer records

185. Epitedia jordani Hubbard 1940.

\section{Sorex vagrans vagrans Baird \\ VAGRANT SHREW}

This shrew which lives west of the Cascades in northern California, Oregon, Washington, and southwestern British Columbia, is tobacco-brown above and grayish below. Its most common flea is:

211. Doratopsylla jellisoni Hubbard 1940, with an occasional

185. Epitedia jordani Hubbard 1940.

\section{Sorex pacificus pacificus Coues \\ PACIFIC SHRew}

CALIFORNIA-This shrew is limited in range to the coastal strip of southwestern Oregon and northwestern California. The writer's records come from Smith River, Del Norte County, where on June 16, 1940, from a pair taken from under the same log, he took:

211. Doratopsylla jellisoni Hubbard 1940, 6 males, 4 females

185. Epitedia jordani Hubbard 1940, 2 males, 1 female

213. Leptopsylla segnis Schonhier 1811, 1 male

200. Peromyscopsylla selenis Rothschild 1906, 1 female.

From a shrew of this species which had tumbled into a pit-fall at Smith River, Del Norte County on January 6, 1942 the writer removed a male and 2 females of:

226. Corypsylloides kohlsi Hubbard 1940.

\section{Neosorex palustris navigator Baird}

From the central Sierra-Nevada Mountains, Augustson records:

171. Megarthroglossus procus J. and R. 1915. This shrew was taken at Tully's Hole, Fresno County, California.

212. Doratopsylla c. curvata Rothschild 1915, is reported off shrews from Montana, British Columbia, and Alberta.

Doratopsylla c. obtusata Wagner 1929, was described off a shrew taken at Abbotsford, British Columbia.

228. Nearctopsylla hyrtaci Rothschild 1904, was: reported off Sorex obscurus from Cariboo, British Columbia. 


\section{THE FLEAS OF WESTERN BATS}

Bats can be secured for their fleas by any one of 3 methods: Shooting at dusk with a shotgun, the load to be very fine shot, is an excellent method. Netting is favored by some collectors. The quickest method, and surest, if it can be accomplished, is to find the sleeping quarters of the bats. The writer has scooped up as many as 25 in the space covered by a shoe box. These sleeping quarters may be attics, caves, hollow trees, cupolas, almost any place that gives the bats protection from the light of day.

In the collection of the writer are 2 species of bat fleas:

\section{OREGON:}

231. Myodopsylla gentilis J. and R. 1921, from Myotis yumanensis sociabilis Grinnell, a series at Narrows, Harney County, July 18, 1937; from Myotis lucifugus alascensis Miller, a series at Forest Grove, Washington County, February 20, 1940; from Myotis yamanensis saturatus Miller, a series at Tillamook, Tillamook County, August 8, 1938

234. Nycteriodopsylla vancouverensis Wagner 1936, from Myotis lucifugus alascensis Miller, Forest Grove, Washington County, March 22, 1939, 2 males; a series at Forest Grove, March 25, 1940; Corvallis, Benton County, April 6, 1939, 1 female.

WASHINGTON-Twenty-five specimens of Corynarhinus rafinesque townsendi Cooper (jack-rabbit bat) collected at Kalama; July 8, 1940:

231. Myodopsylla gentilis J. and R. 1921, a series.

CALIFORNIA-Augustson lists 4 species of bat fleas from southern California:

231. Myodopsylla gentilis J. and R. 1921, off Myotis occultus taken at Blythe, Riverside County

232. Myodopsylla collinsi Kohls 1937, off Myotis velifer velifer taken in the Riverside Mountains, Riverside County

235. Sternopsylla texana C. Fox 1914, off Eumops perotis californicus and Tadarida mexicana taken in city of Los Angeles,

Under the name of:

233. Myodopsylloides piercei Augustson 1941, which is a synonym of

233. Myodopsylloides palposa Rothschild 1904, off Corynorhinus rafinesqui intermedius taken on Santa Cruz Island, Santa Barbara County; and off Antrozous palidus pacificus taken from San Gabriel Mountains, Los Angeles County; and from San Jose; Santa Clara County.

TEXAS-Described off the bat Tadarida mexicana taken at Pecos is the flea: 235. Sternopsylla texana C. Fox 1914.

COLORADO-The writer has determined bat fleas from Fort Collins as: 231: Myodopsylla gentitis J. and R. 1921.

MONTANA-Off Myotis lucifugus carissima taken in Beaverhead County: 231. Myodopsylla gentilis J. and R. 1921; is recorded. 
BRITISH COLUMBIA-The following fleas have their original descriptions coming off various bats:

231. Myodopsylla gentilis J. and R. 1921, off "bat" taken at Okanagan Landing

234. Nycteridopsylla vancouverensis Wagner 1936, off Lasionycteris noctivagans taken at Vancouver

233. Myodopsylloides palposa Rothschild 1904, off "brown bat" taken at - Cowichan.

\section{MISCELLANEOUS MAMMALIAN HOSTS}

The writer has specimens of the flea:

4. Pulex irritans Linnaeus 1758, taken off deer in several parts of Oregon, and Augustson reports the same flea off deer in California.

Augustson reports off the opossum in San Diego County, California:

4. Pulex irritans Linnaeus 1758

7. Ctenocephalides canis Curtis 1826

16. Cediopsylla i. interrupta Jordan 1929.

Off the Pecari in Texas was described:

5. Juxtapulex porcinus J. and R. 1923. 


\section{FLEAS REPORTED FROM MAN}

Tendencies in the United States and Canada do not foster a wide range of flea species from man. The large concentrations of population in cities where the wild rodents and their fleas do not range has had a tendency to bring on man only what we might term the domestic fleas, that is, the human flea, the cat and dog fleas, the chicken fleas, and occasionally a rat flea. The great amount of space covered by forests, deserts and wastes are generally shunned by man, naturally the large variety of fleas in these parts do not contact him. Farms generally are no longer small. Modern machinery has made it possible for a few men to work very large acreages. Most of this machinery is of the riding type, so the agriculturist no longer plods through the fields to pick up wild fleas as he goes.

But as time passes and more persons migrate from the cities to the soil, and as our population grows more, people will come into regions where they will be contacted by our wild native fleas. Naturally, then, as time passes, more and more of our native fleas will be recorded taken off man. At the present time flea records from man are not extensive. Those to come to the attention of the writer follow:

CALIFORNIA-As early as August, 1908, R. W. Doane of Stanford University reports on fleas of man as follows: " 220 specimens of Pulex irritans Linn., were taken from human hosts or on their clothing in the plague laboratory and hospital and in the refugee camps where human plague cases were of frequent occurrence, $\langle 1 \mathrm{P}$. ir. ritans was from the body of a Chinaman who had died of the plague), and 2 Ceratophyllus fasciatus."

Mitzmain during June, 1909, reported the following fleas off man in California:

1. Echidnophaga gallinacea Westwood, sticktight hen flea

4. Pulex irritans Linnaeus, human flea

6. Ctenocephalides felis Bouche, cat flea

7. Ctenocephalides canis Curtis, dog flea

105. Nosopsyllus fasciatus Bosc, European rat flea

131. Ceratophyllus n. niger C. Fox, western chicken flea.

During September, 1943, Gus Augustson reports the following fleas off man in Los Angeles County:

1. Echidnophaga gallinacea Westwood

4. Pulex irritans Linnaeus

6. Ctenocephalides felis Bouche

7. Ctenocephalides canis Curtis

69. Diamanus montanus Baker.

During June, 1938, the writer received a parcel of fleas taken off man at Crescent City, Del Norte County, which contained the human flea, and the cat and dog flea. 
OREGON-The writer reports off man:

4. Pulex irritans Linnaeus, human flea

6. Ctenocephalides felis Bouche, cat flea

7. Ctenocephalides canis Curtis, dog flea

131. Ceratophyllus n. niger C. Fox, western chicken flea

144. Dasypsyllus g. perpinnatus Baker, a bird flea.

To the north and east in Washington, British Columbia, and Alberta, the human flea, the cat and the dog fleas are reported often off man. The writer has seen all 3 fleas taken from homes at Brookings, South Dakota. States:

Irving Fox reports the following fleas off man in the eastern part of the United

Echidnophaga gallinacea Westwood, sticktight hen flea

Pulex irritans Linnaeus, human flea

Ctenocephalides felis Bouche, cat flea

Ctenocephalides canis Curtis, dog flea

Xenopsylla cheopis Rothschild, Oriental rat flea

Hoplopsyllus affinis Baker, a rabbit flea

Cediopsylla simplex Baker, a rabbit flea

Orchopeas howardi Baker, a squirrel flea

Ceratophyllus gallinae Shrank, a bird flea.

In the southeastern portion of the United States it has been suggested that the "jigger" or "chigoe" has been found on man. This flea is (3). Tunga penetrans Linnaeus 1758. Of it Ewing and Fox say in 1943 "Widely distributed in the tropical regions of America and Africa. Although reported from Florida, Louisiana, and Texas, it probably is not permanently established in the United States." 


\section{THE FLEAS OF WESTERN BIRDS}

By far the greatest amount of work on bird fleas in the West comes from Montana and British Columbia. In other sections of the West bird fleas have been badly neglected. Bird fleas seem to hold little interest for the general flea collector. It is true, they are not easy to collect. Only occasionally does a bird actually carry a flea-specimen, and in burrowing birds quite a bit of labor is entailed to dig out the nests. However, bird fleas in most of the West do hold the big field for collecting-it has not been overworked.

It is generally felt by investigators that bird fleas are to be looked for in the bird nest, not on the bird itself. In bird boxes, or in the nests of those which use holes in trees, or burrows in the ground, out of which the fleas cannot easily escape-there the collectors will find good collecting. In the average open bird nest the best method of collecting is to place the nest in a paper sack, keep it slightly damp, then occasionally look for the fleas which will develop out of the larva hidden in the nest.

While there are only 15 true bird fleas so far named from the West, this number is greatly expanded by the presence of numbers of strays on hawks and owls or in their nests, fleas which come to them from their rodent prey. The true bird fleas of the West are:

\footnotetext{
1. Echidnophaga gallinacea Westwood 1875

2. Hectopsylla psittaci Frauenfeld 1860

97. Mioctenopsylla arctica Rothschild 1922

131. Ceratophyllus niger niger C. Fox 1908

132. Ceratophyllus niger inflexus Jordan 1929

133. Ceratophyllus celsus celsus Jordan 1926

134. Ceratophyllus pelecani Augustson 1942

135. Ceratophyllus riparius J. and R. 1936

136. Ceratophyllus idius J. and R. 1920

137. Ceratophyllus garei Rothschild 1902

138. Ceratophyllus diffinis Jordan 1925

139. Ceratophyllus swansoni Lui 1935

140. Ceratophyllus petrochelidoni Wagner 1936

141. Ceratophyllus v. vagabundus Boheman 1866

144. Dasypsyllus g. perpinnatus Baker 1904.
}

It is also suggested that collectors should be on the lookout for:

142. Ceratophyllus gilvus J. and R. 1922, a flea taken off a migrating swallow in Mexico, and for

8. Actenopsylla suavis J. and R. 1923, a flea found in the nest of Cassin's auklet in lower California, but which may be found all along the $\mathrm{Pa}$ cific Coast on this bird. 
OREGON-The writer has taken the following bird fleas:

1. Echidnophaga gallinacea Westwood 1875, not off birds but off deer mice and ground squirrels at The Dalles, Wasco County

131. Ceratophyllus niger niger C. Fox 1908, off chickens in many parts of Oregon

136. Ceratophyllus idius J. and R. 1920, from a bluebird nest box, Tillamook, Tillamook County

144. Dasypsyllus g. perpinnatus Baker 1904, a true bird flea but taken off a mountain beaver, Brookings, Curry County.

CALIFORNIA-Only 3 bird fleas are reported:

1. Echidnophaga gallinacea Westwood 1875, off a large number of birds and rodent hosts from all parts of the state

2. Hectopsylla psittaci Frauenfeld 1860, by Augustson off a great horned owl, San Diego

131. Ceratophyllus niger niger C. Fox 1908 , reported as early as 1909 by Fox and Mitzmain from a whole series of animals and birds around the Bay area.

COLORADO-The bird flea:

132. Ceratophyllus niger inflexus Jordan 1929, was described from Custer County. There is some doubt as to the validity of this subspecies.

MONTANA-Five true bird fleas from nests taken in Beaverhead County:

131. Ceratophyllus niger niger C. Fox 1908, magpie

133. Ceratophyllus celsus celsus Jordan 1926, bank swallow

135. Ceratophyllus riparius J. and R. 1920, bank swallow

137. Ceratophyllus garei Rothschild 1902, ringneck pheasant

139. Ceratophyllus swansoni Lui 1935, long-eared owl.

The following stray fleas have been taken from birds or their nests:

4. Pulex irritans Linnaeus 1758, human flea, off domestic fowl, Gallatin County; off burrowing owl, Beaverhead County

20. Anomiopsyllus montanus Collins 1936, off great horned owl, Ravalli County

26. Orchopeas s. agilis Rothschild 1905, wood rat flea off great horned owl, Beaverhead County

48. Thrassis pandorae Jellison 1937, ground squirrel flea off burrowing owl, Beaverhead County

71.'Opisocrostis t. cynomuris Jellison 1939, prairie-dog flea off burrowing owl, Custer County

79. Oropsylla idahoensis Baker 1904, ground squirrel flea off long-eared owl, great horned owl, Buteo sp., hawk, magpie, Beaverhead County.

The following additional stray fleas. were taken from the nests of Speotyto cunicularia (burrowing owls) in Beaverhead County: Foxella ignota ssp., pocket gopher flea

114. Monopsyllus w. wagneri Baker 1904, deer mouse flea

126. Monopsyllus e. exilis Jordan 1937, grasshopper mouse flea

186. Neopsylla inopina Rothschild 1915, ground squirrel flea.

UTAH-From Steganopus tricolor or Spatula clypeata taken at the mouth of Bear River, Chapin described the flea:

Ceratophyllus utahensis but this designation has been pronounced a synonym of

137. Ceratophyllus garei Rothschild 1902.

WASHINGTON-The common western chicken flea:

131. Ceratophyllus niger niger C. Fox 1908, is found the chief chicken flea in this state. 
GENERAL-1. Echidnophaga gallinacea Westwood 1875, tropical hen or sticktight flea, has a wide distribution over the southwest. The writer has seen specimens from Arizona and New Mexico.

BRITISH COLUMBIA-Seven true bird fleas are recorded so far from this Canadian province:

196. Ceratophyllus idius J. and R. 1920, off Iridoprocne bicolor, Okanagan Landing

138. Ceratophyllus diffinis Jordan 1925, off Colymbus holboelli, Okanagan Falls

133. Ceratophyllus celsus celsus Jordan 1926, off Riparia riparia, Okanagan Falls

140. Ceratophyllus petrochelidoni Wagner 1936, off Petrochelidon lunifrons, Chilcotin

144. Dasypsyllus g. perpinnatus Baker 1904, no host data, Queen Charlotte Islands.

Other bird fleas reported from this province are:

131. Ceratophyllus niger niger C. Fox 1908, general distribution, off chickens

135. Ceratophyllus riparius J. and R. 1920, off Riparia riparia, Okanagan Falls.

ALBERTA-The following bird fleas are reported:

131. Ceratophyllus niger niger C. Fox 1908, off turkeys and chickens in many localities

137. Ceratophyllus garei Rothschild 1902.

ALASKA-Four bird fleas recorded:

- 97. Mioctenopsylla arctica Rothschild 1922, from Sabin gull at Puffin Island

131. Ceratophyllus niger niger C. Fox 1908, from herring gull nest at Skilak Lake

137. Ceratophyllus garei Rothschild 1902, from ptarmigan at Mills Creek

141. Ceratophyllus vagabundus Boheman 1865, from golden eagle at Rapids.

Dr. William L. Jellison, working upon sylvatic plague in relation to its epidemiology in predatory and scavenger birds, reports in his summary on p. 798 of Public Health Reports, Vol. 54, as follows:

"Field and laboratory observations bearing on the possible relationship of flesh-eating birds to the epidemiology of sylvatic plague have been made in a plague epizootic area in southwestern Montana. Predatory species, especially, transport flea-infested rodents and serve as accidental hosts of rodent fleas. The abundance and variety of rodent fleas found in the nest of a burrowing owl suggests that this species may prove of particular interest. Casts from predatory birds fed plagueinfected guinea pig tissue were consistently infectious. Infection was not demonstrated in 2 instances in which portions of a plague-infested ground squirrel found dead in nature were used for the infective feedings. Tests on the infectivity of feces of birds being fed plague tissue were consistently negative, but were restricted to a few species." 


\section{BIBLIOGRAPHY}

This selected bibliography is prepared to follow that built into "Index to the Literature of Siphonaptera of North America" by Jellison and Good, which is National Institute of Health Bulletin, No. 178, and which can be purchased from the superintendent of documents, Washington, D. C., for 25 cents. The selections which follow are those on western fleas which have been published since July 1, 1939, the closing date for entries in the above "Index."

Augustson, Gus F.

1941. A new Geusibia (siphonaptera: Dolichopsyllidae). Bul. So. Calf. Acad. Sci. 39:203-204.

1941. Contributions from the Los Angeles Museum Channel Islands biological survey. No. 20. Three new fleas (Siphonapțera). Bul. So. Calif. Acad. Sci. 40:101-107.

1942. A new flea from the Mohave Desert (California). Bul. So. Calif. Acad. Sci. 40:138-139.

1942. Some new California Siphonaptera. Bul. So. Calif. Acad. Sci. 40:140-146.

1942. Ectoparasite-host records from the Sierran region of east central California. Bul. So. Calif. Acad. Sci. 40:147-157.

1942. The allotype of Amphipsylla neotomae. I. Fox, 1940 (Siphonaptera: Dolichopsyllidae). Bul. So. Calif. Acad. Sci. 41:39-41.

1942. A new flea of the genus Ceratophyllus. Trans. San Diego Soc. Nat. Hist. 9 (37) : $437-438$.

1942. A new subspecies of Foxella ignota (Baker) from California (Siphonaptera: Dolichopsyllidae). Bul. So. Calif. Acad. Sci. 41 (2) : 69-71.

1943. A new subspecies of Orchopeas sexdentatus (Baker) (Siphonaptera: Dolichopsyllidae). Bul. So. Calif. Acad. Sci. 42:49.

1943. Preliminary records and discussion of some species of Siphonaptera from the Pacific Southwest. Bul. So. Calif. Acad. Sci. 42:69.

1944. The flea genus Thrassis and sylvatic plague, with the description of $T$. brennani. N. Sp. Jour. Parasitology 30:237.

BurRoughs, A. L.

1944. The flea Malaraeus telchinum a vector of $P$. pestis. Proc. Soc. Exp. Bio. and Med. 55:10.

\section{Dampf, Alfonso}

1925. Ectoparasitos Del Perro, Collectados En Los Meses De Julio a Noviembra De 1924 Por El Servicio De Desinfecuon Y Desinsectizacion Del Departmento De Salubridad Publica De Mexico. Boletin Del Departamento e Salubridad Publica (Mexico). 2:33-42. 4 figs.

1942. Nuevos Datos Sobre La Pulga Pleochaetis mundus (J. and R.) Revista de la Sociedad Mexicana de Historis Natural Vol. III. Nos. 1-4.-Diciembre, 1942 , p. 135.

1942. Dos Nuevas Pulgas Mexicanas del Genero “Opisodasys" Jordan, 1933. Rev. Brasil. Biol., 2 (4) : 495 Dezembro, 1942. 
ESKEY, C. R. AND V. H. HAaS

1939. Plague in the western part of the United States. Infection in rodents, experimental transmission by fleas, and inoculation tests for infection. U. S.

EWING, HenRy E. Pub. Health Rpt. 54 (32) :1467-1481.

1940. New North American Siphonaptera. Proc. Biol Soc. Wash. 53:35. , AND IRving Fox

1943. The fleas of North America. U.S.D.A. Misc. Pub. No. 500.

Fox, IRving

1939. New species and a new genus of Nearctic Siphonaptera. Proc. Ent. Soc. Wash. 41:45-50.

1939. New species and records of Siphonaptera from Mexico. Iowa State College Jour. Sci. 13:335:339.

1940. Notes on North American Dolichopsyllid Siphonaptera. Proc. Ent. Soc. Wash. 42:64-69.

1940. Fleas of Eastern United States. Iowa State College Press, 191 pp., 166 figs.

1940. Siphonaptera from western United States. Jour. Wash. Acad. Sci. 30:272275.

1941. The Siphonapteran thorax. Proc. Ent. Soc. Wash. 43:6-11.

1941. A new Opisodasys from Idaho. Ent. News 52:45-47. AND H. E. EWING

1943. The fleas of North America. U.S.D.A. Misc. Pub. No. 500.

Good, Newell E.

1942. Key to the males of the genus Atyphloceras, with a description of the male of Atyphloceras echis. Pan-Pac. Ent. 18:87-89.

1943. An evaluation of the genus Stenistomera. Proc. Ent. Soc. Wash. 44:133.

- AND William L. Jellison

1942. Index to the literature of Siphonaptera of North America. U. S. Pub. Health Ser., Nat. Inst. Health Bul. 178.

HAAS, V. H. AND C. R. EsKeY

1939. Plague in the western part of the United States. U. S. Pub. Health Rpts. $54(32): 1467$.

Holland, George P.

1939. Phenomenal infestation of ectoparasites on marmot, weasel, and packrat. Proc. Ent. Soc. B. C. Feb. 1939.

1940. New records of Siphonaptera from British Columbia. Proc. Ent. Soc. B. C. No. 36.

1941. A survey of the rat fleas of the southern B. C. coast with relation of plague studies. Proc. Ent. Soc. B. C. No. 37.

1943. A remarkable instance of retention of a double spermatheca in a Dolichopsyllid flea, Opisocrostis brunneri (Baker). Can. Ent. Sept. 1943, pp. 175-176.

1944. The distribution of some plague-important rodents and fleas in western Canada. Proc. Ent. Soc. B. C. 41:5.

1944. Notes on some northern Canadian Siphonaptera, with the description of a new species. Can. Ent. 76:242.

1939. Siphonaptera of western Canada in relation to sylvatic plague. Proc. Sixth Pac. Sci. Cong. 5:125.

AND M. A. Stewart

1940. A new genus of the family Dolichopsyllidae (Siphonaptera) from Canada. Can. Ent. 72:41. 
Hubbard, C. Andresen

1940. West Coast crested fleas Corypsylla and Nearctopsylla. Pac. Univ. Bul. Vol. 37, No. 1.

1940. American mole and shrew fleas. Pac. Univ. Bul. Vol. 37, No. 2.

1940. West Coast Catalagias. Pac. Univ. Bul. Vol. 37, No. 3.

1940. A check list of the fleas of the Pacific Northwest. Pac. Univ. Bul. Vol. 37, No. 4.

1940. A review of the fleas of the genus Meringis. Pac. Univ. Bul. Vol. 37, No. 5.

1940. A review of the western fleas of the genus Malaraeus and the description of a new Thrassis from Nevada. Pac. Univ. Bul. Vol. 37, No. 6.

1941. Fleas of the Yakima ground squirrel. Pac. Univ. Bul. Vol. 37, No. 7.

1941. Ectoparasites of western Lagomorpha. Pac. Univ. Bul. Vol. 37, No. 8.

1941. The fleas of western rare mice. Pac. Univ. Bul. Vol. 37, No. 9A.

1941. History of the flea genus Micropsylla. Pac. Univ. Bul. Vol. 37, No. 10.

1942. A new Thrassis from California and Oregon. Pac. Univ. Bul. Vol. 38, No. 6.

1943. American pocket mouse fleas. Pac. Univ. Bul. Vol. 39, No. 9 .

1943. Three new fleas from Kansas. Pac. Univ. Bul. Vol. 39, No. 10.

1943. The fleas of California. Pac. Univ. Bul. Vol. 39, No. 8.

1943. Our western giant pocket gopher fleas. Pac. Univ. Bul. Vol. 40, No. 2.

Jellison, William L.

1939. Opisodasys Jordan 1933, a genus of Siphonaptera. Jour. Parasitology 25: 413.

1940. Siphonaptera: notes on two California species. Health Rpts. 55:489.

1941. Siphonaptera: The genera Amphalius and Ctenophyllus in North America. Pub. Health Rpts. 56:2341.

$\longrightarrow$, AND N. E. Good

1942. Index to the literature of Siphonaptera of North America. U. S. Pub. Health Ser., Nat. Inst. Health Bul. 178.

Glen M. Kohls, and Harlow B. Mills

1943. Siphonaptera; Species and host list of Montana fleas. Montana State Bd. Ent., Misc. Pub. No. 2.

JORDAN, KARL

1939. On some Nearctic fleas. Nov. Zool. 41:316.

Kohls, Glen M.

1940. Siphonaptera: A study of the species infesting wild hares and rabbits of North America north of Mexico. Nat. Inst. Health Bul. 175.

, William L. Jellison, and Harlow Mills

1943. Siphonaptera: Species and host list of Montana fleas. Montana State Bd. of Ent., Misc. Pub. No. 2.

Mail, Allen, and G. P. Holland

1939. Siphonaptera of western Canada in relation to sylvatic plague. Proc. Sixth Pac. Sci. Cong. 5:125.

MEYER, K. F.

1939. Sylvatic plague. Amer. Jour. Pub. Health 29:1225.

Mills, Harlow B., Wijliam J. Jellison, and Glen F. Kohls

1943. Siphonaptera: Species and host list of Montana fleas. Montana State Bd. of Ent., Misc. Pub. No. 2. 
Prince, Frank M.

1943. Species of fleas on rats collected in states west of the 102nd meridian and their relation to the dissemination of plague. Pub. Health Rpts. 58:700.

1943. Reports on the fleas Opisocrostis brunneri (Baker) and Thrassis bacchi (Roths.) as vectors of plague. Pub. Health Rpts. 58:1013.

1944. Descriptions of three new species of Thrassis Jordan and the females of T. bacchi (Roths.) and T. pansus (Jordan). Pan-Pac. Ent. 20:13.

1945. Descriptions of three new species of Dactylopsylla Jordan and one new subspecies of Foxella Wagner, with records of other species in the genera. Can. Ent. 77:15.

STANFORD, J. S.

1944. More Utah Siphonaptera. Proc. Utah Acad. Sci, Arts and Letters, Vols. 19 and 20, pp. 173-178.

Stewart, M. A.

1940. Estado que guarda el estudio hecho sobre la Transmision de la Peste Silvestre en America del Norte. Sobretiro de la Revista Medicina tomo XXAno XXI-Num. 369. Agosto 10 de 1940, p. 410.

1940. New Siphonaptera of California. Pan-Pac. Ent. 16:17.

-, ANd F. C. Evans

1941. A comparative study of rodent and burrow flea populations. Proc. Soc. Exp. Bio. and Med. 47:140.

AND G. P. Holland

1940. A new genus of the family Dolichopsyllidae (Siphonaptera) from Canada: Can. Ent. 72:41.

SVIHLA, Ruth D.

1941. A list of the fleas of Washington, Univ. of Wash. Pub. In Bio. 12:2:9.

Traub, Robert

1944. New North American Fleas Zoological Series of Field Museum of Natural History 29:15:211.

WAGNER, JuLIUS

1940. Beitrag zur Kenntnis der Flohe von Brit.-Kolumbien. Zeits. fur Parasitenkunde, Bd. 11 (4) : 463. 


\section{SYNONYMIC INDEX}

For the most part this index covers only the period since 1938, the period prior to that date being covered thoroughly by Jellison and Good in their Index to the Literature of Siphonaptera of North America. Although the opinions of synonymy expressed below have come from various western flea students, the author doubts that in any case has the rule been followed that types must be compared with the species in question before synonymy can be established. The following list of 27 items will give, then, an interesting field for investigation to those students interested in synonymy in western fleas. The arrangement below is in numerical sequence by key numbers of the species in question.

11. Hoplopsyllus glacialis tenuidigitus Stewart 1940 has been suggested a dimorphic form of Hoplopsyllus glacialis foxi Ewing, pp. 68, 69.

22. Polygenis sigmodoni Stewart 1930 is Polygenis gwyni C. Fox, p. 87.

66. Thrassis princei Hubbard 1944 is similar to Thrassis fotus Jordan, p. 143.

72. Opisocrostis tuberculatus ornatus I. Fox 1940 is suggestive of Opisocrostis tuberculatus cynomuris Jellison, p. 154.

74. Opisocrostis saundersi Jordan 1933 has been suggested to be Opisocrostis bruneri Baker, pp. 155, 156.

Aetheopsylla S. and H. 1940 has been said to be Oropsylla and its genotype septentrionalis $\mathbf{S}$. and $H .1940$ is suggestive of Oropsylla rupestris Jordan, p. 166.

85. Foxella ignota acuta is thought to be a dimorphic form of Foxella ignota franciscana Rothschild, pp. 173, 175.

87. Foxella ignota coufferi Augustson 1942 is very similar to Foxella ignota recula J. and R., pp. 176, 178.

Augustsonius Hubbard 1940 has been said to be Geusibia Jordan, p. 268.

164. Catallagia motei Hubbard 1940 is thought to be a dimorphic form of Catallagia charlottensis Baker, pp. 285, 290.

165. Catallagia moneris Jordan 1937 is probably a dimorphic form of Catallagia decipiens Rothschild, pp. 288, 291.

167. Catallagia rutherfordi Augustson 1941 is not essentially different from Catallagia chamberlini Hubbard, pp. 289, 292.

168. Catallagia vonbloekeri Augustson 1941 is probably Catallagia chamberlini Hubbard, pp. 289, 292.

181. Delotelis mohavensis Augustson 1941 is Stenistomera alpina Baker, p. 305.

Phaneris Jordan 1939 is the same as Trichopsylloides Ewing, p. 307.

183. Phaneris hubbardi Jordan 1939 is Trichopsylloides oregonensis Ewing, p. 308.

185. Epitedia jordani Hubbard 1940 has been suggested Epitedia scapani Wagner, p. 312. Epitedia stewarti Hubbard 1940 is probably Epitedia jordani Hubbard, p. 312.

Atheropsylla Stewart 1940 is Meringis Jordan, p. 317.

190. Atheropsylla bakeri Stewart 1940 is Meringis cummingi C. Fox, p. 321. 
197. Peromyscopsylla spinifrons I. Fox is Peromyscopsylla hesperomys Baker, p. 329.

200a. Peromyscopsylla duma Traub 1944 is not essentially different from Peromyscopsylla selenis Rothschild, pp. 333, 334.

211. Doratopsylla jellisoni Hubbard 1940 is suggestive of Doratopsylla curvata obtusata Wagner, p. 345.

226. Corypsylloides spinata I. Fox 1940 is Corypsylloides kohlsi Hubbard, p. 367.

227. Nearctopsylla hygini columbiana Wagner 1940 is suggestive of Nearctopsylla jordani. Hubbard, p. 369.

233. Myodopsylloides piercei Augustson 1941 is Myodopsylloides palposa Rothschild, p. 376.

\section{RAPID INDEX TO WESTERN FLEAS}

Only in this rapid checking index of the fleas of the West has the author placed the describer's name in parentheses, in case the genus has been changed since the release of the description.

abantis, Megabothris, (Rothschild), 213 acamantis, Thrassis, (Rothschild), 125 acuta, Foxella i., Stewart, 175

adelpha, Peromyscopsylla, (Rothschild), 336

adustus, Ceratophyllus, Jordan, 256

adversus, Megabothris, Wagner, 219

affinis, Hoplopsyllus, (Baker), 71

agilis, Orchopeas s., (Rothschild), 93

alaskensis, Oropsylla, (Baker), 169

albertensis, Foxella $i$., (J. and R.) , 182

allos, Phalacropsylla, Wagner, 340

alpina, Stenistomera, (Baker), 305

americana, Stenoponia, (Baker), 362

amphibolus, Anomiopsyllus, Wagner, 83

anomalus, Hoplopsyllus, (Baker), 72

apachina, Foxella i., (C. Fox) , 180

arachis, Meringis, (Jordan), 318

arctica, Mioctenopsylla, Rothschild, 195

arctomys, Oropsylla, (Baker) , 168

aridis, Thrassoides, (Prince), 145

arizonensis, Foxella u., Hubbard, 184

arizonensis, Thrassis a., (Baker), 138

artius, Atyphloceras, Jordan, 279

ashcrafti, Augustsonius, (Augustson), 269

atrox, Megabothris, (Jordan), 218

bacchi, Thrassis, (Rothschild), 142 bisetis, Megarthroglossus d., J. and R.. 302 bitterrootensis, Malaraeus, (Dunn), 202 bluei, Dactylopsylla, (C. Fox), 191 bottaceps, Dactylopsylla, Hubbard, 189 brennani, Thrassis, Augustson, 124 brooksi, Nearctopsylla, (Rothschild), 371 bruneri, Opisocrostis, (Baker), 155 caducus, Thrassis g., (Jordan), 137 caedens, Orchopeas c., (Jordan) , 102 campestris, Thrassoides, (Prince), 146 canis, Ctenocephalides, (Curtis) , 62 carlsbadensis, Sternopsylla, Ewing, 380 carteri, Carteretta, C. Fox, 341 cascadensis, Orchopeas s., Jordan, 96 celsus, Ceratophyllus c., Jordan, 250 chamberlini, Catallagia, Hubbard, 289 charlottensis, Catallagia, (Baker), 285 cheopis, Xenopsylla, (Rothschild), 65 ciliatus, Monopsyllus c., (Baker), 229 collinsi, Myodopsylla, Kohls, 375 coloradensis, Tarsopsylla, (Baker), 263 comis, Dactylopsylla, Jordan, 186 congruens, Anomiopsyllus, Stewart, 81 coufferi, Foxella i., Augustson, 178 cummingi, Meringis, (C. Fox), 321 curvata, Doratopsylla c., Rothschild, 346 cynomuris, Opisocrostis t., Jellison, 154 cyrturus, Monopsyllus e., (Jordan) , 238

decipiens, Catallagia, Rothschild, 288 dentatus, Odontopsyllus, (Baker), 266 desertorum, Thrassis a., Stewart, 140 deuterus, Callistopsyllus, Jordan, 283 dieteri, Orchopeas, (C. Fox), 102 diffinis, Ceratophyllus, Jordan, 253 dipodomys, Meringis, Kohls, 320 dippiei, Hystrichopsylla g., Rothschild, 357 dissimilis, Malaraeus p., Jordan, 204 divisus, Megarthroglossus d., (Baker), 300 dobbsi, Malaraeus, Hubbard, 204 duma, Peromyscopsylla, Traub, 334 durus, Orchopeas c., (Jordan) , 105 
ebrighti, Peromyscopsylla, (C. Fox), 335 echis, Atyphloceras, J. and R., 279 enoplus, Opisodasys, (Rothschild), 115 eremicus, Malaraeus, (Baker), 206 eumolpi, Monopsyllus e., (Rothschild), 237 euphorbi, Malaraeus, (Rothschild), 206 eutamiadis, Monopsyllus, Augustson, 242 ewingi, Amphipsylla, I. Fox, 261 exilis, Monopsyllus e., (Jordan), 243 exsecatus, Megarthroglossus d., Wagner, 301

falsicalifornicus, Anomiopsyllus, C. Fox, 80 fasciatus, Nosopsyllus, (Bosc), 207 felis, Ctenocephalides, (Bouche), 60 felix, Atyphloceras, Jordan, 278 fornacis, Monopsyllus, Jordan, 241 fotus, Thrassis, (Jordan), 143 foxi, Hoplopsyllus g., Ewing, 68 franciscana, Foxella $i$., (Rothschild) , 173 francisi, Thrassis, (C. Fox), 134 fraterna, Rectofrontia, (Baker), 355

gallinacea, Echidnophaga, (Westwood), 50 garei, Ceratophyllus, Rothschild, 253 genalis, Nearctopsylla, (Baker), 371 gentilis, Myodopsylla, J. and R., 374 gilvus, Ceratophyllus, J. and R., 255 gladiolis, Thrassis g., (Jordan), 135 goodi, Micropsylla, Hubbard, 351 gwyni, Polygenis, (C. Fox), 87

hamifer, Peromyscopsylla h., (Rothschild), 337

heiseri, Actenophthalmus, (McCoy) , 352

hesperomys, Peromyscopsylla, (Baker), 329

hirsutus, Opisocrostis, (Baker), 158

howardi, Orchopeas, (Baker), 107

howelli, Thrassis h., (Jordan), 128

hubbardi, Meringis, Kohls, 326

hygini, Nearctopsylla h., (Rothschild) , 371

hyrtaci, Nearctopsylla, (Rothschild), 370

idahoensis, Oropsylla, (Baker), 163 idius, Ceratophyllus, J, and R., 252 ignota, Foxella i., (Baker), 179 inaequalis, Cediopsylla i., (Baker), 74 inopina, Neopsylla, Rothschild, 314 inflexus, Ceratophyllus n., Jordan, 250 intermedius, Orchopeas s., Hubbard, 97 interrupta, Cediopsylla i., Jordan, 76 irritans, Pulex, Linnaeus, 57

jamesoni, Meringis, Hubbard, 325 jellisoni, Doratopsylla, Hubbard, 344 jellisoni, Opisodasys, I. Fox, 112 jellisoni, Thrassis, Hubbard, 124 jewetti, Meringis, Hubbard, 322 jordani, Corypsylla, Hubbard, 365 jordani, Epitedia, Hubbard, 312 jordani, Nearctopsylla, Hubbard, 369 kansensis, Monopsyllus e., Hubbard, 245 keeni, Opisodasys, (Baker), 110

kincaidi, Monopsyllus c., Hubbard, 232 kohlsi, Corypsylloides, (Hubbard), 367

labiatus, Orchopeas, (Baker) , 108 labis, Opisocrostis, (J. and R.) , 156 latens, Orchopeas, (Jordan), 101 leucopus, Orchopeas, (Baker) , 105 littoris, Thrassis a., (Jordan), 140 londiniensis, Nosopsyllus, (Rothschild) , 209 longiloba, Peromyscopsylla $h$., (Jordan), 337 longipalpus, Atyphloceras, Stewart, 280 lucifer, Megabothris, (Rothschild), 217 lynx, Hoplopsyllus g., (Baker), 70

macrodactyla, Stenistomera, Good, 306 mammoth, Hystrichopsylla s., Chapin, 361 megacolpus, Megabothris, (Jordan), 219 moneris, Catallagia, Jordan, 291 mononis, Monopsyllus c., (Jordan), 233 montanus, Anomiopsyllus, Collins, 82 montanus, Diamanus, (Baker), 147 monticola, Phalacropsylla, Augustson, 339 motei, Catallagia, Hubbard, 290 multidentatus, Atyphloceras, (C. Fox), 276

necopinus, Amphalius, (Jordan), 170 neotomae, Amphipsylla, I. Fox, 260 neotomae, Orchopeas s., Augustson, 98 nepos, Orchopeas, (Rothschild) , 99 nesiotus, Opisodasys, Augustson, 114 nevadensis, Orchopeas s., (Jordan) , 95 niger, Ceratophyllus n., C. Fox, 248 nudatus, Anomiopsyllus, (Baker), 79 nuditenacula, Dactylopsylla, Prince, 190

omissa, Foxella i., Prince, 181 opadus, Monopsyllus e., Jordan, 245 ophidius, Monopsyllus w., Jordan, 226 orectus, Megabothris a., Jordan, 216 oregonensis, Megarthroglossus p., Hubbard, 299

oregonensis, Opisocrostis, G. and P., 160 oregonensis, Paratyphloceras, Ewing, 354 oregonensis, Trichopsylloides, Ewing, 308 ornata, Corypsylla, C. Fox, 364 ornatus, Opisocrostis t., I. Fox, 154

pacifica, Dactylopsylla, Hubbard, 188 palposa, Myodopsylloides, (Rothschild) , 376 pandorae, Thrassis, Jellison, 122 pansus, Thrassis, (Jordan), 141 paradisea, Phalacropsylla, Rothschild, 339 parkeri, Meringis, Jordan, 323 pelecani, Ceratophyllus, Augustson, 251 penetrans, Tunga, (Linnaeus), 54 perpinnatus, Dasypsyllus g., (Baker) , 258 petiolatus, Thrassis, (Baker), 120 petrochelidoni, Ceratophyllus, Wagner, 255 pollionis, Amphipsylla s., (Rothschild) , 262 
porcinus, Juxtapulex, (J. and R.), 59 procus, Megarthroglossus p., J. and R., 297 protinus, Monopsyllus c., (Jordan), 230 pseudagyrtes, Ctenophthalmus, Baker, 343 pseudarctomys, Opisodasys, (Baker), 112 psittaci, Hectopsylla, Frauenfeld, 53 pygmaeus, Megarthroglossus, Wagner, 303

quirini, Megabothris, (Rothschild), 211

rara, Dactylopsylla, I. Fox, 194 ravalliensis, Peromyscopsylla, (Dunn), 832 recula, Foxella $i$., (J. and R.), 176 riparius, Ceratophyllus, J. and R., 251 rockwoodi, Thrassis, Hubbard, 132 robustus, Opisodasys, (Jordan), 115 rupestris, Oropsylla, (Jordan), 166 rutherfordi, Catallagia, Augustson, 292

saundersi, Opisocrostis, (Jordan), 156 schefferi, Hystrichopsylla s., Chapin, 359 schisintus, Orchopeas s., (Jordan), 97 sculleni, Catallagia, Hubbard, 287 sectilis, Micropsylla, (J. and R.) , 349 segnis, Leptopsylla, (Schonherr), 347 selenis, Peromyscopsylla, (Rothschild) , 333 setosa, Arctopsylla, (Rothschild), 89 setosifrons, Corypsylla, Stewart, 366 setosis, Thrassis, Prince, 141 shannoni, Meringis, (Jordan), 325 sibynus, Pleochaetis, (Jordan), 246 sicamus, Megarthroglossus, J. and R., 302 similis, Megarthroglossus, Wagner, 302 sinomus, Malaraeus, (Jordan), 201 spenceri, Megarthroglossus, Wagner, 303 spenceri, Thrassis, Wagner, 127 stanfordi, Conorhinopsylla, Stewart, 293 stanfordi, Epitedia, Traub, 812 stanfordi, Thrassis, Wagner, 131 stylosus, Dolichopsyllus, (Baker), 264 suavis, Actenopsylla, J. and R., 63 swansoni, Ceratophyllus, Liu, 254 systaltus, Monopsyllus w., (Jordan), 226

telchinum, Malaraeus, (Rothschild), 198 telegoni, Delotelis, (Rothschild), 294 tenuidigitus, Hoplopsyllus g., Stewart, 69 terinus, Callistopsyllus, (Rothschild), 281 terribilis, Ctenophyllus, (Rothschild), 270 texana, Neopsylla, Stewart, 316

texana, Sternopsylla, (C. Fox), 379 thambus, Monopsyllus, (Jordan), 227 triptus, Monopsyllus e., Jordan, $\mathbf{2 4 5}$ tuberculatus, Opisocrostis t., (Baker) , 152 tundrensis, Ceratophyllus, Holland, 257

ursi, Arctopsylla, (Rothschild) , 88 utahensis, Foxella u., Wagner, 183 utahensis, Thrassis h., Wagner, 130

vagabundus, Ceratophyllus, (Boheman), 255

vancouverensis, Eptescopsylla, (Wagner), 378

vesperalis, Opisodasys, (Jordan), 113 vigens, Peromyscopsylla h., (Jordan) , 337 vison, Monopsyllus, (Baker), 234 vonbloekeri, Catallagia, Augustson, 292

wagneri, Monopsyllus w., (Baker), 221 walkeri, Meringis, Hubbard, 322

wallowensis, Megarthroglossus d., Hubbard, 301

washingtonensis, Opisocrostis, G. and P., 161

wenmanni, Epitedia, (Rothschild), 310

wymani, Catallagia, (C. Fox), 291

\section{WESTERN FLEAS INDEXED ACCORDING TO AUTHORS}

\section{AUGUSTSON (10 listings)}

ashcrafti, Augustsonius (1941), 269

brennani, Thrassis (1944), 124

coufferi, Foxella i. (1942), 178

eutamiadis, Monopsyllus (1941), 242

monticola, Phalacropsylla (1941), 339

neotomae, Orchopeas s. (1943), 98

nesiotus, Opisodasys (1941), 114

pelecani, Ceratophyllus (1942), 251

rutherfordi, Catallagia (1941), 292

vonbloekeri, Catallagia (1941), 292

BAKER (37 listings)

affinis, Hoplopsyllus (1904), 71

alaskensis, Oropsylla (1904), 169 alpina, Stenistomera (1895) , 305

americana, Stenoponia (1898), 362

anomalus, Hoplopsyllus (1904), 72 arctomys, Oropsylla (1904), 168 arizonensis, Thrassis a. (1898), 138 bruneri, Opisocrostis (1895), 155 charlottensis, Catallagia (1898), 285 ciliatus, Monopsyllus c. (1904), 229 coloradensis, Tarsopsylla (1895), 263 dentatus, Odontopsyllus (1904), 266 divisus, Megarthroglossus d. (1895), 300 eremicus, Malaraeus (1904), 206 fraterna, Rectofrontia (1895), 355 genalis, Nearctopsylla (1904), 371 hesperomys, Peromyscopsylla (1904) , 329 
BAKER-continued

hirsutus, Opisocrostis (1895), 158

howardi, Orchopeas (1895), 107

idahoensis, Oropsylla (1904), 163

ignota, Foxella i. (1895), 179

inaequalis, Cediopsylla i. (1895) , 74

keeni, Opisodasys (1896), 110

labiatus, Orchopeas (1904), 108

leucopus, Orchopeas (1904), 105

lynx, Hoplopsyllus g. (1904), 70

montanus, Diamanus (1895), 147

nudatus, Anomiopsyllus (1898), 79

perpinnatus, Dasypsyllus g. (1904), 258

petiolatus, Thrassis (1904), 120

pseudagyrtes, Ctenophthalmus (1904), 343

pseudarctomys, Opisodasys (1904), 112

sexdentatus, Orchopeas s. (1904), 92

stylosus, Dolichopsyllus (1904), 264

tuberculatus, Opisocrostis t. (1904), 152

vison, Monopsyllus (1904), 234

wagneri, Monopsyllus w. (1904), 221

\section{BOHEMAN}

vagabundus, Ceratophyllus (1865), 255

\section{BOSC}

fasciatus, Nosopsyllus (1801), 207

\section{BOUCHE}

felis, Ctenocephalides (1835), 60

\section{CHAPIN}

schefferi, Hystrichopsylla s. (1919), 359 mammoth, Hystrichopsylla s. (1921) , 361

\section{COLI.JNS}

montanus, Anomiopsyllus (1936), 82

\section{CURTS}

canis, Ctenocephalides (1826), 62

\section{DUNN}

bitterrootensis, Malaraeus (1923), 202 ravalliensis, Peromyscopsylla (1923), 332

EWING (4 listings)

carlsbadensis, Sternopsylla (1940), 380 foxi, Hoplopsyllus g. (1924), 68 oregonensis, Paratyphloceras (1940), 354 oregonensis, Trichopsylloides (1938), 308

\section{FRAUENFEUD}

psittaci, Hectopsylla (1860), 53

\section{FOX, C. (14 listings)}

apachina, Foxella i. (1914), 180

bluei, Dactylopsylla (1909), 191

carteri, Carteretta (1927), 341

cummingi, Meringis (1926), 321

dieteri, Orchopeas (1929), 102

ebrighti, Peromyscopsylla (1926), 335

falsicalifornicus, Anomiopsyllus (1929), 80
FOX, C.-continued

francisi, Thrassis (1927), 134

gwyni, Polygenis (1914), 87

multidentatus, Atyphloceras (1909), 276

niger, Ceratophyllus n. (1908), 248

ornata, Corypsylla (1908), 364

texana, Sternopsylla (1914), 379

wymani, Catallagia (1909), 291

FOX, I. (4 listings)

ewingi, Amphipsylla (1940), 261

jellisoni, Opisodasys (1941), 112

neotomae, Amphipsylla (1940), 260

rara, Dactylopsylla (1940), 194

\section{GOOD}

macrodactyla, Stenistomera (1942), 306

GOOD AND PRINCE

oregonensis, Opisocrostis (1939), 160

washingtonensis, Opisocrostis (1939), 161

\section{HOLLAND}

tundrensis, Ceratophyllus (1944), 257

\section{HUBBARD (23 listings)}

arizonensis, Foxella u. (1946), 184

bottaceps, Dactylopsylla (1943), 189

chamberlini, Catallagia $(1940), 289$

dobbsi, Malaraeus (1940), 204

goodi, Micropsylla (1941), 351

intermedius, Orchopeas s. (1943), 97

jamesoni, Meringis (1943), 325

jellisoni, Doratopsylla (1940) , 344

jellisoni, Thrassis (1940), 124

jewetti, Meringis (1940), 322

jordani, Corypsylla (1940), 365

jordani, Epitedia (1940), 312

jordani, Nearctopsylla (1940) , 369

kansensis, Monopsyllus e. (1943), 245

kincaidi, Monopsyllus c. (1946), 232

kohlsi, Corypsylloides (1940), 367

motei, Catallagia (1940), 290

oregonensis, Megarthroglossus p. (1946) , 299

pacifica, Dactylopsylla (1943), 188

rockwoodi, Thrassis (1942), 132

sculleni, Catallagia (1940), 287

walkeri, Meringis (1940), 322

wallowensis, Megarthroglossus d. (1946), 801

\section{JELLISON}

cynomuris, Opisocrostis t. (1939), 154

pandorae, Thrassis (1937), 122

JORDAN (48 listings)

adustus, Ceratophyllus (1932) , 256

arachis, Meringis (1929), 318

artius, Atyphloceras (1933), 279

atrox, Megabothris (1925), 218

caducus, Thrassis g. (1930), 137

caedens, Orchopeas c. (1925), 102

cascadensis, Orchopeas s. (1939), 96

celsus, Ceratophyllus c. (1926), 250 


\section{JORDAN-continued}

comis, Dactylopsylla (1929) , 186

cyrturus, Monopsyllus e. (1929), 238

deuterus, Callistopsyllus (1937), 283

diffinis, Ceratophyllus (1925), 253

dissimilis, Malaraeus p. (1938), 204

durus, Orchopeas c. (1929), 105

exilis, Monopsyllus e. (1937), 243

felix, Atyphloceras (1933), 278

fornacis, Monopsyllus (1937), 241

fotus, Thrassis (1925) , 143

gladiolis, Thrassis g. (1925), 135

howelli, Thrassis $h$. (1925), 128

inflexus, Ceratophyllus n. (1929), 250

interrupta, Cediopsylla i. (1925), 76

latens, Orchopeas (1925), 101

littoris, Thrassis a. (1929), 140

longiloba, Peromyscopsylla $h$. (1939), 337

megacolpus, Megabothris (1929), 219

moneris, Catallagia (1937), 291

mononis, Monopsyllus c. (1929) , 233

necopinus, Amphalius (1925), 170

nevadensis, Orchopeas s. (1929), 95

opadus, Monopsyllus e. (1938), 245

ophidius, Monopsyllus w. (1929), 226

orectus, Megabothris a. (1938), 216

pansus, Thrassis (1925), 141

parkeri, Meringis (1937), 323

protinus, Monopsyllus c. (1929) , 230

robustus, Opisodasys (1925), 115

rupestris, Oropsylla (1929), 166

saundersi, Opisocrostis (1933), 156

schisintus, Orchopeas s. (1929), 97

shannoni, Meringis (1929), 325

sibynus, Pleochaetis (1925), 246

sinomus, Malaraeus (1925), 201

systaltus, Monopsyllus w. (1929), 226

thambus, Monopsyllus (1929), 227

triptus, Monopysllus $e$ : (1938), 245

vesperalis, Opisodasys (1929), 113

vigens, Peromyscopsylla $h$. . (1937), 337

\section{JORDAN AND ROTHSCHILD (14 list- ings )}

albertensis, Foxella i. (1915), 182

bisetis, Megarthroglossus d. (1915) , 302

echis, Atyphloceras (1915), 279

gentilis, Myodopsylla (1921), 374

gilvus, Ceratophyllus (1922), 255

idius, Ceratophyllus (1920), 252

labis, Opisocrostis (1922), 156

porcinus, Juxtapulex (1923), 59

procus, Megarthroglossus p. (1915), 297

recula, Foxella i. (1915) , 176

riparius, Ceratophyllus (1920), 251

sectilis, Micropsylla (1923), 349

sicamus, Megarthroglossus (1915) , 302

suavis, Actenopsylla (1923), 63

\section{KOHLS}

dipodomys, Meringis (1938), 320

collinsi, Myodopsylla (1937), 375

hubbardi, Meringis (1938), 326

\section{LINNAEUS}

irritans, Pulex (1758), 57

penetrans, Tunga (1758), 54

LIU

swansoni, Ceratophyllus (1935), 254

\section{$\operatorname{McCOY}$}

heiseri, Actenophthalmus (1911), 352

PRINCE (7 listings)

aridis, Thrassoides (1944), 145

campestris, Thrassoides (1944), 146

monticola, Dactylopsylla (1945), 193

neomexicana, Dactylopsylla (1945), 192

nuditenacula, Dactylopsylla (1945) , 190

omissa, Foxella i. (1945), 181

setosis, Thrassis (1944), 141

\section{ROTHSCHID (34 listings)}

abantis, Megabothris (1905), 213

acamantis, Thrassis (1905), 125

adelpha, Peromyscopsylla (1915) , 336

agilis, Orchopeas s. (1905), 93

arctica, Mioctenopsylla (1922) , 195

bacchi, Thrassis (1905), 142

brooksi, Nearctopsylla (1904), 371

cheopis, Xenopsylla (1903), 65

curvata, Doratopsylla c. (1915) , 346

decipiens, Catallagia (1915), 288

dippiei, Hystrichopsylla g. (1902) , 357

enoplus, Opisodasys (1909), 115

eumolpi, Monopsyllus e. (1905) , 237

euphorbi, Malaraeus (1905), 206

franciscana, Foxella i. (1910), 173

garei, Ceratophyllus (1902), 253

hamifer, Peromyscopsylla h. (1906) , 337

hyrtaci, Nearctopsylla (1904), 370

inopina, Neopsylla (1915) , 314

londiniensis, Nosopsyllus (1903), 209

lucifer, Megabothris (1905), 217

nepos, Orchopeas (1905), 99

palposa, Myodopsylloides (1904), 376

paradisea, Phalacropsylla (1915), 339

pollionis, Amphipsylla s. (1905), 262

quirini, Megabothris (1905), 211

selenis, Peromyscopsylla (1906), 333

setosa, Arctopsylla (1906), 89

telchinum, Malaraeus (1905), 198

telegoni, Delotelis (1905), 294

terinus, Callistopsyllus (1905), $28 \mathrm{I}$

terribilis, Ctenophyllus (1903), 270

ursi, Arctopsylla (1902), 88

wenmanni, Epitedia (1904), 310

\section{SCHONHERR}

segnis, Leptopsylla (1811), 347

STEWART ( 9 listings)

acuta, Foxella $i$. (1940), 175

congruens, Anomiopsyllus (1940), 81 
STEWART-continued

desertorum, Thrassis a. (1937), 140

hemisphaerium, Peromyscopsylla (1940), 331

longipalpus, Atyphloceras (1940), 280

setosifrons, Corypsylla (1940), 366

stanfordi, Conorhinopsylla (1930), 293

tenuidigitus, Hoplopsyllus g. (1940), 69

texana, Neopsylla (1930), 316

\section{TRAUB}

duma, Peromyscopsylla (1944), 334

stanfordi, Epitedia (1944), 312

WAGNER (15 listings)

adversus, Megabothris (1936), 219

allos, Phalacropsylla (1936), 340
WAGNER-continued

amphibolus, Anomiopsyllus (1936), 83

exsecatus, Megarthroglossus d. (1936), 301

obtusata, Doratopsylla curvata (1929), 345

petrochelidoni, Ceratophyllus (1936), 255

pygmaeus, Megarthroglossus (1936), 303

scapani, Epitedia (1936), 312

similis, Megarthroglossus (1936), 302

spenceri, Megarthroglossus (1936), 303

spenceri, Thrassis (1936), 127

stanfordi, Thrassis (1936), 131

utahensis, Foxella u. (1936), 183

utahensis, Thrassis $h$. (1936), 130

vancouverensis, Eptescopsylla (1936), 378

WESTWOOD

gallinacea, Echidnophaga (1875), 50

\section{GENERAL INDEX}

In this General Index, the number in parentheses is key number of the flea in question, followed by the number indicating page upon which appears its description. In a host index as large as that offered in this volume it is possible to index the hosts only by technical name of genus and common name.

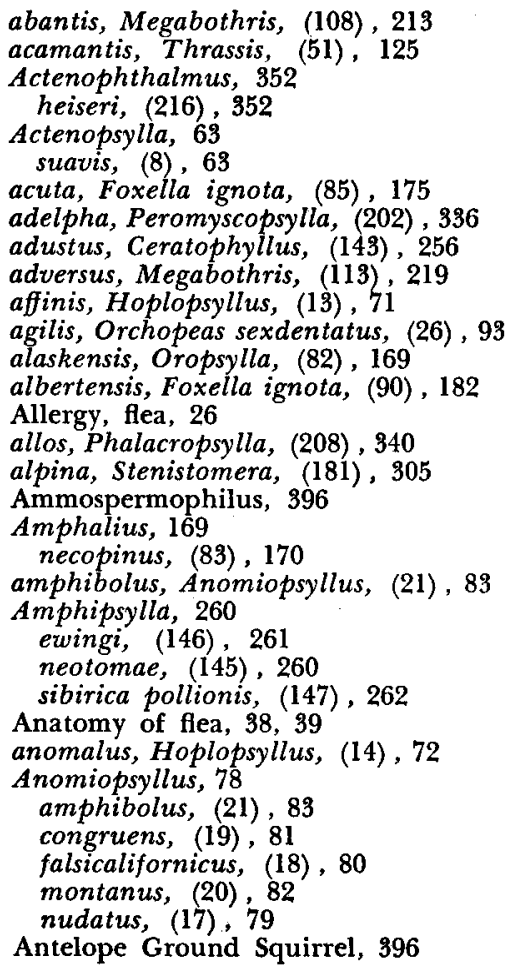

Antigen, flea, 26

apachina, Foxella ignota, (89), 180

Aplodontia, 397

arachis, Meringis, (188), 318

arctica, Mioctenopsylla, (97) , 195

arctomys, Oropsylla, (81), 168

Arctopsylla, 88

setosa, (24), 89

ursi, (23), 88

aridis, Thrassoides, (67), 145

arizonensis, Foxella utahensis, (91a), 184

arizonensis, Thrassis, 138

arizonensis, $(60), 138$

desertorum, (62), 140

littoris, (61), 140

artius, Atyphloceras, (155), 279

asio, Megabothris, 216

orectus, (109), 216

ashcrafti, Augustsonius, (151), 269

atrox, Megabothris, (111), 218

Atyphloceras, 275

artius, (155), 279

echis, (156), 279

felix, (154), 278

longipalpus, (157), 280

multidentatus, (153), 276

Augustson, Gustav, 14

Augustsonius, 268

ashcrafti, (151), 269

bacchi, Thrassis, (65), 142

Badger, 502

Bait, 31

Baker, Carl F., 3 
Bassaricus, 496

Bats, Western, 508

Bears, 497

Black, 497

Grizzly, 497

Beaver

Canadian (Castor), 401

Mountain (Aplodontia), 397

Bibliography, 515

Bird fleas, Western, 512

bisetis, Megarthroglossus, (177) , 302

bitterrootensis, Malaraeus, (100) , 202

Bladderworms, 35

Bleach, 35

bluei, Dactylopsylla, (95), 191

bottaceps, Dactylopsylla, (94), 189

Brachylagus, 398

brennani, Thrassis, (50), 124

brooksi, Nearctopsylla, (229), 371

bruneri, Opisocrostis, (73), 155

Bubonic plague, 17, in

California, 17

Canada, 19

Florida, 19

Louisiana, 18

Nevada, 19

Oregon, 18

Texas, 19

Utah, 19

Washington, 18

How it works, 20

Bubonic, 20

Immunity, 21

Pneumonic, 21

caducus, Thrassis gladiolis, (59), 137

caedens, Orchopeas, 102

caedens, (35), 102

durus, (36), 105

Callistopsyllus, 281

deuterus, (159), 283

terinus, (158), 281

Callospermophilus, 899

campestris, Thrassoides, (68) , 146

Canadian Beaver, 401

Canis

familiaris, 497

latrans, 497

canis, Ctenocephalides, (7), 62

Carbol-xylol formula, 34

carlsbadensis, Sternopsylla, (236), 380

Carnivora, Western, 496

Carteretta, 341

carteri, (209) , 341

cascadensis, Orchopeas sexdentatus, (28), 96

Castor, 401

Cat

Bob, 498

Domestic, 497

Wild, 498

Catallagia, 283

chamberlini, (163) , 289 charlottensis, $(160), 285$

decipiens, (162), 288

moneris, (165), 291

motei, (164), 290

rutherfordi, (167) , 292

sculleni, (161), 287

vonbloekeri, (168), 292

wymani, (166), 291

Cediopsylla, 74

inaequalis, 74

inaequalis, (15), 74

interrupta, (16), 76

celsus, Ceratophyllus, (133) , 250

Ceratophyllus, 248

adustus, (143), 256

celsus celsus, (133), 250

diffinis, (138), 253

garei, (137), 253

gilvus, (142), 255

idius, (136), 252

niger, (131), 248

inflexus, (132), 250

niger, (131), 248

pelecani, (134), 251

petrochelidoni, $(140), 255$

riparius, (135), 251

swansoni, (139), 254

tundrensis, 257

vagabundus, (141), 255

Chaetopsylla, see Arctopsylla

chamberlini, Catallagia, (163), 289

Chapin, E. A., 10

charlottensis, Catallagia, (160), 285

Chemicals for flea technique, 33

cheopis, Xenopsylla, (9), 65

Chipmunks, 426

ciliatus, Monopsyllus, 228

ciliatus, (118), 229

kincaidi, (119a), 232

mononis, (120), 233

protinus, (119), 230

Citellus, 401

Ammospermophilus, 396

armatus, 414

beecheyi,

beecheyi, 404

douglasi, 405

others, 407, 408

beldingi,

beldingi, 409

oregonus, 408

Callospermophilus, 399

columbianus, 410

franklini, 418

richardsoni, 411

townsendi, 417

variegatus, 413

washingtoni, 416

Clearing agents, 35, 36

Clethrionomys, 419 
collinsi, Myodopsylla, (232), 375

coloradensis, Tarsopsylla, (148), 263

comis, Dactylopsylla, (92), 186

congruens, Anomiopsyllus, (19), 81

Conies, 453

Conorhinopsylla, 293

stanfordi, (169), 293

Corypsylla, 363

jordani, (224), 365

ornata, (223), 364

setosifrons, (225), 366

Corypsylloides, 367

kohlsi, (226) , 367

Cotton Rat, 483

Cottontail, 484

coufferi, Foxella ignota, (87), 178

Cougar, 497

Coyote, 497

Ctenocephalides, 60 canis, (7), 62

felis felis, (6), 60

Ctenophthalmus, 343

pseudagyrtes, $(210), 343$

Ctenophyllus, 270

terribilis, (152) , 270

cummingi, Meringis, (190), 321

curvata, Doratopsylla, 346

curvata, (212), 346

obtusata, 345

Cynomys, 421

cynomuris, Opisocrostis tuberculatus, (71), 154

cyrturus, Monopsyllus eumolpi, (123), 238

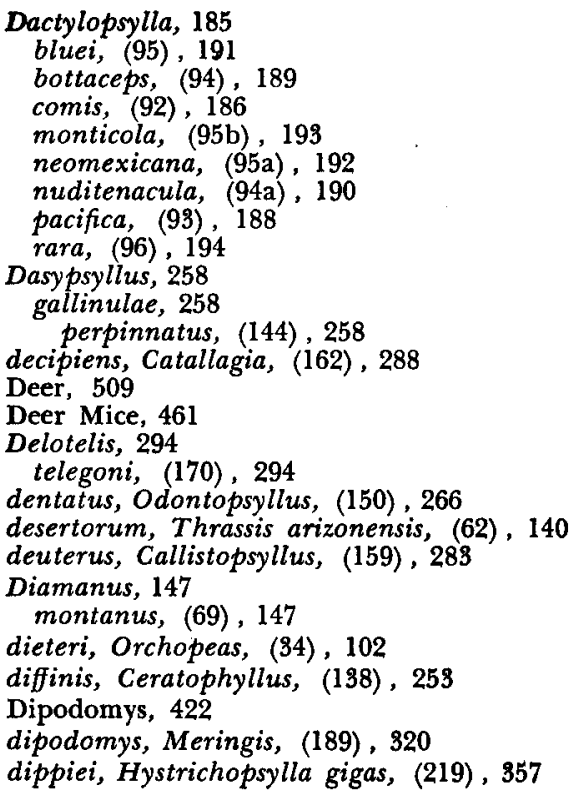

dissimilis, Malaraeus, penicilliger, (102), 204

divisus, Megarthroglossus, 800

divisus, (173), 300

exsecatus, (175), 301

wallowensis, (174), 301

dobbsi, Malaraeus, (101), 204

Dog, 497

Dolichopsyllus, 264

bluei, see Dactylopsylla

stylosus, (149), 264

Doratopsylla, 344

curvata, 346

curvata, (212), 346

obtusata, 345

jellisoni, (211), 344

duma, Peromyscopsylla, (200a), 334

durus, Orchopeas caedens, (36), 105

ebrighti, Peromyscopsylla, (201), 335

Echidnophaga, 49 gallinacea, (1) , 50

echis, Atyphloceras, (156), 279

enoplus, Opisodasys, (45), I15

Epitedia, 309

jordani, (185) , 312

stanfordi, (184a), 312

wenmanni, (184), 310

Eptescopsylla, 378

vancouverensis, $(234), 378$

eremicus, Malaraeus, (104), 206

Erethizon, 425

Euarctos, 497

eumolpi, Monopsyllus, 236

cyrturus, (123), 238

eumolpi, (122), 237

euphorbi, Malaraeus, (103) , 206

Eutamias, 426

eutamiadis, Monopsyllus, (125), 242

Ewing, H. E., 14

ewingi, Amphipsylla, (146), 261

exilis, Monopsyllus, 243

exilis, (126), 243

kansensis, (129), 245

opadus, (127), 245

triptus, (128), 245

exsecatus, Megarthroglossus divisus, (175), 301

falsicalifornicus, Anomiopsyllus, (18), 80

Farm pests, fleas as, 27

fasciatus, Nosopsyllus, (105), 207

Feeding fleas, 87

Felis, 497

catus, 497

oregonus, 497

felis, Ctenocephalides, (6), 60

felix, Atyphloceras, (154), 278

Fiber, 431

Field Manual, 28

Field Mice, 438

Field notes, 34 
Field preservation of fleas, 33

Flea allergy, 26

Flying squirrels, 432

fornacis, Monopsyllus, (124), 241

fotus, Thrassis, (66), I43

Foxes, various, 502

Fox, Carroll, 10

Fox, Irving, 15

Foxella, 172

ignota, 175, 178

acuta, (85), 175

albertensis, (90), 182

apachina, (89), 180

coufferi, (87), 178

franciscana, (84), 173

ignota, (88), 179

omissa, (89a), 181

recula, (86), 176

utahensis, 183

arizonensis, (91 a), 184

utahensis, (91), 183

foxi, Hoplopsyllus glacialis, (10), 68

franciscana, Foxella ignota, (84), 173

francisi, Thrassis, (57), 134

fraterna, Rectofrontia, (218), 355

gallinacea, Echidnophaga, (1) , 50

garei, Ceratophyllus, (137), 253

genalis, Nearctopsylla, (230), 371

gentilis, Myodopsylla, (231), 374

Gibb's Mole, 505

gigas, Hystrichopsylla, 357

dippiei, (219), 357

gilvus, Ceratophyllus, (142), 255

glacialis, Hoplopsyllus,

foxi, (10), 68

lynx, (12), 70

tenuidigitus, (11), 69

gladiolis, Thrassis, 135

caducus, (59) , 137

gladiolis, (58), 135

Glaucomys, 432

Gnome Mice, 436

Golden-mantled Ground Squirrel, 399

Good, Newell, 13

goodi, Micropsylla, (215) , 351

Grasshopper Mice, 456

Gray Digger, 405

Ground Hog, 434

Ground Squirrels,

Belding, 409

California, 404

Columbian, 410

Douglas, 405

Franklin, 418

Oregon, 408

Richardson, 411

Rock, 413

Sage, 417

13-lined, 415

Uinta, 414
Washington, 416

Wyoming, 412

Gulo, 498

Guns, 32

gwyni, Polygenis, (22), 87

hamifer, Peromyscopsylla, 337

hamifer, (203), 337

longiloba, (205), 337

vigens, (204), 337

Harvest Mice, 480

Hectopsylla, 53

psittaci, (2), 53

heiseri, Actenophthalmus, (216), 352

hemisphaerium, Peromyscopsylla, (198) , 331

hesperomys, Peromyscopsylla, (197), 329

hirsutus, Opisocrostis, (76) , 158

Holland, George, 13

Hoplopsyllus, 67

affinis, (13), 71

anomalus, (14), 72

glacialis

foxi, (10), 68

lynx, (12), 70

tenuidigitus, (11) , 69

House Mice, 447

Household pests, fleas as, 26

howardi, Orchopeas, (38), 107

howelli, Thrassis, 128

howelli, (53), 128

utahensis, (54), 130

Hubbard, C. A., 14

hubbardi, Meringis, (196), 326

hubbardi, Phaneris, (183), 308

hygini, Nearctopsylla, (230), 371

Hystrichopsylla, 357

gigas dippiei, (219), 357

schefferi mammoth, (221), 361

schefferi schefferi, (220), 359

idahoensis, .Oropsylla, (79), 163

Idaho Pygmy Rabbit, 398

idius, Ceratophyllus, (136), 252

ignota, Foxella, 179

acuta, (85) , 175

albertensis, (90), 182

apachina, (89), 180

coufferi, (87), 178

franciscana, (84), 173

ignota, (88) , 179

omissa, (89a), 181

recula, (86), 176

inaequalis, Cediopsylla, 74

inaequalis, (15), 74

interrupta, (16), 76

inopina, Neopsylla, (186), 314

inflexus, Ceratophyllus niger, (132), 250

Insectivora, Western, 504

intermedius, Orchopeas sexdentatus, (30), 97

interrupta, Cediopsylla inaequalis, (16), 76

irritans, Pulex, (4), 57 
Jack Rabbits, 433

jamesoni, Meringis, (194), 325

Jellison, William L., 12

jellisoni, Doratopsylla, (211), 344

jellisoni, Opisodasys, (41), 112

jellisoni, Thrassis, (48), 124

jewetti, Meringis, (192), 322

Jordan, Karl, 5, 7

jordani, Corypsylla, (224), 365

jordani, Epitedia, (185), 312

jordani, Nearctopsylla, (227), 369

Jumping Mice, 494

Juxtapulex, 59

porcinus, (5), 59

\section{Kangaroo Rats, 422}

kansensis, Monopsyllus exilis, (129), 245

keeni, Opisodasys, (40) , 110

kincaidi, Monopsyllus ciliatus, (119a), 232

Kohls, Glen M., 12, 13

kohlsi, Corypsylliodes, (226), 367

Labeling slides, 37

labiatus, Orchopeas, (39), 108

labis, Opisocrostis, (75), 156

Laboratory Manual, 34

latens, Orchopeas, (33), 101

Leptopsylla, 346 segnis, (213), 347

Lepus, 433

leucopus, Orchopeas, (37), 105

littoris, Thrassis arizonensis, (61) , 140

longiloba, Peromyscopsylla hamifer, (205), 337

londiniensis, Nosopsyllus, (106), 209

longipalpus, Atyphloceras, (157), 280

lucifer, Megabothris, (110), 217

Lutreola, 498

Lynx, 498

lynx, Hoplopsyllus glacialis, (12), 70

macrodactyla, Stenistomera, (182), 306

Malaraeus, 196

bitterrootensis, $(100), 202$

dobbsi, (101), 204

eremicus, (104), 206

euphorbi, (103), 206

penicilliger, (102), 204

dissimilis, (102), 204

sinomus, (99), 201

telchinum, (98), 198

mammoth, Hystrichopsylla schefferi, (221), 361

Man, 510

Marmot, 434

Marmota, 434

Martes, 499

Martin, 499

Meadow Mice, 437
Megabothris, 210

abantis, (108), 213

adversus, (113), 219

asio, 216

orectus, (109), 216

atrox, (111), 218

exilis, see Monopsyllus

lucifer, (110), 217

megacolpus, (112), 219

quirini, (107), 211

megacolpus, Megabothris, (112), 219

Megarthroglossus, 296

bisetis, (177) , 302

divisus, 300

divisus, (173), 300

exsecatus, (175), 301

wallowensis, (174), 301

procus, 297

procus, (171), 297

oregonensis, (172), 299

pygmaeus, (179), 303

sicamus, $(176), 302$

similis, (178), 302

spenceri, (180), 303

Mephitis, 499

Meringis, 317

arachis, (188), 318

cummingi, (190), 321

dipodomys, (189), 320

hubbardi, (196), 326

jamesoni, (194), 325

jewetti, (192) , 322

parkeri, (193), 323

shannoni, (195), 325

walkeri, (191), 322

Microdipodops, 436

Micropsylla, 348

goodi, (215), 351

sectilis, (214), 349

Microtus, 437

Microtus, Nests of, 442

Mink, 498

Mioctenopsylla, 194

arctica, (97), 195

mohavensis, Delotelis, 305

Moles, 504

Mole, Gibb's, 505

moneris, Catallagia, (165), 291

mononis, Monopsyllus ciliatus, (120), 233

Monopsyllus, 219

ciliatus, 228

ciliatus, (118), 229

kincaidi, (119a) , 232

mononis, (120), 233

protinus, (119), 230

eumolpi, 236

cyrturus, (123), 238

eumolpi, (122), 237

eutamiadis, (125), 242 


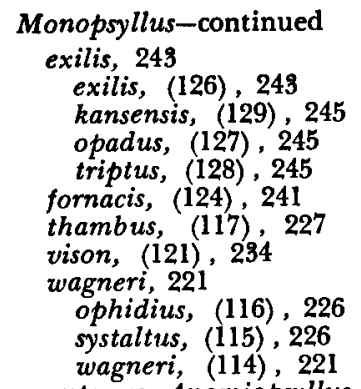

montanus, Anomiopsyllus, (20), 82

montanus, Diamanus, (69), 147

monticola, Dactylopsylla, (95b) , 193

monticola, Phalacropsylla, (206), 339

motei, Catallagia, (164), 290

Mountain Beaver, 397

Mountain Lion, 497

Mounting Technique, 36, 37

multidentatus, Atyphloceras, (153), 276

Mus, 447

Muskrat, 431

Mustela, 500

Myodopsylla, 373

collinsi, (2,32), 375

gentilis, (231), 374

Myodopsylloides, 376

piercei, 376

palposa, (233), 376

Nearctopsylla, 368

brooksi, (229), 371

genalis, (230), 371

hygini hygini, 371

hyrtaci, (228), 370

jordani, (227), 969

necopinus, Amphalius, (83), 170

neomexicana, Dactylopsylla, (95a), 192

Neopysylla, 314

inopina, (186), 314

scapani, 312

texana, (187), 316

wenmanni, (184), 310

neotomae, Amphibsylla, (145), 260

neotomae, Orchopeas sexdentatus, (31), 98

Neotoma, 448

Neotoma, Nests of, 452

nepos, Orchopeas, (32), 99

nesiotus, Opisodasys, (44), 114

Neurotrichus, 505

nevadensis, Orchopeas sexdentatus, (27), 95

niger, Ceratophyllus, 248

inflexus, (132), 250

niger, (131) , 248

Nosopsyllus, 206

fasciatus, (105), 207

londiniensis, (106), 209

nudatus, Anomiopsyllus, (17), 79

nuditenacula, Dactylopsylla, (94a), 190
Nycteridopsylla, see Eptescopsylla

vancouverensis, (234), 378

obtusata, Doratopsylla curvata, $\mathbf{3 4 5}$

Ochotona, 453

Odontopsyllus, 266

dentatus, $(150), 266$

omissa, Foxella ignota, (89a) , 181

Onychomys, 456

opadus, Monopsyllus exilis, (127) , 245

ophidius, Monopsyllus wagneri, (116), 226

Opisocrostis, 150

bruneri, (73), 155

hirsutus, (76), 158

labis, (75), 156

oregonensis, $(77), 160$

saundersi, (74), 156

tuberculatus, 152

cynomuris, (71), 154

ornatus, (72), 154

tuberculatus, $(70), 152$

washingtonensis, (78), 161

Opisodasys, 109

enoplus, (45), 115

jellisoni, (41), 112

keeni, (40), 110

nesiotus, (44), 114

pseudarctomys, (42), 112

robustus, (46), 115

vesperalis, (43), 113

Opossum, 509

Orchopeas, 90

caedens, 102

caedens, (35), 102

durus, (36), 105

dieteri, (34), 102

labiatus, (39), 108

latens, (33), 101

leucopus, (37), 105

nepos, (32), 99

sexdentatus, 91

agilis, (26), 93

cascadensis, (28), 96

intermedius, $(30), 97$

neotomae, (31), 98

nevadensis, $(27), 95$

schisintus, (29), 97

sexdentatus, (25) , 92

wickhami, (38), 107

orectus, Megabothris asio, (109), 216

oregonensis, Megarthroglossus procus, (172), 299

oregonensis, Opisocrostis, (77), 160

oregonensis, Paratyphloceras, (217), 354

oregonensis, Trichopsylloides, (183), 308

ornata, Corypsylla, (223), 364

ornatus, Opisocrostis tuberculatus, (72), 154

Oropsylla, 162

alaskensis, (82), 169

arctomys, (81), 168

idahoensis, (79), 163

rupestris, $(80), 166$ 
pacifica, Dactylopsylla, (93), 188

Packrat, 448

palposa, Myodopsylloides, (233), 376

pandorae, Thrassis, (48), 122

pansus, Thrassis, (63), 141

paradisea, Phalacropsylla, (207), 339 '

Paratyphloceras, 353

oregonensis, (217), 354

parkeri, Meringis, (193), 323

Pecari, 509

pelecani, Ceratophyllus, (134)', 251

penetrans, Tunga, (3), 54

penicilliger, Malaraeus, 204

dissimilis, (102), 204

Perognathus, 458

Peromyscopsylla, 328

adelpha, (202) , 336

duma, (200a), 334

ebrighti, (201), 335

hamifer, 337

hamifer, (203), 337

longiloba, (205), 337

vigens, (204), 337

hemisphaerium, (198), 331

hesperomys, (197), 329

ravalliensis, (199), 332

selenis, (200), 333

Peromyscus, 461

Peromyscus, Nests of, 470

perpinnatus, Dasypsyllus gallinulae, (144), 258

petiolatus, Thrassis, (47), 120

petrochelidoni, Ceratophyllus, (140), 255

Phalacropsylla, 338

allos, (208), 340

arachis, see Meringis

cummingi, see Meringis

monticola, (206), 339

paradisea, (207), 339

shannoni, see Meringis

Phaneris, 307

Phenacomys, 475

Pika, 453

Plague, 8, 9, 10, 17

Plague in Carnivora

Badger, 502

Lutreola, 498

Mink, 498

Taxidea, 502

Plague in rodents, 393

Ammospermophilus, 396

Antelope Ground Squirrel, 396

Callospermophilus, 400

Chipmunk, 427

Citellus, 402

Cottontail, 486

Cynomys, 421

Deer Mice, 461

Dipodomys, 423

Eutamias, 427

Field Mice, 438
Flying Squirrels, 432

Glaucomys, 432

Golden-mantled Ground Squirrels, 400

Gopher, Pocket, 493

Grasshopper Mice, 457

Ground Squirrels, 402

Harvest Mice, 480

Jack Rabbits, 434

Kangaroo Rats, 423

Lepus, 434

Marmot, 435

Marmota, 435

Meadow Mice, 438

Microtus, 438

Neotoma, 448

Onychomys, 457

Pack Rat, 448

Peromyscus, 461

Pocket Gopher, 493

Prairie Dogs, 421

Rat, 477

Rattus, 477

Reithrodontomys, 480

Sylvilagus, 486

Tamiasciurus, 490

Thomomys, 493

White-footed Mice, 461

Woodchuck, 435

Wood Rats, 448

Pleochaetis, 246

sibynus, (130), 246

Pocket Gophers, 490

Pocket Mice, 458

pollionis, Amphipsylla sibirica, (174), 262

Polygenis, 86

gwyni, (22), 87

porcinus, Juxtapulex, (5), 59

Porcupine, 425

Prairie Dog, 421

Prince, Frank M., 13

procus, Megarthroglossus procus, (171), 297

protinus, Monopsyllus ciliatus, (119), 230

pseudagyrtes, Ctenophthalmus, (210), 343

pseudarctomys, Opisodasys, (42), 112

psittaci, Hectopsylla, (2), 53

Pulex, 56

irritans, (4), 57

Pulicidae, 56

pygmaeus, Megarthroglossus, (179), 303

quirini, Megabothris, (107), 211

rara, Dactylopsylla, (96), 194

Rat, 476

Rattus, 476

ravalliensis, Peromyscopsylla, (199), 392

recula, Foxella ignota, (86), 176

Rectofrontia, $\mathbf{3 5 5}$

fraterna, (218), 355

Red-backed Mice, 419

Red Digger, 410 
Removing fleas from host, 33

Reithrodontomys, 480

Ring-tailed Cat, 496

riparius, Ceratophyllus, (135), 251

rockwoodi, Thrassis, (56), 132

Rock Rabbits, 453

robustus, Opisodasys, (46), 115

Rodent Plague, 393

Rothschild, House of, 6

Rothschild, Nathaniel Charles, 6

rupestris, Oropsylla, (80), 166

rutherfordi, Catallagia, (167), 292

Sage Rats, 416

saundersi, Opisocrostis, (74), 156

scapani, Neopsylla, 312

Scapanus, 504

schefferi, Hystrichopsylla, 359

Sciurus, 482

schisintus, Orchopeas sexdentatus, (29), 97

sculleni, Catallagia, (161), 287

sectilis, Micropsylla, (214), 349

segnis, Leptopsylla, (213), 347

selenis, Peromyscopsylla, (200), 333

setosa, Arctopsylla, (24), 89

setisofrons, Corypsylla, (225) , 366

setosis, Thrassis, (64), 141

sexdentatus, Orchopeas, 91

agilis, (26), 93

cascadensis, (28), 96

intermedius, (30), 97

neotomae, (31), 98

nevadensis, (27), 95

schisintus, (29), 97

sexdentatus, (25), 92

shannoni, Meringis, (195), 325

Shrews, 506

sibirica, Amphipsylla, 262

sibynus, Pleochaetis, (130), 246

sicamus, Megarthroglossus, (176), 302

Sigmodon, 483

sigmodoni, Polygenis, (22), 87

similis, Megarthroglossus, (178), 302

sinomus, Malaraeus, (99), 201

Skunks, 499, 501

Sorex, 506

spenceri, Megarthroglossus, (180), 303

spenceri, Thrassis, (52), 127

Spilogale, 501

spinifrons, Peromyscopsylla, 329

Squirrels, 482, 483, 487

Stanford, J. S., 11, 16

stanfordi, Epitedia, (184a), 312

stanfordi, Thrassis, (55), 131

Stenistomera, 304

alpina, (18I), 305

macrodactyla, (182), 306

Stenoponia, 362

americana, (222), 362
Sternopsylla, 379

carlsbadensis, (236), 380

texana, (235), 379

Stewart, M. A., 14

stimsoni, Dactylopsylla, 191

stylosus, Dolichopsyllus, (149), 264

suavis, Actenopsylla, (8), 63

swansoni, Ceratophyllus, (139), 254

Sylvatic Plague, see plague in rodents, 393

Sylvilagus, 484

systaltus, Monopsyllus wagneri, (115), 226

Tamiasciurus, 487

Tarsopsylla, 263 coloradensis, (148), 263

Taxidea, 502

telchinum, Malaraeus, (98), 198

telegoni, Delotelis, (170), 294

tenuidigitus, Hoplopsyllus glacialis, (11), 69

terinus, Callistopsyllus, (158), 281

terribilis, Ctenophyllus, (152), 270

texana, Neopsylla, (187), 316

texana, Sternopsylla, (235), 379

thambus, Monopsyllus, (117), 227

Thomomys, 490

Thrassis, 116

acamantis, (51), 125

arizonensis, 138

arizonensis, $(60), 138$

desertorum, (62), 140

littoris, $(61), 140$

bacchi, (65), 142

brennani, (50), 124

desertorum, arizonensis, (62), 140

fotus, (66), 143

francisi, (57), 134

gladiolis, 135

caducus, $(59), 137$

gladiolis, $(58), 135$

howelli, 128

howelli, (53) , 128

utahensis, (54), 130

jellisoni, (49), 124

pandorae, (48), 122

pansus, (63), 141

petiolatus, (47), 120

princei, 143

rockwoodi, (56), 132

setosis, (64), 141

spenceri, (52), 127

stanfordi, (55), 131

Thrassoides, 144

aridis, (67), 145

campestris, (68), 146

Traps, 29-31

Traub, Robert, 16

Tree Mice, 475

Trichopsylloides, 307

oregonensis, (183), 308

hubbardi, 308 
triptus, Monopsyllus exilis, (128), 245

tuberculatus, Opisocrostis, 152

cynomuris, (71), 154

ornatus, (72), 154

tuberculatus, $(70), 152$

Tularemia, 24

Tularemia in

Castor, 401

Fiber, 431

Lepus, 434

Microtus, 447

Rattus, 477

Sylvilagus, 486

tundrensis, Ceratophyllus, 257

Tunga, 54 penetrans, (3), 54

Typhus, Murine, 21 vectors of, 22

Urocyon, 502

ursi, Arctopsylla, (23), 88

Ursus, 492

utahensis, Foxella utahensis, (91), 183

utahensis, Thrassis howelli, (54), 130

vagabundus, Ceratophyllus, (141), 255

vancouverensis, Eptescopsylla, (234), 378

vesperalis, Opisodasys, (43), 113 vigens, Peromyscopsylla hamifer, (204), 397

vison, Monopsyllus, (121), 234

vonbloekeri, Catallagia, (168), 292

Vulpes, 502

wagneri, Monopsyllus, 221

ophidius, (116), 226

systaltus, (115), 226

wagneri, (114), 221

walkeri, Meringis, (191), 322

wallowensis, Megarthroglossus divisus, (174), 301

washingtonensis, Opisocrostis, (78) , 161

Weasels, 500

wenmanni, Epitedia, (184), 310

Where to trap, 31

Where not to trap, 32, 33

White-footed Mice, 461

wickhami, Orchopeas, 107

Wolverine, 498

Woodchuck, 434

Wood Rat, 448

wymani, Catallagia, (166), 291

Xenopsylla, 64

cheopis, (9) , 65

Zapus, 494 